

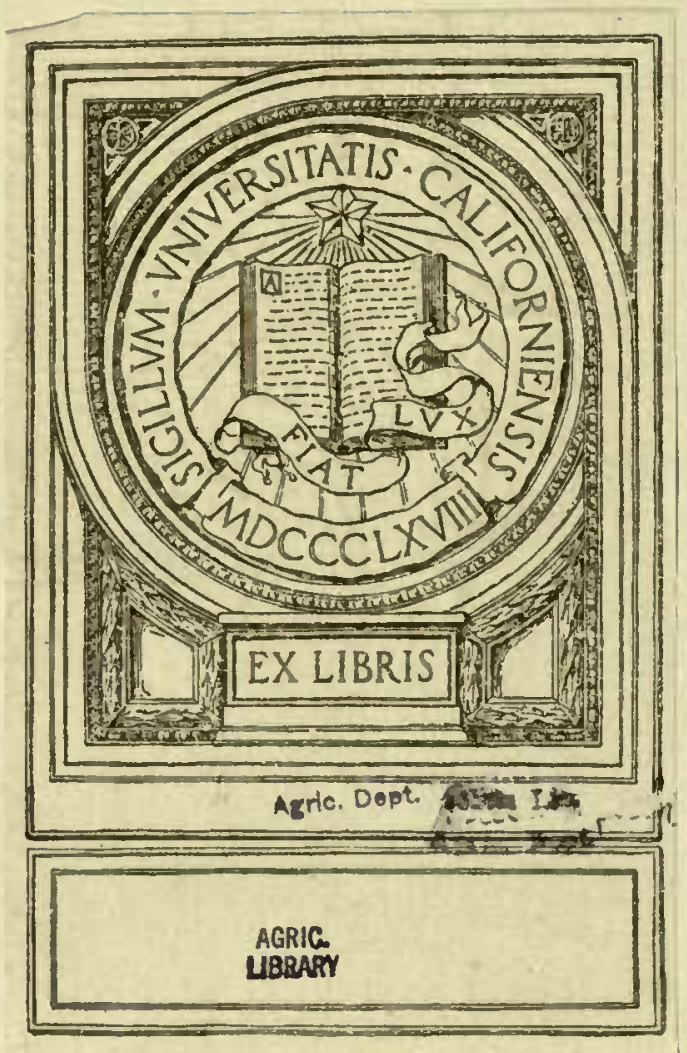






Bacteria in Relation to Plant Diseases. 


$$
-
$$





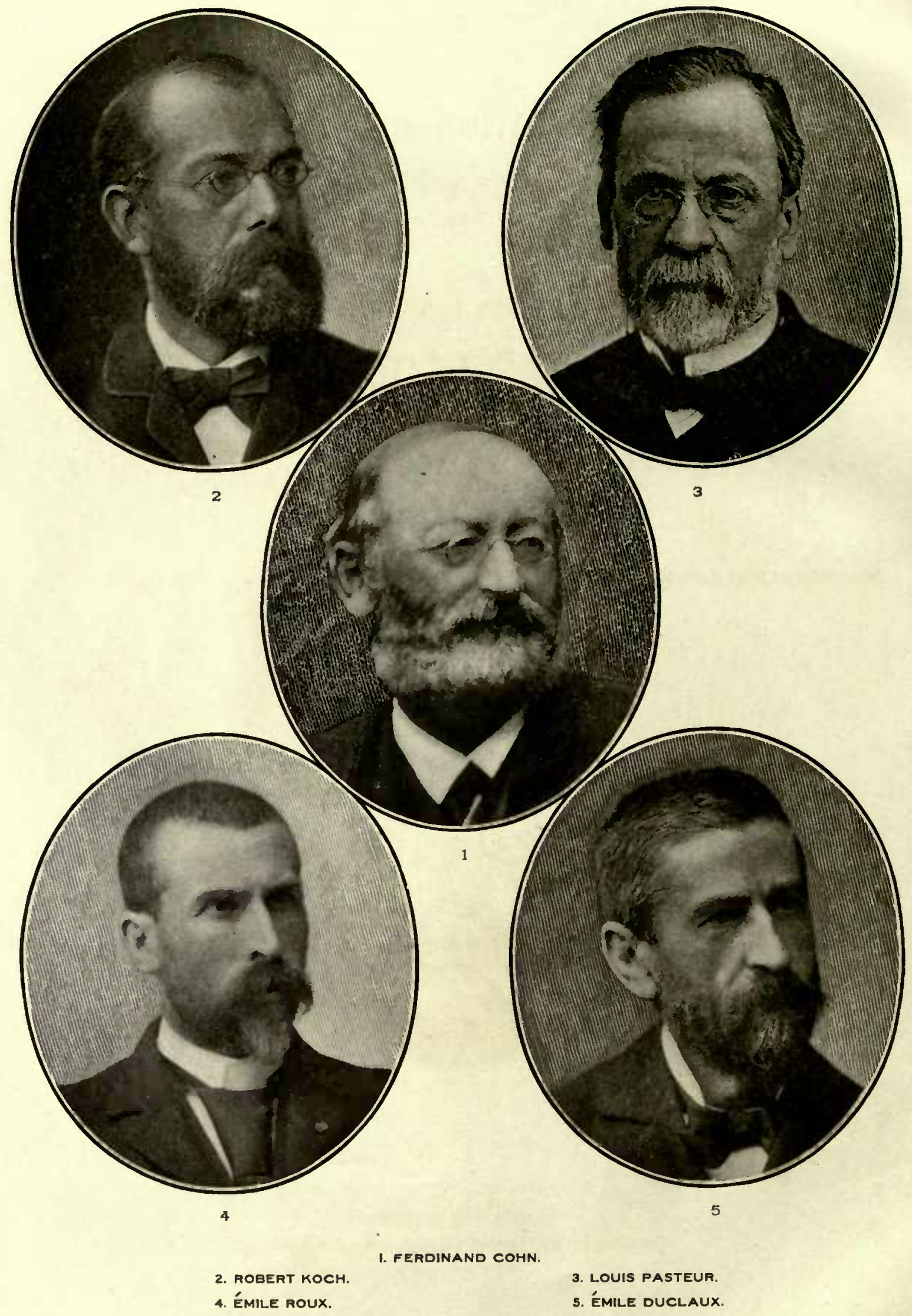




\title{
Bacteria in Relation to Plant Diseases
}

\author{
BY \\ ERWIN F. SMITH, \\ In charge of Laboratory of Plant Pathology, Office of Physiology and Pathology, \\ Bureau of Plant Industry, U. S. Deparment of Agriculture.
}

\section{VOLUME ONE.}

\section{METHODS OF WORK AND GENERAL LITERATURE OF BACTERIOLOGY EXCLUSIVE OF PLANT DISEASES.}

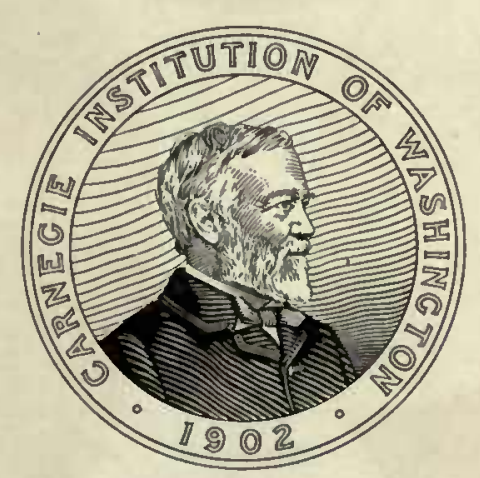

WASHINGTON, D. C. :

Published by the Carnegie Institution of Washington

September, 1905 . 


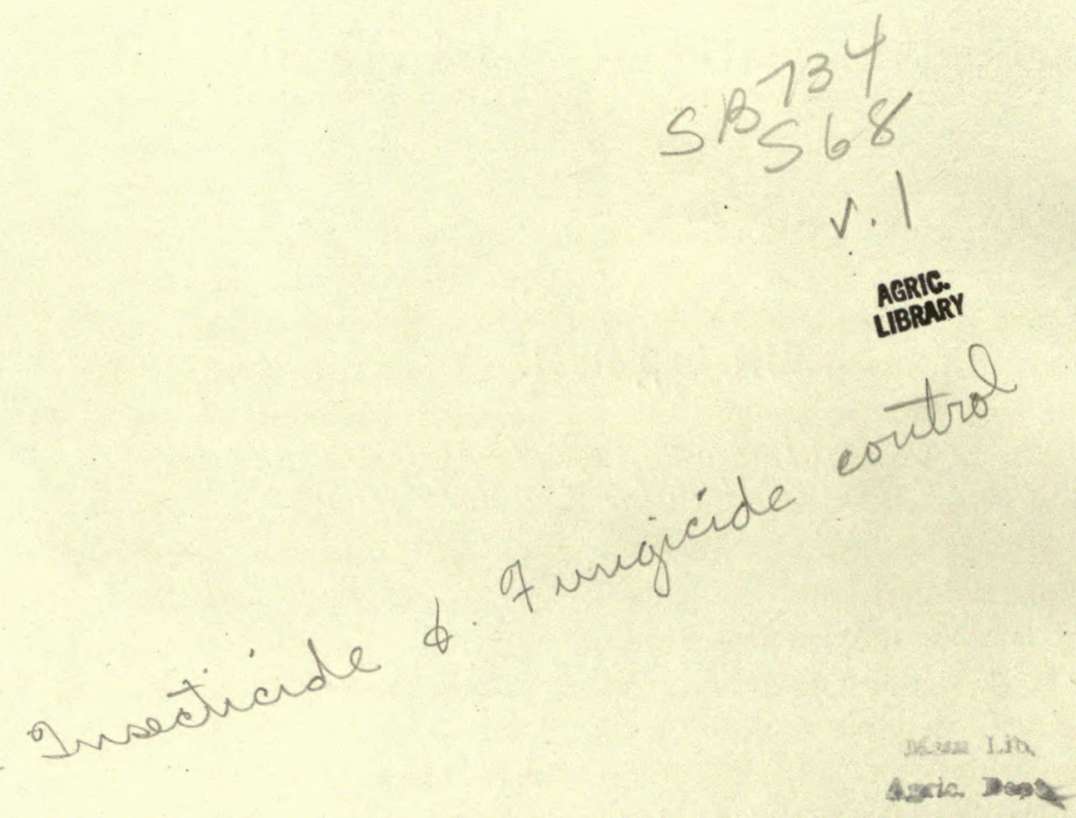

CARNEGIE INSTITUTION OF WASHINGTON

PUBLICATION NO. 27

FROM THE PRESS OF

THE HENRY E. WILKENS PRINTING CO,

WASHINGTON, D. C. 


\section{PREFACE.}

The subject of bacteriafidiseases of plants is older than the ponred-plate method of Koch, but nutil recently our knowledge of it lias been in a very chaotic state, it having been for the 1110st part for twenty-five years a recognized but u11cultivated field. In recent years, lowever, publications on plant bacteria have multiplied, and they now annount to several hutidred titles.

The writer's studies of the bacteria themselves and of the diseases which they cause, as distinct from the literature of the subject, began in I893. At that time there was very little reliable information on this subject. The literature is now 1110re extensive, but it is nowhere gathered together in one place and properly sum1narized. It has seemed, therefore, for a long tine, that a work of the scope of the treatise here presented night be clarifying and useful to niany people. There have been published, and are still appearing, so 1uany papers on the subject of bacterial diseases of plants by writers ignorant of bacteriological methods and indifferent to the requirenents of modern pathological inquiry that this whole subject has been brought into disrepute. This is the only possible explanation of the fact that up to a very recent date writers on patlology and bacteriology have been telling their readers that there is no good evidence of the existence of any sicli diseases.

The following editorial paragraph fron the Botanical Gazctte, February, r893, 111ay be cited as indicating the general feeling on this subject at that date:

What is especially needed at this stage of advancement is the continuous and systematic examination of the whole ground by one or more well-equipped investigators, and the publication of a critical statement of what may be safely accepted as proven. Even a summarization of the present status of the subject, without critical laboratory study, would be helpful, if well done.

That this feeling has become intensified with the progress of time and the 1111tiplication of literature is shown by the following citation from the large Treatise on Bacteriology, by Miquel and Cambier, published in 1902:

The list of bacteria capable of attacking the higher plants increases rapidly from day to day; but whether the experiments of plant pathology offer greater difficulties than those of animal pathology, or whether the authors who have undertaken them have ignored the multiple resources which bacteriology offers to-day, many of the species described must be studied anew, their monography offering regrettable lacunx. By the side of some fruitful and well-conducted labors we find, unfortunately, altogether too many which must be done over entirely.

It was with the hope of making useful discoveries and clearing up part of this contradiction and uncertainty that the writer began his study of this class of diseases. His first effort in the way of preparation was to supplennent his botanical training with a knowledge of bacteriological 111etlods which he obtained from standard literature and conpetent teachers. His second effort was to gatlier 
together and properly digest all of the literature relating to this subject. This resulted in the projection of a critical review of the literature, begun in I 896 in the American Naturalist but left unfinished, owing to pressure of research work, and a card catalogue which is now here published in full witl critical renarks. His third endeavor was to carefully work over, in the laboratory, field, and greenhouse, as opportunity offered, all of the so-called bacterial diseases of plants, subinitting each supposed parasite to all of the tests of modern pathology. The latter has proved a far larger undertaking than was anticipated, the number of diseases attributed to bacteria liaving increased rapidly in recent years. It is expected that more tlian 125 diseases will be treated or touched upon in this nonograph, many of which have come under the writer's own observation. An attempt las been made to cover the literature of the whole world and to work over personally every disease so far as 111aterial could be obtained.

The present volume contains an "ontline of 111ethods of work," whicli was written up in substantially the same form fonr years ago, in connection with the investigations of the Laboratory of Plant Pathology, Bureau of Plant Industry, United States Department of Agriculture, its publication having been delayed in order to bring the rest of the mannscript into suitable shape. The nonograph is published in this form with the approval of the Secretary of Agriculture.

The bibliograplsy at the end of this volume covers the general subject of bacteriology, exclusive of plant diseases, and is arranged chronologically by subjects. Not every good paper is referred to, but for the most part only such as have fallen under the writer's owil observation. It is believed, lowever, that by consulting these the student will soon be able to get liold of the entire literature of any special brawch. The reader wlio wishes to keep pace with the advance of the science should consult the International Catalogue (R) publislied by the Royal Society of London.

The illustrations, especially those dealing with histology, have been drawn, with very few exceptions, under the direct personal supervision of the writer, every one of then when near completion having been inspected critically and modified in various details to correspond as closely as possible to the actual object. The slides from which the drawings have been made will be placed on file in the Laboratory of Plant Pathology, where they nuay be consulted.

This monograph is not intended to take the place of ordinary text-books of bacteriology, of which there are now many, but rather to supplement the same, giving information where they are silent or misleading. It is hoped that it will be of value not only to plant pathologists, for whom it is prinarily intended, but also to physicians and animal pathologists for purposes of conparison. In its prepatation the writer has had also an eye to the service of gardeners, fruit-growers, and all who take an intelligent interest in plants. It is presented with a keen sense of its imperfections, but with the hope that it may at least serve its main purpose. While the writer has made every effort to be accurate in statement and just in criticis11, it is too n11uch to hope that lie has always succeeded, and, therefore, he desires to crave pardon in advance for all errors of omission and commission, taking 
shelter behind Lavoisier's well-known and convenient apology: "Man would never give anything to the public if he waited till he had reached the goal of his undertaking, which is ever appearing close at hand and yet ever slipping farther and farther as he draws nearer." Those who dwell in the clearer light of the next generation will build better than we have done and will scarcely realize how slowly and painfully many of us have groped about for what seems to them so plain.

In conclusion, I desire to make grateful mention of Dr. Theobald Smith, professor of comparative pathology in Harvard University Medical School, and Dr. Veranus A. Moore, professor of comparative pathology and bacteriology in Cornell University, each in turn in charge of the animal pathological investigations of the Bureau of Animal Industry, United States Department of Agriculture, at a time when the writer was beginning his bacteriological studies and was perplexed in many ways. To friendly advice and helpful suggestions from these distinguished men he owes more than he can well repay.

AUguSTT 25, 1905 . 



\section{CONTENTS.}

\section{OUTLINE OF ME'THODS OF WORK.}

\begin{tabular}{|c|c|c|}
\hline \multicolumn{2}{|c|}{ Page. } & m. \\
\hline General Remarks........ & 3 & The Organism--Continued. \\
\hline 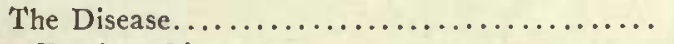 & 4 & Physiology-Continued. \\
\hline Previous Literature................... & 6 & Fermentation-products \\
\hline 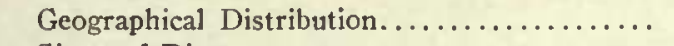 & 7 & Alkalies (Ammonia, Amins, etc.). \\
\hline 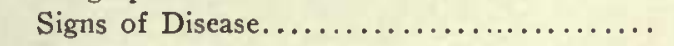 & 7 & Reducing Powers............... \\
\hline Pathological Histology................... & 8 & Hydrogen Sulphide.... \\
\hline Direct-infection Experiments............. & 9 & Mercaptan and Other Odors............ 62 \\
\hline 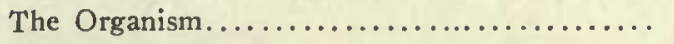 & 9 & Indol, Phenol, Leucin, Tyrosin, ete....... 62 \\
\hline Pathogenesis & 9 & action of Nitrates, etc........... \\
\hline ol 1.1001. & 9 & tion of Free Nitrogen, etc...... \\
\hline Morphology $\ldots \ldots \ldots \ldots \ldots \ldots \ldots \ldots \ldots$ & 18 & nilation of Carbon Dioxide......... 64 \\
\hline Size, Shape, etc................... & 18 & ients $\ldots \ldots \ldots \ldots \ldots \ldots \ldots \ldots$ \\
\hline ules $\ldots \ldots \ldots \ldots \ldots \ldots \ldots \ldots \ldots \ldots \ldots \ldots$ & 19 & als $\ldots \ldots \ldots \ldots \ldots$. \\
\hline $11 a \ldots \ldots \ldots \ldots \ldots \ldots \ldots \ldots \ldots \ldots \ldots \ldots$ & 20 & $\operatorname{mes} \ldots \ldots \ldots \ldots \ldots$ \\
\hline es-Endospores, Arthrospores.......... & $2 \mathrm{I}$ & reness to Plant Acids............ \\
\hline oeae, Chains, Filaments. . & 22 & tiveness to Alkalies. . \\
\hline rms $\ldots \ldots \ldots \ldots \ldots \ldots \ldots \ldots$ & 23 & Effect of Desiccation................ 7o \\
\hline t. $\ldots \ldots \ldots \ldots \ldots \ldots \ldots \ldots$ & 23 & inlight.............. $7 \mathrm{I}$ \\
\hline gy & 25 & ity on Various Media. . \\
\hline$\ldots \ldots \ldots \ldots \ldots \ldots \ldots \ldots \ldots \ldots$ & 26 & d Cultures and Mixed Infections...... 72 \\
\hline$\ldots \ldots \ldots \ldots \ldots \ldots \ldots \ldots \ldots \ldots \ldots$ & 27 & ptics and Germicides.... 74 \\
\hline Chemotropism $\ldots \ldots \ldots \ldots \ldots \ldots \ldots \ldots$ & 27 & Thermal Relations: Maximum, Minimum, \\
\hline Reaction to Stains.................... & 27 & and Optimum Temperatures for \\
\hline$\ldots \ldots \ldots \ldots \ldots \ldots \ldots \ldots \ldots$ & 29 & Growth; Thermal Death-point; Effect \\
\hline elatin.......... & 29 & $\ldots \ldots \ldots \ldots 75$ \\
\hline$\ldots \ldots \ldots$ & $3 \mathrm{I}$ & Other I \\
\hline ..................... & 36 & to Animals.. 88 \\
\hline Solid Vegetable Substances............. & 39 & eects........... \\
\hline (with and without the addi- & & 90 \\
\hline er) $\ldots \ldots \ldots \ldots \ldots \ldots \ldots$ & $4 \mathrm{r}$ & $\ldots . . . .6$ dr \\
\hline 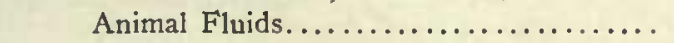 & 45 & the Disease.... 93 \\
\hline 西, & 45 & . 93 \\
\hline$\ldots \ldots \ldots \ldots \ldots \ldots \ldots \ldots \ldots$ & 46 & $\ldots \ldots \ldots .94$ \\
\hline k..................... & 48 & atory.............. 94 \\
\hline 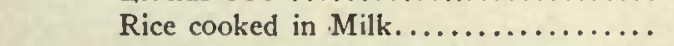 & 48 & boratory........... \\
\hline olidified Blood-serum........ & 48 & ....... \\
\hline umen...$\ldots \ldots \ldots \ldots \ldots \ldots \ldots$ & 48 & Preparation and Care of Culture-media...... 97 \\
\hline$\ldots \ldots \ldots \ldots \ldots \ldots \ldots \ldots$ & 49 & The Cleaning and Sterilization of Glassware \\
\hline dia and Other Special Media. & 49 & ats............ \\
\hline ee Oxygen................. & 51 & Cultures... IC \\
\hline and Deep Growths.............. & 51 & 1 of Infectious Material.... I 106 \\
\hline Fermentation-tubes $\ldots \ldots \ldots \ldots \ldots \ldots$ & 52 & Methods of Inoculation................ 108 \\
\hline rogen, in Carbon Dioxide, & & . IC \\
\hline & & of Collections............... I \\
\hline 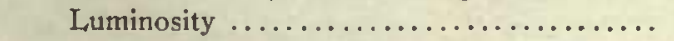 & $\infty 0$ & Distilled Water....................... \\
\hline
\end{tabular}




\begin{tabular}{|c|c|}
\hline eral Considerations-Continued. & ormulæ \\
\hline Microscopes ....................... 129 & Stains: \\
\hline Photography and Photomicrography......... Iзо & laneous. . \\
\hline $\begin{array}{l}\text { Some Milestones in the Progress of Bacteri- } \\
\text { ology } \ldots \ldots \ldots \ldots \ldots \ldots \ldots \ldots \ldots \ldots \ldots \ldots \ldots\end{array}$ & ng $\ldots \ldots \ldots \ldots \ldots \ldots \ldots \ldots \ldots \ldots$ \\
\hline$\ldots . .154$ & \\
\hline$\ldots \ldots \ldots .159$ & \\
\hline icters......... 176 & edia............. \\
\hline haracters............. I78 & alture-media.............. \\
\hline Work........... & neous ... \\
\hline A Final Caution.................... 184 & Fixing Fluids.............. \\
\hline
\end{tabular}

\section{BIBLIOGRAPHY, GENERAL I,ITERATURE.}

I. Journals $\ldots \ldots \ldots \ldots \ldots \ldots \ldots \ldots \ldots 203$

II. Transactions, Beiträge, Jahresberichten, Festschriften, etc......... 204

III. Manuals ....................... 204

IV. Physical, Chemical, Zoological, and Botanical Works of special use to the Plant Pathologist.......... 206

V. Books and Papers of more or less general intcrest..............2210

VI. Important Books and Papers on special human and animal diseases. 212

VII. Predisposition, Conditions Favoring Infection or Immunity........ 214

VIII. Symbiosis, Antagonism.......... 214

IX. Carriers of Infection........... 2I5

X. General Morphology of the Bacteria. 2I5

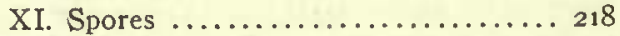

XII. Flagella ................... 219

XIII. Capsules .................... 220

XIV. Stains and Staining Methods...... 22I

XV. Morphological and Physiological Changes due to Changed Environment ....................222

XVI. Culture-media ................ 223

XVII. Methods of Work, Apparatus, etc... 226

XVIII. Special means of Differentiating Bacteria .................. 229

XIX. Aerobism, Anaerobism........... 230

XX. Fermentations, Gas-formation, Enzymes, etc................ 232

XXI. Ptomaines, Toxins, Antitoxins, Serums, Phagocytosis, etc......... 235

XXII. Attenuation, Virulence........... 236

XXIII. Pigments, Green Bacteria......... 236

XXIV. Reduction and Oxidation......... 239

XXV. Nitrifying and Đenitrifying Organisms, Use of Free Nitrogen...... 239

XXVI. Use of Free Carbon Dioxide....... 24I

XXVII. Luminous Bacteria.............. 24I

XXVIII. Hydrogen Sulphide and otherwise unclassified By-products........ 242
XXIX. Action of Light on Racteria....... 243

XXX. Effect of Electricity............ 244

XXXI. Action on Bacteria of Roentgen Rays, Radium Rays, etc........ 245

XXXII. Effect of High Pressure on Bacteria.. . 245 XXXIII. Action of Heat and Cold on Bacteria. 240 XXXIV. Thermophilic Bacteria........... 247

XXXV. Resistance to Dry Air ............ 248

XXXVI. Action of Acids and Alkalies...... 249

XXXVII. Agglutination and Precipitation..... 249 XXXVIII. Antiseptics and Germicides........ 250

XXXIX. Chemotropism, Thermotropism, Gcotropism, Contact-Irritation, etc.... 253

XL. Osmotic Pressures............... 254

XLI. Chemical Analysis of Bacteria.....254

XLII. Distribution of Bacteria-Geographjcal and Altitudinal........... 254

XLIII. Soil-Organisms; Putrefactive Or-

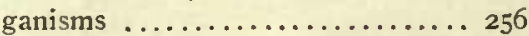

XLIV. Vinegar-bacteria ............. 256

XLV. Silage-bacteria, Fermentation of Tobacco, of Indigo, Retting of Flax, of Sisal Hemp, etc., Softening of Pickles, Sauerkraut, etc.......256

XLVI. Bacteria in Water and Ice; Dungbacteria ................... 258

XLVII. Milk-bacteria ; Cheese-bacteria; Butter-bacteria; Meat-bacteria....... 259

XLV.III. Bacteria in Bread.............. 260

XLIX. Iron-bacteria................ 261

L. Sulphur-bacteria...............26I

LI. Bacteria in Prehistoric Times...... 262

LII. Preparation of Slides, Cultures, etc., for Museums, etc............ 262

LIII. Stock-cultures, how best kept; Vitality on Media................ 263

LIV. Color-charts; Nomenclature of Colors ...................... 263

LV. Photography and Photomicrography.. 263

LVI. Methods and Systems of Classification 264

LVII. Useful Catalogues.............. 265 


\section{ILLUSTRATIONS.}

\section{PLATES.}

Plate I. Frontispiece.

Page.

(I) Ferdinand Cohn, founder of modern systematic bacteriology. Deceased.

(2) Robert Koch, founder of German school of bacteriology, director of the Institute for Infectious Discases at Berlin.

(3) Louis Pasteur, founder of French scliool of bacteriology. Deceased.

(4) Dr. Roux, one of the leading spirits of the Pasteur Institute.

(5) Em. Duclaux, professor in the University of Paris and director of the Pasteur Institute. Deceased.

2. Bacterial Olive-knots produced on four plants by needle-pricks....... Io

3. Cross-section of Petiole of Muskmelon, showing bundles disorganized by Bacillus tracheiphilus......

4. Datura metclloides eight days after Inoculation with Bactcrium solanacearum ........................ 16

5. Zciss Horizontal Photonicrographic Outfit ..................... 26

6. Arnold Steam Sterilizer, Lautenschläger Dry Oven, Hot Plate, and Chamberland's Autoclave......... 48

7. Hydrogen Generator and Wash Bottles in use................... 55

8. Thermostat-roon $\ldots \ldots \ldots \ldots \ldots \ldots . . .674$

9. Chamberland Autoclave............ 8.4

10. Engine for furnishing Vacuum and Compressed Air................

Plate il. Culture-room, i. $\varepsilon$., place for making Cultures of Bacteria in Still Air... 104

12. Movable Hood of Wood and Glass, under which Bacteriological Transfers may be made............ 106

13. The Reinlold-Giltay Nicrotome..... 120

14. Distilled-water Apparatus.......... 124

15. Zeiss Stand ITa.............. 129

16. Zeiss Photomicrographic Stand Ic... 129

17. Mounted Camera for Enlarging, Reducing, and Natural-size Work.... 134

18. Lantern-slide Room............. 144

19. Black Spot of the Plım........... 148

20. Bacterial Disease of Broomcorn..... 150

21. Bacterial Black Spot of Walnut..... I74

22. Ditto, Late Stage............. I76

23. Transmission of Wilt of Cucumber by Insects............... 178

24. Brown Rot of Potato. Natural Infection of Tuber, Artificial Infection of Stems ................... 202

25. Brown Rot of Potato. Shoots wholly destroyed by inoculation ....... 202

26. Tomato-plant inoculated with Bac:terium solanacearum............ 202

27. Bacterial Wilt-disease of Tobacco....202

28. Young Pear-shoots blighted by Bacillus amylovorus.............. 202

29. Grcen Pear-fruits eight days after Inoculation with Bacillus amylovorus. 202

30. Quince-shoots and Pear-fruits (crossscction) showing Blight due to Bacillus amylovorns........... 202

31. Sinall Green Apples blighted by $B a$ cillus amylovorus............... 202

\section{TEXT FIGURES}

Ftc. 1. Cross-section of Sweet-com Stem parasitized by Bacterium Sfercarti........

2. Cross-section of a Raw Carrot, showing wedging apart of Parenchyma Cells by Bacillus carotovarus............

3. A Detail from Fig. 2...............

4. Turnip-root, slowing Bacterium campestre confined to vicinity of Vessels....

5. Bacterium campestrc. A small portion of Fig. 4 cnlarged...............
Fic. 6. Turnip-root, showing Bundle occupied by Bactcrium campestre and the commencement of a cavity; a later stage than Fig. 5................. II

7. Caulifower-petiole, showing Bundle destroyed by Bacterium campestre..... I2

8. Melon-wilt due to Bacillus tracheiphilus. 13

9. Cross-section of Bundle of a Cucumberstem, showing Bacillus tracheiphilus restricted to the Spiral Vessels and Three pitted vessels.............. 
Fic. 1o. Datura metelloides Inoculated by Needlepricks with Bacterium solanacearum. The same plant as in Plate 4 , but six days later.

II. (a) Capsule of Organism plated from Black Spot of Plum; (b) Viscid Culture-medium from which $a$ was obtained

12. Yellow Ooze from Black Spot of Plum stained by ordinary method .........

13. Tenuous Threads of Bacillus tracheiphilus drawn from a Muskmelon Stem ..

14. A detail from Fig. I3, highly magnified.

15. Flagella stained from a pure culture of a Bacterium grown in Water containing a few drops of Uschinsky Solution.

16. Beyerinck's Drop Bottle..............

I7. Double Blow Bulb............... 22

18. Short Form of Bacterium campestre when crowded................. 23

19. Long Form of Bacterium campestre when grown on Sugar-agar ........ 23

2o. Hanging-drop Culture .............. 24

2I. Involution-forms of Bacillus tracheiphilus ....................... 24

22. $\mathbf{Y}$-shaped Forms from Root-tubercles of Clover ....................... 2

23. Zeiss Compensating Ocular, with Screw or Filar Eye-piece Micrometer ...... 25

24. Zeiss Upright Photomicrographic Camera ........................ 26

25. Hand-lens for examining Bacterial Cultures ....................... 27

26. Hand-lens for examining Bacterial Cultures, showing another form of mount.

27. Zeiss Cover-glass Measurer...........

28. Nelson's Photographic Gelatin....... 30

29. Agar-agar as received from Japan. (Slender "Kanten").............. 3I

30. Another form of Agar-agar made in Japan (Square "Kanten")........ 32

31, 32. Gelidiums furnishing Agar-agar... 33, 34

33. Agar-agar Flour as received from European Manufacturers.............. 35

34. Schleicher and Schüll's Folded Filter Papers ..................... 36

35. Thermo-regulator for Blood-serum Oven. 37

36. Iris-rhizome-rot Organism grown on Sterile Raw Carrot.............. 4I

37. Tin-box in which Pipettes, Scalpels, etc., may be sterilized ............... 42

38. Fluid Culture showing rise of Viscid Precipitate when twirled rapidly......
FIG. 39. Platinum-iridium Transfer Wires ..... 43

40. Simple way of filtering with Chamberland Bougie................. 44

4I. Roux Filter for separating Bacteria from their Products ...............

42. Section of the Arnold Steam Sterilizer, showing Principle of Action ........ 46

43. Lautenschläger Centrifuge.......... 47

44. Wire-crate for holding Media to be sterilized..........................

45. Oven for use in solidifying Blood-serum, ctc., at Temperatures below $100^{\circ} \mathrm{C}$...

46. Simple Rack for holding Fermentation tubes....................... 52

$47,48,49$. Fermentation-tubes in actual use.. 53

50. Ordinary Kipp Gas-generator........ 54

5I. Hempel's Burettes for Gas-analysis.... 55

52. Hempel's Simple Pipette for I,iquid Reagents .......................... 56

53. Small Novy Jar............... 57

54. Large Novy Jar; the most convenient Form ..................... 58

55. Simple Device for growing organisms in Nitrogen ..................... 59

56. Test for Reduction of Nitrates to $\mathrm{Ni}$ trites ......................6 63

57. Crystals formed in Nutrient Agar as the Result of Bacterial Growth......... 66

58. Thick-walled Flask for Filtration or Evaporation in vacuo............ 67

59. Titration-devices ................ 68

6o. Sodium-hydrate Bottle............ 69

6r. Effect of Sunlight on Pear-blight Bacillus ..................... $7 \mathrm{r}$

62. Effect of Sunlight on Bean-spot Bacterium ..................... $7_{r}$

63. Water-bath for Thermal Death-point Experiments ................. 76

64. Roux Metal-bar Thermo-regulator .... 77

65. Thermometer for Thermal Death-point Experiments ................. 79

66. L.eveling Apparatus............... 80

67. Dewar Glass for Experiments with Liquid Air ................. 8

68. Petri-dish Poured Plate inoculated with a measured quantity of a Bouillon Culture of Bacillus tracheiphilus..... 82

69. The same as Fig. 68, but poured after Exposure to Liquid Air.......... 83

70. Stomatal Infection by Bacterium pruni in Green Fruits............... 84

71. Stomatal Infection by Bacterium pruni in Leaf.

72. Stomatal Infection by Bacterium prunia Later Stage in Fruit........... 88 
FrG. 73. Seedling Sweet-corn Plant in Stage when most of Infections occur ...... 89

74. Stomatal Infection of Sweet-corn Leaf by Bacterium Stcwarti..............

75. A Detail from Fig. 74, highly magnified. 76. Water-pore Infection by Bacterium campestre ........................

77. Bacteria from Fig. 76, enlarged 2,000...

78. Single Spiral Vessel occupied by $\mathrm{Bac}$ terium campestre.................

79. Water-pore Infection in Cabbage; a later stage than that shown in Fig. 76. 94

80. Angular Leaf-spot of Cotton, Nearly Natural Size................... 95

81. Find of Vacuum-pipe on Laboratorytable .......................

82. Portion of Work-table, showing Simple Apparatus for Distilling Water... . . 97

83. Apparatus for rapidly filling Test-tubes with Measured Portions of Fluid Culture-media ................... 98

84. Can for holding Culture-media....... 99

85. Wrapped Petri Dishes.............. I00

86. Meyer's Hypodermic Syringe......... IOI

87. Sections through Tooth of a Cabbageleaf, showing Entrance of Bacterium campestre .................... 102

88. Green Cucumbers soft-rotted by Bacillus carotovorus................... 10 3

89. Block for holding Test-tube Cultures... I04

9o. Constant Burner, with Cut-off for reducing size of Flame............... 105

91. Steel Sewing Needle (Nu. Io) set into Bone-handle and used for Punctureinoculations ................... 106

92. Compressed-air Tank and Spray-tube... I07

93. Atomizers for use with $92 . \ldots \ldots \ldots \ldots$...... 108

94. Hand-sprayer for Distribution of Bacteria ........................ I09

95. Inoculation Cage for Herbaceous Plants. IIo

96. Labels froin Test-tube Cultures........ II I

97. Wooden Labels from Inoculated Plants. I I I

98. Temperaturc-record Sheets........... II2

99. Nitrate-bouillon Records............. II3

100. Sample from Card-catalogue, Two-thirds Actual size................... II4

IoI. Heading of Large Sheet for Voluminous Abstracts................. II 4

I02. Green-cucumber Skin, Contents rotted out by Bacillus aroideae........... 115

103. Pillsbury Slide-boxes .............. 116

I04. Another Form of Pillsbury Slide-box... II7

105. Sinall Paraffin-oven used by writer.... II 8
FIG. 106. Infiltrated Tissues cmbedded in Paraffin in a Watch-glass............ I ig

107. Infiltrated Material mounted ready to cut....................... I is

108. Drawer with Compartments for holding cmbedded material........... 120

Iog. Coplin's Staining Jar............. I2I

I10. Coplin's Staining Jar, cross-section.... I2I

II A. A Series of Coplin's Staining Jars Ready for Use................ 121

112. A Page from the Paraffin-record-book. 122

113. A Mounted Slide of Serial Sections.... I 122

I 4. A, Rodgers knife for serial sections; $B$, Lentz knife for cutting hard material with slant stroke; C, Torrey knife for serial sections; $D$, Torrey knife for free-hand scctions. $a, b, c, d$, end views of $A, B, C, D \ldots \ldots \ldots \ldots$ I23

115. Leaf-tooth of Cabbage infected by Bacterium campestre............... 124

II6, II7. Details from Fig. 115 ....... I24, I25

II8. Stomatal Infection of Cotton-leaf by Bacterium malvacearum........... I26

119. The Reinhold-Giltay Microtome Arranged for cutting Celloidin, etc..... 127

120. Sub-stage Arrangement on Zeiss Stand Ic................... I30

121. Newer Form of Zeiss-Abbe Camera.... I3I

122. Zeiss Planar Lenses.............. 132

123. Apparatus for Photographing Natural Size ....................... 133

124. Swinging Camera for Equal Lighting of Exposed Object............. 134

125. Petri-dish Poured Plate photographed by transmitted light ........... 135

125. Green Leaf (Delphinium) with Black Spots; photographed on a rapid nonisochromatic plate ............. 138

127. Green Leaf (Delphinium) with Black Spots; photographed on a slow isochromatic plate............... I39

128. The Wager Exposure-scale.......... I4I

129. The Collins-Brown Camera, made by Folmer \& Schwing............. 145

130. Cross-level for use with Camera...... I46

131. Device for cutting out light in Air-shaft. 146

132. Side-view of a Dark-room, convenient for a few persons.............. I47

133. Top-view of a Dark-room, convenient for a few persons.............. I48

134. Side-view of another Small Darkroom ..................... I4 8

135. Top-view of a Small Dark-room sliown in Fig. $134 \ldots \ldots \ldots \ldots \ldots \ldots \ldots \ldots$ 
FIG. 136. Case for protecting Squeegee-plates from Dust and Scratches .......... I49

I37. Bacterium triloculare, Ehrenberg's first figure $\ldots \ldots \ldots \ldots \ldots \ldots \ldots \ldots \ldots \ldots \ldots \ldots \ldots$

138. Bacterium triloculare, Ehrenberg's second figure................... 169

I39. Bacterium termo, figured by Cohn.... I70

I40. Dallinger and Drysdale's conception of Bacterium termo................. I70

I4I. Termo-like Organism obtained by throwing Beans into Water........ I70
Page.

FIG. I42. Iris-rhizome-rot; Crowded Agar-plate after 45 hours at $25^{\circ} \mathrm{C} \ldots \ldots \ldots \ldots$. I 79

I43. Iris-rhizome-rot; Thin Sowing on Agar at end of 4 days; temperature $25^{\circ} \mathrm{C}$. $\quad$ I80

144. Bacillus aroideae grown on Agar-plate at $37^{\circ}$ to $38^{\circ} \mathrm{C} \ldots \ldots \ldots \ldots \ldots \ldots \ldots \ldots \ldots \ldots$

145. Bacillus aroideae grown on Agar-plate at $25^{\circ} \mathrm{C} \ldots \ldots \ldots \ldots \ldots \ldots \ldots \ldots \ldots \ldots \ldots$

146. Apparatus for Graduai Substitution of Alcohol for Water in Tissues....... I84 


\title{
Bacteria in Relation to Plant Diseases.
}

\author{
BY ERWIN F. SMITH.
}





\title{
Bacteria in Relation to Plant Diseases.
}

\author{
BY ERWIN F. SMITH.
}

\section{Part I.-An Outline of Methods of Work.}

\section{GENERAL REMARKS.}

The following ontline of methods for the study of bacterial diseases of plants, which are now in use in the I aboratory of Plant Pathology, United States Department of Agriculture, has gradually assumed its present sliape as a result of the writer's field, lot-liouse, and laboratory experiments during the past thirteen years. In nearly the same shape, so far as arrangement is concerned, but in a less complete form, it was published in the American Naturalist in 1896.*

The sclieme here presented is entirely practicable and is believed to be not more extended than the exigencies of the case require; in the interest of better metlods of work in plant patliology it is reconnunended to all who contentiplate a special study of bacterial diseases of plants, and also particularly to those who intend to describe and nanne species of bacteria, whether pathogenic or nonpathogenic. Those who doubt the necessity for so much work are advised to read procedures recommended for the study of bacteria by a committee of the American Public Health Association, and the earlier paper by H. Marshall Ward (Bibliog., III). $\dagger$ It would be still more to the point if they would isolate a dozen bacterial organisuns from the soil, air, or water, and undertake faitlfully to identify them by means of any of the older descriptive works, e.g., Eisenberg's Diagnostik or Saccardo's Sylloge Fungorum, or even by such recent manuals as those of Sternberg, Lelımann \& Neumamn, Flïgge, Migula, or Cliester (Bibliog., III). Everyone who has carefully inquired into the matter knows that the brief statement of the beliavior of an organism on nutrient agar, on gelatin, and on two or three other media, with perlaps a loose staten1ent of its color and size, no longer constitutes a description which describes. Such accounts, of which there are a great nnany, usually fail to mention just those things which night serve to distinguish the organism from its fellows. If a new species is not to be described so that it can be identified by others, what then is the use of any name or any description? The nane will only serve to encuunber future synonyny and to recall the incapacity of its anthor.

*The bacterial diseases of plants: A critical review of the present state of our knowledge, parts I-VI, Am. Nat., August and September, I8g6.

†For Bibliography see end of volume. 


\section{THE DISEASE.}

The line between disease and health is sometines a very narrow one, especially when nothing more is involved than some slight change in function. The difference, however, is very striking in many of the diseases here considered. The writer has used the word "disease" in the common acceptation of the term, neaning thereby

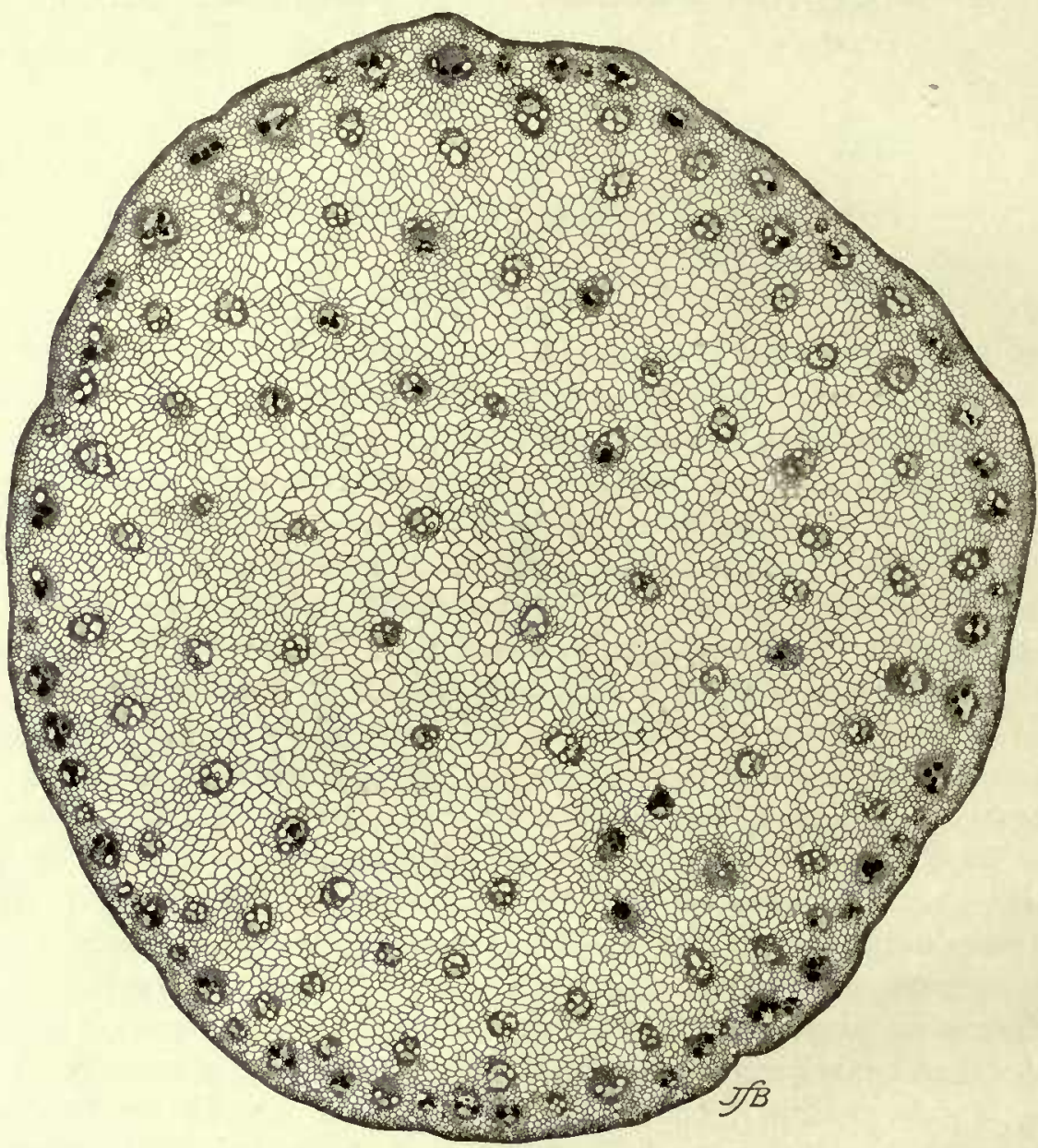

Fig. 1.*

any marked deviation from the nornal functions or structure of the plant as it now exists, whether wild or greatly modified by cultivation. In a sense, such a change as has taken place in the cauliflower, the normal flower-shoots of which liave becone

*FIG. I.-Cross-section of the upper part of a sweet-corn stem parasitized by Bacterium Stezuarti (Erw. Sm.). The location of the bacteria is indicated by black slrading. Most of the affected bunkles are on the periphery. The bacteria have not escaped into the parenchyma. Jamaica, Long Island, N. Y., July 16, 1902. The section was taken several feet from the ground, but the stem infection undoubtedly took place through one or more of the llawer nodes. Drawn from photomicrograph of a section stained with carbol-fuchsin. Exactly similar sections, but with a larger number of infected bundles, have been cut from stems of sweet-corn plants infected by the rwriter in August, 1902 , during the seedling stage sllown in fig. 73. 
compacted, aborted, and enlarged into a flesliy edible mass, might well be regarded as a diseased condition, but it is not so regarded for the purposes of this book. On the contrary, a soft rot of the cauliflower head is regarded as a disease. Bacterial diseases of plants usually involve both functional and structural changes.

Inasn111cl as the word "symuptouns" lias a subjective as well as an objective connotation in medical terminology, the writer has preferred to substitute the word "signs" for those objective cliaracters whicl serve to distinguish one plant disease from anotler.

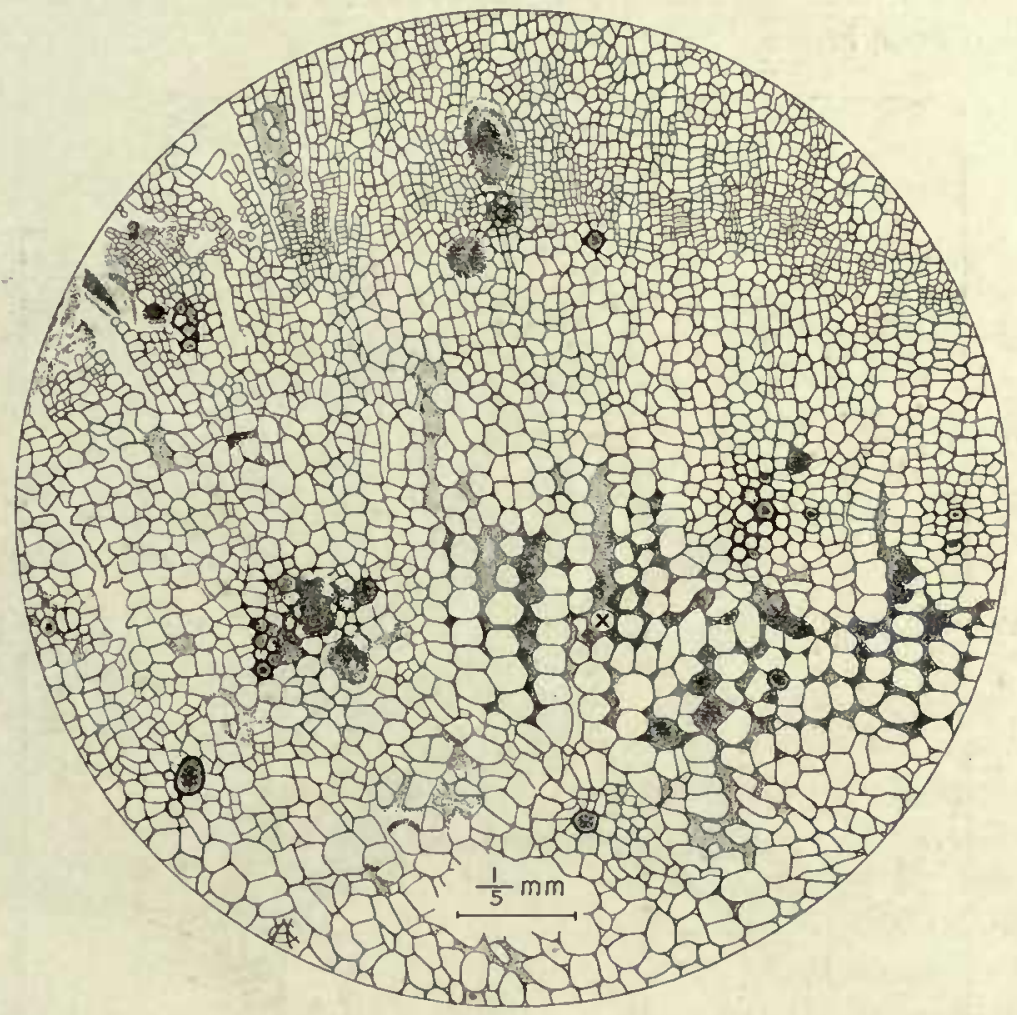

Fig. 2.*

'The student will, naturally, first turn lis attention to a careful study of the disease. Under this head should be considered: (1) Previous literattre; (2) Geographical distribution; (3) Signs of the disease ; (4) Pathological histology; (5) Direct-infection experiulents.

* Fig. 2.-Cross-section of a raw carrot, showing wedging apart of parenchyma cells by Bacillus carotovorus Jones; from paraffin-infiltrated material. The carrot was fixed in strong alcohol 72 hours after placing on its cut surface one loop of a fuid culture. The inoculation was made in the middle af a cross-section of the whole root, I cm. thick, placed in a sterile Petri dish. The surface of the root was sterilized in mercuric chloride water. This section was made several millimeters below the inoculated surface. A small portion of it at $\mathbf{X}$ is shown more highly magnified in fig. 3 . This section was stained with carbol-fuoh sin and bleached in 50 per cent alcohol. Drawn under Zeiss I $6 \mathrm{~mm}$, apochromatic objective with No. 4 compensating ocular and the Abbe camera. 
In the present state of our knowledge (I) and (2) can usually be cousidered only after a very careful study of (3), (4), and (5), and of the organisin itself. They involve a knowledge of modern languages, and a very considerable faniliarity witl scientific literature.

\section{PREVIOUS LITERATURE.}

One of the first requisites in a student is a knowledge of how to use literature. Previous literature is, lowever, often of such a fragmentary and uncertain sort, as we sliall see, that it is impossible to decide whether a disease is actually new or has been written upon before.

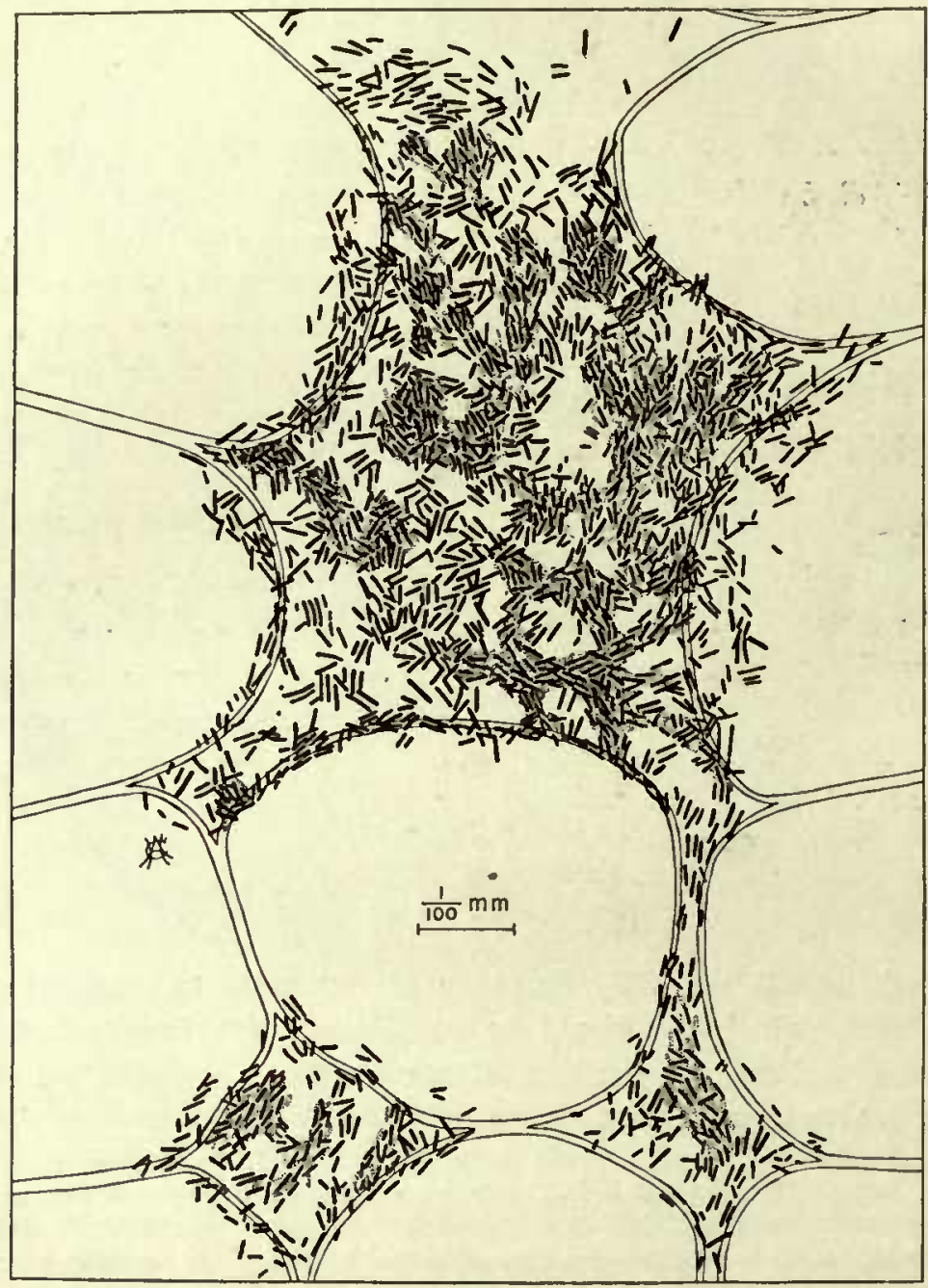

Fig. 3.*

The literature of plant diseases will not be referred to in this volume, except occasionally and incidentally. The bibliography of this volume deals only with general bacteriology-human and animal diseases, 1nethods of work, etc.

*FIG. 3.-A detail from fig. 2. Bacillus carolovortus wedging apart cells of the carrot. Drawn mostly from one plane. In placing the cover-glass a few of the bacteria have been crowded out of the intercellular spaces into parts they did not originally occupy. $\times 1,000$. 


\section{Gl:OGRAPHICAL, DISTRIBUTION.}

Geographical distribution is an exceedingly interesting problem to many naturalists. The writer shares this feeling and lias made every effort to determine it, as far as possible, for each disease. There arc, however, still many gaps in our knowledge-the whole subject is so new, and information from all parts of the world is desired. The inner temperature of plants conforms nearly or quite to that

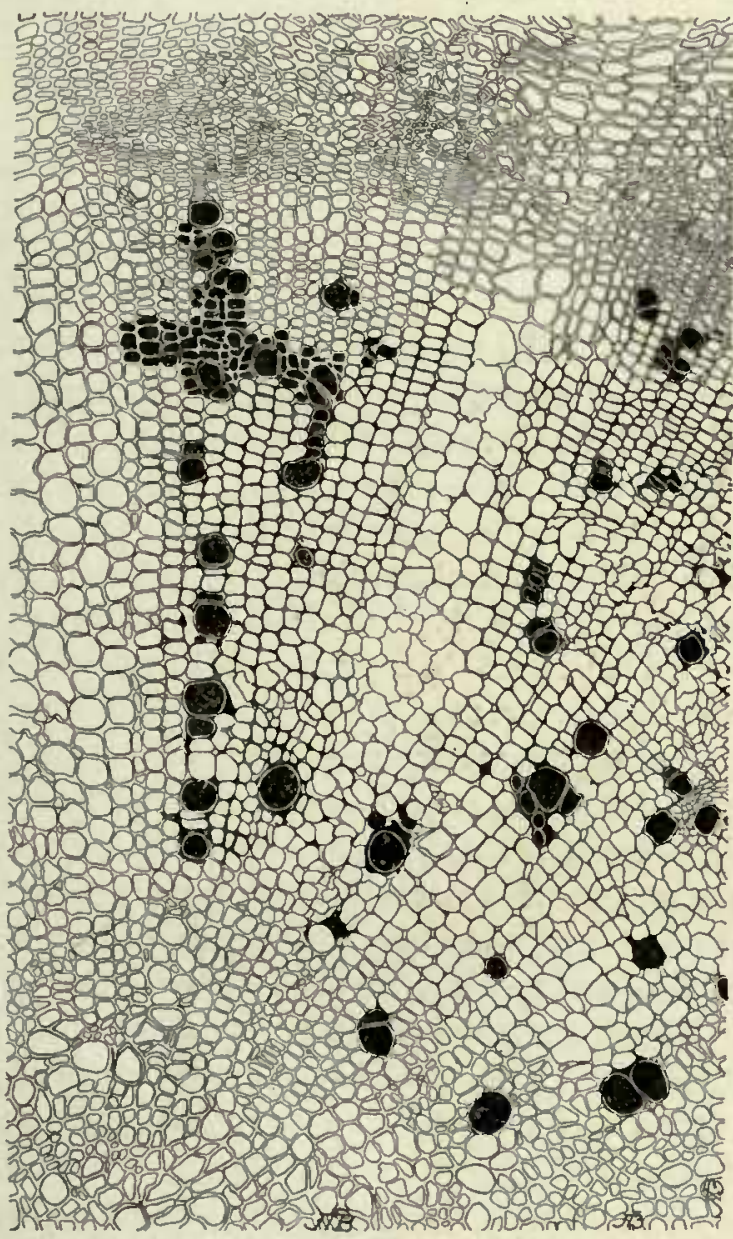

Fig. 4.* of the surrounding medium, and we night therefore expect, in some cases at least, to find a rather more sharply restricted distribution than in diseases of the warm-blooded animals. Fronn theoretical considerations we shonld expect the distribution of plant diseases to be more like that of diseases of fish and other cold-blooded aninals. Whenever the bacterium is able to endure as wide a range of temperature as the host-plant, we slould expect to find it as widely distribited.

\section{Signs OF ThF Disfasf.}

Great care should be exercised in the description of the physical signs and of the lesions due to the parasite, so that the disease may be identified from these alone, if necessary. A great many cases should be examined and the signs must be recorded in detail and with great accuracy. It should be remembered that here is a frequent opportunity for error to creep in, since the plant may be affected by two distinct diseases which liave been confused. Good figures are always desirable, but are not absolutely essential. If possible, however, photographs, pen or pencil drawings, and good water-color sketches should be secured.

*FIG. 4.-Cross-section of a turnip root, showing vessels occupied by Bacterium campestre as the result of a pure-culture inoculation hy means of needle-pricks on the leaves. Material fixed in strong alcoliol, infiltrated with paraffin, cut on the microtome, stained with safranin-picro-nigrosin, and the differential washing stopped at just the right stage. The bacteria are confined to the vessels and their immediate vicinity. They do not occur in the phloem, a small portion of which is shown at the top of the picture. Section made from the same root as fig. 6 , but lower, in the tapering part. Drawn from a photomicrograph. $\times 85$. 
When all is said, the signs of 11any plant diseases, it must be admitted, are n1ncl alike, and this is particularly true of the bacterial soft rots. This is an added reason for studying then in each case as critically as possible. The captious reader miglit also rennember that while an enormous annount of painstaking labor has been devoted to animal pathology, including twenty centuries in case of hu1wan medicine, we are only in the beginining, so to speak, of our knowledge of the minute pathology of plant diseases, and especially of those due to bacteria.

\section{PATHOLOGICAL Histology.}

The relation of the parasite to the tissues of the lost should be studied both in fresh inaterial and in stained microtome sections inade from material properly fixed and infiltrated with paraffin. The organisn may be a wound-parasite, or it may be able to enter through uninjured parts, $i . e$., in the absence of visible wounds. Often it affects special tissues or systems of tissues. Sonnetimes the bacteria are quite closely restricted to the vascular system, forming occlusions (figs. r, 4, 5, 7, and 9). Sometimes they spread widely in the intercellular spaces of the parencliyna, forming numerous cavities (figs. 2, 3, and 6). Sometines there are striking reactions on the part of the host, e.g., an enormous multiplication of cells resulting in cankers or tumors (plate 2). The liabits of the parasite and the behavior of the tissues of the host are best learned from serial sections. The student should not fail to preserve (properly labeled) in strong alcohol an abundance of typical diseased material for future study, exchange, or reference. Stained cover-glass preparations and stained sections should also be mounted in xylol-balsain, carefully labeled, and filed away. Neglect of these precautions prevents the experimenter from furnishing the convincing proofs in case his printed or oral statenents are called in question.

As to the best methods of fixing plant 111aterial containing bacteria mucl renains to be learned. The writer has had best success with strong alcohol ( 90 per cent to absolute) and with picric acid dissolved to sattration in absolute alcholıol and used boiling hot. In general the watery fixatives can not be used because they do not hold the bacteria in place; even alcohol as strong as 70 per cent allows many kinds of bacteria to diffuse out into the fluid. Boiling absolnte alcohol saturated with mercuric chloride is sometimes 11seful. The alcolıol may be boiled in an open Erlenmeyer flask set on wire gatuze on an iron tripod over a small Bunsen flame. The alcohol is first brought to a boil. The pieces of tissue are then thrown in and allowed to remain 3 to 5 minutes. It is better to divide the material iuto pieces suitable for embedding before fixing rather than after. Uswally sucl a piece should not measure more than one-half square centineter or one-half cubic centineter. As far as possible only fresh material should be used for this purpose. Old inaterial has often absorbed air in quantity sufficient to render infiltration with paraffin inpossible or at least very difficult. In such cases infiltration in vacuo will often render good service. The writer uses a specially devised air-tight paraffin batli connected to the vacuum-punp. Even this device will not in every instance insure perfect infiltration. 


\section{DIRECT-INFECTION EXPERIMENTS.}

Direct-infection experinents will frequently separate out a parasite wlich is overwlielu1ed by sone saprophyte and thus funish better material for plate-cultures, and they are also sometines very useful when one is remote from laboratories and so situated that it is impossible to obtain pure cultures. It is, however, a crude metlood and only to be employed when more exact methods can not be used or would not serve as well. By "direct" infection is meant the transfer of fluids or solids from the diseased plant directly into the tissues of the healthy plant, an effort being made to include some of the supposed parasites in this transfer. It is a convenient expression and will be used often in this book.

\section{THE ORGANISM.}

This nuay be considered n11der three heads-its ability to produce disease, its form, and its pliysiological peculiarities. Many of the latter might equally well be denoninated cultural characters, and the pathogenic properties really belong under pliysiology, but are kept distinct for sake of convenience and because they constitute not only tlie 1110st in1portant attributes of the organisn, econonically speaking, bnt also a distinct and peculiar pliase of the investigation.

\section{PATHOGENESIS.}

What constitutes proof of the pathogenic nature of any organisn? Upon the ability of the student to give a proper answer to this question depends very largely his success or failure as an investigator. Henle perceived clearly what was necessary as long ago as 1840 , and Koch's rules are still fresh in the 111inds of all. There is consequently now so good an understanding of this strbject among anininal pathologists and professional bacteriologists that if this book were designed principally for such persons 110 comment would be necessary. A glance, however, at the literature of plant diseases slıows that n11any of the writers on bacterial diseases of plants have not had this professional training. The four cardinal requirenents, as understood by the writer, are as follows:

\section{RULES OF PROOF.}

(a) Constant association of the organism witl the disease.

(b) Isolation of the organism from the diseased tissues and careful study of the sane in pure cultures on varions media.

(c) Production of the characteristic signs and lesions of the disease by inoculations froul pure cultures into liealthy plants.

(d) Discovery of the organism in the inoculated, diseased plants, re-isolation of the same, and growth on various media until it is determined beyoud doubt that the bacteria in question are identical with the organisn1 which was inoculated. 
Under $(a)$ there should be numerons observations on many plants, with very careful microscopic examination of stained and unstained material. The cells of many plants contain granules which often dance about so actively (pedesis or Brownian movement) as to be very deceptive, and yet they are not bacteria. Living bacteria in plant tissues can always be stained so as to stand out distinctly if the sections are well prepared and sufficiently thin. When bacteria occur in plants as parasites they are usually very abundant in the vascular system, or the parencliyma, or both, and there is, so far as yet known, always a distinct breaking down (solution) of some portion of the tissues (see figs. 6 and 7 , and plate 3 ). If the parenchynnatic tissues are sound, if there is no bacterial ooze on unaking sections, if the vascular

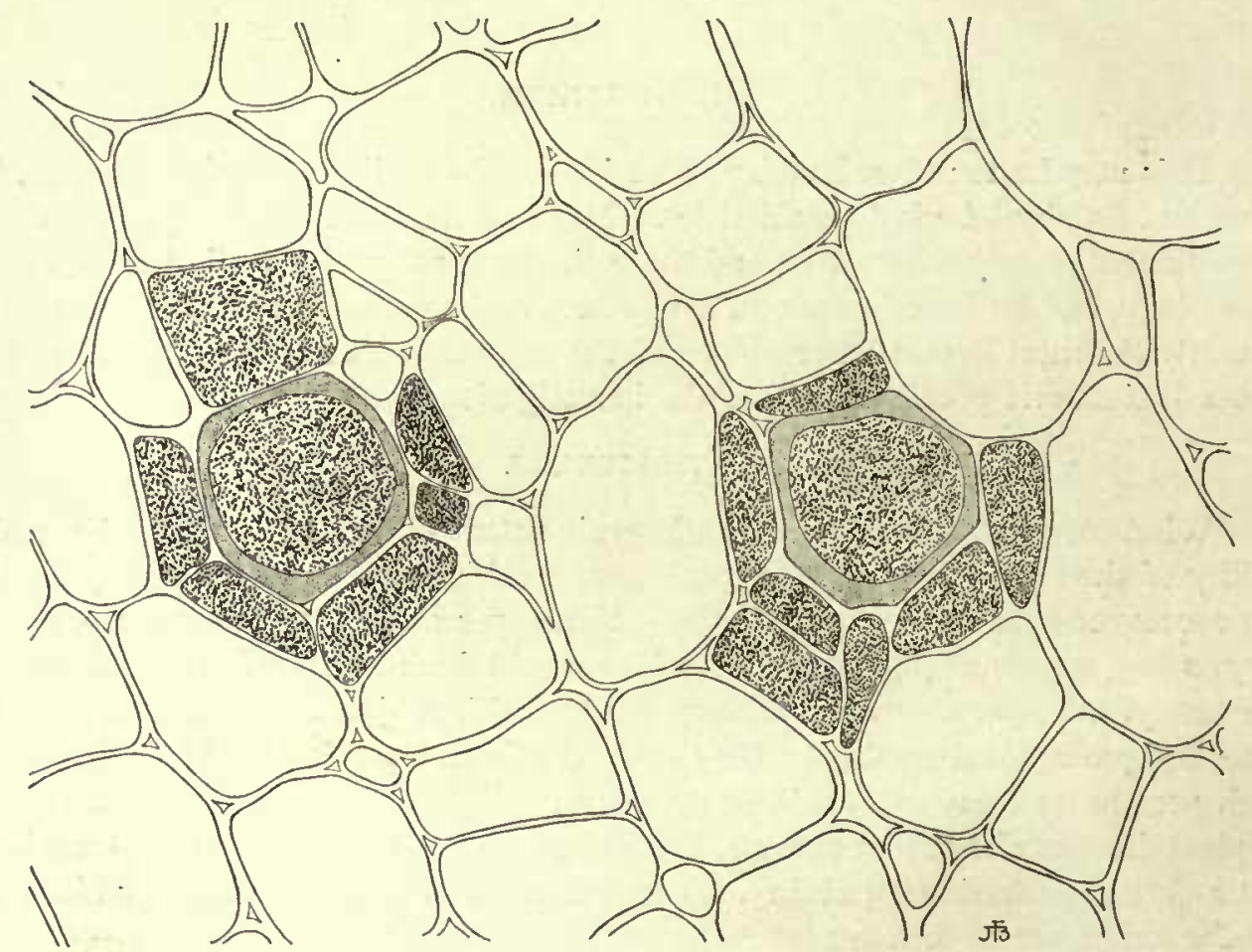

Fig. 5.*

system is not occupied, and if bacteria can not be demonstrated in the tissues by proper staining, then it is very unsafe to infer their existence from dancing particles, no matter how many may be visible in the unstained sections. Moreover, bacteria may be present in some of the plants and not in others, $i . e .$, not constantly present, and so not the cause of the disease. It is conceivable that they might also be present

*FIG. 5.-Bacterium campestre parasitic in a turnip-root (inoculated plant No. 53). This figure shows the bacteria crowding out into the cells surrounding the reticulated vessels. The lignified portion of each vessel is indicated by fine dots. Material fixed in strong alcohol, infiltrated with paraffin, cut on the microtome, stained with carbol-fuchsin, and the excess of stain removed in dilute aloohol, section then dehydrated and mounted in xylol-balsam. Drawn from a photomicrograph, the contrast here indicated being not greater than that shown in the seotion. $\times 500$ circa. 
PLATE 2.

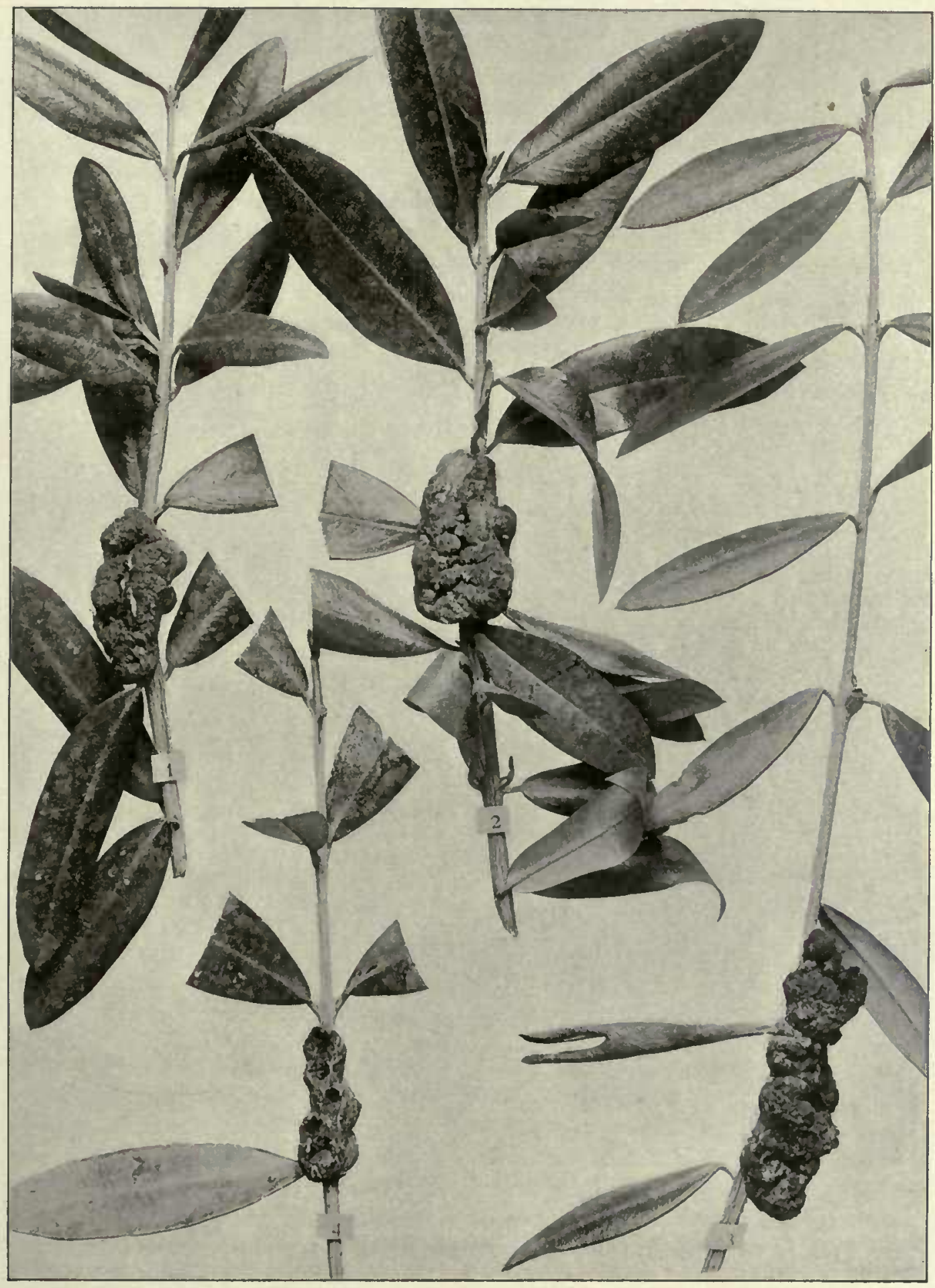

Bacterial olive-knots produced on four plants by delicate needle-pricks.

Inoculated January 4, 1904. Pholographed May 16, 1904, nearly natural aize. The organism came originally from an olive-knot obtained in California, where the divense has been very destructive for n number of years. A pure culture obtained from one of the Californin knots was inoculated into young growing olive-shoots and numerous knots resulted. From one of these, after about three montha, the organism was plated out and a subculture from one of the colonies was used to produce the knots here ahowa. 
and 
quite constantly, but merely as followers of sometling else. When possible, therefore, diseased plants should be exanined for the suspected pathogen, in large numubers, in different years, and from widely separated localities. Of conrse, if fungi are also present they nunst likewise be examined as to constant occurrence and patlogenic properties.

Under $(b)$ all of the standard nutrient media should be tried, and that repeatedly, until the student is entirely faniliar with the appearance and beliavior of the organism. It is usually best to isolate the organisn for experin1ent from selected portions of the tissue by means of Esmarcli roll-cultures or by the use of poured plates (Petri-disli cultures), generally the latter.

Isolations may also be made by inserting a sterile platinum needle or loop into the diseased tissue, obtaining therefrom a little fluid, and drawing this over the

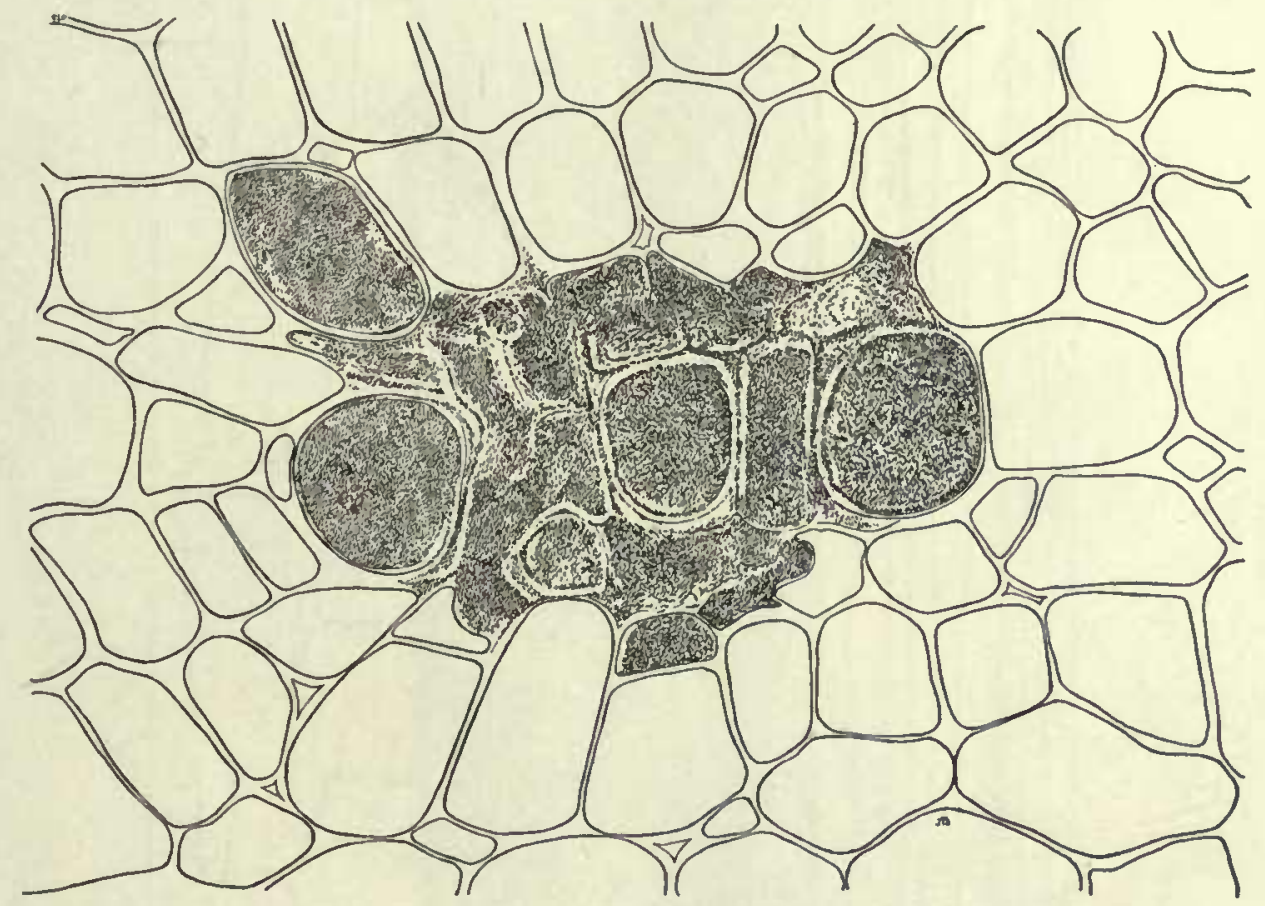

Fig. 6.*

surface of slant agar, gelatin, or potato a number of times. This is an old nethod introduced by Koch in I88I. If ten or twelve tubes are used, the final streaks will often consist only of scattering colonies, from one or more of which the subcultures 111ay be 111ade. The plate method has the great advantage of slowing just how many kinds of bacteria are present in the tissues (provided they will all grow in the nnedinn used and under the conditions of the experinnent), and just how numerons they are. In case of viscid organisms, or those forming compact zoogloex in the

*FIc. 6.-Cross-section of root of plant No. 53 (turnip) parasitized by Bacterium campestre, showing an early stage in the formation of a bacterial cavity. 'The original section was made from material fixed in alcohol, infiltrated with paraffin, stained with carbol-fuohsin, and washed in a mixture of alcohol and water. Drawn from a photomicrograph. $\times 500$. 
tissues, it is son1etines desirable to grow them for a day in bonillon before attempting the plate-cultures; but one must then be on his gnard, since it is quite possible by this method to start with enormous numbers of the right organism and have the bonillon culture filled with something else at the end of the 24 hours.

Pure cultures may also sometines be obtained by cutting ont pieces of the tissue and throwing then into tubes of c11ture media. This netlod, lowever, shows little or nothing as to the prevalence of the organisn in the tissues, and in

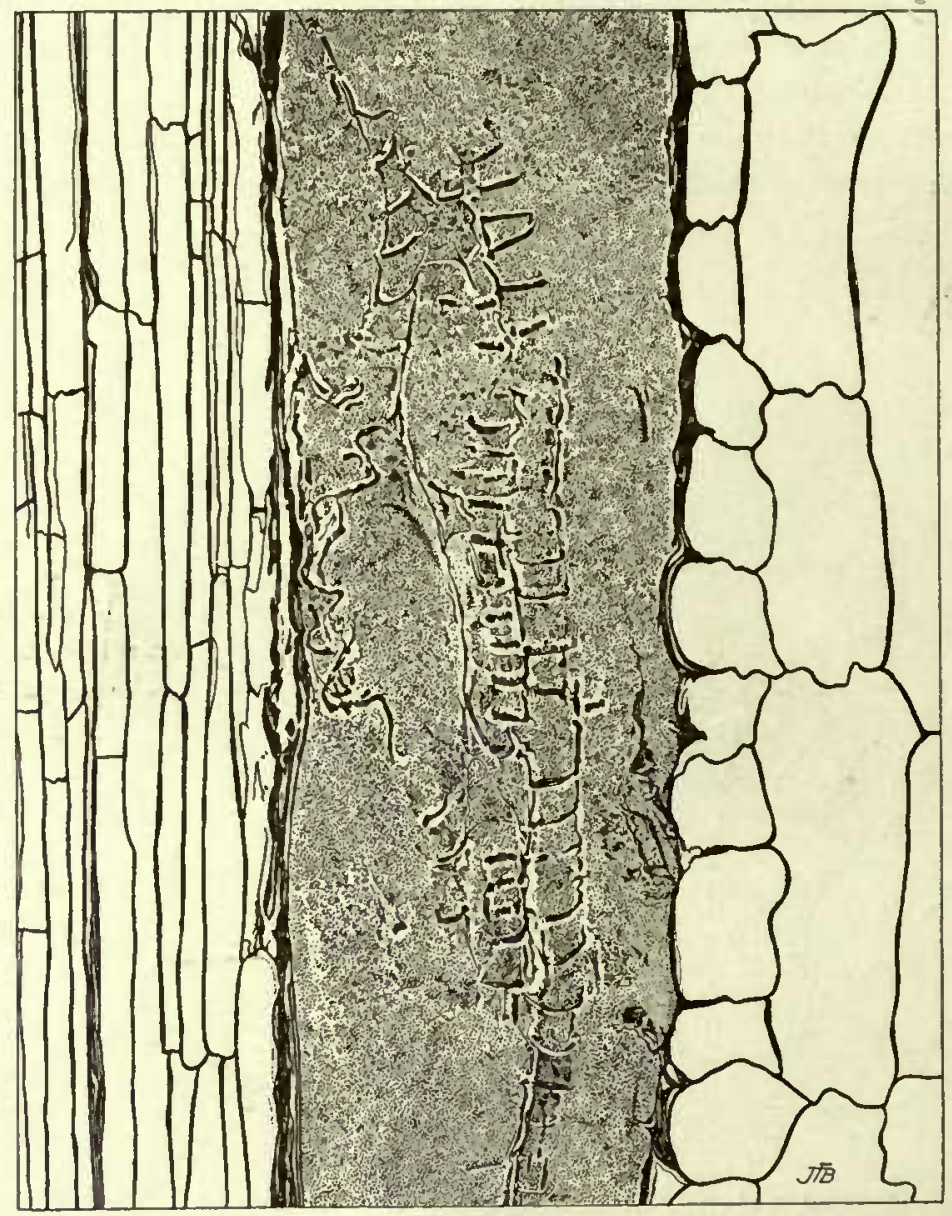

Fig. 7.*

the hands of beginners is very liable to miscarry. If growth is obtained it may indeed have come from many organisms of one sort pervading the tissues and cansing the disease, but it is not certain that it did not result entirely from one or

*FIG. 7.-Bundie in a cauliflower-petiole entirely destroyed by Bacterium campestre. The result of a pure-culture inoculation. Plant No. 112 inoculated March 10, 1897 , by needle-punctures on the blade of a leaf without hypodermic injection. First signs of disease March 20. Petiole put into a.lcohol on April 5. Longitudinal section. Tissues surrounding the bundle entirely free from bacteria. Section not made from the inoculated leaf, but from the first leaf that showed socondary signs. Drawn from photomicrograph of a paraffin section stained with carbol-fuchsin. $\times 206$. 
PLATE 3.

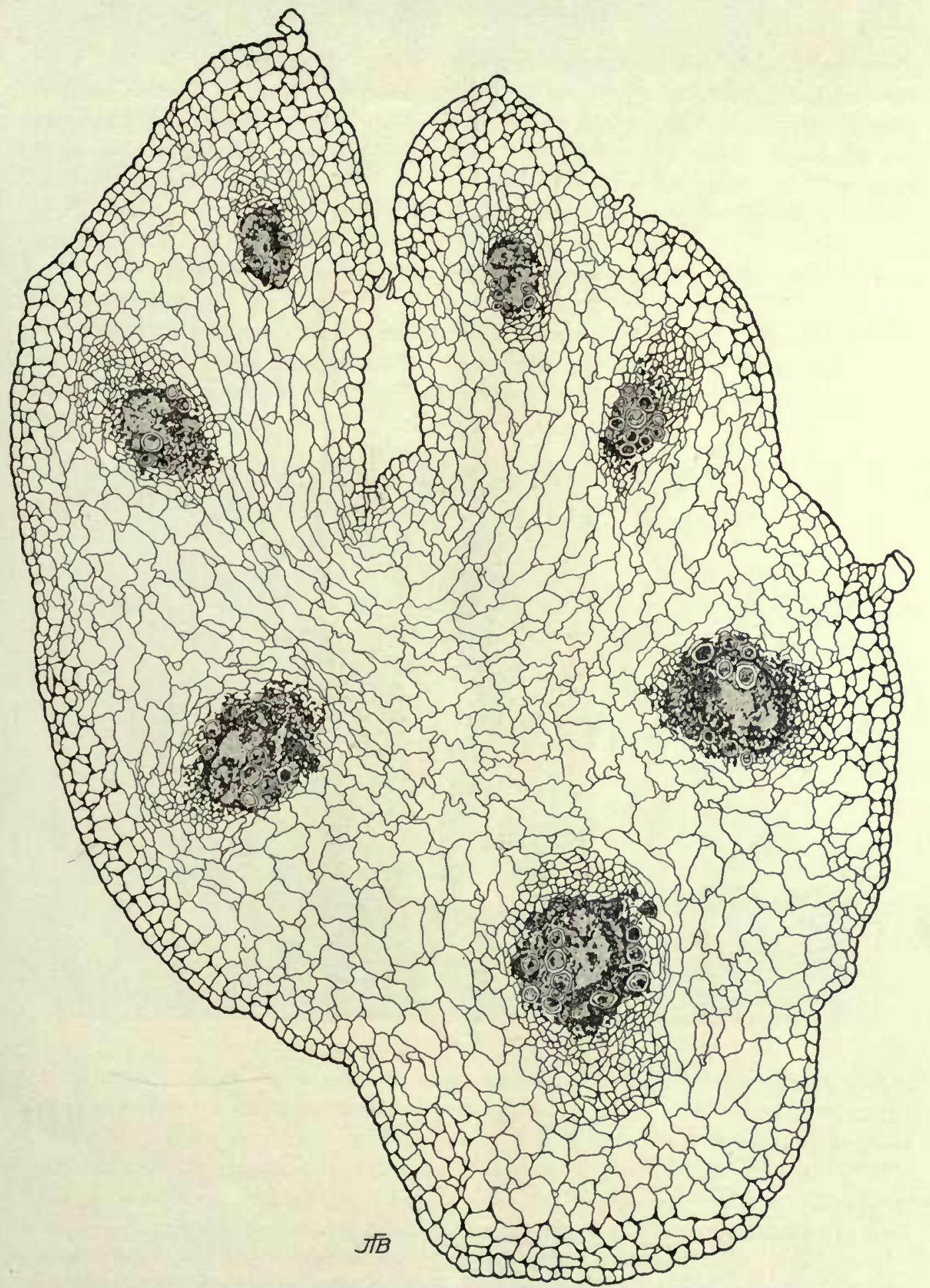

Cross-section of petioje of muskmelon No. 150 attacked by Bacillus tracheiphilus.

The bacteria are confined to the bundles, in each of which cavities have appeared. This section was taken from oear the point marked $\mathrm{X}$ on the inoculated leal (see fig. 8). The inoculations were made on the blade of the leat by means of delicate needle-pricks. The material was collected and fixed in atrong alcohol on the 6th day after the appearance of the disease. 
and ond 
more bacteria accidentally introdnced from the surface of the plant, from one's clothing or body, or from the air ; or it may have resulted from a few non-pathogenic organisuns accidentally present in the inner tissues of the plant, particularly in case of roots which liave been dug some time. It is therefore mucl better for the student to begin with plate cultures. Generally speaking, the parasite will be more easily obtained in a state of purity from plants or organs of plants recently attacked and from deep tissues, or from just within the margin of advancing diseased areas, rather than from near the surface, or from parts which have been diseased for a considerable time.

Parts long affected almost always contain mixed growths due to the multiplication of saprophytes of various kinds. From such parts it is usually much easier to obtain the saprophyte than the parasite, even if the latter has not been entirely crowded out and destroyed.

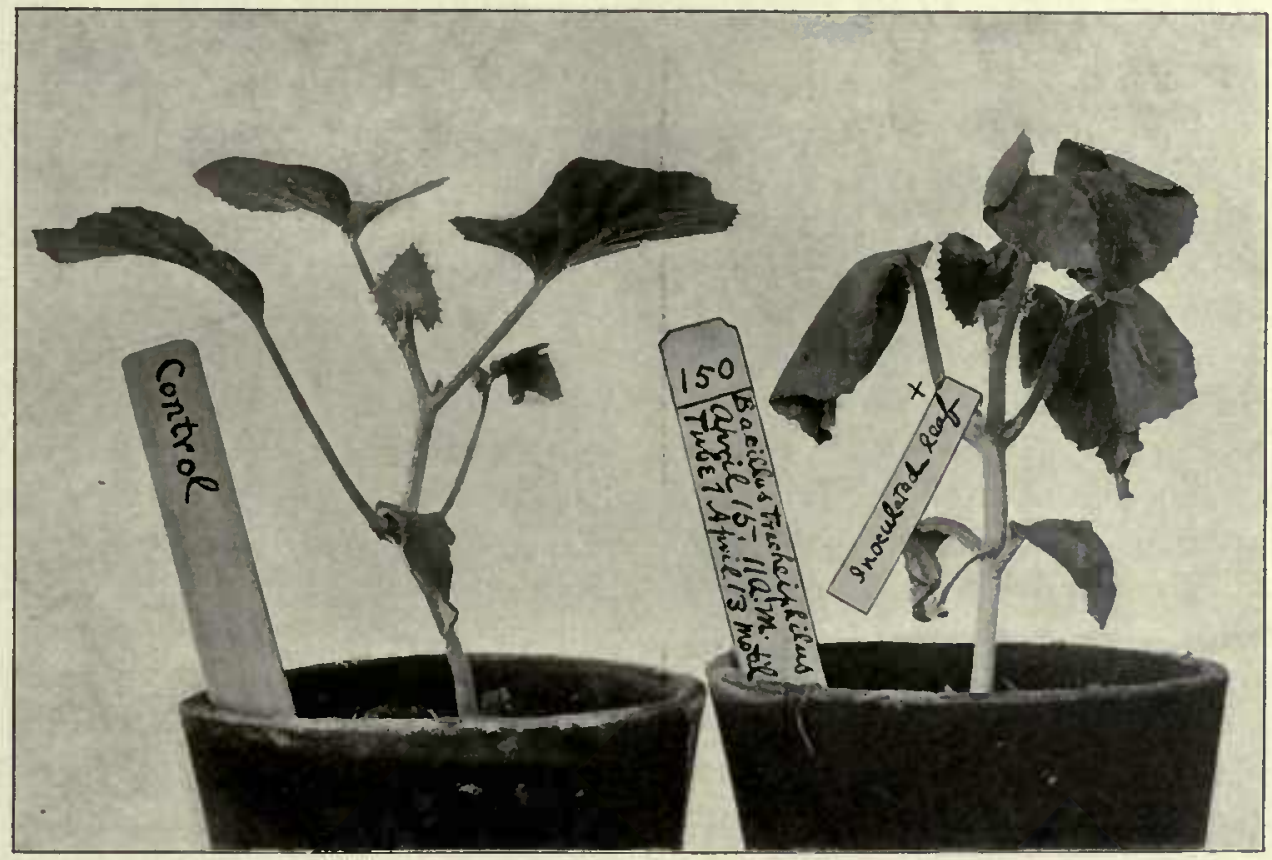

Fig. 8.*

Great care must be exercised to avoid introduction of surface organisuls which might complicate results, especially if rapid growers. The easiest and most satisfactory way, when the tissues will admit of stucl treatment, is to sear the surface with a hot knife or spatula so as to burn all surface organisms and then cut or dig through this sterile surface with hot or cold sterile scissors, scalpels, forceps, or needles to a part which has not been affected by the heat, from which some of the diseased fuids and solids may be removed on a sterile platinum loop. I frequently sear upon sound tissues at one side of the spot from which I desire to nake cultures

*FIG. 8-Muskmelon plant No. 150, inoculated with a pure culture of Bacillus tracheiphilus. The pricked leaf is on the left side. The section shown in plate 3 was taken from the point marked $\mathrm{X}$, three days after the photograph was made and ten full days after the inoculation. 
and then dig under into the periphery of the diseased portion. If the tissues are rather dry the bacteria may be forced into the cavity by careful squeezing, or some drops (loops) of sterile water or beef-bouillon may be introduced into the cavity and stirred around before the bacteria are removed. If heat is inadmissible, the specimen may be washed or soaked for a time ( 5 seconds to 60 minntes) in mercuric chloride water (I:IOOO) and the surface thus freed from many contaminating organisms. Carbolic acid (5 per cent in water) or lysol (5 per cent in water) may also be used for sterilizing surfaces. Of course these substances must be removed as far as possible before the surface is broken. This may be done to some extent by swabbing with sterile absorbent cotton dipped into sterile water or by plinging into sterile water and shaking. The disinfectants will be more certain to touch and sterilize every part of the surface if all adhering particles of air are driven off by first plunging into alcohol for a moment.

In case of bacterial leaf-spots the writer generally obtains satisfactory cultures by cutting ont the spot and plunging it for a few seconds ( 5 to 45 ) into r: rooo mercuric chloride water, then rinsing in sterile water for a few miuutes, crushing and throwing into a tube of bouillon from which the plates may be ponred in conrse of an hour, $i . e_{\text {, }}$, as soon as the bacteria from the interior of the spot liave lad tine to diffuse into the bouillon. I frequently crush with a sterile glass rod, after throwing the material into a tube of bouillon, or else on a small sterile cover-glass which is then thrown into the bouillon.

In cases where heat and chemical disinfectants are both inadmissible on account of danger of destroying the organisms within delicate tissues, as in thin leaves and other soft parts, the bacteria or fungus-spores accidentally lodged on the surface may be greatly reduced in number by gently rubbing all parts of the surface between the thinmb and finger under distilled water and then washing them in three or four successive beakers of distilled sterile water, the fragments being transferred from one beaker to the other by means of sterile forceps. Of course, the thinmb and fingers must be well cleaned in advance by scrubbing and sometimes by the use of alcohol and corrosive sublimate, followed by sterile distilled water. When dry, these washed specimens may be scraped into, directly for plate cultures, or after the epiderninis has been peeled off with cold sterile knives and forceps.

Quantitative determinations may be made by grinding up a given quantity of the suspected plant tissue, $e . g$., a cubic centimeter or a gram, in a sterile mortar with clean sterile sand and ro or $20 \mathrm{cc}$. of beef-broth or sterile water, and then making plates from carefully measured portions of the fluid, $e . g$., from one 2-11mm. loop, from 0.1 cc., 0.5 cc., etc. A like number of clieck plates made from equal portions of healthy tissues ground under precisely sinilar conditions will soon demonstrate about how many colonies are to be expected per plate (and what kind) as the result of surface contamination or air-borne bacteria introduced during the process of grinding.

The procedures described under $c$ and $d$ should be repeated a number of times (the more the better) and always with uninoculated plants in abundance for comparison. These control-plants or check-plants must remain healthy. If they also become 
diseased, then the experinents nust be done over with nore care and times enough to remove all possible chance of error. When check-plants become diseased, especially in any number, there is always room for grave suspicion. Either the experimenter lias been grossly careless, ass1111ing that he used the riglit organism in his inoculation-experiment, or else he is working in a locality where the cause of the disease is naturally abundant. In either case, lowever well convinced he himself may be, his readers will generally have a lingering suspicion that even his inoculated plants succumbed not to what he inserted into them, but to some entirely different cause naturally present and overlooked by the investigator. The remedy for the

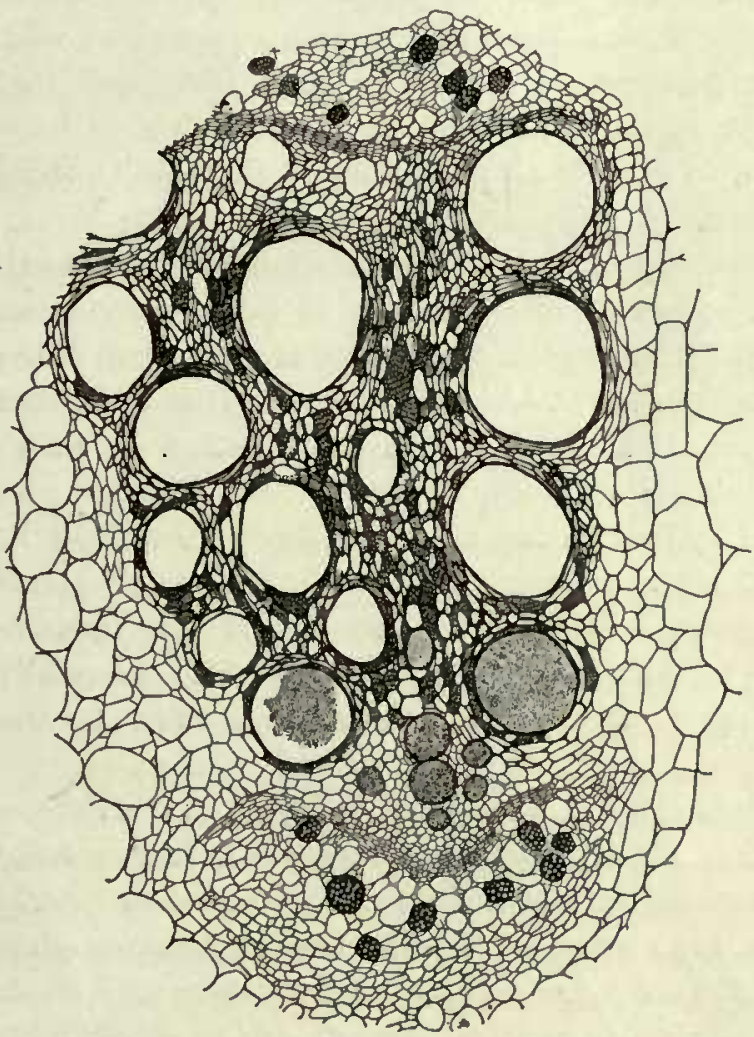

Fig. 9.*

first is to learn to use infectious material with more caution, and for the second is to make the inoculation-experiments in localities or under conditions where the plant sliall be less subject to natnral infection.

If the experiments must be performed in localities where the disease is naturally present, then a large number of plants must be selected for inoculation and for control, and such a high percentage of infections secured in the inoculated plants that the few cases occurring naturally in the control-plants may be neglected as not casting any doubt on the general result. For example, if, in a region subject to the given disease, roo plants were reserved for control and roo similar plants were inoculated, and out of this number $5^{\circ}$ of the latter and 40 of the former should contract the disease, it is manifest that no deductions of any value could be made from the experiment. All might be the result of some cause totally different from the

*FIG. 9.-Cross-section of a small part of a cucumber stem, showing the parasitism of Bacillus tracheiphilus in one of the inner bundles. As yet there is no bacterial cavity, the bacilli being confined to the spiral vessels and a very few of the adjacent pitted vessels. Material itaken from a field near Washington, D. C., in 1893. Sectioned from paraffin. Drawn from a photomicrograph. $X$ 50. Introduced for comparison with plate 3 . Beginning at the top, the tissues oocur in the following order: (I) Outer phloem, showing sieve plates; (2) cambium; (3) immature xylem; (4) mature xylem, consisting of pitted vessels and pitted connective tissues; (5) spiral vessels embedded in non-lignified living parenchyma, which is finally destroyed by the bacteria; $(6)$ pseudocambial layer; (7) inner phloem; (8) large-oelled parenchyma to either side, separating this bundle from its neighbors. 
assumed cause, the different number of cases in the two groups of plants being accidental variations. If, in sucl a locality, only a very few plants are inoculated and a few held as checks, the evidence becon1es still weaker and would not be considered entirely conclusive even though all of the inoculated plants slould contract the disease and all of the checks should remain free, since in a region subject to a given disease five or six healthy plants may sonietimes be found in proxinity to five or six diseased ones, although all may liave appeared healthy earlier in the season. The case is quite different if out of roo control-plants and roo inoculated plants 95 per cent of the latter and only 2, 5, or Io per cent of the former contract the disease. It then becomes a question of probability which may be converted into reasonable certainty by several repetitions of the experiment with like results. Of course, the ideal experiment is one in which all the inoculated plants contract the disease and none of the control-plants, and in which a large number of plants has been used so as to exclude all possibility of the results being due to anything but the organism used.

Whenever the disease occurs naturally in the vicinity selected for the experiments, too much emphasis can not be laid on the necessity of having numerous inoculated plants and numerous controls, and on the desirability of repetitions of the experiment in different years and under different local conditions. It is important also that the inoculated plants should be under healthful conditions, $i$. $e$, under conditions as nearly natural as possible. For exanple, proper (natural) conditions would be much more nearly attained by inoculating vigorous plants growing in the open air or in well-kept greenhouses than by inocnlating parts of the same plants cut away from the stems and kept under bell-jars. It is conceivable that inoculations which would succeed very well under the conditions last named, especially at abnormally high temperatures, might entirely fail when under a more natural environment.

Not one of these four requirements can be onitted safely. A chain of evidence is not stronger than its weakest link. Particular stress, therefore, is laid on being able to produce at will the characteristic signs and lesions of the disease in healthy plants by inoculation with pure cultures of a given sort; also on the re-isolation of the organism from the artificially-infected plants after they have become diseased; on the subsequent proper behavior of the organism in nutrient media; and on its ability to produce the disease when again inoculated. This is the whole thing in a nutshell. The experiments must be continued until there is no doubt whatever as to the pathogenic or non-pathogenic properties of the organisn1. "Almost certainly pathogenic" always leaves room for grave doubt in the mind of every thoughtful reader. As a rule, the re-isolations should be made at a considerable distance from the point of inoculation, particularly if there is any doubt whatever as to the identity of the physical signs, since saprophytes have been known to live in plant tissues for a considerable number of weeks near the place of inoculation, and, if abundant, might cause various disturbances of nutrition without being the pathogenic organism sought for. For example, one would be more likely to obtain the cause of the disease in pure culture by attempting isolations from a plant in the stage shown in 


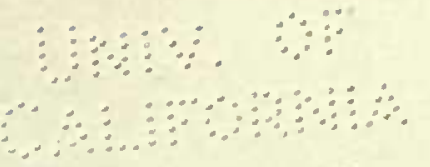

PLATE 4.

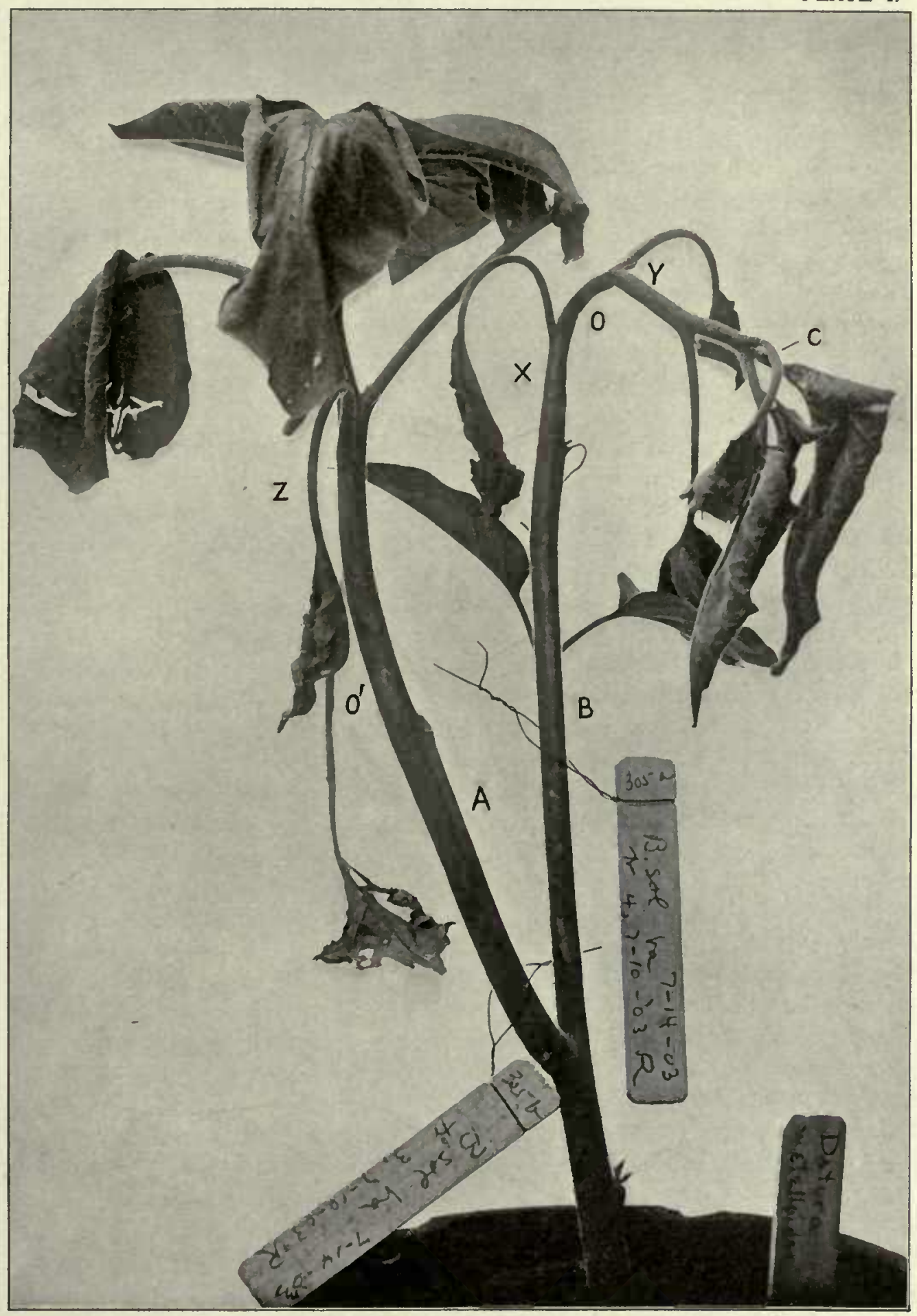

Dafura metelloides inoculated by needle-pricks with Bacterium solanacearum (Erw. Sm.).

The stems were pricked at $O$ and $O^{\prime}$ on July 14, 1903, and the photograph was made July 22. The firs rigns of wilt appeared the 4th dey, Aboul one-thind natural size. 

plate 4 than from the same plant a week later (fig. Io). One would also be more certain of pure cultures by plating from the interior of the plant at A, B, or C, rather than at $\mathrm{X}$ or $\mathrm{Y}$.

The judgment of experienced bacteriologists as to the pathogenic nature of

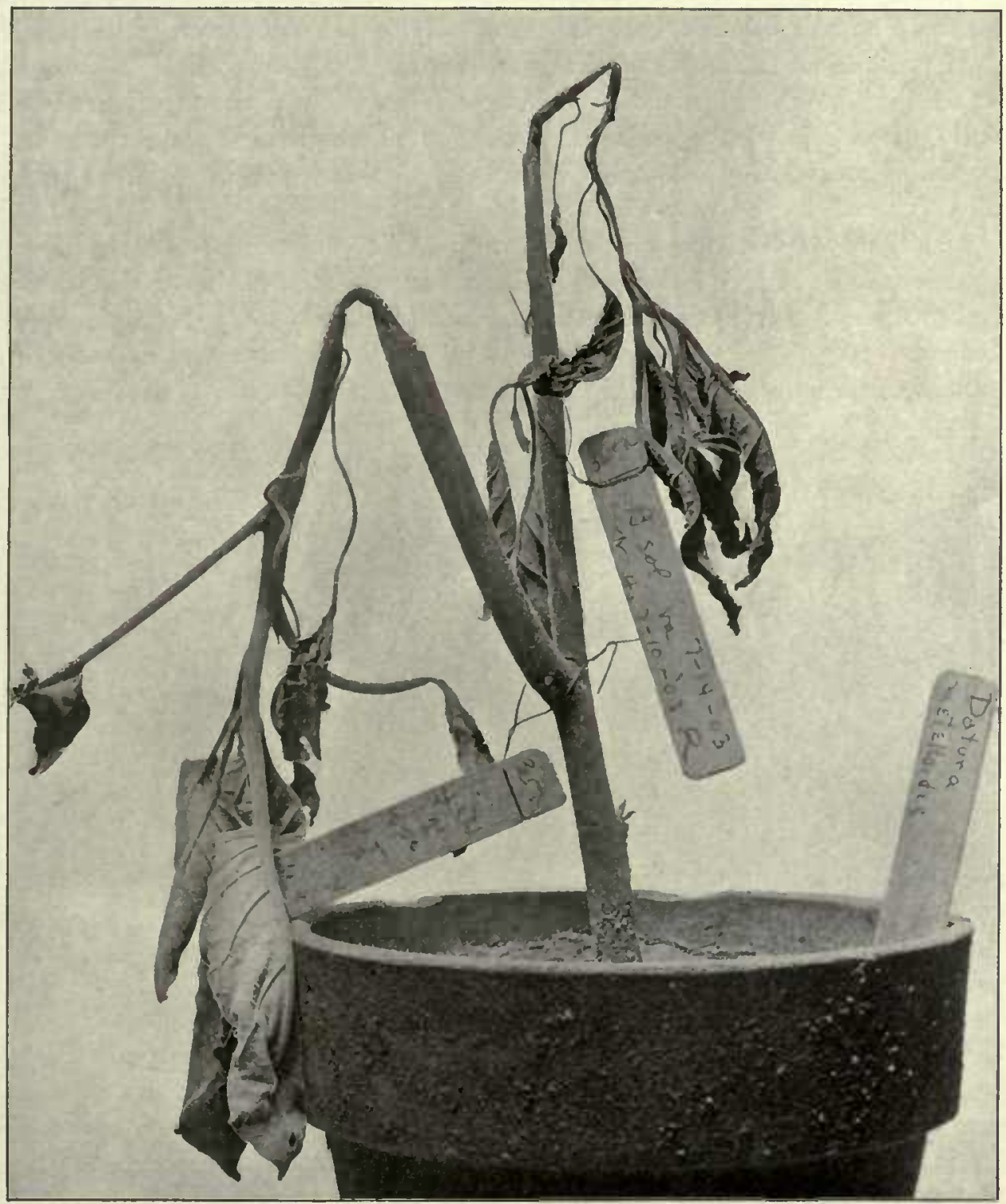

Fig. 10.*

an organisnn may to a certain extent be accepted in absence of full proof, but only for the time being. Nothing is absolutely certain whicli lias not been experimentally demonstrated.

*F1G. 10,-Datura metelloides, inoculated by needle-pricks with Bacterium solanacearum. The same as plate 4 , but six days later, $i$. e., on July 28. 
If all experimenters in plant patlology, even in recent years, had been careful to conform to these four rules of practice, the first three of which in essence were formulated by Robert Koch as long ago as I882, some very deep chagrins iniglit lave been avoided.

Owing to insurmountable difficulties many aninal pathologists, especially those who study human diseases, now frequently rely on the first two rules as sufficient, but, if possible, one should comply also with $c$ and $d$. Plant pathologists are under no such linitations, and should conform to each one of the above-mentioned require1nents, particularly if they desire their work to take high rank and to be generally accepted as conclusive. Material for plant-inoculation experiments is so cheap and easily procured that a writer who undertakes to describe a bacterial disease of plants has usually no good excuse for leaving any doubt whatever as to the pathogenic properties of the organism. There is also no excuse for liniting the inoculations to mixtures of bacteria or to crude material taken directly from the diseased plant, since every tyro in bacteriology now knows how to separate one organism from another in nutrient agar or gelatin by means of poured plates or Petri-dish cultures.

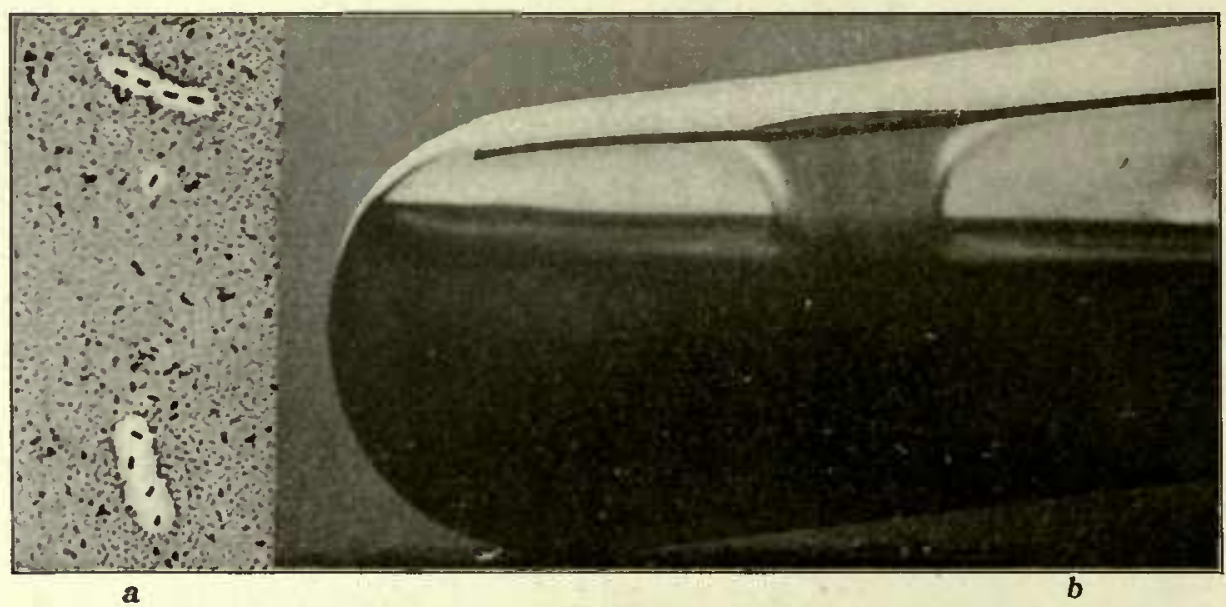

Fig. 11.*

MORPHOLOGY.

SFEE, SHAPE, E'TC.

The smallest observed bacteria are only a small fraction of a micron in diameter. Migula states that the stained rods of Ps. indigofera (Voges) Mig. from colonies 36 hours old measured only 0.18 by 0.06 micron. Bacillus denitrificans (Anp. \& Gar.) Mig. is also a very small rod-I.O to 1.5 by $0 . x$ to 0.3 micron, according to Migula. Micrococcus progrediens Schröter is said to be only o. 5 micron in diameter. The organisn11 of peri-pneumonia isolated by Nocard \& Roux is more minute. It is probable also that still smaller organisms occur, $i . e$., so small as to be invisible under the higliest magnifications. In this way are interpreted the results obtained by animal pathologists in the foot-and-110uth disease and in some other diseases. Photographs witl ultra violet light may in the end render sone service here. The

*FIG. II. $-a$, Capsule of organism obtained from black spot of the plum. Bacteria grown in Uschinsky's solution and stained by Ribbert's method; $b$, ropy Uschinsky solution from which a was made. 
largest bacteria are several thousand times as bulky as the smallest. Errera has described a spirillum the largest specimens of which measured 23 to 28 by 3 to 3.4 micra ('O2, Errera, Bibliog., X), and Schaudinn has described a bacillus the largest forms of which are 24 to 80 by 3 to 6 micra ('o2, Schaudinn, Bibliog., XI).

In shape the bacteria vary according to genera and species and sometimes within the limits of the species, from globose cells or very short straight rods, through curved forms or spirals, to filaments which are many times the dianeter of the organisin. To what extent does form vary under changed conditions? With the eye-piece micrometer make careful measurements of unstained organisms taken from the hostplant and from cultures of various ages and kinds. There is frequently considerable variability in the size of individuals of the same species. Is the breadtl more constant than the length? Does the size or

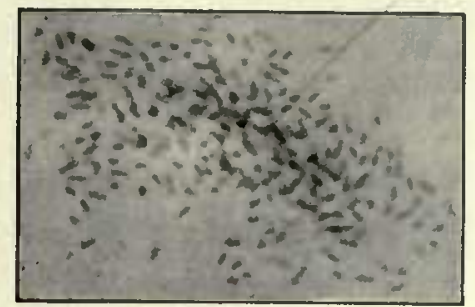

Fig. 12** shape as observed in the plant differ from that observed on culture nnedia? How does the living organism differ in size and general appearance from the dead, stained one?

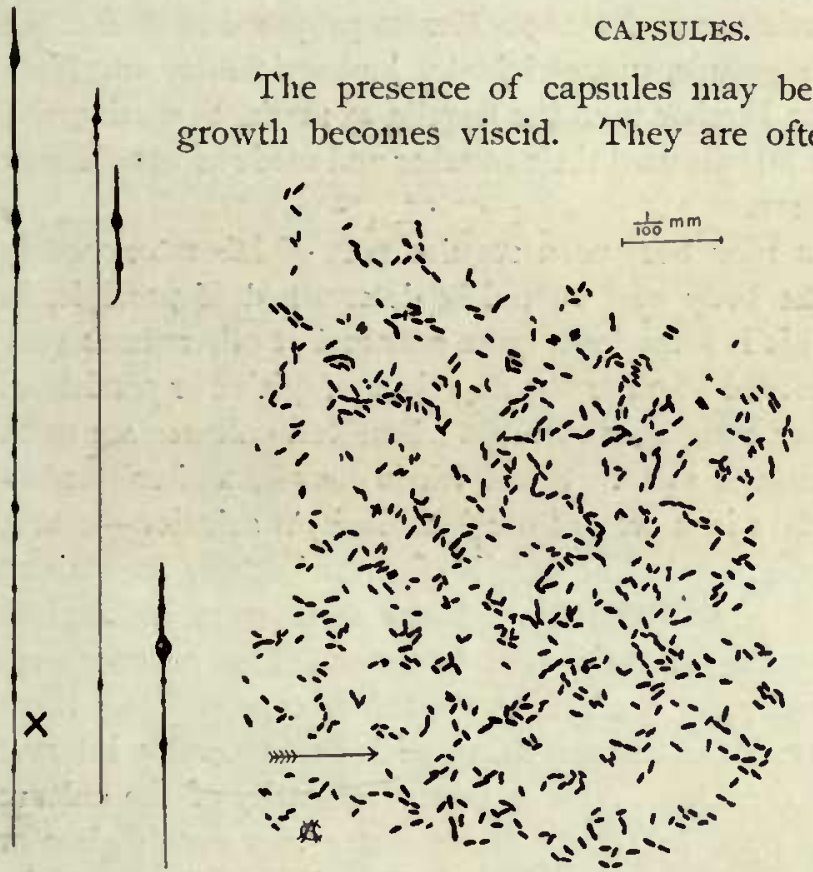

Fig. 13. +

Fig. 14. suspected whenever a bacterial difficult to see because their index of refraction is so nearly that of the fluid in which they are usually examined. In examining unstained material the field should be illuminated witl a narrow pencil of rays, and the effect of illumination with oblique light should be tried. Several methods of contrast staining are in use. By one method the capsule remains unstained or nearly so, while the central portion of the bacterium and the sline lying on the cover between the bacteria stain more or less deeply. By another inethod which lias been spe-

*FIG, 12.-A portion of the yellow ooze from the black spot of the plum, stained by ordinary methods. $\times 2,000$.

†FiG. 13.-Cobwebby, sticky threads of Bacillus tracheiphilus drawn from the cut end of a muskmelon stem, arranged on a slide and stained with carbol-fuchsin. About three times natural size. Buzzards Bay, Mass., Oct. 8, 1903. Fig. If was drawn from the left-hand thread at the point marked $X$.

$\ddagger$ FIG. 14. - Bacillus tracheiphilus Erw. Sm. A pontion of one of the threads shown in fig. I3. The arrow indicates the direction of the thread, which was extremely tenacious. The distance between the bacterial rods indicates very clearly the extreme viscosity of the unstained substance lying between them and holding them together. $\times 1,000$. 
cially connunended by Dr. Welch ('92, Bibliog., XIII), the capsile is also stained, bit ren1ains distinctly paler than the body of the bacteriun1. They may also be counterstained, as in Muir's method or Moore's metlod. Well-defined capsules are shown in fig. Ira. This n11ay be compared witl fig. I2, in which the san1e organisin is slown without capsules. Fig. I $b$ shows the extreme viscidity of a culture due to the formation and deliquescence of capsules. Fig. I3 shows the tenuons threads into which Bacilhus tracheiphilus may be drawn as it oozes from the cut stens of cucurbits. Fig. I4 is a detail from the same more lighly magnified, the viscid connecting substance being unstained.

\section{FIAGEII,A.}

Ehrenberg was the first to describe flagella on bacteria (Bacterium triloculare, 1838). Nothing more was done until 1872 , when Coln discovered them on Spirillum volutans. In 1875 Dallinger \& Drysdale saw and fignred then on Bacterium termo. In 1875 Warming determined their existence on Vibrio mgula and Spirillum undula. In 1877 Koch demonstrated their existence on a nu111ber of species by the 11se of stains. In I 878 Dallinger, using unstained 111aterial, saw then11nany times on Bacterium termo and also on Spirillum volutans. After 1879 no one appears to have disputed their existence. In I890 Messea proposed to divide the flagellate bacteria into four large groups, monotrichiate, lophotricliate, an1 phitricliate, and peritrichiate. In I895 Fischer 11sed the flagella as 111arks to distinguish subfanilies. In the previous year Migula used their number and node of attachnent as a means of distinguishing genera.

The staining of flagella lias now become a regular part of laboratory work. Their number and position on the body wall shonld be deternined, if possible, in case of each species studied. This is sometimes quite easy and at other times very difficult. It should also be determined whether the flagella are fugitive or persistent.

Flagella may be stained from young agar cultures. Bouillon cultures are to be avoided because of the intense ground stain. Some kinds may be stained readily frow cultures grown for some days in a very dilute Usclinsky's solution-I to 3 drops in ro cc. of distilled water (fig. I5). The flagella of some bacteria are stained readily, those of others only witl great difficulty. Many sorts seen inclined to throw off their flagella when transferred from agar to water. The cover-glasses must be clean. When cleaned ready for 11se seize with the forceps and pass then three times through the upper part of the Bunsen flane, with a considerable interval between each flaming, to avoid cracking. Use a minin quantity of the culture stirred in a big drop of water, or even in 2 to xo cc. of water in a watcli glass or test tube. Give the bacteria time to diffuse by waiting half an hour or 111ore. Take the cover between the thumb and finger of the left hand, tonch the end centineter of a platinum needle to the water containing the bacteria, and sweep it deftly across the cover glass. In this way the fluid is spread in a very thin sheet over nearly the whole surface of the cover and is dry almost at once, with the bacteria well separated. If the fluid will not spread, then the cover is not clean and should be discarded. The bacterial sheet may be mordanted and stained at once, or first fixed by gentle heat. To avoid scorching, the cover should be held between thumb and finger when it is passed rapidly tlirough the flame. Beginners usually burn the bacterial layer. 
Smeary dark lines and other deceptive artefacts must not be mistaken for the flagella. The following methods have been tried by the writer and have given good results, but none can be depended upon always, and much time and patience are sometimes required to get good preparations of a refractory organism : Fischer's

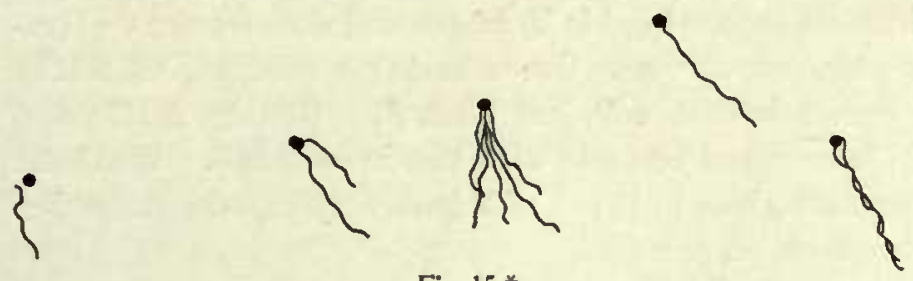
modification of Loeffler's stain; Moore's modification of Loeffler's stain ; Van Ermengem's nitrate of silver method; Löwit's copper-sulphate fuchsin

Fig. 15.* mordant, followed by Elhrlich's anilin-water gentian violet. (For other methods consult "Fornulæe" and "Bibliography of General Literature," XII.)

In connection with flagella-staining a white porcelain trav, such as plotographers use, will be found very convenient for washing, and also the double blow-bulb shown in fig. 17. This should be attached to a wash-bottle, such as that shown in fig. 16. This will deliver a small stream, very good for washing excess of mordant and stain from the covers. To furnish a steady stream the bulb has to be compressed only about once a minute. The flask used for this purpose slould hold a liter.

\section{SPORES-FNDOSPORFS, ARTHROSPORES.}

Do arthrospores really occur? If so, in what respect do they differ from the ordinary vegetative rods? Test spores for resistance to high tenuperatures in the

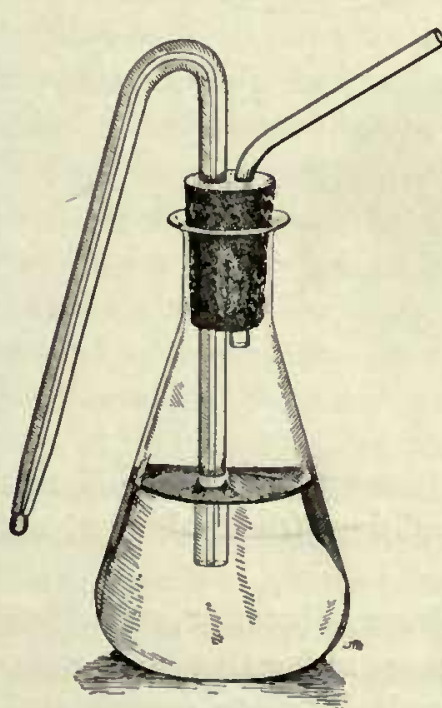

Fig. $16 .+$ water bath and to steam heat; study germination in hanging drops. Do the spores require a period of rest or refuse to gernininate except in special media? The suspected existence of spores may be definitely settled by seeing the problematic bodies germinate. In the absence of such proof, considerable certainty may be reaclied by a combination of two methods: ( $I$ ) the use of watery basic anilin stains, and (2) the use of moist lieat. If at room temperatures the glistening bodies refuse to take the simple stains even on long exposure and at the same, time are very resistant to steam heat or to hot water, $i$. $e$, mucl more so than the ordinary vegetative rods, it may be assumed that they are spores. If, on the contrary, they are destroyed by temperatures only slightly above the recorded thermal deathpoint of the vegetative rods, it must not be assumed that they are spores, no matter how they behave toward

*FIG. 15.-Flagella of yellow organism plated from black spot of plum. Stained from culture grown in ro $\propto$. distilled water containing a few drops of Uschinsky's solution. $X 1,000$.

†F1G. 16.-Beyerinck's drop-bottle. The size and number of drops in a given time are regulated by sliding the bent tube through the cork. It is very convenient to have this fiask on the microscope table. By a minim infection of the fluid it may also be arranged so that eaoh drop shall deliver a single spore or bacterium for hanging-drop studies. About two-fifths nat ura! size. 
stains, unless they can be made to germinate. Many of the older identifications of spores are untrustworthy. Alfred Fischer has shown that 111any of these determinations rested on plasmolysis of the rods, $i$. e., on misinterpretations. Omélianski reports finding an oval spore which stains readily witlt ordinary anilin stains. This occurs in a rather large bacillus acconpanying his liydrogen cellulose ferment. Dannapple reports finding spores which are very sensitive to lieat ('99, Bibliog., XXXIII). Usually only one endospore occurs in each cell, but Kern ('8I, Bibliog., VIII), and Scluaudinn ('O2, Bibliog., XI) have found bacteria with two in each cell. Excellent directions for the study of spores are given in Part I of Migula's Systen der Bakterien (see especially the second paragraph on p. 209).

\section{Chim-Unions-Zooglatat, Chains, Filaments.}

In some media bacteria are much inclined to separate after division; in otlers they remain attached in various ways. The most connon method of union is an irregular clumping, which in fluids gives rise to a fine or coarse flocculence. Such unions also occur on solid media and may be designated zooglœæ, or pseudozooglae, if one prefers to retain zooglœæ for the more intimately fused and compacter gelatinous unions. Sonetimes the organisms remain attached end to end. Where the segmentation is distinct, such unions are designated chains. When very long and with obscure segmentation, they may be called filaments. Is there any true branching? What especial conditions of the culture medium favor the formation of zooglœx, of chains, and of filaments? Many bacteria form zooglœex, chains, or very long filantents under certain conditions, wlile under other

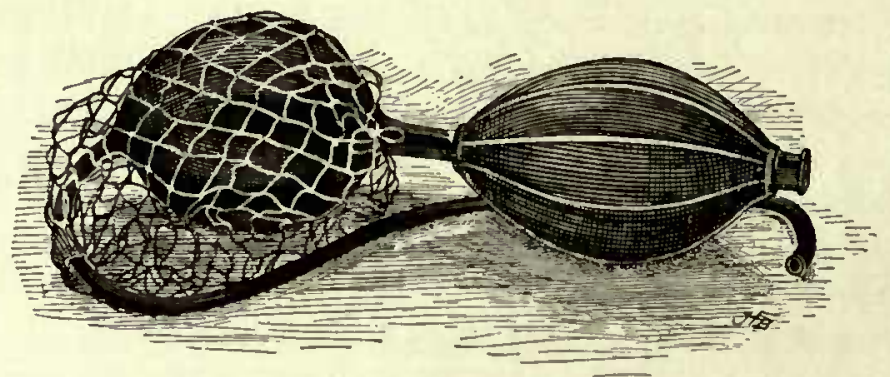

Fig. 17*

conditions they remain as very short, straight rods. (Compare figs. I 8 and I9.) As in case of involution forms unfavorable cultural conditions (thermal, 1nitrient, etc.) appear to have much to do with their appearance.

The growth of bacteria nuy be studied in hanging drops of bouillon, etc. Hollow-ground slides (fig. 20) should be used for this purpose, rather than ring-cells, especially with high powers. Hill's lianging-block metlod is also serviceable ('O2, Bibliog., XVII).

*Fig. I7.-Double blow-bulb for attachment to drop-bottle shown in fig. I6. By use of this device one obtains with a minimum of pumping a constant small stream of water very suitable for washing stained covers, etc. Made by Emil Greiner. It is best used with a larger flask than that shown in fig. I6. Bulbs which have been long in stock should not be purchased, as the rubber deteriorates rapidly. 


\section{INVOL,UTION · FORMS.}

Under this name we desiguate swollen and distorted forms common in old

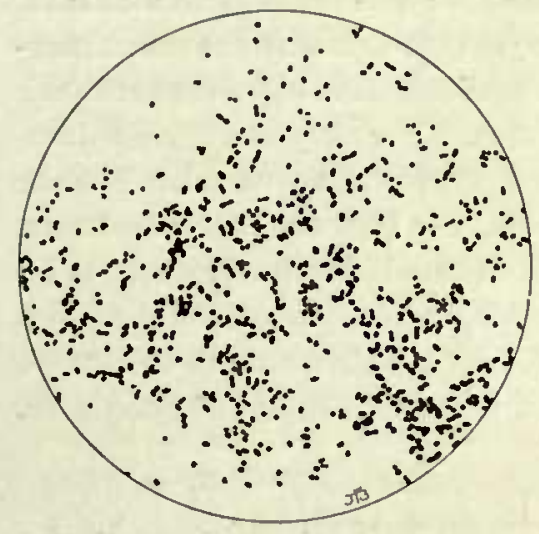

Fig. 18.* cultures (fig. 2r). Under what conditions do they occur? Are they living or dead? Isolate in hanging drops of bouillon and determine whether they are stages in development or only degeneration forms. Are Y-sliaped or branched forms such as occur in old cultures of $B$. tubercilosis Koch, and in the root-tubercles of clover (fig. 22) to be considered as involution forms? Are such organisıns fungi or bacteria? Branching forms lave been detected by many observers. (Consult 11umerous citations in the Bibliography of General Literature, $\mathrm{X}$ ). The most recent paper is by Albert Maassen (Arb. a. d. Kais. Gesundh., Bd. XXI, H. 3,

r 904, p. 377,6 pl.). He found chloride of lithium specially advantageous for provoking these growths, which are regarded as teratological. He obtained them in 24 hours.

\section{GENERAI. COMMENT.}

Great care should be paid to the minute norphology of each organism, not only in the lost-plant but also in a variety of cultures, old and young, so that a body of knowledge more exact than we now possess shall be gradually accumulated for differential and systematic purposes. Careful drawings and photographs should be made. The Abbe camera is a great help in making drawings (fig. I 2 r). For'such study the Zeiss apochromatic lenses and conpensating oculars can not be recommended too highly, particularly the $16 \mathrm{~mm}$, with the $\mathrm{I} 2$ and $\mathrm{r} 8$ compensating oculars for studying the inargins of colonies, and the $2 \mathrm{~mm}$. I.3O 11. ap., with the 8 and I 2 compensating oculars for the more detailed study of the individual rods. The writer has also made much use of the Zeiss 3 mun. I.40 n. ap. apochromatic objective. The Zeiss screw, or filar, micrometer conbined with a No. 12 compensating ocnlar (fig. 23) will be found very useful. For plotographic purposes the projection oculars or the 4 or 6 compensating oculars may be used. Robert Koch was entirely correct in saying: "A general use of plotograplyy in microscopic works wonld certainly liave prevented a great number of unripe publications."

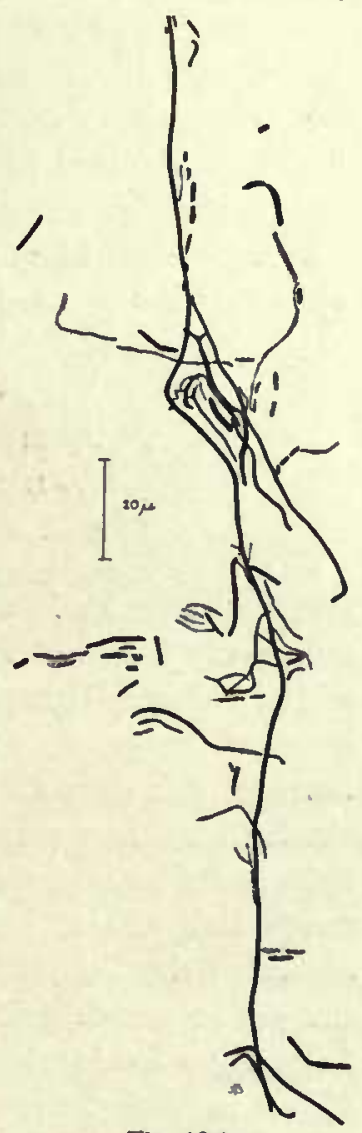

Fig. 19.†

*FIG. I8.-Bacterium campestre. Cover-glass (smaar) preparation from the vessels of a cabbage plant received from Racine, Wis., Sept. 19, 18g6. Stained with carbol-fuchsin. Drawn from a photomicrograph. $\times 1,000$ circa.

†FIG. 19.-Bacterium campestre from an old culture on 23 per cent grape-sugar agar, showing long filaments. Cover stained I hour and 20 minutes in gentian violet (I part saturated alcoholic solution plus 1 part water). Many of the rods stained feebly. Tube inoculated June 30,1898 . Cover prepared Aug. 8. Drawn directly from the slide. $\times 1,000$. 
Good photonicrographs should be secured if possible. Koch's first photomicrographs were of various enlargements. He afterwards recommended $\times$ I,OOO as the standard magnification, but $\times$ I,500 and $\times 2,000$ are also convenient sizes and occasionally $\times 5$ oo is better than $\times \mathrm{I}, 000$. Most important is it that the exact magnification should always be indicated. The Zeiss apochromatic objectives are nuch better for photograplic work than the achromatic ones. For very small magnifications the writer has found the old Zeiss 35 11111. and 70 111m. very useful. For the same purpose the newer Zeiss planars, series Ia Nos. I-5 (fig. I 22) are adinirable. These have sharp definition and a very flat field, but not 1111ch depth of focus. With them objects several centimeters in diameter may be satisfactorily photographed with magnifications from 2 or 3 diameters to 50 or n1ore. The writer obtains as sharp a foctis as possible with wide-open diaphragin and then stops down about two-thirds.

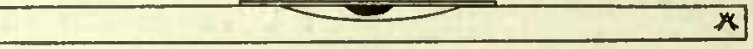

Fig. 20.*

One of the best simple photomicrographic outfits is the Zeiss upright cannera (fig. 24). All apparatus is to be rejected which requires the nilicroscope to rest on the same platform as the camera. It slould rest on the table independent of

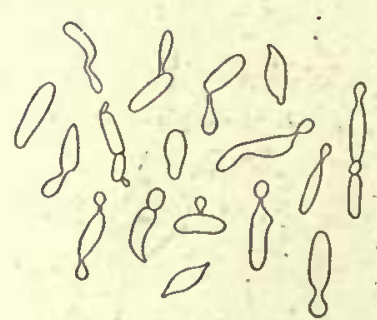

Fig. 21.† the cannera, unless a weak light is used and the exposures are very long, in which case a slight jarring is of no great consequence. Direct sunlight is the best light, but the light of the open sky may be insed (with full open diaphragm) if one is willing to make 5 to 20 minute exposures. Electric light is often used by those who live in cloindy regions or who occupy roons not exposed to the sun, but the writer has had 110 experience with it. Very good pictures also may be made by gaslight if the

Welsbach burner is used. Ordinary lamp light (kerosene) is to yellow and not sufficiently intense. Photographs can be made with a kerosene light, but the time and trouble involved make it scarcely worth while to consider this source of light. The writer has obtained the best results by using direct sunlight and slow isochromatic plates behind Zettnow's light filter. Of course, with upright cameras a dry light-filter must be used, such as the yellow one devised by Carbutt or by Ives. In using a horizontal apparatus, such as that

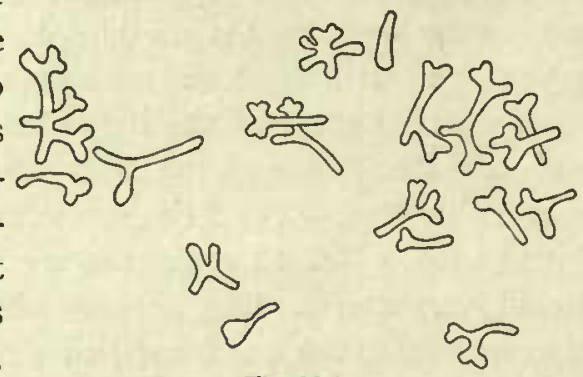

Fig. 22.t shown in plate 5, the sine qua non is to get it properly leveled up and to keep it so.

*FIG. 20.-Hollow-ground slide with cover-glass bearing hanging drop for examination under the microscope.

†FIG. 2I.-Involution forms of Bacillus tracheiphilus from extremely ropy potato broth. Drawn free hand, $X$ I,000 circa. Many as large as 8 by 2 micra and others larger. Nov., 1894 .

$\ddagger$ FIG. 22. - Y-shaped (dichotomously branched) bodies from the root-tubercles of clover ('Trifolium). From a photomicrograph by the author, made from a slide furnished by Dr. Geo. T. Moore. $\times I, 500$. 
For the inspection of colonies and of subcultures in tubes the best land-lens known to the writer is the Zeiss aplanat 1nagnifying six tines (fig. 25). That magnifying Io tines is also very useful, but will not reach to the center of an ordinary test tube. Those in apple-tree wood cases are in some respects more convenient than those provided with metallic swing covers (fig. 26).

The best general work to consult on the n1orphology of the bacteria is undoubtedly Migula's Systen1 (see Bibliog., III).

\section{Physiology,}

In the description of bacteria we are compelled to make large use of pliysiological peculiarities, owing to their very simple and monotonous morplology. Within the linits of the genera now recognized the form differences are so very slight

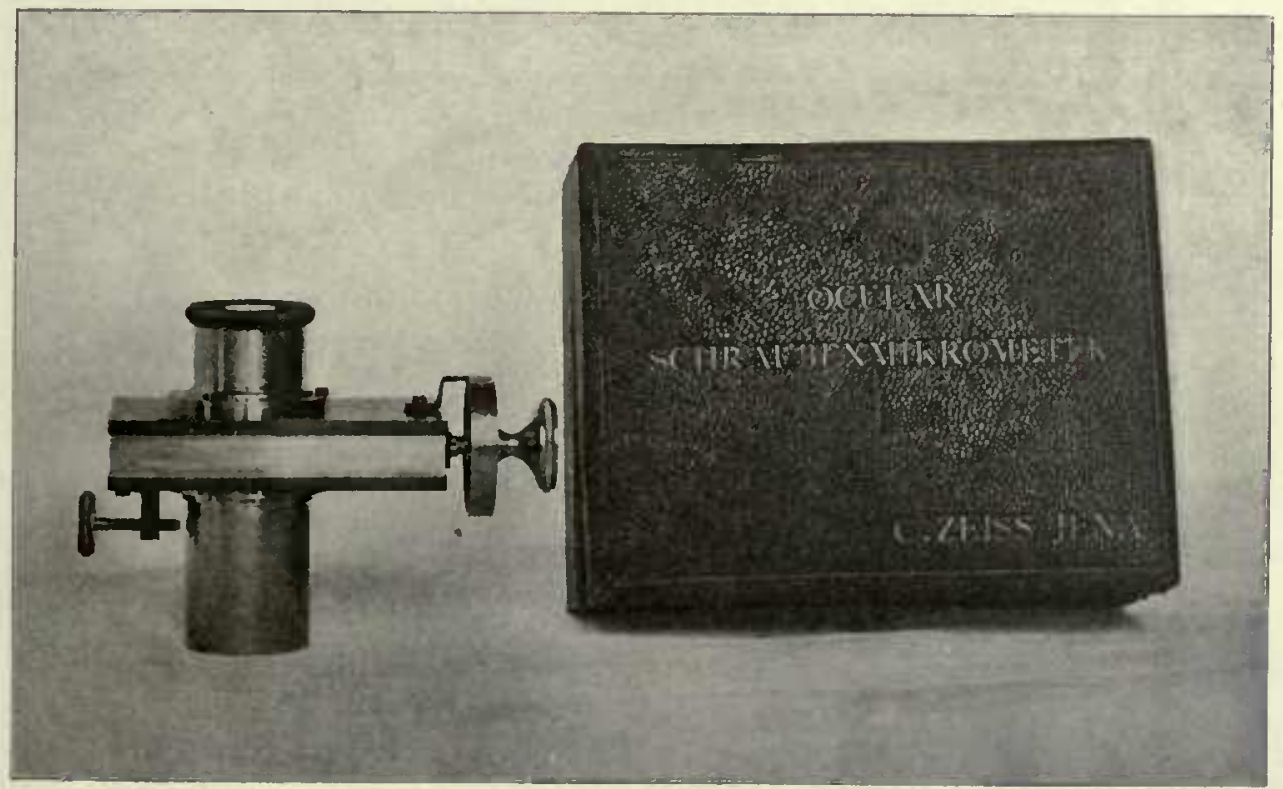

Fig. 23.*

that many bacteria, e. $g$. , Bacillus coli, $B$. cloace, B. suipestifer, $B$. typhosus, $B$. amylovorus, etc., are indistinguishable under the microscope. In mixed cultures, or stained preparations, no one could distinguish one from the otlier with any certainty, and in pure cultures of unknown origin certain identification by means of the mincroscope would be equally impossible. Nevertheless, these sane forms are so widely different in their beliavior in culture media, in their pathogenic properties, in their relation to heat, air, antiseptics, etc., that we are certainly warranted in regarding them as distinct species, using the word "species" in its com11on acceptation. These well-ascertained facts should not, however, lead one to neglect slight differences of form, even when they can be expressed only in fractions of a 111icron. On

*F1c. 23-Zeiss compensating ocular No. 12 with screw-filat micrometer. 
the contrary, as mucli as possible sliould be made out of morphology, particularly that of the living organism, and in this connection the recent efforts of Migula and Fischer are especially deserving of commendation.

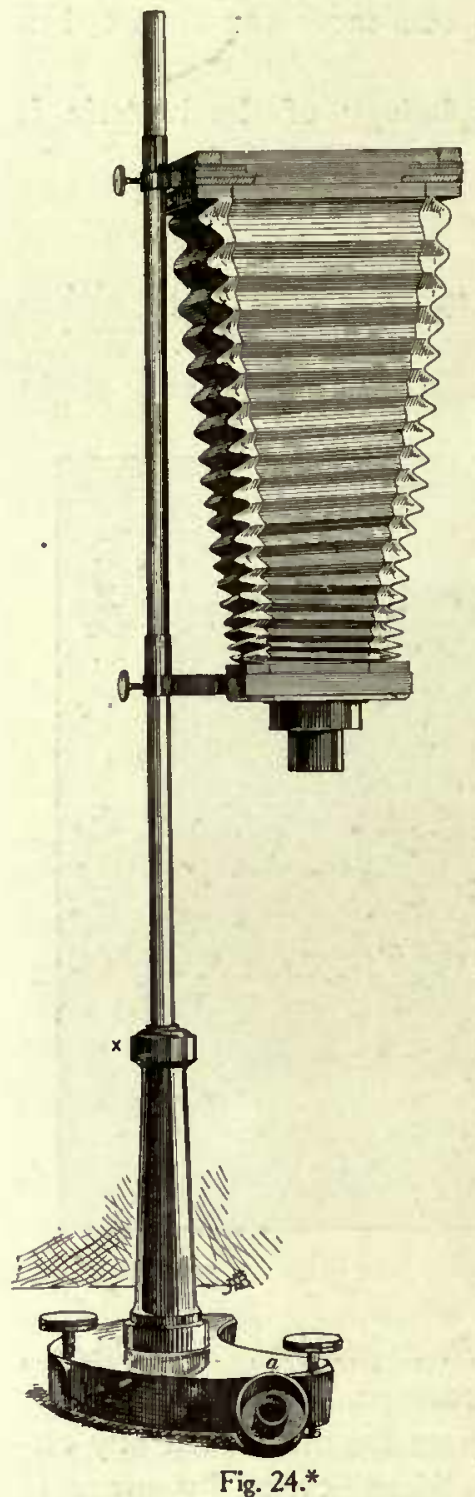

MOTILITY.

If motile, determine kind of motion and rapidity (margin of small hanging drops on thin covers suspended over hollow-ground slides). $\uparrow$ The cover may be prevented from sliding by touching one edge with a very little vaseline or cedar oil; if too much is used it runs under, mixes with the hanging drop, and spoils the mount, and possibly in the end the objective is ruined, if the student continues to search for a clear field. The beginner is very apt to mistake Brownian movement for self-1notility. It sometimes requires very careful observation to be quite certain. Rods which appear to be motionless will sometimes be seen to dart away quite suddenly if watclied. In some species yonng cultures are mucl more apt to be motile than old ones; in others motility appears to be an alinost constant characteristic. The movements of bacteria are sometimes quite characteristic for particular sorts. They may be slow or rapid tumbling motions centering in the shorter axis, or straight or sinuous slow or rapid darting novements in the direction of the longer axis, with rotation on this axis. The media of Hiss ('97, Bibliog., XVI) and of Stoddart ('97, Bibliog., XVI) are sometimes nseful for distinguisling macroscopically between motile and non-1notile forms. The former spread as a thin layer over the whole surface, the latter pile up in restricted areas around the points of inoculation. The student should not remain content with inerely determining motility, but when this has been settled he should turn his attention to staining the organs of motion.

*FIG. 24,-Upright Zeiss camera for photomicrographic work. The cup (a) slips over the end of the microscope and forms a light-tight connection with the bellows without touching it. The microscope rests on the table independent of the camera. The stout rod turns freely in the socket $X$ and is locked in place by a set-screw on the side opposite the observer. The height is about 45 inches.

†Lehmann and Fried (Arch. f. Hyg., Bd. XLVI, 1903, p. 3II) found the swiftest movement of bacteria to be I mm. in 22 seconds; the slowest I $\mathrm{mm}$. in 222 seconds; average: cholera, $1 \mathrm{~mm}$. in $34^{\mathrm{T} / 4}$ seconds; typhoid, I mm. in 56 seconds; $B$. vulgare, $1 \mathrm{~mm}$. in 73 seconds; $B$. subtilis, $1 \mathrm{~mm}$. in 40 seconds; $B$. megaterium, I $\mathrm{mm}$. in 2 minutes II seconds. 
PLATE 5.

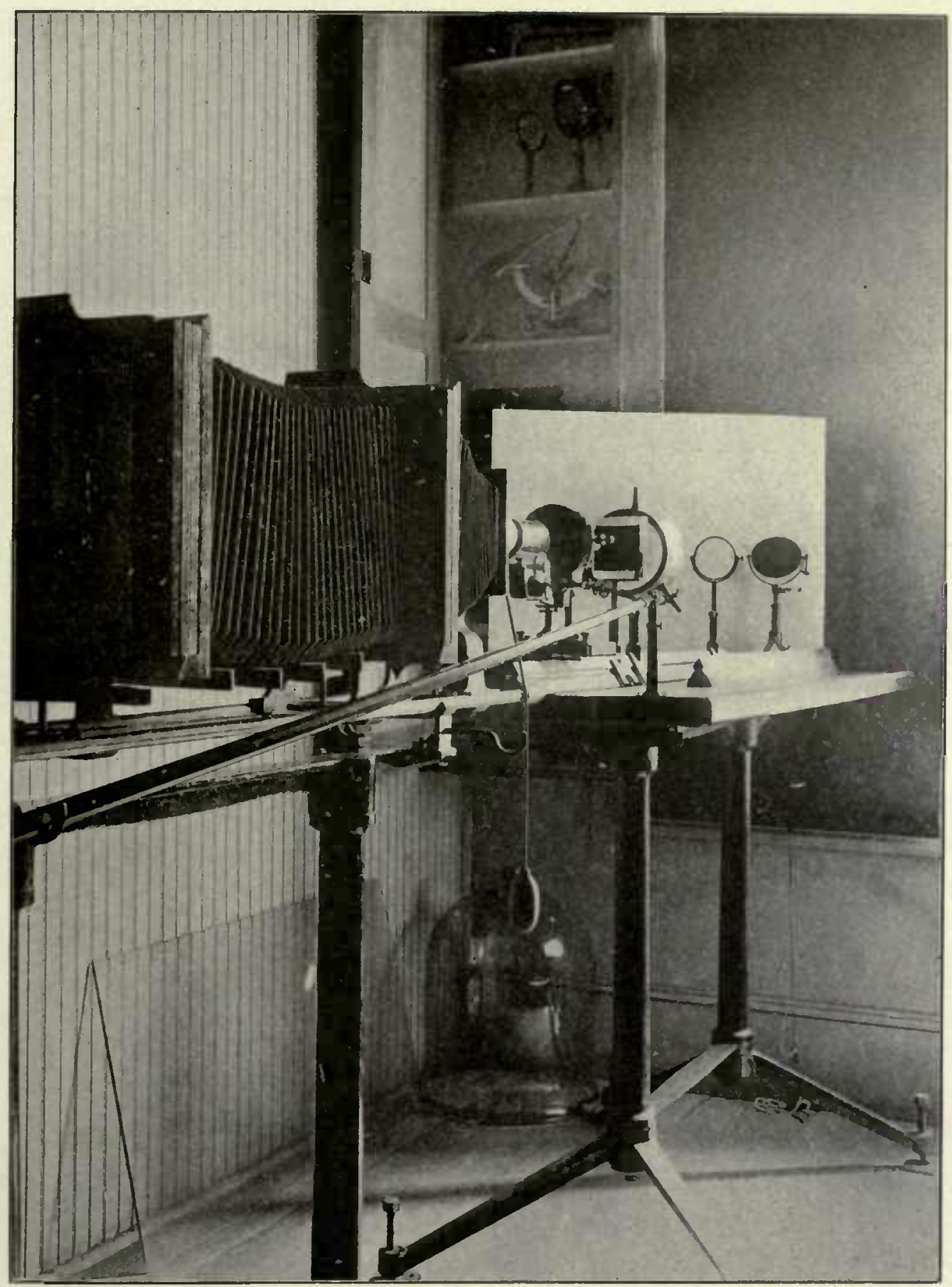

Large horizontal Zeiss photomicrographic outfit ready for use,

except that when photographing the curtain in raised and the mirsor in placed farther away, i. e., out of the south window on the triangular extenzion shown on the front table at the right. In the newer forms each table top may be raised or lowered at will. There is also a device for raising or lowering the plate on which the microncope rests. 
a 40 


\section{GROWTH.}

The manner of growth and rapidity of growtli at given temperatures in lianging drops and also on the nargin of young colonies on plates of nutrient gelatin and

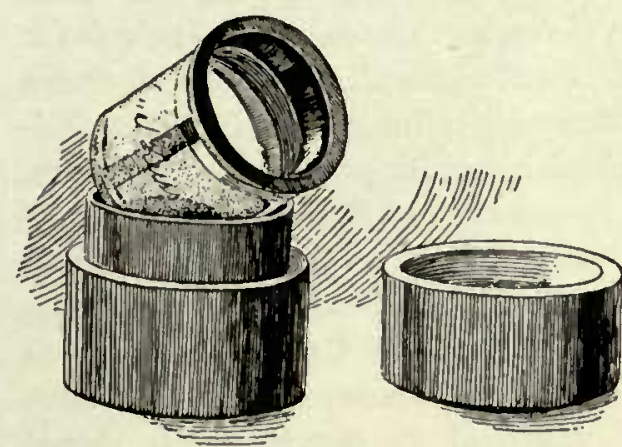

Fig. 25.* agar of varying density slould be determined. Frequently characteristic and interesting arrangements of the rods forming the surface layers of the colony, especially when it is young, may be discovered by nueans of a direct inspection of the colonies under low powers of the microscope or by means of cover-glass impressions. Covers are carefully placed on the colony, removed, dried, flamed, and stained. There are also often curious arrangements of the deeper layers of the

surface colony. In directexanination the colonies shonld be viewed by reflected as well as by transinitted light. Drawings or plotograplis of surface colonies should be niade under low or nuedium magnifications. By a little practice using Lister's dilution netlod (' 78 , Bibliog., XVII), hangingdrops containing a single bacterinin for study under the microscope may be obtained with Beyerinck's capillary drop-flask ('9r, Bibliog., XVII).

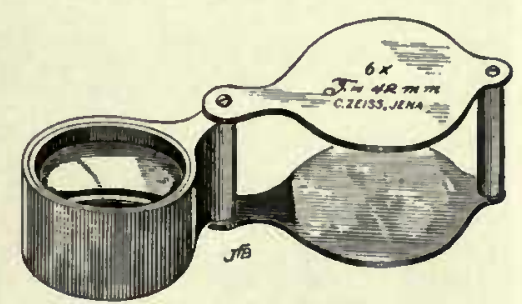

Fig. 26.†

\section{CHEMOTROPISM.}

On the general subject of chemotropism, see papers by Pfeffer, Miyoshi, Jennings, Buller, Rothert, etc. Jennings maintains that contact irritation inducing motor reflex is responsible for movements which were formerly attributed to chemical stinulus. Consult Jennings, "Contributions to the study of the behavior of lower organisuns," Carnegie Institution of Washington, r904, and especially Jen11ings and Crosby, "The manner in which bacteria react to stimuli, especially to chemical stinuli," A11. Jonr. Physiol., Vol. VI., pp. 3r-37, and Jonr. Roy. Mic. Soc., r902, p. 88. Spirillum volutans was used in the tests.

RFACTION TO STAINS.

Proper staining is a very important part of the study of bacteria. Its foundation principle is the fact that the bacteria, in a living vegetative condition, all slow a great affinity for the basic anilin dyes. Spores ordinarily show no sucli affinity, but may be made to take up stains by acting on then with strong acids or alkalis, or by heating then very hot. Flagella also show 110 affinity for stains until acted

*FIs. 25.-Hand Jens suitable for examining bacterial cultures. Zeiss aplanat magnifying six times. Three-fourths natural size.

fFig. 26.-Zeiss swing-cover aplanat magnifying six times. This is now sent out in a neat little chamois-skin purse. About two-thirds natural size. 
on by severe reagents, when they may be stained in mordanted solntions or in dyes which have been preceded by a mordant. The outer wall of the bacteriun generally reacts to stains in the same way as the flagella, $i . e$, it usually remains unstained.

Staining media may be roughly divided into four groups: (a) Simple stains dissolved in water, $e . g$., fuchsin (basic), gentian violet, nethylene blue; $(b)$ alcolıolic solutions and various complex stains, $e . g$., saturated alcolıolic solutions of anilin dyes, alcohol-iodine, iodine potassium iodide, Russow's cellulose test, Ziehl's carbolfuchsin, Loeffler's alkaline methylene blue, Ehrliclı's anilin-water gentian violet, Gabbett's stain, Gran's method, Delafield's hæmatoxylin, Elırliclı's acid hæmatoxylin, Heidenhain's iron-hæmatoxylin, Fleming's triple stain; $(c)$ flagella and capsule stains, e.g., Loeffler's stain, Moore's modification, Fischer's modification, Bunge's stain, I,öwit's stain, van Ermengem's nitrate of silver metlod, Zettnow's gold method, etc.; $(d)$ stains for spores, $e . g$. , prolonged exposure to simple stains

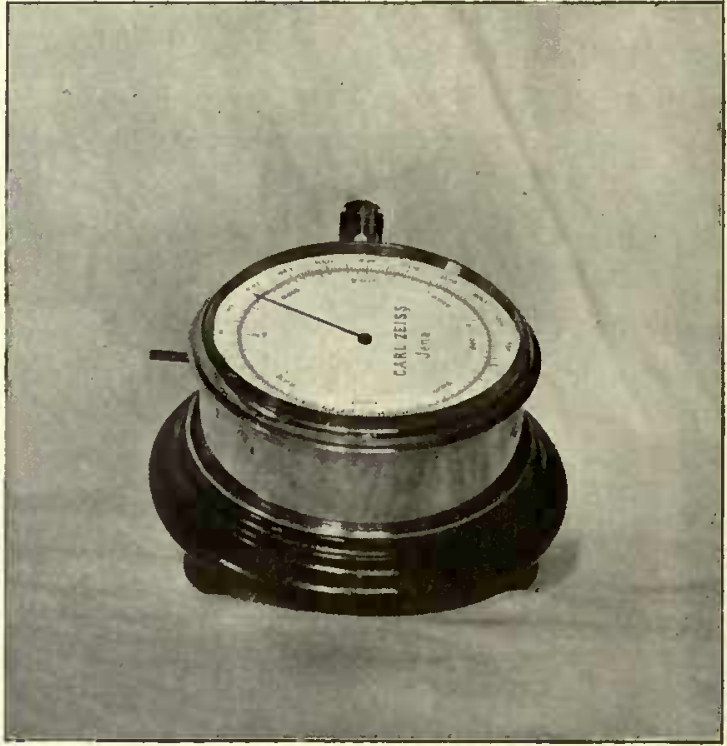

Fig. 27.* dissolved in water (which should liave little effect), steaming carbolfuclısin with nietlyylene blue for contrast, etc. (see "Fornulle" and Bibliography of General Literature under "Flagella," "Spores," etc., for varions observations on staining).

Grübler's stains are preferred. Cover-glasses should be clean and free from fat, traces of which are easily removed in a Bunsen flane. A little experience is necessary in flanning thin covers in order not to crack them. They may be passed through the flame three times, waiting a moment or two after eacli pass for them to cool. The student slould see that the water used in making the cover-glass preparations or the stains does not itself contain bacteria. It is usually wise first to dry a drop of the water on the cover and stain withont addition of the bacteria. Eternal vigilance is the price of trustworthy results. It is best to make all mounts on coverglasses of a known and uniform thickness (O.I 5 mm.). Many a good preparation has been spoiled for examination with lenses of a short-working distance by mounting under a thick cover-glass, and sometimes the lens itself lias been ruined in the attempt to focus. The thickness of covers often varies greatly from the statements of dealers, and they should not be accepted until tested with a reliable cover-glass ineasurer (fig. 27).

*FIG. 27.-Zeiss cover-glass measurer. The cover in place shows a registered thickness of 0.18 $\mathrm{mm}$. Fractions of an inch are also registered on this instrument. 
To determine whether bacteria are properly stained examine with the diaphragm of the condenser wide open. If they can not be seen distinctly with this flood of liglit they are not well stained. The bacteria should be well separated on the cover and deeply stained, while the background should be very free from stain.

Dr. Weigert seems to have been the first to use anilin stains for the demonstration of bacteria in tissnes. This was abont 1875 . Since that time staining in tissues has been worked up carefully for bacteria causing animal diseases, but very little is known respecting best metlods of staining bacteria in vegetable tissnes. The difficulty lies in the fact that the tissues of the higher plants often take the basic anilin stains as readily as the bacteria and retain them even more tenacionsly. Special remarks may be looked for nuder particular diseases.

\section{CULTURE MEDIA.}

\section{NUTRIENT GHLATIN.}

(a) Plate Cultures.-Colonies, young and old, buried and superficial, crowded and wide apart, shonld be exaninined for color, translucency or opaqueness, shape, thickness of the surface growth, and cliaracter of the margin. They should also be studied under low powers of the conponnd microscope for lobes, branches, granulations, wrinkles, flecks, concentric rings, radial filanents, arrangement of the dividing rods on the margin of the colony, iridescence, etc. The microscopic appearance of the surface colony during the first 48 honrs is often different from that later on. The rapidity of growth shonld be compared with that of some comıon and easily accessible organisun, e.g., Bacillus coli, B. amylovorus, Bacterium campestre. The comparative rate of growtl of buried and surface colonies should also be carcfilly noted. How is the appearance of the colony changed by increasing the amount of gelatin, or varying the brand of gelatin? Are the surface colonies viscid, or can they be lifted bodily in one mass from the substratnun?

(b) Stabs. - The nature of the surface growths and of the deeper growtlis should be carefully examined. Is there any marked tendency of the latter to grow downward or ontward into the body of the gelatin, either in distinct masses or as a diffused cloudiness? Observe effect, if any, on growth when the gelatin is acid or only feebly (litmus) alkaline. If liquefaction of the gelatin occurs, note its rapidity and whether it is mostly restricted to the surface or is equally rapid along the line of the stab in the depths; note also whether the liquefied gelatin is clear or cloudy in tubes which have not been shaken, and whether a pellicle lias formed on its surface. Liqnefaction may be very rapid (taking place within a few hours), inay occur after three or fonr days, may be long-delayed and feeble (only visible after some weeks), or may not occur at all. It is the cases of feeble and long-delayed liquefaction which lead to contradictory statements on the part of different observers, and consequently cultures shonld renain under observation for a considerable time and on a variety of gelatins. Various substances interfere with liquefaction. Determine whether liquefaction can be prevented by the addition of grape-sugar or cane-sigar (1o per cent). Look for gas-bubbles, for crystals, for any fluorescence or staining of the medium (green, brown). Inasmuch as the growth of some bacterial plant 
parasites is restrained by some nutrient gelatins which are neutral or only feebly alkaline to litmus, it is advisable to add to a part of the stock 11nore caustic soda than is commonly used, i. e., enough to render it neutral to phenolphthalein (strongly alkaline to neutral litn11s), especially if gelatin is selected as the first medium for isolation experiments; otherwise perplexing failures may result.

(c) Streaks.-Record the character of the streak, whetler wet or dry, s111ooth, wrinkled, or rough, thin or piled up, margin well defined or indistinct. Note also whether the surface is ever iridescent, whether growths are sent down from the under surface into the substratum, whether the streak spreads rapidly and widely over the

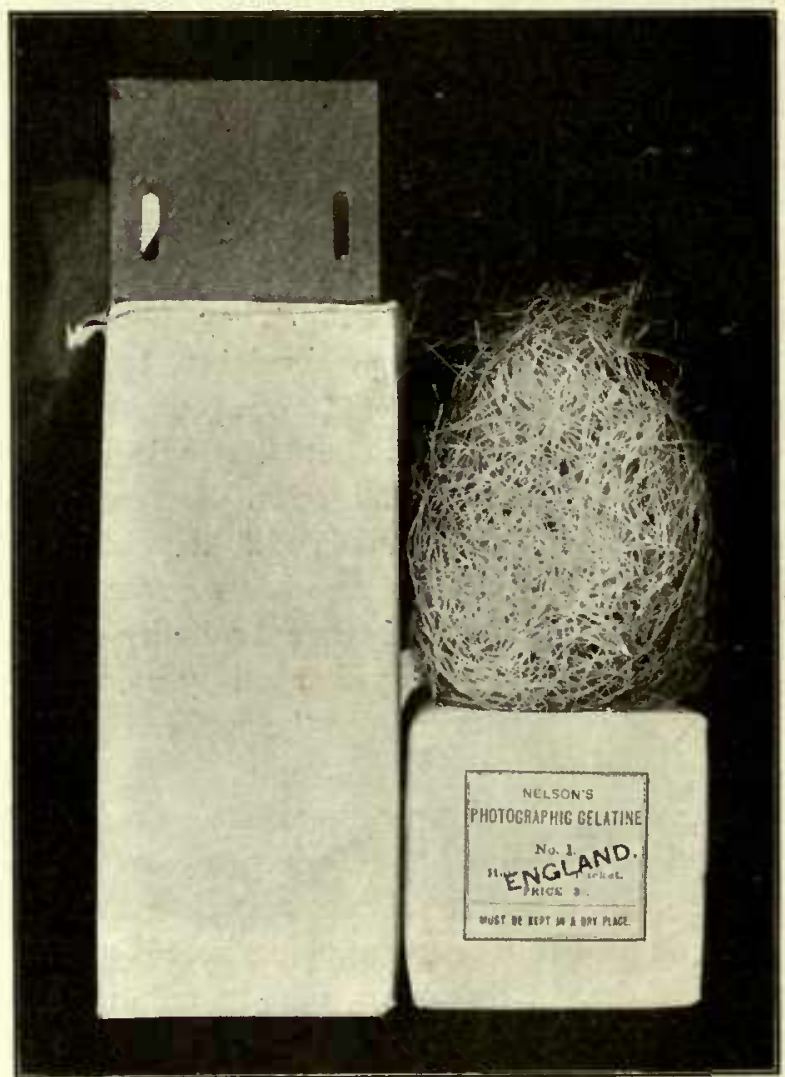

Fig. 28,* surface or very slowly. The surface behavior depends to some extent on the motility of the organis11, on the annownt of water in the surface layers, $i . e$., whether the slants are fresh or old, and on the amount of gelatin in the mediun1, which in tenperate climates should usually be ro per cent, but may be 15 or even 20 per cent. By minimizing lieat in preparation and by increasing the quantity of gelatin to 20 or 30 per cent a nnediuni may be obtained which will remain solid at $30^{\circ} \mathrm{C}$. Growtl is less satisfactory, however, on such a dense medinm, or at least was in the few tests wnade by the writer. Cliester has applied the ordinary botanical terminology to the varying nuargins of colonies, etc., and lias publislied some useful figures ('or, Bibliog., III).

No substance used in the bacteriological laboratory is so uncertain and variable in its composition as gelatin. The gelatin fron different factories varies greatly and hardly any two batches fron the same factory are alike. One glue chemist has defined gelatin as " 80 per cent glue, Io per cent dirt, and Io per cent doubt." It varies greatly in its melting point and power of setting, and in anount of peptones and albumoses it may contain, whicl is sometimes large. It always contains calcium salts and plosphates, which are often antiseptic, and the nature of which varies according as hydrochloric or sulphurous acid has been used in its 111anufacture. Formaldehyde is sometimes added to it, we are told; and occasionally agar also, it is

*FIG. 28.-Nelson's photographic gelatin No. I. Recommended for baoteriological use. 
said, is added to certain table gelatins to increase their body. Gelatin also contains a variety of decomposition products due to the growth in it of various fungi and bacteria while it is in the vats or in the drying-liouse. If there is any delay in the drying it is spotted all over witl molds and bacteria. It also contains some wax or grease, used to anoint the surface on which it is spread to dry, and this wax or grease is probably also a variable substance. Gelatins also polarize, it is said, in many different ways. An absolutely pure gelatin of miform cluaracter for bacteriological purposes is not to be had. That which perhaps comes the nearest to it and which is here recommended is Nelson's gelatin, snade in London and well known to the makers of photograplic dry-plates, who use it in large quantities. It comes in two grades, a hard and a soft, and costs about \$r.25 per pound. No. I, that which I like best, conles in shreds resembling "excelsior" used for packing (fig. 28). No. 3, which comes in long, broad strips, contains much cell detritus, etc., and filters with difficulty. Other expensive gelatins, said to be of quite uniforn quality, are

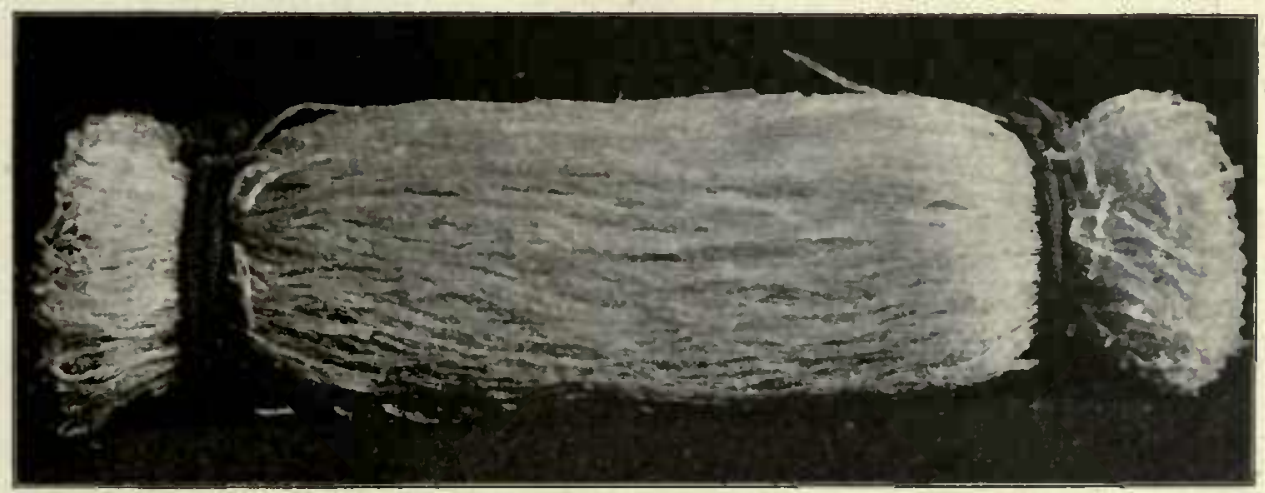

Fig. 29.*

Liclitdruck gelatin, made by Carl Crentz, Michelstadt, in Hesse, and Geneva Red Cross gelatin made by Wintertlunr, in Switzerland, under direction of Dr. Eder, of the Imperial Institnte of Vienna (Cockayne).

\section{NUtrient AGar.}

Agar, or agar-agar, as it is usually called, from a Malay word meaning "vegetable," is a manufactured product obtained from varions sea-weeds growing in Chinese and Japanese waters. Various species are used as food and the trade is considerable. It nsually comes into the liands of the bacteriologist as long, slender, yellowish-white strips (fig. 29) or as blocks (fig. 30), or more especially in recent years, in the form of a gray-white fine powder of Etropean manufacture (fig. 33). It is reputed to be the product of species of Gelidiun (figs. 3 I and 32 ).

*FIG. 29. -The kind of agar-agar ustally employed in bacteriological work. This is a manufactured produt known to the Japanese as slender "Kanten." The figure represents first quality "Kanten," in mubroken package. (Courtesy of Dr. Hugh M. Smith, Deputy Commissioner of the United States Bureau of Fisheries, who brought the package with him from Japan.) 
Of the Japanese algæ in this group the following, according to Rein (pp. 8I-82), deserve special mention:

(I.) Choudrus punctatus Sur.

(2.) Gigartina tenella Harvey; Jap. Ogo.

(3.) G. intermedia Sur.

(4.) Gloiopeltis tenax Kg. (Sphaerococcus tenax Ag.)

(5.) Gl. capillaris Sur.; Jap. Shiraga-nori.

(6.) Gl. coliformis Harv.; Jap. Kek'Kai.

(7) Gl. intricata Sur.; Jap. Fu-nori.

(8.) Gelidium corneum Lamouroux; Jap. Tokoroten-gusa.

(9.) G. Amansii Lamour.

(то.) G. cartilagincum Gail.

(II.) G. rigidum Grev.; Jap. Tosaka-nori, i. e., cockscomb algre.

(12.) Sphaerococcus confervoides A.; Jap. Shiramo.

(13.) Gymnogongrus flabclliformis Harv.; Jap. Itome-nori.

(I4.) G. japonicus, Sur.; Jap. Tsuno-mata.

(15.) Kallymenia dentata; Jap. Tosaka-nori.

(I6.) Porphyra vulgaris Ag.; Jap. Asakusanori.

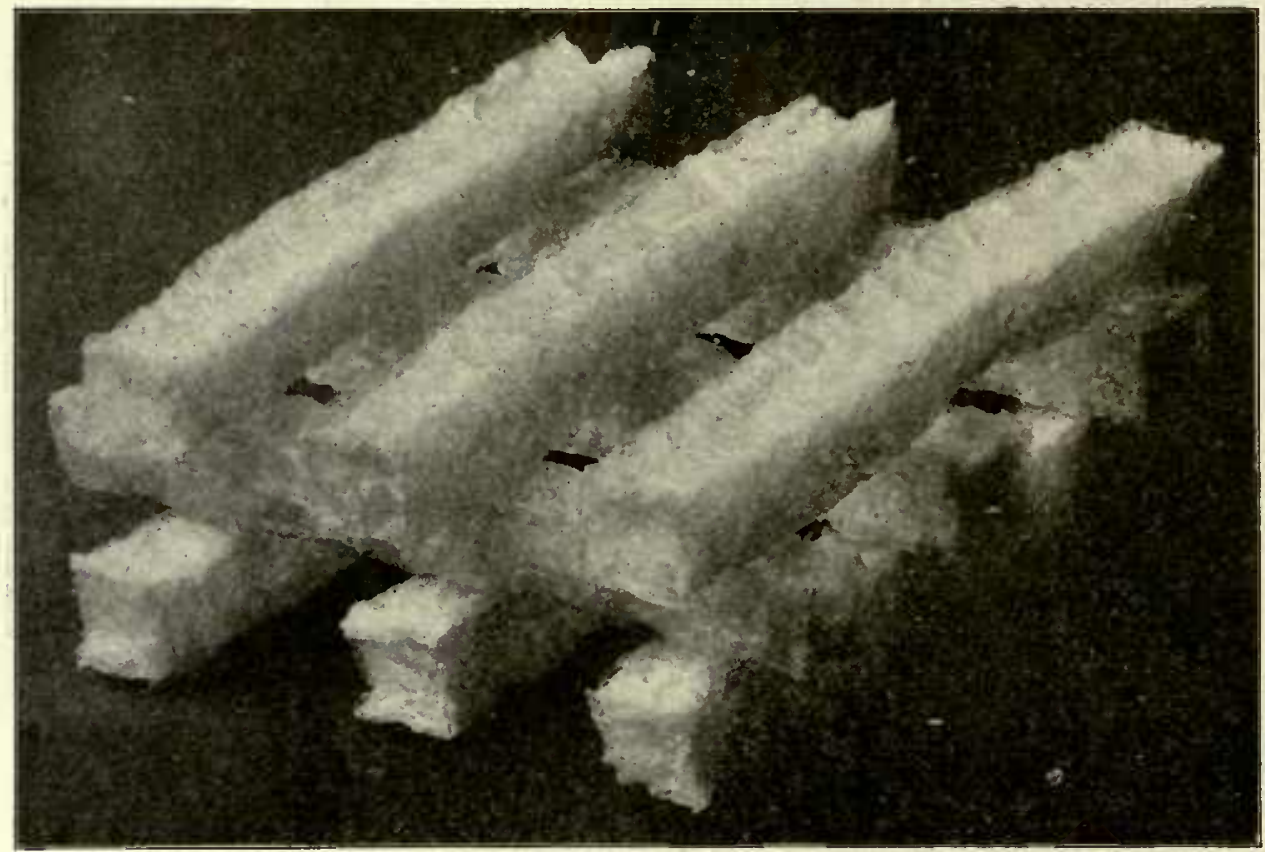

Fig. $30{ }^{*}$

Agar-agar is a neutral or nearly neutral substance which is couverted by boiling with water into a stiff jelly that hardens in I per cent solution at $39^{\circ}$ to $40^{\circ} \mathrm{C}$., and is not easily liquefied either by the growth of organisms $\dagger$ or by heat less than that of boiling water. It is a kind of vegretable glue forning a good 1natrix for various nutrient substances. A clienical analysis by Karten (Descript. Cat. Int. Health, Exhib., London, I884) gave the following proximate composition : I I.7 I per, cent nitrogenous matter (albumen [?]), 62.05 per cent non-nitrogenous n11atter (evidently glue, the pararabin of Reichardt), 3.44 per cent ashes, and 22.80 per cent water.

*FIG. 30.-Another form of agar-agar known to the Japanese as square "Kanten." The bulk of this goes to Holland, where it is used for clarifying schnapps. Courtesy of Dr. Hugh M. Smith.

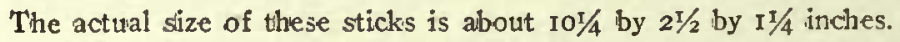

†Metcalf has described a bacillus which slowly softens it, and the writer has observed similar phenomena. 
For a full account of Japanese methods of making agar-agar consult a paper entitled "The Seaweed Industries of Japan," by Dr. Hugh M. Snith, in the Bulletin of the United States Bureau of Fisheries for r 904.

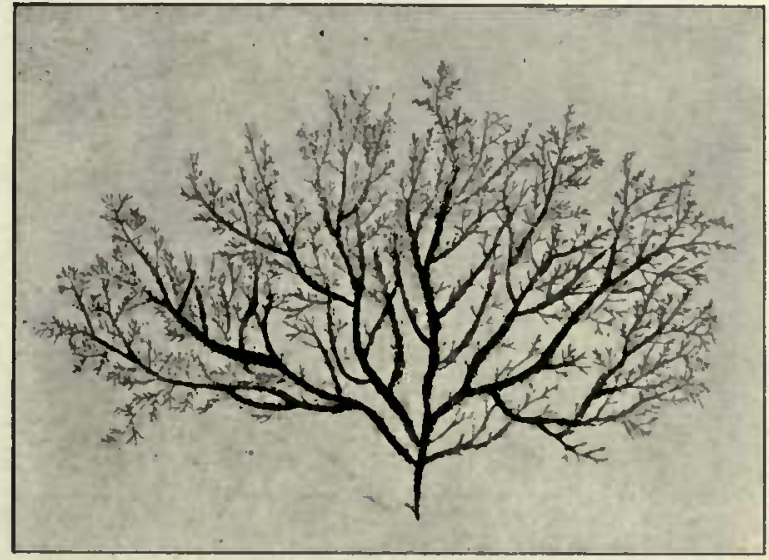

$a$

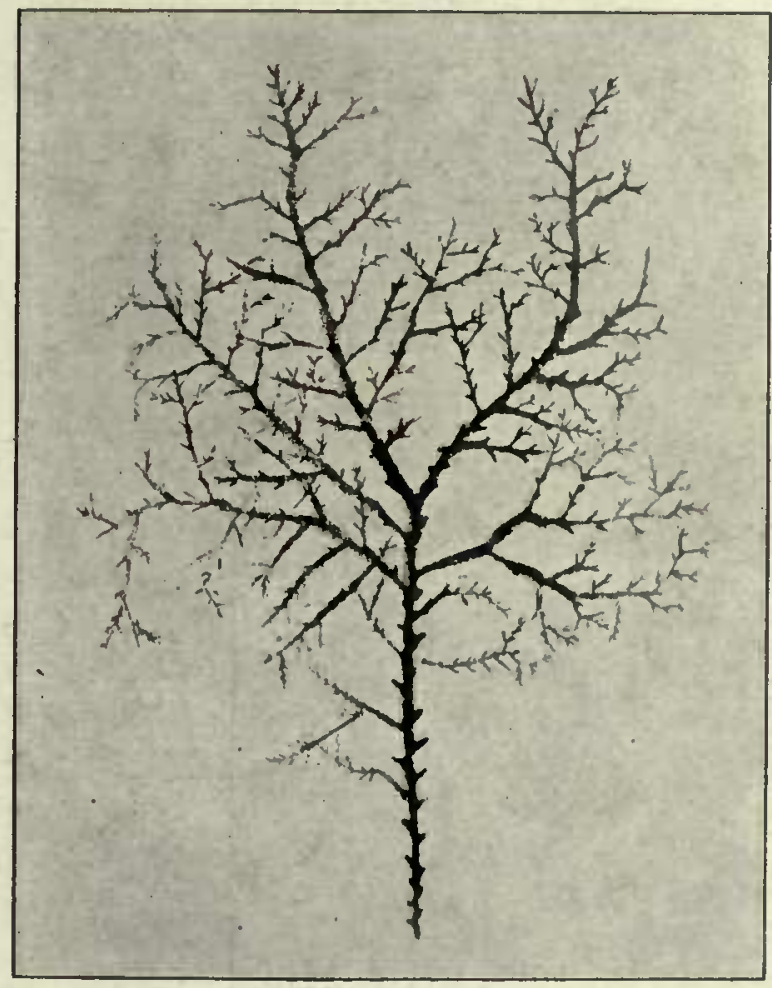

b

Fig. 31.*
In addition to beef bouillon, or in place of it, various substances, organic and inorganic, may be added to the agar with advantage. The writer makes much use of litmus-lactose agar, which is made out of ordinary nutrient agar by adding I per cent milk-sugar and enough pure litınus water to give a purple-red color. Glycerin-agar, maltose-agar, etc., may be inade 11p with any amount of the substance desired, generally $\mathrm{I}$ or 2 per cent.

Formerly it was difficult to filter agar perfectly clear and it was therefore used less than gelatin, but in recent years it has been discovered that this difficulty may be overcoine if the agar is first brought into complete solution by prolonged boiling or by a sliort boiling at a temperature somewhat above $100^{\circ} \mathrm{C} ., c_{.} g ., 110^{\circ} \mathrm{C}$.

The writer formerly obtained filtered clear agar by soaking the snipped agar in 5 per cent acetic-acid water for some lours, after wlich a thin eloth was tied over the mouth of the beaker securely, and tap water allowed to run into it for an hour or more $i$. e., until all trace of acid was removed. The softened agar was then put into the bouillon, boiled for two lours, and finally filtered through S. \& S. filter

*Fic. 31.-Red sea-weeds from which agar-agar is inanufactured. a, Gelidium corncum Lam., one-third natural size; $b$, Gelidium subcosiatum Iam., one-half natural size. From a colored Japanese ohart showing "The principal aquatic plants of Japan," supposed to be an official publication. Original in the library of the United States Fish Commission. 
paper, * 11sing a hot-water fun11el. Later lie followed Scli1tz's nuetlod ('92, Bibliog., $\mathrm{XVI}$ ), which is a very good one. This consists in cutting the agar into snall bits and first lieating it very hot in a beaker or enan1eled-iron dish in a 11111in1111 quantity of water or beef-bouillon over a hot Bunsen flane with constant and rapid stirring and
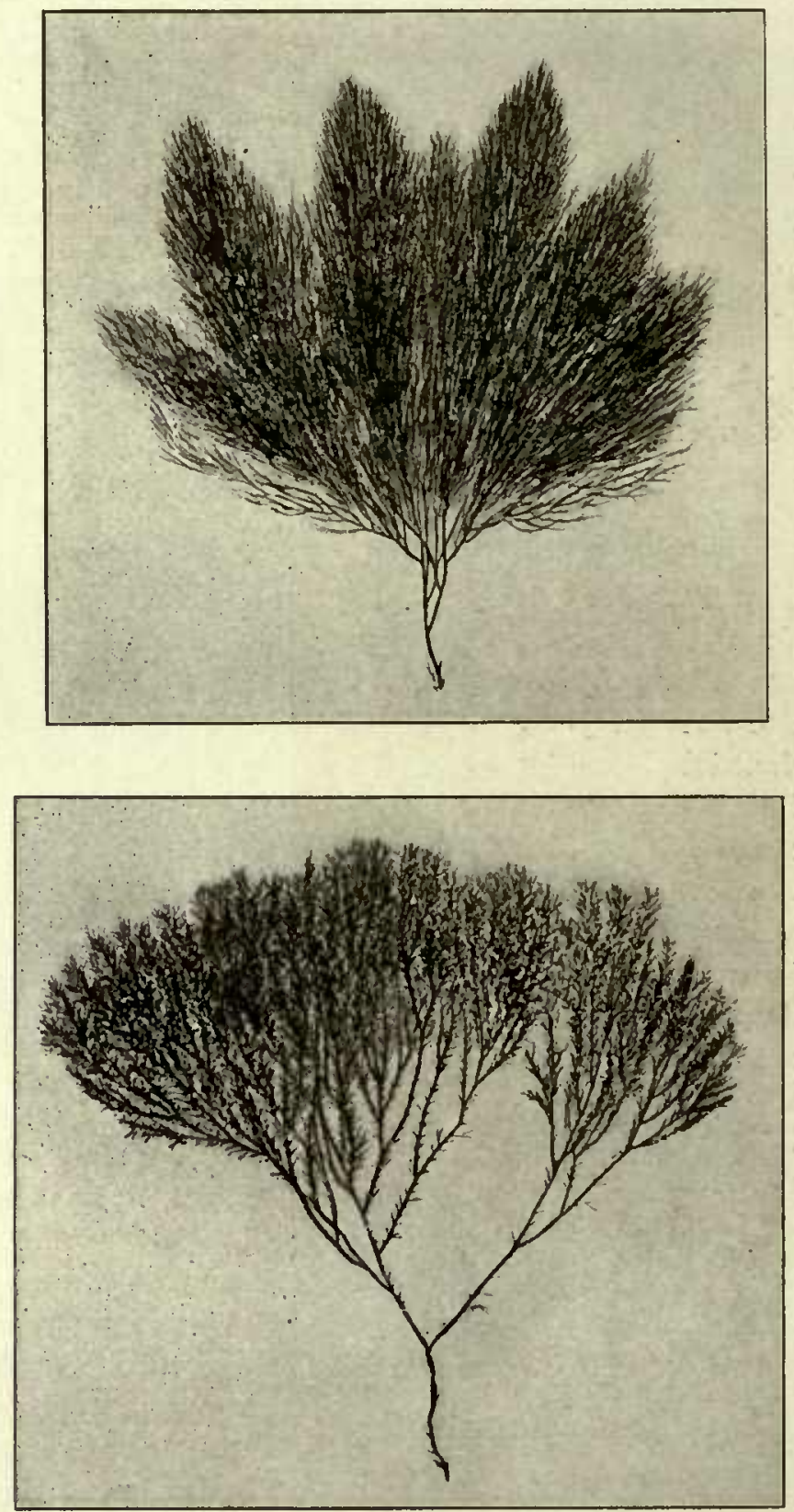

Fig. 32.t

*The folded filter papers are the most convenient (fig. 34). These filter papers give the starch reaction (blue) with iodine, and reduce Fehling's solution on being boiled in it.

†Fig. 32.-Unnamed species of red sea-weeds (Gclidium) furnishing agar-agar. From a Japanese chart showing "The principal aquatic plants of Japan," supposed to be an official publication. One-half natural size. Original in library of United States Fish Comnission. 
occasional additions of sunall quantities of water until it is thoroughly cooked in the form of a thick musl. It is then put into the remainder of the water or bouillon and subjected to streanining stean for two hours, after which, if the first heating was sufficient, it filters readily withont the use of a hot-water filter, or the necessity of keeping it in the steamer during the filtering. The stirring rod must touch all parts of the bottom of the dish exposed to the flane, every few seconds during the preliminary heating, otherwise the agar will burn on and be spoiled. On some

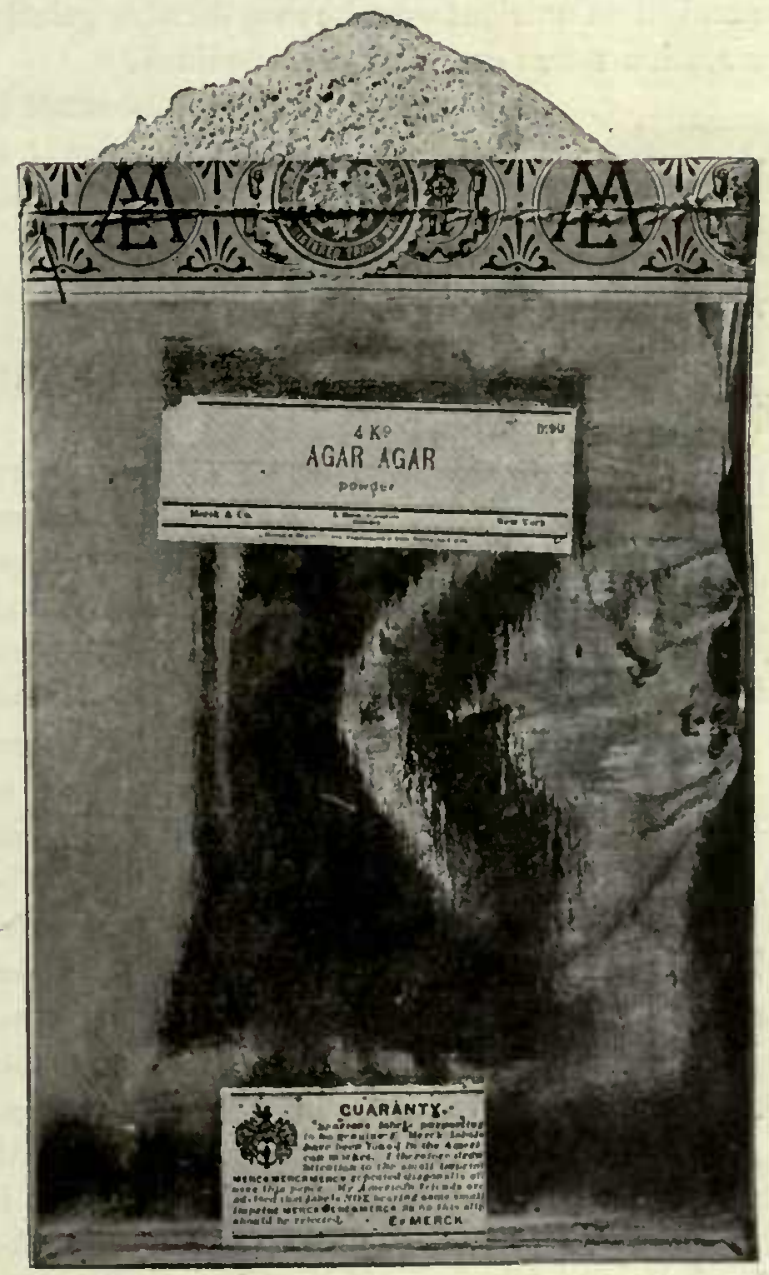

Fig. 33.* accounts it is best to begin operations with beakers rather than the enameled iron disles. In this way all likelihood of 11sing burned agar is avoided, since the 1110ment the agar burns on the beaker cracks and the agar is spilled. For bacteriological use agar should be clear, not clondy or filled with unremoved precipitates.

The writer now eniploys an antoclave and uses an agar flour procured from Lautenschläger or Merck (fig.33). If one has an autoclave the preliminary heating of the agar in an open dislı with a minimum quantity of water and all the subsequent stages may be dispensed with and the entire process carried on in the autoclave, unless it is known or suspected that media heated in the antoclave are less well adapted to the growth of particular organisins than those prepared at $100^{\circ} \mathrm{C}$. The an1ount of agar added to the culture fluid is usually I per cent. On the making of nutrient agar

consult "Forn111le," and the various standard text-books.

Is there any difference in the appcarance of colonies when grown at $5^{\circ}$ to $10^{\circ}$, $15^{\circ}$ to $20^{\circ}$, and $30^{\circ}$ to $37^{\circ} \mathrm{C}$ ? Observe the anonnt of precipitate that collects in the fluid in the V. For other observations as to growth on this substratu1n see "Gelatin." Every organisun should be stıdied in numerous Petri-dish ponred-plate

*Frg. 33.-Agar-agar flour as received from European manufacturers. Package of Merck's agar flour. 
cultures. Too many plate cultures can scarcely be made. Dishes with flat and very thin bottoms ( 0.3 1111.) are desirable for some purposes, but are difficult to procure. For quantitative work, plates with flat bottons are necessary, and when plotographs are likely to be wanted plates nunst be selected which do not have rings, wavy places or otler flaws in the glass on the bottom. There is roon for 111uch inprovenent in the quality of the Petri dishes now on the market.

The student is advised to use agar media for all general laboratory work. When he has learned the behavior of an organism on nutrient agar, he may then try gelatiu. Do any of the organisms wuder observation soften or liquefy the medium?

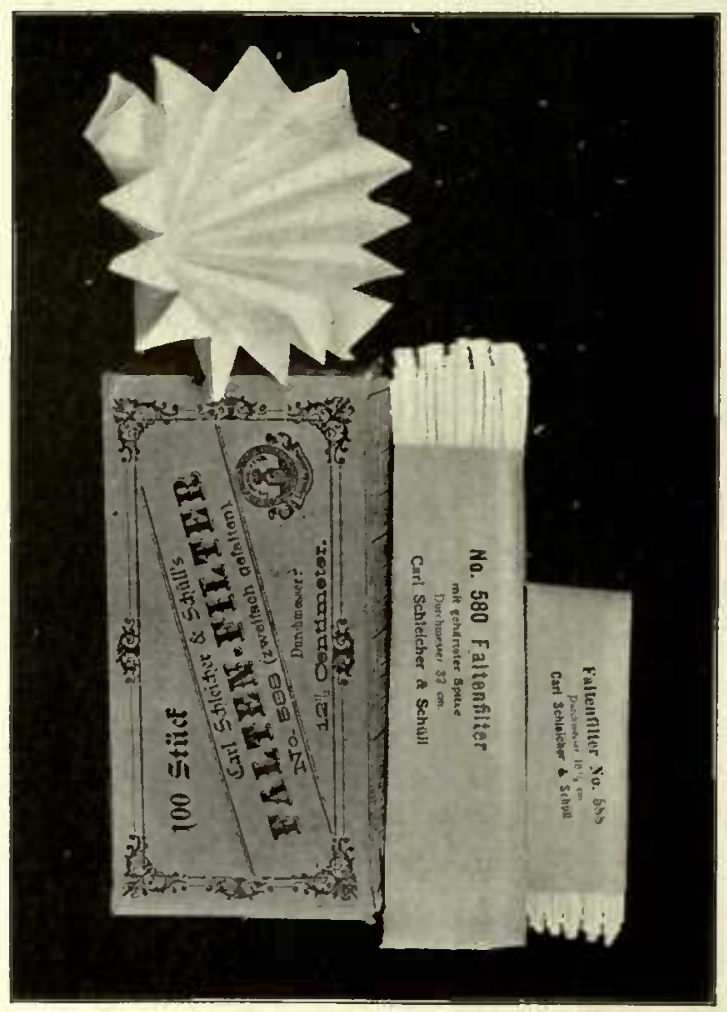

Fig. 34.*

Agar roll cultures may be made in test tubes readily if the annount of fluid agar is reduced to one-half cubic centineter.

When colonies are to be counted, special pains must be taken to distribute the gelatin or agar uniformly over the bottom of the dish.

Various persons - Pake, Jeffer, Weiss, Macé, et al.-liave devised ruled plates for connting the number of colonies of bacteria in Petri-dish poured plates. The writer prefers to conint by square centimeters or fractions thereof. When the plate is sown thin enough, the entire number of colonies should be counted. When it is very dense, the average may be taken of ten square centimeters selected with care, provided the bottom is flat, otherwise the whole plate must be counted. If the counting plate is to be placed under the dish, it may

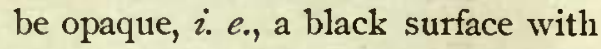
white lines, not the reverse. If it is to be placed on top of the dish, the latter preferably bottom up, then it should be of glass or some other transparent sibstance. The spaces may then be ruled on with a diamond, or drawn on in very fine black lines with India ink. The gelatin film of an nnexposed, fixed photographic dry-plate is a very good surface for holding the ink. For counting colonies on very densely sown plates, the writer has found conveuient a rectangle $20 \mathrm{~mm}$. by $5 \mathrm{~mm}$. divided into tenths.

\section{SILICATE JELLYY.}

In recent years, in the hands of Winogradsky and his students, silicate jelly has played an important part in the isolation of various organisms, which do not take

*FIG. 34.-Folded filter papers made by Schleicher \& Schüll. 
kindly to culture media containing animal and vegetable products. It is desirable also for exact experiment with other organisms. It may be used in Petri dishes or flasks, or slanted in test tubes. Along with some disadvantages, $e . g$., tendency to split, it lias a number of valuable characteristics, not least an1ong which is the fact that it enables one to offer the organism a solid substratum whicli is at the same

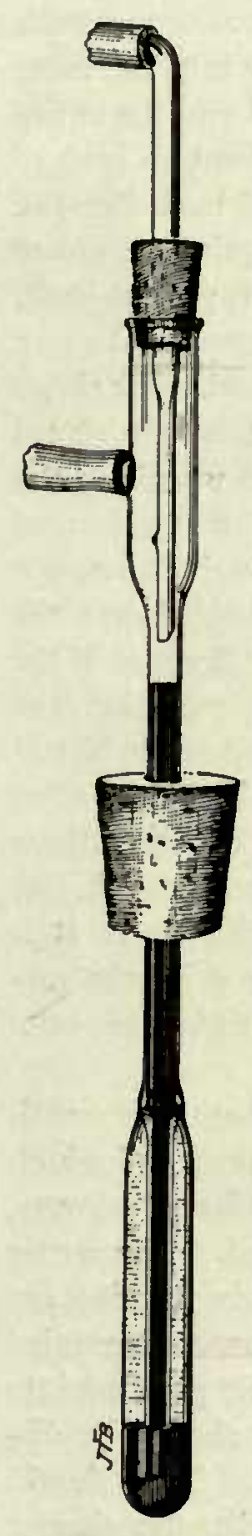

Fig. $35 .^{*}$ time purely synthetic. It is generally considered to be very difficult to nnake, but by following the most recent directions of Omélianski ('99, Bibliog., XXV), and especially certain slight modifications introduced by Moore \& Kelleruman and by the writer and his assistants, it can be prepared without difficulty, and to it niay be added any mineral nutrient substances desired. The writer makes it in the following way:

To each $100 \mathrm{cc} . \mathrm{HCl}$ (sp. gr. I. $10^{\circ}$ Beaumé) is added drop by drop roo cc. sodiun silicate (sp. gr. I.09), the mixture being stirred continually with a glass rod. This is now placed in a collodion sack and dialyzed for some hours in running water. To this is then added in concentrated sterile form whatever synthetic culture mediun is desired, after which the jelly is put into Petri dishes or test tubes and sterilized by heating for three hours in the blood-serum oven (fig. 45 ) on five consecutive days at $90^{\circ} \mathrm{C}$, or by one steaming in the autoclave for 15 minutes at $110^{\circ} \mathrm{C}$. The thermo-regulator shown in fig. 35 is useful for maintaining a constant high temperature in the oven. The oven must also contain sonne water in a capsule or beaker.

It is believed that a more detailed account of the manipulations connected with the preparation of silicate jelly will be welcome to many. First of all, one must have dialyzing sacks. Collodion sacks are much more convenient than parchment sacks, since they can be prepared at any time, and dialysis takes place through them with great rapidity. They are useful for so many purposes that material for making them should be on hand in every laboratory.

The writer follows Kellerman in making his sacks inside of test tubes. These may be large or sullall according to what the sacks are to be used for. If for dialyzing silicate jelly in some quantity, it is very convenient to make the sacks inside of test tubes 7 inches long and having an internal diameter of $I$ inch. The first thing is to prepare the collodion mixture. This is made by dissolving soluble guncotton, such as is used by plotographers, in a mixture of absolute alcohol and sulphuric ether. The writer uses equal parts of these two fluids. If too wutch alcohol is used, the sacks dry slowly, and if too much etler they are said to become brittle. After some

*FIG. 35.-Tollen's thenmo-regulator for maintaining blood-serum oven at $80^{\circ}$ to $90^{\circ} \mathrm{C}$. The stem and battom of the bulb contain mercury. The remainder of the bulb is filled with glycerin. In the similar thermo-regulator used for the paraffin-bath chloroform replaces the glycerin. Actual height, 12 inches. Chloroform and glycerin are very useful in such thermo-regulators because their coefficient of expansion is much greater than that of mercury. Thluene may also be used with mercury. 
experimenting it was found that 5 grams of the clean, white guncotton per Ioo cc. of the fluid gave a solution very satisfactory to work with. Abont 24 hours is required to dissolve the guncotton into a homogeneous mixtnre, of which there should be at least $800 \mathrm{cc}$. This should be stored in a cork-stoppered bottle of shape convenient to hold in one hand. It is then ready for use. The clean test tube, thoroughly dry on the inside, is now held in one hand in a slanting position, 111ontl up, wliile with the other the collodion is poured slowly and steadily into the tube, while the latter is slowly rotated. In this way air-bubbles are avoided and the entire interior of the tube is moistened. When this has taken place and about an inch of flinid has accumulated in the bottom of the tube, the excess is poured back into the bottle, slowly rotating the slanted tube, as before, so as to cover again the entire interior with as uniform a layer as possible. When the bulk has been ponred back, the tube is stood upright, mouth down, to drain on a sheet of clean paper. In two or three minutes it will have drained sufficiently, the excess of accumnlations abont the mouth being wiped off on the paper now and then. The tube is then seized and rotated in a horizontal position for four or five minutes with the month in the draft of an electric fan, or the rotation may be somewhat longer if no air-current is available. A little experience will tell when the sack is dry enongl to renove from the tube. The strong smell of ether must have somewliat subsided and the collodion must not feel wet around the mouth of the tube, as will be the case if the layer of collodion is too thick in places. If it is taken ont in this condition, the thick, wet places will become clouded. The collodion is now cut free at the lips of the test-tube by means of a pin-point or other sharp instrument and the tube is filled with cool water, taking care to let it also flow between sack and wall of tube if there is any shrinkage. In a minnte or two, if the work has been well done, the sack, free from air-bubbles and filled with water, may be readily lifted ont of the tube. It is then placed in a jar of water, where it remains nutil it is ready to receive the substance to be dialyzed. These sacks are quite tough, and there is little danger of tearing them during filling and tying.

When the silicate jelly or other substance has been placed in thenn, the mouth is brought together and tied by means of a small rubber band, the elasticity of which keeps the sacks perfectly tight. Silicate jelly should be dialyzed for at least 12 lrours, and sometimes for 24 hours, if every trace of salt must be removed. The writer fills the sacks with the silicate jelly in the afternoon and leaves then in ruming tap water over night. The next morning they are taken out, their contents emptied into a clean beaker, the nutrient salts added, and the fluid immediately pipetted into tubes, flasks, etc., and sterilized by lieat. The nutrient substances should be dissolved in advance, so as not to delay the preparation of the medinm. They slionld be added for this purpose to a minimum quantity of water. Some dissolve slowly, and there is a preferable order of solution, the glycerin being added last in case of Fermi's solution.

For the preparation of silicate jelly a Beanmé hydrometer for liquids heavier than water is used. C.P. hydrochloric acid of any specific gravity is diluted with distilled water until it tests $1.10^{\circ}$ on the scale of the hydrometer when cooled 
to $60^{\circ} \mathrm{F}$. Clear homogeneous sodium silicate of any specific gravity is then mixed with distilled water until it is of sp. gr. $1.09^{\circ}$ Beanme at $60^{\circ} \mathrm{F}$. A great deal of water must usually be added to the sodium silicate, and the first dilution is tedious. For example, IOO cc. of a sodium silicate of sp. gr. $1.42^{\circ}$ required the addition of $750 \mathrm{cc}$. of distilled water to give a fluid registering r.07 Beauné. On adding the fluid containing the nutrient salts, and hardening, sodiun silicate of sp. gr. $1.07^{\circ}$ Beauné gave a rather too fluid n11edium, and sodiun silicate of much higher sp. gr. than $1.09^{\circ}$ Beaume is apt to set before it has properly dialyzed, or after adding the nutrient salts and before it can be tubed and slanted. Several liters of the diluted acid and sodiun silicate nay be conveniently made up at one time. When these are ready, equal volumes of the two are mixed. This is done by adding the sodinin silicate drop by drop to the acid, rather rapidly, stirring meanwhile with a glass rod. The top part of the apparatus shown in fig. 146 may be used for this purpose. The saity, acid fluid is now ready to be placed in the collodion sacks for dialyzing in running water. It is ready for removal from the water when it is no longer acid to litmus and shows only traces of sodium chloride remaining. An exposure to the running water for 6 hours is scarcely sufficient, unless the sacks are si11all.

For many purposes Fermi's solution is a good one to add to the dialyzed jelly. This is made as follows, for this purpose: Freshly-boiled distilled water, roo; magnesium sulphate, 0.2 ; monopotassium phosphate, r.o; ammonium phosphate, I0.O. Dissolve. Then add glycerin, 45.0.

The dialyzed silicate jelly is now poured ont of the collodion sacks into a clean beaker and brouglit to a boil for a minute or two over an open flane (to drive off the absorbed air). It is now cooled down to $50^{\circ} \mathrm{C}$. and the Fermi added. If this has been dissolved over night it ınust also be brought to a boil and cooled, or liave the air renloved under an air-pump before adding it to the silicate jelly. To $500 \mathrm{cc}$. of the dialyzed fluid, $90 \mathrm{cc}$. of the Fermin may be added. This is stirred with a clean glass rod and then quickly pipetted into test tubes.

It is now placed in the antoclave without delay in the position desired and leated for 15 minutes at $110^{\circ} \mathrm{C}$. To avoid tearing the surface of the jelly by stean, the antoclave must be carefully shut stean1-tiglit as soon as the air is driven out, and it must not be opened until the temperature lias again fallen to $100^{\circ} \mathrm{C}$. It is also necessary to keep the autoclave closed on acconnt of loss of an1110nia from the annmonium salt. For this reason it is desirable to dissolve the Fermi in fresllyboiled water and to pump ont any absorbed air rather than to boil it out.

Other nutrient salts m11ay be added-Uschinsky's solntion, etc. The writer has lad very good success with Fenui for differential purposes. Many organisı1s grow ren1arkably well on this s11bstratı11, while otliers do not vegetate, or make only a scanty growtl.

The observations on this medium are the same as for gelatin or agar. Observe cliaracter of growth, staining of substratun (grcen, pink), etc.

$$
\text { Solid Vegetable Substances. }
$$

These should consist of slant cylinders in cotton-plugged test tubes lialf covered witl distilled water and steamed 20 minutes at $100^{\circ} \mathrm{C}$. on eacli of three consecutive 
days. The addition of considerable water enables one to keep the culture under observation for several months without danger from drying out if the cotton plugs are properly made. Drier culture media may also be used. If one wishes to do so, the potato or other substance may be lifted entirely out of the water by making a constriction in the lower part of the test tube, à la Roux, or by thrusting a wad of absorbent cotton into the bottom of the test tube before the potato is introduced. The writer has not found these methods necessary. In general, I prefer vegetable media which have been sterilized in the steamer rather than in the antoclave.

The following are some of the vegetable substances recommended:
(1) Potato.
(2) Sweet potato.
(3) Carrot.
(5) Turnip.
(6) Radish.
(4) Sugar-beet.
(7) Salsify.
(8) Parsnip.
(9) Onion.
(II) Coconut.
(I2) Peanuts.
(13) Brazilnuts.
(14) Apple.
(I5) Pear or quince.
(Ió) Pineapple.

These substances may be extended almost indefinitely and are very useful for making preliminary studies, inasmuch as they include many different kinds of chemical substances. The writer has used them for many years. They should be prepared with great cleanliness, especially the roots, so as to avoid including resistant spores. Sterilization is an easy and siruple process if these substrata are free from spores when the steaming begins. Roots and tubers should be selected with great care, only those being taken which are sound and free from blemishes. They are now to be washed thoroughly in tap water with scrubbing and then rinsed in distilled water. With clean hands and a clean knife they are then pared, witl care to remove all black specks, and thrown into a beaker of distilled, filtered or boiled water. Cylinders of the proper size may now be punched with' a clean cork-borer or cut with a clean sharp knife and, after the npper part has been slanted, are thrown into another beaker of distilled water, from which they are transferred to two others before they are finally put into the tubes. It is not necessary to soak them in water over night or in antiseptic solutions. They will not brown by oxidization if they are kept under water dnring the early stages of preparation and are steamed as soon as they are placed in the tubes, i.e., exposed to the air. They way be put into the tubes with clean fingers or by means of a pair of clean forceps.

On these different media observe the nature, amount, and rapidity of growth (always with due regard to the air-temperature, which should be recorded). Carefully determine whether there is any retardatiou of growth at first and, if so, to what it is due, so that more exact studies may be made subsequently in other nuedia. Irook for gas-bubbles, formation of acids and alkalies, fornation of hydrogen sulphide, of crystals, of stains, of odors, destruction of starch, disappearance of the middle lamella, softening of cellulose, etc. For the first few days all cultures slionld be exanined at least as often as once in 24 hours and, generally speaking, cultures should not be discarded until after the sixth or eightl week. These experiments should be repeated a number of times and the student should avoid drawing a hasty conclusion, since different samples of potatoes, carrots, etc., vary somewhat in composition and will at times give slightly varying results or even results which seem to be contradictory, e.g., a brown pigment in some instances and not in others. 
The sanne media, and as many other sorts as are available, should be tested raw in sterile, dry, Petri dishes Io c11. broad and 2 to $3 \mathrm{~cm}$. deep. For this purpose the vegetables are prepared as follows: First, select sound, clean specinens, especially avoiding those which are cracked open; next, scrub their surface thoroughly under the tap, and rinse then in distilled water. They are now soaked 5 or 10 ininutes, or even 20 minutes, in $\mathrm{r}$ :IOOO water solution of mercuric cliloride. They are then renoved and dried with or without a preliminary rinsing in sterile water. When dry they are put on a sterile paper or plate, are cut into slices about 1.5 to $2 \mathrm{~cm}$. thick with a cold sterile knife, are picked up with sterile forceps, and are put into

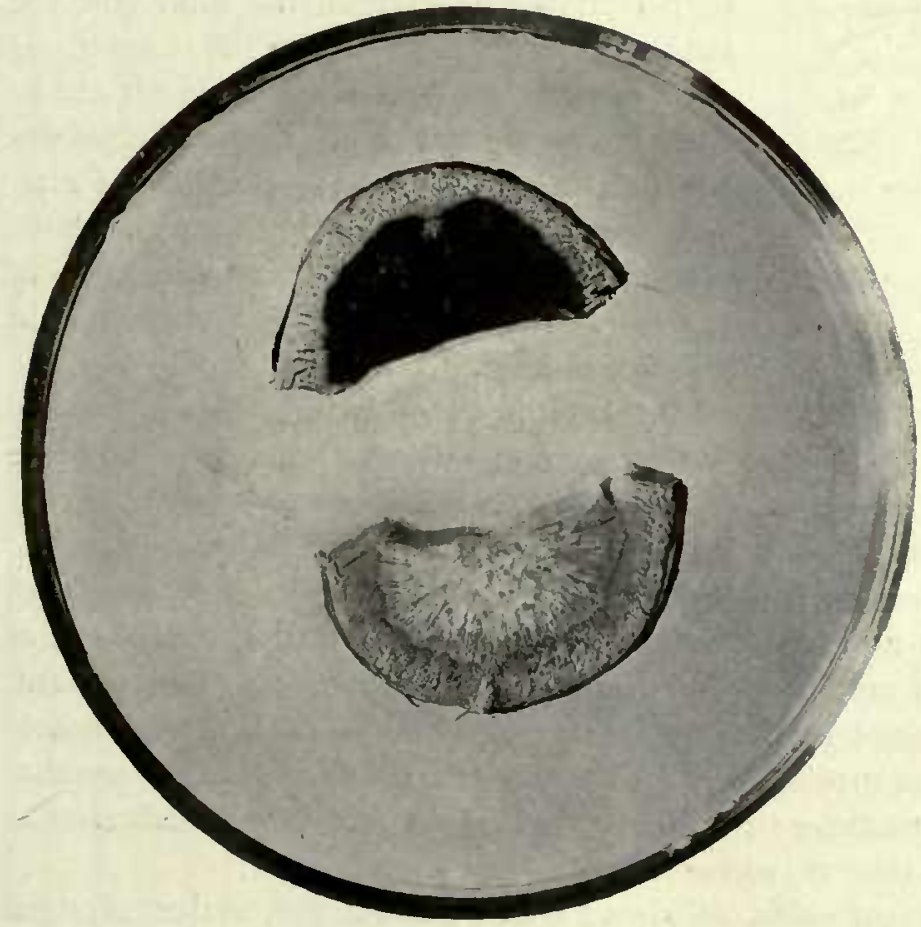

Fig. 36.* the Petri dishes in pairs or fours, the cover being immediately replaced. Enough of the mercuric chloride remains on the surface to inhibit the growth of any surface organisms which have not been killed ontright, and experience shows that intruders are rarely dragged over the cut surface. The slices may be inoculated at once or after 36 lours incubation in a noist chamber at $30^{\circ} \mathrm{C}$, or 48 hours at $25^{\circ} \mathrm{C}$. The latter course is preferable. In either case, half of the slices in each dish inust be kept uninoculated for comparisou (fig. 36). This method is well adapted to the study of various soft-rot organisus such as Bacillus carotororus, B. aroidea, B. oleracee, etc.

PLANT JUIChS (WITh aNd Without THE aDDition OF Wathr).

(I) Juice of the host-plant.

(2) Potato-broth.

(a) With sodium hydrate.

(b) Without alkali.

(3) Cabbage or cauliflower broth.
(4) Prune-juice.

(5) Orange-juice.

(6) Coconut-water (unsteamed). $\uparrow$.

(7) Yellow corn-meal broth.

(8) Timothy-hay infusion.

*FIG. 36.-Iris-rhizome-rot organism grown on raw carrot. The check piece is unchanged, the inoculated piece has browned and softened. Incubated 4 days at about $23^{\circ} \mathrm{C}$.

tThis is removed directly from the nut to sterile test-tubes by means of sterile pipettes, which are useful in many ways. The pipettes should be dry-heated and kept from contamination in long, narrow, covered tin boxes. These boxes may be cylindrical or rectangular, with an end cover. The upper end of the pipette should be plugged firmly with cotton before sterilization, and this should be pushed in a short distance beyond the end, so that when the finger is placed on the end there will be an air-tight union. Scalpels, etc., should be sterilized in shorter boxes of the same kind (fig. 37). 
These fluids are only a few of many that may be used. Some of then, e.g., potato-broth, require special care in preparation. My own method of making potatobroth is to pass the clean pared potatoes rapidly through a grating nuachine and

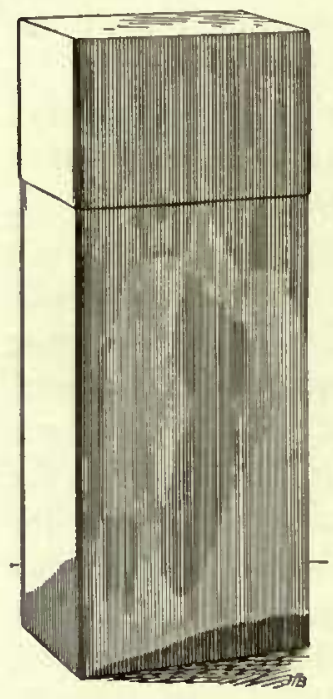

Fig. 37.*

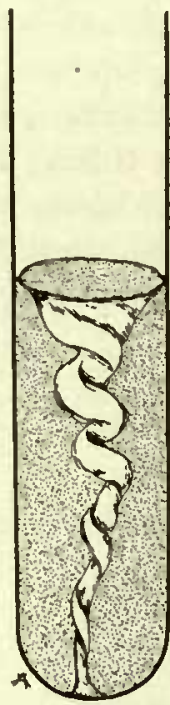

Fig. 38. † immediately throw the pulp into the required quantity of distilled water (which should be twice the weight of the potato). The beaker is now put into a water-bath and the temperature rapidly raised to $55^{\circ} \mathrm{C}$. and kept there with frequent stirring for an hour. The pulp is now filtered from the fluid and the latter is innmediately put into the steaner. If the steaning is long delayed the broth will be dark brown (oxidizing action of the potatoenzyme on tannins in the presence of air), and if the temperature rises nunch above $60^{\circ} \mathrm{C}$, before the pulp is renioved, some of the starch becomes gelatinous and the fluid will not filter.

All nedia which have boiled away to any up to the original volume or weight just prior to final sterilization.

In these culture-fluids observe the rapidity, density, and persistency of the clouding; whether the clouding is simple or turbid from the presence of zooglore; and finally, whether it is uniform in all parts of the tube. Note the character of the rim and pellicle, if any are formed, and how soon they appear ; also the amount, color, and general appearance of the precipitate. The amount of the precipitate varies greatly with different media. Its quality also varies. Sometines it consists of loose, easily separable particles; in other cases it is a viscid mass which rises as a rope-like unit when the tube is twirled (fig. $3^{8}$ ).

Record the formation of acids, alkalies, $\ddagger$ odors, gas-bubbles, stains, crystals. Does the fluid become viscid or ropy? Some organisms bring about this condition quickly in a variety of media, e.g., Bacterium pericarditidis (Bacillus pyocyaneus pericarditidis), others rarely or never. Precipitates in test-tube cultures vary all the way from a scarcely perceptible trace to masses a centimeter or 1110re in depth. Do not confound chemical precipitates with bacterial growth. Before inoculation always examine media in test-tubes for presence of slight precipitates and for contaninating organisms. In cultures of rapidly growing species, at optimun tenperatures, clouding may occur in less than twenty-four hours; with slow-growing species, and

*FIG. 37.-Tin box for holding scalpels, forceps, etc., to be sterilized by dry heat. About onefourth actual size. A similar tin box which is very convenient for holding sterile pipettes measures 2 by 3 by 15 inches.

†FIG. 38.-Twirled culture of the olive-tubercle arganism in Uschinsky's solution, showing viscidity of the precipitate in old cultures.

$\$$ Bacterial ash is alkaline, and this ash must be carefully washed from the platinum loop in distilled water each time before it is used to transfer drops of the culture-fluid to litmus paper. The wire must, of course, be re-flamed after washing. 
when the medium has a retarding action, it may not occur intil after two or three weeks. Of conrse, the rapidity of the clouding depends to a considerable extent on the size of the loop and on whether the inoculation was froin a young or old, a fluid or a solid culture.

Among other tools, the student should be provided with five platinum-iridium wires set into glass handles, three of which are bent at the free end into loops of a definite size, $i . e$., with an inside diameter of $\mathrm{I}, 2$, and $3 \mathrm{~mm}$. These are made by bending around wires of the given size, and will enable one to measure out approxi111ately uniform quantities of fluids and solids. Smaller quantities nay be transferred on the extreme tip of a straiglit platinum needle. It is also convenient to have a platinum* needle bent at the end into a sliort hook (see fig. 39). In comparing rates of growth in fluid cultures it is best to inoculate them from other fluid cultures of a given age and not from solids.

If there is any reason to think that boiling changes the nature of any of these fluids, they should be sterilized cold by forcing them through a Chamberland or Berkefeld filter. The Clianberland has the finer pores, the Berkefeld filters quicker. The simplest way of nsing such a filter is that first described by Dr. Theobald Sinitll, viz, to put the fluid inside and force it out by means of clean compressed air. For this purpose select a flat-bottomed cylindrical glass vessel (a round-bottomed one is less convenient, but may be set into a hole bored in a block of wood) of a larger diameter and 5 or ro centimeters longer than the bougie, which should be clean (previously unnsed), but washed by having had some liters of distilled or filtered water forced throungh it. Wrap the nipple-end of the filtering cylinder firmly with clean cotton for a distance of 5 or $10 \mathrm{~cm}$. down. Thrust the wrapped bougie into the glass vessel securely, so that only the nipple and the cap or shonlder projects. The top of the bougie should also be wired so that it can not possibly slip down during the filtering. This apparatus should now be sterilized by putting it into the dry oven for two hours at $145^{\circ} \mathrm{C}$. Wrap in clean Manila paper and heat at the same time a large cotton plug, $i . e$, one which has been made to fit the mouth

*Platinum-iridium is preferred to pure platinum because it bends less easily. The wire used by the wrriter thas a diameter of $0.48 \mathrm{~mm}$. The alloy as usurally found on the market is said to contain about to per cent of iridium, sometimes less, but never more. The wire shown in fig. 39 was made to order and contains 20 per cent iridium.

†FIG. 39.-Platinum-iridium wires set into glass rods, for bacteriological work. I, needle; 2, hook; 3, one-millimeter loop; 4, two-millimeter loop; , three-millimeter loop. The size of this wire is about one fifty-fifth inch. 
of the cylindrical glass vessel. When sterilized and ready for 11 se, select a piece of rubber cloth Io or I $5 \mathrm{~cm}$. in dianeter, cut a small slit in its center and draw it over the nipple of the bongie to protect the cotton from accidental wetting and the filtered fluid from consequent possible contamination. Now ponr the fluid into the bougie (if one with a large neck has been selected this will not be difficnlt,

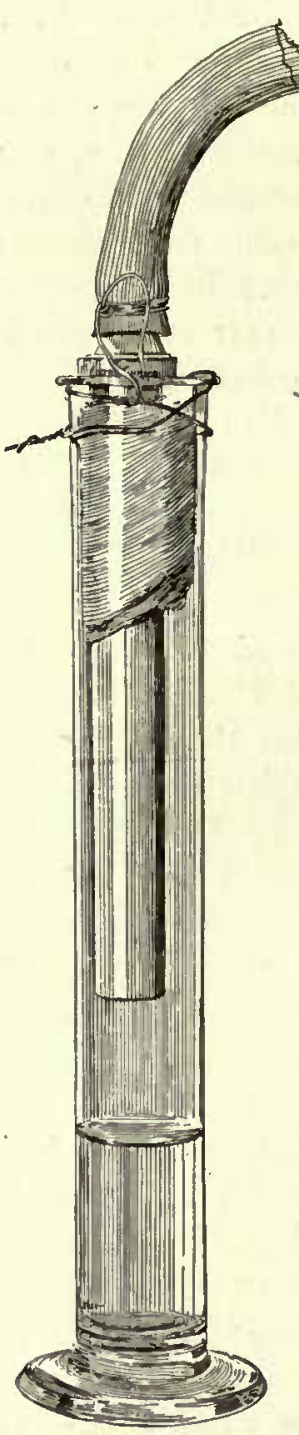

Fig. 40.* especially if a small funnel is used and this is kept from close contact on one side by means of a small wire, sliver, or bit of paper), and connect the nipple with the ontflow-tube of the compressed-air pipe by means of an extra-thick rubber tube, which should be securely wired at each end, and turn on the compressed air cautiously. Fluids which are not colloidal usually filter very readily with a pressure of 15 or 20 pounds per square inch.

The filtering should always be done slowly with a minimum pressure in order to avoid the possibility of iorcing small organisms through the walls of the filter. With heavy pressure this sometimes occurs when no cracks are detectable in the bougie. When the desired quantity of fluid has been filtered (fig. 40) cut off the air-blast, disconnect the tube, tilt the cylinder as much as possible, remove the bougie, and substitute the sterile cotton plug. The fluid should now be transferred immediately, in 5 or 1o cc. portions, to sterile cotton-plugged test-tubes by means of sterile pipettes. The removal of the bongie and the transfer of the fluid should be done in clean still air, under a lood or in a special culture-room. The tribes should not be used for several days, $i$. e., time should be given for contaminations to show themselves, but if proper care lias been exercised there should be very few contanninations or none at all. A pressure mich greater than 20 pounds per square inch may be obtained by means of steam-pumps or by 11se of cylinders of compressed air, oxygen, or carbon dioxide, and this is sometimes necessary for colloidal strbstances, but should be used cautiously. These cylinders may be had from the Eagle Oxygen Company, New York. One of the most convenient filters on the market is that shown in fig. 4I. It was designed by Roux and is made by Maison Wiesnegg (P. Lequeux), Paris. It is well made, very durable, quickly sterilized, and easily operated if one can command an air-blast or other gas-pressure of 2 or 3 atmospheres.

Chamberland bougies ought not to be used continuously for more than three days. They should then be removed and baked for two hours at $145^{\circ} \mathrm{C}$. (or at the

*FIG. 40.-Simple method of obtaining small quantities of sterile fluids by means of the Chamberland filter. The other end of the rubber tube is wired securely to the outflow pipe of the compressed-air system and the fluid is forced from the inside of the filter out. This method was first described and figured by Dr. Theobald Smith. About one-fourth actual size. 
tenperature of an oven in which bread is baked). The reason for this lies in the fact that in three or four days time certain small organisms are able to grow through the

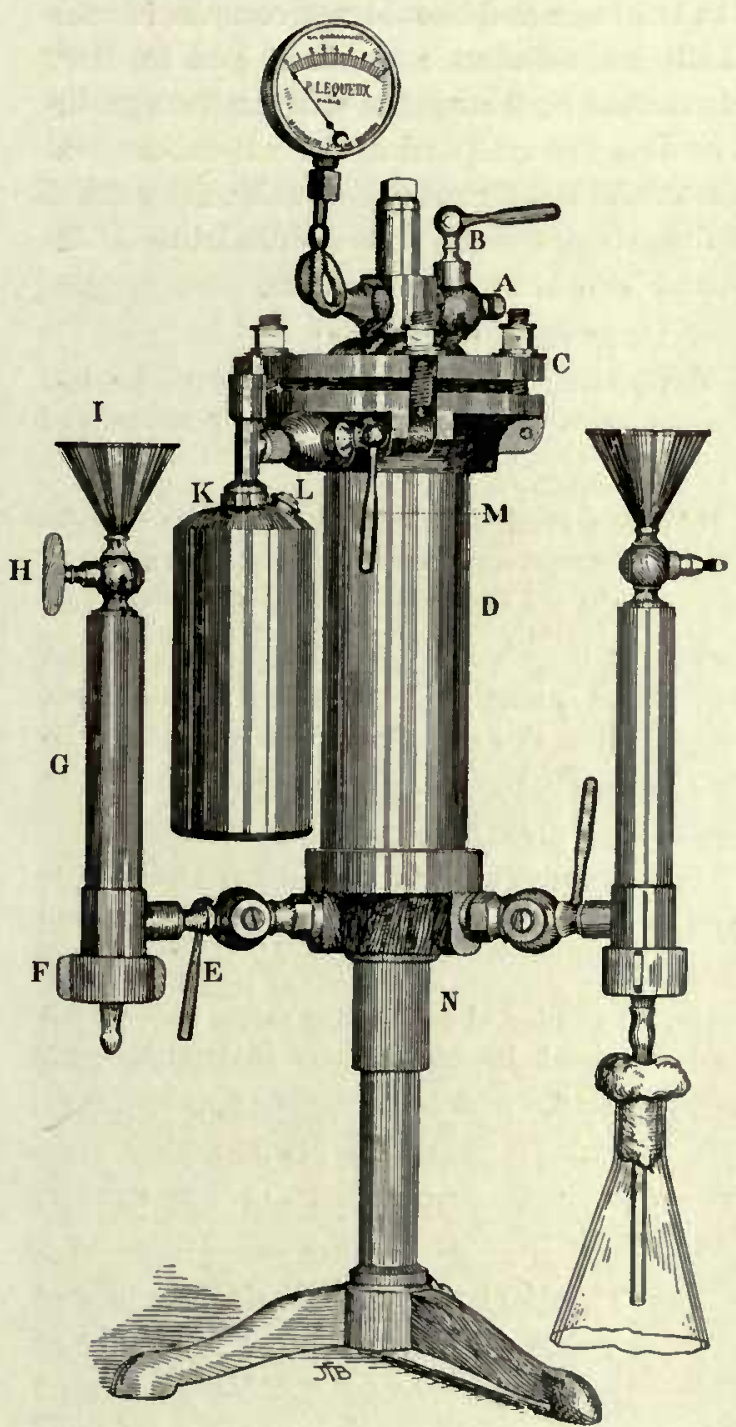

Fig. 41.* walls of the filter and make their appearance in the filtered fluids on the other side. Persons who never bake their water-filters rest in unwarranted security. The bougies must also be handled with great care and inspected carefully after each baking for the appearance of minute cracks. To detect cracks, immerse the tube in water and blow into it. Clogged filters should be sent to the firers of china, where they may be purified by heating to dull redness.

\section{Animal Fluids.}

BEEF-BROTH.

(a) Acid, neutral, and alkaline.

(b) The same, with addition of 0.5 per cent c. p. sodium chloride and I per cent peptone (Witte's peptonum siccuin, Merck's brown peptone, Savory \& Moore's brown peptone, etc.). 'This is ordinary peptonized beef-broth.

Examine as in case of plant juices. The tern peptone, as it occurs in bacteriological literature, usually means connulercial peptone, which is a mixture of true peptone and various proteoses or albumoses. It is therefore gencrally best to specify just what peptone is used. The writer now generally uses Witte's dry white peptone. Savory \& Moore's brown peptone from flesh is very good for solne purposes.

*FIg. 4I.-Dr. Roux's pressure-filter, made by Maison Wiesnegg (P. Lequeux), Paris: The working capacity of this filter is about 1.3 liters. The principal parts are: $\mathrm{A}$, tube for connection with compressed-air system; $\mathrm{B}$, cut-off; $\mathrm{C}$, cover held in place by strong bolts; $\mathrm{D}$, central reservoir; E, cut-off; F, screw collar which holds the bougie in place; G, heavy metal cylinder surrounding the bougic; $H$, cut-off, which is closed of course when the apparatus is in use; 1 , funnel through which $G$ and $D$ are filled; $K$, device for sterilizing the interior of the apparatus by steam under light pressure (it consists of a copper ohamber partly full of distilled water, to the bottom of which the Bunsen flame is applied; the chamber may be unscrewed and removed); $L$, button which is unscrewed to fill the chamber with water (in its center is a steam safety valve acting under feeble pressure); $M$, valve which cuts the steam-generator out of the general circulation when fluids are being filtered; $N$, tripod-top on which the apparatus turns freely. Height, 33 inches. 
Milk.-Milk from a clean dairy and free or nearly free from cream should be selected for use. If some creain remains it may be filtered out or remioved by the centrifinge (fig. 43). The milk should not be acid to the taste and shonld not contain formaldelyd or other antiseptic substances which milk-dealers sometimes add to dirty $111 \mathrm{ilk}$ to improve its keeping qualities. It shonld be steamed in wire-crates 15 minutes at $100^{\circ} \mathrm{C}$. on each of four consecutive days (Io cc. portions in test-tubes), and should not be used nntil at least a week after the last steaming. Such milk slionld titrate $+I_{2}$ to $+I 7$ or thereabouts with sodium hydrate and phenolphtlialein. Milkcultures should be kept under observation at least six or eight weeks.

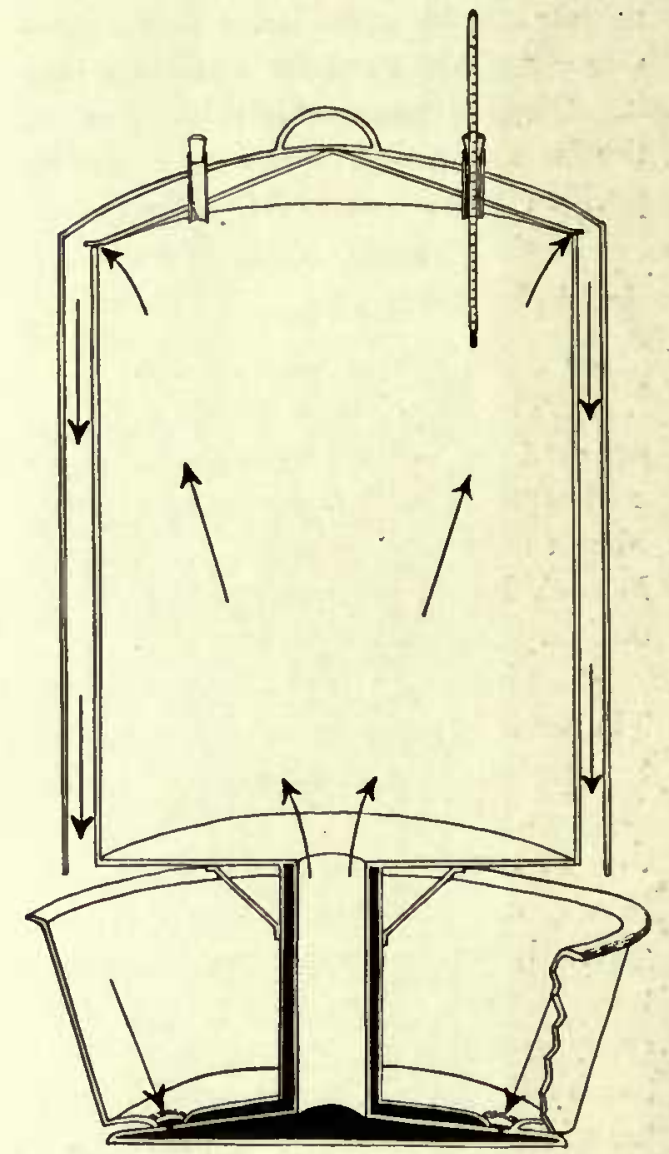

Fig. 42.*
Observe in particular:

(a) Separation of the casein withont the development of any acid, indicating the presence of the lab, or rennet, ferment. The milk usually becomes more alkaline.

(b) Saponification of the fat. The fluid becomes transparent without any precipitation of casein; but the caseinogen may be thrown down subsequently by acidifying the clear liquid.

(c) Ropiness. The fluid becomes viscid, and strings when touched. This viscidity is sometimes so great that an entire pail of milk may be inverted without immediate loss of its contents. See striking figures in Ward's papers ('99 and 'or, Bibliog., XLVII).

(d) Formation of acids. This occurs with or without evolution of gas, and usually with the final separation of the whey from the casein at room temperatures or on boiling. Boil if necessary.

(e) Re-solution of precipitated casein (trypsin ferment); formation of crystals (tyrosin, leucin, etc.).

(f) Gelatinization of old cultures. Milk alkaline.

$(g)$ Changes in smell, color, and taste.

In using milk it should not be forgotten that anaerobes are sometimes present ('Theobald Suith) and also organisus of the dunghill which will grow only at temperatures above $40^{\circ} \mathrm{C}$. Very resistant spores of aerobic species, growing at temperatures below $40^{\circ} \mathrm{C}$, are present also sometimes, especially in dirty milk, and the $111 \mathrm{ilk}$ is then difficult to sterilize.

Several experiments made by the writer with milk from Waslington dairies have shown that Franz Lafar's statement in Technische Mykologie, Bd. I, p. r89, while probably trtie for the milks which he tested, is not true when stated as a general proposition. In brief, this statement is that nine out of ten milks are not

*FIg. 42.- Section of Arnold steam sterilizer. Water enters the double bottom through a ferw small openings indicated by two arrows in the water-pan. The other arrows show movement of the steam. In this form the outer jacket (of copper) is lifted off to put in or remove media. 
sterilized by steaming twenty to thirty minutes on three consecutive days, but will develop bacterial growths when put into the thermostat. If such were really the case, millk would be one of the worst of culture-media instead of one of the best. 'The general experience of bacteriologists is not in accord with this statement. Occasionally, in my own experience, a single steaming of five or ten minutes has

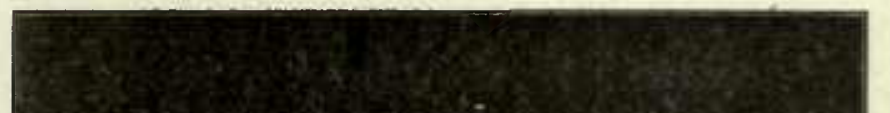
sufficed to sterilize milk coinpletely, at least so far as relates to organismis which grow aerobically and at temperatures under $40^{\circ} \mathrm{C}$. Such milks have remained unchanged for two or three months at room temperatures $\left(20^{\circ}\right.$ to $25^{\circ} \mathrm{C}$. $)$, and also in the thermostat at blood heat. For anaerobes, or organisuns which will grow only at temperatures above $40^{\circ} \mathrm{C}$., I have not tested.

One possible source of error in the use of steam for sterilization is ignorance of the exact temperature of the stean-chamber. Every steam-sterilizer should have a hole punched through the top, into which is fitted a cork through whiclı a thermometer projects into the chamber. I11 this way may be determined beyond doubt for just how many minutes the media has been exposed to steain at $100^{\circ} \mathrm{C}$. The Arnold stean-sterilizer, which is one of the best, $f$ is greatly improved by this simple device (fig. 42 and pl. 6). In this sterilizer there is a double bottom under the water-pan. The lower bottom is in contact with the Bunsen flame. Throngl sinall holes in the upper

*Fic. 43.-Improved Lautenschläger centrifuge. Capacity, $540 \mathrm{cc}$. Revolutions per minute, 3,000 to 4,000 . It requires about 3 horsepower to run the apparatus at this high speed. About oneeleventh natural size.

†This remark does not apply to the Arnold combination steamer and dry oven, which can not be recommended. 
bottom the water drips to the lower bottom and is quickly converted into steam which streans through a central chimney. into the bottom of the sterilizing chamber. The latter has two walls, with a considerable air-space between, open at the botton. The streaning steam passes over the top of the inner wall dowinward into this airspace and escapes into the pan as condensation water. Theoretically this is a very

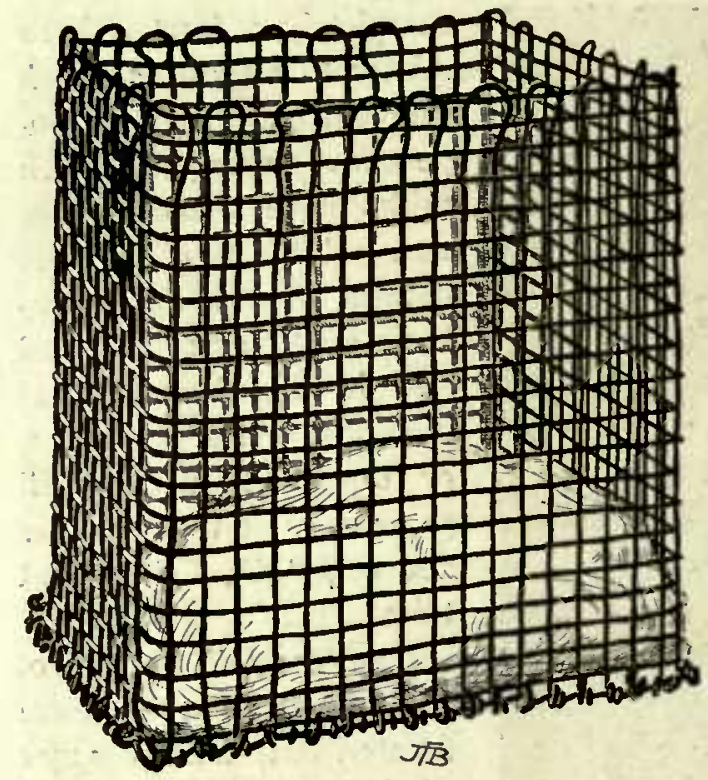

Fig. 44.* perfect sterilizer, and it is so in practice wlien new, but not infrequently it leaks, and sometines tile openings in the upper bottom are too large or beconne clogged by mind. When in perfect working order it takes only a few minutes to get a temperature of $100^{\circ} \mathrm{C}$.

'Tubes should always be steaned in wire-crates (fig. 44) so that the streaning stean may have full access to all parts. Tubes of media steamed in cans or beakers often spoil. They seen to retain a cushion of air about then which interferes with the action of the stean.

Litmus milk.-Litmus milk of a good quality may be made by dissolving Merck's dry, lime-free c. p. blue litmus to saturation in distilled water (I:I5) and then adding one part of this blue fluid to each fifty parts of milk. The milk should be a deep lavender color. Much inferior litnus is on the market. Large nse should be made of this fluid. In addition to observations under "Milk," note how rapidly the litmus reddens, blues, or becomes reduced, and how soon the color-returns. Will it return at once on steaming the culture?

Rice cooked in milk.-(One or two grans to ro cc. in eacli test-tube). This is useful for study of some chromogens.

Loeffler's: solidified blood-serum.-Observations 111der this and the following heads are the same as for gelatin slant cultures. The plant bacteriologist must in general obtain blood-serum from the anin1al bacteriologist. The solidified serum may also be used plain, $i$. $e$, withont the addition of grape-sugar.

Egg-albumen.-This is solidified and used in the same way as blood-serum. The end of the egg from which the albumen is poured must be thoroughly flaned before it is broken, and care must be used in the transfer to test-tubes so as to exclude air-borne germs as far as possible, otherwise the sterilization will be difficult. The albumen of eggs may be cut with sterile scissors.

*FIG. 44.-Wire-crate for holding tubed culture-media which is to be steamed. About twofifths actual size. A tuft of cotton on the bottom prevents the breaking of tubes. 
PLATE 6.

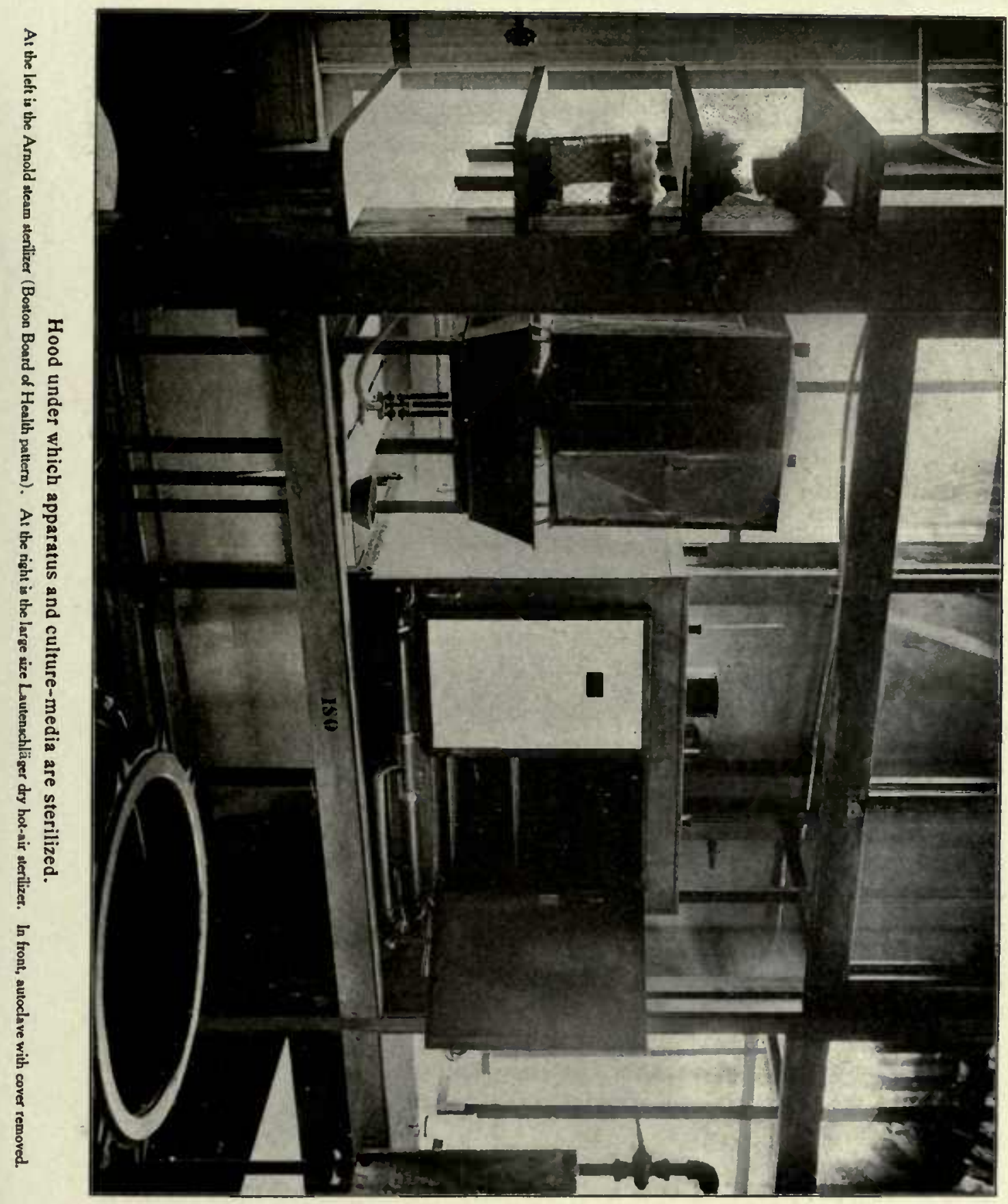



Egg-yolk.-This is poured into test-tubes and solidified in a slanting position by heat $\left(80^{\circ} \mathrm{C}\right.$.), or the egg may be boiled hard and the yolk cut with a sharp knife and transferred to sterile Petri dislies. If desired, the yolk and white may be mixed before solidifying, $i_{.} e_{\text {., }}$ by shaking the egg vigorotsly before breaking the shell.

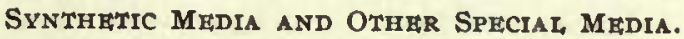

The student should try the following media. He should also invent media to suit special cases. The kinds of media I have in mind are the opposite of universal,

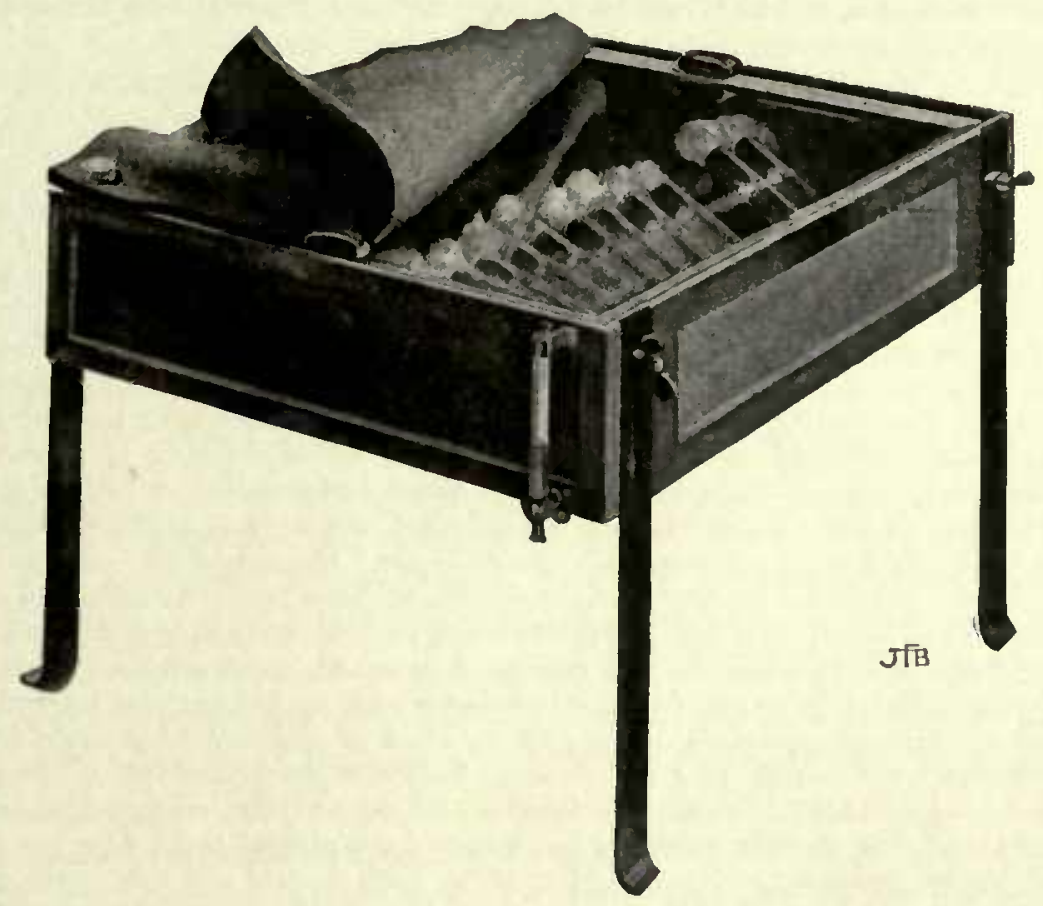

Fig. 45.*

to-wit, such as will favor the growtl of some organisms while preventing that of others. The acid phosphates and many other substances are useful for this purpose. The field is comparatively new, and much is to be learned by careful experimenting.

1. Dunham's solution. acids, etc.

2. Peptone-water ( 1 or 2 per cent) with addition of various carbohydrates,

3. Sugar-free beef bouillon with Witte's peptonum siccum (for the indol test).

4. Cohn's solution.

5. Uschinsky's solution.

*Fig. 45.-Oven for solidifying and sterilizing blood-serum, nutrient starch-jelly, silicate-jelly, etc., at temperatures below $100^{\circ} \mathrm{C}$. When in use the temperature is controlled by means of a Tollen's therno-regulator (see fig. 35). 
6. Uschinsky's solution with various carbon compounds substituted for the glycerin (fermentation tubes).

7. Fraenkel and Voge's solution.

8. Ratulin's solution.

9. Fermi's solution.

I0. Water(distilled), I,000,000 mg.; dipotassium phosphate, 2,000 mg .; ammonium phosphate, $100 \mathrm{mg}$.; magnesi11m sulphate, 100 mg.; sodium acetate, 5,000 $\mathrm{mg}$.

I I. Same, with the carbon compound changed, $e . g$., with sodium formate substituted for sodium acetate. Sodium formate and phenolphthalein may be added also to bouillon or agar ( 2 per cent) for observations during the early stages of growth, some organisms reddening this medium promptly by decomposition of the sodium salt. (See a recent paper by Omélianski).

12. Nutrient starch-jelly for study of diastasic action. (See Proc. Am. Asso. Adv. Sci., I898, p. 4ri, or Centralb. f. Bakt., 2te Abt., Bd. V., p. 102.)

One gram of starch is rubbed up with a sterilc glass rod in Io cc, of the sterile nutrient fluid (Uschinsky's solution, etc.), placed in a slanting position, in test-tubes, and solidified in a bloodserum oven (fig. 45) or in the top of a steamer with the vents left open. There should be several heatings of two hours each to insure sterilization. The temperature should not exceed $93^{\circ} \mathrm{C}$. nor fall much below $85^{\circ} \mathrm{C}$. Sterilization is rendered much easier if the starch is prepared in a cleanly way. The only difficulty the writer has experienced is in the formation of a thin film of semiopaque solidified starch on the walls of the tubes above the slant. This often cracks off, however, during the heatings, and is largely obviated by placing the tubes in a slanting position before the starch is rubbed up in the fluid, taking care to soil the walls above the slant surface as little as possible during the operation. The potato-starch is prepared as follows:

One-half bushel of large smooth potatoes are serubbed, and the black specks dug out; they are then soaked for 45 minutes in I: 1000 mercuric-chloride water. Meanwhile the hands are scrubbed clean and given a five minutes washing in the mercuric-chloride water. The tubers are now rinsed in sterile water, pared deeply, grated as for potato-broth, and thrown into beakers containing several liters of distilled water, where the pulp is worked over with the hands to liberate as much starch as possible. The starchy water is now removed from the pulp by passing it through several folds of surgeon's gauze, squeezing out of the pulp as muoh of the fluid as possible. When the starch has settled the brownish fluid and floating fragments are poured off or decanted, and fresh distilled water is added. The smaller fragments of cell-wall, etc., are then removed by forcing the stanch (stirred up in water) through a moderately fine-meshed towel (not too fine) with gentle hand-rubbing, into another beaker. Most of the medium-sized and finer starch-grains pass through, leaving in the towel the coarser grains and those fragments of cell-wall which passed through the coarser meshes of the sungeon's gauze. The purified staroh is now allowed to stand for about a week in the ice-box in distilled water ( 3 liters or more per beaker or jar). The water is siphoned off twice a day at first, and afterwards once a day, the starch being stirred up thoroughly every time fresh water is added. Finally the starch is drained very free from water, scooped out with sterile spoons or spatulas, placed in uncovered sterile Petri dishes, and dried in the blood-serum oven at $56^{\circ} \mathrm{C}$, , the cover being raised an inch (on corks) to let the moisture out. One-thalf bushel of sound potatoes should yield from 400 to 500 grams of air-dry aseptic starch.

Potato starch has been selected because it is easy to prepare, but other starches might yield interesting results. Bacteriologists now pay great attention to the fermentation of sugars, but thus far very little consideration has been given to the action of bacteria on starches and celluloses. Whatever starches are used, they should be prepared in the laboratory, under aseptic conditions, so as to exclude spore-bearing organisms.

13. Starch-jelly with addition of various sugars, guins, and alcohols (for study of organisms having little or no action on starch).

I4. Tubes of slant nutrient agar ( +15 of Fuller's scale) with varying allounts of c. p. glycerin, 2 to ro per cent or more. 
15. Tubes of ro cc. slant agar with 10,20 , and 30 grams of grape-sugar.

16. The same, with the same amounts of cane-sugar.

17. Gelatin with cane-sugar, varying amounts.

18. Gelatin with malic acid. (17 and 8 may be combined.)

19. Gelatin plates with soluble starch and I per cent potassium iodide and with or without I per cent potassium nitrate. Try a mixture of the pear-blight organism and $B$. coli. Can the colonies be distinguished in this way using the nitrate?

20. Agar plates with various sugars and the addition of calcium carbonate, or zinc carbonate, for detection of acid-forming colonies. ('9r, Beyerinck, Bibliog., XX.)

21. Silicate-jelly. See p. 36 . Known also as silica-jelly.

22. Nitrate bouillon ( +15 bouillon with $r$ per cent potassium nitrate).

23. Triple-distilled water and nutrient mineral substances free from nitrogen. The same, with addition of potassium nitrate. The same, with other nitrogen foods, $e . g .$, sodium asparaginate.

24. Bouillon with lead acetate.

25. Bouillon with neutral red.

26. Salt bouillon, i. e., +15 bouillon with varying amounts of $c$. p. sodium chloride (I to 5 per cent).

27. Standard peptonized bouillon with varying amounts of sodinm hydrate (from +40 to -40 ) for determining the optimnm reaction and the tolerated range of acidity and alkalinity.

Synthetic media may be varied indefinitely to fit special cases and are often extremely useful as differential tests. They have frequently been condemned because some particular organisin has not grown well in them. The very fact of feeble growth or of 110 growth is, lowever, a matter of interest, and not infrequently a means of distinguishing organisms which resemble each other in many particulars. The value of such media becomes apparent at once when a number of organisms are compared. Synthetic media afford more exact methods of researcli than do the common media, and their value must increase rather than diminish as time goes on. (Consult Grimbert in Archives de Parasitologie, T. I, pp. I9I-216.) It does not follow, lowever, that the common media should be at once abandoned. Festina lente is a good rule. The formula for some synthetic media are given under "Formulæ." For others see various text-books and the papers cited in the Bibliography under XVI, XVII, XVIII, XXV, etc.

\section{RELATION TO FREE OXYGEN.}

(I) Surface and deep growths.-Note the behavior of deep stabs in tubes of recently steamed gelatin and agar, or of the colonies in shake-cultures of gelatin and agar which are protected from the free action of air by pouring into the tubes as soon as solidified another tube of gelatin or agar in the surface layers of which, as an additional precaution, some active aerobe may be grown, $e . g$. , Bacillus subtilis. Observe also the relative rate of growth of buried and surface colonies in plate cultures, growth under sterile mica plates, etc. Of course, whetler an organism will or will not grow under the conditions mentioned depends often to a large extent on the composition of the culture medium. It might be able to respire in the presence of grape-sugar or cane-sugar, but not when milk-sugar or glycerole is substi- 
tuted. It will not do to conclude that an organism is a strict aerobe until it has been tested anaerobically in the presence of a variety of carbon foods with uniformly negative results. One who has had some experience may often give a shrewd guess as to behavior in fermentation-tubes by carefilly noting the growth of buried and surface colonies in ordinary media.

(2) Fermentation-tubes. - The fluids may be Uschinsky's solution (withont the glycerin unless this is the carbon compound to be tested); peptone water (2 per cent Witte's peptone with 0.5 per cent sodium chloride); and filtered tap water, or sugar-free beef bonillon with addition of I per cent Witte's peptone (preferably for most purposes this latter fluid). The substances to be tested (which should be cheinically pure or as nearly so as possible) are grape-sugar, fruit-sugar, cane-sugar, milk-sugar, galactose, maltose, dextrin, ${ }^{*}$ mannit, dulcit, raffinose, glycerin, ethyl alcohol, $\uparrow$ methyl alcohol, acetone, annonium lactate, anmonium tartrate, asparagin, sodium asparaginate, urea, etc. One to 5 per cent of the varions sugars, etc.; may be used; 2 per cent is a good quantity.

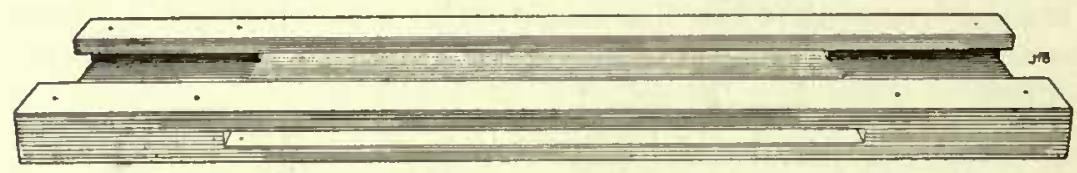

Fig. 46.

Observe carefully what substances induce clouding in the closed end and whether any gas is produced. Test from time to time for acids. The relative vigor of growth in the open end should also be noted. Does growtl stop in the $\mathrm{U}$ with a sharp line of demarcation? Does the addition of calcinm carbonate reduce or prevent the formation of gas or favor growth in any way? Is the reaction in the closed end, as the result of growth, different from that in the open end? Pipette ont all the fluid from the open end, determine its reaction to litmus, and then test the reaction of that which remains. How is the difference, if any, accounted for? If growth finally ensues in the closed end, is there any reason for thinking it due to absorbed air? How can this be determined?

It sliould be remembered that often, after a time, air is absorbed into the closed end of fermentation-tubes and may lead to confusing results. For this reason, if they have stood on the shelf any length of time after sterilization, they should be re-steamed and the bubble of air tilted out before they are inoculated. They

*The dextrin should be freely soluble in cold water and should not give any red reaction with iodine-i. e., should be free from amylo-dextrin (erythro-dextrin). Such dextrin is hard to procure.

†This and the next four should be added, after sterilization, by means of sterile pipettes. The ammonium salts may be obtained in a sterile condition without loss of ammonia by dissolving 10 grams in $200 \mathrm{cc}$. of water and forcing this through a Chamberland filter into a sterile flask, from which the proper quantity may be pipetted into the culture medium after sterilization.

$\ddagger$ Frg. 46.-Wooden carrier for fermentation-tubes, the flanging base being held under the grooves. Murh reduced. 
slould be disturbed as little as possible after inoculation, and especially all tiltings or rough jarring should be avoided. They may be carried in a wooden rack (fig. 46). All culture-media, whether inoculated or not, should be protected from light.

Figs. $47,48,49$ slow fermentation-tubes in actual use.

The pattern of fermentation-tube preferred by the writer is that slight modification of Einlorn's tube designed by Dr. Theobald Smith (see Wilder Quarter Century Book). The tubes may be had from Emil Greiner, New York. Certain

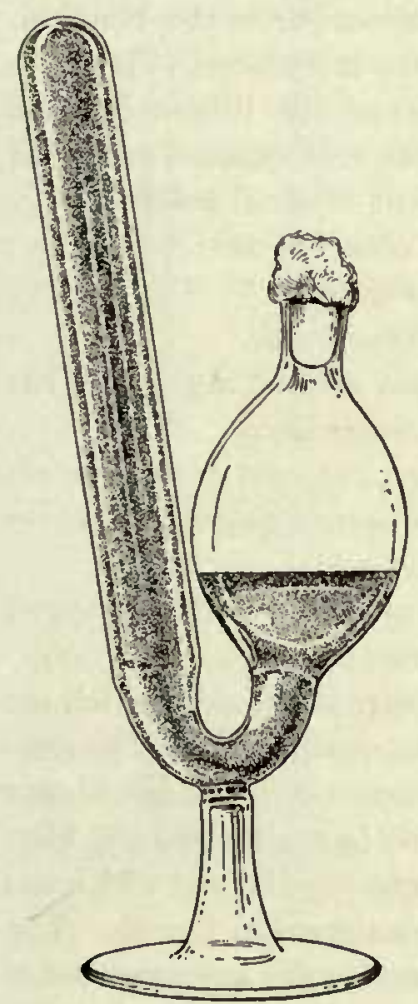

Fig. 47.*

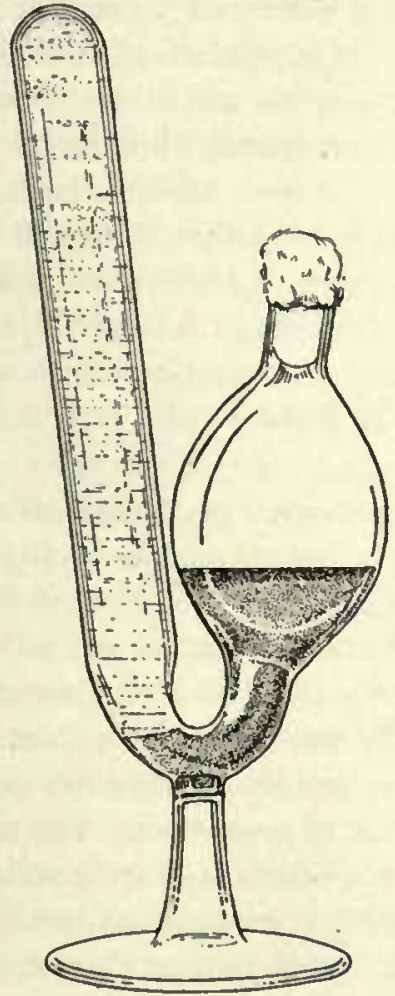

Fig. 48.†

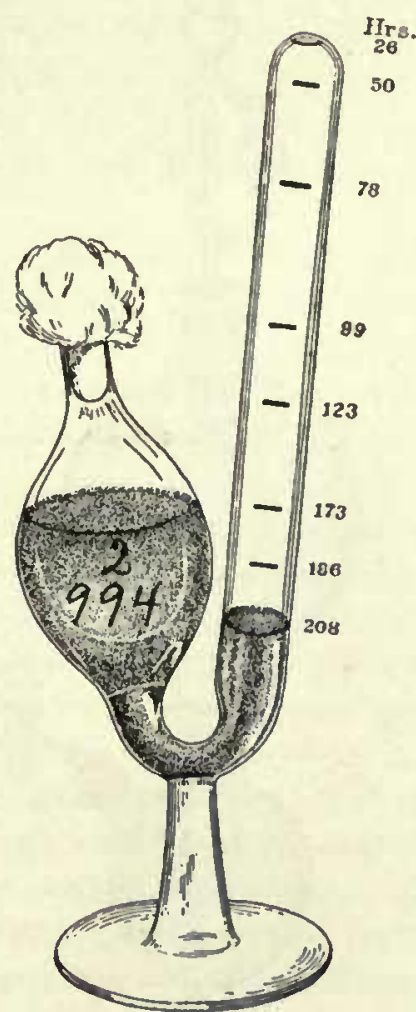

Fig. $49 .+$

forms of tubes sloould not be used. One of these, a slort, thick tube witl a wide $U$, in use in some laboratories in this country, allows air to pass readily into the closed end and is entirely wortlless. A sample tube of this sort was filled with

* FIG. 47.-Fermentation-tube with Bacillus tracheiphilus, showing absence of gas and uniform clouding in open and closed end in the presence of grape-sugar. The fluid consisted of water, 400 ; Savory \& Moore's peptone, 4; sodium chloride, 1; c. p. grape-sugar, 2; saturated solution carbonate

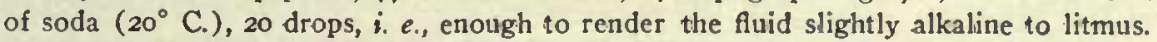

†FIG 48.-Fermentation-tube with Bacillus tracheiphilus, showing inability of organism to grow anacrobically with glycerin as the carbon food. Fluid, distilled water with I per cent Witte's peptonum siccum and 1 per cent Schering's c. p. glycerin. Copious growth in open end and in outer part of $U$; none in the closed end.

†FIG. 49.-Fermentation-tube of cane-sugar peptone water inoculated with a white, gas-forming organism plated from a spot disease of sisal hemp. The total amount of gas produced and its rate of evolution at $20^{\circ}$ to $23^{\circ} \mathrm{C}$. are indicated by marks on the closed end of the tube. 
beef-bouillon and steamed every twenty-four hours for seven or eight days, a large bubble being tilted out each time and appearing just as regularly during the next steaning. Naturally, no strict anaerobe would grow in such a tube and every aerobe would appear to be a facultative anaerobe. The neck of the fermentationtube should be as narrow as consistent with filling and cleaning. All wide-necked tubes should be discarded. The behavior of the closed end with reference to the

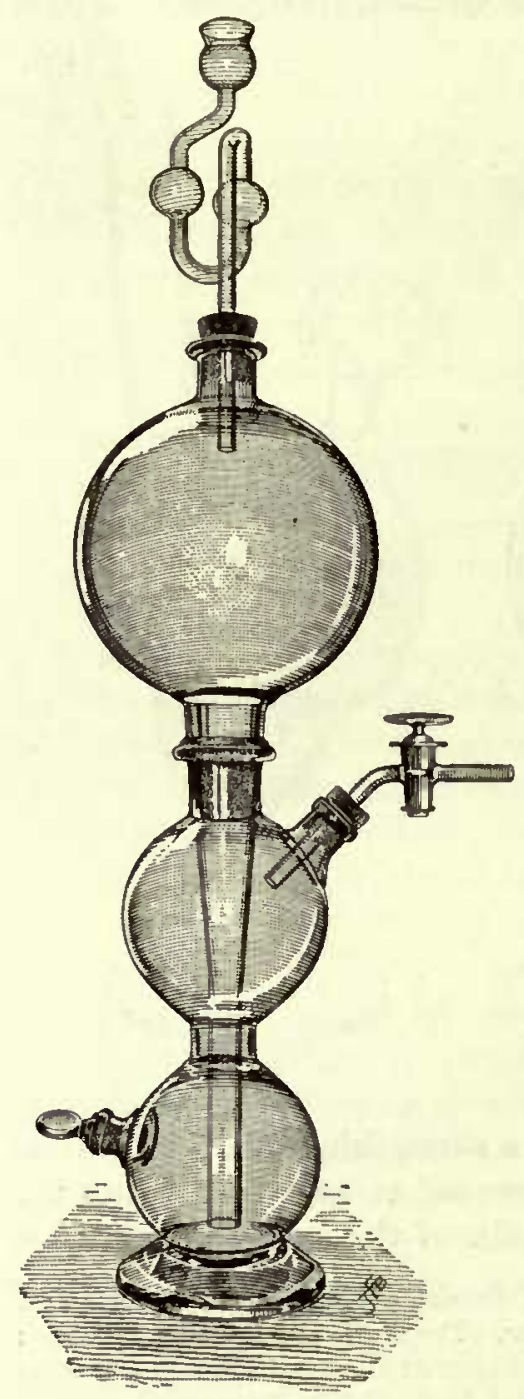

Fig. 50.* absorption of air nnay be tested by adding litınuswater and 5 per cent grape-sugar to the bouillon. On steaming, the litmus is reduced. If there is no air in the closed end the litmus remains reduced, while in the open end exposed to the air it soon oxidizes back to its original color.

Other things to be observed are:

(3) Growth in hydrogen.

(4) Growth in carbon dioxide.

(5) Growth in vacuo, various degrees of exhaustion.

(6) Growth in vacuo, remnant of oxygen absorbed by the mixture of caustic potash and pyrogallol (same as pyrogallic acid).

(7) Growth in nitrogen (air with the oxygen absorbed, normal air-pressure).

The hydrogen and carbon dioxide, which are required in considerable quantities, may be generated in Kipp gas-generators. There is a choice in generators. The writer has not found any kind whicl is entirely satisfactory. The one which has given the least trouble is shown in fig. 5 o. The objection to this generator is the large volume of dead acid which soon accunnulates at the bottonl. The accumulation of dead acid is entirely obviated in the de Koninck generator, but the writer has only recently obtained this apparatus and lias not yet had enough experience with it to speak unqualifiedly. It furnishes a large amount of gas and its generation may be stopped very quickly, but the acid chamber is inconveniently bulky (Io liters) and in case of breakage a destructive flood would be poured out into the laboratory. To avoid this the apparatus should be set into a deep enameled iron pan. The action of the apparatus depends on the fact

*FIG. 50.-Kipp gas-generator for making carbon dioxide or hydrogen. When not in use the pressure of the gas forces the acid off the marble or zinc (in the middle compartment) and stops its evolution. Much reduced. 
that acid on which zinc has reacted has a greater specific gravity than unused acid and diffuses downward through the whole fluid when it is forced back from the zinc-chamber into the top of the acid-tank.

Another form of hydrogen generator is slown on plate 7 . When in use the lower bulb is filled with acid and also the stem of the upper one. This gives a

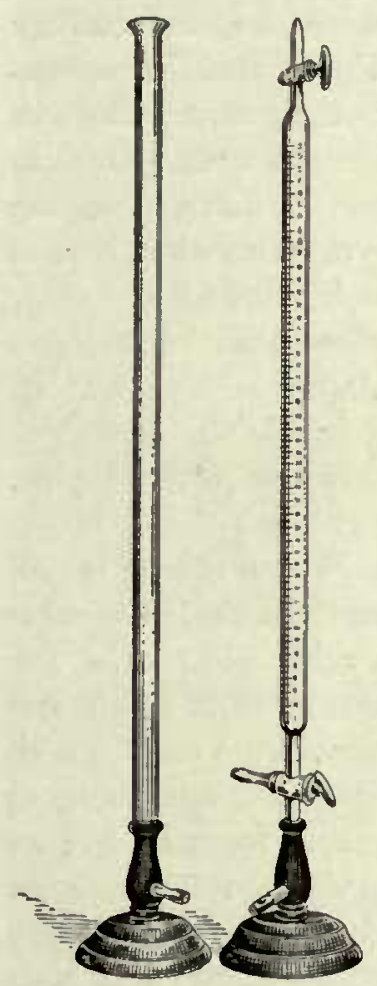

Fig. 51.* sufficient column of liquid to force the gas through the five wash-bottles. All the joints should be coated with Darwin's wax-1nixture, set together firmly, and wired in place. Excessive liberation of hydrogen sulphide is avoided by standing the generator in ice water. The ruler is 12 inches long. The same style of apparatus may be used for the generation of carbon dioxide.

These gases must, of course, be carefully washed to remove accidental poisonous impurities, by passing them throngh wash-bottles containing various solutions. For the carbon dioxide, which is usually generated from c.p. hydrochloric acid, diluted with twice its volume of boiled water, and marble chips (which should be boiled in advance), it is sufficient for many purposes to pass it through strong solutions of sodium liydrate (ro per cent), potassium perinanganate (Io per cent), and water, arranged in the order indicated. Most of the oxygen may be removed by passing through three wash-bottles containing a mixture of pyrogallol and strong caustic-potash water or caustic-soda water (ro per cent). When in use the stopcock between the generator and the first wash-bottle must not be cut off, otlerwise the small amount of carbon dioxide in the wash-bottle will soon be absorbed by the soda and fluids will be forced over (backward) from the other bottles by inequalities in the gas-pressure. The place to cut off the gas-flow is close to the Novy jar or other receptacle.

For testing the purity of the gas, $i . e$., its freedom from air, roo cc. may be drawn off into a Hempel burette. (fig. 5r), equalized with the air-pressure and run into the siniple Hempel pipette for liquid reagents (fig. 52 ), the bulb of which is filled with strong potash water ( 2 water $+I$ potassium hydroxide). If any gas remains after thorough exposure to the potash, it may be measured by.passing it back into the burette. One should get with the pipette an iron stand and about 2 yards of capillary glass tubing.

The scrap-zinc used for generating the hydrogen shonld contain some lead, but slould be free from arsenic, antimony, and phosphorus, and the sulpliuric acid shonld be chemically pure. For use the acid is diluted largely with water ( $1: 9$ ). Hydrogen generated with zinc, especially if the evolution is rapid so that the solution is warmed, contains considerable hydrogen sulplide and may contain phosphureted

*Fic. 51.-Hempel's burettes for gas-analysis. Height, 25 inohes. 
hydrogen or arseniureted hydrogen; it should therefore be passed not too rapidly throngh the following solutions in the order indicated: Saturated solntion of lead acetate, 5 per cent solution of silver nitrate, ro per cent potassinm permanganate, ro, per cent soditm hydrate containing pyrogallol, distilled water. When ready for use the purity of the hydrogen may be tested by burning in test-tubes (inouth

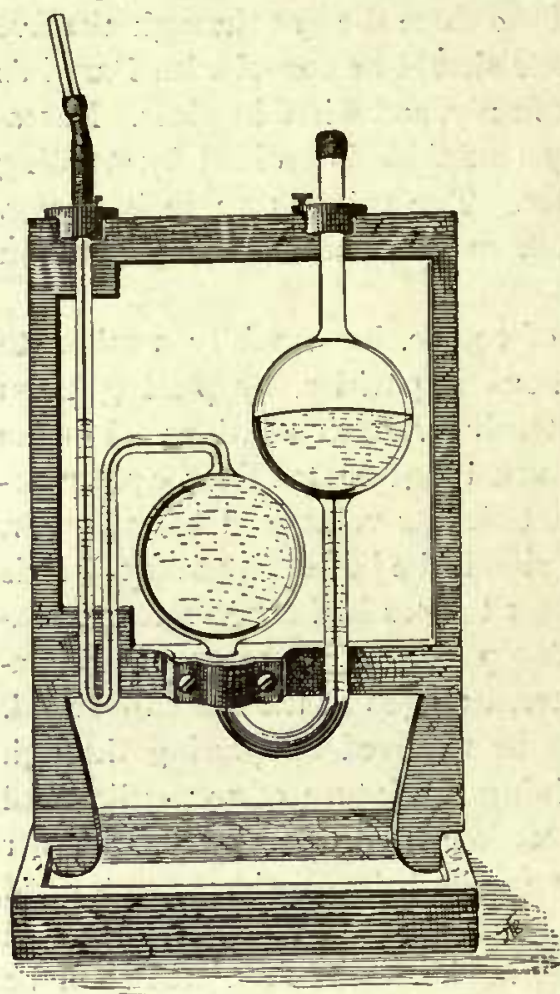

Fig. 52.* down ; and also, if necessary, by the ordinary methods of gas-analysis. To avoid the evolution of hydrogen sulphide the generator may be plunged into a jar of ice-water, as slown in plate 7. Special care must be taken in sealing jars containing hydrogen, otherwise it will escape. In use, the gas is allowed to bubble slowly through the fluids into the culturechamber, a large well-clamped Novy jar, the other tubular opening of which is connected air-tight. with the tube of the yacuum pipe. The jar is first pumped out and the hydrogen is then allowed to enter. When the jar is full, the glass stopcock nearest it (at the left in plate 7) is turned, and then, after allowing a few minutes for diffusion, the mixture of air and gas is pumped ont. The vacuum cock is then turned off and the hydrogen is again turned on slowly. This process is repeated five or six times, the gas being passed into the jar very slowly the last two times, so that it may be washed very clean. The Novy jar is then sealed, disconnected, and set away in the dark.

The gas must, of course, enter each wash-bottle through the long stem. It is desirable to have each wash-bottle two-thirds full of fluid; and there niust be no leaks in any.part of the apparatus. $\uparrow$ The hydrogen should be cut off before each exhaustion of the jar by turning thie stop-cock mearest the jar. The cock also should be turned off before sealing giass tubes with flame and it must, of coirse, be known that the gas is free from admixture with air, otherwise an explosion will occur.

It is easier to keep air out of gases than to remove it. The greatest care should therefore be taken to drive it out of a culture médium before it is inoculated. For the same reason gas should be allowed to flow for some time before it is collected so as to displace air which may liave diffused into the generator and wash-bottles. . This is also the reason why the water which is used to dilute the acid and the marble chips should be boiled. If there is much air mixed with the gas $t . t$ is not at all likely, that a single wash-bottle of sodiun hydroxide and pyrogallol,

*FIG. 52.-Hempel's simple pipette for liquid reagents used in gas-analysis. Breadth of stand, 7 inches.

†Consult a paper by Ewell, Centralb. f. Bakt., 2 Abt., III Bd., p. 188. 
PLATE ?.

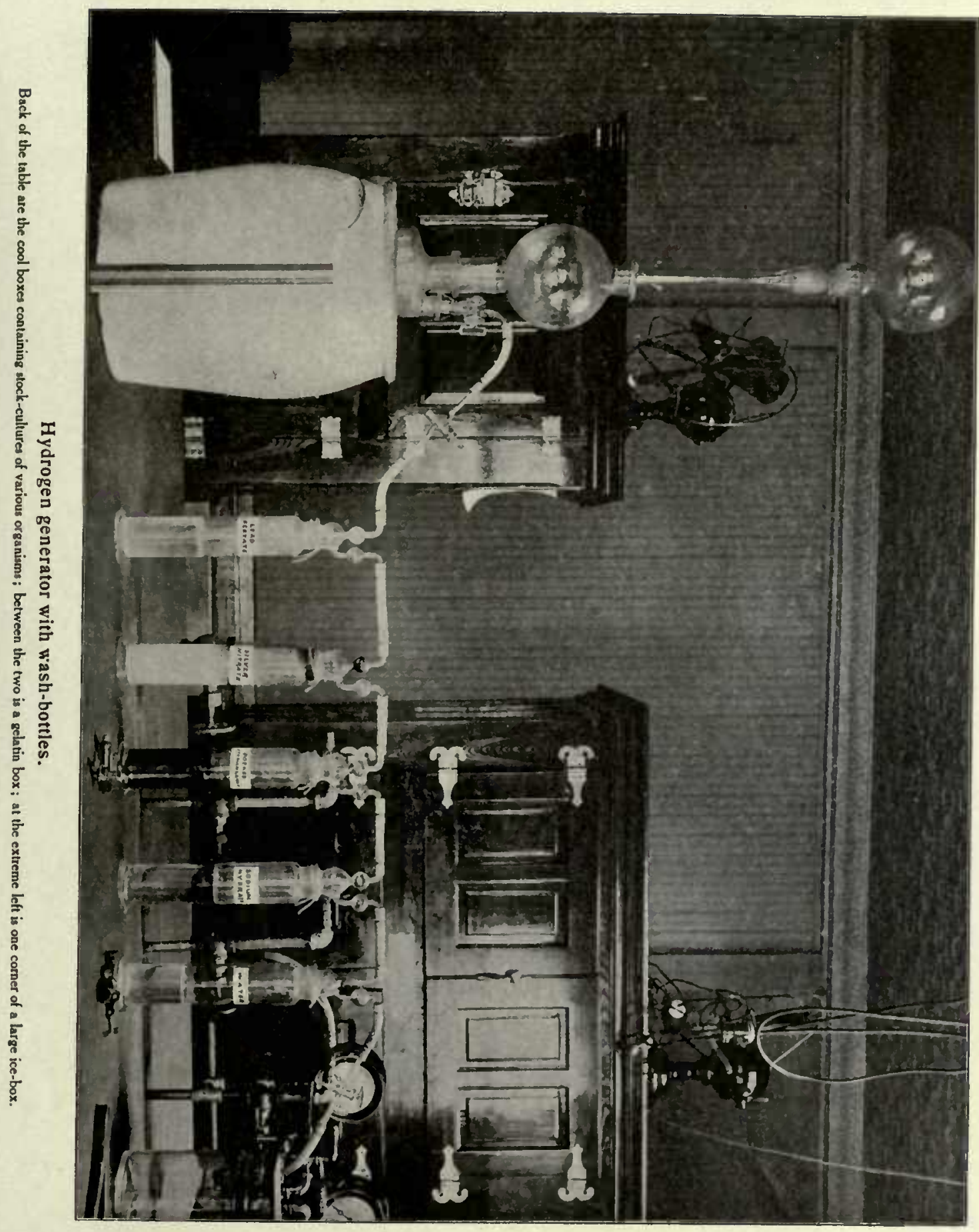



or even two or three in series, will completely remove it, since the bubbles of gas are in contact with the fluid only at their surface and for a very brief time. Hydrogen must be passed througl 5 wash-bottles of sodium liydroxide and pyrogallol if every trace of oxygen is to be removed. From nitrogen or carbon dioxide the last traces of oxygen may be removed by passing it over copper filings inclosed in a piece of gas-pipe which is heated red hot in a small furnace containing about 20 Bunsen flames in series. The gas-pipe may be 0.75 inch in diameter and about 3 feet long, plugged at the ends with tight-fitting rubber stoppers, the middle 2 feet filled with the copper fragnients. The gas should be allowed to flow only in rapid bubbles, not in a streain (Dr. Day).

The test-tube cultures may be placed in Novy jars, securely waxed (fig. 53),

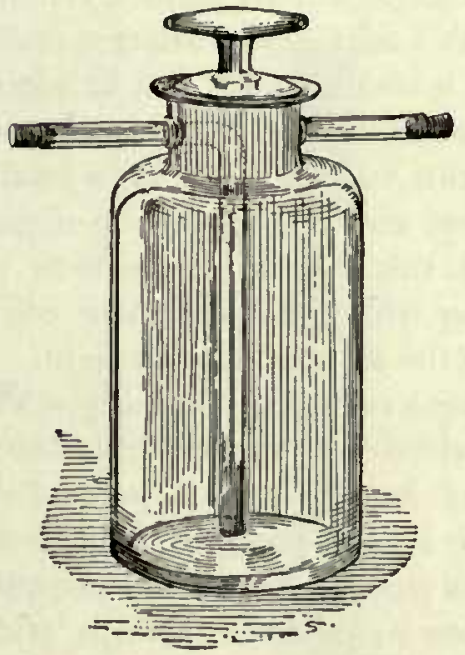

Fig. 53.* or in large, thick-walled test-tubes made impervious with sealing wax (see Sternberg, Manual, fig. 53; Text-Book, fig. 53). Media designed for use in any of these gases should be resteamed immediately before inoculation, and if one is experimenting with unknown or with very sensitive anaerobes the boiled media should be allowed to cool in an atmosphere of hydrogen. Francis Darwin's wax-mixture has been found useful for luting.

When large Novy jars are used (fig. 54), the thoroughly waxed gaskets must be claniped down securely and tested for leaks by preliminary exhaustions. If any are discovered, additional wax must be used and the clamps must be screwed tighter. To determine whether there is any subsequent entrance of air it is always best to include along with the cultures one or more tubes containing some substance which is reduced in the absence of free oxygen, but which readily oxidizes to some different color as soon as traces of air are mixed with the gas in the jar. Metliylene blue in recently steamed bouillon or gelatin with 5 per cent grape-sugar is one of the best pigments for this purpose. In the absence of free oxygen it becomes a colorless substance; with the entrance of traces of air it becomes blue. Usually, however, the fluid or solid holds on to a trace of color at its surface. A solution of bilirubin is also said to be very sensitive to free oxygen and a good test for its presence.

Some care is necessary in order to avoid erroneous conclusions when pyrogallol and caustic potash are used to absorb the oxygen. The vessel must not leak, enough of the mixture must be used to absorb all the oxygen, and the action must be rapid enough so that the oxygen will have been removed completely before visible growtl of the organism can possibly lave taken place. Neglect of these

*FIG. 53.-Novy jar. Small size (wide mouth) for test-tube cultures. Only those with mouths at least $2^{1 / 2}$ inohes wide are serviceable. Height to mouth of jar, $71 / 4$ inches. 
precantions lias led to the statement that certain strict aerobes are able to grow on ordinary 111edia in the absence of oxygen, and that anaerobes are very uncertain in their behavior on standard media. Old pyrogallic acid should be avoided and some preliminary experiments slould be made as to the rapidity of the absorption of the

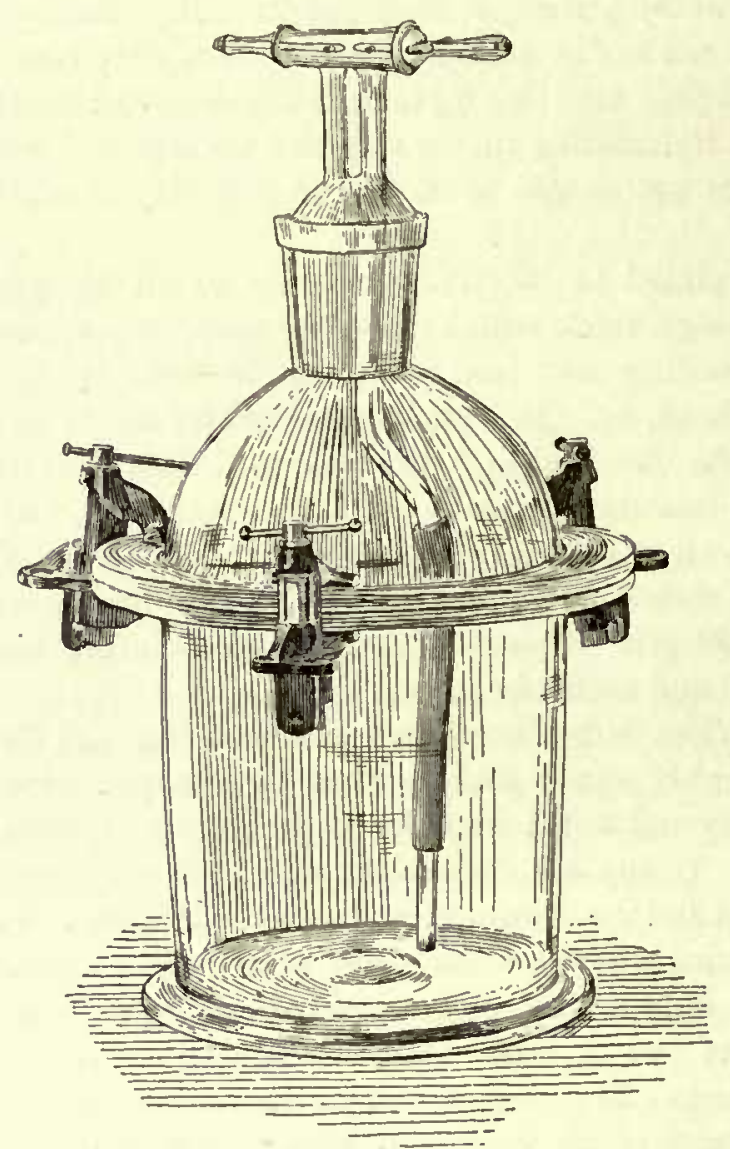

Fig. 54.* oxygen from a given space before the organisin is tested. The writer fon111 one brand of pyrogallol which removed the oxygen from a small space in six hours, another required about eighteen hours, a third required several days (time enough for a strictly aerobic organism to make a visible growtl1). Leaks may be detected readily by including with the cultures a fermentation-tube, the inclosed arm filled with water except for a si11all bribble of air: On absorption of the oxygen this bubble expands to a diameter which should remain constant if the jar continues air-tight.

The gas renaining in receptacles from which the oxygen lias been removed by the potash-pyrogallol n11etlod is not pure nitrogen, but nitrogen plus a variable small a111ou11t of carbon 111onoxide, which is said to be most abrundant when the oxygen is absorbed slowly. This snall an1ount of $\mathrm{CO}$ is harmless to many bacteria, but the writer has some reason for suspecting that it is injurions to others, even if it does not entirely inhibit growth.

The writer has found the following contrivance (fig. 55) a very simple one for testing the ability of organisms to grow in 11itrogen : A U-tube of thick, clear glass, with arms about Io to 2 inches long, open at the ends and liaving a uniform inside dian1eter of about I inch, serves as the culture-chamber and gas-receptacle. Two short, rimless, cotton-plugged test-tubes containing the 111edia to be tested are inoculated and thrust one above the other into one arn of the $U$-tube, into which is then

*FIG. 54.-Novy jar of large size for Petri dishes and numerous test-tube cultures. Clamped as when in use. Between the clamped parts is a rubber gasket, carefully waxed and vaselined. Darwin's wax-mixture is advised. The writer also usually wires in the rwaxed top parts. The gas inflow is cut off by twisting the uppermost (horizontal) ground-glass stopper, which must be carefully vaselined. One-third actual size. 
crowded a tiglit-fitting, soft, rubber stopper. This end is finally buried for an inch or so in a sulall beaker of glycerin and is perfectly air-tight. A rimless test-tube abont 5 inclies ( 3 cin.) long and of a dianeter sucli that it will just slip easily up the other arnu of the $U$-tube, is 11ow packed by means of a pencil or glass rod with 8 or

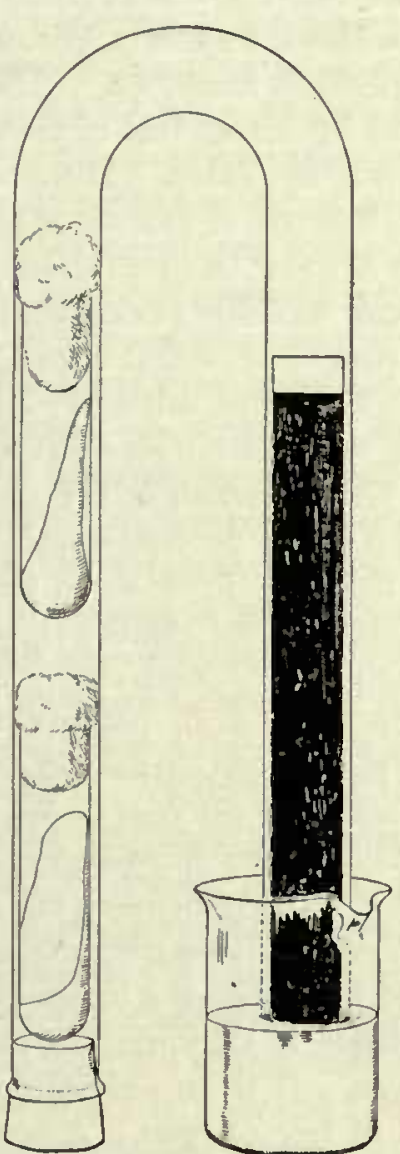

Fig. 55.*

Io grams of pyrogallic acid, covered quickly witl $25 \mathrm{cc}$. of ro or 15 per cent caustic-potash water, and slipped up the open end of the tube, which is immediately plunged into a dish of mercury and held there (under a shelf) 11ntil enongl of the oxygen is absorbed so that it will stay down of its own weight. The exposure should be made at $25^{\circ}$ or $30^{\circ} \mathrm{C}$., or at least at temperatures considerably above zero, since the absorption of the oxygen is slow in cool air.

The tube containing the pyrogallic acid and potash 111ixtnre floats on the mercury and rises, of course, in the arm of the $U$-tube as the oxygen is absorbed and the n11ercury enters it. This tube nust not, therefore, be too long so as to hit against the curves of the U-tube before all of the oxygen has been absorbed; otherwise the nercury will pass up between the two tubes and overflow into the mixture. In other words, several centimeters 111ust be allowed for the rise of the 111ercury.

A few experinents will determine low much of the inixture is necessary for a tube of a given bore and how long it takes to absorb all of the oxygen.t The level of the mercury in the open end with all the oxygen absorbed may be recorded by a scratch on the tube as a rouglı guide in subsequient work. At least lialf a dozen of these tubes will be found useful. They may be made in any laboratory or inay be procured from dealers in glassware.

In the 11se of carbon dioxide, especially with sensitive organisms, two factors m111st be considered, (I) the simple exclusion of air, as in case of lyydrogen, and (2) the change in the reaction of the medium due to absorption of the gas (formation of carbonic acid).

*FIc. 55.-A simple devicc for growing organisms in air deprived of its oxygen. In the left arm are the cultures; in the right arm is a test-tube containing a mixture of pyrogallol and causticpotash water. The beaker contains mercury. About one-third actual size. A modification of Ganong's apparatus for study of germinating seeds.

† Mace states that I gram of the pyrogallol and Io cc. of the ro per cent potash-water are sufficicnt for each $100 \mathrm{cc}$. of air space. 


\section{LUMINOSITY.}

Nunnerous saprophytic bacteria are luminons under certain special conditions. Luminosity is also a striking characteristic of at least one bacterial animal diseasethe white disease, or sluggish disease, of sand fleas (Talorchestia longicornis and $T$. megalophthalmia), common on the shores of France and of Massachusetts at Woods Hole. Decaying potatoes and other vegetables are sometimes luminous. The question of luninosity should therefore be kept in mind by the student of plant diseases, althougln no luminous species are known to live in plants. Most of these interesting luminous bacteria lave been found in salt water or near it, or on the flesh of quadrupeds and fish. Gorlaam has been able to grow them on strictly synthetic media. The most recent treatise is by Hans Molisch (Leuchtende Pflanzen, Jena, Gustav Fischer, I904, pp. IX, I69, with 2 plates and I6 text figures).

Molisch records 26 species of luminous bacteria. He found that salt-water fish and the flesh of cattle exposed in the markets were very often luminous- 48 per cent of 70 samples of the latter and nearly all the former. Of horse flesh 65 per cent and of cattle flesh 89 per cent became luminous on putting it into 3 per cent solution of sodium chloride, allowing a part of it to project into the air. Fresh-water fish are very seldom luminous. Seedlings exposed to Petri-dish poured plates curved heliotropically toward the light, but they did not become green. Other clilorides than that of sodium stimnlate growth and liglit-production, $e . g$., potassium, magnesium, or calcium chloride. Certain non-clilorides, such as potassimm iodide, potassium sulfate, and magnesium sulfate have the same action ( 3 per cent or less). Potassium nitrate was also active on $B$. phosphoreum but not on $B$. photogenus. Manganese sulfate stimulated growth very noticeably but had no corresponding effect on the luminosity, which was weak. The spectrum of $B$. phosphoreum differs from that of the West Indian beetle, Pyrophorzes noctilucus, and from that of a luminous fungus known as inycelium $X$. No biological importance is attributed to the luminosity which is ascribed to an hypothetical photogen. It is an oxidization phenomenon which can take place only in the presence of free oxygen. A ten1perature of $30^{\circ} \mathrm{C}$. for forty-eight hours is sufficient to kill $B$. phosphoreum in gelatin cultures. The minimum temperature for this organism is below zero, the optimum is about $16^{\circ}$ to $18^{\circ} \mathrm{C}$, and the maximum is $28^{\circ} \mathrm{C}$. The bacteria are luminous from minus $5^{\circ}$ to plus $28^{\circ} \mathrm{C}$. Light production is most intense from $5^{\circ}$ to $20^{\circ} \mathrm{C}$.

\section{FERMEN'TA'TION PRODUCTS.}

The old conception of fermentation involves an evolution of gas (fervere, to boil), but the term is now nsed with a wider meaning. Like many other terms, it is difficult to use it always logically. In general, it means the breaking up of carbon compounds into simpler substances, either by the direct action of the protoplasm of the organism (liypothetical) or by chemical substances (enzyms, diastases) secreted by the protoplasm. Acids and alcohols are produced; gases may or may not be evolved. Other volatile products are also produced, $e . g$., esters, but usually only in very small quantities. Certain of the bacterial fermentations are of large commercial inportance, $e_{.} g$., the acetic, the lactic. The breaking up of albumen and 
other complex nitrogen compounds, $i$. $e$, putrefaction, is also sometimes called fermentation, and at present there is really no very sharp line to be drawn. Consult Green and Duclanx for the English and French views (Bibliog., XX). The student slionld observe :

(I) Gases. Amount, rate of development, kinds (carbon dioxide, oxygen, liydrogen, nitrogen, marsh gas).

(2) Acids. Volatile and non-volatile (lactic, acetic, butyric, etc.).

(3) Alcolıols (ethyl, methyl, butyl, glycerin, mannit, etc.).

(4) Eithers and esters.

(5) Aldeliyds, sugars, gums.

(6) Albumoses, peptones, amido-bodies.

The isolation and determination of the annount of these various products belongs to the province of the chemist, but the work should be done in the bacteriological laboratory and under the eye of the biologist if all sorts of errors, due to the unsuspected multiplication of intruding organisns, are not to creep in and render the work wortliless. Only some crude determinations, as of proportion of the various gases evolved, may be made by the bacteriologist who is not a chemist. The volume of gas evolved from day to day may be neasured in fermentation-tubes (fig. 49). Frost has devised a convenient gasometer for roughly estimating it (see his Laboratory Guide, plate I). These may be made in any laboratory out of cardboard.

If the gas is carbon dioxide it nay be absorbed by shaking with ro per cent $\mathrm{NaOH}$. To do this, fill the bowl (fig. 49) even full of the strong caustic-soda water, place the thumb or forefinger over the mouth so as not to include any air, invert the tube so that the gas sliall flow into the bowl and cone into contact with the alkali, and shake vigorously until all of the carbon dioxide is absorbed. Tilt the fluid back into the open end, and remove the finger so as to equalize the pressure. If any gas remains after equalizing the air-pressure, place the finger over the moutl of the tube, tilt the gas into the bowl and apply a lighted match close to the mouth as the finger is removed. If it is hydrogen or marsh gas it will explode in the open end of the tube when the finger is removed and a flame applied. If it is nitrogen it will not support combustion (see Bibliog., XX, especially'9o Smith and '93 Smith).

How distinguish marsh gas from hydrogen?

Organisms easily inlibited by their own acid products may be kept alive a much longer tine by adding a little calcium carbonate to the bouillon or agar.

In simple tests for acids, discard bright blue litmus paper, wlich is very sensitive to carbonic acid (try carbonated water on it), and use instead a good grade of reddish-violet (neutral) litmus paper. Such paper may be made in the laboratory (the best way) or may be purchased of H. Struers, Copenhagen.

ALKALIES (AMMONIA, AMINS, CARBONATES OF THE ALKALI METALS).

Deternine rapidity of formation. Note that they are often masked by the simultaneous formation of acids. Try the litmus test and Nessler's test. Do not put Nessler's solution into the culture fluid, but expose it to stean from the culture. Observe the beliavior of the organism when grown in peptone rosolic-acid water 
with just enough $\mathrm{HCl}$ added to connteract the alkali in the peptone, and in neutral or slightly acid peptone-water or sugar-free bonillon containing acid fuchsin. On titration of acids and alkalies see Sutton (Bibliography of General Literature, IV).

REDUCING POWERS.

Determine rapidity of reduction of litmus, methylene blue, and indigo carmine in varions fluids and solids (with and withont grape-sugar). Probably all bacteria can reduce litnuus, etc., but as the rapidity of reduction varies greatly in different species and in different media, it is desirable to make comparative tests. Consult a recent paper by Albert Maassen ("Ueber das Reduktionsvermögen der Bakterien, und ueber reduzierende Stoffe in pflanzlichen und tierischen Zellen," Arb. a. d. Kais. Gesundlieitsante, Bd. XXI, 3 Heft, I904, pp. 377-384).

\section{HIYDROGEN SULPHIDE.}

This gas is the product of a reduction. From what nnedia and under what conditions is hydrogen sulphide given off with browning of lead acetate paper? This paper is readily prepared by dipping strips of white filter paper into a strong solution of lead acetate in distilled water. It should be kept in a tight tin box or a glass-stoppered bottle. Probably most, if not all, bacteria are able to produce hydrogen sulphide in nutrient media containing readily decomposable sulplur compounds. Is an enzyme necessary? When an organism grays potato cylinders in test-tubes, why is no hydrogen sulplide given off? The student should read papers by Petri and Maassen (Bibliog., XXVIII).

\section{MERCAPTAN AND OTHER ODORS.}

We need an odor chart to go along with our color cliarts. If we could have a set of standard substances with peculiar smells for comparison witl the many odors evolved from bacterial cultures it wonld certainly be a great convenience. The difficulty at present is that the judgment of people varies greatly, in many instances, as to what the smell should be likened. As it is, the bacteriologist must do the best he can to define these penetrating smells, wlich are sometimes very characteristic of particular organisms. Some of the fishy odors are dite to aninis. Mercaptan is a very vile-smelling sulphur compound.

INDOL, PHENOL, LEUCIN, TYROSIN, ETC.

The production of indol is best studied in peptonized beef-broth naturally free from sugar or which has been deprived of its muscle sugar by growing in it (for a few hours only) Bacillus coli (Theobald Smith), after which it should be filtered clear. If $B$. coli or $B$. cloacae will not produce gas in beef-brotli in the closed end of fermentation-tubes, it is free from sugar and suitable for this use. Many organisuns give the indol reaction in Uschinsky's solntion to which peptone has been added. The writer has never been able to obtain the indol reaction in any culture medium which did not contain peptone (using this word in the commercial sense.) Cultures which do not show the red reaction with sodium nitrite (0.02 per cent solution) and sulphuric acid at room temperature will frequently do so when put into hot water 
for five minutes $\left(70^{\circ}\right.$ to $80^{\circ} \mathrm{C}$.). The browning of media due to excess of sodium nitrite must not be mistaken for this pink or red reaction. Uninoculated tubes sliould be included in the test, which may be made on the second and tenth day.

For nethods of determining plenol see Lewandowski in Deutsche Med. Wochenschrift, I89o, p. I I86, and Chester's Manual, p. 33. Schinidt (Bd. II, p. roo8) gives the following as a qualitative reaction for tyrosin: Dissolve by boiling in water and add a solution of 111ercuric nitrate. The red reaction is sharper if a little funing nitric acid diluted in water is added. Try also the violet reaction with neutral iron clloride.* Leucin crystallizes in white soft scales.

RFDUCTION OF NITRATES (AND MORE COMPLEX NITROGEN COMPOUNDS) TO NITRITES, TO AMMONIA, AND TO FREE NITROGEN.

For the pathologist the iodine-starch reaction is the most satisfactory test for nitrites, because it is not superlatively sensitive and consequently does not indicate

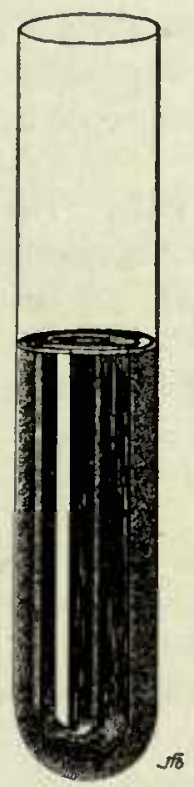

$a$

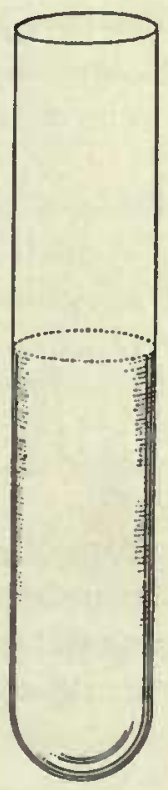

b
Fig. 56.t traces of nitrite absorbed from the air. It is made as follows: Twenty-five cubic centimeters of distilled water are added to one-half gran (n1ore or less) of pure potato starch and the fluid boiled. One cubic centimeter or more of this starch-water and I cc. of freshly prepared potassium-iodide water ( 1 : 250) are now put into the culture fluid, to which is then added a few drops of strong sulphuric-acid water $(2: \mathrm{I})$. If any appreciable quantity of nitrite is present the culture immediately becomes blue-black from the liberation of free iodine, which acts upon the starch. Old potassium iodide water sliould never be used withont first testing carefully, as it usually contains sone free iodine. It is always best to first make a trial test without the bacteria. Commercial starch frequently contains products of bacterial decomposition and starch prepared aseptically sliould be substituted.

At least one-third of the organisnis which have fallen nnder the writer's observation in recent years give the nitrite reaction when grown in peptonized beef-bonillon containing potassium nitrate.

*Mann (p. 323) gives the following as a specific tyrosin reaction: Denigès has recommended the well-known phenol aldehyde reaction for the detection of tyrosin. Nasse, in repeating Denigès' observations, has found the following to be a very delicale test for tyrosin, as neither proteids nor peptones give the color-reaction. Proceed thus: Add a few drops of formol solution to concentrated sulphuric acid, when, on warming with tyrosin, a brown-red color is obtained, which, on addition of acetic acid, becomes green.

†Fic. 56.-Bacterium syringae (van Hall). Nitrate bouillon cultures 5 days old, to each of which has been added boiled starch water, potassium iodide water, and sulphuric acid. In tube $a$ the potassium nitrate was reduced to the nitrite, and on addition of the reagents free iodine was liberated, and the starch blued. In the other no nitrite had formed, no iodine was liberated, and the starch remained colorless. For discrepancy see text. 
Fig. 56 shows how differently quite similar-looking cultures may react when submitted to this test. Botlı of these organisms were received from van Hall under the name of Psendomonas syring $\mathscr{e}$, $a$ being van Hall's own isolation and $b$ being supposedly a subculture from Beyerinck's isolation. Neither one would produce any blight in lilac sloots.

There is no simple way known to the writer of distinguishing ammonia from the anins, as both react to Nessler's reagent. Nitrogen may be distinguished from the other gases of fermentation by the fact that it is not absorbed by sodium or potassinn hydroxide and will not burn or support combustion. This gas is produced readily from nitrates by a number of green-fluorescent organisms (dung-destroyers) but not by all of thein.

FIXA'TION OF FREE NITROGEN AND THE, OXIDATION OF AMMONIA AND AMMONIUM SAL'TS TO NITRI'TES AND NITRATES.

These processes are probably common enongh to organisms of the soil, many of which have not been investigated, but they are not known to be brought about by plant parasites exchusive of the root-tubercle bacilli of the Leguninosae, which some believe to be parasites (see Peirce).* They are believed to be of rare occurrence in bacteria which grow well on ordinary culture media.

The nodules on roots of plants will hereafter be considered more fully. The reader should consult a paper by Geo. T. Moore on "Soil Inoculation for Legunes," Bureau of Plant Industry, United States Department of Agriculture, Bull. 7 I, Janwary 23, r905; and one by Maria Dawson, "Further Observations on the Nature and Functions of the Nodules of Legnuminous Plants," Plilosophical Transactions Royal Society of London, Series B, Vol. CXCIII, pp. 5I-67, I900, with 2 plates.

\section{ASSIMILATION OF CARBON DIOXIDE.}

Some soil organisms are believed to obtain their carbon directly from carbon dioxide, and would thus be exceptions to the law that all non-chlorophyllous plants must obtain their carbon from organic substances. This supposition, while probably true, has not, we believe, been established satisfactorily. Its elucidation offers a most interesting line of research (see Bibliog., XXVI.)

PIGMENTS.

Bacterial growths are often bright colored, and an examination of the pigments should form part of one's study of an organism. They may be considered as follows :

(I) Under what conditions formed? Can they be eliminated by growing the organisms in the dark or under unfavorable conditions, $e . g$., near the maximum or minimum temperature? Bacillus prodigiosus is a favorable organisin for experiment.

(2) In what soluble (water, hydrogen-peroxide in water, ethyl alcolıol, methyl alcohol, glycerin, acetic ether, petroleum ether, sulphiric ether, acetone, cliloroform, turpentine, benzine, benzole, xylol, toluol, carbon bisulphide, etc.)? Tlie pigment should be tested in as many solvents as possible.

*Peirce, George James. The Root-tubercles of Bur Clover (Mcdicago denticulata Willd.) and of Some Other Leguminous Plants. Proc. Calif. Acad. Sci., 3d series, Botany, Vol. II, No. to, San Francisco, Cal., June 21, 1902, pp. 295-328, with I plate. 
(3) How are they acted on by acids, alkalies, and otler reagents?

(4) Of what use are they to the organism? Are they oxidation-products? Exannine spectroscopically, if possible.

On the addition of acids or alkalies, a bacterial pigment may remain unchanged, may be clianged into some different color, may be destroyed, or may be converted into some colorless compound which will regain its original color on changing back the reaction. The yellow piginent of several species of Bacterium (Pseudomonas) remains unclianged in the presence of acids and alkalies. The blood-red color of Bacillus prodigiosus becomes carmine in the presence of certain acids and yellowishbrown in the presence of certain alkalies. The blue color of Bacterium syncyaneum is said to be produced only in acid milk. The beautiful green fluorescence of Bacterium pericarditidis (Bacillus pyocyaneus pericarditidis), and probably of all this group of bacteria, is produced only in alkaline media. According to Jordan two pigments are normally produced by many green-fluorescent organisms. The blue pignent pyocyanin is visible by gaslight and is soluble in chloroform. The greenfluorescent pigment is insoluble in chloroform and yellowish by gaslight. By this latter test the two can be distinguished when mixed. Soluble phosphates and sulphates are necessary for the production of green fluorescence. The ability to produce pyocyanin is easily lost. Its production in the culture-medium, unlike that of the fluorescine, is not dependent on the presence of phosphates or sulfates. Pyocyanin turns red with acids, fluorescine becomes colorless; both return to their original color on adding alkali sufficient to change the reaction. "Asparagin, ammonium succinate, ammonium lactate, and ammonium citrate all proved suitable for the development of the fluorescent pigment." The yellow and black pigments are the result of oxidations. (See papers by Gessard, Thumm, and Jordan, Bibliog., XXIII).

The pigments of bacteria range from one end of the spectrum to the other. Thus we have various shades of black, brown, violet, indigo, blue, green, yellow, orange, and red. Many bacteria produce no pigment, $i . e_{\text {., }}$ are white when seen in mass. Others produce several distinct piginents. Many of the plant parasites are yellow, e.g., Bacterium campestre, Bact. phaseoli, Bact. hyacinthi, Bact. Stezvarti, Bact. juglandis. Some of these yellow organisms stain the host-plant and certain nutrient substrata a deep brown. Other plant parasites are white but also stain the lost and certain substrata brown, e.g, Bacterium solanacearum, Bacillus carotovorus, $B$. aroidece. Others are pure white and are apparently destitute of any pigmentproducing powers, e.g., Bacillus amylovorus, B.tracheiphilus. Very many bacteria when grown on cooked potato produce a gray stain in this substratum, especially in

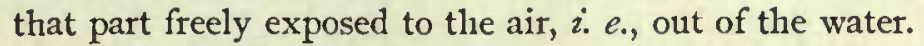

Some other color changes in the host should be mentioned. Various brown and red stains visible in certain plants when attacked by bacteria are not attributable directly to the presence of the microorganisms in the tissues. These are oxidation plienomena likely to occur when the plants are wounded or destroyed by any agent whatsoever. A few illustrations will make ny meaning clear. When the limbs of pear trees are destroyed by blight the foliage becomes black, but this blackening 
also occurs frequently when the flowers, green fruits, or foliage are killed by other causes. In the leaves of Amaryllis atamasco the writer obtained red stripes by injecting the yellow Bacterium hyacinthi, but no bacterial disease followed, and the same plant reddens when brnised. Brooncorn shows conspicnous red blotches when attacked by the broomcorn organism, but the parasite itself does not produce a red pigment, while the plant reddens easily as the restilt of apliis-punctures or wonnds of any sort. Sugar-cane attacked by Bacterium vascularum shows a conspicuous red stain in the bundles, but other canses, such as the gnawings of an insect or the presence of a fungus, may lead to a similar stain, while the bacterimm itself does not produce any red pigment.

\section{CRYSTAIS.}

Deterninine the nature of the crystals observed in the varions media. Many of these are double ammonium salts; others result frow the action of trypsin on proteids. Crystals which are not due to the drying out of the nedia are conn11non

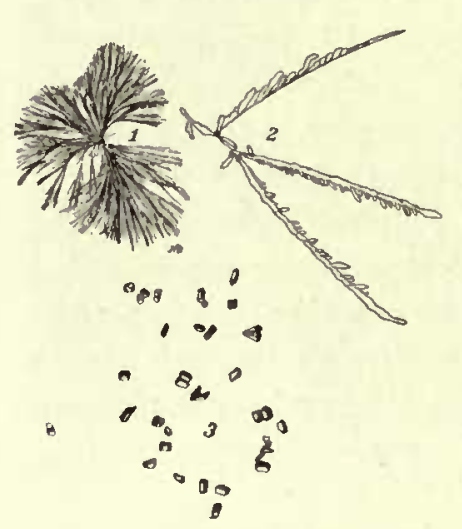

Fig. 57.* phenomena in old cultures of nuany sorts, especially if the media were not originally saturated with alkali (soda or potash). Fig. 57 shows two types of crystals forned in + I5 11utrient agar by two green-fluorescent organisws received froul van Hall as Pseudomonas syringe, and a third type produced by the olive tubercle organisil.

\section{QUFSTION OF EXISTENCE OF ENZYMES.}

The enzymes of Englisli writers are the diastases of Duclanx. They are chenical substances, the exact composition of which has not been deternined. They may be regarded as the working tools of protoplasin. The following are some of the best known kinds :

(r.) Diastasic (starch-destroying).

(2.) Inverting (stugar-splitting).

(3.) Cytoliydrolytic (cellulose-dissolving.)

(4.) Proteolytic (peptonizing).
(5.) Lab or reninct (casein-forming).

(6.) Lipase (fat-splitting):

(7.) Pectic (pectin-splitting).

(8.) Oxidases (oxidizing).

Trypsin is common. Pepsin is not known to be prodnced by bacteria and shoild be searched for.

Many bacteria invert cane-sugar, but invertase is believed to be rare. This, however, may be an ill-fonnded conclusion. The experinents of various aninal plysiologists have shown that when cane-sugar is injected into the blood-strean it is excreted unchanged, and according to Julius Saclis cane-sugar, inulin, etc., inust

*FIG. 57.-Crystals formed in cultures of Bacterium syringae (van Hall). 1. From tube II, Aug. 14 (agar stock 693), from van Hall's II, i.e., his own isolation corresponding to $a$, fig. 56. 2. From tube I, Aug. I4 (stock 693), from van Hall's I, which is from Beyerinck's old isolation (sce $b$, fig. 56) $\times$ 3. Nos. 1 and 2 drawn Aug. 30, 1902. 3. Crystals formed on slant litmus-lactose agar which was inoculated with the organism causing olive-knot. About one-half inch of slant in middle part of culture I month old, $i$. e., made January 20, 1904; drawn February 17-19. $\times$ 3. . Temperature during growth, $20^{\circ}$ to $25^{\circ} \mathrm{C}$. 
first be reduced to glucose (grape-sugar), before they can be used as food by plants. When no invertase has been detected the general hypothesis lias been that this inversion was due to the direct action of the protoplasm, but the recent isolation by Buclner and others of an invertase (Zymase) from yeast, in which it was long believed that none existed, once more emphasizes the nncertainty of negative conclusions.

Diastase is connmon. Is there nore than one kind, i. e., a sort which can only convert the starch into anylodextrin and another which converts it into maltose and dextrine? In many cases, when the organism is grown on potato, the conversion is carried only a little way and stops, there being always a copious purple or red-purple reaction with iodine. In other cases, e.g., when Bacterium campestre is grown on potato, the starch conversion is so complete that after a few weeks there is little or no color reaction when the potato-cylinder is maslied up and iodine water

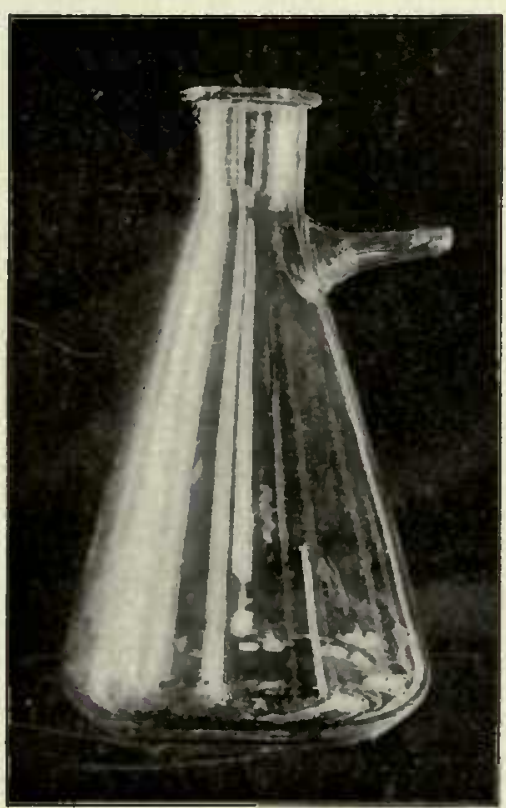

Fig. 58,* added. What makes this difference?

A substance capable of dissolving the middle lamella appears to be common to all bacterial plant parasites and a true cytase presumably occurs, but much additional study is necessary. Probably several enzymes are confused under this name, just as several chemically different substances are still called "cellulose." The substance which dissolves the middle lanella in some cases is probably ammonium oxalate. The writer has not been able to dissolve it by means of pure oxalic acid, but that of turnips softens in ammonium oxalate.

The lab or rennet ferment is rather common. Its action slrould not be confused with the curdling of milk due to the formation of acids. Tests may be made in litmus milk. Is there more than one kind of such fernent? Some organisms coagulate the milk promptly into a solid mass which finally shrinks, extruding whey. Others cause the casein to separate out of the fluid very slowly as a 1111titude of separate particles which only become compacted very slowly.

The writer las not met with the oxidizing enzymes, unless the substance in bacterial cultures which causes rapid evolution of oxygen from liydrogen peroxide is such an enzyne, as Dr. Loew maintains (Bibliog., XLV). Many other enzynes undoubtedly occur and play their part. The student sliould search for einulsin, lipase, lactase, inaltase (glucase), etc.

All known enzymes when freely exposed to steam heat are destroyed at temperatures considerably under $100^{\circ} \mathrm{C}$. They are less sensitive to heat than the bacteria themselves, but are destroyed by a few ininutes exposure to temperatures $15^{\circ}$ to $30^{\circ} \mathrm{C}$. (moist heat) above the thermal deatli-point of the organisms which have produced

*FIc. 58.-Thick-walled Kitasato flask for filtration or evaporation in vacuo, etc. Much re-
duced. 


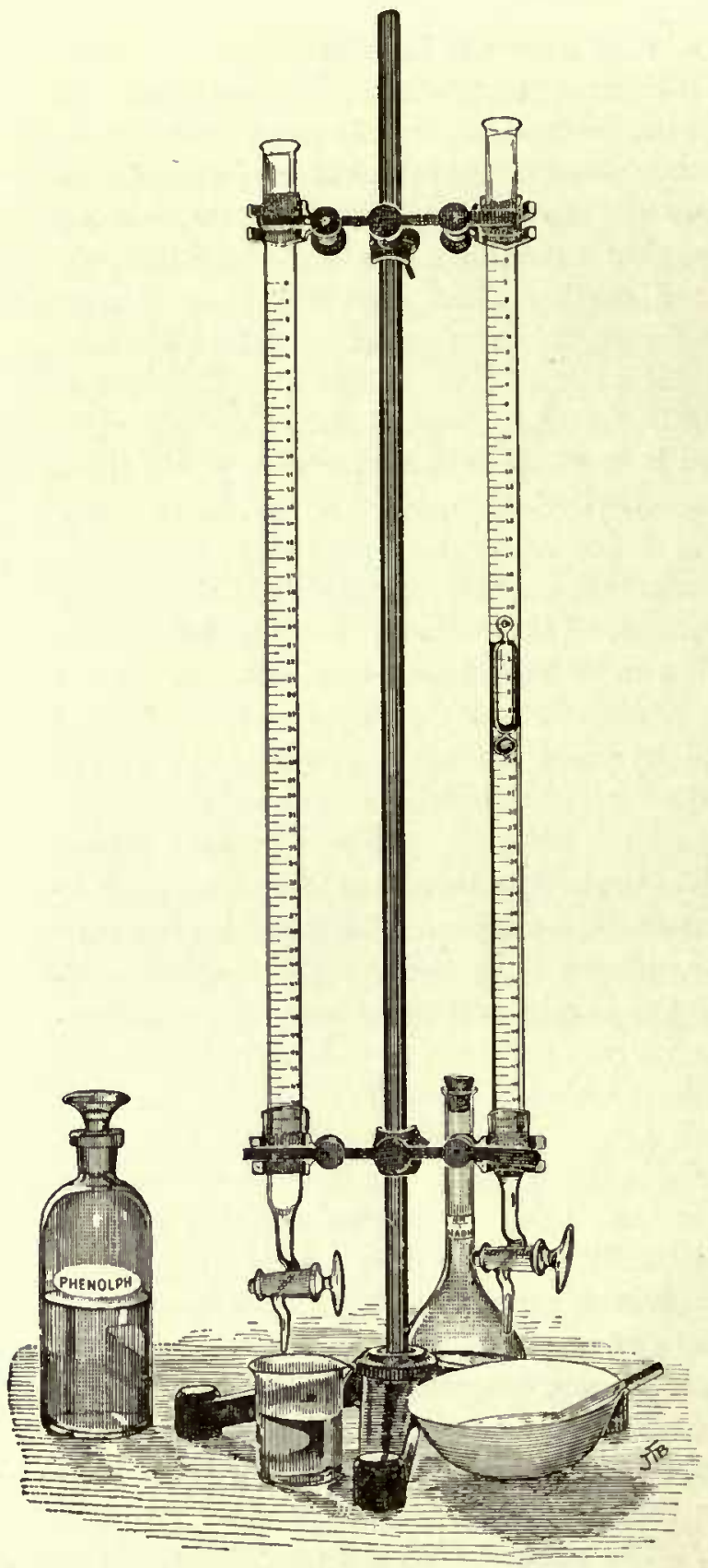

Fig. 59.t

them.* Some of them are very sensitive to the presence of acids, alkalies, strong alcohol, or antiseptics, or their action is inlibited by the presence of other enzymes or of products of enzymic fermentation in excess, or by the absence of some conibining substance, such as lime or some weak acid. Some do not pass readily througl the Chainberland filter or through filter papers. Some are destroyed at lower temperatures after precipitation. Some are not produced except in presence of the substance which they can decompose, but this is not true of all. Usually an organism produces more than one ferment and some bacteria are known to produce five or six. Bacterium campestre produces at least three and probably four, viz, diastasic, cytohydrolytic, proteolytic, and rennet. It also inverts cane-sugar, but it is not yet known whether this cliange is accomplished by neans of an invertase. On enzymes derived from bacterial soft-rot organisus the reader should consult recent papers by Jones (Centralb. f. Bakt, 2 Abt., and Vermont Exp. Sta. Rep.). Levy has publislied an interesting paper on "Some physical properties of enzymes" (The Jontr. Infect. Diseases, Vol. II, I905, pp. I-48).

For concentrating fluids in vacuo at low temperatures $\left(50^{\circ}\right.$ to $60^{\circ} \mathrm{C}$.) the thick-walled Kitasato flask shown

*The same amount of dry heat does not affect them, and Loeffler has recently advised exposure of thoroughly air-dried tissues and cultures to $150^{\circ} \mathrm{C}$, dry hcat, as an easy way of eliminating the bacteria prior to grinding and extraction of the uninjured cnzymes and other soluble products. Non-sporiferous bacteria may be heated at $120^{\circ} \mathrm{C}$. for 2 to 3 hours. Tissues and sporiferous bactcria should be heated at $150^{\circ} \mathrm{C}$. for one-half hour. (Deutsche Med. Wochenschrift, Dec. 22, I904.)

†FIG. 59. Burcttes used by the writer for titrating culture media. Twentieth-normal sodium hydrate is used to determine the acidity,-" and the medium is finally brought to the desired alkalinity with quadruple-normal sodium hydrate. The fluid is boiled and titrated hot, using phenolphthalein as the indicator. The burettes should be graduated to tenths of a cubic centimeter and should hold $50 \mathrm{cc}$. Alkali should not be allowed to stand in them. 
in fig. $5^{8}$ is very convenient. The side tube is attached to the suction-pipe of an air-pump and into the neck is thrust a rubber stopper carrying a thermometer and a U-shaped glass tube of sinall bore, the outer arm ( 36 inches long) ending in a beaker of mercury. Heat may be applied by means of a water-batli. By substituting a funmel for the thermometer the same device may be used to hasten the filtration of thick liquids, hard-pointed filter papers being elnployed.

\section{SENSITIVENESS TO PLANT ACIDS.}

The tests slrould be made with malic, citric, lactic, oxalic, and tartaric acids added to neutral beef-broth, peptone-water, or plant-broths, or to synthetic media (see An1. Nat., I899, p. 208). It is best to titrate with $\frac{\mathrm{N}}{\mathrm{IO}}$ or $\frac{\mathrm{N}}{2 \mathrm{O}}$ solutions, to acidify with $\frac{2 \mathrm{~N}}{\mathrm{I}}$ or $\frac{4 \mathrm{~N}}{\mathrm{I}}$ solutions, and to reckon the acidity in cubic centimeters of normal

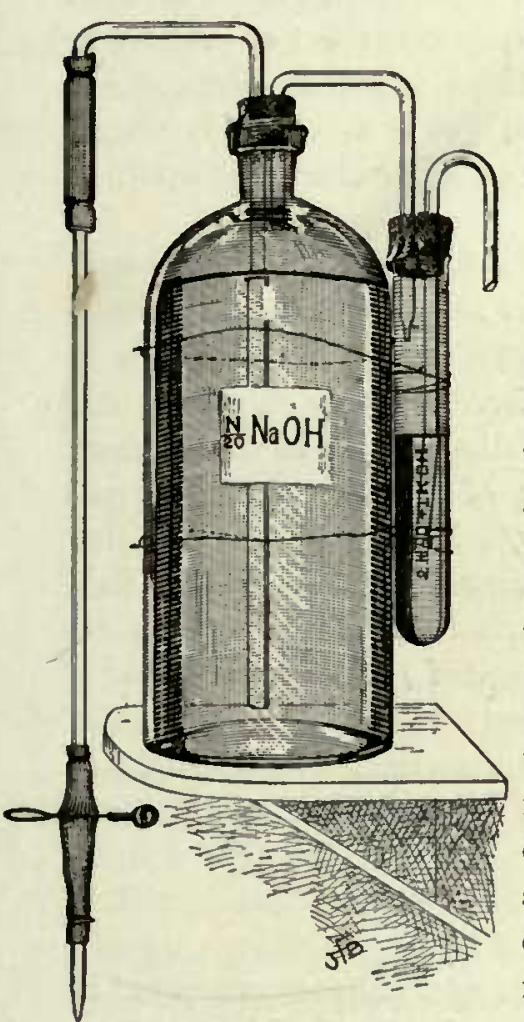

Fig. 60.* solution $\left(\frac{N}{I}\right)$ required per liter of medium. If preferred, it may be calculated on roo cc. portions and expressed in per cents, but there is no advantage in this, and it has the disadvantage of introducing fractions.

\section{SENSITIVENESS TO ALKALIFS (POTASSIUM OR SODIUM HYDRATE).}

Determine in each case the optimum reaction of the medium for growth. For the majority of bacteria this is said to lie between + ro and $+I_{5}$ of Fuller's scale. $\dagger$ The best neutral litmus paper should be used freely, but acid and alkaline inedia should be titrated with phenolphthalein and $\frac{\mathrm{N}}{10}$ or $\frac{\mathrm{N}}{2 \mathrm{O}}$ solutions. In some mediae. $g$., gelatin, juices of various plants-the end-reaction with phenolplithalein and caustic soda is not very sharp. In these cases the titration should be stopped at the first trace of change of color. If one adds alkali until the fluid is decidedly red, then a distinct statement to that effect should be made, since otherwise no comparisons of any value can be made. All of the writer's + and - references to media are based on a reaction stopped at the first distinct trace of pink color. As much again alkali must sometimes be added to obtain a deep-red color.

*Fic. 60.-Stock bottle of $\frac{N}{20}$ sodium bydrate solution. The small bottle at the right holds concentrated potash liquor to remove the carbon dioxide from the air which enters the bottle. About one-fourth actual size.

†The plus and minus on Fuller's scale denotes, respectively, acid and alkaline media. The +10 , for example, means that exactly 10 cubic centimeters of normal alkali must be added to a liter of the culture medium to render it exactly neutral to phenolphthalein, and, correspondingly, - 10 means that the fluid is alkaline to phenolphthalein and that to cc. of normal acid would need to be added to bring I liter back to the neutral point. The student should not confuse the litmus neutral point and the phenolphthalein neutral point, as they are abott $23^{\circ}$ apart, $c$. g., + ro of Fuller's scale (acid side) is distinctly alkaline to litmus. (Consult '95, Fuller, Bibliog., XVI.) 
The writer lias used the foregoing method of determining the reaction of culture 111edia for several years and has, in general, found it exceedingly exact and valuable, but it does not appear to be well adapted for deterninining the annount of alkali (ammonia and amins) produced by bacteria in culture media (see Sutton, Bibliog., IV). The apparatus required to make these titrations is shown in figs. 59 and 60.

Some experinents recently made by the writer witl Bacillus tracheiphilus in peptonized beef-bonillons of varying degrees of acidity (acid of beef-juice) and alkalinity seem to show that toleration of sodium hydrate can be considerably increased by inoculating each time from alkaline bouillons rather than from acid ones. Taken from +20 bouillon (descended from +20 bonillon) this organism would clond the same bouillon only down to o; taken frown o or -5 bouillows (descended from -2.7 bonillon) it would cloud the same bouillon down to - Io and probably farther, but not to $-2 \mathrm{O}$. Bouillon containing various amounts of c. p. sodiun chloride behaved in the same way. The organism would tolerate the largest amount of salt (I.5 to 2 per cent) when first grown in an alkaline bouillon. When inoculated from a +20 bouillon tlie organism finally grew in I per cent salt bouillon, but only after a decided retardation, and would not grow at all in + I 5 peptonized beef-bonillon containing I.5 per cent sodium chloride.

Bacteria vary greatly in their toleration of acids and alkalies, the range of growth being from minus IOO (or 1nore) of Fuller's scale to plus Ioo (or more). Thic linits of growth are not known, but it is probable that the extremes of toleration in particular aberrant species is mucl greater than that here given, e. $g$., on the acid side in sulphuric acid and vinegar bacteria, and on the alkaline side in case of those organisms wlich are able to grow in the lime-vats of tanning establishnients and in alkaline springs. Lehmann \& Neumann ('96, Bibliog., III), state tlat they have found bacteria that will endure roo cc. of normal acid per liter of fluid culture media, $i$. e., equal to abont I per cent sulphuric acid. Some species are indifferent to a considerable degree, having a wide range of growth eitler side of the (phenolplithalein) neutral line; others prefer alkaline inedia; others acid media. Many are extremely sensitive to their own acid products (acetic, lactic, butyric, etc., acids). Not a few are differently affected by different acids and alkalies. Every new organisin presents a whole series of special problens.

\section{EFFECT OF DESICCATION.}

Drops of fluid cultures or small masses of gelatin or agar cultures are spread on stuall ( $\pi / 4$-inch) clean, sterile cover-glasses, in covered sterile Petri dishes, and are set away in the dark, in dry air (a dry room). The test is finally made by seizing one of these covers with a pair of sterile forceps and dropping it into a tube of sterile bouillow or other medium of a stock previously deternnined to be exactly adapted to the growth of the organism, i.e., one which does not exert upon it any retarding influence. Occasionally a tube will becone contaninated, but enongh 1nust be inoculated so that this will not affect the final result (20 at one time is not too many). Fluid cultures are preferred. Solid cultures do not give strictly. comparable results, 
Organis111s believed to be non-sporiferous slow great differences, sonve being killed by an exposure of a few minutes or a few hours, while others renain alive for nuany weeks. For further information see the special chapters on Bacillus tracheiphilus, B. carotovorus, Bact.hyacinthi, etc. Tests may also be made in air dried over sulfuric acid or calcium cliloride. Harding \& Pruclia have shown recently that Bacterium campestre remains alive much longer when dried on cabbage seed than when dried on glass cover-slips. In their experiments this organism was dead on glass at the end of ten days, but alive on seed at the end of thirteen months.

\section{EFFECT OF DIRECT SUNLIGHT.}

The exposures should be made in a thin stratum of nutrient agar, not sowed too thickly (there may be several luundred colonies on the plate, if properly distrib11ted), in thin-bottomed Petri dishes, to an unclouded sun for 5, IO, I 5, 30, 45, and 60 nininutes, a portion of the bottom of the plate, which is placed uppernuost, being covered by some substance impervious to light, such as several folds of Manila paper

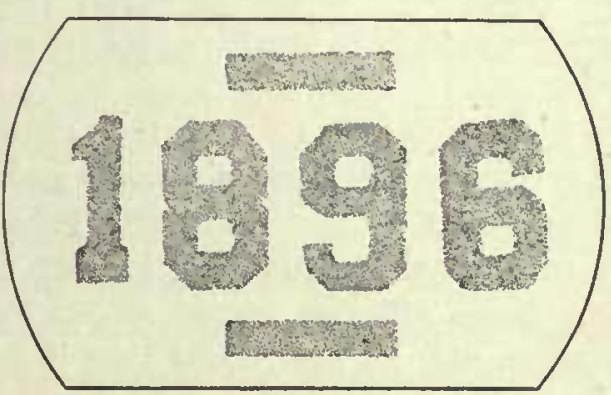

Fig. 61.*

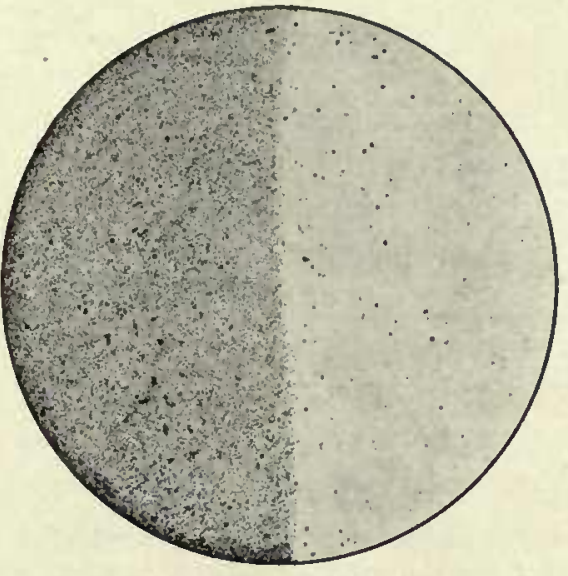

Fig. 62.†

or of the black paper which comes wrapped around pliotograplic dry plates, covered in turn by white paper. Exposures of several hours are not reconiniended. If the layer of agar is very deep, or if the sowings are too thick, some organisms will screen others and all will not be killed. Ten cubic centinteters is a proper amount of agar to nse for a plate having an area of 60 square centimeters. The latitnde, altitude, time of year, time of day, and intensity of the light should also be recorded. In the summertime it is very important that the exposures should be made on blocks of ice or,

*Frg. 61.-Gelatin culture of Bacillus amylovorus (Burrill) Trev. in a Petri dish. Exposed in 1896 to direct sunlight for four hours on icc after covering portions of the plate with pasteboard figures. The bacteria grew only under the protected parts. Drawn from a photograph made after five days incubation of the culture at about $24^{\circ} \mathrm{C}$. The temperature of the gelatin during exposure was about $25^{\circ} \mathrm{C}$. Three-fifths natural size.

†FIg. 62.-Agar culture of Bacterium phascoli(Erw. Sm.) in a Petri dish. Right one-half exposed to direct sunlight for thirty minutes, on ice, the other half protected by several folds of Manila paper. Dish then set away in the dark for several days. One-half natural size. The scattering colonies on the right side undoubtedly grew from bacteria which were sheltered from the direct rays of the sun by overlying organisms, i. e., the plate was sown too thickly. 
better, on larger Petri dishes filled witl pounded ice; otherwise, in case of 30 to 60 minute exposures, the temperature may rise nearly or quite to that of the thermal death-point of the organism, and then we shall have the effect of heat complicating that of light. To avoid errors it is always best to take one-lialf of eacli dish as a check (ratlier than the whole of a separate dish), and the rise of temperature slionld be carefully recorded. In some tests made by the writer in Washington in May the temperature of the plates exposed in the open air to the sun for 45 minutes (withont ice) rose from $25^{\circ}$ to $5 \mathrm{I}^{\circ} \mathrm{C}$. Figs. $6 \mathrm{I}$ and 62 show the effect of sunlight upon thin sowings of Bacillus amylovorus and Bacterium phaseoli in poured-plate (Petri-dish) cultures.

\section{VITALITY ON VARIOUS MEDIA.}

By this I mean the determination of the resistance of organisuns to their own decomposition products. This varies greatly. Much may be learned by the study of old cultures. Do not discard test-tube cultures until after many weeks. Exanine frequently. Make transfers from tubes which lave been inoculated for a year or more. Determine whether this vitality is due to spores or persists in the ordinary vegetative rods. On what kinds of media does a particular organisu live longest? Can lengtl of life be increased by occasionally neutralizing decomposition products (acids) witl sterile carbonate of lime? or by occasional additions of food? Some bacteria are veritable revelers in filth; others are extremely sensitive; all are soon nunder abnormal conditions in our culture-tubes.

Another way of keeping bacteria alive for a long time is by reducing their growth to a minim11n. Stock-cultures, especially of perisliable organismis, shonld, generally speaking, be kept in the ice-box at temperatures under $15^{\circ} \mathrm{C}$. This greatly reduces the always heavy burden of keeping alive cultures of organisns which are not in immediate demand for actual experiment. Sonne will also rentain alive a long time when sealed airtight. Particular organisws may be kept a long time in particular media, e. g., Bacterium vascularum in dilnted peptonized cane-juice gelatin, Bact. Stezearti in milk, etc. Some organisms are quite resistant to their own decomposition products, e.g., Bacillus coli, Bact.pericarditidis. In the cool box $B$. coli will often live a year in agar stab cultures.

\section{MIXED CULTURES AND MIXED INFECTIONS.}

The behavior of mixed cultures and mixed infections may be tested in various fluids, making poured plates from time to time; in tubes of agar, potato, and other solid inedia; in crossed streaks on agar or gelatiu plates; and in the plants themselves.

When two bacteria, or a bacterium and a fungus, are sown together in a culture111edium, there may be (I) antagonism, with the crowding ont of one species; (2) a nore or less complete indifference, botl organisms growing well; or (3) a distinctly favorable effect, $i . e$, a marked increase in growth or in patloggenic effeet due to the presence of the second organism. The antagonism nnay result in the prompt destruction of one of the organisms, or only in a retardation or inlibition which finally disappears after the first organis11 has 111ade its growth and subsided. In some cases the favorable effect of one organism upon another is due to the fact that it prepares food for it out of an unfavorable substratum, e.g., 111altose from starch. 
In the plant one organisn1 often paves the way for others which complete the destruction, e.g., Bacterium campestre and Bact. solanacearum are often followed by soft white rots. Sonne of the latter, however, are able to make their way nnaided, a fact observed and known to the writer for a white rot of the cabbage as long ago as 1896 .

The simplest way of studying the antagonistic action of bacteria is by neans of crossed streaks on agar or gelatin plates. These may be nuade either simultaneously, or one after the other has begun to develop. The action of the antagonistic organisn may also be obtained by letting its products diffuse througl a collodion sac into bouillon inoculated witl the other organism. In practice, the bottom of a test-tube is removed and a collodion sac is securely fastened in its place. This tube is filled witl the usual quantity of bouillon and lowered into a larger receptacle (tube or flask), the collodion part being surrounded by bouillon. The inner and outer receptacles are now plugged with absorbent cotton, and the apparatus is sterilized in the steamer or antoclave. The two tubes are then inoculated sinultaneously, or the outer one some hours or days after the inner one. (See an interesting paper on Antagonism, by Frost, in Jour. Infect. Diseases, Vol. I, I 904, pp. 599-640). Frost has also devised two new methods for studying this subject, viz, the divided-plate method and the agar-block method. The first is a modification of the ordinary streak method. It is managed as follows: A Petri dish is divided into two equal parts by means of a glass rod fastened to the bottom with collodion. A tube of melted agar is inoculated with the antagonistic organisnin and ponred into one half of this plate. Into the other half sterile agar is poured. Streaks of the other organisw1 are now made crosswise of the hardened surface. If there is marked antagonism there will be a decided difference in the behavior on the two sides of the plate, i. $e$, on the sterile agar as compared with the inoctrlated. To insure a uniforn1 streak the inoculated loop should be swept across one half of the plate, then reinoculated and swept across the other half of the plate.

The method by agar-blocks consists in substituting agar-walls for collodion walls. A sterile 3 -cmi.-deep Petri dish is poured full of untrient agar. When it has solidified it is cut into rectangular blocks, $\mathrm{x}$ by $\mathrm{I}$ by 3 centimeters, using a sterile knife and taking all possible precautions to avoid contanination by air-borne organisms. A platinum needle is now dipped into a culture of the supposed antagonistic organism and thrust into the block lengthwise but not entirely through it. The nouth of the needle-track is sterilized and sealed by tonching it for a 111oment witl a red-hot iron. The head of a small wire nail set into a suitable handle will answer the purpose. The block is picked up with sterile forceps and dropped into a tube of sterile bouillon, which then may be inoculated with the other organis11. More than one block and tube slould be inoculated, and it is best to test the sterility of the outer surface of the agar-block by delaying the inoculation of the bouillon for a day or two after the inoculated agar-block has been dropped into place.

Still another 11ethod has been described by Frankland and Ward. They use the walls of a Chamberland filter to keep the bacteria separate. Bonillon for the one 
organism is placed in a flask or large tube. That for the other organisw1 is placed inside a Cliainberland filter, which is then sunk into the other receptacle, whereupon it is sterilized and inoculated as in the collodion-sac method.

The favorable influence of a second organism may be stndied in crossed streaks on sterile raw potato, carrot, turnip, etc.; on starclı jelly; or on agar, gelatin, or silicate jelly with addition of varying announts of the different plant acids, or plant juices; or other vegetable substances. Frost's divided Petri dish nuay be used for the jellies.

\section{REACTION TO ANTISEPTICS AND GERMICIDES.}

Antiseptic has been defined recently by Duclaux as follows: Any substance the intervention of wlicl modifies in any form whatsoever the marcl of the phenomena (Bibliog., XX, Fermentation alcoolique, p. 46I).

I still use the word with its old prinlary nieaning (anti, against, and sepsis, decay). In this sense an antiseptic is any substance wlich prevents the 1urltiplication of bacteria in putrescible substances. Large doses of antiseptics often exert a germicidal action, but such action does not necessarily follow. Often when the antiseptic substance is removed or diluted beyond a certain point growth takes place. The first seven substances mentioned below possess very active gernicicidal powers and are antiseptic in correspondingly sinall doses; the remainder are n110re or less valuable antiseptics, but are not valuable gernicicides.
(I.) Mercuric chloride.
(5.) Lysol.
(2.) Sulphate of copper.
(6.) Trikresol.
(3.) Formaldehyd (formalin).
(7.) Methyl violet (Pyoktanin).
(4.) Phenol (carbolic acid).
(8.) Thymol.
( 9.) Benzoic acid.
(Io.) Salicylic acid.
(II.) Chloroform.
(I2.) Sulphuric ether.

This list may: be extended indefinitely. The student slould consult valuable digests in Sternberg's Text Book of Bacteriology and in Miquel \& Cambier's Traité de Bactériologie. Some cantion must be used in drawing conclusions fron experiments. Mercuric chloride does not always destroy when the culture medium contains albuminoid substances. Sulphate of copper is more active in water than in bouillon.* Some. organisms will grow in a solution saturated witl thy111ol (e.g., in bouillon). Others will grow in the presence of cliloroform $(5 \mathrm{cc}$. of clilorofornin in test-tubes with Io cc. of milk or beef-bouillon). Ten organisins have been found by the writer which, under the conditions naned, grew in the presence of chloroform and two whicl grew vigorously in the presence of thymol. Russell reports one capable of growing in the presence of sulphuric ether. It is, therefore, not always safe to depend on these substances as antiseptics. Newcombe has made the same observation (Cellulose Enzymes, Annals of Botany, Vol. XIII, I899, p. 60). In the opinion of the writer the statements of plysiologists respecting tlie existence of enzymes in the tissues and fluids of the lighler plants and animals must be taken with: much allowance when cliloroform, thymol, and sinilar antiseptics have been

*Moore, George 'T., and Kellerman, Karl F. A Method of Destroying or Preventing the Growth of Algae and Certain Pathogenic Bacteria in Water Supplies. U. S. Department of Agriculture, Bureau of Plant Industry, Bulletin 64, 1904, pp. 44; sec also Bull. 76, Burcau of Plant Industry. Certain pathogenic bacteria, such as Vibrio cholerac and Bacillus typhosus, are destroyed within a few hours in water containing traces of copper salts or dissolved particles of metallic copper. 
PLATE 8.

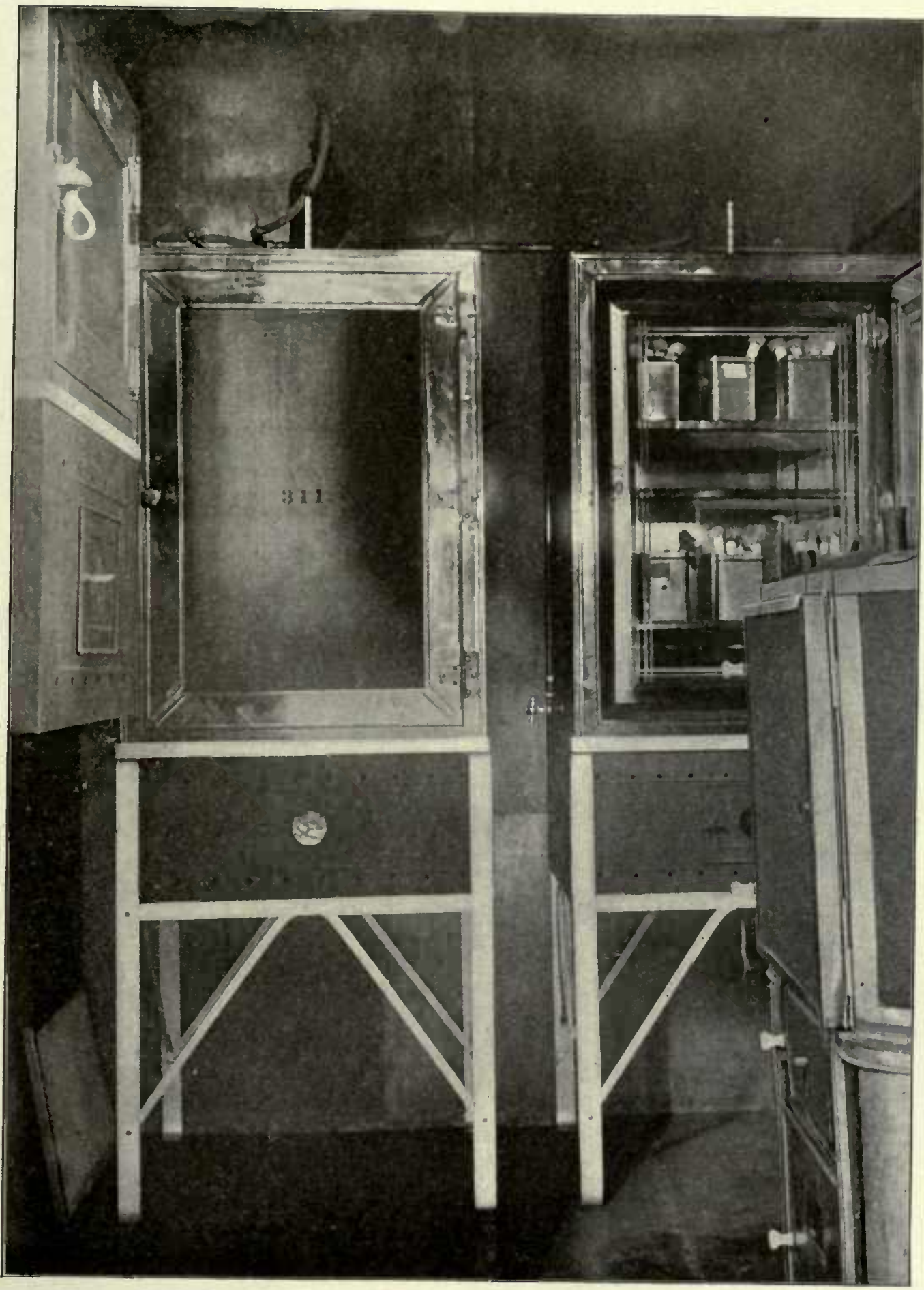

\section{A thermostat-room.}

In the center of the building and lighted by electricity. Ventilated in the same way as the photographic dark-rooms, i. e., by an exhaust-fan run by an electric motor. Three of the thermostats were made by Bausch \& Lomb, the fourth (felied) is a Rohrbeck. 

depended upon to keep the solutions free from bacteria. This lias been the case very frequently, and in several places in Greene's interesting book on Fernentations, pnblished in I899, it is said or inferred that the addition of chloroforn will prevent the growth of bacteria. This night or might not be trie; mucl wonld depend on the kind of organisms present. The medium to which chloroform or thymol has been added must be shut in and shaken continuously if the full antiseptic value of these substances is to be obtained.

THERMAL RELATIONS.

The student should determine-

(I) Maximum teinperature for growth (thermostat).

(2) Minimum temperature for growth (ice-box).

(3) Optinum temperature for growth (room or thermostat).

(4) Thermal death-point (ten minutes exposure in the water-bath, in thinwalled test-tubes of resistant glass liaving a diameter of I 6 to $I 7$ 111n., ordinarily in Io cc. of moderately alkaline peptonized beef-bouillon, viz, + I 5 of Fuller's scale).

(5) The effect of freezing (exposure to liquid air or to pounded ice mixed with coarse salt).

Thermal relations are annong the most interesting and should be studied with great care in case of every organisw. They offer valuable means of differentiation and also very useful suggestions as to geographical distribution and habitat. Good thermostats are made by various people. Several items of construction are important. The water or oil jacket should be of considerable volume (thickness) so as not to change temperature quickly; the cover should be thick and of the best nonconducting substances. The opening for the thermo-regulator should be at least $\mathrm{I} / \mathrm{2}$ inches in diameter (so as to take a Roux metal-bar therno-regulator); the warm chamber should be of good size; the space beneath should be high enough between floors to accommodate any pattern of safety bumer; and last, but not least, the workmanship should be of the very best quality, so that the apparatus will not leak. Nearly every worker has probably had experience with leaky thernostats at some time in his life and knows what a vexation of spirit they cause, particularly if filled with oil. A very excellent kind of thermostat is the old, large-pattern, feltcovered instrument devised by Dr. Hermann Rohrbeck and figured in the lower right-hand corner of plate 8 . This plate shows a thermostat room with four thermostats in use. All are provided with Roux metal-bar thermo-regulators and Kocl safety burners. One is for quick shifts as needed; and others are generally kept at $30^{\circ}, 371 / 2^{\circ}$, and $40^{\circ}$ or $43^{\circ} \mathrm{C}$. These temperatures, in conjunction with the cool boxes, thermal baths, and various room temperatures, enable one to quickly determine the thermal relations of an organism. The heiglit of the room is ro feet, its depth 7 feet, and its breadth 5 feet 3 inches. A larger roon would be more convenient. Such a roou should be located and constructed so as to be as little subject as possible to external changes of temperature. It sliould be lined with asbestos and sheet iron, and efficient safety burners sliould be used to the exclusion of all others (see Lautenschläger's catalogue). The improved Koch safety burner is probably the best. All burners require frequent inspection. 
The writer lias no very satisfactory way of making exposures for determining the minimum temperature for growth. His method is to make such exposures in the bottom of a large, well-filled ice-box, which is opened as little as possible during the progress of the tests, and then only for the briefest periods. The degree of cold

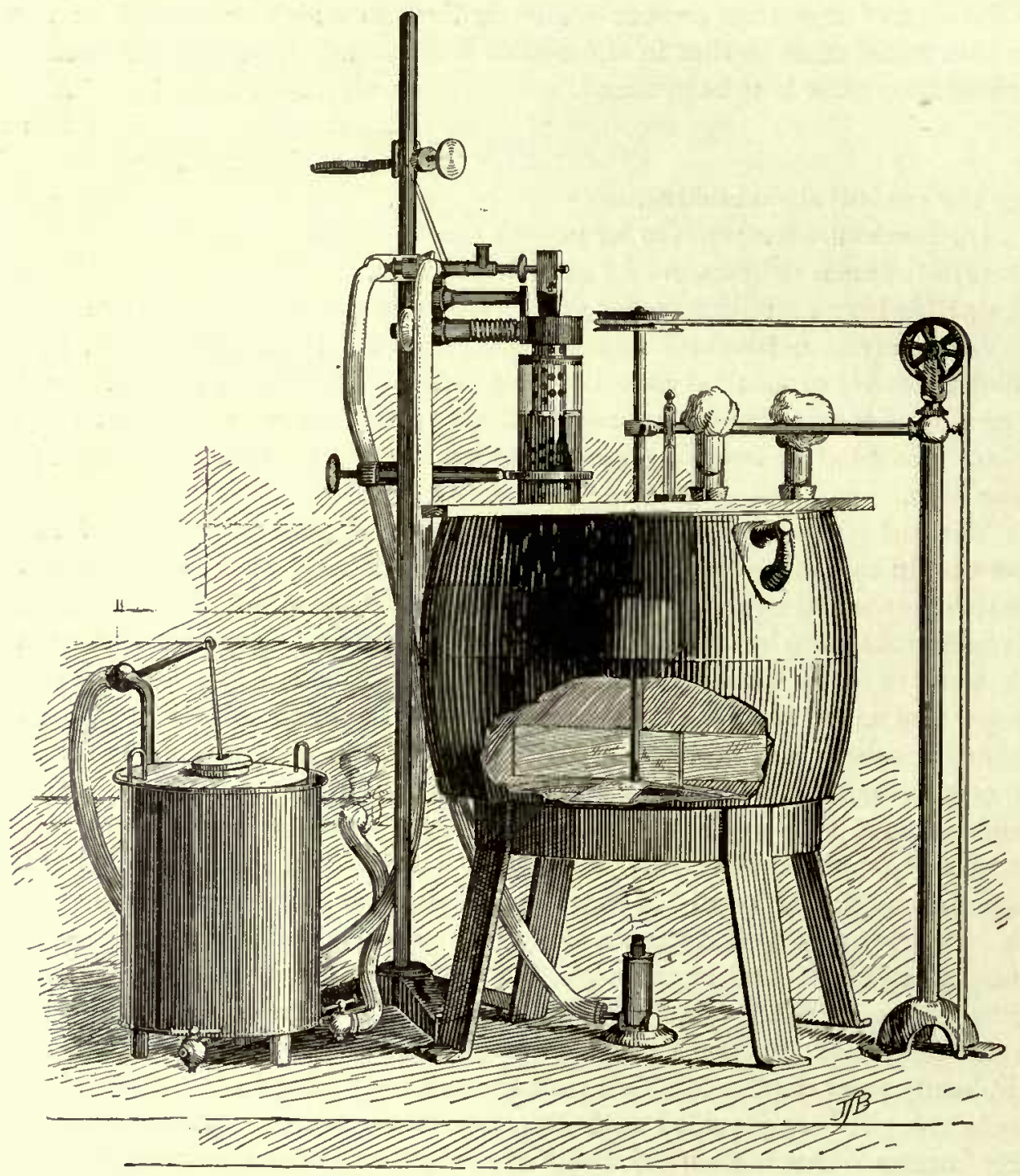

Fig. 63.*

is governed by the amount of ice. A good thermometer is exposed in the midst of a bundle of inoculated tubes, and if the temperature shows any tendency to rise more ice is added. Under the most favorable circumstances the temperature of the

*FIG. 63.-Modification of the Ostwald water-bath used by the writer for thermal death-point experiments. This consists of a porcelain-lined pot II inches in diameter at the top. This is filled with water kept in motion by a water-wheel turned by electricity. The heat is applied by means of a Friedburg burner and is controlled by Roux's thermo-regulator. Murrill's gas-pressure regulator is shown at the left. 
air in the bottom of the chest may be kept fairly constant for some days or weeks, but with marked external fluctuations of tenperature trustworthy results can be obtained only by constantly watching the box. What one needs for this work is a goodsized room kept at $0^{\circ} \mathrm{C}$., or a little below, in which thermostats may be installed at temperatures a little above freezing, e. $g$., $+2^{\circ},+5^{\circ},+7^{\circ}$, etc. It would then be very easy to determine the minimum temperature at which any organism will grow-as easy as it is now to determine the maximum. Different levels in the same room may afford constant and useful differences in temperature.

The thermal death-point, which is a purely arbitrary standard, depending on the age and kind of culture, its volume, and the length of exposure, as well as the temperature, is when properly determined not least valuable. The writer, following that one of Dr. Sternberg's methods which is easiest to carry out, uses ro cc. portions of moderately alkaline ( + Io or $+I_{5}$ ) peptonized beef-broth $t$ in test-tubes of uniform diameter ( 16 to $17 \mathrm{~mm}$.), inoculates from recent bonilloncultures with care not to touch the sides of the tube above the fluid, thrusts the tubes deep into the hot water, and exposes for ten minutes. All who make this test are urged to use standard alkaline beefbouillon (for all organisins growing well in this medium) and to linit the exposure to exactly ten minutes, so that easy comparisons may be made. The five minutes exposure which has been recommended by some authors is rather too short, since it only a little more than suffices to wann the fluid up to the required temperature. Inoculation while the tubes are in the bath and after the fluid has been brought to the required temperature is inconvenient and has no special advantage.

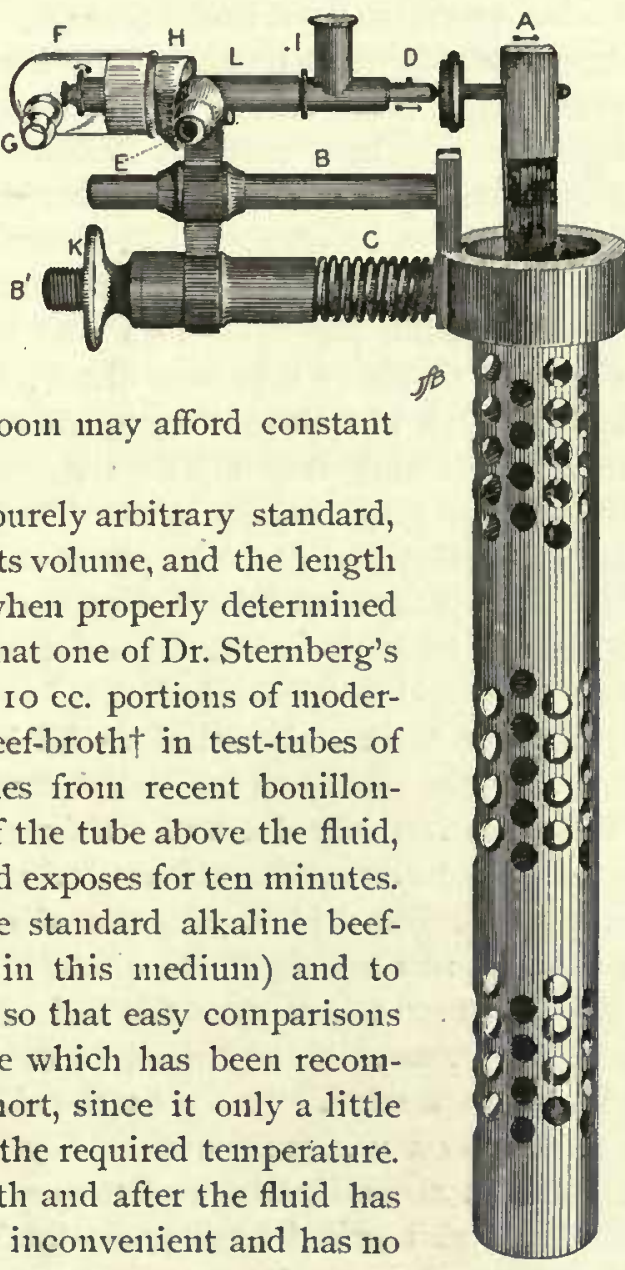

Fig. 64.*

*F. IG. 64.-Roux's thermo-regulator, made by Maison Wiesnegg (P. Lequeux), Paris. The parts requiring description are as follows: A, bar composed of two metals (which expand and contract unequally) attached at bottom and free at the top, which moves with increased heat in the direction of the arrow; B, arm on which the upper part of the apparatus moves freely when $\mathrm{K}$ is turned; $\mathrm{C}$, stiff spring; D, long rod which controls the gas-inflow, and the spring movement of which is in the direction of the arrow except when controlled by the counter movement of $A$, due to lessened heat; E, gas-inflow; F, gas-chamber, of glass; G, gas-outflow, to the burner; H, rubber stopper; $I$, cylinder screwing into $L$, and provided with capped upright tube filled with vaseline to prevent gas from escaping in the direction of D. The button shown in the gas-cliamber at the left is part of $\mathrm{D}$, and the gas enters the chamber between it and the left end of $\mathrm{L}$, the size of the opening, and consequently the amount of gas, varying with the slightest movement of A. Different temperatures are obtained by turning the button $\mathrm{K}$. The constant gas-flow is provided for by a small opening on the lower side of $\mathrm{L}$ at its extreme left, in the gas-chamber. About two-fifths actual size.

tThe thermal death-point in acid media is considerably higher-at least that of several organisms which have been tested in the author's laboratory. 
An excellent water-bath is that known as the Ostwald-Pfeffer. The experimenter may, however, construct one for himself ont of a mediun-sized, thickwalled, porcelain-lined iron kettle (fig. 63). This should rest on a ring of heavy strap-iron supported by four stont iron legs. The burner required may be Dr. Friedburg's safety burner (a very inexpensive and good pattern). The thermoregulator may be a common Reichert if the mercury seal is cleaned from oxide frequently. In such regulators a sliarper contact and a longer freedom from obstruction is said to be obtained (Dr. Harris) by putting a drop of olive oil on top of the mercury. A nuch better instrument is the metal-bar nechanism known as the Ronx regulator (fig. 64). This may be procnred fron the Maison Wiesnegg, in Paris. It should be kept from direct contact with the water and consequent rusting by burying it in a close-fitting glass tube filled with olive oil or glycerin. This tube is then sunk deep into the water and clamped to the wall of the kettle, which should have perpendicular sides. The water is kept in motion by means of a horizontal paddle-wheel at the botton of the kettle. This consists of four light, oblique zinc or copper vanes (nickeled copper is preferable) soldered to a long central rod which fits into a socket, below, and near its upper end passes through a lole or loop in a horizontal metal arm (a foot or less above the kettle), the other end of which is clamped to the upright rod of a solid iron tripod, or fastened to a rod bolted to the table. If compressed air can be had, a stiff cardboard windmill fastened to the upper end of the vertical rod completes the mechanisun. The central part of the windwheel may be of cork. Tlie vertical rod may be a piece of glass tubing, in which case it is cemented into a socket of the short metal post to which the vanes of the water-wheel are soldered. If a wind-wheel is attached, it is more convenient to have the vertical rod in two parts, fastened by a coupling. The rod, with its water-wheel attachment, may also be turned by some electrical device. The latter is the most convenient method. In fig. 63 the electric notor is not shown. This stands in a small box screwed to the under side of the table at the riglit. The switch is fastened to the wall above and back of the top of the thernio-regulator. The pulley band is of smooth rounded leather one-eighth inch in dianeter. The electric current is passed through an Edison lamp screwed under the table to reduce the velocity of the motion. With the lamp in place and the current cut down to the minimum the number of revolutions per minute is 55 , and the temperature of the water is the same in all parts of the bath. The simplest contrivance of all is to make the water-wheel and upright shaft of wood, to be turned by hand.

In localities where the gas-pressure is exceedingly variable, Paul Murrill's gaspressure regtulator (at the left in fig. 63) will be fonnd useful. This is made by Eberbach \& Co., Ann Arbor, Micl. (see Jounnal of Applied Microscopy, Vol. I, p. 92, or Centralb. f. Bakt., I Abt., Band XXIII, 1898, p. 1056.) The gas-pressure may be somewhat inproved by simply passing the gas through a big bottle (see top of thermostat 3 I I in plate 8). The Anschïtz normal thermometers, with long stem and scale divided into fifths, are very convenient for determining temperatures (fig. 65). They come in sets of seven, but may also be had separately. The most frequently useful are No. I (scale $-\mathrm{I}^{\circ}$ to $+55^{\circ}$ ) and No. 2 (scale $+45^{\circ}$ to + 105). 
They cost 9 marks each when ordered direct from Berlin, and can be had without delay. Good American thermometers are made by Henry Green, New York.

With this open bath it is easy to keep the range of temperature down to 0.I to 0.2 of a degree, and the writer has frequently exposed tubes for ten minutes without appreciable change in temperature. Temperatures may be read easily to o. I degree by means of a Zeiss aplanat lens magnifying six times (fig. 25), and should be recorded for each half ininute during the exposure. Under 110 circunstances should exposures be made in water which is not agitated. Of course, for accurate reading the eye and the center of the lens must be level with the top of the column of mercury. The lens may be supported at the proper level on a grooved piece of cork. If possible the thermometer used should be compared with some standard instrument. If not, it should at least be compared with several other good thermometers in the same laboratory. The test-tubes are supported by perforated corks thrust into holes bored through a rectangular piece of hard, heavy wood.

The writer formerly made use only of the first four tests. It seemed hardly worth while to recommend that all bacteria be tested for the killing effect of cold, so long as we had nothing but the inconvenient and inore or less inexact 111ethods of salt and pounded ice or of ether and frozen $\mathrm{CO}_{2}$; but now that liquid air may be obtained at a small price in many of the larger cities, can be shipped long distances, and can be 11sed with so little inconvenience, there is no good reason why the effect of freezing should not be determined in all cases, since in some instances it is likely to prove a valuable means of differentiation. The bacteria may be exposed in $5 \mathrm{cc}$. portions of distilled water or bouillon in block-tin test-tubes, or preferably in tubes of resistant glass, for standard periods, $e . g$., one-half hour, I hour, 6 liours, I 2 hours, 24 hours, 48 hours, etc. They may also be exposed to alternate freezing and thawing every fifteen minutes or thirty minutes until all are dead. To avoid endospores, the depressing effect of by-products, etc., young cultures should be used, and, of course, all should be of the same age and grown in the same medium, $i$. e., bouillon cultures 24 hours or 48 hours old. The tests should be quantitative rather than qualitative. They may be made as follows: Into $5 \mathrm{cc}$. of sterile water or standard bouillon a carefully-measured quantity, $i . e$, one loop, 5 drops, $1 / 2$ cc., etc., of the culture is placed, stirred very thoroughly, and allowed some time for diffusion. To avoid zooglœæ, which form early in sonne species, and to reach more uniform measurements, it is recommended to take the loop from a bouillon culture rather than from agar or other solid media. After sufficient time has elapsed for 11niform diffusion, six Petri-dish poured plates are made from each of the inoculated tubes. The plates should be of the same diameter (area of 60 sq. cm.). The an1ount of agar used for each plate should be ro cc., and the an11onnt of infec-

*FIg, 65.-Anscliütz normal thermometer with degrees divided into fifths (Centigrade scale). For use in thermal death-point tests. About three-fourths actual size. 
tious material used should be the thinnest obtainable filn of fluid across a carefullymeasured I mu1. loop, so as to avoid crowding the plates. The sane loop should be used in all cases, and it slould be dipped into and out of the fluid always in the same way. After pouring, set the plates on a perfectly level spot (fig. 66), 11ntil the agar has hardened. If the work has been well done, there should develop an approxinately uniform number of colonies in each plate. The tubes of inocnlated water or bonillon are then inmediately lowered into the liquid air and exposed to it for the predetermined time, after which six additional Petri-disl poured plates, of the same size and inoculated in the same way, are made from each tube for comparison with those prepared before the exposure. The tubes may be thawed out by exposure to the air for three minutes and then to tap-water for five to seven minutes. The exposures are best made in Dewar glasses (fig. 67). When the exposures are long, a loose tuft of absorbent cotton should be placed in the inouth of the glass, or it should be covered with a hair-cloth cap; to prevent excessive

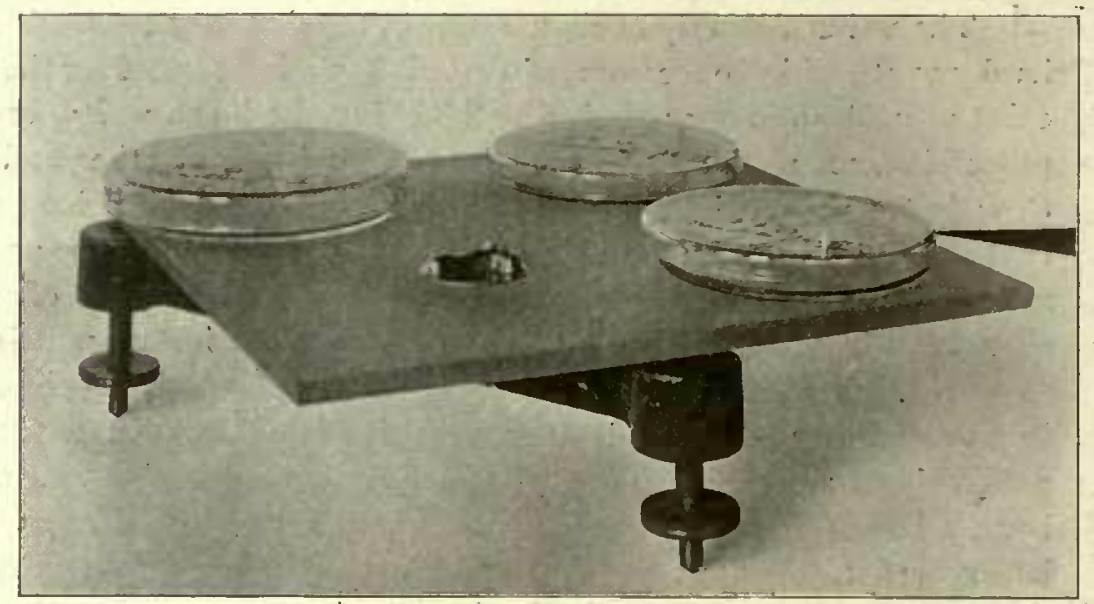

Fig. 66.*

evaporation. Under these conditions the air remains liquid for a number of days. At first the temperature is about minus $190^{\circ} \mathrm{C}$, rising gradrally to minus $180^{\circ} \mathrm{C}$, since the nitrogen evaporates somewhat faster than the oxygen. The glasses are fragile and should be handled carefully, especially when filled with the air. As long as they contain liquid air it is safer to keep them in their containing-case, packed about with cotton or felt. One should be careful to avoid cracking the inner wall of the glass, as might happen by dropping some hard substance into the receptacle, otherwise an explosion will occur, the space between the two walls of the Dewar glass being a very perfect vacuun11.

When the exposures are made in block-tin tubes, the culture should be frozen at once on pouring into the tube and the second set of plates should be made as soon as the fluid has thawed, i.e., within about ten minutes, for whicl purpose the culture should be poured out in to a glass tube, otherwise complications due to

*FIG. 66.-Leveling (nivelling) apparatus for use in making poured plates. About one-third actual size. 
the germicidal action of the nietal might arise. In no case should the cultures be incubated in the tin tubes. When exposures are n11ade in test-tubes of resistant Jena glass, the cultures must be lowered into the liquid air gradually, the fluid being frozen from the botton upward to avoid cracking the tubes. It requires about four 111intes to properly freeze a culture in a glass test-tube. Large volumes of culture nedia should not be lowered into the liquid air, as it is wasteful, the air boiling away rapidly. The writer began his experiments witl block-tin tubes, as shown in fig. 67 , but now uses tubes of Jena glass. The latter crack occasionally in spite of care.

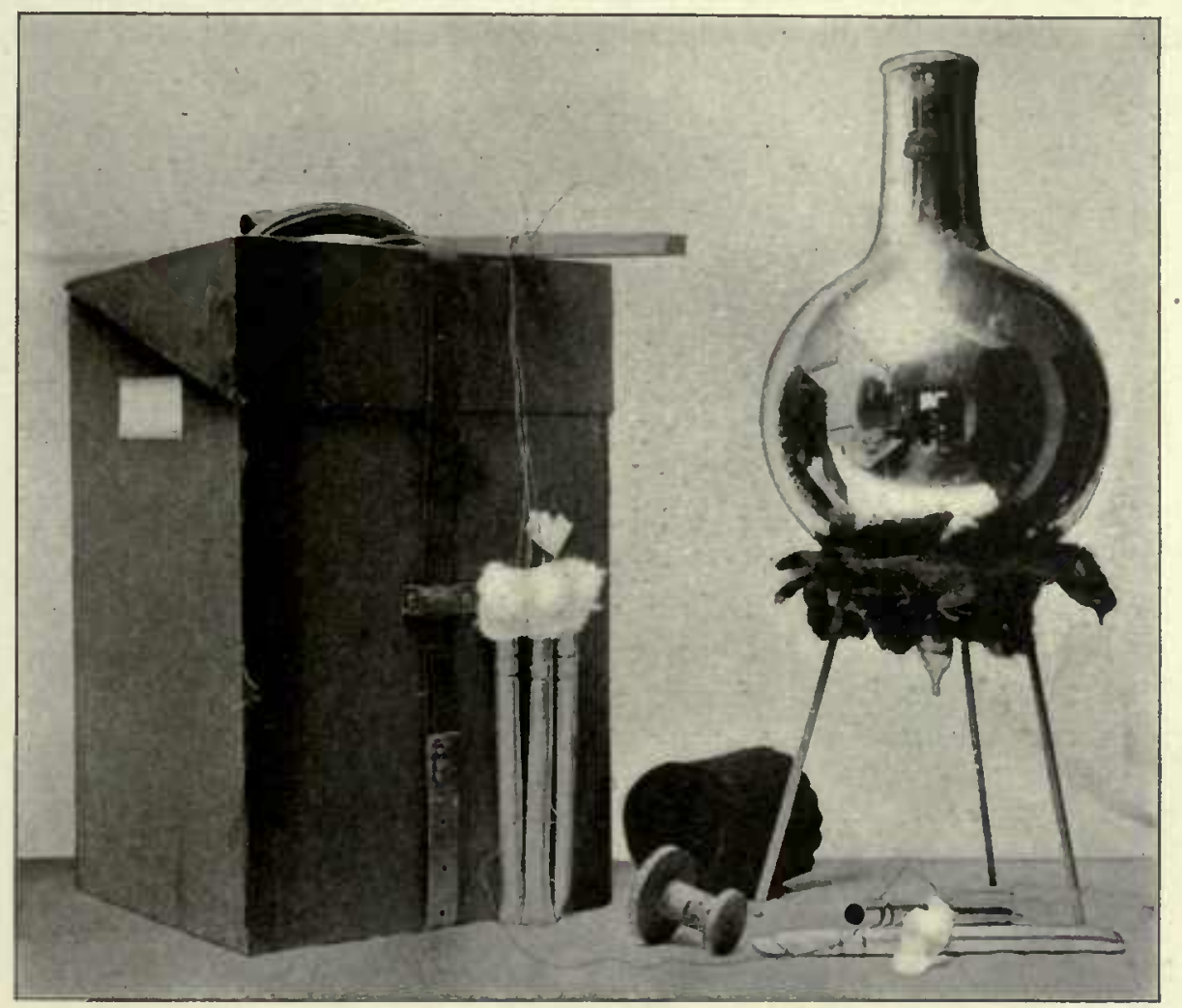

Fig. 67.*

For very rapid freezing the anount of fluid in the tube may be reduced to I cc. Liquid air in Dewar glasses, and compressed oxyge11, hydroge11, and carbon dioxide (?) in steel cylinders 111ay be had from the Eagle Oxygen Conpany, Incorporated, I 2 I West Eighty-ninth Street, New York City. The tanks of compressed gases may be bought or rented. The following sizes may be had: Fifty gallous (28o pounds pressure per square incli); Ioo gallons (240 pounds pressure); I50 gallous (225 pounds pressure); and 200 gallous (280 pounds pressure). Cylinders may also be had with the gas under much greater pressure. The cost of the oxygen is $2 \mathrm{l} / 2$ cents

*FIG. 67.-Dewar glass for liquid air, and block-tin test-tubes used in first low temperature experiments with bacteria. About one-sixth actual size. 
per gallon. The wrouglit-steel cylinders cost abont \$io each. A good quality of resistant-glass test-tubes may be had from Greiner \& Friedrichs, Stützerbach, Gernnany. One sort has a faint-blue longitudinal stripe blown into the glass, another kind has the letter " $R$ " etched on the upper part of each tube. Tubes without any distinguishing mark should not be purchased, as they are likely to become mixed with ordinary non-resistant tubes. The cost of these tubes, duty free, is about \$16 per thousand. Good Petri dishes may be obtained from the same firm, and also from E. H. Sargent \& Co., Chicago.

The temperature deniands of bacteria are extren1ely variable. Whole gronps of them are able to live under conditions which would be in1possible for the lighler

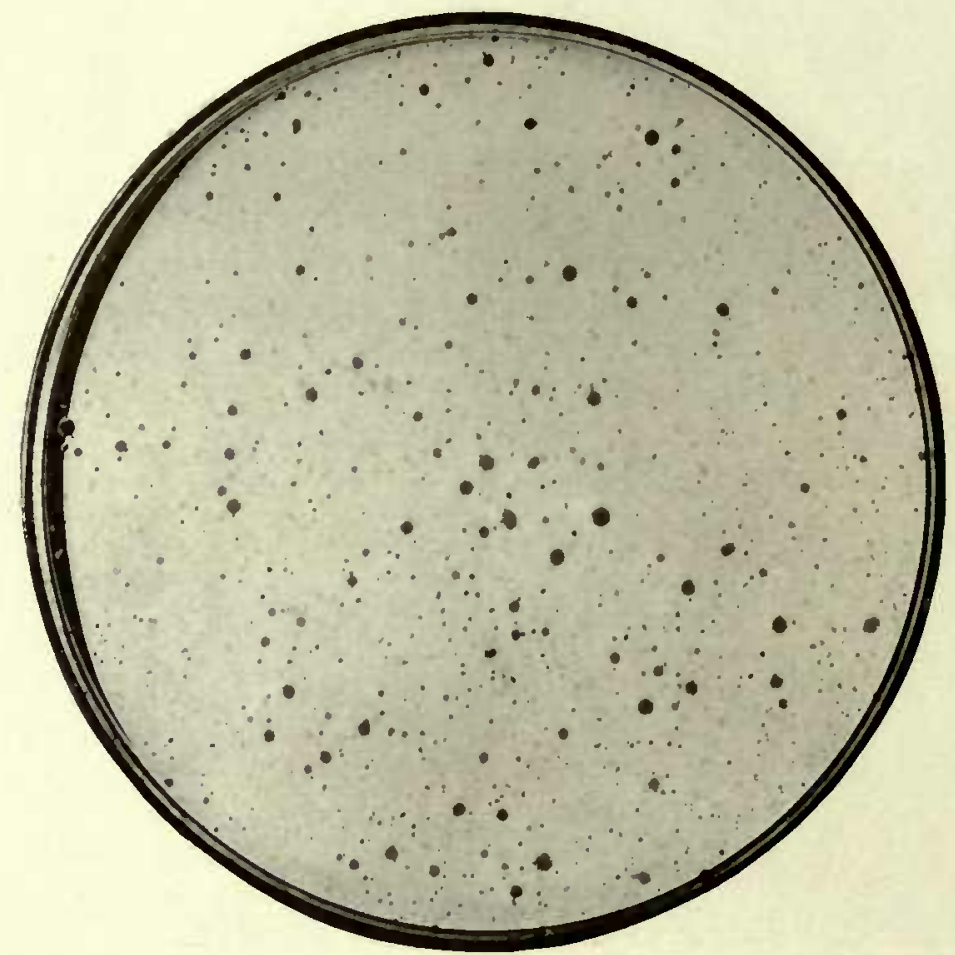

Fig. 68.*

plants and animals. Many of the northern forms, especially those which grow in water, are adapted to low temperatures. The organisuns of ding-lieaps and thermial springs, and the tropical forms, often grow at higli temperatures.

For a very few species it lias been known that prolonged freezing or repeated freezing and thawing destroys the weaker individuals and finally all. (See Bibliog., XXXIII, especially papers by Sedgwick \& Winslow, and by Park; consult also an earlier paper by Prudden, Bibliog., XLVI.) For the bacteria as a whole, however, it las been assuned that ordinary freezing or even very intense cold simply inlibits

*FIG. 68.-Petri-dish poured plate of Bacillus tracheiphilus. The ro cc. of nutrient agar was inoculated with a carefully measured loop of a fuid culture. The fluid culture was then exposed in block-tin test-tubes to the tempcrature of liquid air, after which another plate (fig. 69) was made. 
growth for the time being. Such statements have been based on certain qualitative tests and do not tell the whole truth. In the writer's experiments with liquid air great differences have been detected, the reduction by exposure for one-half hour varying from 15 per cent, or less, to 90 per cent, or more, according to the species tested. Fully 50 per cent of many sorts, grown in bouillon, are destroyed by a single short exposure (see figs. 68 and 69). Query: Is intense cold any more harniful to bacteria than simple freezing? Are young or old cultures most susceptible? Are they killed by the rupture of the cell-wall due to the formation of ice-crystals, or sinnply by the abstraction of water? Why do sone resist several freezings? Can endospores be killed in this way? Consult 'OI, d'Arsonval (Bibliog., XXXIII) and

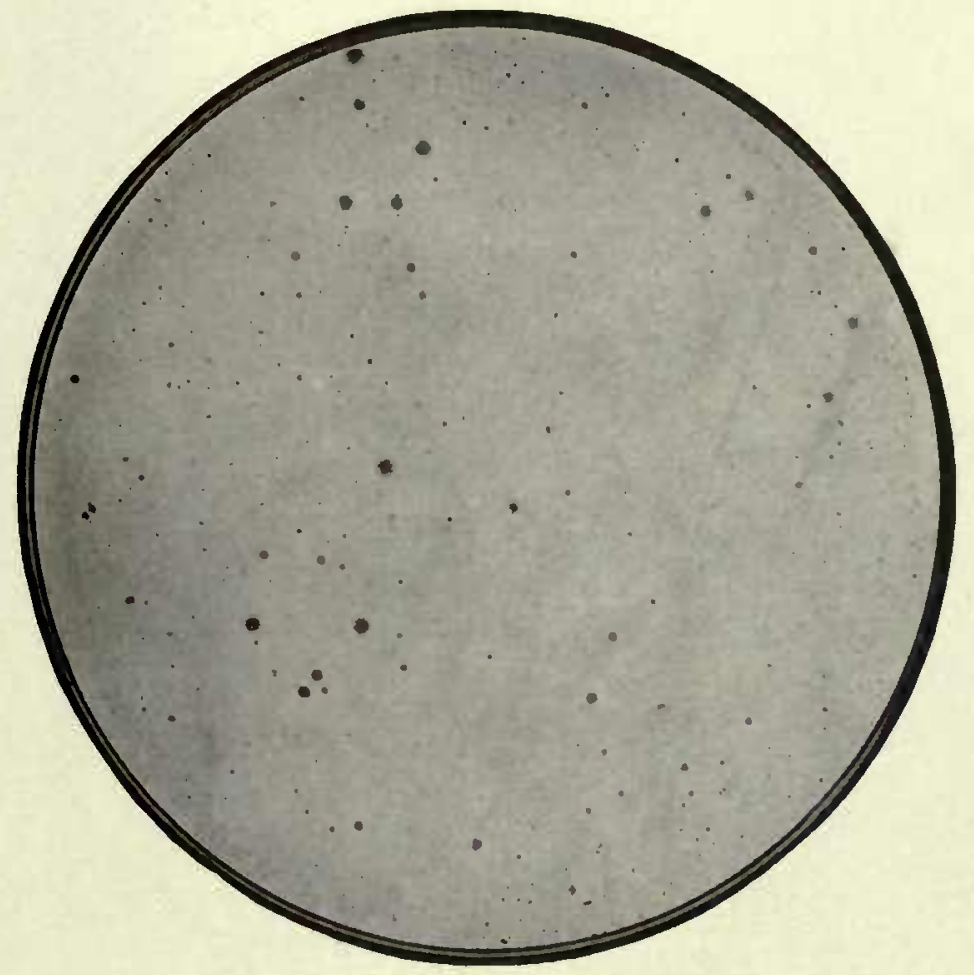

Fig. 69.*

Smith \& Swingle, the Effect of Freezing on Bacteria, Proc. Sixtl An1. Meeting Soc. Am. Bacteriologists, December 27, I904; Science, N. S., Vol. XXI, I 905, pp. 48I-483. For opposing views see 'o2, Macfadyen, Bibliog., XXXIII.

Live steam acts upon the growing bacteria very quickly. All bacteria not in spore form, or in some other way protected from the direct action of the heat by what surrounds them, are promptly destroyed by steam lieat at $100^{\circ} \mathrm{C}$., an exposure of a minute or two being ample, except, possibly, in case of some of the thermo-

*Fig. 69.-Same as fig. 68, but made after exposture for twenty hours to liquid air. Number of colonies reduced two-thirds. Exposed in test-tubes of Jena-glass for one-half hour, the reduction was nearly as great, $i . e$., over 50 per cent. In this latter case the agar plates were incubated 7 days at $30^{\circ} \mathrm{C}$, before the count was made. 
philic species. Usually even the most resistant spores, if freely exposed, are destroyed by one to two hours exposure to $150^{\circ} \mathrm{C}$, of dry heat, or by thirty minutes exposire on each of three consecutive days to streaming steam at $100^{\circ} \mathrm{C}$. Some very resistant spores have survived a single steaming or boiling of five or six hours duration (eight hours in one of Tyndall's experiments), and it is not unlikely that son1e. slowly germinating sorts may be able to resist discontinuous steanings for three days. It is possible also that there may be some sorts able to germinate and again assume a resistant spore form in less than twenty-four hours although this is not probable. Some spores are destroyed by a short boiling at $100^{\circ} \mathrm{C}$., and all spores are quickly destroyed by stean under pressure, i. e., in an autoclave. A

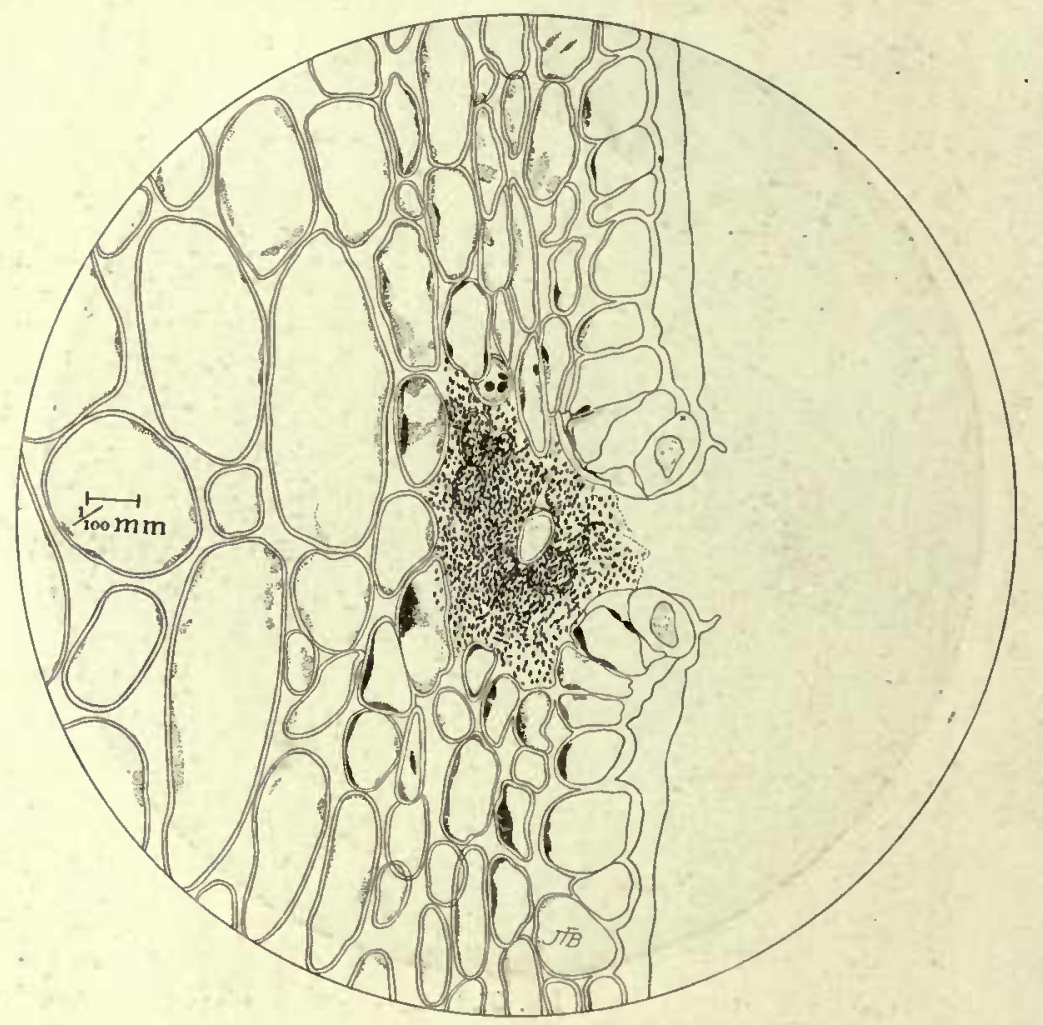

Fig. 70.*

temperatire of $1 \mathrm{IO}^{\circ} \mathrm{C}$. for ten or fifteen minutes is sufficient. Exposure of media to higher temperatures and for longer periods should be carefully avoided. It m111st be remeinbered, however, in using autoclaves, that all of the air must be replaced by steain before the apparatus is closed, otherwise the temperature to which the 111ediun is exposed will not correspond to that indicated by the pressure gage. The -nost convenient autoclaves known to the writer are the large sizes of the

*FIC. 7o.-Earliest stage of fruit spot on green plums, due to Bacterium pruni (Erw. Sm.). 'The bacteria have entered through the stoma. They disappear farther in, and also a few micra to either side of this stoma, as shown by an examination of the serial sections. Material fixed in strong alcohol, infiltrated with paraffin, and cut on the microtome in series. Section stained with carbol-fuchsin and drawn directly from the microscope with the aid of a camera lucida. 
PLATE 9.

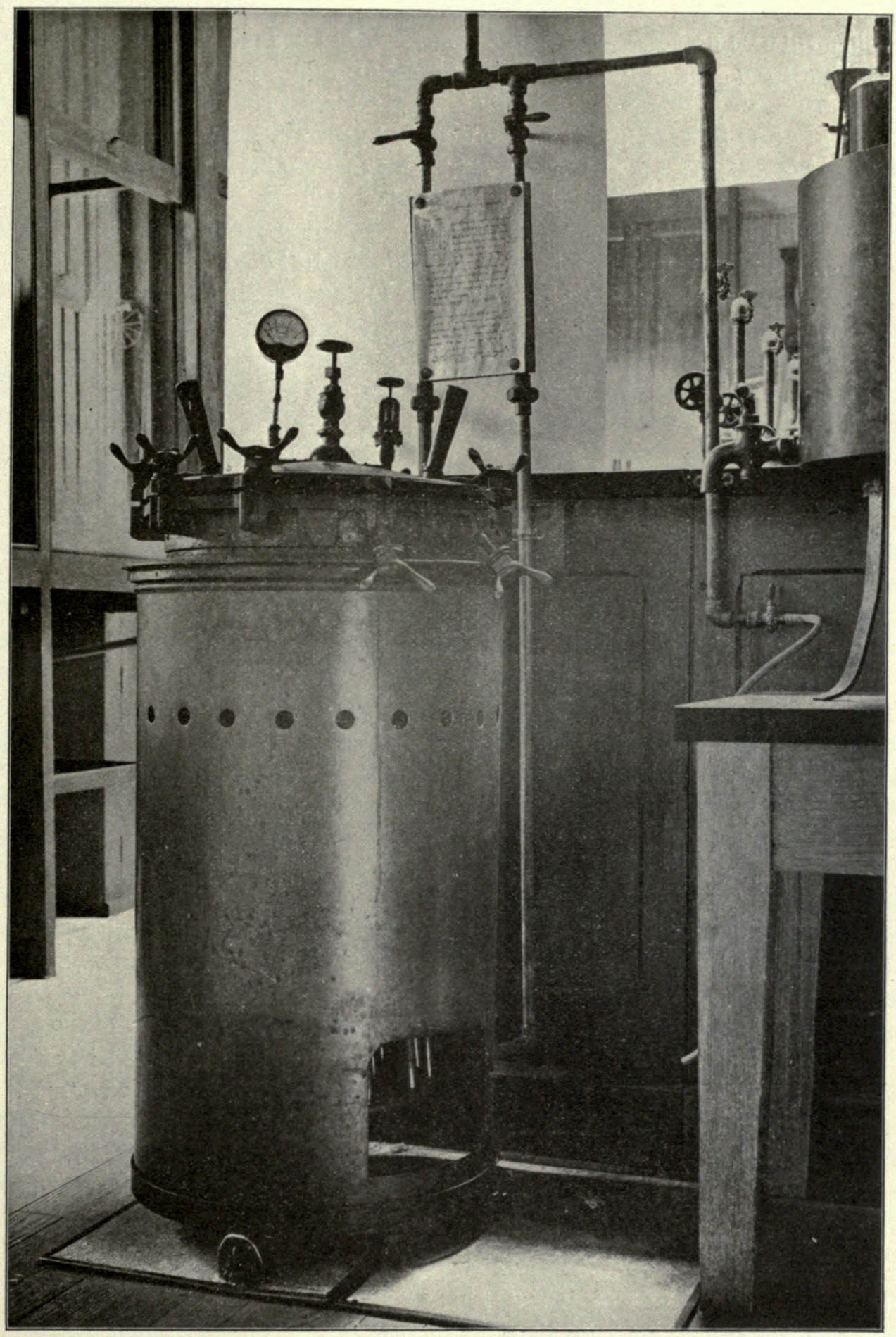

Chamberland autoclave.

Heat is applied to the bottom by means of a double ring of Bunsen burners. No wrench is required for fastening on the top. About one-eighth natural size. 
ambls 
pattern designed by Clamberland and made by the Maison Wiesnegg (P. Leqneux), Paris, France, the stean being generated by gas (plate 9). The stean gage is at the left; in the middle is the valve through which the hot air is allowed to escape when the instrument is warmed up; at the right is the stean safety-valve. The temperature is manipulated by regulating this valve. By leaving the vent open the apparatus may be used as an ordinary stean sterilizer. It may also be used as a distilled-water apparatus by attaching a condenser to the exit pipe of the middle vent, but such water must not be used for culture media. A very good antoclave is also made by the Kny-Scheerer Co., New York. Harding recommends for antoclaves the use of steam from the engine-room boiler. This is convenient, provided one can always have steam ready during the summer months. An autoclave, like a stean boiler, which it is, must be watched carefully if it is not some time to explode from excess of heat or lack of water. Each time before use one should see that the apparatus contains sufficient water.

Soils are rather difficult to sterilize. They may be spread in thin layers and dry-lieated for several hours at $150^{\circ} \mathrm{C}$., or may be heated in the autoclave for an hour under a pressure of two atmospheres, taking care to drive all the air out of the soil before closing the apparatus. It is not likely, however, that soils can be treated in this way without undergoing certain physical and chemical changes. Small pots of soil may be heated in the steamer at $100^{\circ} \mathrm{C}$. for two hours on each of five successive days.

The reason for preparing all media in the autoclave, or by heating in the steamer at $100^{\circ} \mathrm{C}$. on three successive days (the ordinary way), is because we are never certain in what particnlar case resistant spores may be present. One short steaning is often sufficient to sterilize media prepared in a cleanly way, as every bacteriologist knows who has had much experience, but now and then, in spite of all care, resistant spores will find their way into culture media, and for this reason it is best in all cases (especially in teacling students) to adhere to a routine of tliree steamings. Large masses of fluid (beakers, flasks) require longer steamings than test-tube cultures. The writer gives double time, or triple time. Discontinuous boiling as a means of sterilization was introduced in 1877 by Tyndall, who well says respecting the sterilization of liquids: "Five minutes of discontinnous leating can accomplish more than five hours continuous heating."**

Most plant-pathogenic bacteria of temperate and cold regions have a lower optimum and maxinum temperature for growth and a lower thermal death-point than species pathogenic to warm-blooded animals. The naximum temperatnre for growtl is usually at or below $36^{\circ} \mathrm{C}$. We should not, lowever, expect this to be true of bacterial plant parasites in tropical and sub-tropical regions, abont which, however, little is known beyond the mere fact that such parasites occur. Savastano states that the optimum temperature for the olive-knot organism, which is said to be more prevalent at the sonthern than at the northern limit of olive-growing,

*This method appears to have been known to housewives for a much longer time. In Dr. Samuel Johnson's Dictionary (first Am. from eleventh London ed.) I find the following definition: "Biscuit, A kind of hard, dry bread made to be carried to sea. It is baked for long voyages four times." 
i. e., commonest in southern Italy, Sicily, and Algeria, lies between $32^{\circ}$ and $38^{\circ} \mathrm{C}$. In my own experiments witl this otganism, obtained from olive trees in California, I lave found its maximum temperature to be above $35^{\circ}$ and below $37.5^{\circ} \mathrm{C}$. The optimum temperature of Bacterium solanaccarum, which is very destructive to potatoes and tomatoes in the southern United States, is probably about $35^{\circ} \mathrm{C}$. - at least it grew readily and remained alive for a long time in bonillon kept at $37^{\circ} \mathrm{C}$. Its maximum temperature is $39+^{\circ} \mathrm{C}$. Bacillus carotovorus, one of the best known of the soft-rot organisms, grows well in the thermostat at $33^{\circ}$ to $34^{\circ} \mathrm{C}$. Its maxiinn1111 temperature is at $39^{\circ} \mathrm{C}$. or slightly below (Jones). Bacillus aroidece, whose temperature relations were recently studied carefully by 'Towusend, has a maximu11

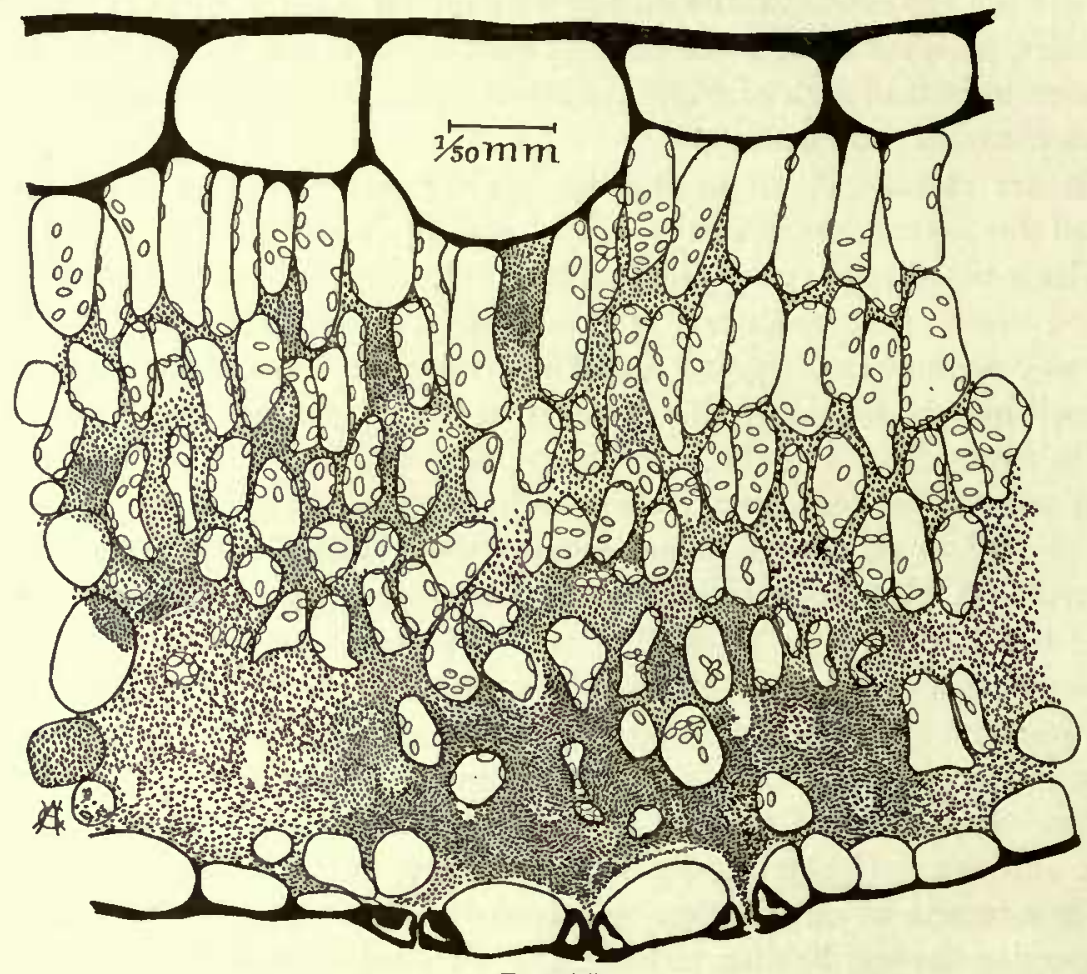

Fig. 71.*

temperature of $4 \mathrm{I}^{\circ} \mathrm{C}$. A temperature of $40^{\circ} \mathrm{C}$. retards growtli, but does not prevent it. This organism was isolated from calla-lily corms, but is capable of cansing a soft rot in potatoes, carrots, turnips, and many other plants (fig. I02). The maxiinuin temperature of Bacillus oleraceac, recently described by Harrison, is said to be about $42^{\circ} \mathrm{C}$. This causes a soft rot of caulifiower.

The range of temperature suited for the growtl of particular bacteria varies greatly. Some species are able to grow through a range of $50^{\circ} \mathrm{C}$. Many tolerate a range of only about $30^{\circ} \mathrm{C}$. Certain animal-pathogenic forms have throngl long subjection to a peculiar enviroument become restricted to a still narrower range.

*FIG. 71.-Bacterium pruni. Early stage of a leaf-spot in the plum. The small spot was watersoaked in appearance, but it had not yet collapsed. The bacteria, which are most abundant in the mesophyll, undoubtedly entered the lcaf through the stomata, three of which are shown in the section. Material treated as in fig. 7o. Section drawn with the aid of an Abbe camera. It represents as nearly as possible one plane. 
Some bacteria grow well only in the cool box, others only in the thermostat at blood-heat or at higher temperatures,-temperatures elevated enougli to quickly destroy the unprotected protoplasm of the ligher plants and aninials. Few of the bacteria commonly studied will grow at temperatures much above $40^{\circ} \mathrm{C}$., but this by 110 means expresses the whole truth.

The lowest temperature at which growtl will take place ranges in different species all the way from $0^{\circ} \mathrm{C}$, and probably a few degrees below (certain salt-water bacteria) to $+40^{\circ},+50^{\circ},+56^{\circ}$, and even $+60^{\circ} \mathrm{C}$. (certain thermoplinic species found in dung-heaps, hay-1nows, silos, hot springs, etc.). The highest temperature at which growth will take place ranges from as low as $30^{\circ} \mathrm{C}$. (and probably lower*) to as high as $75^{\circ}$, or $80^{\circ} \mathrm{C}$, or even $89^{\circ} \mathrm{C}$, according to Setcliell. Higher temperatures liave been recorded, but I have liere used only those deternined with care in the exact places frequented by the bacteria. This will be better appreciated if it is remembered that a temperature of $60^{\circ} \mathrm{C}$. $\left(140^{\circ} \mathrm{F}\right.$.) can be endured by the fingers only a few seconds, while $70^{\circ} \mathrm{C}$. (the optinnum for some of these species) is intolerable to the hand even for the shortest period. It seenis incredible, on first thouglit, it is so opposed to our customary observations, that any organism whatsoever sliould be able to live at a temperature only II degrees below the boiling point of water Nevertheless, protoplasm is an extremely adaptable substance, and it is conceivable that some organisms niglit grow at a temperature considerably higher.

The thermal death-point (Io minutes exposure) ranges from $43^{\circ} \mathrm{C}$. for Bacillus tracheiphilus, the lowest yet recorded, $\dagger$ to temperatures only a few degrees under the boiling point $\left(\mathrm{IOO}^{\circ} \mathrm{C}\right.$.). For many species the thermal deatli-point lies between $50^{\circ}$ and $60^{\circ} \mathrm{C}$. Russell \& Hastings have recently discovered in 1111lk a Micrococcus whose therriral death-point is $76^{\circ} \mathrm{C}$.

As the upper and lower thermal boundaries of growth are approached some functions are extinguished in advance of others; $e . g$. , pigment production, pathogenicity, and sporulation disappear considerably in advauce of loss of power to reproduce by fission.

\section{OTHER HOST PLANTS.}

Plants of related species, genera, and families should be tested. If the disease appears to be new to literature, it is also especially important to inoculate tlose plants which have been reported to be subject to bacterial disease and the nature of which disease is still in doubt. Many facts of scientific and economic interest will be brought to light in this way, and now and then the experimenter n11ay be able to clear away some of the fog which, owing to the uncertain and contradictory statements of a majority of our plant pathologists, still hangs over the origin and nature of most of these diseases.

Some plant pathogenes appear to be quite narrowly restricted. They attack only one host plant, or at most a few hosts belonging to related species or genera. Others, particularly some of the soft-rot bacteria, attack many kinds of plants belonging to widely different families. The history of pear-blight, however, slows us that

* Since this was written Molisch states (1. c., p. 93) that gelatin cultures of his Bacterium phosphorcum were dead at the end of 48 hours when exposed to a temperature of $30^{\circ} \mathrm{C}$. The maximum temperature of this organism is said to be about $28^{\circ} \mathrm{C}$.

+Very recently Marsh has found a fish parasite which is said to have a thermal death-point of $42^{\circ}$ C. (See VI, Bibliography of General Literature.) 
the restriction of an organisin to a single host-plant 111ay be only an inference based on insufficient observation rather than an actual fact. After a tine the apple and quince were added to the pear as host-plants, and now we may add also the plum and the loquat.

\section{PATHOGENIC OR NON-PATHOGENIC TO ANIMALS?}

If the organism will not grow in the thermostat at $37^{\circ} \mathrm{C}$, or grows only feebly, as is the case witl many plant parasites, it may be assumed to be non-pathogenic to animals with warm blood. Only those organisms which grow readily in the thermostat at $37^{\circ} \mathrm{C}$, and which closely resemble animal-pathogenic forms or which are suspected of causing some particular disease of animals, need be tested

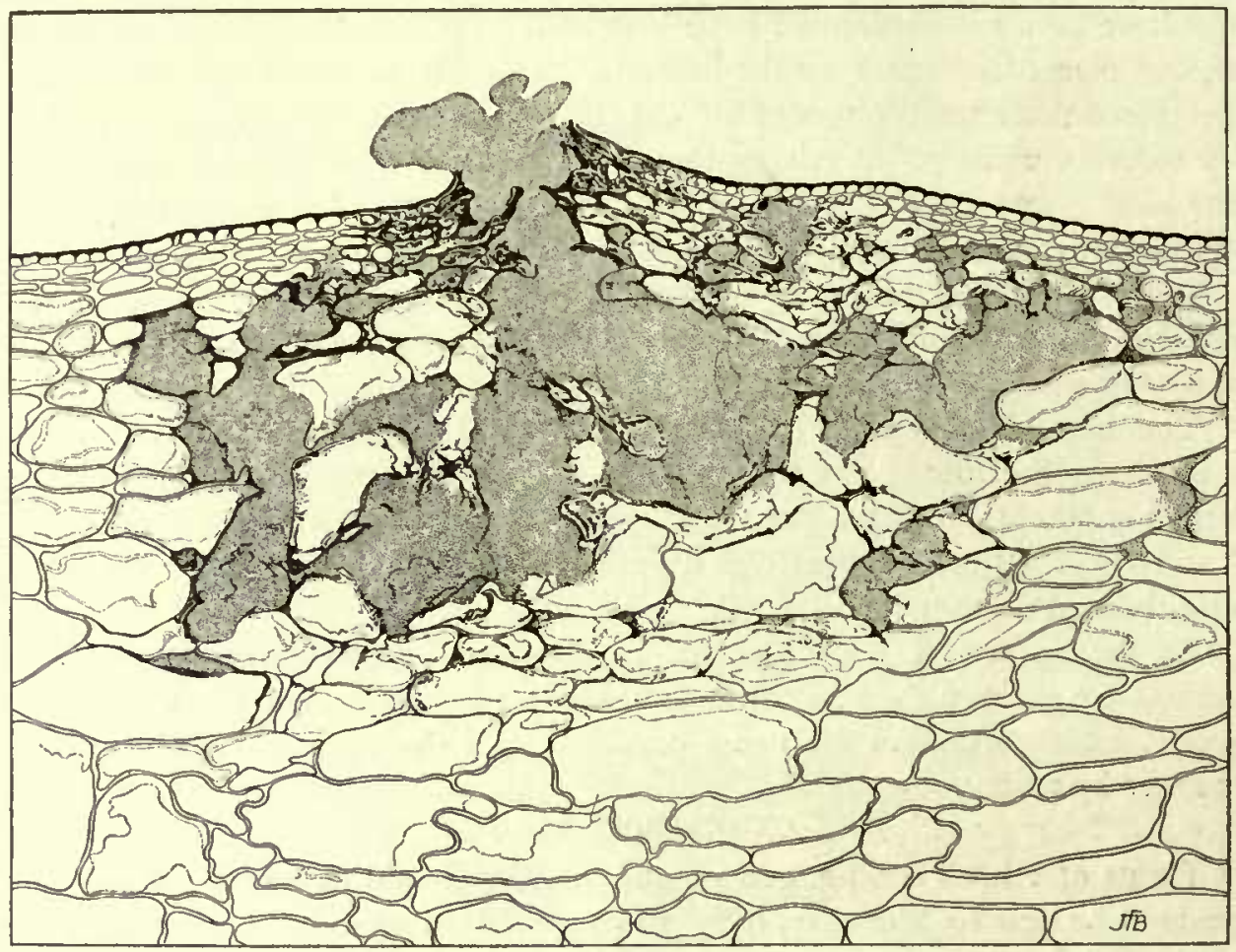

Fig. 72.*

by animal experimentation for economic purposes. In general, it is best to leave this part of the work to the animal pathologist, for the san1e reason that the more abstruse chemical problems are turned over to the cliemist.

All of the plant-parasitic bacteria, so far as tested, liave turned ont to be nonpatlogenic to warm-blooded animals, but it is not unlikely that some exceptions may be discovered.

Another question, of special interest to animal pathologists, arises here, 11amely, whether forms known to be pathogenic to aninuals and especially to man are ever

*Fig. 72.-Bacterium pruni. Vertical section through a green plum fruit (var. Hale) showing bacterial cavities and the escape of the organisms through the ruptured stoma. In this case beyond doubt the central stoma is the one through which the infection originally took place. Drawn from a photomicrograph. The material was fixed in alcohol, infiltrated with paraffin, cut on the microtome, and differentially stained. 
liarbored by plants. Of those known to canse animal diseases none liave ever been found naturally present in plants, but some of them, sucl as the typhoid bacillus, the anthrax organism, etc, have been shown to live for a number of days or weeks when injected into varions living plants, and in some instances have been found to multiply a little in the vicinity of the wounds. In general, their life is short in sucl situations, they do not penetrate far into the tissues, and they are

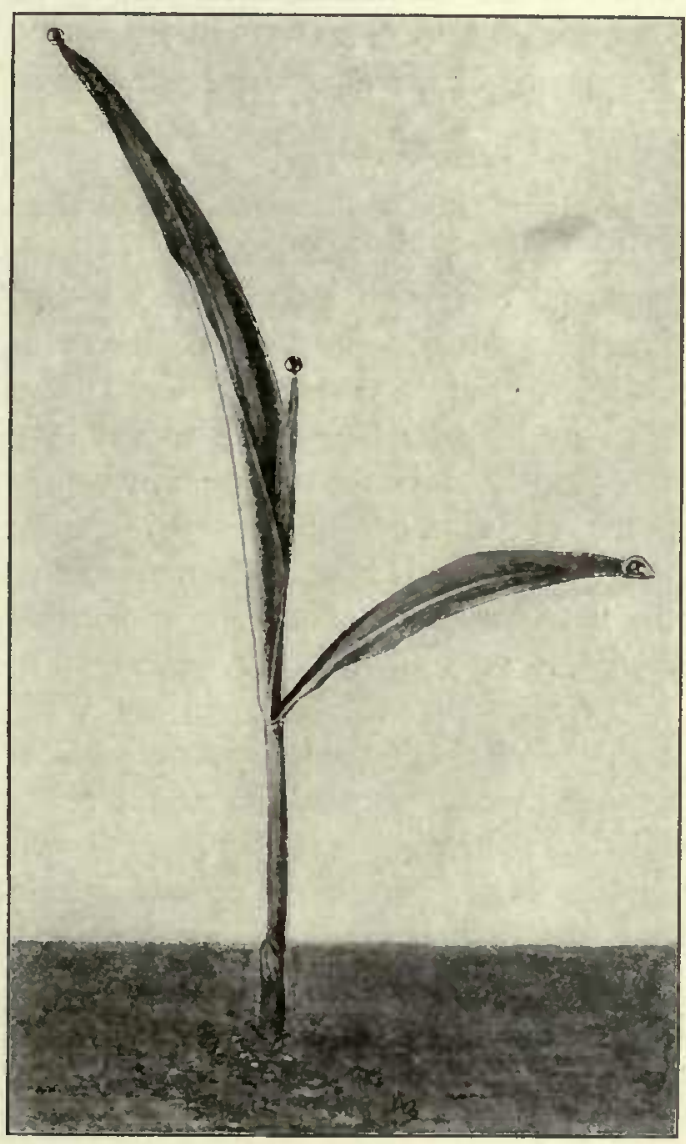

Fig. 73.* manifestly on the defensive. If they can do no better when injected into vegetable tissues in enormons quantities, it seems rather unlikely that under ordinary natural conditions they wonld find their way into plants so as to make then dangerous for food. In this connection the reader is referred to Volume II, where this subject is discussed more fully. More danger is likely to result from pathogenic organisms carried on the surface of plants, especially on salads and fruits whicl are not cooked. In times of the general prevalence of typhoid fever, cholera, or the bubonic plague, the writer for one would certainly prefer to forego salads and to eat only freshly cooked vegetables. The danger from such foods in time of epidemics is very great, especially in localities wliere ditch-water is frequently sprinkled on the vegetables to freshen them, e. $g$., in parts of southern Italy.

Most saproplytes when injected into living plants behave in the same way as the animal parasites, i. e., they either die at once or maintain a precarious existence for some weeks in the vicinity of the wound and then succumb. The writer has made many experinents, witl negative results. The most extensive published series of experiments are those of Zinsser (Jahrb. f. wiss. Bot., I897). To get a particular disease, the parasite must be used and not some other organism. This the writer has observed over and over again. This statement holds good with plants the same as with animals. In case, however, of the less typical plant diseases (soft rots) varions 111enbers of a group of closely related organisnis 111ay produce essentially similar phenomena. This is paralleled, lowever, in certain of the less typical animal diseases.

*FIG. 73.-Seedling swect-corn plant extruding water from its leaf-tips. Most of the infections by Bacterium Stewarti take place during this stage of growth, the bacteria passing down the leaf through its vessels and entering the stem through the lower nodes. Natural size. 


\section{ECONOMIC ASPECTS.}

The econonic aspects may be considered under four heads: (I) Losses; (2) Natural nrethods of infection; (3) Conditions favoring the spread of the disease;

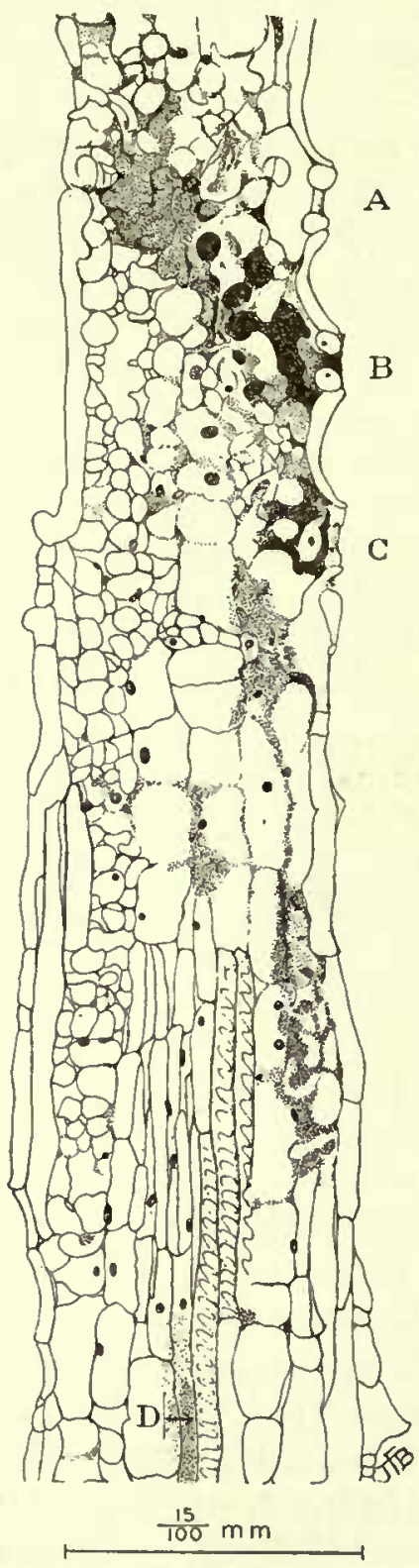

Fig. 74.*
(4) Methods of prevention.

In the United States Department of Agriculture and in our State Experiment Stations, naturally, much stress is laid on economic considerations, especially on 2, 3, and 4. A knowledge of 2 and 3 will frequently lead to some simple and effective means of prevention.

\section{LOSSES.}

It is desirable that there slrould be made from time to time a careful estimate of the losses caused by each particular disease, not only as a warning to farmers, fruit-growers, 111arket-gardeners, and florists of the existence of these dangers, but also as an aid to legislatures and governments in deciding how much money may be judiciously appropriated for the scientific investigation of these problems. Pathologists are urged to make and publisli such records. It is perhaps nunecessary to add that the determinations should be reasonably accurate, otherwise it were nunch better not to make any records. Occasionally, when diseases are widespread and destructive, so that depreciation of land values and the hostility of a community might result from great publicity, the pathologist may have to consider discretion the better part of valor and refrain from publishing, but in this event he slould not fail to make full records which may subsequently be published or at least consulted. What we need and inust finally have is a large body of accurate statistics, covering a series of years, 1nany localities, and many diseases. To make these statistics most useful, certain meteorological data should be collected in tlie same localities. To be of most service this data concerning the weather should be recorded by the pathologist himself, who will be better able than anyone else to note down just those things likely to influence the hostplants favorably or unfavorably. Some of these things

*Fig. 74.-Bactcrium Stcwarti (Erw. Sm.) attacking sweet corn (Zca mays). The section was cut from the extreme upper part of a seedling leaf which was fixed in strong alcohol six days after placing the bacteria on its tip. At the time of inoculation water was extruding from the leaf-tip, as shown in fig. 73. This figure represents a longitudinal vertical cut. The dotted and heavily shaded parts show the location of the bacteria which have entered through the ordinary stomata and have not yet penetrated the vascular system, although in places, as at $D$, they are close to the spiral vessels. At A, B, and C are three stomata. The substomatic chamber under $A$ is free. $B$, with its surroundings, is shown more highly magnified in fig. 75. Drawn with help of the Abbe camera. 
are cloudy weather (especially if prolonged), sunny weather, frequent or excessive fogs or dews, amount of rainfall, and frequency of rainfall, snowfall, hail, excessively hot weather, cold spells and frosts, droughts, daily maximum and minimum tenperature, prevalence of special diseases correlated with special peculiar conditions, absence of other diseases, etc.

\section{NATURAL METHODS OF INFECTION.}

Under this lieading the student should be on the watch for transmission of the disease throngh fungons or insect injuries, by mollusks, by birds or quadrupeds, and by the hand of man. Man contributes to the spread of diseases in various ways,

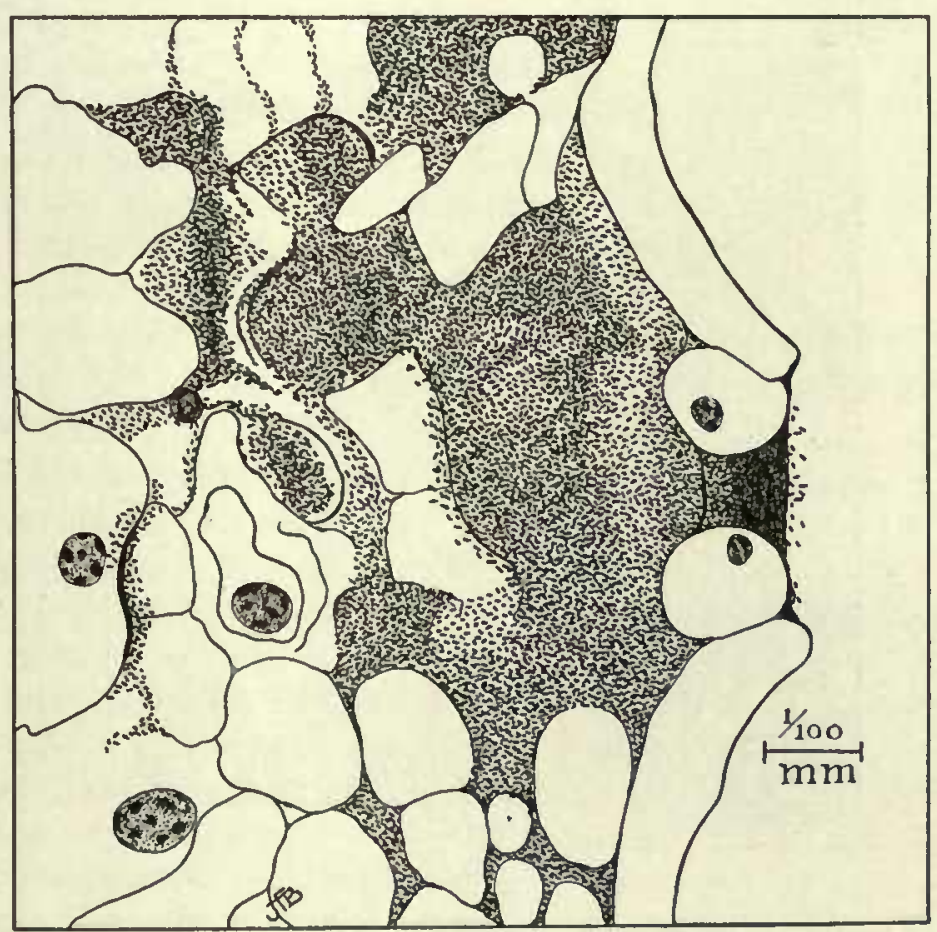

Fig. 75.*

e.g., by neglect to remove diseased plants, by use of infected knives and other tools, by the introduction of infected seeds, or manures, or soils, or water, and by subjecting his plants to a variety of depressing and unwholesome conditions.

A great variety of parasites find their home in the earth, the top crust of which swarms with bacteria and fungi. Sucl parasites are frequently introduced from one locality to another in infected soils adhering to wagons and other farm tools, to the feet of men and animals, to the roots of transported plants, etc. The soil is a living thing and it should not be transported even from one field to another on the same

*FIG. 75.-Bacterium Stcruarti filling the substomatic chamber and pushing out into the deeper tissues of a maize leaf. The result of an inoculation made by placing a small quantity of a pure culture on the tip of a sweet-corn leaf in the seedling stage. For orientation see fig. 74 . The globose bodies are nuclei, which are not enlarged (?). 
farm without due consideration of what may happen. Certain bacterial diseases might be distributed very readily in this way and good fields rendered worthless for certain crops.

The parasite may gain entrance to the plant through wounds (plates 2 and 4 and fig. 8) or by way of the stomata (figs. 70 to 75 ), lenticels, water-pores (figs. 76 to 79), and nectaries. In recent years the writer has discovered a number of very characteristic infections by way of the stomata and the water-pores, which are only modified stomata, e. $g$., in cabbage, unustard, plun, bean, soy-bea11, cotton (fig. 80),

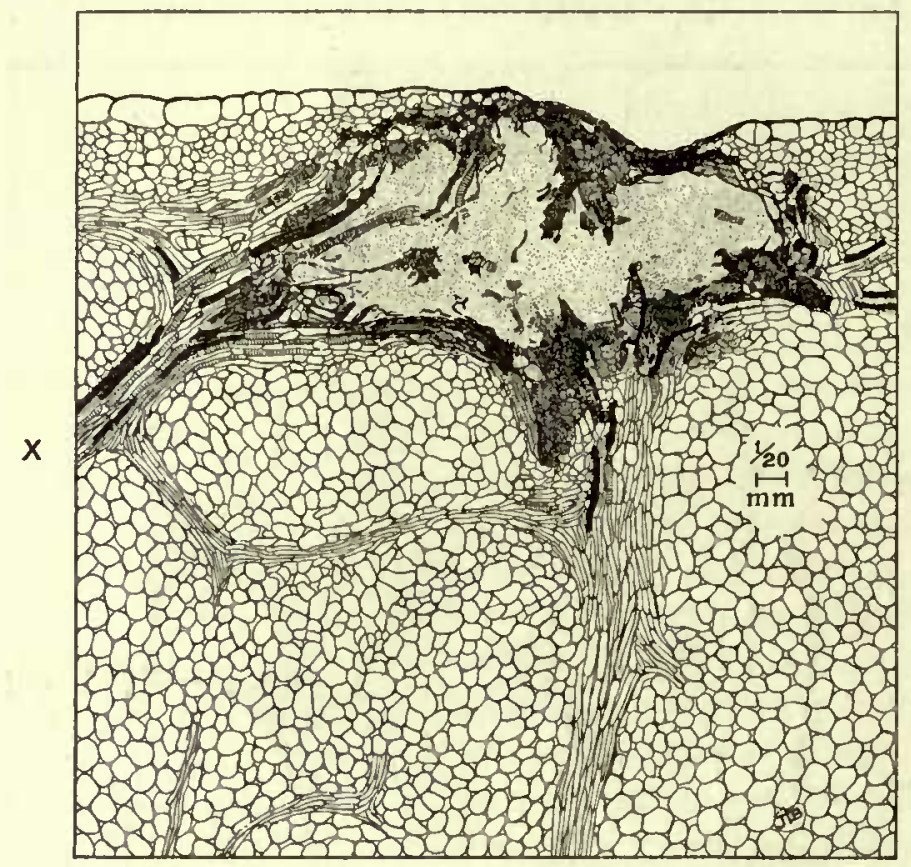

Fig. 76.*

pelargonitum, larkspur, broomcorn, sorghum, maize, cucumber; etc. Pear-blight affords one of the most striking examples of wholesale infection by way of the nectaries. The wilt of cucurbits affords an equally good example of infection throngh wounds-namely, leaf-injuries due to beetles.

*Fig. 76.-Bacterium campestre. Section of a cabbage leaf parallel to the surface and near the margin, showing the result of infection through the water-pores. The tissues are browned and destroyed. Immediately under the leaf-serrature a cavity has formed and the bacteria have begun to penetrate into deeper parts of the leaf by way of the spiral vessels, not all of which are occupied. This figure is slightly diagrammatic, but only to the extent of omitting the protoplasmic contents of the parenchyma cells and of introducing six occupied spiral vessels which belong to the next section in the series. No spiral vessels are visible in the lower part of the section because the knife passed just below them. Material collected on Long Island, July 16, 1902, and fixed in strong alcohol. The spirals here shown are a little too densely occupied by the bacteria to make a good drawing under the oil-immersion objective, but a little farther in (beyond $X$ ) they are less abundant and entirely satisfactory for this purpose. 


\section{Conditions Favoring the SPREAd OF THE Disease,}

The conditions favoring the spread of diseases may be wholly telluric, such as ligh temperature, unusual dronglit, cold weather, fogs, heavy dews, and excessive

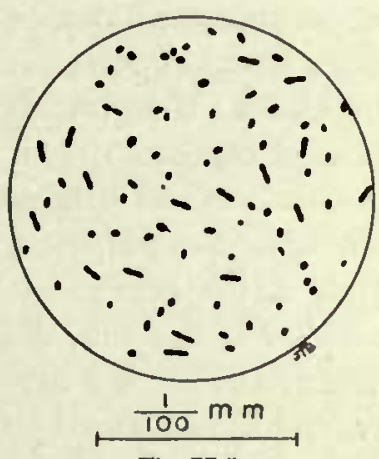

Fig. 77.* or continuous rainfall. These diseases n11ay be favored by lack of natural drainage, or may be brouglit on by a variety of causes which are largely within the control of the grower, such as selection of improper varieties, $i . e$, very susceptible ones, overcultivation, storage at too high teniperatures (in case of cabbage and root crops), the use of infected soils, or manures, or seeds, or plants, and, especially in lot-houses, by the mismanagennent of water and heat, and by the neglect to destroy the first diseased plants that appear and such transmitters of disease as insects and slugs, which frequently abound in hot-louses.

\section{Methods of PREVention.}

In case of certain diseases, copper fungicides have been found useful, $e . g$. , in walnut bacteriosis and some of the leaf spots, but in general we know as yet very little about bactericidal treatinents. In the early stages of an outbreak some of these diseases inay be controlled by extirpation of the affected parts, or by the removal of whole plants as soon as they show signs. Also, if possible, the conmon carriers of infection should be eliminated. Finally, one should not forget that the substitution of resistant varieties for susceptible varieties is one of the most lopeful methods for disposing of certain of these vexatious diseases. Whenever anything specially noteworthy has been discov-

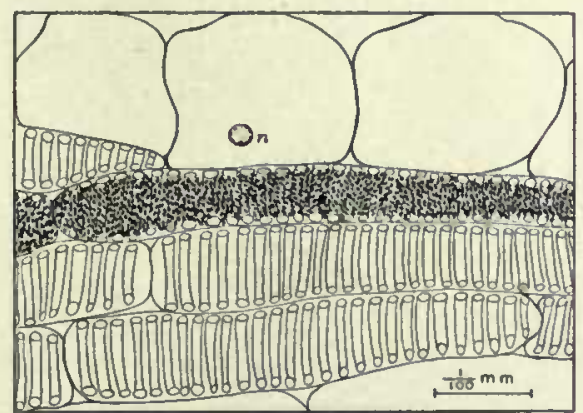

Fig. 78. ered in the way of treatment it will be mentioned under eacl particular disease.

*FIG. 77.-Bacterium campestre from the cavity shown in fig. 76 , illustrating water-pore infection of the cabbage. $\times 2,000$.

†FIc. 78.-Bacterium campestre occupying a spiral vessel in a cabbage leaf near a group of infected water-pores. The tissues to the right and left of this vessel, and also above and below it (slide $223 \mathrm{a3}, \mathrm{I} 8.6$ by 9.7), are entirely free from bacteria. The body of the leaf and all its inner tissues up to within a few millimeters of the leaf-tooth, and also the outer surface of the leaf up to the water-pores, are sound. On the contrary, an unbroken bacterial occupation can be traced from this vessel outward to the water-pore region. The bacteria in this vessel are also less abundant than in those nearer to the group of water-pores, $i$. e., its occupation is of more recent date. Even if there were no other evidence of infection by way of the hydatodes than that afforded by this vessel, the presence of the bacteria in it under the circumstances mentioned points conclusively to marginal (water-pore) infection as their only possible source. The position of this vessel is in a small vein a little below and at the left of $X$ in fig. 76 . Its distance from the left margin of the bacterial cavity is one field of the $16 \mathrm{~mm}$. Zeiss objective with the 12 comp. ocular. Its distance from the sound leaf margin is two-thirds the diameter of such a field. A nucleus is shown at $n$. 


\section{GENERAL CONSIDERATIONS.}

\section{LOCATION OF THE IABORATORY.}

If possible, the laboratory should be in a clean building in the middle of a green lawn. If it must be in a crowded and dirty city it should be on an upper floor, as far renioved as possible from the dust of the street and from the tramp of feet. It ought not to be located on streets filled with the dust of lieavy traffic. If a groundfloor or basement roon in a dirty locality is the only available place, then the air which enters the room should be filtered througli absorbent cotton. A south front is desirable for the mounting of a heliostat and for other plotograplic purposes; a nortl liglit is desirable for microscopic use, if one is to work at the instrument continuonsly. By arranging one's time according to the position of the sun, the light from east or west windows niay be used to advantage five or six hours a day, which is quite long enough to fatigue ordinary eyes. The writer has managed to

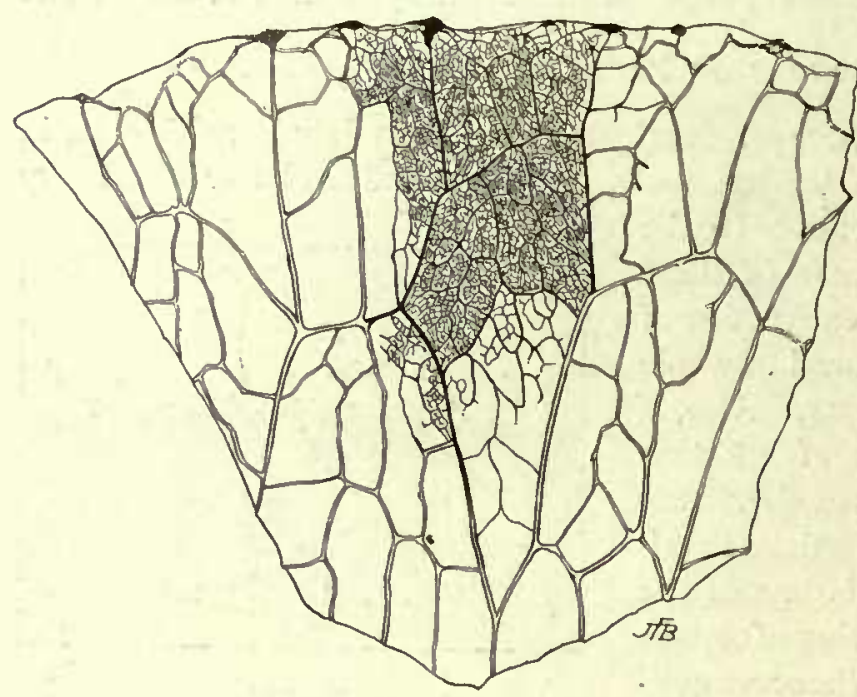

Fig. 79.* get along very well without north light for the last ten years. If one decides to use with the microscope only artificial light, such as that of the Welsbacl burner, workroonis for this purpose niray be lacated anywhere. If possible, several rooms sliould be secured and apportioned to the various kinds of work, e.g., general laboratory rooms, cliambers for special workers, sterilization-roon, thermostat-room, cold-storage and stock-culture rooms, storage rooms for chenicals, small glass-inclosed rooms for transfer of cultures, photograplic rooms, dark rooms for developing, etc. The general photographic rooms should have overhead light as well as side light.

\section{EQUipMENT OF TIIE Laboratory.}

Many pieces of apparatus may be procured from time to time, as the exigencies of the work demand or as the funds will permit. Other apparatus unust be provided on the start, and some of it when the building is constructed or reconstructed.

*FIG. 79.-Small portion of a cabbage leaf from Long Island, New York, showing characteristic water-pore infections due to Bacterium campestre. The blackened veins correspond to the location of the bulk of the bacteria which have gained entrance to the vascular system of the leaf by way of the groups of water-pores situated on the serratures of the leaf, particularly those which are conspicuously blackened. Those parts of the leaf where only the larger veins are shown were green and normal in appearance. Coll. July 16, 1902. Drawn from a photograph. 
PLATE 10.

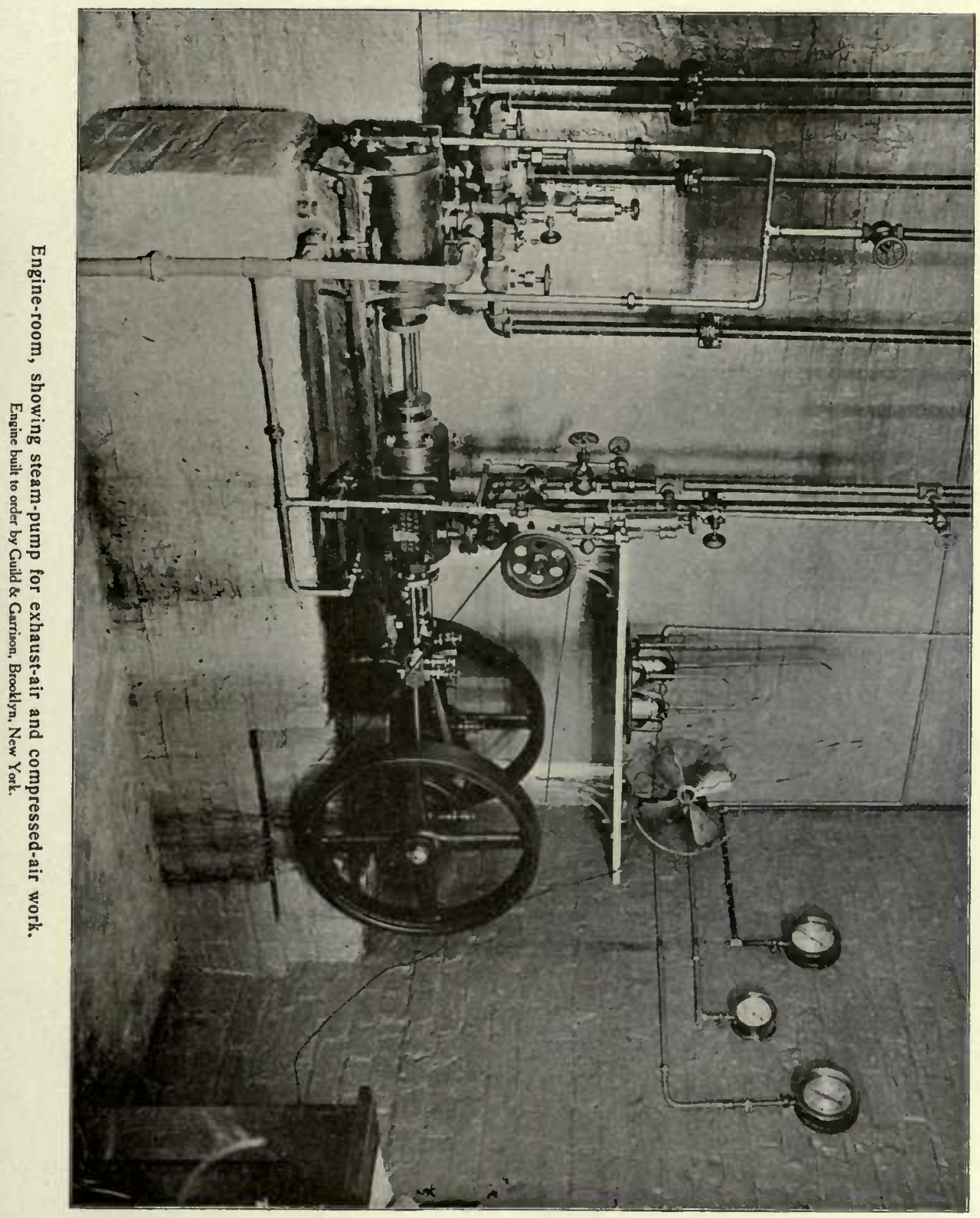



There should be hot-water pipes, cold-water pipes, steam pipes, a steam bath, gas-pipes, conpressed-air pipes, exhaust-air pipes (plate Io and fig. 81), and electrical wires for light and motive force. There should be thermostats, waterbaths, cooled roons, ice-boxes, steamers, dry-ovens, autoclaves, a distilled-water outfit, an alcolıol-still (by which waste alcohol may be recovered or absolute alcolıol prepared), an ether-still, filters, gas-generators, gas-furnaces, anaerobic apparatus, the very best microscopic ontfits including apochromatic lenses, photographic and photomicrograplic appliances, liquid-air receptacles, cylinders of compressed carbon dioxide and oxygen, nicrotomes, paraffin baths, glassware, balances, chemicals, and many minor pieces of apparatus.

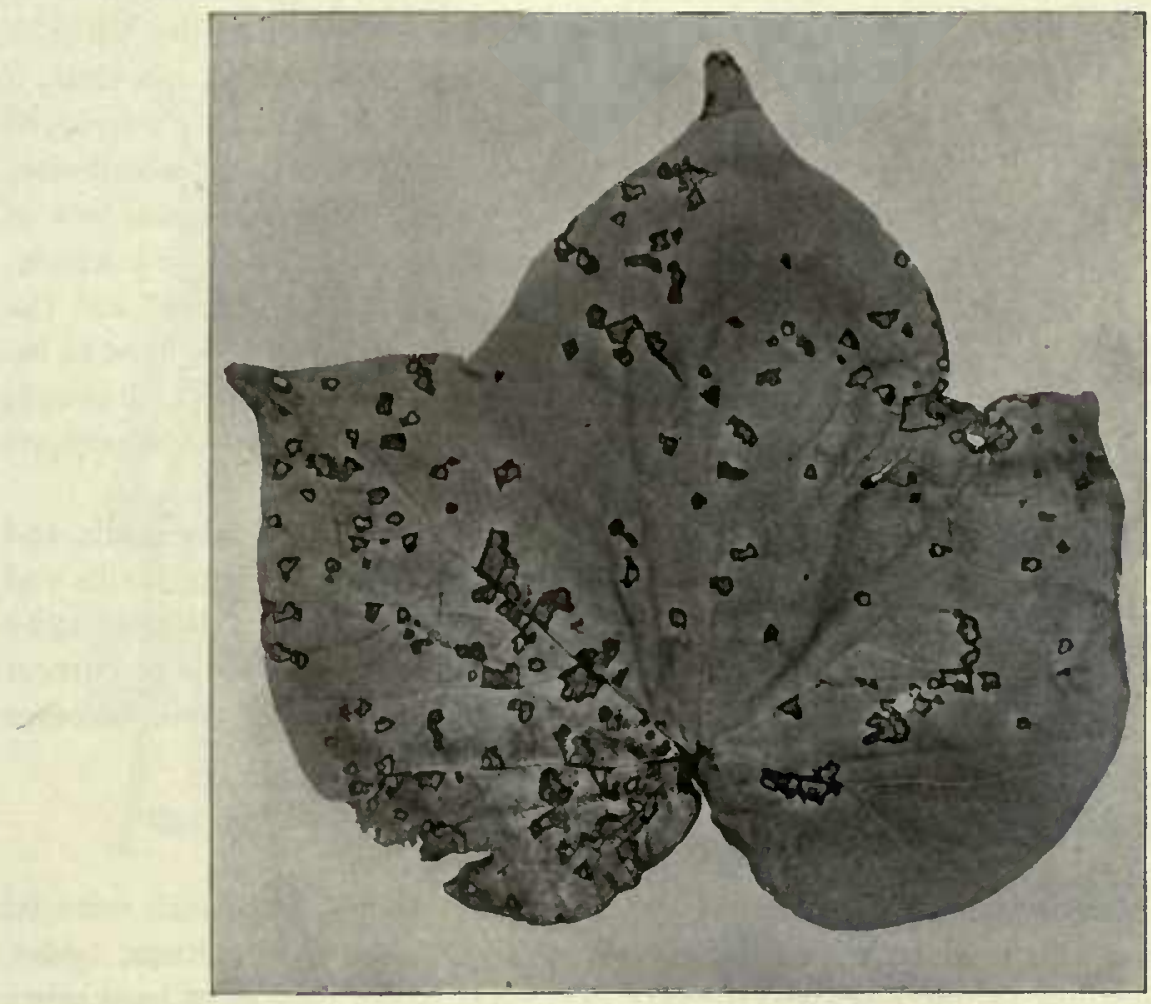

Fig. $80 *$ *

*Fig, 80.-Angular leaf-spot of cotton in which stomatal infections appear to be the rule. This leaf represents the secondary stage of a natural infection, i.. ., the spots have browned and shriveled, and they involve the entire thickness of the leaf. In an earlier stage of the disease the spots are limited to the under side of the leaf (mesophyll), and occur in the form of small water-soaked, uncollapsed areas surronnding stomata, under which nests of bacteria occur. These spots gradually deepen so as to involve the palisade tissue, and then they become visible on the upper surface of the leaf. The spots are not yet shriveled or browned, but if the leaf is held up and viewed by transmitted light they appear as translucent areas, while by reflected light they are dull and wet-looking. A little later they present the appearance shown in this figure. The writer has obtained all stages of this disease in Washington by spraying upon the plants young agar cultures of Bacterium malvacearum suspended in slerile water. 
In general, the working capacity of a laboratory will be greatly increased by giving the director a stipulated sum of money per annum and carte blanclie to buy laboratory necessities whenever and wherever and in whatever quantity he sees fit, requiring only that he submit vouchers; also by the employment of a number of subordinate assistants of special fitness, to whom nnay be assigned mucl of the purely mechanical and routine work of the laboratory, such as the proper cleaning of glassware, the making of ordinary culture media, the keeping alive of stock cultures, the preparation of staining media, the embedding, cutting, and staining of microtome sections, the making of photograplss, the indexing of literature, etc.

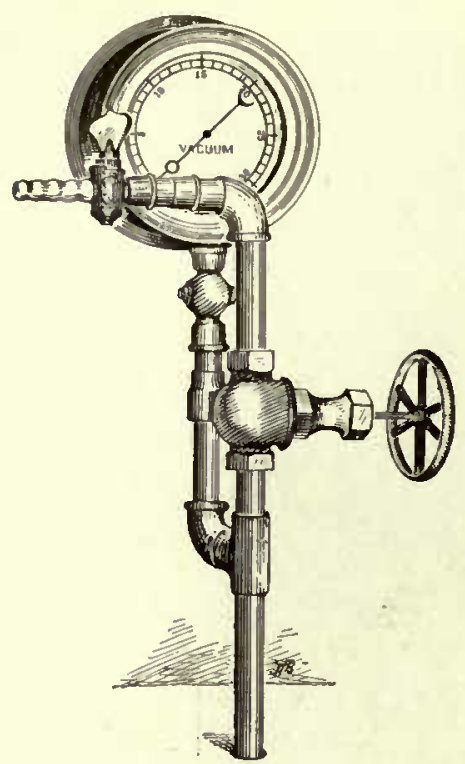

Fig. 81.* No scientific man should be willing to trust any piece of work in lis own line to an assistant unless he call do it as well himself, or better, but when it lias become to him the merest rontine, his time, if wortl anything, can be more profitably employed in something else. In most American laboratories whicl the writer has visited there is a woeful lack of intelligent subordinate assistance, such, for example, as that furnished by the Gemman "Diener" and the Malays of Java. Every assistant can not hope to become at once an independent investigator, althougl, if competent, his work should always be shaped toward this desirable end.

A good library should be within easy reach, and as a suggestion to this end a list of nseful books and papers is appended under the head of Bibliograply of General Literature. A card catalogue of current literature is also very useful and in time becomes invaluable if properly made.

\section{CARE OF THE LABORATORY.}

The laboratory should be a clean place. Its walls should be of such nuterial that they can be rinsed or wiped down occasionally. The floors, doors, tables, window-sashes, etc., should be wiped every day, every other day, or at least every third day, with clean cloths wet in distilled water, boiled water, or clean lake or artesian water. The use of river water, swarming as it does very frequently with all sorts of bacteria, is not to be commended for cleaning purposes, and broons should be taboo. No one should enter the laboratory who lias not business there, and order and quiet should prevail.

*FIG. 8I.-End of the vacuum-pipe on laboratory table. The gage serves to show the degree of exhaustion, $i$. e., whether there is any leak in the piping between the engine-room and the laboratory. The two rooms should be connected by a speaking-tube. 


\section{PREPARA'ION AND CARI: OF CULTURE, MFDIA.}

Everything should be carefully weighed or measured. Everything should be clean as possible to begin with. By water is usually meant distilled water, and this shonld be free from copper or other germicidal metals (see Bolton, Bibliog., XXXVIII). Moore \& Kellernan have shown very recently that the Bacillus typhosus is destroyed in distilled water if the merest trace of metallic copper is present. Water swarning with this organisnu was sterilized simply by standing three honrs in a copper vessel. The writer found the connt of Bacillus tracheiphilus reduced. over 30 per cent by exposure in bouillon in block-tin tubes for twenty-one hours. Exposure for forty-eight hours gave the sanne result, i.e., 33 per cent destroyed. A simple glass still is shown in fig. 82. As far as possible the clienicals should be

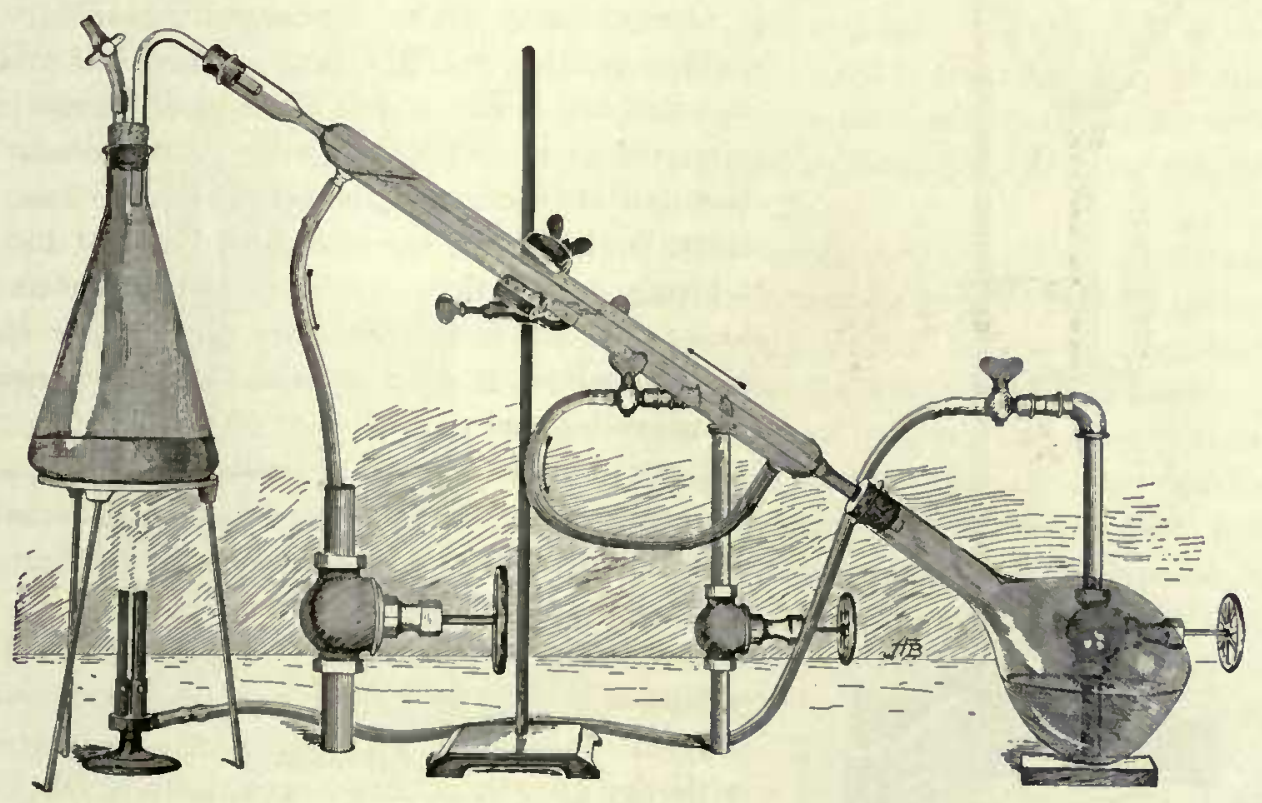

Fig. 82 *

c. p., and in many cases it is necessary to make the test for oneself, no matter what the reputation of the firm or the statement on the label. When possible, broken packages should be avoided. It is therefore best to procure most chemicals in several small packages rather than in one large one. If the preparation of culture media is broken off before its completion, by nightfall or interruptions of any kind, the unsterilized or incompletely sterilized media should be put into the ice-box, especially if it is warm weather. Neglect of this precaution frequently results in the spoiling of the media. In steam sterilization one shonld begin to connt tine only after the thermometer registers $100^{\circ} \mathrm{C}$, or at least $99^{\circ} \mathrm{C}$. Those who live in high

*Fig. 82.-Portion of a work-table showing method of distilling water for use in making culture media. The flasks should be insoluble glass. The cold hydrant water passes through the condenser in the direction of the arrow. In actual use the upright flask and the flame are sheltered from airdrafts by sheet asbestos. One-ninth actual size. 
monntain regions nutsst use autoclaves. Agar, potato, etc., in test-tubes, may be steaned twenty minntes on each of three consecutive days. Gelatin, beef-bouillon, and all other fluids likely to be injured by long heating should be steamed only ten or fifteen minutes on each of three consecutive days, if in tubes. The writer frequently steams stuch media fifteen minutes the first day, ten minutes the second, and five minutes the third. Agar, gelatin, bonillon, etc., stored in flasks in large quantity must be steamed a longer time-usually thirty to forty-five minutes on each day.

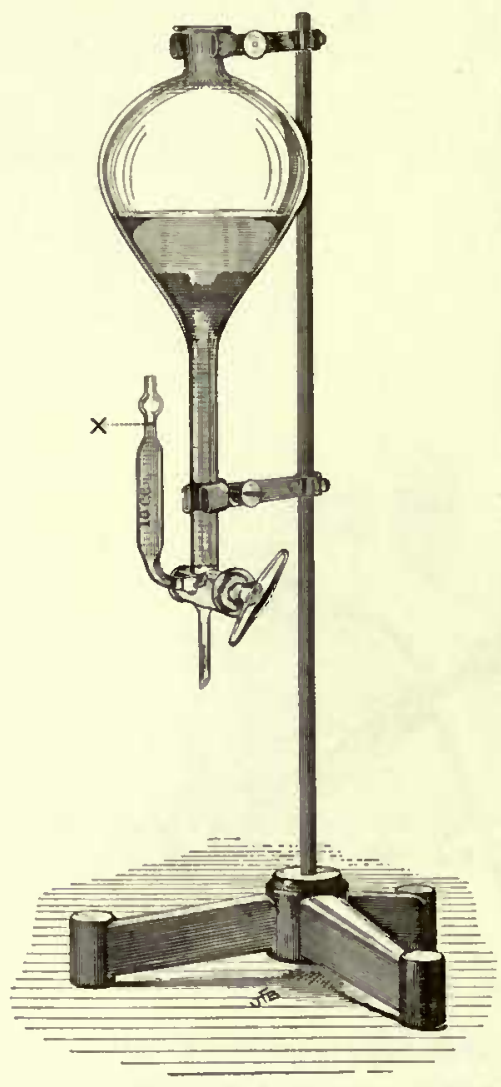

Fig. 83.* The first steaming, when softened gelatin is added to bonillon, usually requires thirty w11inutes. To melt flasked agar quickly, shake it into fragments or break it with a sterile glass rod before putting it into the steamer.

Oversteaming should be carefully avoided. It softens gelatins or altogether prevents their solidification, and is very apt to cause troublesome precipitates in a variety of n1edia. Precipitates in bouillon often occur if the tubes are not clean, or if the bouillon was not well boiled at first before filtering and placing in tubes. If the beef-broth looks greenish in the beaker or flask, rather than a clear yellow, it may be assumed that it needs more boiling and that if tubed in this condition it will throw down whitish particles on subsequent steanning. The writer prefers to obtain his ordinary + boutillons by incomplete neutralization with sodium hydrate rather than by addition of hydrochloric acid after full nettralization. The adding of liydrocliloric acid precipitates out certain nutrient substances and also seen1s to interfere with the growth of some organismis. Distilled water and river water slionld be sterilized in quantity in the autoclave. For details concerning the making of particular media the student should consult the standard text-books, a dozen or nore of which should be kept within easy reach in every laboratory. Sonne fornule are given in the middle part of this volume. The autoclave may be used for the preparation of sterile water and some media, but, in general, I prefer n1edia which has not been heated above $100^{\circ} \mathrm{C}$., especially for use with sensitive organisms. Media should be heated in the autoclave only for a brief time and at a minimum pressure, generally not more than ten minutes and at not more than II ${ }^{\circ} \mathrm{C}$. Milk, gelatin, and media containing sugars slonld never be sterilized in the autoclave. Sugars

*FIG. 83.-Apparatus for rapidly filling test-tubes with Io cc. portions of agar, bouillon, etc. By means of thris device an expert assistant can fill 500 tubes an hour. Made to order by Emil Greiner. Height, 23 inches. The bulb above $X$ is essential. 
and other stibstances decompose at these high temperatures and the results obtained by the growth of bactcria in such media are not comparable with those obtained on media sterilized at $100^{\circ} \mathrm{C}$. Hitclrens has recently slown that detri111ental acids are formed when bonillon containing sugar is autoclaved. Peptone water, agar, and bouillon may be sterilized in the autoclave. For titrating culture media the writer uses the burettes shown in fig. 59. The twentieth-normal alkali is stored as shown in fig. 60. Quadruple-1rormal sodinn hydrate solution is used for neutralization. The plrenolphthalein solution is made by adding I gram of the dry powder to roo cc. of 50 per cent alcohol, and then enough $\frac{\mathrm{N}}{20}$ sodium hydrate to carry it fully into solntion, removing the yellow color withont making the fluid

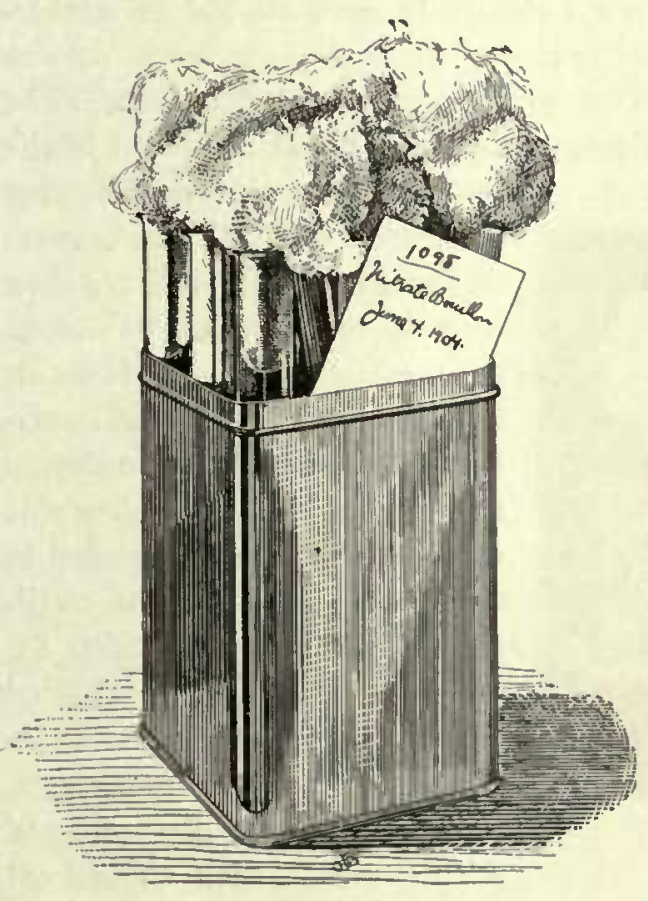

Fig. 84 . a very decided pink. Fluid media may be filled into tubes very rapidly by means of the device sliown in fig. 83. For storing media sterilized in test-tubes and for holding cultures made on sucl media the writer has found ordinary quinine cans very useful (fig. 84).

'The proper care of culture media after sterilization involves considerable thought if they are not to be used immediately. Stored media lose water and along with this loss, of course, there are physical clianges, so that the results obtuined are not always comparable with those obtained from similar media containing the standard volume of water. Various devices lrave been recommended for preventing this loss of water. Rubber caps keep in the moisture, but are apt to favor the development of fungi. Paraffined plugs made by rennoving the cotton plug, dipping the lower end of it quickly into and out of hot sterile paraffin, and replacing it in the moutl of the tube or flask before the inelted paraffin has liad time to cool, answer the purpose very well, but have the objection that all of the tubes must be placed in turpentine or some other solvent of paraffin before they can be cleaned for a second use. On the whole, the use of moderately tight plugs and the storage of the media in cool or cold air are the best methods of retaining the water content of the medinn. Nutrient media should be made in small quantities and often, rather than in large quantities and at infrequent intervals. The cotton sliould be dry-lreated in bulk before plings are made from it.

*FIG. 84,-Ordinary quinine cans with a little cotton in the bottom are very convenient for holding cultures and culture-media in test-tubes. One-third actual size. 
THE CLEANING AND STERILIZATION OF GLASSWARE AND INSTRUMENTS.

New glassware may be boiled in soap-suds, rinsed thoronglily, soaked in the chromic-acid cleaning mixture for some hours, rinsed in hydrant water, soaked in several changes of distilled water, soaked or shaken in alcohol, and finally rinsed in distilled water. Neglect to wash in alcohol will frequently leave behind on the walls of the test-tubes an invisible film which causes vexatious precipitates in beefbouillon, etc. Discarded tubes, flasks, and dishes containing living organisn11s 1111st be autoclaved or filled with the chronic-acid cleaning 111ixture before they are washed. Solne responsible person should attend to this. If acid is used it should be allowed to act for sone liours.

Petri dishes should fit together well, but not tightly, and shonld be doublewrapped in clean Manila paper before placing them in the hot-air oven, or else should be inclosed in suitable tin boxes. The writer prefers to wrap them. The paper for this purpose may be I 2 by 12 inches. The dish should be placed in the

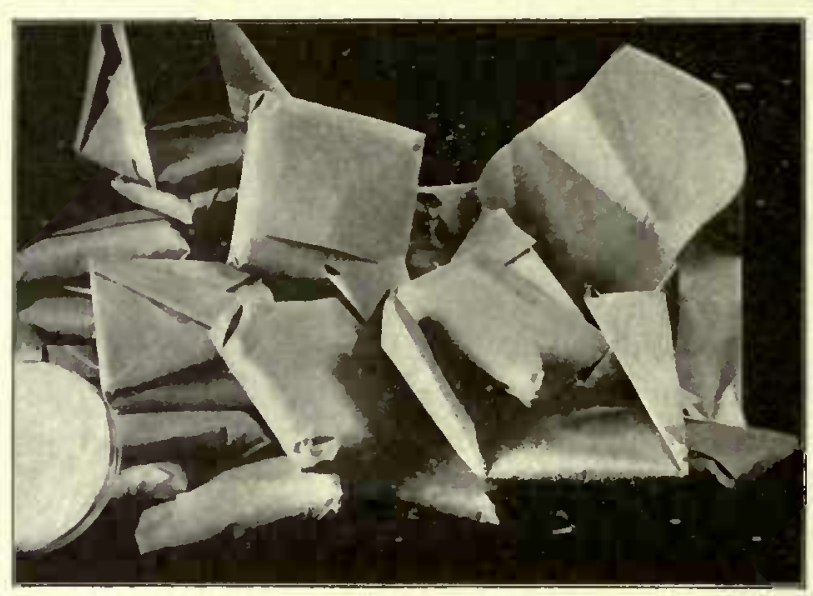

Fig. $85 . *$ middle. The sides of the paper are folded over it; the corners of the projecting ends are then turned in, leaving $V$-shaped flaps, which are folded down on to the plate. The second covering is folded at right augles to the first and on the other side of the dish. Dishes treated in this way and ready for sterilization are shown in fig. 85 . Pipettes sliould be dry-lieated in the tin boxes already me11tioned (fig. 37) after having the upper end carefully plugged with cotton, which should not project. Knives, scalpels, scrapers, spatulas, needles, forceps, etc., may be sterilized in the Bunsen flame, or, if needed cold in quantity, 111ay be wrapped in Manila paper or put uncovered into short tin boxes and heated in the dry oven at $140^{\circ} \mathrm{C}$. for two hours. Petri dishes, test-tubes, and all other apparatus wrapped in paper and put into the oven for sterilization by dry heat should have air spaces between them, $i . e$, they should not be crowded together tightly, and the recording thennoneter shonld project well down into their inidst. The investigator should test the behavior of his oven when full and empty. Many cheap ovens give very different temperatures in different parts, especially if filled with apparatus, so that cotton or paper n11ay be scorched in one part and not sterilized in another. The best oven known to the writer is that made by Lautenschläger. The improved form of the Lantenschläger oven shown in plate 6 does not require watching and gives a nniform temperature

\footnotetext{
*FIG. 85.-Petri dishes wrapped in two layers of Manila paper and ready to be dry sterilized.
} They are set on edge in the oven. 
in all parts. It also furnishes a maxim11n temperature with a minimum consumption of gas, hot air being fed to the flan1e. The apparatus has an inner, outer, and middle wall. A lorizontal iron gas pipe, of tle relative size shown in the front of the picture, passes entirely aronnd the apparatus at the bottom between the outer and middle wall. On top in this tube are many small openings through which gas escapes and when liglited forms so many small Bunsen flames. Air is drawn in at first and mixed with the gas in the middle open part of the feed pipe in front. The products of conbustion escape through the chinney on top of the oven. There are pilot liglits, so that the apparatus is set going easily. The result of this arrangenent is that the middle wall beconnes heated very hot, and consequently the air between this wall and the inner wall rises, cool air entering through loles in the bottonn to take its place. Tliere is thus created a powerful upward mount of hot air. This enters the oven through several hundred holes in its ceiling, is forced downward and escapes through as many holes in the floor. From this place the hot air is continually crowded sidewise and
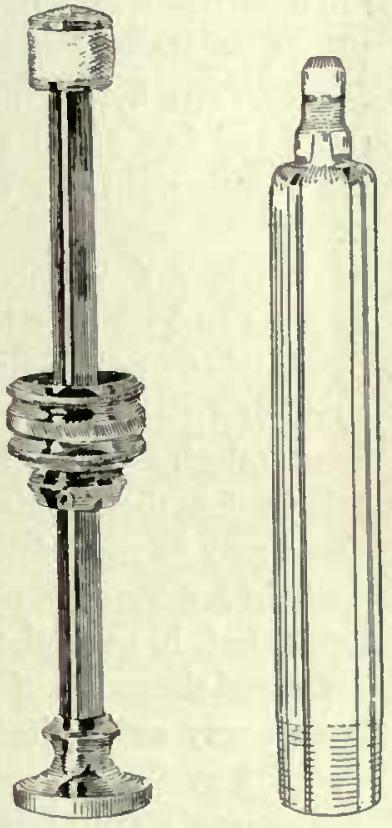

Fig. 86.* backward througli brass tubes in to the furnace chamber where it serves to support the con1bustion.

Unless the dry-oven has a very uniform temperature thronghout, so that there is no danger of scorching the cotton, plugged test-tubes should be tied togetlier loosely and stood on end, cotton 11ppernuost. Petri dishes (wrapped in paper as directed) may be set on edge. If the test-tubes lave been properly cleaned, dry-heating is not necessary for such as are to hold steanl-heated media, provided the cotton used for the plugs is dry-sterilized in advance. The best surgeon's absorbent cotton is not too good for this work. It should be unrolled and put into the dry-oven in a loose armful and heated just below the scorching point for several hours ( 2 to 3 hours at $145^{\circ} \mathrm{C}$. will answer), witl occasional unfoldings and turnings so that all parts nuay be lieated nniforn1ly. It is now taken out, re-rolled and put away in clean paper until needed. By this neans all fungous spores lodged in it are destroyed and

*FIg. 86-Dr. George Meyer's hypodermic syringe, made by Lautenschläger. Desirable on account of perfect workmanship, and because it is easily sterilized without injury. This size holds I cc. By twisting the button of the piston the packing at the other end is tightened or loosened at will. 'The separate parts are enlarged one-fourth. 
an oil is driven off which otherwise would be deposited as a whitish distillate on the inside of the test-tubes near the plugs. Hypodernic syringes may be sterilized by boiling in distilled water if the contaminating organisin is non-sporiferous, or by soaking twenty-four hours in 5 per cent carbolic-acid water or lysol water and

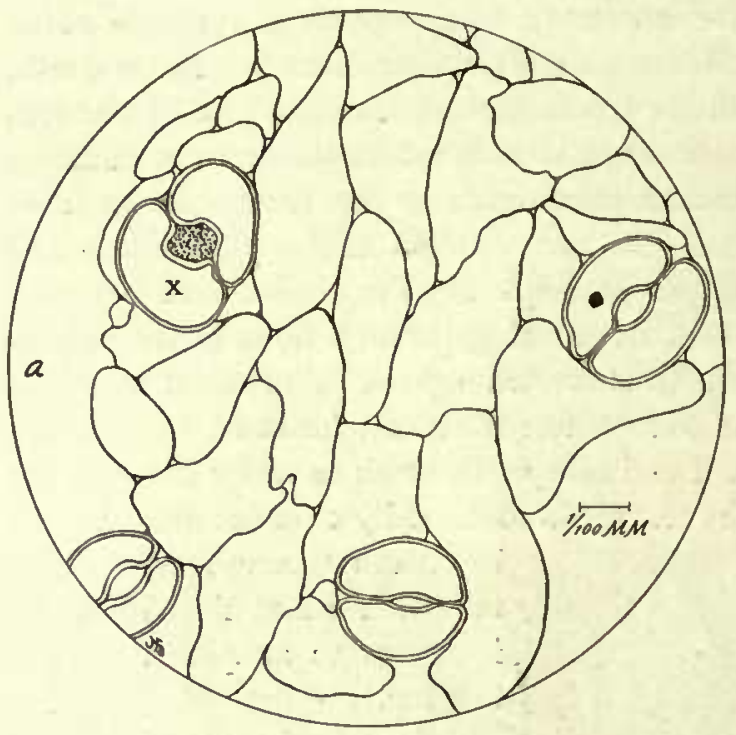
a subsequent soaking and boiling in pure water. The writer prefers the Meyer syringe, made by Lantenschläger (fig. 86). Syringes which allow the culture media to ooze out around the piston whenever any strong pressure is exerted are dangerous and should never be used with infections material. Those which do not admit light or allow the experimenter to see how much fluid has been used or whether air is present are unsatisfactory. In case of many plants, needle-pricks are n11ore satisfactory than hypodernic injections (pl. 4 and figs. 8 and 88). Needles are sterilized in the open flame as needed.

When conveniences are not at hand, as on long trips in the country, the kitchen-oven may be used for sterilizing glassware, or even an open flame (alcohol lamp), and agar and gelatin for the making of poured plates may be inelted by placing the tubes in hot water in a tin cup or tea kettle, but, in general, the writer has not found the rooms of ordinary farm houses very well suited for research work. Usually they are too dusty.

Surgeon's ganze is very convevient for laboratory use, for coarse filters, wipe-cloths, etc.

*FIG. 87.-Early stage in the infection of a cabbage leaf by Bacterium campestre; a, epidermal layer on the apical part of the tooth of a leaf, showing one of the four stomata $(X)$ full af bacteria. For the condition immediately under $\mathbf{X}$ see $b$, which was drawn from the third section in series, the intermediate one including part of the guard-calls. Slide $338, \mathrm{Br}$, stained with carbol-fuclisin. Drawn with the Abhe camera, $3 \mathrm{~mm}$. Zeiss apochromatic objective and 12 compensating ocular. Material collected and fixed 8 days after infection, which was accomplished by atomizing upon the plant water containing a pure culture of Bacterium campestre grown on slant agar. When collected many of the serratures had begun to show traces of the brown stain which invariably appears when this organism grows in cabbage. The plant was inclosed in the cage shown in fig. 95, and was extruding fluid from its water-pores when it was sprayed. $\times 500$. 
THF, MAKING AND TRANSFERENCE, OF PURE, CULTURES.

In addition to what has been said under Pathogenesis, the following suggestions may be of service to the beginner.

For the making of plate cultures and for the transfer of organisms from one culture medium to another, select a still day and, if possible, a day when a gentle rain or snow is falling. This offers ideal conditions, since the earth is wet, the outside air has been waslied free from dust, and there is no wind to stir up dist within the laboratory. A strict adhereuce to this rule is sometimes very inconvenient and it is

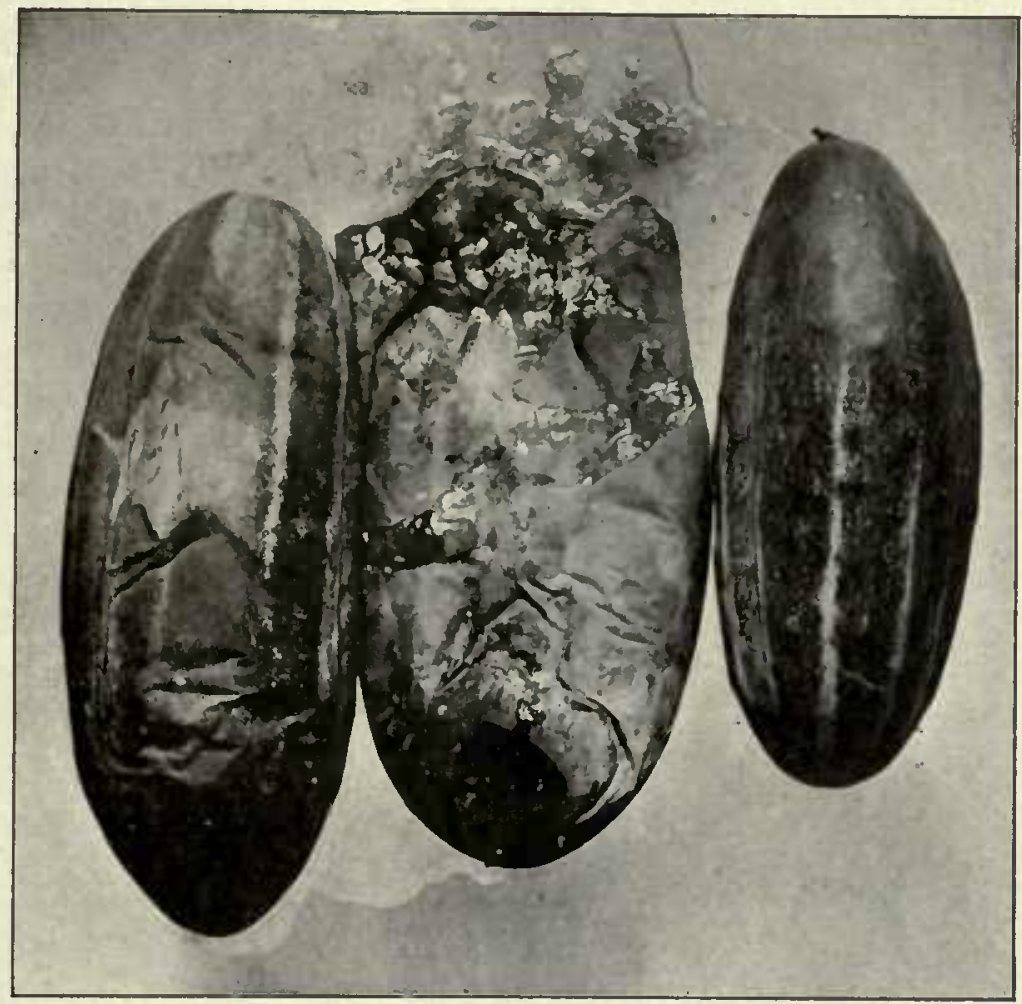

Fig. 88.*

not meant to be iron-clad. It is, however, of immense service in keeping cultures free from contaminations, and those who propose to disregard it should remember that haste in the beginning of an experiment often leads to vexation and delay in the end, especially when the success of the experiment depends absolutely upon the purity of the culture.

*Fic. 88.-Soft rot of green cucumbers inoculated by needle-punctures from a pure culture of Bacillus carotovorus. The only parts not softened are those through which the infected needle entered, $i$. e., the parts rubbed with mercuric-chloride water. In each a little button of tissue under the disinfected area did not decay. The sound fruit at the right was punctured at the same time, but with a sterile needle. The cucumbers had been removed from the vine, but were not flabby. They were exposed after inoculation to the ordinary air of the laboratory. The photograph was made on the seventh day. About two-fifths nalural size. 
When ready to make the transfers or to pour the plates, close the windows, wipe up the tables, and wet down the floor, window-sashes, etc., with distilled water or boiled water, and reduce the air-currents witlin the laboratory to a minimum (especially when transfers are to be made in the open rooin) by keeping the doors shut and restricting tlie movements of all persons who nnay be in the roon. It is nuch better to do all of this work in specially constructed small rooms (plate I I) than under hoods (plate I2). Hoods are open only in front. They may be made of any convenient size. The one here figured is is 32 by 39 by $20 \mathrm{r} / 2$ inches, ontside measurements. When one is far from laboratories sw1 lll hoods may be extemporized out of clean paper, or cultures nnay be ponred and transfers made inside of a cleau pail or jar, tumed down on its side. Any metlod, in fact, which restricts

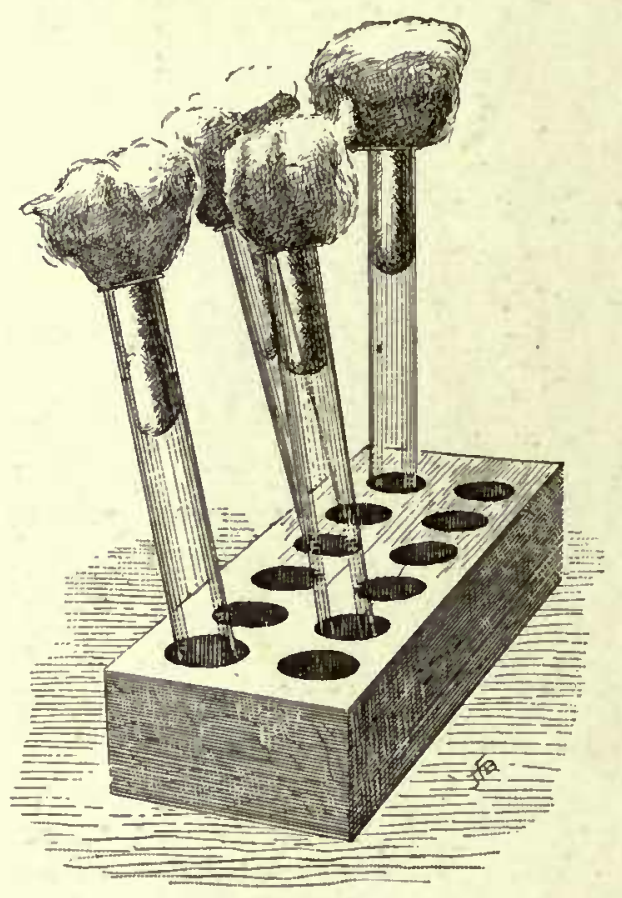

Fig. 89.* the movement of air past open plates and tubes will be found serviceable.

The work-shelf of the room shown in plate I I faces a window as wide as the room, and extending from the level of the slielf to the height of the other windows in the roonl. This window faces south and is only 6 feet from a well-lighted window in the onter wall of the building. The room also receives bright light from the west side. At the front end of the shelf are a Bunsen burner with cut-off flame, a box of safety matches, a box of rubber bands, and two tumblers-one for burned matches and one for platinum loops, needles, forceps, etc. Immediately under this part is a narrow drawer for pencils, note paper, knives, etc. At the back end are a few wrapped Petri dishes, a nivellation apparatus, a flask of sterile water, and a crate of media. Underneath this part is a second shelf 3 inclies below the first, where Petri dishes and tubes containing solid media may be put out of the light as fast as inoculated. The size of this room (inside measurement) is 4 by 4 by ro feet, and it is large enongl. No provision is made for ventilation, because air-currents in a culture-roon are very objectionable. The windows, walls, and floor are wiped up with distilled water before naking transfers. Ontside is a bit of the antlior's private laboratory. At the right is the microtome and behind it on the wall are deep and shallow drawers; 69 is for bulk paraffin; 7० A, B, C, D, E, are cut into small compartments used for paraffin blocks. 'The very shallow drawers are for ribbons which can not be mounted the day they are cut; 72 has a series of shelves opening on the south side and is used to hold photographic printing frames.

*Fig. 89.-Pine block with inch holes, convenient for holding test-tube culture during examination, or tubes of media which are to be inoculated. A good size is $91 / 2$ by $3 \frac{1}{2}$ by $17 / 8$ inches. 
PLATE 11.

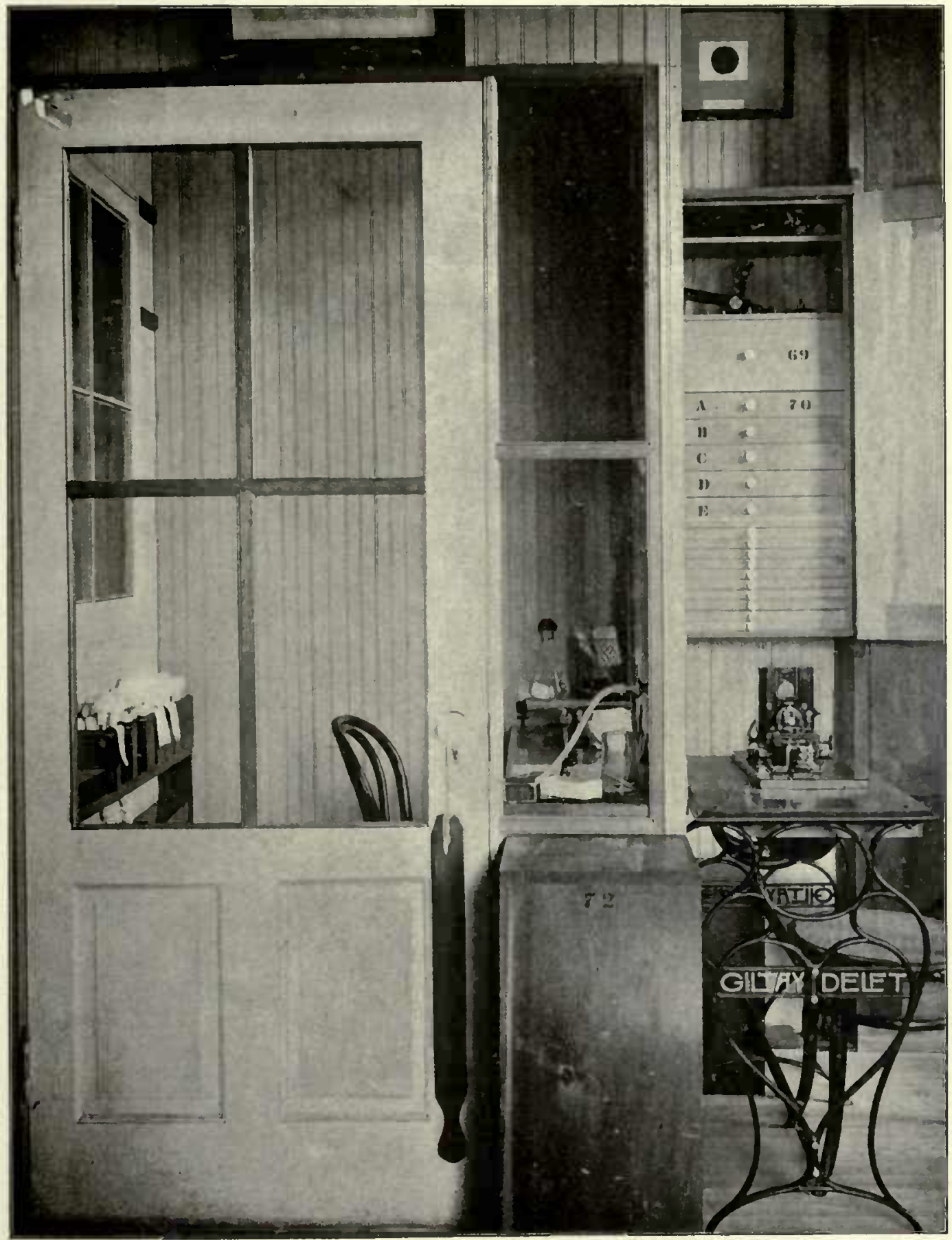

The author's culture-room.

At the left hand (back) are narrow shelves for cullure-media, pipelte-boxes, efc. At the right is the work-shell, covered with plate ghaw. 

The agar may be poured at $42^{\circ} \mathrm{C}$. in case of organisms whose thermal deathpoint is known to be high $\left(50^{\circ} \mathrm{C}\right.$. or above). For all others it must be cooled carefully to $40^{\circ} \mathrm{C}$, before inoculating for poured plates. 'This requires five or six minutes in the water bath at $40^{\circ} \mathrm{C}$. Even this temperature is too high for some organisms and then gelatin at $30^{\circ} \mathrm{C}$. may be used. When ready to pour, take a clean absorbent clotli and carefully wipe all water from the outside of the tube (the lips of which have been previously flaned gently with a rotation of the tube on its long axis), lift the cover of the dish only as much as is necessary, hold the cover over the dish (not at one side), pour quickly but gently, and re-cover, tilting the dish about quickly but gently, if the fluid has not already covered the bottom. To entirely cover the bottom sometimes requires a smart little jerk, if the agar is not very fluid. The student must learn to work rapidly and dextrously, then there will be no complaint that the agar has solidified before the plates are poured. 'The

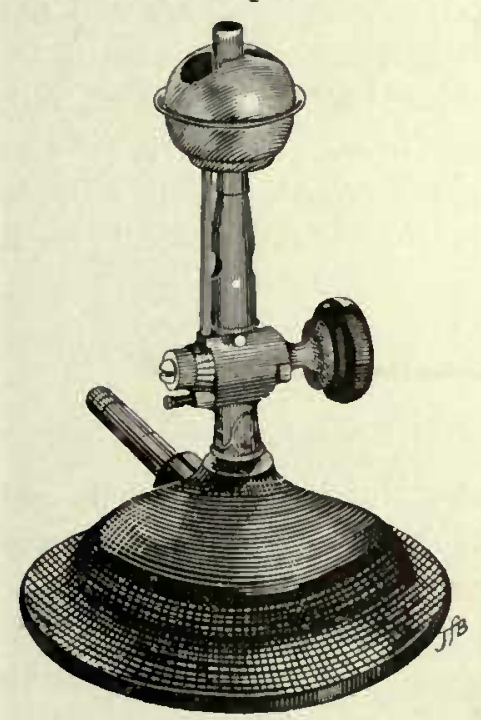

Fig. 90.* plates should be set on a level shelf while the agar or gelatin is hardening, or, if the colonies per square centimeter are to be determined, a nivelling apparatus such as that shown in fig. 66 must be used, and the dishes should have flat bottoms. When plates liave been inoculated too abundantly to secure subcultures from single colonies, these may sometimes be obtained from the traces of agar or gelatin left in the tubes from which the plates were poured. With this and in view, these tubes should be replugged and laid away, for a few days, the lips and top of the tube which were wet by the agar or gelatin being first heated hot in the flame, care being exercised not to crack the tubes.

All tubes containing fluids should be opened and inoculated in a position as nearly horizontal as their contents will permit, and tubes of solid nedia, sucl as agar, may be held level or inverted for inoculation. A convenient block for holding test-tube cultures during examination is shown in fig. 89. It is usually best to flame the plugs slightly before their removal, particularly if they have been exposed to the air for sonne days. As an additional precaution the transfers should be made under a glass lood, or in a special culture-chamber. If sterilized needles, loops, knives, forceps, pipettes, or anything else designed to be used in making the transfers have accidentally touclied anything whatsoever, they are presumably contaninated and must be rejected or reflaned. Do not handle the lips of test-tubes containing gelatin or agar from whicl plates are to be poured. Your hands may be contaminated by resistant spores. Take hold of the tubes lower down. 'To economize gas and avoid heating the air of the small work-chamber to an uncomfortable degree, small, cut-off, constant-flame burners are very convenient (fig. 90).

*FIG. 90.-A constant Bunsen burner with cul-off flame. Very useful for the laboratory table and the culture room. About two-fifths actual size. 
Plates, tubes, and flasks containing pure cultures or designed for inoculation should never be opened in the general laboratory on a windy day or in air currents. Ponr two 11ninoculated agar or gelatin plates in the proper way. Keep one covered

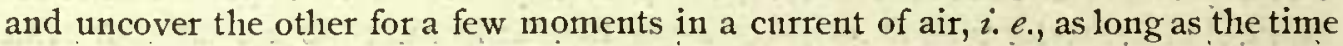
required to make a plate culture. Then keep the two plates together and compare from time to time. A few experiments of this sort will convince the most skeptical of the necessity of avoiding drafts.

The person and clothing of the experimenter should be as clean and free from dust as possible. White duck coats are very convenient. They show at once when they are soiled and need washing and ironing.

Organisms which for some reason may be difficult to obtain in ordinary plate cultures and which differ markedly from their associates in some particular way, $e: g$., by more rapid growth, by indifference to heat, to acids, to thymol, to chloroform, to absence of air, etc., or which can use, as food, substances which will not support the growth of most bacteria, may sometimes be isolated very readily by providing conditions suited to their growth and unsuited to that of the bacteria with which they are mixed. 'This is Winogradsky's principle of elective culture. As he defines it, this is a culture "which presents conditions favorable only to a single definite function or, more exactly, to a function as strictly limited as possible." Such

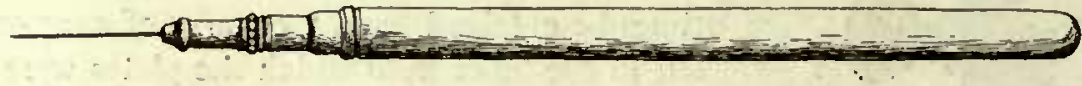

Fig. 91.*

media or methods are exactly the opposite of universal. Nutrient starch jelly and nutrient silica jelly are good examples or such media. Nutrient fluids rich in acid potassium phosphate or destitute of nitrogen are additional examples.

Heat is often an excellent means of separation. Winogradsky separated his Clostridium pasteurianum from all but two of the contaninating species by heating ten minutes at $75^{\circ} \mathrm{C}$. (Archives des Sci: Biol., Vol. III, p. 310). The isolation of Streptococcus (Leuconostoc) mesenterioides by Liesenberg \& Zopf and of Bacillus hortulanus by Sturgis are other examples of separation by heat. Ornélianiski's separation of his hydrogen-cellulose ferment from his methane-cellulose ferment by exposure of the recently established methane ferment to $75^{\circ} \mathrm{C}$. for fifteen minutes is another good example.

\section{THE, FINAL DISPOSAL OF INFECTIOUS MATERIAL.}

Diseased naterial should not be left around the laboratory any longer than is necessary. When it has served its immediate purpose that which is not to be preserved permanently shonld be throwi into the firmace. Sinall annonnts may be sterilized by putting into beakers or jars and covering with cleaning mixture or equal parts of crude sulphuric acid and water: Crude vegetable and aninal sub-

*FIG. 9I.-Instrument for making puncture-inoculations. It consists of a bone handle with a metal-screw socket, into which a sewing needle is thrust. The needle is usually of small size-a No. 8 or 10. 
PLATE 12.

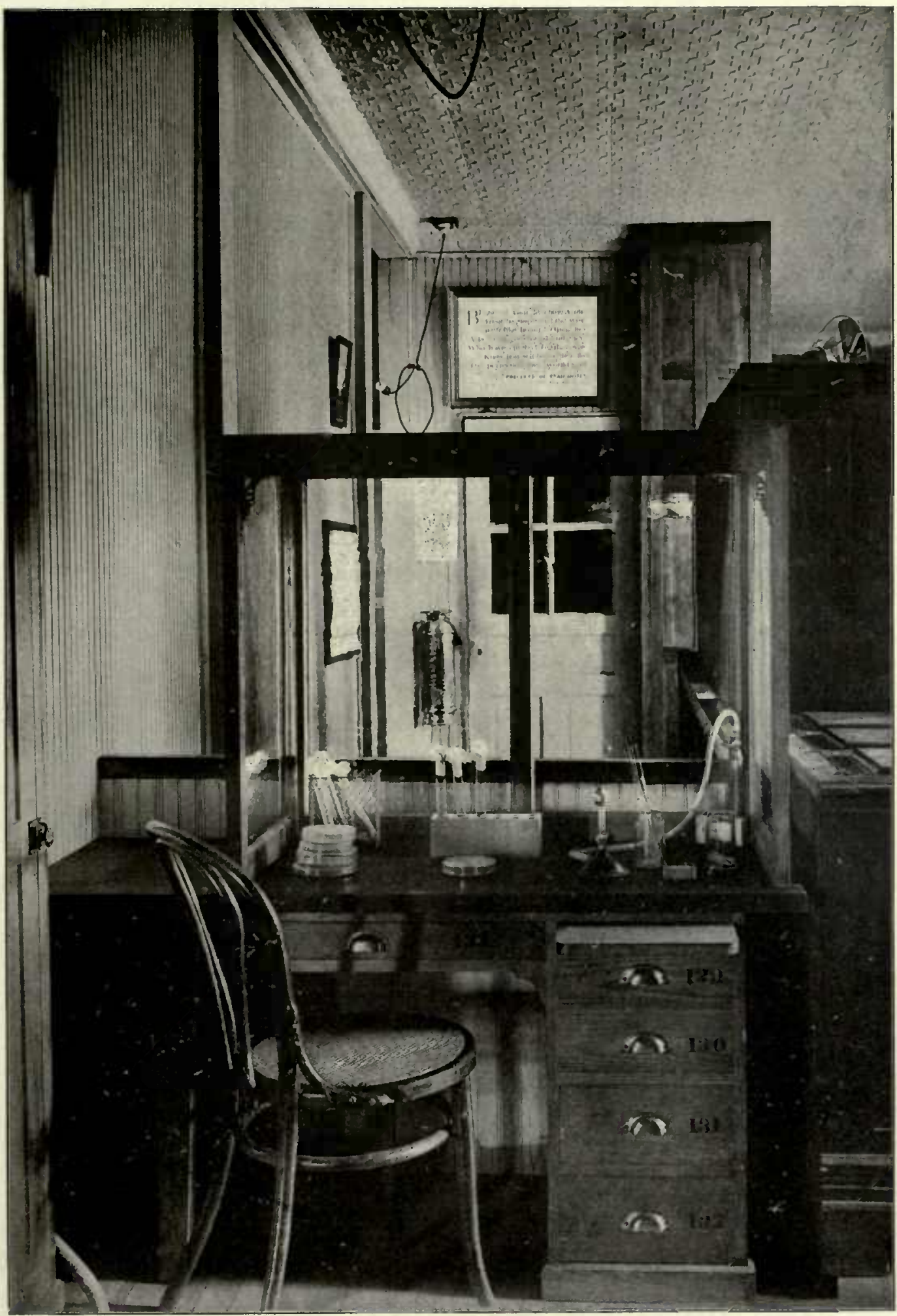

Work-table with movable frame of wood and glass.

Bacteriological transfers may be made under this frame in the open roon if windows and doors are kept clooed. 

stances likely to become moldy must never be stored in refrigerators designed for pure cultures. The open ice-box is the proper place for such substances, and they must not be left there indefinitely. Some people have a mania for collecting everything and then keeping it a long tine withont making any use of it. An ice-box treated in this way soon becones an intolerable nuisance.

Discarded plates, tubes, slides, covers, pipettes, contaminated litmus paper, etc., should be autoclaved, or covered or filled witl cleaning nixture, or dropped into it, as the case nuay be. Deep, narrow glass jars or long, rectangular enanneled pans are necessary for the pipettes. Soiled hands nuay be disinfected with nercuric-chloride water (1:1000), which should always be on liand in the laboratory in quantity prop-

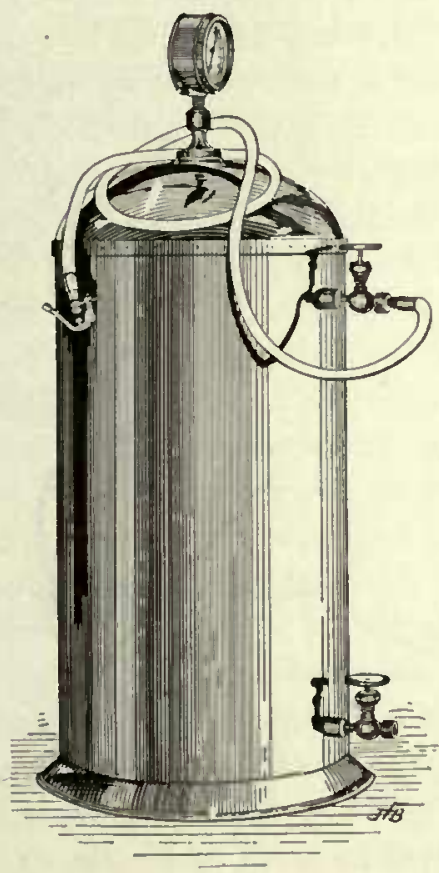

Fig, 92.* erly labeled. Slight wounds shonld be washed five or ten minutes in this fluid. Surfaces of floors, tables, etc. soiled by spilled bacterial cultures should be covered immediately with mercuric-clıloride water (1:1000) and wiped up carefully after ten or fifteen minutes with distilled water. Spilled cultures of molds should be soaked in mercuric cliloride ( $1: 1000)$ for at least an hour before wiping up. Neglect of these simple rules 111eans the seeding down of the ice-boxes, culture-chambers, and the general laboratory with all sorts of resistant mold spores and bacteria. An abundance of cheap carbonate of line should be kept on hand for the prontpt neutralization of spilled acids. A mass of cotton waste is convenient for the prompt 1nopping up of spilled fluids.

All contaminated needles, loops, knives, scissors, forceps, etc, may be sterilized in the open flame. Instruments which are too valuable to be flaned may be sterilized in carbolic acid ( 5 per cent) or formaldehyd (5 per cent) or lysol (5 per cent). Never put down a platinum needle or loop which has been used in making transfers until it has been passed carefully its whole length through the flame. Dissections are best made on trays whicl can be easily cleaned and sterilized.

*FIG. 92.-Compressed-air tank and spray-tube. The one here shown, made by Bocckel, Philadelphia, is nickel-plated and very substantially constructed. It is filled by means of a small pump similar to a bicycle pump. The gage registers up to Ioo pounds per square inch, but 40 pounds pressure is ample. The bacterial fluid is placed in atomizers of the form shown in fig. 93. The method of attachment is not satisfactory. This device is very convenient when trees or low plants covering a considerable area are to be inoculated. Hcight, 29 inches. The same firm has devised a compact traveling outfit, the compressed-air tank being about one-half the size of the one here figured. The whole is packed into a neat portable box, and the only disadvantage is the small size of the air-chamber, which requires more frequent pumpings. Of course the apparatus may be used equally well for the distribution of fluid germicides or insecticides. 


\section{ME'THODS OF INOCULATION.}

Inoculations nuay be by punctures with a delicate needle (fig. 9I), by abrasions of the surface, by hypodernic injection, by watering the soil with infective material, by phunging aerial parts into infections liquids for a longer or shorter time, by simply putting the bacteria into drops of water on parts of the plant and protecting from sunlight and evaporation for some hours, or on a larger scale by spraying portions of the surface with very dilute culture fluids or, preferably; with water containing the bacteria (figs. 92, 93, 94), by brushing or rubbing cultures into some part of the surface, by allowing insects, snails, etc., to feed on diseased material and then colonizing them on healthy plants. The writer has made good nse of this last method in case of three different bacterial diseases. Stomatal infections may be secured by subjecting the plants to conditions similar to those occurring in nature on dewy nights or during heavy fogs or prolonged rains, $i$. $e$, by placing the potted plants on wet sand, atomizing thoronghly with sterile water and covering with tall, roony bell-jars. The experinent shonld be undertaken in a cool rather than a warn honse. When

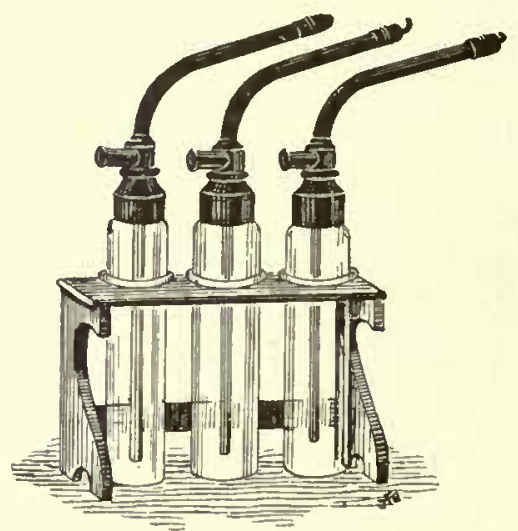

Fig. 93.* the riglit conditions have been obtained, moisture covers the surface of the plant in tiny drops which do not evaporate. The bell-jar may now be raised and the plant again atomized lightly with sterilized water containing the bacteriun. The best time to do this is late in the afternoon, so as to take advantage of the cooler night temperature. When the bell-jar is returned, which shonld be immediately after spraying, it should be covered with cloth or paper to protect from the light. Ustrally bell-jars should be relnoved at the end of twenty-four hours, but exceptionally they may be left on thirty-six to forty-eight lours, if not exposed to the sun. Inoculation cages are very convenient for small plants (fig. 95). In case of trees, or shrubs, or masses of tall herbs, tight-fitting covers of tent-cloth will be found serviceable for obtaining conditions similar to those prevailing in wet weather. They may be left on I to 3 days, the outside of the tent as well as the plants within being sprayed with water often enough to keep everything moist until infections lave been secured.

When the nature of the plant will permit it and when only a few inoculations are to be made, the surface which is to be punctured should be rubbed thoroughly for three to five minutes with mercuric-chloride water (r:IOOO) and then

\footnotetext{
*FIG. 93.-Atomizers for use with the air-tank (fig.92). These are made by the Davidson Rubber Company, Boston, Mass. About one-fourth actual size. The De Vilbiss sprayer, made in Toledo, Olio, and now used by the writer, has several distinct advantages. It is all metal and can be sterilized in boiling water without becoming twisted out of shape, it can be attached more easily to large flasks and to the tube leading from the compressed-air tank, and the spray may be directed up, down, or straight ahead without changing nozzles. It requires, however, more force to operate than the Davidson sprayers, and consequently is less convenient when used with a land-bulb.
} 
washed with equal care in sterile distilled water. When many inoculations are made with large numbers of clieck plants and when due care has been taken to work wnder conditions such that accidental contaminations from the same organisms are not to be feared, the writer has not found this precaution neccssary. The use of nuercuric chloride shonld be avoided, if possible, especially on leaves, as the writer's experiments have slown that it penetrates into the plant (some plants) for a considerable distance and prevents the action of the bacteria to this extent (fig. 88 ), if not altogether, as has lrappened in sonne cases.

\section{THE KFEPING OF RECORDS.}

If one contemplates doing much work, a careful record of what lias been done is as important as the experiment itself, since exact remembrance is certain to pass away with lapse of time.

In all his work, the student shonld accustom himself to make very exact statements, so that others may be able to follow hin. For exanple, he slould not describe his organism as "yellow" or "red" withont qualifications, since there are many yellows and reds, but slould carefully compare it with some standard color-scale (Ridgway's, Saccardo's, Standard Dictionary, etc.), and govern hi1nself

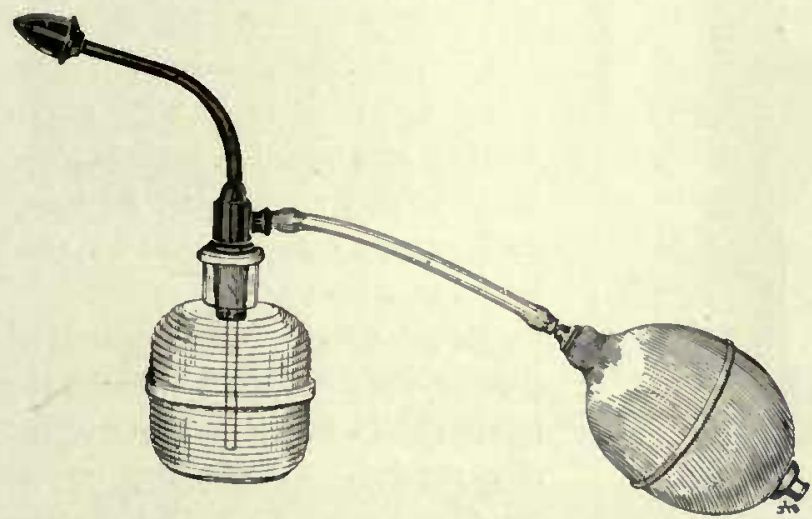

Fig. 94.* accordingly. He shonld not say, "Organism does not grow at roon1-temperatures," but rather should state the temperature at which growth does not occur, as I $5^{\circ}, 25^{\circ}$, or $35^{\circ} \mathrm{C}$, , any one of which may be "room-temperature," depending on the latitude, altitude, and time of year. He should not say, "Organism is killed at temperature of $65^{\circ} \mathrm{C}$.," without at the same time stating the age of the culture, conditions of exposure, and time required, whicl might be ten days or five minntes.

Every independent worker will in the end devise a method of note-taking which is more or less characteristic of liis personal pectliarities and best adapted to lis own particular needs. For all persons there is no one best method. The methods described in the following paragraphs lave been settled upon as those most convenient for the writcr, but it does not follow that they are the most econonical of time, or the best devisable, or the ones which independent workers shonld follow. They are here given as hints for beginners and because the metlod a man employs in his work is always a matter of more or less interest to his fellow-workers.

First of all, there should be provided a record book in which the method of preparation of each culture mediun is carcfully described. This should be a good-

*FIG. 94.-Hand-sprayer which may be used for distributing bacteria on plants. Some form is usually kept in every pharmacy and sold as a cologne atomizer. 
sized book, well bound in leather, so as to stand long and hard usage. The entire quantity of a culture medium is known as a "stock" and receives a special number, which is written, pasted, or stamped on any flask or tube that contains it and which serves to identify it. If a stock is subsequently divided and a portion of it is treated in some different way, $e . g$, receives more sugar, acid, or alkali, this portion receives a new number, or the old number with the addition of a letter of the alphabet. Each stock described in the record book is numbered serially from I, and the book continues in daily use as long as the laboratory, or 11ntil it is filled witlı records and carefully filed away as "Culture Media, Volıme I."

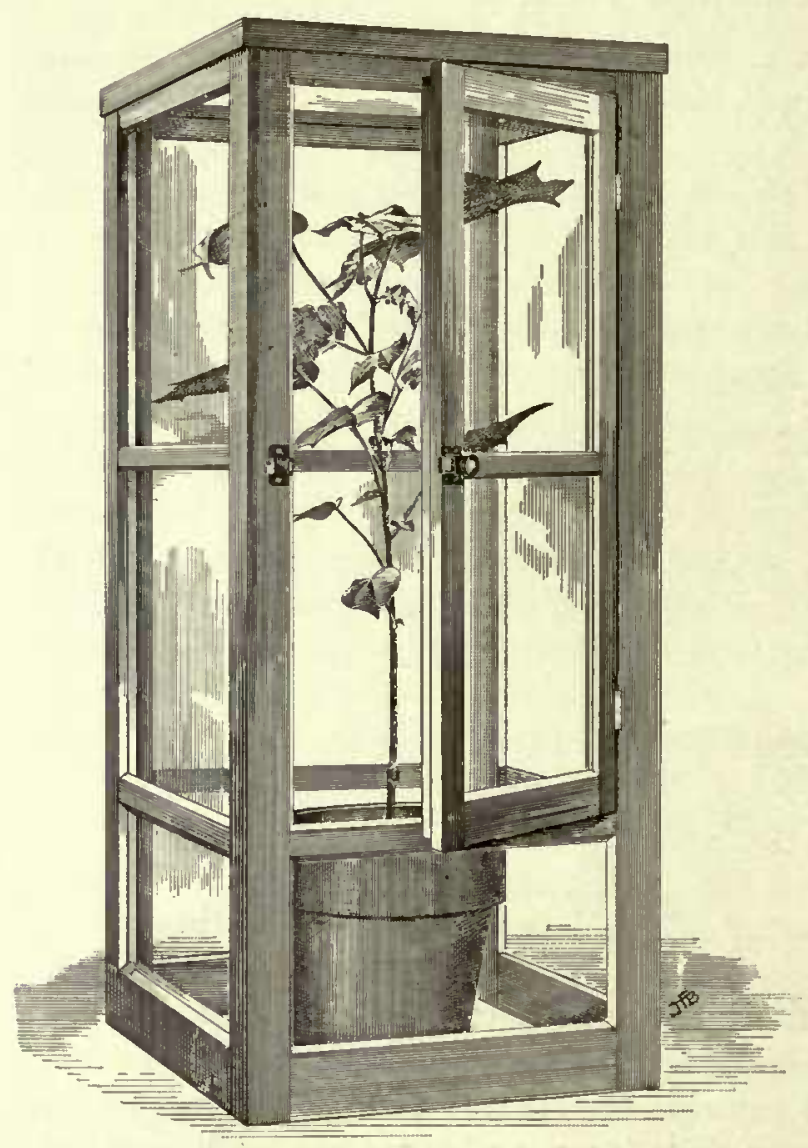

Fig. 95.*

The small pocket ledger, No. 492 of A. C. McClurg \& Co., Chicago, is very convenient for certain kinds of notes, especially those made in thefield and those required for the identification of alcoliolic specimens and stained slides (fig. II2). All records slould be in ink, of a sort which does not fade, and in field work a good fountain pen is invaluable. Pencil records, especially those made with rapidwriting soft pencils, soon become illegible and should not be tolerated except on paper to be subjected to stean heat.

Large sheets of well-gummed paper should be procured and the labels cut in the laboratory to the size needed. Labels may be cut rapidly in quantity with the apparatus used to trim plotograplic prints for mounts. When exposed to streaming steam such labels come off easily, and it is best not to paste thein on the tubes or flasks until after the final steam steriliza-

tion. In moist climates, stock quantities of such gummed labels must be kept in air-tight boxes or between sheets of paraffined paper. Test-tubes in crates are kept separate during steaming by writing the number of the stock on a slip of paper and thrusting this into the crate with the test-tubes. The number slould be written with a lead pencil. Faber's pencils for writing on glass are useful in case of flasks and

*FIG. 95.-Small cage of wood and glass in which herbaceous plants may be placed for inoculation by spraying. The inside measurements are 12 by 12 by 30 inches. The large door is a great convenience. Hook-fastenings are better than spring catches. 
fermentation tubes, since records made with these pencils will bear streaming steam. An inexpensive black pencil wlich writes on clean glass very readily and bears stean well (even better than Faber's) may be made by stirring into melted beeswax enongh lanp-black to make a thick-flowing liquid (as thick as will flow). This is

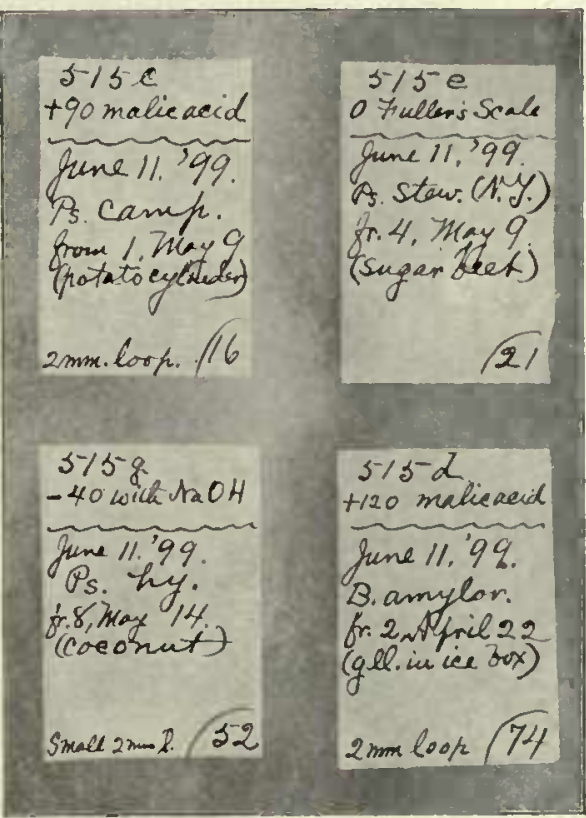

Fig. 96.* poured into molds made by wrapping writing paper, in several turns, around a lead pencil or thick glass rod, tying near one end, renloving the rod, squeezing the other end flat, turning over its edge, and fastening this flattened end in a split stick or clanp. The paper should be retained as a cover, the string being removed and the loose edge pasted down. A dozen such pencils may be made at a cost of Io cents. In the absence of such pencils, flasks and fernentation tubes may be distinguished in the steaner by dropping over the neck different-sized rubber bands or different numbers of the same kind of band, or by writing with a lead pencil the number of the stock on a square of letter paper, cutting a loole in its center and slipping this over the neck of the flask or tube. When the steaming is over, the regular labels should be pasted on or the stock number written on with the proper pencil.

All plate cultures and all subcultures made on a given day, no matter of what organism, are numbered serially, beginning with $\mathrm{I}$. These are $\mathrm{I}, 2,3$, etc., of that particular day. Those of any other day are also numbered I, 2, 3, etc. The writer
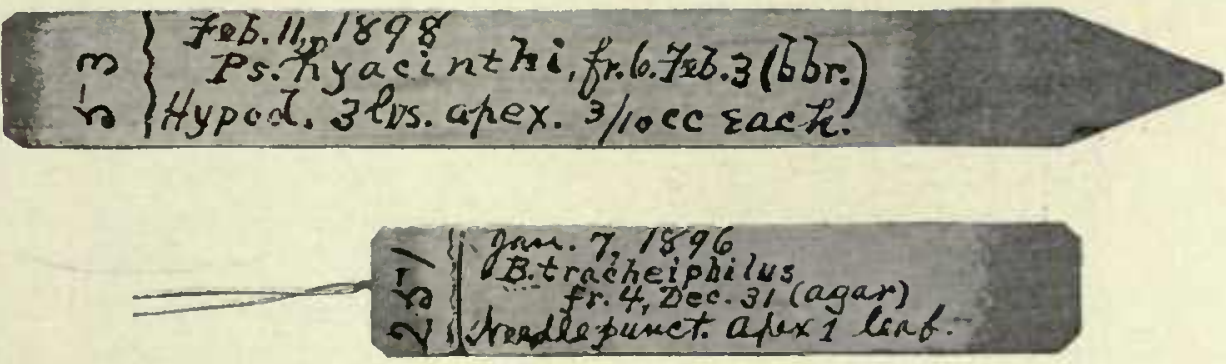

Fig. 97.*

usually numbers his plates I, II, III, etc. Labels may be pasted on the covers of the Petri dislıes, or all may be done with the glass pencil. Cultures in tubes subject to frequent handling and likely to be needed for some tine should have gummed-paper labcls written in ink. The above transcripts from labels on four test-tube cultures

*Fig. 96.-Labels from test-tube cuitures.

*FIG. 97. -Wooden labels from inoculated plants. 
(fig. 96) sufficiently indicate what is necessary to form a satisfactory record. This could, of conrse, be considerably abbreviated by a systen of symbols or by depending to a larger extent on the "Notes."

In case of the inoculations, on the contrary, only as many series are made use of as there are diseases under consideration. Eacl plant is generally given a single number, no matter in how many places it may be inoculated, the separate inoculations being kept distinct, if necessary, by sub-1numbers. Each series begins with

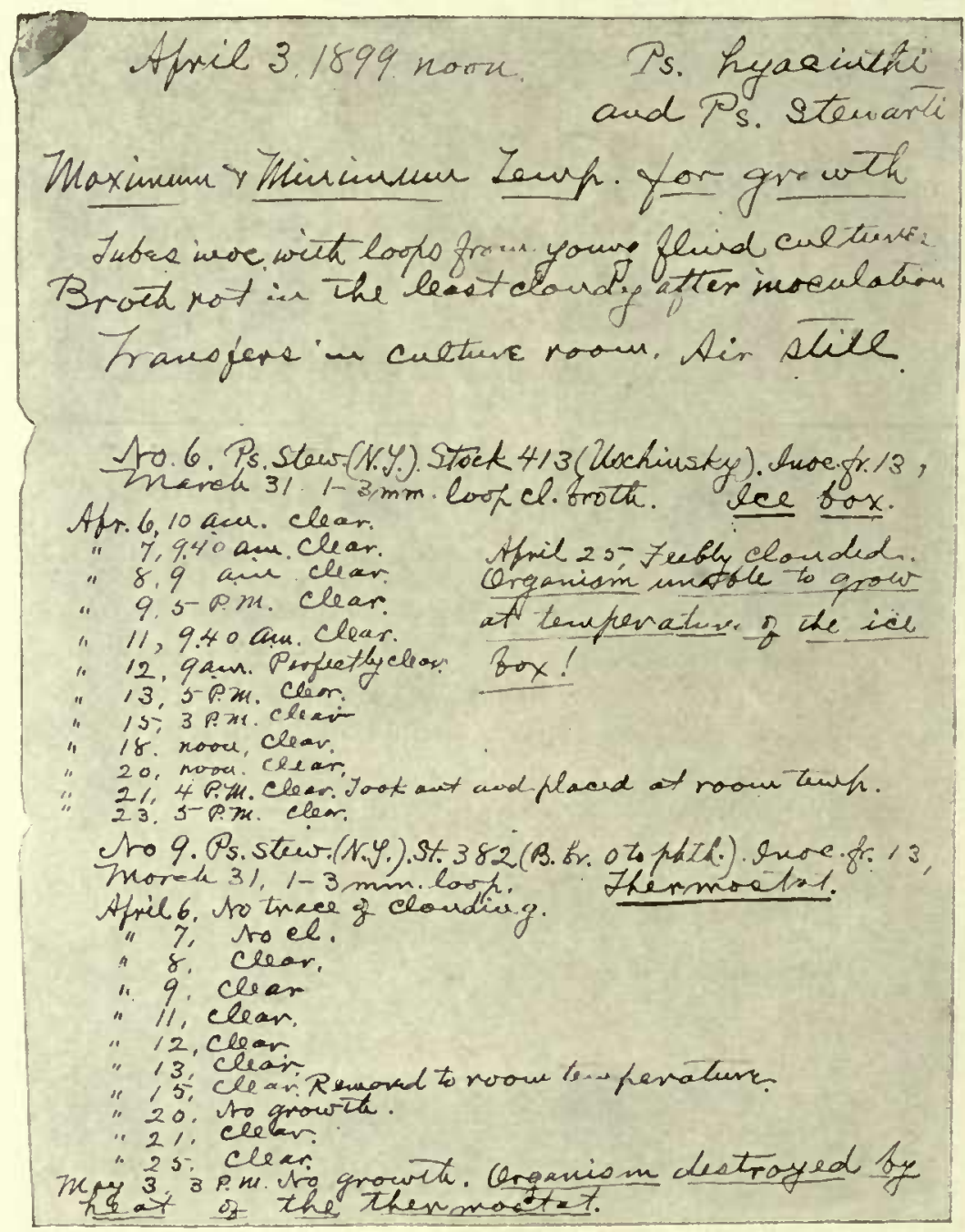

Fig. 98.*

No. I and continnes in an nubroken sequence as long as the disease is under consideration. The labels written on soft wood, covered for this purpose on one side with white paint, are stuck into the earth or wired to the plant. Transcripts fron two such labels are show1 in fig. 97 .

*FIG, 98.-Three sheets showing method of keeping maximum and minimum temperature records. One-half actual size. 
After trying varions methods, the writer has settled down (in the absence of a stenograplier) to the following style of pen and ink notes on cultures, inoculated plants, etc., as extremely flexible and convenient. Reans of ordinary typewriter paper are cut crosswise into three equal portions, so as to form slips about 8 by $3 \frac{1}{2}$ inches. As many of these as are necessary for the particular purpose are fastened together at one comer with $B, J, N, C$, or Z eyelets and the Triumpli punch, sold by The W. Schollhorn Company, New Haven, Conn., or by the neat little saw-

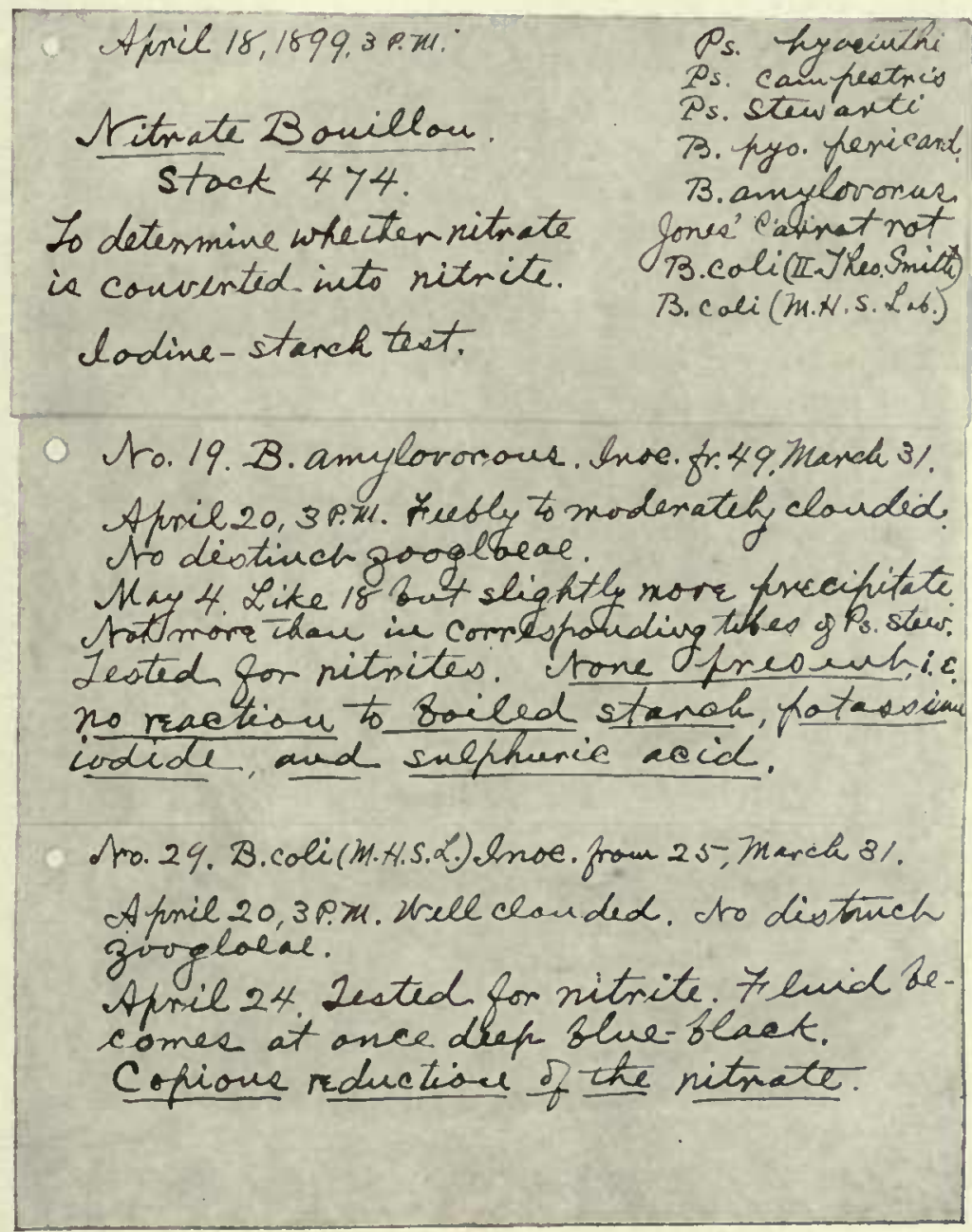

Fig. $99 . *$

toothed clamp made by 'The Middleton P. F. Co., Philadelphia. The first page of the slips is devoted to the name of the organism under examination, the kind of experiment, the date of its beginning, etc. The subsequent sheets are numbered serially and are devoted to particular plants or to particular cultures. If there is an overflow in any particular part of the record, it is very easy to insert additional

*FIc. 99. - Sheets showing method of keeping nitrate-bonillon records. One-half actual size. 
slips. The following transcripts fron actual records will serve to illustrate the method (figs. 98 and 99). As fast as the notes are completed they are filed away in boxes or large envelopes n1ntil the whole subject has been worked over, when they are sorted out according to their varions sub-heads, and all the data which they

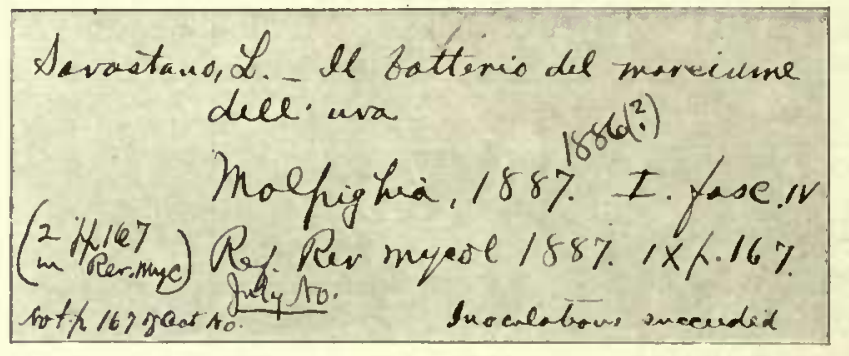

Fig. 100* contain is thus easily available.

The writer also uses a stenographer whenever possible, and the typewritten sheets, after immediate careful scrutiny for errors of fact, are filed away in stont Manila envelopes with the name of the parasite written on one corner; I 6 by i 2 inches is a good size for the envelopes.

Card-catalogues should be made on the L. B. index slips, made and sold by the Library Bnrean, Boston, Mass. Figure Ioo is a san1ple from the writer's catalogue by anthors. A larger size should be selected if it is desired to include abstracts. When long abstracts or considerable extracts are made from literature which has been borrowed, or may not be readily accessible in future, leavy slieets ( $67 / 8$ by $83 / 8$

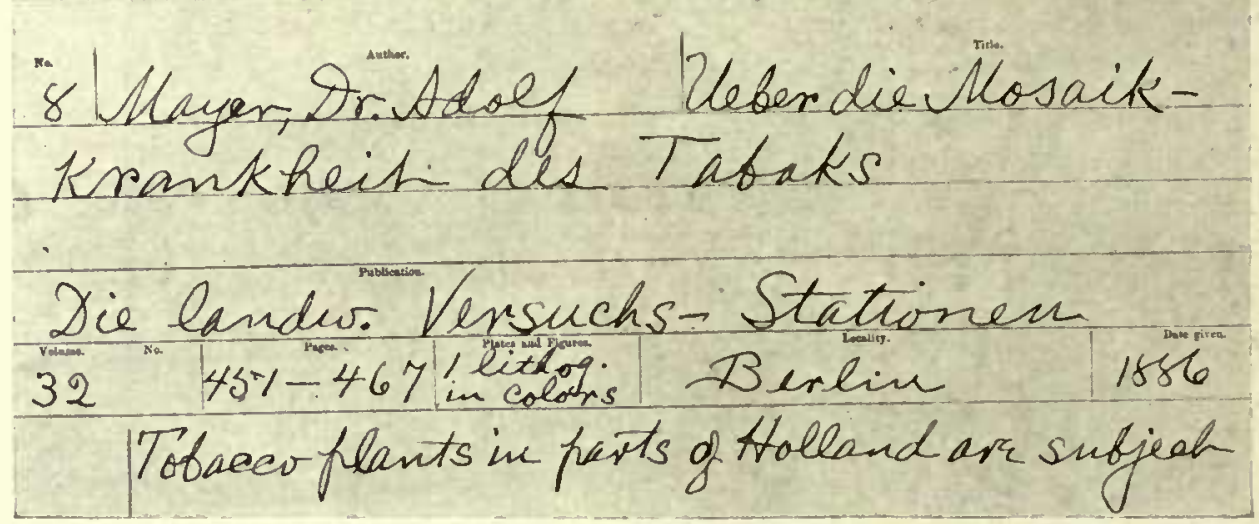

Fig. 101.†

inclies) liave been used by the writer. These have headlines, as shown in fig. Ior, and are preserved by tying into covers made for the purpose. A red line down the left side of the sheet preserves a space for a marginal index.

A serions objection to the making of many abstracts is the time involved and the danger of degenerating into a mere student of literature in the effort to make a complete catalogue; another is the fact that, if made in advance of actual need, or

*FIG, I00.-Sample from card-catalogue. Two-thirds actual sizc.

†FIG. IOI.-Top of large sheet used for voluminous abstracts. A red line near left-hand margin marks off a space on which summarizing catch-words or phrases are written. Breadth of sheet, $67 / 8$ inches. 
by some one not entirely faniliar with the subject, it not infrequently lappens that the statements in the paper which have been omitted from the abstract as nnimportant prove in the end to be the essential ones so far as the owner of the abstract is concerned. For this reason, when they are within reacl, the writer prefers to consult the original papers and to save for original work the time consumed in making long abstracts. When they are rare, frequently needed, and only to be had by borrowing, the writer has son1etines

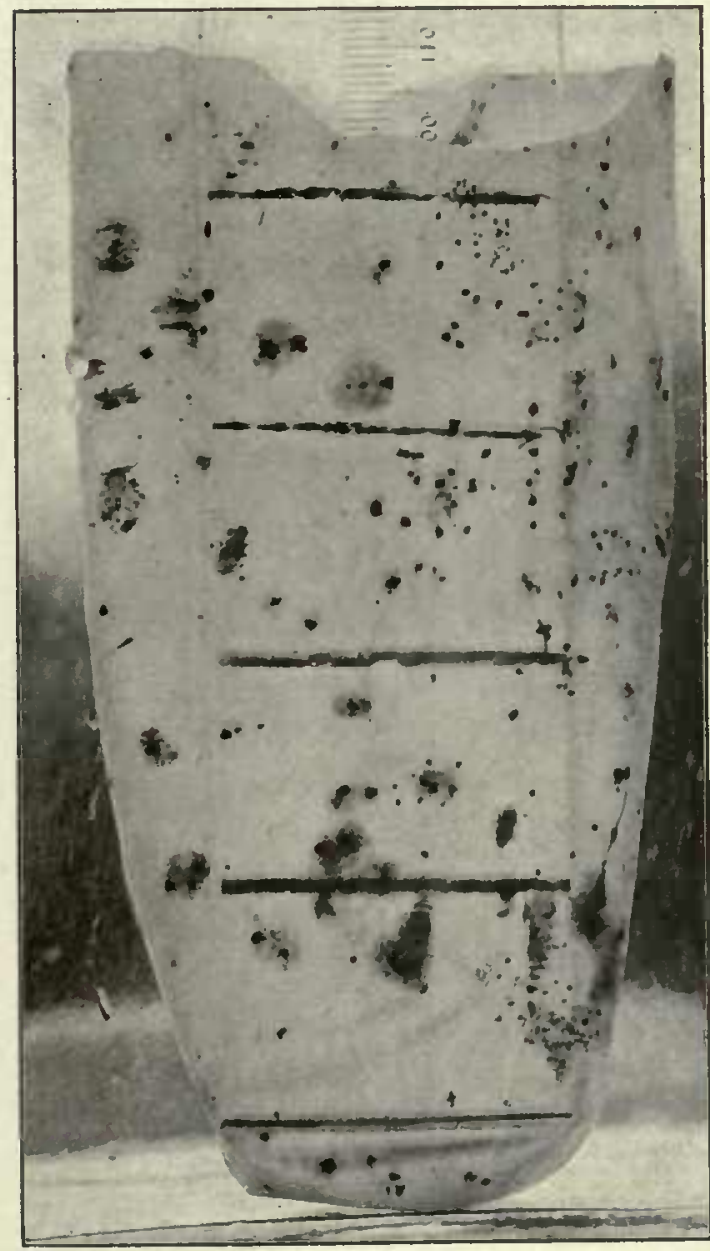

Fig. 102.* plotographed the nore essential parts. In one instance a pamplilet was borrowed from Europe for this purpose.

For the exact measurement of colonies, etc., a strip of plate glass $35 \mathrm{~cm}$. long and ruled into $350 \mathrm{~mm}$. spaces may be lrad from Carl Zeiss, and will be found very convenient (fig. IO2).

Steel rules of any size and of very excellent workmanship, graduated according to the English or the n11etric system in any degree of fineness, may be had from the L. S. Starrett Comlpany, Athol, Mass. 'Two of these rules much used by the writer are, respectively, I 2 inches and 30 centimeters long. They are one inch wide and abont three sixty-fourths of an incl thick. They are graduated on both sides, the metric rule into centimeters, millimeters, and one-half millimeters, and the English into inches, halves, quarters, eightlis, sixteenths, thirtyseconds, and sixty-fourtlis.

Stage micrometers made by Zeiss are recommended for the finer measurements. These have I millineter divided into tenths, twentietlis, and one-hundredths very accurately. All the magnifications of microscopic objects figured in this book are recorded in terms of sncl a micrometer. After the drawing has been made it is custonary to substitute for the section-slide this stage micrometer and throw the image of some portion of the ruled scale on the paper

*FIG. I02.-Green cuscumber soft-rotted by Bacillus aroideae. Contents emptied out and skin filled with water and so photographed, 3 days from date of inoculation, which was by means of a few needle-pricks. The fruit was kept at about $25^{\circ} \mathrm{C}$. The black bands are pencil marks on the millimeter rule placed inside. The numerous small dark spots are denser bits of tissue whicl did not wash free on rinsing out the sack with water. At the left drops of water may be seen oozing through the skin and falling. Plotograpl, nearly natural size, by Townsend. 
where it is drawn, taking care, of course, in case of high magnification, to start one cross line from the outside and the other from the inside of the inage of the lines. This nethod of recording magnifications is urged on all. It takes but a monnent, does away with troublesone conputations, and enables anyone at any tine to determine just what was the magnification. The magnification is determined, of course, by dividing the apparent size by the actual portion of the scale showis. For

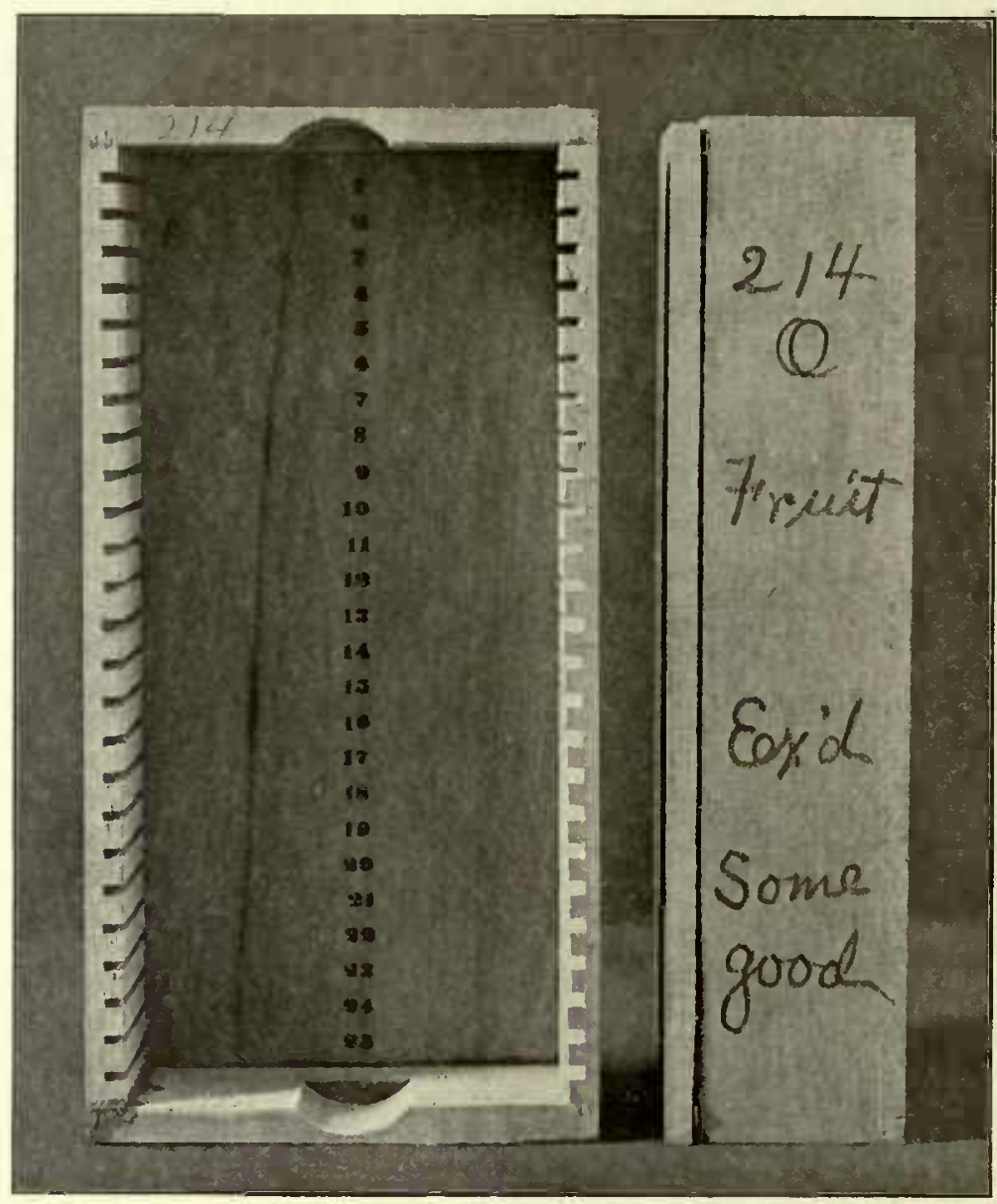

Fig. 103.*

exanple, if the scale drawn on the paper is ro 11111. long and represents o.or mu1. of the actnal nicrometer scale, then the magnification is $X$ Iooo; if it represents the entire nillineter of the micrometer scale, the nuagnification is $X$ ro.

For fine weighings, Christian Becker's balances are very satisfactory.

*FIG. I03.-Pillsbury slide-boxes empty and full, made by Bausch \& Lomb, Rochester, N. Y. These boxes are simple, inexpensive, and satisfactory, especially for serial sections. 
THF, MAKING OF COLLECTIONS.

A good, representative collection of diseased material is a prine necessity in every pathological laboratory. This grows into completeness only with the lapse of much time and the aid of many hands. It should include photograpls, drawings, paintings, dried material, representative specinens preserved in strong alcohol, and serial sections properly stained and mounted in Canada balsan or Dammar balsam, which nust not be dissolved in chloroform, since this gradually removes the stain. With the accumulation of much material, some sort of classification beconnes in1-

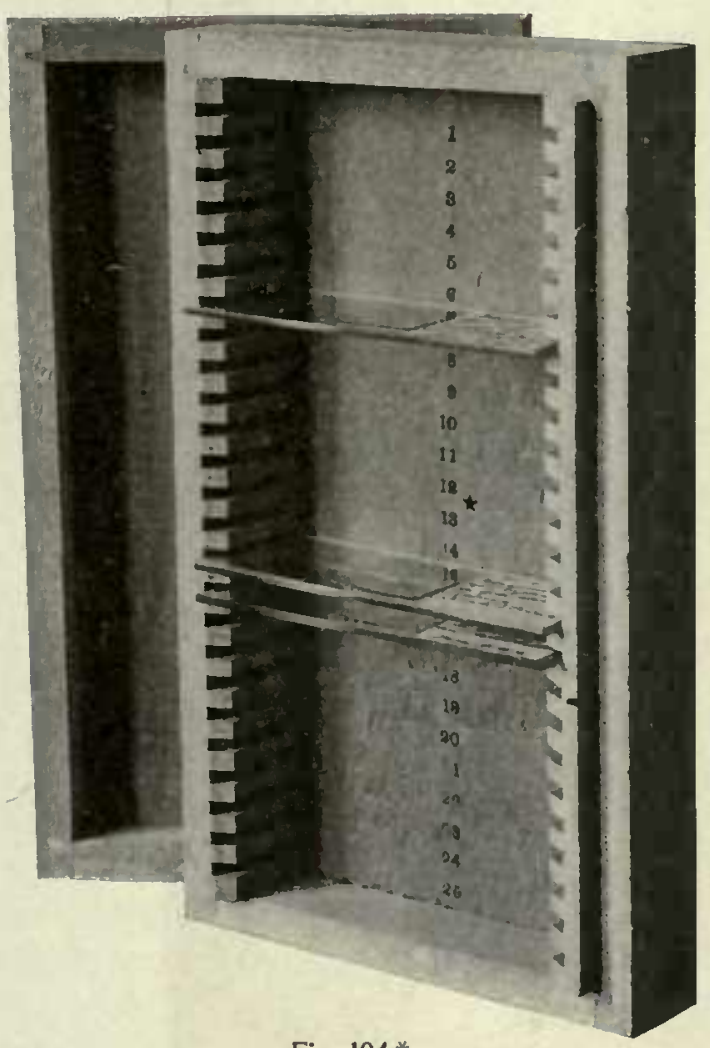

Fig. 104.* perative. At present the writer keeps the material designed for sections in 95 per cent alcoliol, arranged in as 111any groups as there are parasites involved. Eacl jar of inaterial finally receives the same number as the paraffin block from which sections are cut. This material inust be exanined at least once a year to see that the alcohol has not evaporated, especially if corks are used. Only the best relvet corks should be purcliased, and as an additional precantion they should be sealed in with paraffin. The negatives are filed away in similar gronps, protected by negative bags. The stained sections, monnted in balsan1, are filed away in cheap wooden boxes (Pillsbury boxes), each holding 25 slides (figs. 103, 104). These are very convenient, if properly made, but some boxes of this sort lead to 1nucl vexation of spirit, the grooves being too narrow to receive any but the thinnest slides. Those sold in recent years by Bansch \& Lounb liave given no tronble. In the form shown in fig. Io4 the cover remains on better and the monnted slides are easier to take out, but in drying the preparations with the cover off, these boxes tip over at the least touch. During this drying, which requires from a few days to several weeks, the slides should, of course, lie flat, not on edge.

*Frg. I04.-Another style of slide-box. The advantages of this box are that the cover is not likely to fall off and that the slides, in case of full boxes, are withdrawn more easily. The disadvantages are that it is tipped over very easily when standing on end open, that the cover is readily mistaken for the bottom when it is closed, and that if the cover is put on upside down the writing on the edges is divided. These may also be had from Bausch \& Lomb. 
The writer passes material designed for sections from alcolol through chlorofonm (or xylol) into paraffin. Chloroform is preferred in case the infiltration is to be completed in vacuo; otherwise xylol is generally employed. A mixture of xylol and alcohol is first used, then pure xylol, after this xylol with as much paraffin as can be dissolved in it cold. The vial is then placed on top of the paraffin bath and

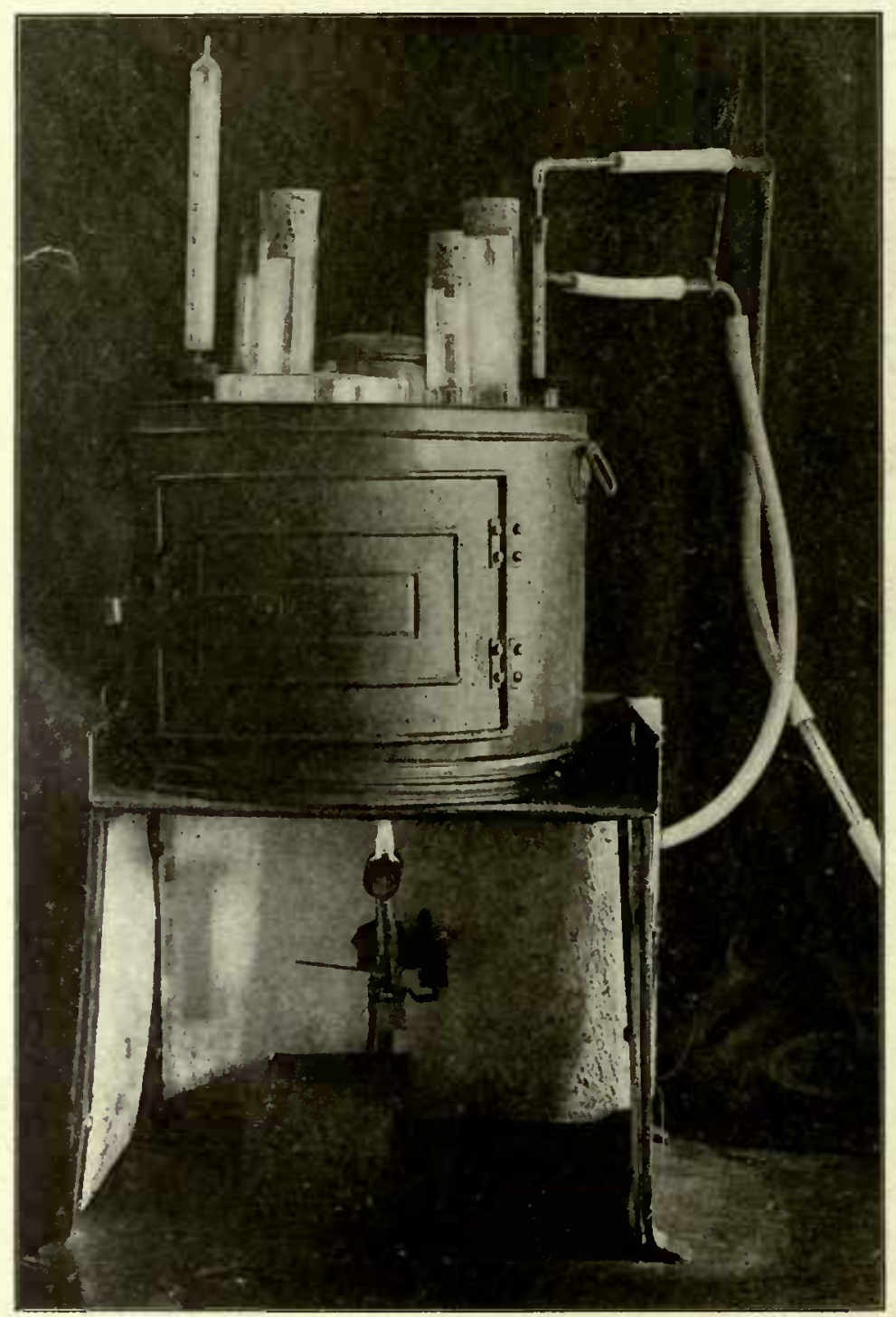

Fig. 105.*

shaved paraffin added until it will dissolve no more at this temperatnre; the material is then placed inside the apparatus in pure melted paraffin, and it is finally mounted from a second dish of pure paraffin. The temperature of the paraffin bath is usually

*FIG. I05.-A small paraffin oven much used in the writer's laboratory. The capacity of the cliamber is 6 by 7 by 5 inches. The thermo-regulator is like that shown in fig. 35, but with chloroform substituted for glycerin. 
kept at $59^{\circ} \mathrm{C}$, and the material is subjected to this temperature only long enongh to secure proper infiltration. Generally a few lours are sufficient. A sulall oven used for this purpose is shown in fig. 105. For large laboratories or classes of students the separate-compartment paraffin oven designed by Dr. Lillie is very convenient. Griibler's paraffin is preferred, and for the climate of Washington we use mixtures of three grades of hardness, viz, melting point $52^{\circ} \mathrm{C}$., $58^{\circ} \mathrm{C}$, and $60^{\circ} \mathrm{C}$., increasing or decreasing the amount of the harder sorts according to the time of year. Dirty paraffin slould never be used. All the stock paraffin should

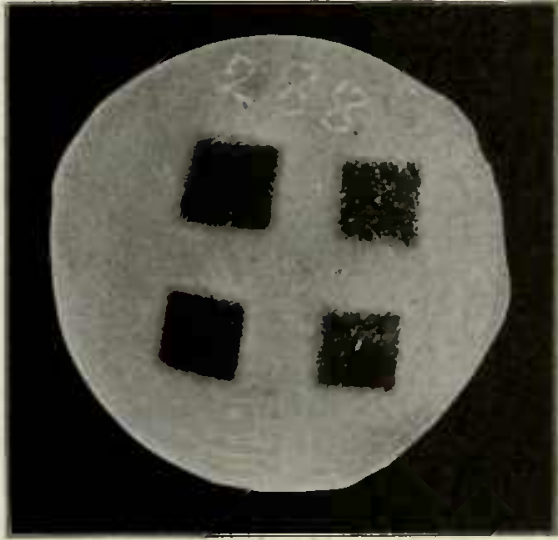

Fig. 106.* be carefully protected from dust. 'The same remark applies still more pertinently to the sections cut on the microtome. They should be made in still air, in a clean roon, and should be carefully protected from dust until stained and mounted. The paraffin-infiltration is usually a simple process unless the material contains air. The embedded material is given a serial number which is scratched on the paraffin (fig. 106), until it is fastened to the cutting block, when it is written on the latter (fig. 107). These blocks are kept as shown in fig. I08. The sections are fastened to clean slides by a very thin layer of Mayer's egg albumen fixative (see Lee's Vade Mecum, 5th ed., p. 143), or with pure water, or preferably with 0.5 per cent gelatin water (which will not keep untreated, but may be preserved by adding 3 per cent phenol); the paraffin is removed (after cautions melting) by exposure to turpentine or xylol, alcohol is then substituted, and thereafter graded mixtures of alcohol and water down to alcohol containing 50 or 60 per cent of water, followed by the stain. Water is then removed by passing through graded alcohols into absolute alcohol; xylol or bergamot oil is substituted for the alcohol, and the section is finally mounted in balsan. Coplin's staining jar is preferred (figs. I09, I IO). A series of staining jars, ready for use, is shown in fig. III. The section properly fastened to the slide, and dry, is started in at the left after inelting the paraffin with gentle heat, and is taken out at the riglit ready for mounting in balsam. $f$ In this series of jars the gradations are as follows, beginning

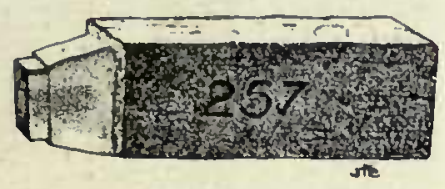

Fig. 107. $\nmid$

*FIG, I06.-Infiltrated tissues embedded in paraffin in a watch-glass and now ready to cut out and mount on blocks for the machine.

$\nmid$ FIG. I07.-Infiltrated material embedded in paraffin and mounted on a pinc block rcady to cut on the microtome. Actual size.

†Sections designed for photo-micrographic work must not only be cut in clean air, but mounted in absolutely clean balsam. So mucls trouble has been experienced in finding sucli dissolved balsam on the market that the writer now makes his own. The dry balsam is heated in an oven unti] all easily volatile products are driven off and it becomes brittlc. It is then dissolved in xylol and filtered under a bell jar to exclude dust. The filtcring usually requires several days. 
at the left: Xylol, second xylol, xylol one-third absolute alcohol two-thirds, 95 per cent alcolıol, 75 per cent alcohol, 55 per cent alcohol, 40 per cent alcohol, carbolfuchsin, 40 per cent alcohol, second 40 per cent alcolıol, 55 per cent alcohol, 65 per cent alcohol, 75 per cent alcolol, 95 per cent alcoliol, absolute alcoliol, second absolute alcolol, xylol, second xylol. From this last jar the material is nounted in balsan1. Turpentine nuay be substituted for xylol in jars $i$ and 2. After the paraffin is fully removed, the slides are passed rapidly from jar to jar (a minute or two

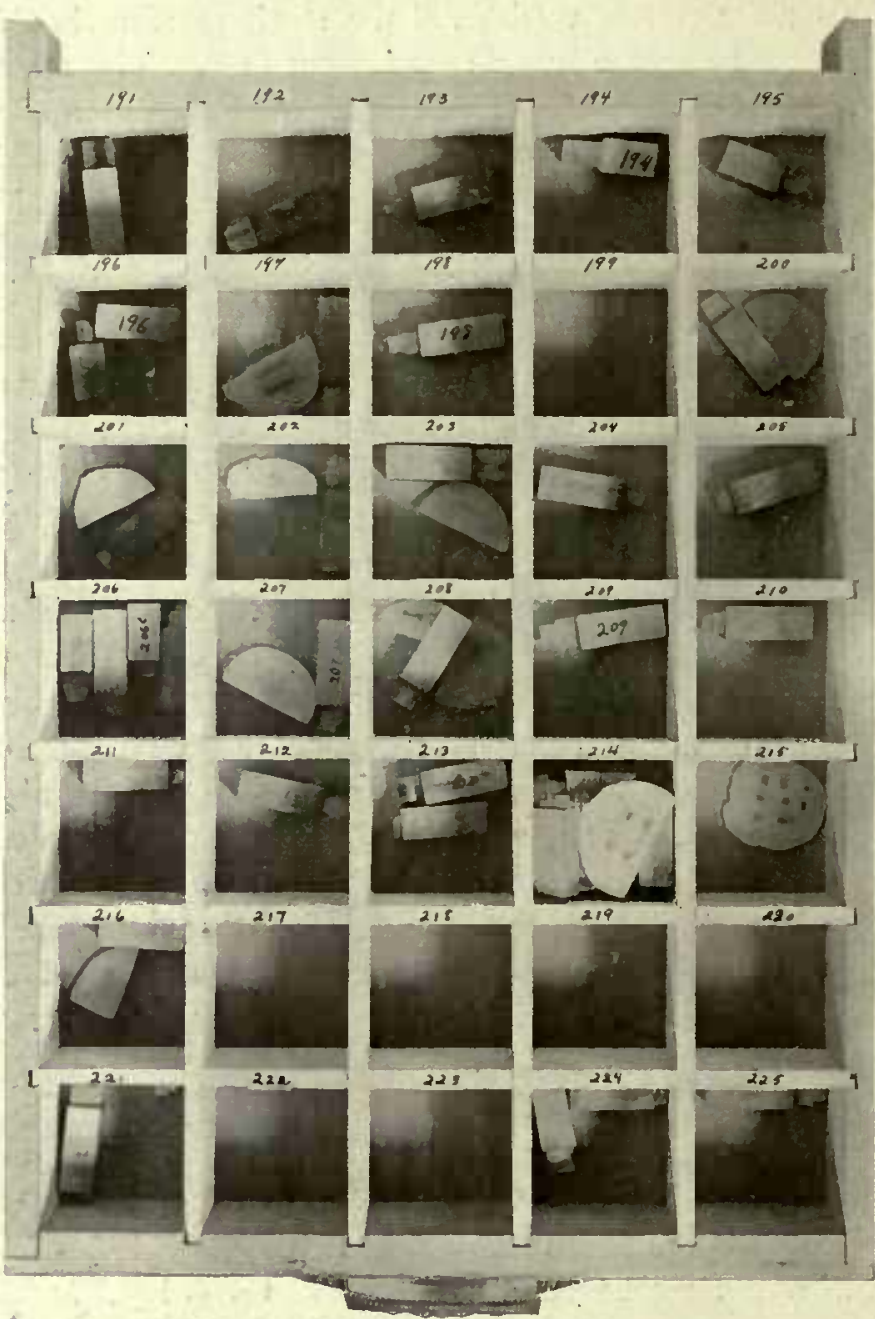

Fig. 108.* in eachi being generally sufficient) until the stain is reached. After renlaining in the stain the proper length of time (nswally thiree to tein ininutes, but sometinies intich longer) the slides usually are allowed to renain in the 40 per cent alcohols for a number of minutes, witl frequent inspection. When they appear to be properly bleached (rather pale) they are passed rapidly throngh the remaining jars nutil they reach the xylol, in whicl they may remain for some time without injury, if they can not be n11ounted innmediately, but they 111tst not be allowed to stand for any great length of time in any of the alcohols. The secret of success lies in obtaining just the proper annount of differentiation in the 40 per cent alcohol and in not losing any of this later o11. To retain the stain it is necessary sometimes to omit some of the graded alcohols.

The time required for properly staining sections varies from one or two ninintes to a half day or inore, according to the subject and the stain en1ployed. No general rule applicable to all cases can be given. When the nuaterial is selected for enibedding, its serial number, with a full description, is entered in the record book (fig. I I 2 ).

*FIG. I08.-One of a series of drawers divided into small compartments for holding infiltrated, enibedded material, cut and uncut. 
PLATE 13.

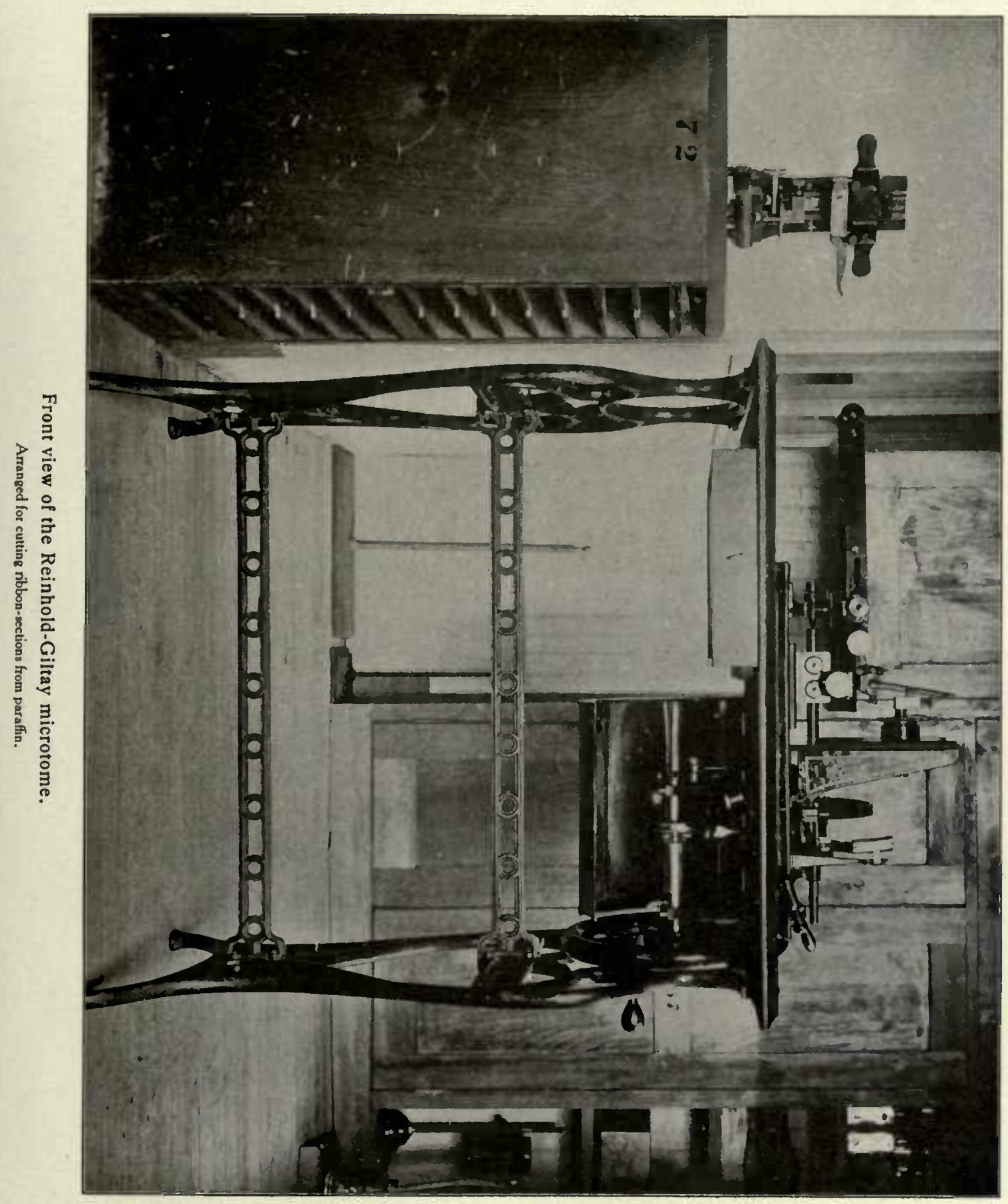



This book must not be lost or misplaced. The advantage of liaving the serial number written also on the bottle containing the stock of preserved material is very evident if a thing of this sort ever happens. The serial number is written on one edge of the slide-box, and serves to identify it (fig. I03). Some record besides a nere number should also be placed on the slide-boxes. All the slides within bear this numl-

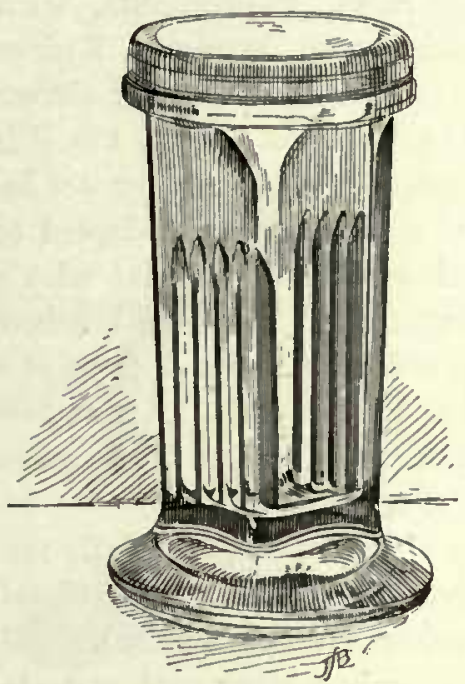

Fig. 109* ber, e. $g ., 256$, and also a series number of their own, $i$. e., I to 25 . The slideboxes are then filed away on shelves either serially or in groups, according to the parasite. Slides containing particularly good

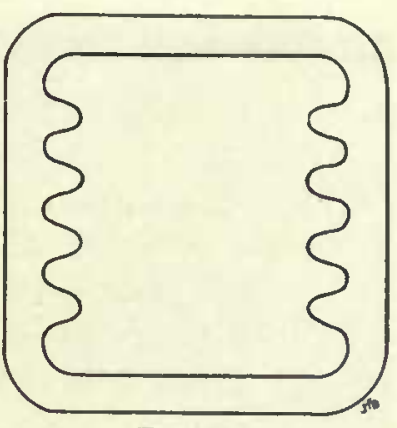

Fig. $110, \dagger$ fields are marked $X$, and when the best fields are finally decided upon their location is recorded as determined on the mechanical stage. In case a dozen or more serial sections are included on one slide the the extra good ones are marked $X$ on the first exanination, and the others $O$, as slown in fig. Ir 3 . When one of these sectious lias been drawn or photographed, the $\mathrm{X}$ is underscored or inclosed by a circle. This nnethod enables one to keep track of any number of sections. Free-hand sections may be made with the Torrey razor shown in fig. Ir $4 \mathrm{D}$. This is altogether the best razor the writer has used. When very dull it may be sharpened on an India oil-stone. These stones are said to be made of a mixture of carborundun and clity, baked at a high temperature. They may be

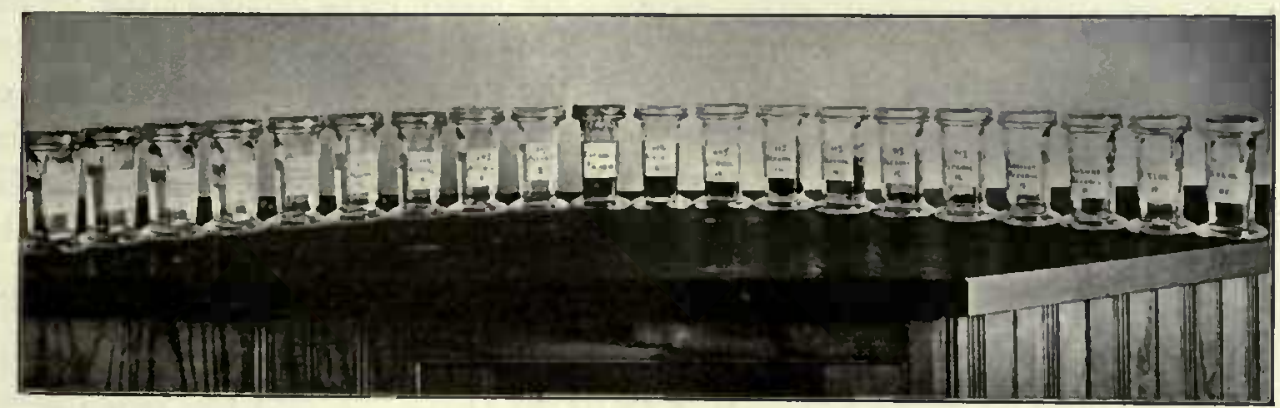

Fig, $111 . \neq$

had of tlie Norton Emery Wheel Company, Worcester, Mass., in three grades of fineness, the finest being usually coarse enough for the dullest razors. The size needed is 8 by 2 by $\mathrm{I}$ inch. The finishing nuay be done on an Arkansas oil-stone, with a

*Fic. rog.-Coplin's staining jar. About one-half actual size.

†FIG, II0.-Cross-section of Coplin's staining jar. About actual size.

$\$$ FIG. III.-A series of Coplin's jars filled and properly arranged for staining sections fastened to slides. 
few final touches on a good leather strop. The maintenance of good edges on microtome knives is a matter of great importance and considerable difficulty, and where much material is to be cut it is very economical of time to send away such

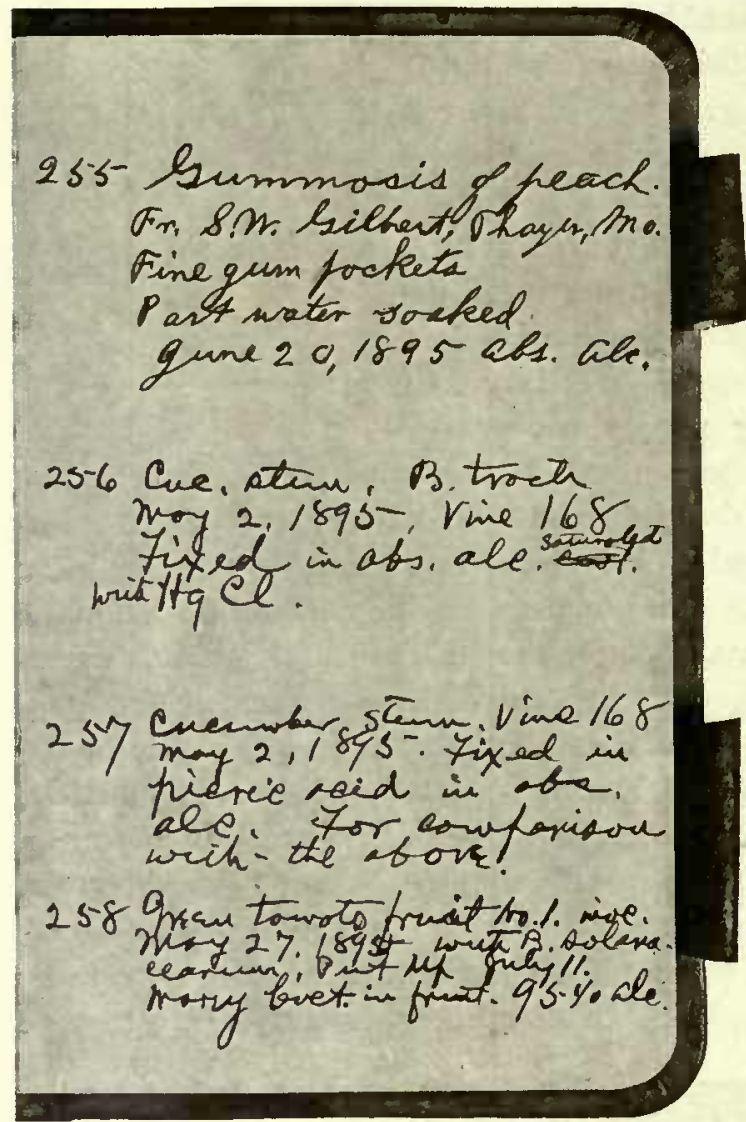

Fig. $112 .^{*}$ knives to be put in order by some expert. In recent years the writer has sent all such knives to Charles Lentz \& Sons, Philadelphia, with very satisfactory results. Knives suitable for serial sections are shown in fig. I $44 \mathrm{~A}$ and $\mathrm{C}$. In fig. II $4 \mathrm{~B}$ is shown one of a set of knives not inclined to spring and well adapted to the cutting of hard material with a long slant stroke. These knives were made to order by Lentz \& Sons at a cost of about $\$ 6$ each. An end-on view of all these knives is shown in fig. I I $4 a, b, c, d$.

Many plant tissues, especially mature leaves, are full of very hard calciunn oxalate crystals, and the difficulties of properly cutting such material are very great. The cutting of thin sections of bone would be quite as easy. After even a few sections the edge of the knife looks like a miniature saw and the sections themselves are badly torn, partly by the dulled knife and partly by the movement of the crystals themselves. In case of the yellow disease of the hyacinth the writer has never been able to make satisfactory thin sections, many of the soft cells being filled with bundles of very hard raphides which he has not been able to dissolve without serious injury to the tissues. In such cases thick free-hand sections are about all that can be hoped for.

Serial sections are cut on the microtome. The one shown in pl. $\mathrm{r}_{3}$ and fig. I 99 leaves nothing to be desired in the way of a

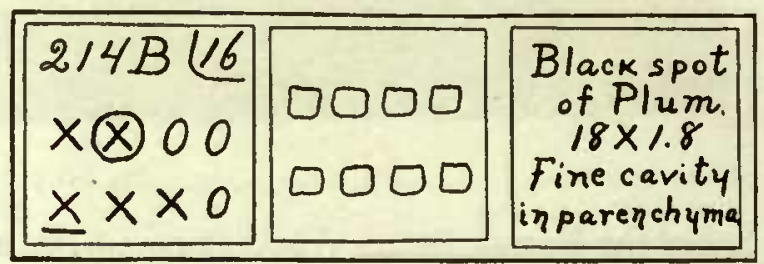

Fig. 113.† perfect-working durable instrument. The ribbon-carrier is above the table at the left. The knife is stationary. The block moves up and down, and the razor-carrier

*Fig. I12.-A page from the paraffin record-book. The numbers on the slide-boxes (fig. IO3) correspond to numbers in this book. Two-thirds actual size.

†FrG. I13. - A mounted slide of serial sections, showing manner of labeling. 
moves forward at each stroke a distance governed by the set-screw of the scale $(1 / 2 \mu$ to $40 \mu)$. By substituting a wide knife-carrier, sections several centimeters in diameter may be cut, and by using a slanting knife, as for celloidin, very hard material may be cut. By loosening a set-screw, the razor as liere shown may be turned a few degrees to riglit or left, and the paraffin block may also be moved through a considerable arc in any direction, it being held securely in any position by pressure of a collar-screw on a ball-and-socket joint. On 72 in plate $I 3$ is an apparatus for trueing the edges of the paraffin blocks.
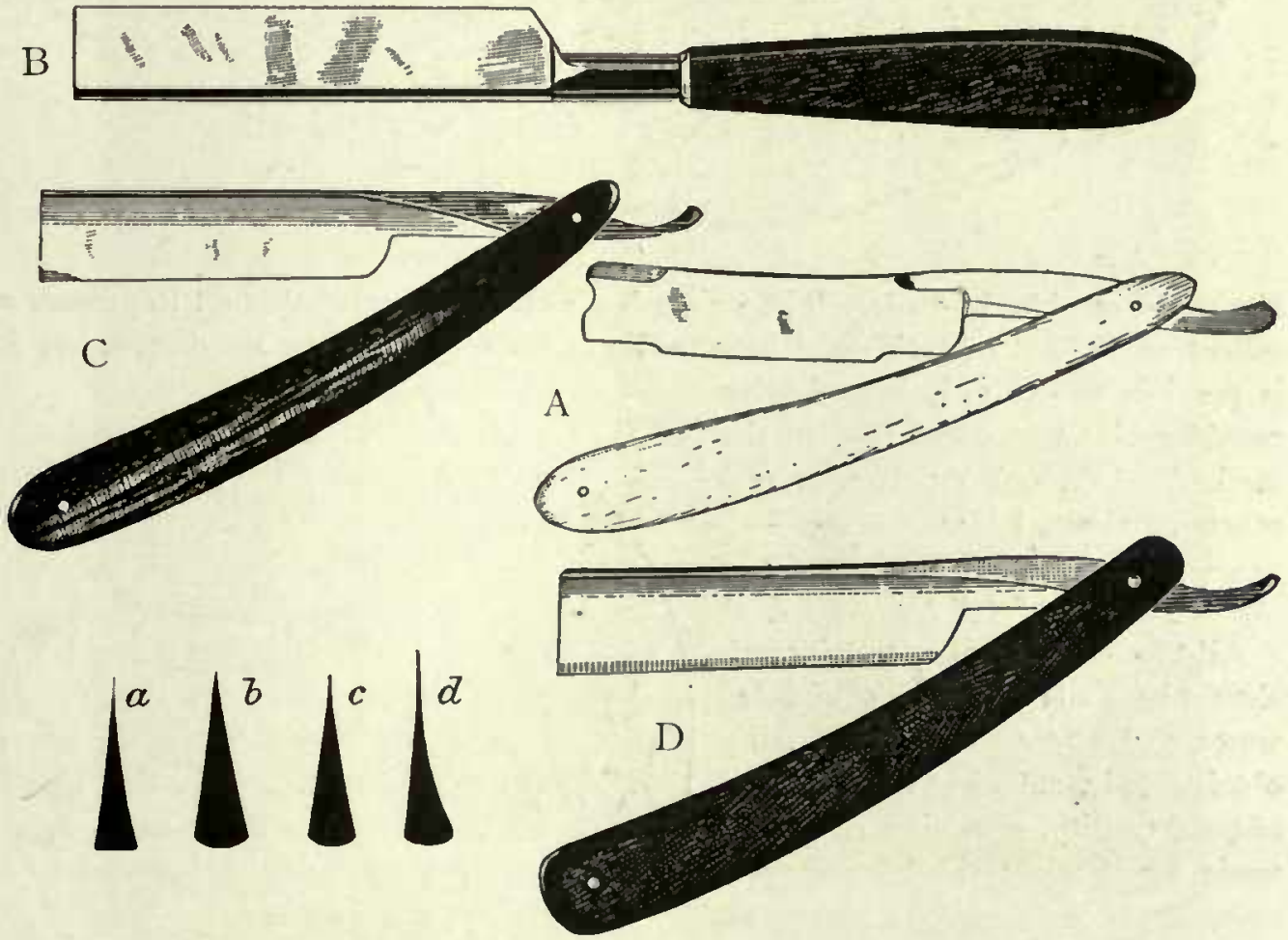

Fig. 114.*

Collections of living bacteria are also necessary. Fortunately many may now be obtained, as needed, from Král, in Prague; but, unfortunately, they do not always correspond to their name. Others must be kept on hand, and the cultures (of some sorts) must be renewed at frequent intervals. That way which has given the writer

*FIG. II4.-A. Knife for serial sections, furnished with the Reinhold-Giltay microtome. This is made by Joseph Rodgers \& Son, Sheffield, England. One-half actual size.

B. Microtome knife made to order by Charles Lentz \& Sons, Philadelphia, and found useful in cutting hard material with long slant strokes. One-half actual sizc. The broad wedge-shaped blade of this knife is shown in $b$.

C. Knife obtained from J.R. Torrey \& Co., Worcester, Mass., and found very useful for making serial sections on the microtome. One-half actual size.

D. Torrey razor, recommended for free-hand sections. The very thin blade is flat on one face and hollow-ground on the other, as shown in $d$. It is made of the very best steel and holds an edge well. One-half actual size.

$a, b, c, d$, end views of the cutting edge of knives shown in A, B, C, D. Actual size. 
least inconvenience is by storage in cool boxes (refrigerators) at temperatures of $10^{\circ}$ to $I 5^{\circ} \mathrm{C}$. By this method some organisms can be kept alive on agar a year without transfer, and even sensitive organisms will generally live for some months, especially

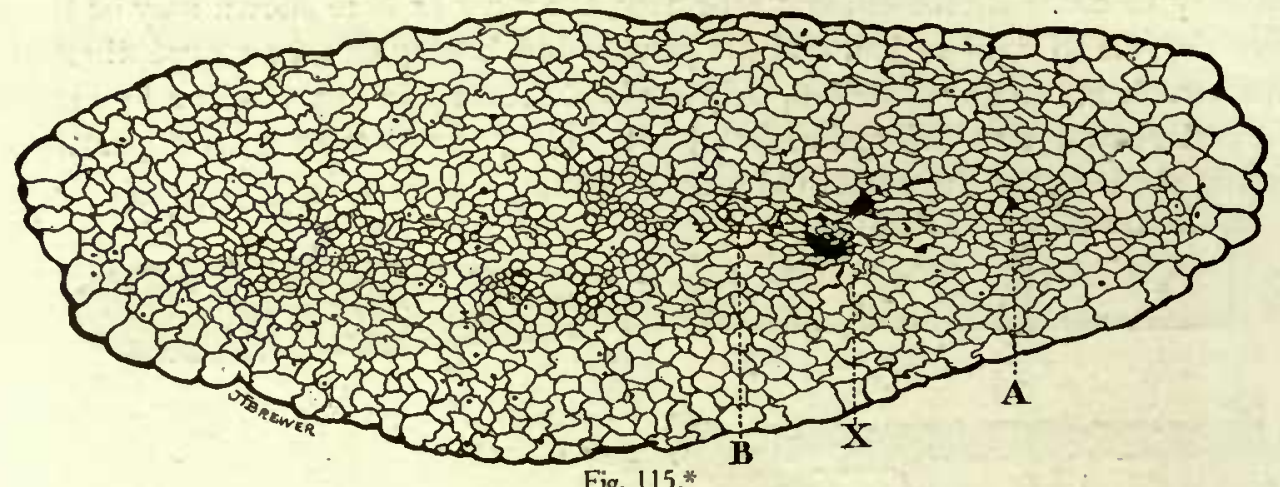

Fig. 115.*

if planted in proper media. The writer has never made any attempt to prepare a collection of dead bacteria on culture media to serve as museum specimens, but it is possible to do so, it is said, with considerable success by following the methods described by Hauser and others (Bibliog., LII).

\section{DISTILILED WATER.}

All laboratories doing much work should have an abundance of distilled water, and where this is not readily obtainable in sufficient quantity and of good quality, provision should be made for it when the laboratory is constructed or wlien the necessity for it arises. In the construction of such a still many things must be kept in mind, if it is to work satisfactorily and yield water of the desired purity.+

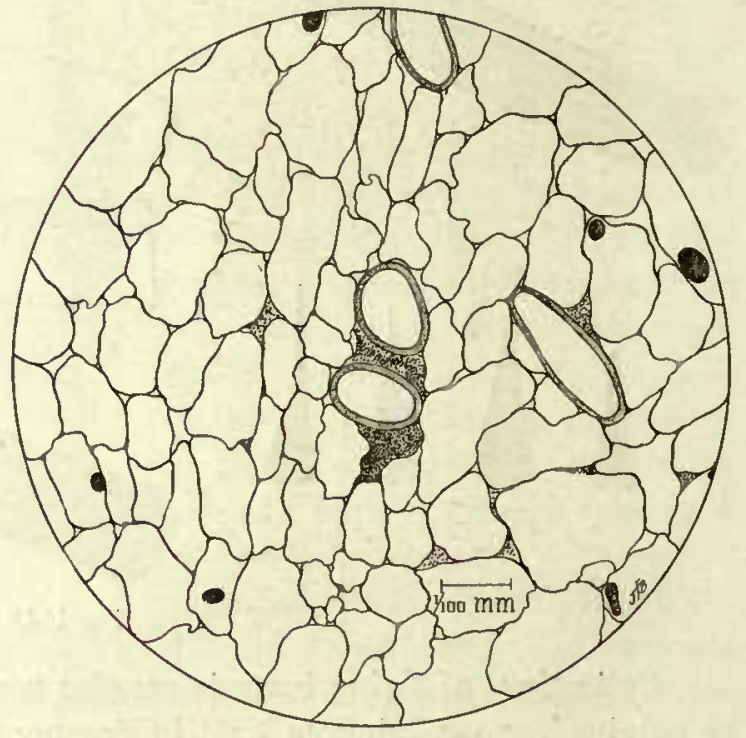

Fig. 116.t

*FIG. II5.-Cross-section of tooth of cabbage-leaf infected by Bacterium campestre. Plant No. $40 \mathrm{I}$ sprayed with water containing an agar-culture. Bacterial occupation limited to points between $\mathrm{A}$ and $\mathrm{B}$. At $\mathrm{X}$ vessels are occupied. At $\mathrm{A}$ and $\mathrm{B}$ the bacteria lie in the intercellular spaces and have not yet entered the vessels. For details of $A$ and $B$, see figs. II6 and II7. This section, which is one of a series, was cut $270 \mu$ below the apex of the leaf-tooth. A few micromillimeters further down $(370 \mu)$ all trace of the bacteria disappears. In other words, the bacteria are still confined to the leaf-tooth, and there is no cavity like that shown in fig. 76 . When sprayed this leaf was extruding fluid from the water-pores. Actual length of section, slightly under I millimeter. Slide $33 \mathrm{I}^{\mathrm{c}} 3$ Plant sprayed December 9, 1904; slightly blackened leaf-tooth fixed in 95 per cent alcohol on December 17, I904. Inked from a photomicrograph.

†FIG. II6.-Cross-section of leaf-tooth of cabbage infected by Bacterium campestre. A detail from fig. II5 at A. The bacteria have not yet entered the vessels.

$\ddagger$ That thing which has given the writer most trouble was an entirely umexpected difficulty, viz, a plague of tiny red house ants. These got into the reservoir in spite of all that could be done to render it tight, and, of course, spoiled the water for all delicate work. 
PLATE 14.

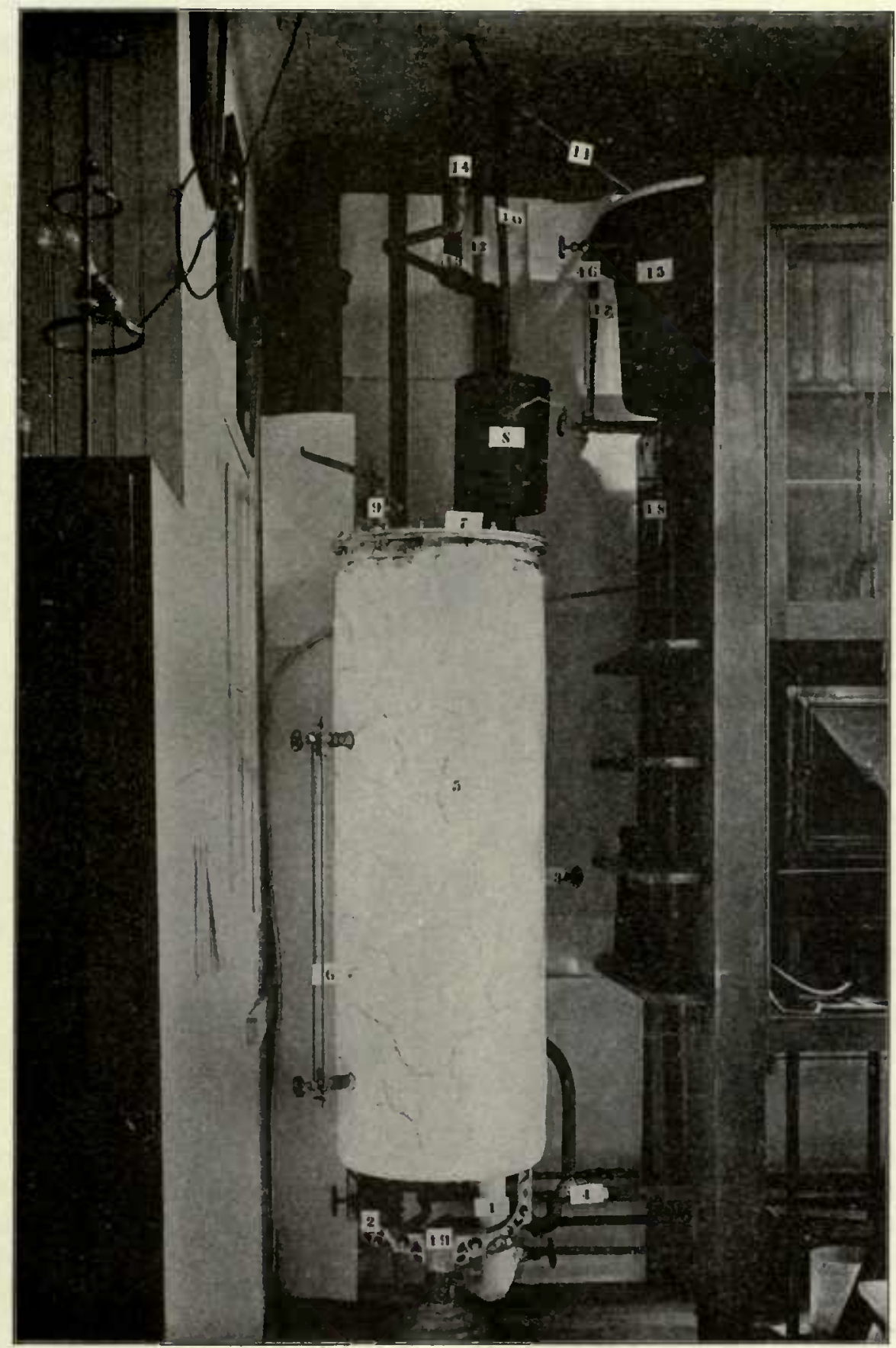

Apparalus for Distilling Water.

(1) Steam inflow pips: (2) waut-steam pipe: (3) hydeant-water iofow pps; ; (4) hydrant-water outflow pipe (flush) to sewer: (5) galvanized-iron boiler; (6) waler gage; (7) brass top, tianed on the under side: (8) copper catch basin ; (9) steam safety valve; (10) block-tin team pipe to condenser; (11) block-tin water pipe from condenser; (12) hydrant-water pips into condenser lank: (13) hydrant -water pipe from condenser taak; (14) flush pipe for condenser tank: (15) reservoir, capacity 80 gallons: (16) water gage: (17) overflow pipe from reservoir : (18) blocktin pipe leading to various rooms: (19) iron support. 

The following description and figure of a distilled-water apparatus devised by the anthor for use in the Laboratory of Plant Pathology, United States Department of Agriculture, may be of interest, therefore, to some. The apparatus consists of a galvanized-iron boiler similar to those used in kitchen ranges. It is 18 inches in diameter and abont 5 feet high. The top is sawed off and to it is bolted a stout iron ring with a flange, on which rests a $1 / 4$-inch brass cover. In the lower half of this boiler is a coil of 52 feet of inch copper pipe, the upper end bent downward and securely fastened in the bottom of the boiler to a steam pipe (I inch) connected with a $I \frac{1}{2}$-inch stean pipe leading to the ordinary steam boiler in the engine room in the basement; the lower end connected with an iron steam pipe ( $\mathrm{I}$ inch) leading to a steain trap (Mark traps are said to be the best). Around this copper steam

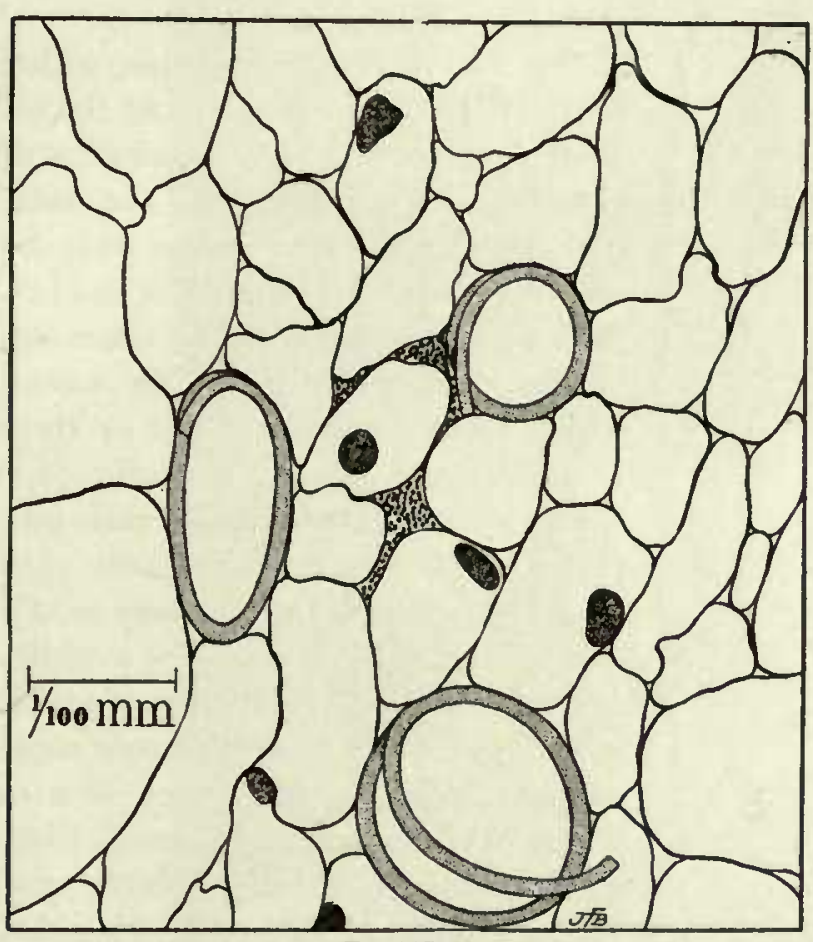

Fig. 117.* pipe, which is of course tinplated, stands the river water which is to be converted into steam by contact with the hot pipe. This hydrant water is kept always at about the same level (level of fig. 5 in plate I4), by nieans of a tinned-copper ball float (automatic cut-off) which closes the mouth of the inflow pipe when the water rises beyond a certain point. The upper part of the cylinder is a stean chamber under very moderate pressure (o to $1 / 2$ pound, rarely more). The excess of pressure is dissipated either by escape of steam through the safety valve (9), which is not weighted, or through the coil of pipe in the condenser. The steam passes from a securely riveted tin-lined copper catch basin (8) into a $3 / 4$-inch block-tin pipe (IO), which is fastened to a tubular projection from the catch basin by means of a collar screw. The tubular projection from the top of the catch basin is soldered in place and also held by a flange inside the copper top, so that it can not be forced out by any attainable degree of steain pressure. The $3 / 4$-incl block-tin pipe passes to the room above, where it is coiled for a length of 35 feet inside a tin-lined copper tank resting on the floor. The height of the condensing tank is 18 inclies and its dianeter is the same. When in operation this tank is full of running water. Theoretically, this condensation tank is large enougl, and it is so practically when the hydrant pressure

*FIG. II7.-Detail from fig. 1I5 at B, showing an early stage of water-pore infection of cabbage. The bacteria have not yet entercd the spiral vessels. The large dark bodies are nuclei. 
is good, but when it is feeble or when the stean pressure is higll the water becomes too lot and steam sometimes escapes into the reservoir. The water therefore inust be hurried through the tank by the use of a steam pump, or else less steam must be allowed to enter the copper pipe. If the writer were to build another siniliar apparatus he would make the condensing tank 2 feet higher and add ro feet to the lengtl of the coil of tin pipe. The condensing tank is provided at the bottonn with a $I$-inch inflow pipe for the cold water (it should be $I / 2$-inch), and at the top

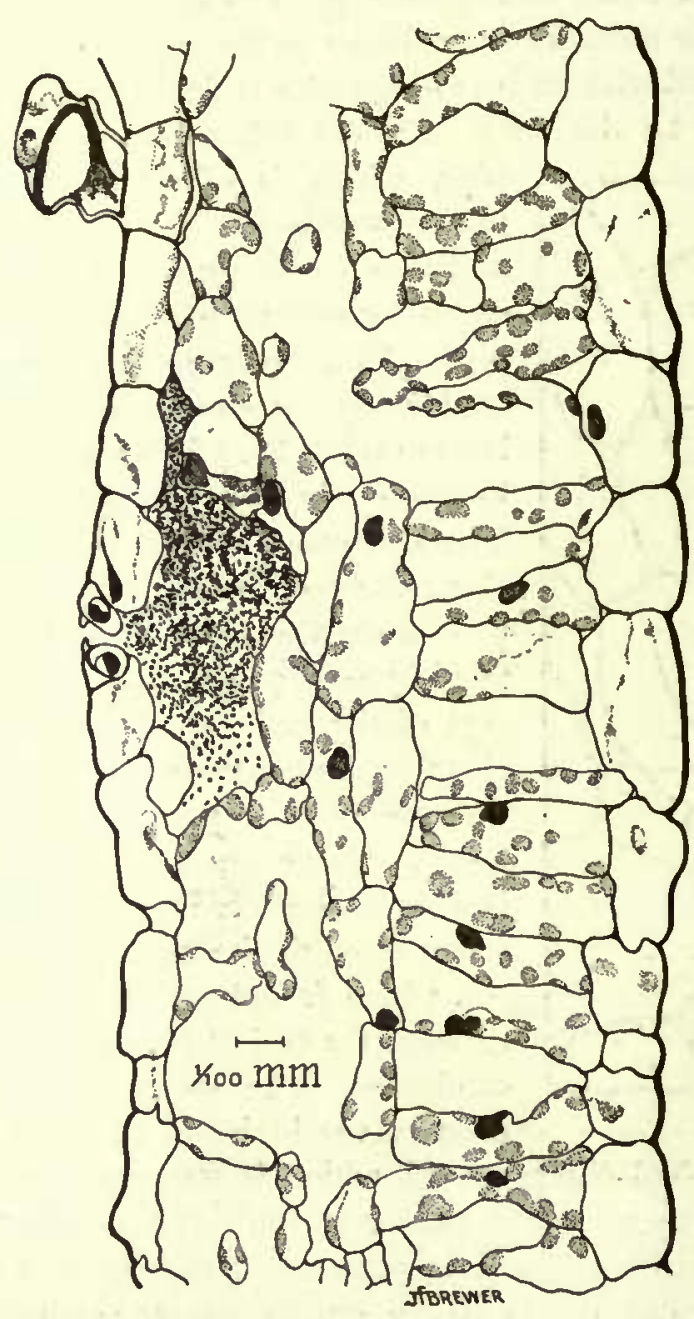

Fig. 118.* with a $1 \frac{1}{2}$-inch ontflow pipe (it should be 2-incli), for the exit of the warmed water. There is also a I-inch flusl pipe at the botton for the occasional removal of sedinent.

The size of the outflow pipe, which 1nust be somewliat larger than the inflow pipe, prevents any possibility of clogging and overflow. All the nietal parts which conne into contact with the distilled water are tinned or nickelplated. Connected with the lower end of the block-tin coil (by tin solder, which must not contain lead or zinc) is a sinaller ( $1 / 2-$-incli$\left._{1}\right)$ block-tin pipe (II), which leads the distilled water into (I5) the storage tank ( $3 / 4$-inch pipe would be better, and without any joint). The reservoir in this case is a whiteenameled batli-t11b, on the top of which is clamped down a cover of thin slieet copper $\left({ }_{80}^{1}-\right.$ incli), the inner face of which has been carefully tinned. Plate glass ground to fit would be better, and the tub itself is likely to be discarded in the near future, $i$. e., when some nore satisfactory storage tank can be found. The problem of the proper storage of distilled water in quautity is the hardest one, the solvent power of the water is so great. From the bottonin of this bath-tub several hundred feet of $1 / 2$-inch block-tin piping lead to various roouns in the building. In addition to the terminal faucets there is a general cut-off just above I8, which is necessary in case of an accident to any faucet or part of the piping. There is also an overflow pipe (I7), which does not enter the sewer, but

*FIG. I18.-Early stage of stomatal infection in angular leaf-spot of Rivers cotton. Hothouse infection produced by spraying Bacterium malvacearum upon the surface of the leaves. For a much later stage see fig. 80 . 
ends free in the laboratory about I foot above a deep sink. The sides and top of the boiler, the copper catch basin, and the $3 / 4$-inch block-tin pipe leading to the condenser are all coated with 3 inches of best non-conducting magnesia covering. The catch basin, designed to hold back solid particles carried up with the steam, is 9 by $\mathrm{I}_{2}$ inches and is made of $\frac{1}{16}$-inch copper, securely riveted and soldered with tin solder. It is bolted down to the flat brass top and a stean-tight connection

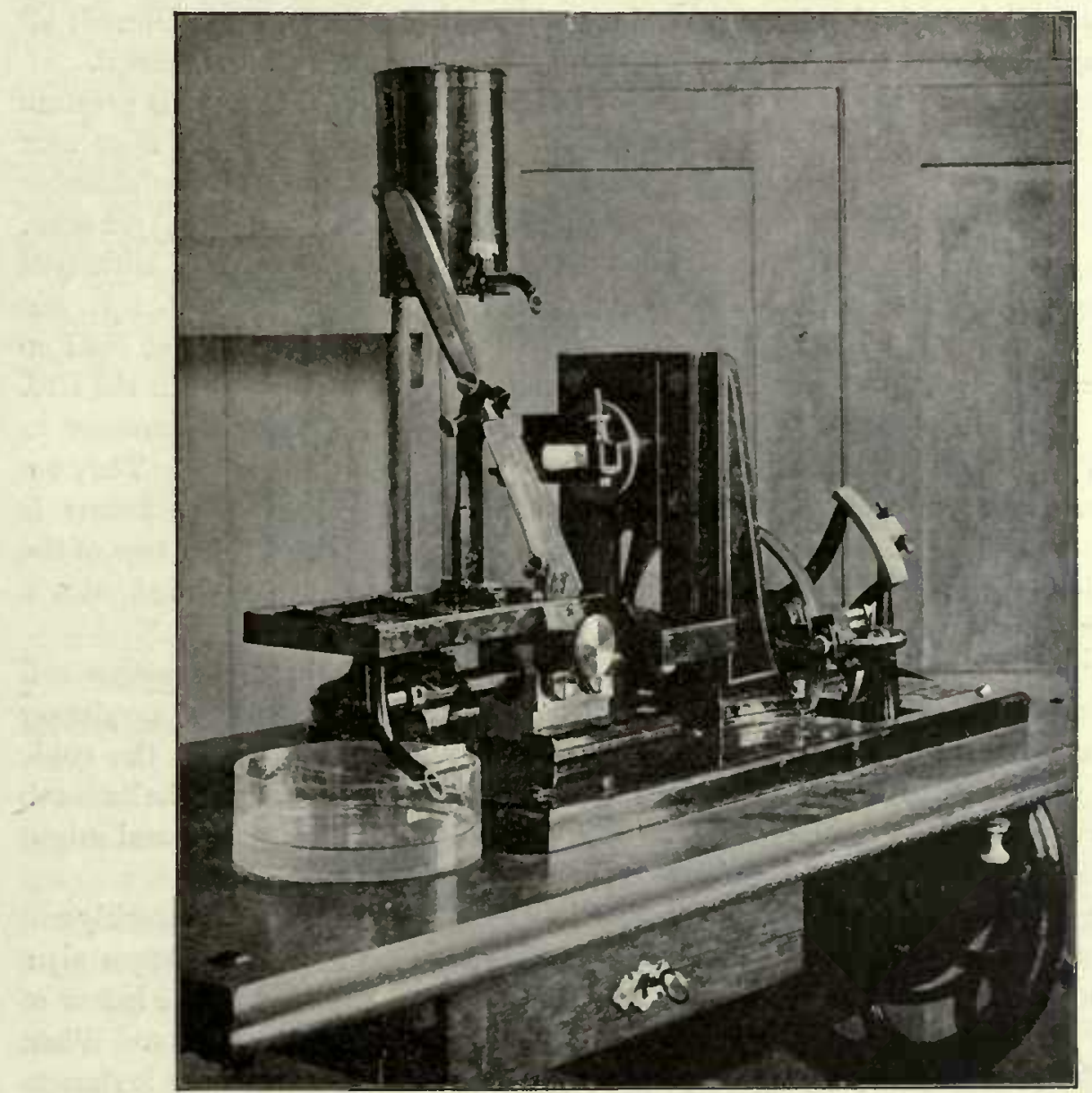

Fig. 119.*

is secured by means of a red rubber gasket. The heavy brass top ( 7$)$ is tinned on the inner surface and is bolted securely to the iron flange on the top of the boiler by means of 18 screw-bolts. The junction is made stean1-tight by meaus of a corrugated

*FIG. 119. - The Reinhold-Giltay microtome arranged for cutting celloidin or very hard paraffin sections. The machine is very solidly and accurately constructed out of the best materials, and, in addition, provision is made by means of set-screws for compensating the wear due to long use. The device governing the thickness of the sections is especially ingenious. This partictular machine has been in constant use by various persons for over four years, and nothing has been paid out for repairs. With good use it ought to last a lifetime. About one-fifth actual size. 
tinned-copper gasket. The steam which runs the apparatus is brought to the laboratory floor through a $I \frac{1}{2}$-inch pipe, in which (in the engine room) there is a steam gage registering up to $5^{\circ}$ pounds, and a reducing valve set at 55 pounds. This very considerably lessens the steam pressure in the copper coil, moderates the violence of the ebullition, and makes the apparatus perfectly safe. The hydrantwater outflow pipe (flush) to the sewer, for occasionally washing out accumulated mud (4) passes from the bottom of the boiler inmediately above fig. I9. Gate-valves are used. All brass and copper parts in contact with the steam are tinned; all metal parts in contact with the distilled water are tin, tinned, or nickel-plated.

With 60 pounds steam pressure in the engine-room boiler, 40 pounds pressure at the reducing valve, 35 pounds pressure in the pipe at the laboratory floor near where it enters the still, and one-half pound pressure or less in the steam chamber above the coil of copper pipe, the capacity of this still is 60 liters ( 16 gallons) per hour.

The apparatus must be built very substantially in all parts, so as to withstand at least twice as much steam pressure as any part of it will be subjected to, e.g., I6o pounds in the iron pipes and in the copper coil and its attachments, and at least 20 pounds in the catch basin, and other parts subject to steam generated in the still. A steam gage, in addition to the one in the engine-room, shows the pressure in the coils, and another the pressure in the steam chamber above the coils. They are not shown in the plate, as they were put on after that was made. The former is attached to the steam supply pipe near the floor, and the latter to an arm of the safety-valve pipe. The boiler should be taken down and the parts retinned once a a year, or at least once in two years.

If a much greater quantity of water is needed the block-tin condensation coil should be lengthened to 60 feet, the diameter of the inflow pipe of the condenser should be increased to 2 inches, and the outflow pipe to $21 / 2$ inches, and the cubic contents of the condenser tank should be quadrupled. The capacity of the bath-tub (or other receptacle), for a large laboratory should be at least 500 liters, and might well be $\mathrm{I}, 000$ liters.

The above apparatus has been in use for two years. It works very smoothly and satisfactorily when the proper amount of steam is let into the coil of copper pipe, which ordinarily should not be nearly the whole amount available. The inflow of steam is governed by the valve a few inches below fig. I in plate I4. When too inuch steam enters the coil, the pressure in the steam cliamber above it rises to five pounds or more, hot water is forced back through the feed pipe (3) into the neighboring pipe which furnishes cold water to the condenser (I2), and stean instead of distilled water is furnished to the water tank. This is at once obviated by cutting off part of the steam inflow and moderating the force of the boiling. It might also be obviated by reducing the length of the arm of the safety valve (9), which in any event should not be weighted.

Sufficient water for small quantities of culture-media and pure enough for most purposes nnay be obtained from the simple glass still shown in fig. 82 by one distillation. Water of a high degree of purity may be obtained by two distillations, adding 0.5 gram to I gram of potassium permanganate per liter of water before the 
first distillation, and 5 grams of c. p. sulphuric acid per liter before the second distillation. The flasks in which such water is collected or stored should be of resistant (non-soluble) glass and absolutely clean to begin with. With use such flasks or bottles become more valuable and should not be employed for other purposes.

The solubility of glassware is best tested by determining from time to time the degree of electrical conductivity of pure water stored in it. The specific resistance of pure water stored for a week in such tubes, flasks, or bottles should not fall below 250,000 ohuss. The specific electrical resistance is determined upon I cubic centimeter of water exposed between electrodes having an area of I square centimeter, and is read by means of a special Wheatstone bridge. Distilled water redistilled with chromic-acid cleaning mixture, and afterwards with alkaline potassium permanganate (nethod used by the Physical Laboratory in the Bureau of Soils) gives a resistance of 700,000 ohms.

The following determinations made by the Physical Laboratory of the Bureau of Soils show the diverse behavior of two lots of clean test-tubes recently purchased as non-soluble glass by the Laboratory of Plant Pathology.

\begin{tabular}{|c|c|c|}
\hline Klud of tube. & $\begin{array}{l}\text { Tlme of exposure, } \\
\text { In days. }\end{array}$ & $\begin{array}{l}\text { Speclfic resistance, } \\
\text { In ohms. }\end{array}$ \\
\hline 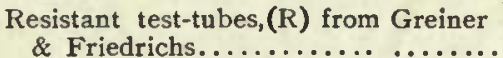 & & \\
\hline 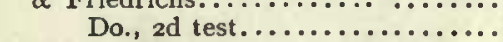 & I I & 219,000 \\
\hline Tubes received from the School Sup- & & \\
\hline ply Co $\ldots \ldots \ldots \ldots \ldots \ldots \ldots \ldots$ & ro & 41,400 \\
\hline Do., $2 \mathrm{~d}$ test.................. & II & 34,000 \\
\hline
\end{tabular}

The twice-distilled water used was taken from a Jena flask and its initial specific resistance was 240,000 ohms.

\section{MICROSCOPES.}

Microscopes of ' much better grade are required for bacteriological investigations than for ordinary histological work. The writer has for many years employed those made by Carl Zeiss, of Je11a, as, on the whole, most serviceable. Good microscopes are also made by E. Leitz, of Wetzlar, and recently by the Spencer Lens Company, of Buffalo, N. Y. The Zeiss stand shown in plate I 5 does very well for all ordinary work, but is not well adapted for the making of photomicrograplis or for recording the exact location of particular spots in the section. The latter difficulty may, however, be overcome by means of a removable slide-carrier attached to the stage. The stand may also be used with the small upriglit photomicrograplic outfit shown in fig. 24 when the lens does not require a microscope having a wide tube. This microscope has a half-nechanical stage, an excellent fine adjustment, and good substage apparatus. It is thoroughly well made and very durable. One in the writer's laboratory has been in use for twelve years. The lacquer has disappeared in places and it is no longer attractive to look at, but it has required no serious repairs during this tine and is still serviceable.

For photomicrographic work and also for recording the exact location of desirable fields in a section, the writer uses the large plotomicrographic stand shown in plate 16 . This is provided with a specially wide barrel, a fine adjustment of very 
PLATE 15.

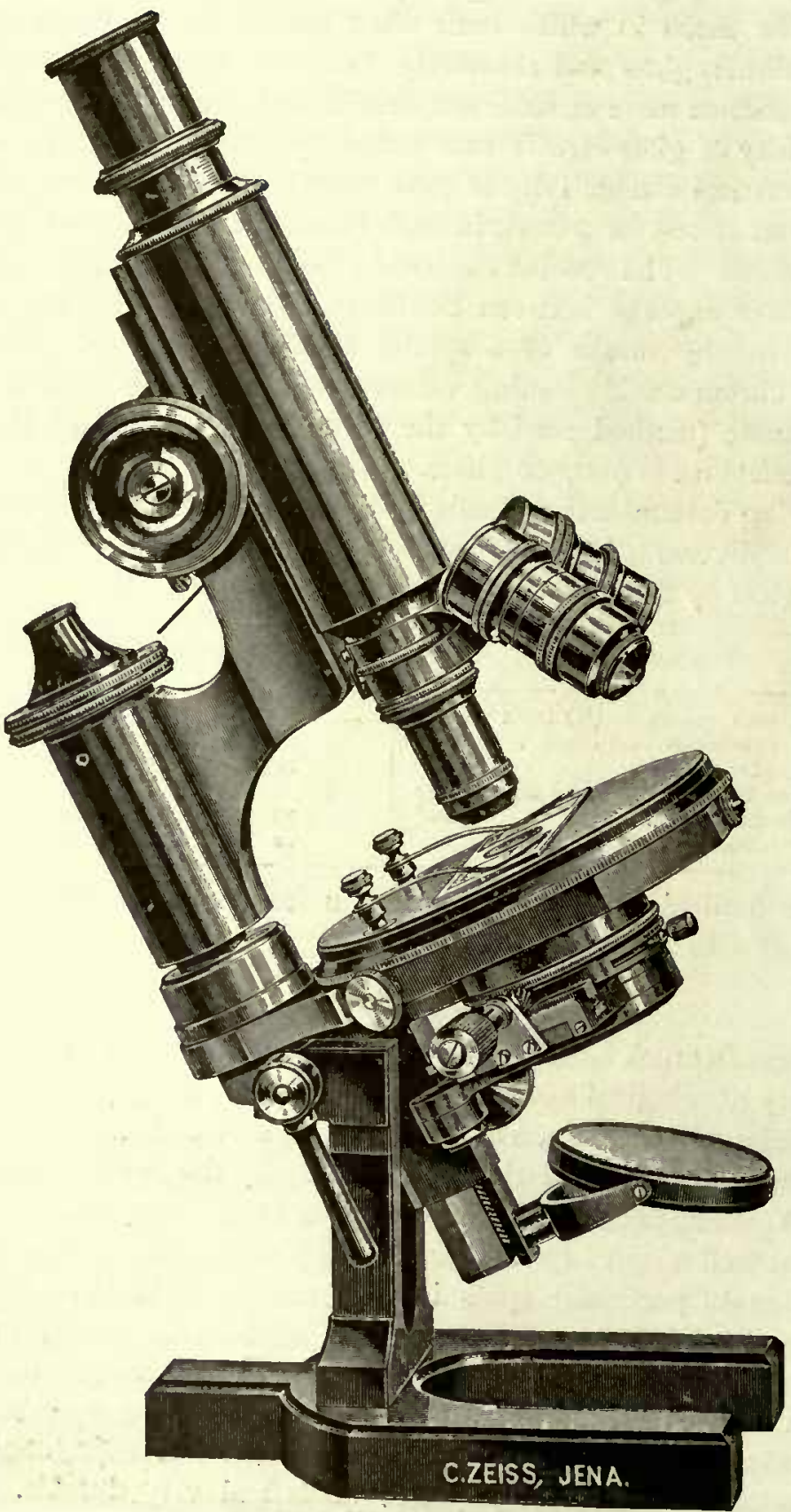

Zeiss microscope stand $I^{\mathrm{a}}$.

This form of microscope and that represented on plate 16 are the two pattern used principally in the Laboratory of Plant Pathology, U. S. Department of Agriculture. The objectives are apochromatic, and have proved very serviceable. In carrying do not grasp by any part above the level ol the stage, as this brings an undue weight upon the fine adjustment. Seize by the base. 
PLATE 16.

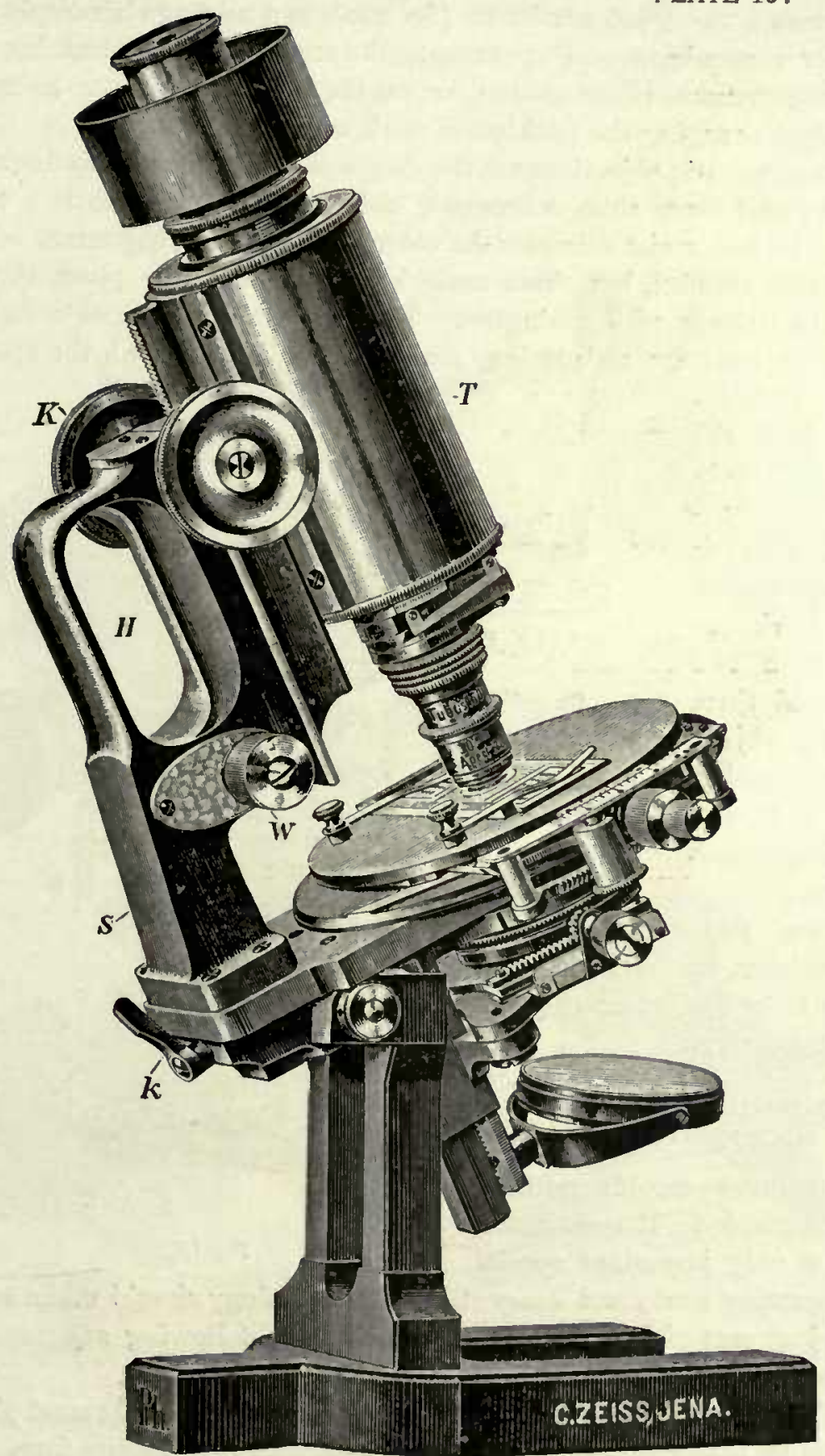

Zeiss photomicrographic stand Ic.

The barrel " $T$ " is of greater diameter then in stand lla. The fine adjuatment is at " $\mathrm{W}$ " and no weight rests nn it in lifting the instrument by the handle " $H$." The set screw " $\mathrm{K}$ " locks the upper part of the instrument at any angle. The objective is set in place by means of a very convenient alide carrier. The fine adjustment acrew has an extremely slow movement; and the vernier acrews are on the same axis (a great ennvenience). The stage rotates and may be locked at the desired place by means of a set screw. For the subutage arrangement see figure 120. 
slow movement, a swing-ont condenser (fig. I20), two substage iris diapliragms, and various other conveniences. For example, the screw-heads, determining the cross and sidewise movement of the section, are on the same axis and nay be reached and moved without changing the position of one's arm.

The apochromatic objectives are the only ones recommended for bacteriological work. They cost more than achromatic objectives, but expense is a minor consideration. In hot, moist climates the older apochromatic objectives of Zeiss frequently became clouded, but those made in recent years have given the writer no trouble in the latitude of Washington. They yield sharp images even with high eye-pieces. Of course, compensating oculars must be used with the apochromatic objectives. It is desirable to have the whole series of objectives and eyepieces, but if one is limited for means, very good work can be done with two objectives and three oculars, viz, objectives $16 \mathrm{~mm}$. and 3 mm. r.40 n. a., and compensating oculars 4,6 , and I2.

The newer forms of the Abbe camera furnished by Zeiss (fig. I2I) leave little to be desired in the way of a drawing camera.

\section{PHO'TOGRAPHY AND PHOTO- MICROGRAPHY.}

For permanent records nothing equals photography. It constitutes, therefore, a very important special part of laboratory work, and every student of pathology should make a knowledge of this subject part of his education. Some of the following suggestions will be useful to beginners.

The Zeiss Double-Protar lenses, series VII $a$, are the best all round photographic lenses made by that firm, and are excelled by none made by any firm. The back or front lens is usually as good as the combination. Excellent photographic lenses are also made by Voigtlaender and by Goerz. Zeiss photographic lenses may be

*FIG. I20.-Swing-out condenser and other substage arrangements on Zeiss photomicrographic stand, No. IC. There is an iris diaphragm in $\mathrm{D}$, and a second one in $\mathrm{S}$, which is for use when the condenser is thrown out as shown in this figure. D swings under when $C$ is thrown into place. $\mathrm{W}$ racks the entire substage up or down. 
obtained from Bauscl \& Lomb, who are under contract to manufacture then1 according to the Zeiss formula. In buying a photographic outfit it is economy to get one of the high-priced lenses. It is frequently stated, by those who do not know, that "just as good results" can be obtained with cheap lenses, but one may easily satisfy himself that such is not the case by photograpling buildings on a

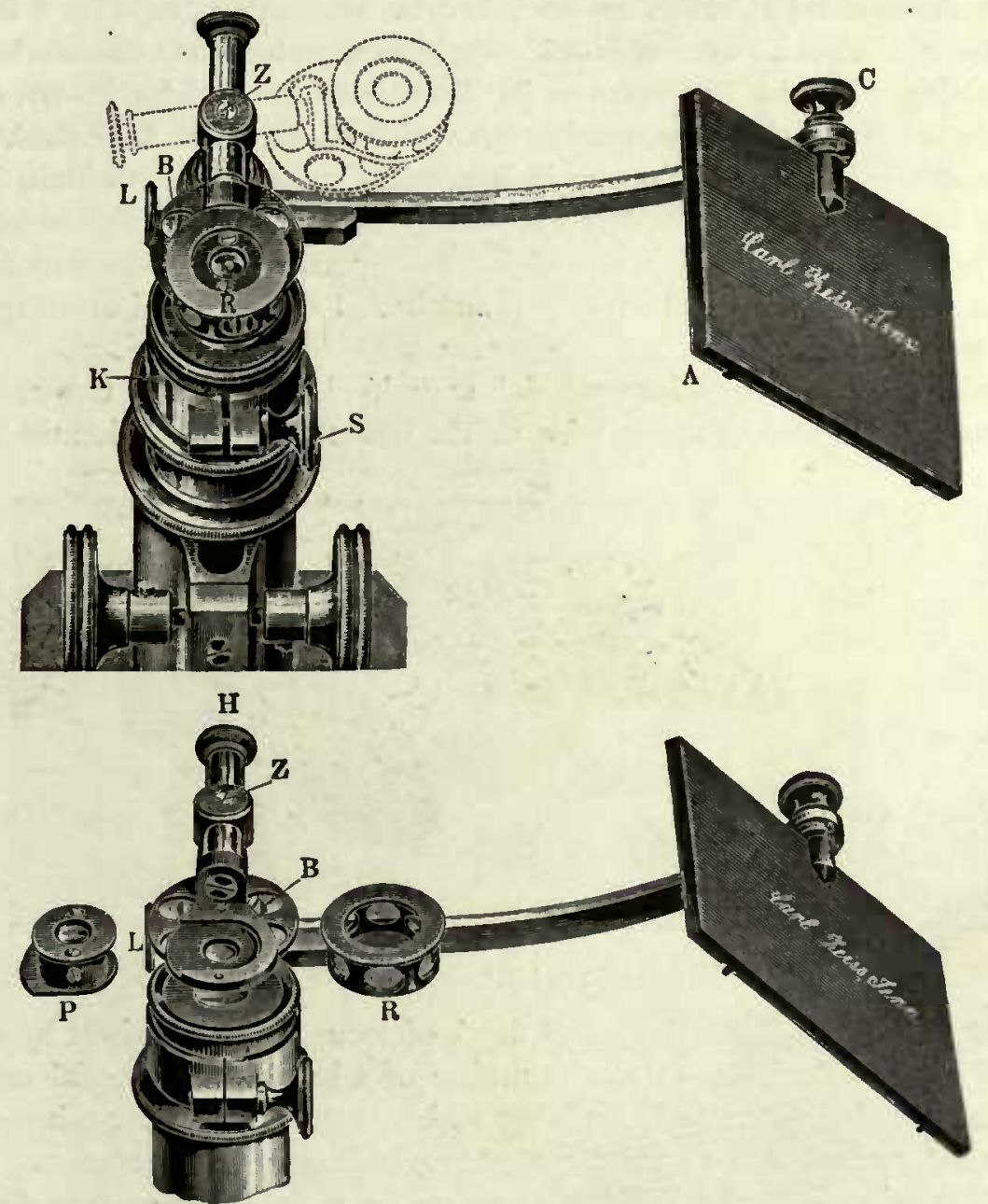

Fig. 121.*

street or any object having inany vertical parallel lines and other lines crossing at right angles. The pictures made by the cheap lenses generally show serious distortions. In buying a lens one should know in advance exactly what he wishes to do with it, otherwise he may be greatly disappointed. If he wishes to photograph only

*FIG. I21. - Newer form of Zeiss-Abbe drawing camera. The camera is clamped at $\mathrm{K}$ by means of $\mathrm{S}$. The prism within $\mathrm{R}$ is centered over the eye-piece by screw movements of $\mathrm{L}$ and $\mathrm{Z}$. When not in use the prism is swung to the right, as indicated by the dotted lines. The mirror $A$ throws down the prismatic image to the drawing paper. The amount of light is governed by the substage iris-diaphragm and by rotating. $\mathbf{B}$ and $\mathrm{R}$, which contain smoky glasses of graded densities. $\mathbf{P}$ is an extra prism. The image on the paper will also be clearer if it is placed in shadow by means of a screen of some sort. 
flat surfaces he will select a lens with no great penetration, but with a very clear field,

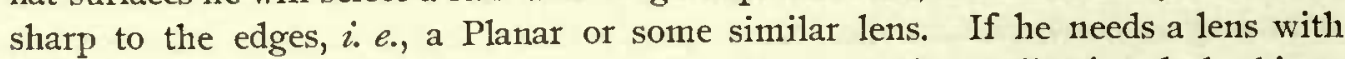
very little deptl of focus (but more than the Planar) and one allowing dark objects to be photograplied in a very short time, e.g., luminous bacteria by their own light, he will select a Zeiss Unar or its equivalent, $i_{.} e$, an extremely rapid lens. If lie desires in one picture as much as possible of a landscape, $e_{.} g$, a large tree or an interior, he will select an extremely wide-angle lens rather than one distinguished for its rapidity or for the perfection of its definition, $e_{.} g_{\cdot}$, a Zeiss Protar, series V. The Double-Protar, series VII $a$, combines as wide an angle, as flat a field, as great rapidity, and as sharp a definition as it is possible, apparently, to obtain in a lens and at the same time have great depth of focus. These lenses 111ay also be unscrewed and each half used separately, if one wishes some portion of a picture more highly m11agnified. They are furnished with front and back lenses of equal or unequal focal distance, as may be desired.

In using Planars and all lenses which magnify, it is necessary to secure a very exact focus with the stop wide open, for, 11nlike lenses which give pictures less than

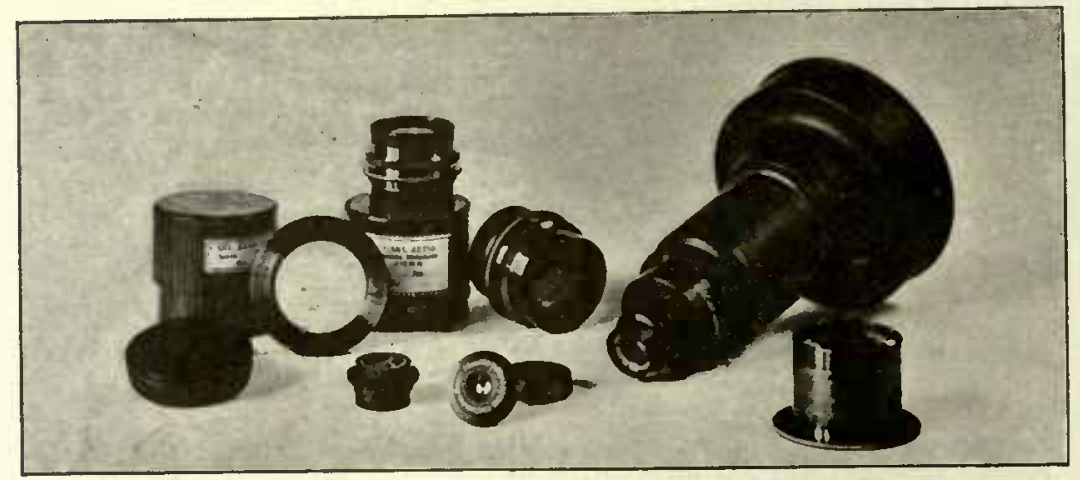

Fig. 122.*

actual size, only a very little increased deptlı of focus can be obtained by stopping down. With many objects-e. $g$., the surface of a leaf, or of bacterial coloniesthere is considerable difficulty in deciding which is the proper focus when a Planar is used, what seemed like a good focus often yielding a poor negative. On this account the writer is in the habit of focusing on a fragment of very fine, sharp print laid on the surface of the leaf or of the agar-plate near the colonies to be photographed. A lens magnifying 6 times is used in judging of the image on the ground glass, and when the best possible focus has been secured, the paper is relloved, the lens is stopped down two-thirds, and the photograpli is made. In case of white colonies the best results are obtairied by resting the Petri dish on a piece of black paper while the photograph is being made. The exposure is shortened by illu11inating the surface of the object with a bright beam from a mirror. The apparatus

*FIg. I22.-Zeiss Planar lenses, series Ia, Nos. I to 5. Nos. I, 2, and 3 may be attached to the funnel-shaped carrier shown in the figure. This screws into the top of the microscope barrel in place of the eye-piece tube. The one attached is No. 3. The condensing lenses necessary for these Planars are also shown in this figure, at right and left. 
shown in fig. 24 may be used for this purpose. To avoid shadows the inirror should be held some distance above the object when the surface is not even. The first five of the Zeiss series of Planars are all that are uswally required. No. I gives the highest

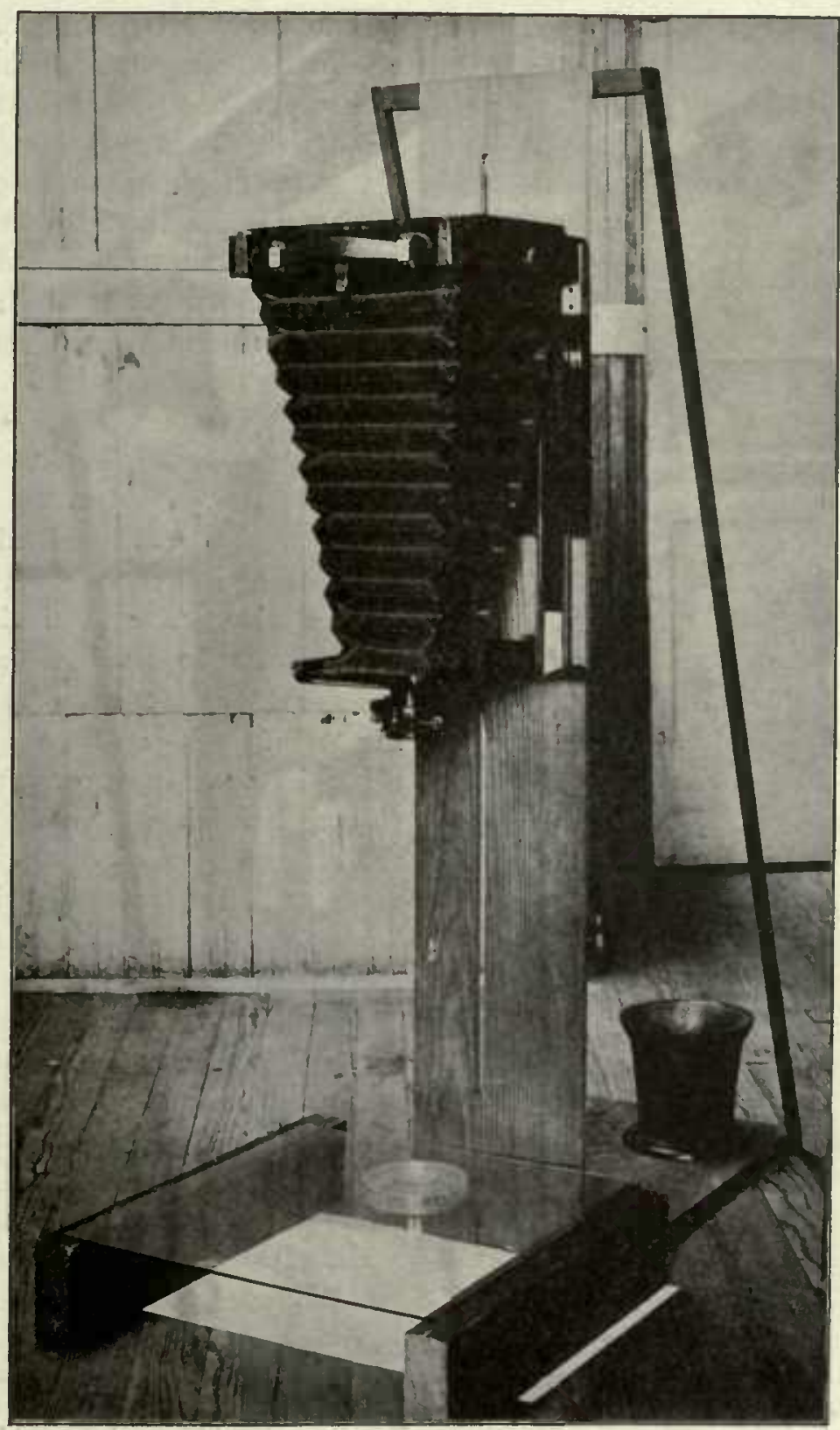

Fig. 123.*

*F1G. 123. - Simple apparatus for holding the camera in place when one wishes to photograph down. The camera here shown is a Rochester Optical Company, reversible back 5 by 8 , fitted with a Bausch \& Lomb rapid universal lens, and has been used very often by the writer for natural-size work and for lantern slides. 


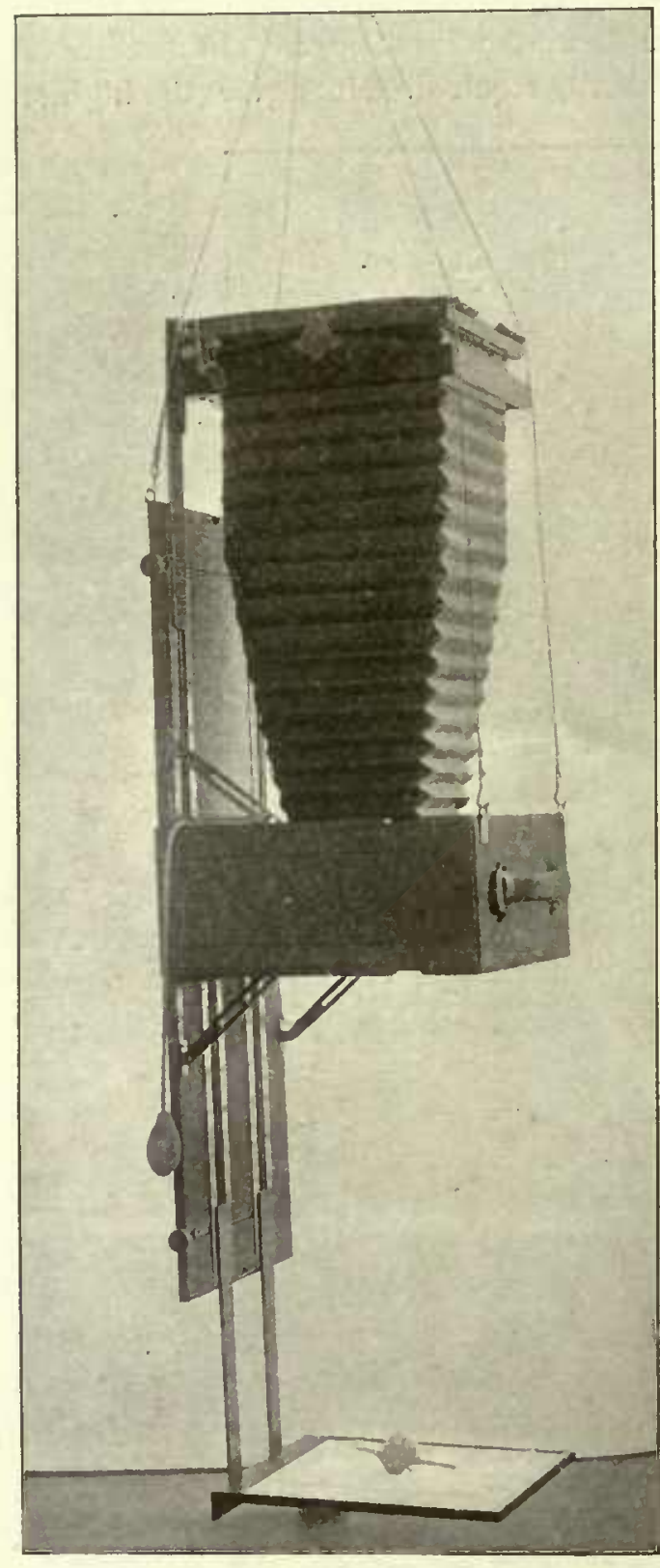

Fig. 124.* magnification; No. 5, the largest field; No. 3 will give a sharp image of a flat object a centimeter in diameter. Special condensing lenses are required. These fit into the substage in place of the Abbe condenser. One condenser serves for Nos. 1, 2, and 3, and another for Nos. 4 and 5 (fig. 122).

In photograpling poured-plate colonies natural size, there are several ways. It may be done by reflected light, as shown in fig. 123, in which case the colonies sometimes cast deep shadows. Such shadows may be avoided by mounting the camera as shown in fig. I 24 and gently twirling it during the exposure. The Petri dish may also be photographed by transwnitted light exactly as if it were a negative for a lantern slide. The Petri dish is then held in place in the darkened window or in front of the camera box by crowding it into a hole cut in a square of thick leather, paper, or sheet-rubber ( $\frac{1}{8}$ inch), which is then fastened over the kit or framework by eight thumbtacks, or, better, it may be held in place by two stout rubber bands, as shown in the photographs (plate 17 and fig. 125). With stop 32 u. s. and Seed's 27-X plates the right exposire in Washington is usually somewhere between $\frac{1}{5}$ second and $\frac{1}{2}$ second in sunny weather and 3 to 5 seconds in clondy weather, using a Voigtlaender collinear lens, series III, No. 6, and sonth light. Atkinson gets very good results by

*FIG. I24.-Modified Collins-Brown camera swung from the ceiling and set to magnify about $X$ 13/4. The four suspending strings, which are of very strong fish-line, end in an S-shaped hook, the upper end of which hooks over a ring attached to a stout cord pendant from the ceiling. The length of bellows in this camera as modified by the writer is 25 inclres. The lens used with it is a Zeiss Double-Protar, Series VII a. No. 13, made by Bausch \& Lomb, Rochester, N. Y. This is the type of lens known also as the Zeiss Convertible Double Anastigmatic. This lens has a focal distance of $91 / 4$ inches, or, when only the front or back half is $115 e d, 161 / 2$ inches ( 16 according to Zeiss catalogue). It is provided with a Bausch \& I,omb No. 2 Volute shutter. A cork support was placed under the object carrier to steady the apparatus while it was being photographed, but in actual use the camera swings frec, and if one desires to avoid shadows the apparatus is given a gentle twirl just as the exposure begins. The object carrier is easily removed, and is held in place at any level by two set-screws. 
PLATE 17.

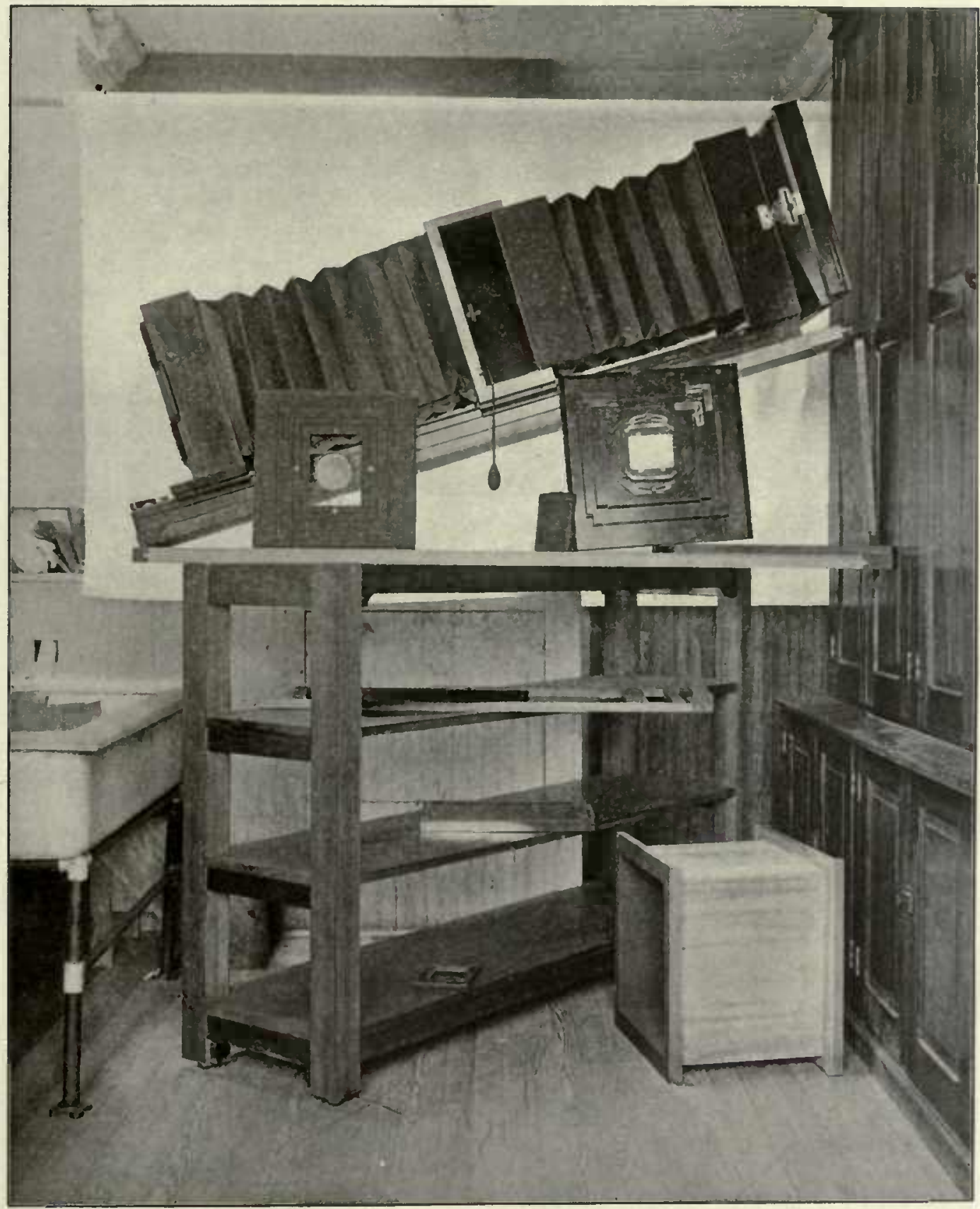

Enlarging and reducing camera, showing method of mounting the apparatus.

On the table at the left is a Petri-dith poured plate held in place by two rubber bands and ready for photographing. On the table at the right is a apecia camera-back used in making lantern slides. This allows the ground glaw to be raised or lowered, pushod to right or left, or rotated at will. 

placing a circular black disc centrally some distance belind the plate to be pliotograpled, 11sing for illumination the diffused light which comes in aronnd this disc. The result is a very sliarp contrast, $i$. e., white colonies on a black background (Bull. Torrey Bot. Club, r893, Vol. XX, p. 357).

In plotographing test-tube cultures the chief trouble is the great number of confusing lighl-lights due to the curved surface of the glass. From an artistic standpoint these are to be desired, but inasmuch as they are sometines liable to be mistaken for bacterial growths the naturalist desires to eliminate them. This may

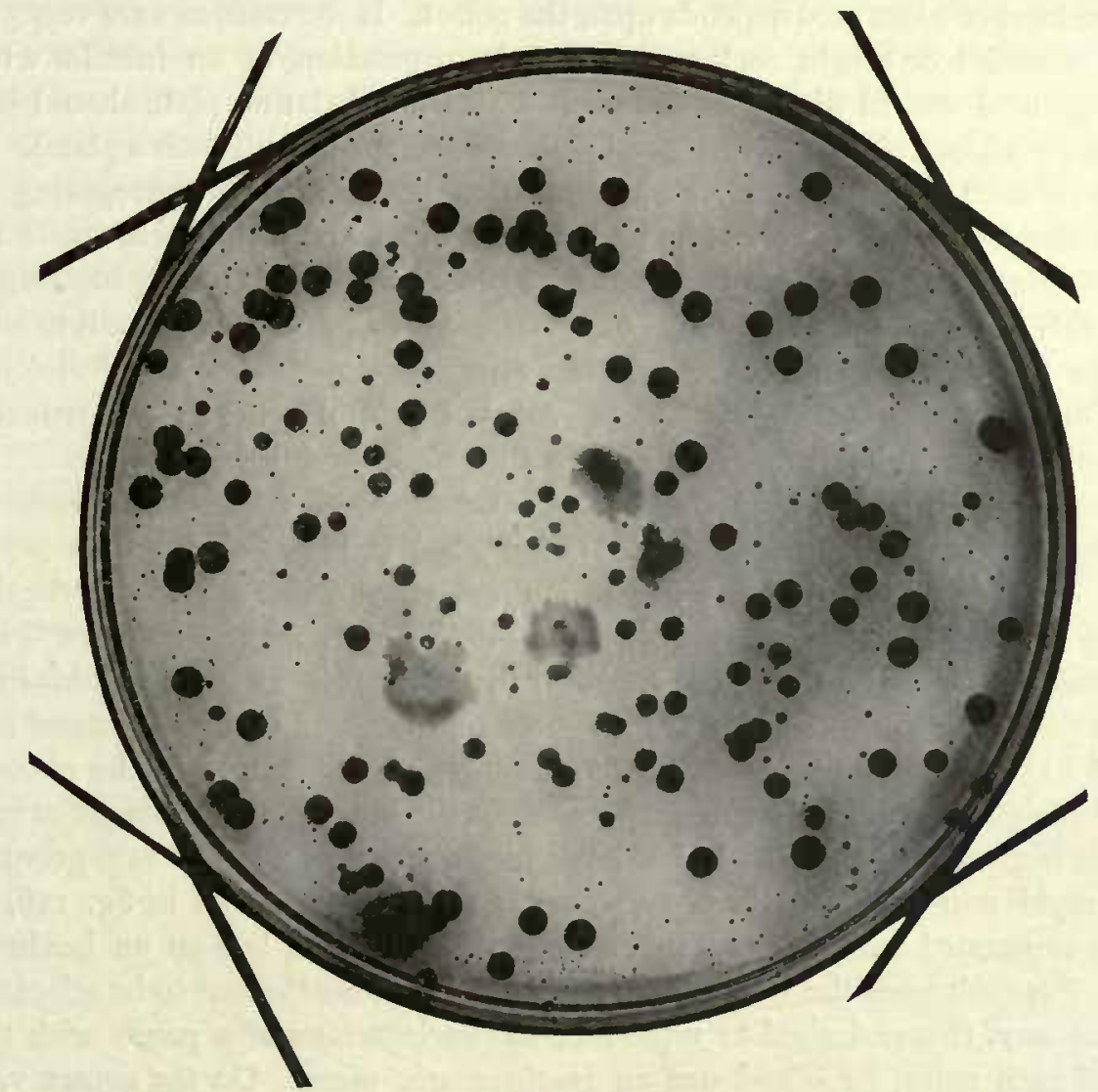

Fig. 125.*

be done in several ways. One of the best ways is to photograph the tubes through a thin sheet of distilled water. For this purpose jars of clear white glass are necessary. These slould be about $5 \frac{1}{5}$ wide $\times 5 \frac{3}{4}$ deep $\times 1 \frac{3}{16}$ inches thick (inside measure), witlı parallel walls and a flat bottom. Such jars may be obtained of Eimil Greiner. Only those witlout flaws or wavy lines slould be accepted. Better jars with perfectly parallel flint-glass walls may be had fronı Carl Zeiss. Good results

*FIG. 125.-Showing method of holding Petri-dish poured plates for photographing by transmitted light with camera shown in plate 17. The dish is held in place by two stretched rubber bands, exactly as if it were a negative to be used for making lantern slides. For manner of suspension, $i$. e., relation to the camera, see plate 17 . The organism is a 48 -hour agar culture of van Hall's Ps. syringae II, grown at $24^{\circ}$ to $27^{\circ} \mathrm{C}$. 
may also be obtained by plotographing the tubes against a north light inside a box witl blackened walls. The box may be $8 \times 8 \times$ r 2 inches, open at each end, and painted inside witl a mixture of lamp-black and turpentine. One open end is pointed to the window, the other to the lens of the camera. In the middle of the box, crosswise, on top, a row of $3 / 4$-inch holes ( $1 \frac{1}{2}$ inches apart) is bored, and the tubes to be photographed are thrust througli these. If images of outside objects appear on the ground glass, they may be cut out by pasting white tissne-paper on the window-glass (this slould be glued only at the corners).

The kind of plate used depends upon the object. If the contrasts are very greate. $g$., a waterfall or bright rock surrounded by vegetation, or an interior with the camera pointed toward windows-a double-coated 11011-halation plate slould be used (Hammer's Aurora plates are very good; plate 6 was made with sucli a plate). In the absence of such plates most of the halation may be avoided by squeegeeing to the back of the dry plate, before loading, a black paper soaked in glycerin (plate 14 was made in this way). The dry plate sliould be placed face down on dry blotting paper during this process, and, of course, the glycerin-soaked paper must be cut in advance to fit the dry plate. Mucl may be done during development to avoid violent contrast if one knows how, the quantity of pyrogallol or ortol being greatly reduced and the developinent prolonged. This gives a thin negative full of detail.

For many purposes isochromatic plates are invaluable; for other purposes ordinary plates will give better results. Which kind is best adapted to a particular subject will depend on what is wanted. In general, for this sort of work, the full contrast of the original is desired, and the kind of plate which will give it is best. Even some exaggeration of the contrasts of the original is not objectionable in many cases if the prints are to be used for half-tone reproductions, since contrast is often reduced in the half-tone process, and there must be exaggeration in the photograph if the half-tone pictnre is to correctly represent the object. An example or two will lielp the beginner to judge. If we have black spots on a green background and use a rapid non-isoclironlatic plate, we will get the result shown in fig. I26, which may be contrasted with fig. 127 , made from the same leaf, but on an isochromatic plate. For sucl cases the isochromatic plate is of course the one to be selected. In the same way, if one desired to reproduce the variegations of a pansy with the full value of each color, he would use an isochromatic plate. On the contrary, white spots or stripes on a green leaf, or yellow colonies on an agar or gelatin plate, or red spots on a white ground, will stand ont better if the photograph is made on a Seed's 27-X non-isochromatic plate or its equivalent. Red spots on a green background require an isochromatic plate. Black spots on a yellow or orange ground usually require for good contrasts an isochromatic plate. Some yellows, lowever, take pale, while others take dark.

In making pliotomicrographs little trouble is experienced with low powers, but there is considerable difficulty in making good negatives of bacteria in tissues, using high powers. A few hints may be of service. With upright stands and certain objectives the beginuer frequently las difficulty in securing a 111iformly lighted field. This trouble may be obviated by throwing the light from the mirror not 
directly on the substage mirror of the microscope, but on a sheet of gronnd glass (it n1ay be the focusing plate of the camera) placed in front of the mirror of the inicroscope. The coarse adjustment of the microscope slould not work too easily, or else the mere weight of the nicroscope tube may throw out the focus after it has been secured and before the picture can be taken. The connection betwcen camera and microscope must be light-tiglit. In absence of a proper device (foot of stand in fig. 24), light may be cut out by several folds of black velvet pinned close. The stage of the microscope sliould also be protected from bright reflected light when photographing by transmitted light. If there is a rigid connection between the camera and the top of the microscope, or if the latter rests on the base of the former, the focus is apt to be injured by slight jars incident to putting in the plate-holder or drawing the slide. For this reason it is better to have them separate, and the carrier and draw-slide should be scraped, sandpapered or filed, and waxed, soaped, or vaselined, so as to work very smoothly. An entire day spent in accomplishing this end should not be counted as wasted time.

With large horizontal cameras (plate 5) the work-table and the bellows-table must be leveled 11p accurately with reference to each other, siclewise as well as vertically, and then mist be bolted to the floor. The order of apparatus beginning at the window is: mirror, condensing lens, alım-cell, light-filter (Zettnow's fluid), ${ }^{*}$ microscope, antonatic shutter, front board of the camera, large black diaphragnin in middle part of bellows, ground glass of the camera. The newer styles have a screwdevice for elevating or lowering the camera and another for elevating or lowering the microscope, or the optical bench. Dr. Novy has added to his Zeiss table a very convenient device by means of which the services of an assistant are dispensed with, one person behind the ground glass of the camera being able from this position to move the slide in any direction desired. The cost of the attachinent is about \$I 5 .

Beginning with the center of the mirror at the far end of the work-table or beyond it, and ending with the center of the ground glass at the back of the camera, all parts of the apparatus must be centered accurately, i. e., the light reflected from the center of the mirror must pass in a straight line through the center of the condensing lens, Abbe condenser, objective, and eye-piece to the center of the ground glass at the back of the camera, otherwise a first-class negative will not be obtained. The Abbe condenser must also be at the right distance from the stage of the microscope; the innage will then be on the center of the ground glass, circular, uniformly lighted, and free from distortion and color fringes, if the optical parts are in proper working order. The distance of the Abbe condenser varies, of course, with the objective. The Planar lenses require special substage condensers, such as those shown in fig. I22. When the centering is perfect all the rest is easy, or becomes easy with a little experience. If sunlight is used, an automatic shutter should be placed on the end of the camera next the inicroscope, so that accurately-timed short exposures may be made. The sun's rays should pass through several inches of fluid

*This is a mixture of copper nitrate and chromic aeid in distilled water. It lets through only the greenish-yellow rays. This fluid acts on the cement of the flint-glass container, and should not, therefore, be allowed to stand in it longer than necessary. The latter should then be washed in pure water and properly drained. 
before they enter the objective; otherwise, if the focus of the condensing lens should accidentally coincide with the balsain mount of the lenses for a few ininutes, it inay be softened and the objective ruined. Pure water is as good for this purpose as alum water, which was formerly n1uch recommended. It removes more than 50 per cent of the heat rays.

The writer uses a Zeiss 3 -inch mirror with microneter-screws for throwing the sun's rays. This serves quite as well as the more expensive heliostat, if one can

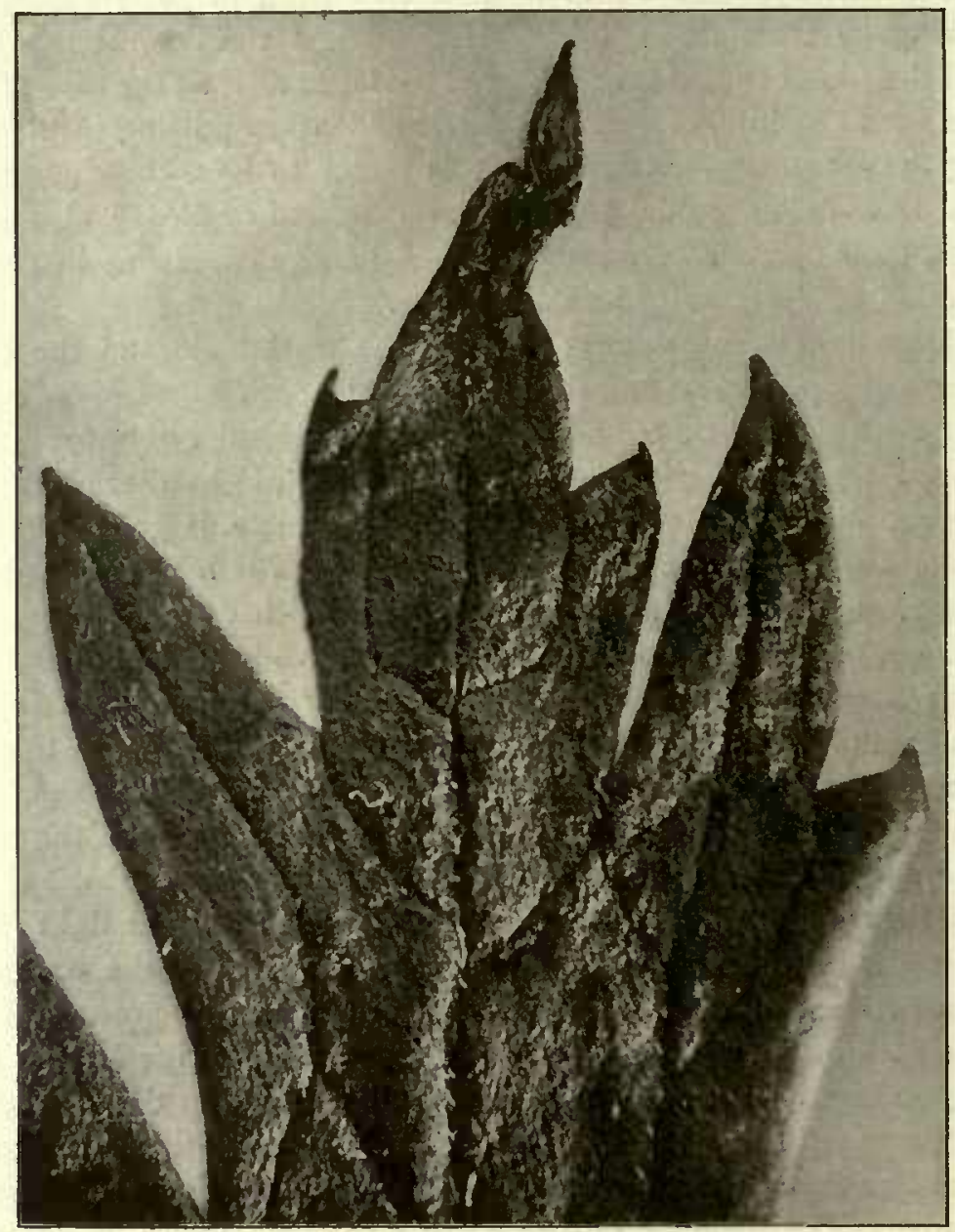

Fig. 126.*

work quickly. The order of procedure is to obtain the proper focus and see that it "holds ;" the plate holder is then introduced and opened, and consequeutly the bellows must be light-tight; last of all, the sunlight is accurately re-centered and the shutter snapped. The photomicrograph should be made with light from the central

*FIG, I26.-Fragment of a green leaf bearing black spots. Enlarged $61 / 2$ times with a Zeiss Planar lens and photographed on a Seed's $27-\mathrm{X}$ plate. Introduced for comparison with fig. 127. Notice that although stopped down considerably, part of the leaf is out of focus. 
portion of a considerable image of light. My custom is to nearly close the iris diaphragm below the Abbe condenser and throw with the condensing lens a small circle of light into the center of this diaplnagm; the condensing lens is then slid along the track about 12 or 15 inclies nearer; the iris diaphragm is then opened wide and the exposure made at once by squeezing the bulb of the shintter.

I now always use apochronatic lenses and never make negatives withont an eye-piece. I have used Zeiss projection oculars, but now use in preference a Zeiss

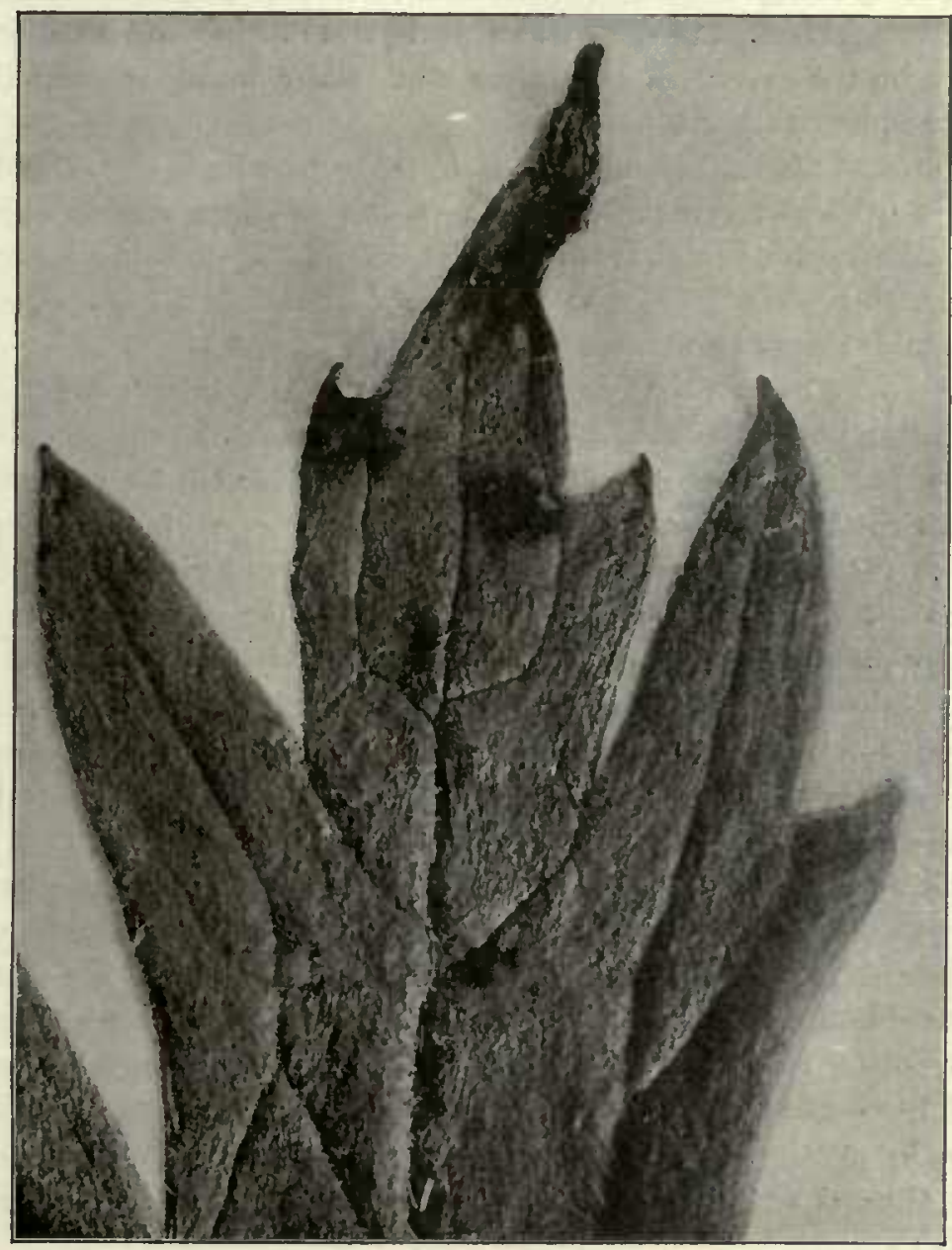

Fig. 127.*

No. 4 compensating octlar, or Spencer No. 3, which is kept solely for this purpose (so as to be always clean). It is of the utmost importance that mirror, walls of liglit-filter, alum-cell, and surfaces of condenser, slide, objective, and ocular be absolutely free from dirt, grease, and dust particles, even the smallest, if a good negative

*FIG, 127.-Bacterial leaf-spot of the larkspur (Delphinium). Same as fig. 126; but photographed on Cramer's isochromatic slow plate. In this photograph the black spots on a green background come out distinctly; in fig. 126 they do not. 
is desired. When using oil-immersion objectives see that there are no air-bubbles or particles of dirt in the cedar oil. The innage on the ground glass should be observed the last thing before introducing the plate-liolder, to see that it is free from images of objects not actually embedded in the slide. For the same reason slides and covers for mounting objects to be photograplied must be cleaned with great care and kept clean until ready for use. Many really beautiful sections are ruined for photonilicrographic purposes by laving been mounted in dirty balsain or on dusty slides, or by being covered with soiled cover-slips. Sections slonld be cut and mounted in dust-free air, and the balsam used in mounting wust be free from dirt. Much balsam on the market is very dirty and totally unfit for monnting sections designed to be photographed.

Glass surfaces througli which it is designed to pass light sliould not be touclied by the hands, greasy or otherwise. This applies to slides, covers, objectives, condensers, ray-filters, photographic lenses, mirror surfaces, ground glasses, negatives, lantern-slides, and what not. The least tonch of the finger on a polished glass surface generally leaves its mark.

In 11sing the common acliromatic objectives for inaking photonicrograplis, the "focus-difference" must be taken into account. Sucl objectives, being corrected only for two portions of the spectrum, require a different focus for the sensitive plate than for the hruman eye. In other words, an innage which is perfectly sharp to the eye is not sharp for the sensitive plate and will yield a negative which is out of focus. By turning the fine adjustment a measured distance the image becomes hazy on the ground glass, but will tlien yield a sharp negative. A few exposures will determine just how much and in which direction the eye focus must be thrown out to give the sharpest result. The focus-difference may also be disposed of by using monochromatic light. The writer uses such light almost altogether, even with the best objectives. Another defect of achromatic objectives, and to some extent of all objectives, is an arching field, the center being out when the edges are in sharp focus. For this reason it is customary to select a small portion in the center of the field, make this as sharp as possible, and neglect the margins, whicli may be trimmed off on the print. The Spencer I6-1nillimeter apochromatic objective has the flattest field of any objective of like quality known to the writer. Lack of depth of focus is a serious defect in photomicrographic work, and must be con1pensated for by making the sections uniformly thin and monnting them perfectly flat. The student should read Sternberg in English and Nenlaniss in German (Bibliog., LV).

For most stained sections involving bacteria, isochronatic plates are to be preferred, and slow rather than rapid ones. Exposure should be for contrast, and consequently as short as will give the necessary detail in the heavily stained parts. Development slould be rather long and with an effort to obtain good contrasts. The writer formerly 11sed hydrochinon, but now uses pyro, and develops until the inage is visible on the back.

For general photographic work ortol is an excellent developer, and its preparation is extrenely simple. If one nses the Hauff inixtures sold by Gennert, of New 
York, all that is necessary is to dissolve one package of A in 20 ounces of distilled water and one package of $B$ in an equal volume of water in another jar. For nornal exposure on $5 \times 7$ plates, add 3 ounces of $A$ to 3 ounces of $B$ and dilnte witl 2 ounces of water. The picture begins to appear in thirty to forty seconds and developinent is completed in three to four minutes. To soften the harsh contrasts of underexposed plates or plates overexposed in parts, give a longer developinent, using 3 ounces of the alkaline solution to $I$ ounce or $1 / 2$ ounce of ortol and 4 or 5 of water. In the middle of a long development it is often important to cliange to a fresh portion of the developing solution. For overexposed plates, reverse the proportions, using 1 ounce or $1 / 2$ ounce of alkali and 3 ounces of the ortol solution with several ounces of water. The advantages of this developer are its quick action and its freedom from stain and tendency to fog. The mixed developer may be used

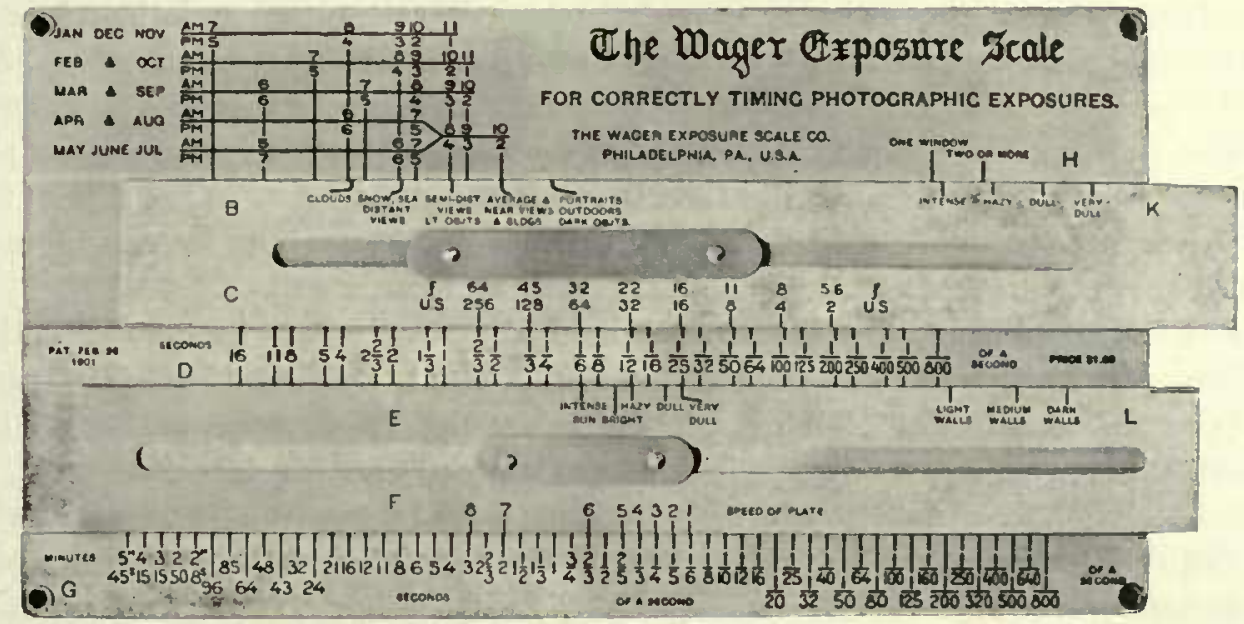

Fig. 128.*

over and over until exhausted (browned). The quantity named above will suffice for a dozen $5 \times 7$ plates properly exposed. This developer may also be used with Velox paper. In this case it should be diluted with more water, say I ounce of the ortol solution, I ounce of the alkali, 6 ounces of water, and 6 drops of ro per cent potassium-bromide water.

*FIG. I28.-Exposure scale sct to show proper time for buildings and average near views at io a. $\mathrm{m}$. to $2 \mathrm{p} . \mathrm{m}$. in July, witl stop $64(32 \mathrm{f})$ and an intense sun. The various makes of plates are divided into eight classes, and the time is read from the middle scale for intense sun and the most rapid plates. Under above conditions a Seed's $27-\mathrm{X}$ plate, or its equivalent (1), would require one-sixth second. For light of a less degree of brightness $\mathrm{F}$ is set on the proper stop, and the lime is read from the bottom scalc. The latter scale $(G)$ is also used for slow plates. With intense sun, i. e., as set above, a Cramer's isochromatic slow plate, or its equivalent (7), would rcquire 2 scconds. In indoor work, scale $\mathrm{K}$ is first set on $\mathrm{H}$, according to the quality of the light and number of windows. Scale L (kind of walls) is then set on the proper stop, and the time is read from the bottom scale, according to the speed of the plate used. In latitudes far to the north of Philadelphia there must be considerable increase of time, and there must be a corresponding shortening of time in tropical regions or desert regions. Considerable judgment must also be used in making indoor exposures, especially toward sunset and soon after sunrise. Near sunset, exposures have to be increased cnornously. About three-fourths actual size. 
Previous to development the exposed plate should be placed in the tray, flooded with water, and gently rubbed with the balls of the fingers, particularly if the exposures have been made for some time, or in dusty weather, or on plates which have been opened for some time. Many "pin holes" will be avoided by this practice, and frequently one will be astonished at the amonnt of dust which can be felt as the fingers are passed over the plate.

Negatives should be fixed in strong hypo for ten minutes (a little longer exposure will not larm them), hardened in alun1-water (saturated) five or ten minutes if the weather is lot, and washed in running water one to two hours. If these rules are followed, negatives which are good on the start will not spoil afterward. Weak hypo should not be used, neither should the solution be saturated, but only nearly so, $i . e$., a saturated solution diluted with one-sixth water. This is made up in small quantities in advance. The saturation is accomplished, not by throwing the crystals into a jar containing water, but by putting them into a cloth-sack which is brought into contact only with the top layers of the water. On removal from the washing-box the back and face of the negative should be rubbed over carefully under running tap water with a wad of soft cotton, and set away in a clean place to dry after rinsing in distilled water. If one is in a great hurry to get a print from a wet negative, it may be dried in about ten minutes by soaking for eight minutes in 95 per cent alcohol and then holding it near an electric fan.

In developing in deserts or in southern climates, in very hot weather, all the fluids must be iced, including the wasll-water, or else the plate must be hardened in 2 per cent formalin water for five minutes before the development begins. Alumwater can not be used for this purpose, since it greatly retards development.

It often happens, especially with beginners, that a good negative (one rightly exposed) is spoiled by being left in the developing solution too long or by being taken out too soon. An overdeveloped negative may be reduced after soaking it in water (or preferably before it has dried) by placing it for a few minutes in a tray of clean water, to which has been added a small quantity of hyposulphite of soda and a few drops of a Io per cent solution of red prussiate of potash (Farmer's reducing solution), which, of course, must be uniformly distributed. Thin negatives, free from hypo, may be intensified, if they are thin simply from underdevelopment, by exposure for from two to five minutes (occasionally a little longer) in a strengthening solution made of Agfa intensifier 20 parts and water I 80 parts, or by soaking then in a strong watery solution of mercuric chloride until they are whitened through uniformly on the back, and then blacking them by soaking in ammonia water strong enough to give off disagreeable funces. If the time of exposure is not nearly correct, another negative should be made. Negatives thin from overexposure do not intensify well; neither do those which were much underexposed. All negatives should have the subject, date of making, and degree of magnification written on them with a lead pencil as soon as they are dry. The proper place for a record is on the margin of the negative itself rather than in a book or on a bag. which may become misplaced, although it is convenient to have it also on the envelope, or negative-bag. 
The correct time of exposure for pliotomicrographs varies so greatly with the size of stop, length of bellows, kind of slide, number of objective, quality of light, rapidity of plate, etc., that no very definite rules can be laid down, the right time in special cases in Washington varying all the way from several ninintes to $\frac{1}{100}$ of a second. If the bellows-length is doubled, of course the time of exposure must be quadrupled. Low powers, and especially Planars, let through a great flood of light and require correspondingly short exposures. With low powers and sunlight the student might begin on $\frac{1}{25}$ second. With an oil-immersion lens and bright light he might try $\frac{1}{2}$ second or $\frac{1}{5}$ second. If the section is densely stained, much allowance must be made for that. It is well, at least for a time, to keep a record book of subjects and exposures to refresh one's memory. It saves the spoiling of many plates. Such a record slionld include subject, length of exposure, stop used, objective and eyepiece used, length of bellows, distance of the condensing lens from the Abbe condenser, time of day, time of year, quality of light, kind of screen, kind of stain and density of section, kind of plate, developer used, time required for development, and quality of negative, viz, overexposed, underexposed, or correctly timed.

For outdoor work, and also for natural-size or slightly inagnified indoor work, a good exposure scale is sometimes useful. The best ones known to the writer are the Wynne and the Wager. Success with the Wynne depends on one's judgment as to the proper clianges in a good sensitive paper; with the Wager it depends on one's judgment as to the quality of the light in the sky. After a little experience very uniform and excellent results may be obtained with either. Personally, the writer prefers to use the Wager (fig. I28), because it is simpler and takes less time. No scale is always to be depended on, there are so many variations in light and so many unprovided-for contingencies. Experience is after all the best guide, but until one lias obtained it, genuine aids are not to be neglected. The beginner should first become faniliar with the right exposure for one stop and one kind of plate, e.g., stop f. I6 and Seed's 27, with a given bellows length. Having learned correct exposures under these constant conditions, it will be comparatively easy to cliange to other makes of plates and to other f. stops. Slow isochromatic plates require ro to I 2 times as long exposure as fast plates. In the matter of stops the length of exposure is, of course, quadrupled every time the f. stop number is doubled, and quartered every time it is halved, e.g., if stop 16 will give a perfect negative with one second exposure, stop 8 will require one-fourtl second and stop 32 , four seconds. Under the same conditions, stop 4 will require one-sixteenth second, and stop 64 sixteen seconds, and so on. With the Universal stops (those commonly used on the shutters made in this conntry and England) the exposure is doubled for the next higher stop and halved for the next lower one, instead of quadrupled or quartered, as in the case of the f. stops.

For lantern slides the writer converts a small room into a camera box (plate 18). This room has a floor space about 6 by 5 feet. It has a north window and a west window. Each window is provided with a double set of roller curtains, the outer made of yellow cloth, the inner of a very dense black cloth known in the trade as double-faced, opaque, black shade-cloth, which lets scarcely any light through, 
even when held directly toward the sun. A cross-bar is screwed across the base of the 11prights of the window frame, 35 inches from the floor and a few inches above the window sill. To this bar a swing shelf is hinged and drops down ont of the way when not in 11se. This shelf is about 24 incles wide by 30 inclies long. When in use it is supported in a horizontal position by a removable leg. On top of this shelf is placed a cracker-box or some similar box, to the sides of which, at the bottom, beveled cleats are nailed, which slide through corresponding cleats screwed to the top of the shelf. This enables one to push the box toward the window or draw it back on a regular track. On the top of this box, at the back end, or farthest point from the north window, the camera is placed facing this window and is screwed fast to the top of the box the same as to a tripod. Sidewise 1110vement is provided by extending the screw-hole in the top of the box into a slot 6 or 8 inches long. In sliding the camera sidewise it is of conrse necessary to keep the ground glass parallel to the negative in the window, and this is done by drawing parallel lines on top of the box about $1 / 8$ inch apart and exactly at right angles to the negative-carrier. In moving the camera sidewise all that then remains is to see that one side of the camera at front and back matches one of these ruled lines. This gives ample sidewise movement, and some 11p-and-down movement is usually provided in the camera itself. The rest is obtained by moving the negative. The upper half of the north window is covered by the curtains. The lower part is filled with a removable wooden framework, the negative-carrier, so arranged that the negative itself may be moved up and down or sidewise, or twisted around at will. The framework of the negative-carrier is made of inch stuff. When in use it is placed upright about 3 inches in front of the window pane and just behind the cross-bar which keeps it in place. In the widdle of this frame is a circular wooden disc (which must turn freely), held in place on the back by a ledge and in front by four buttons, and open in the center. The breadth of this disc is 24 inclies, and it slould be made of well-seasoned lumber of a sort not inclined to warp. On this disc at either side two broad vertical cleats are fastened. These are grooved on the inner edges next the franework, and under them, close to the circular piece, two wide $3 / 8$-inch pieces slide up and down freely, carrying the negative between them. The latter fits into marginal grooves and is held in place by buttous. The marginal grooves extend the whole length of the 3/8-inch pieces and consequently allow the negative to be moved sidewise to any extent desired, while the np-anddown movement is obtained by sliding the two 3/8-inch pieces and the negative between them as a unit. Over the first grooved cleats, at riglit angles, $i . e_{.}$, lorizontally, two similar cleats are screwed. These also have wide $3 / 8$-inch pieces moving under their grooved edges. These sliding pieces cover the sides of the negative and shut out the side-light in whatever position the negative may be placed. Behind the negative against the window is pasted (by its corners) a good-sized piece of white tissue-paper, which serves to distribute the light evenly and to cut out inuages of trees, buildings, etc. When in use the double curtains of the west window are drawn down and the door is shut. The north light which enters the room then conles through the negative placed in front of the canera. The focus is obtained 
PLATE 18.

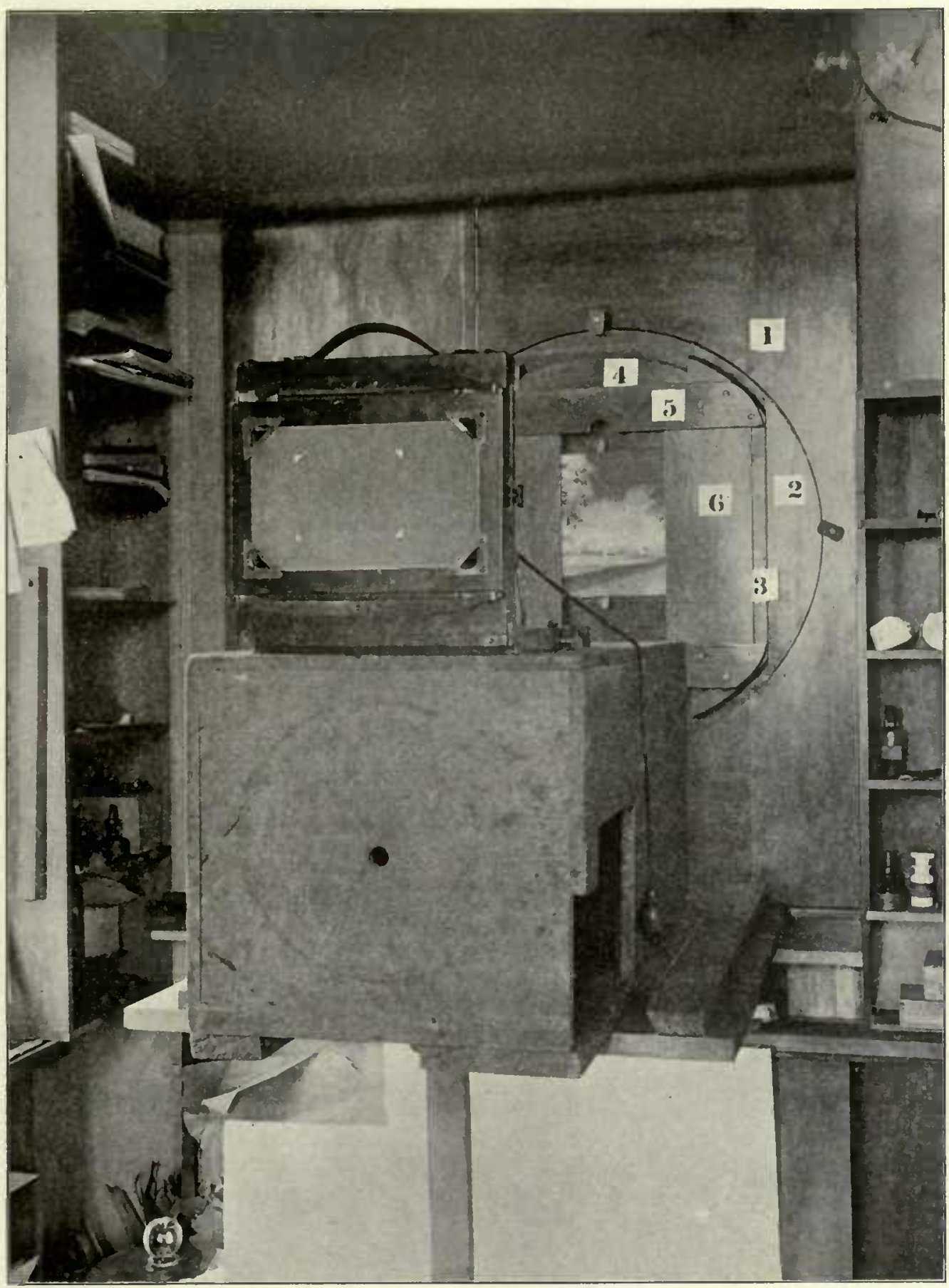

Small room arranged for making lantern slides and enlargements on bromide paper.

The parts of the window shutter are as follows: (1) frame work, (2) circular piece giving rotary motion, (3) one of two stationary pieces under which No. 4 slides, (4) nega tive carrier, (5) one of two stationary pieces under which No. 6 slides, (6) side pieces designed to cut out all the side fight except that which comes through the negative. 

on the ground glass as for any picture, remembering that a wide margin ( $1 / 2$ inch or more) must be left for binding strips, and that if the negative has any up and down its image must be placed crosswise on the lantern-slide. The writer focuses as

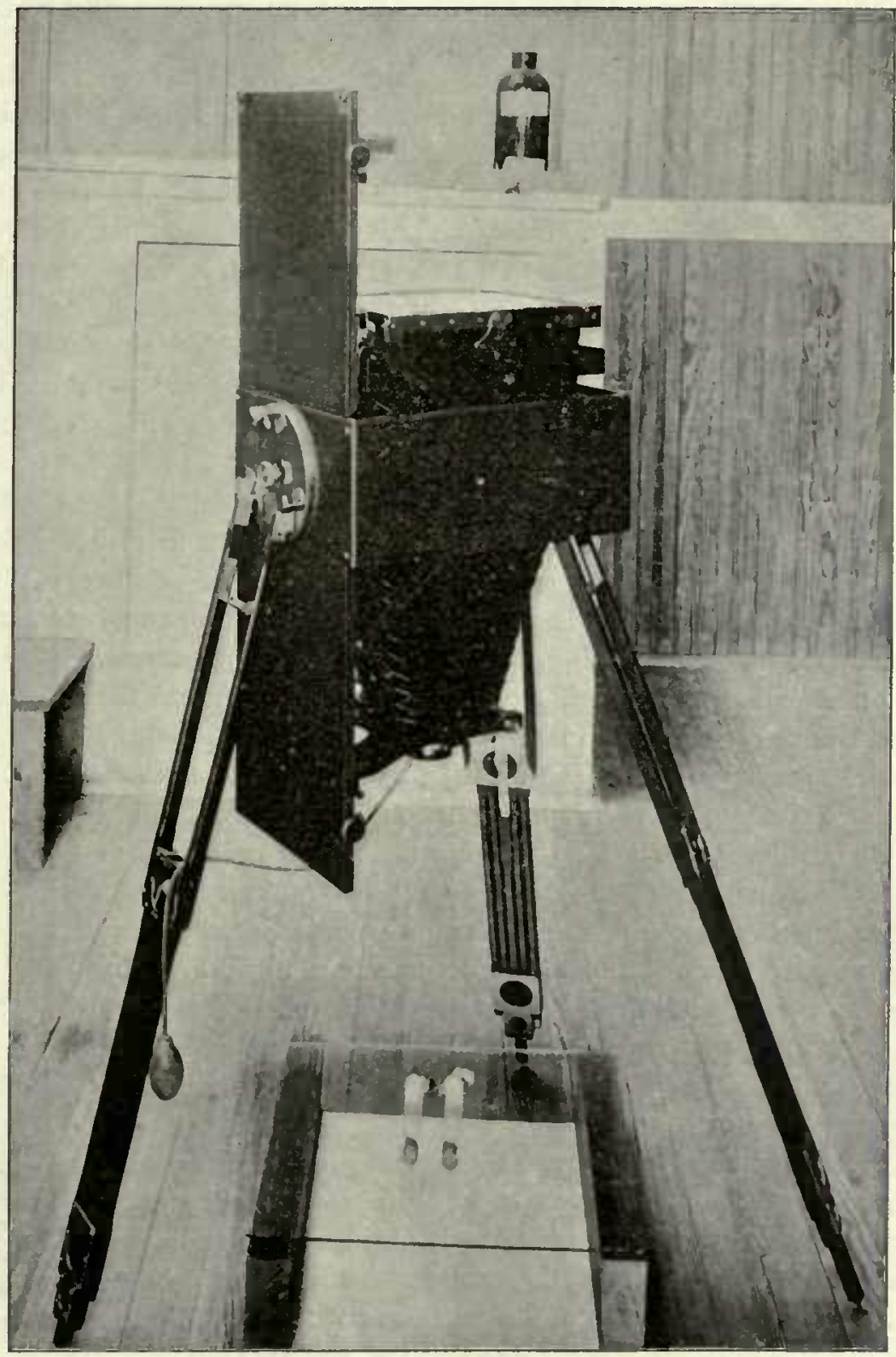

Fig. 129.*

*FIG. I29. -The modified Collins-Brown camera used with tripod for natural-size pictures. Heavy shadows are dissipated by using the glass plate. The size of the camera box is $10 \% / 4$ by $123 / 4$ by $5 \%$ inches, and its weight, including lens and shutter, is about 15 pounds, or with tripod 19 pounds. The camera takes a $61 / 2$ by $81 / 2$ plate. It is solidly constructed, of the very best workmanship, and the only objection is its weight, which is no disadvantage in laboratory use. It is not recommended for field use. 
sharp as possible with stop wide open and then stops down to I6 1 . s. before inaking the picture.

There are two other ways of making lantern-slides, i. e., by contact exposure, the gelatin films face to face, and by nieans of a long box-camera with the negative in one end, the lantern-slide carrier in the other end, and the lens between the two, i.e., inside the cainera-box, held in a framework sliding between the two ends and having

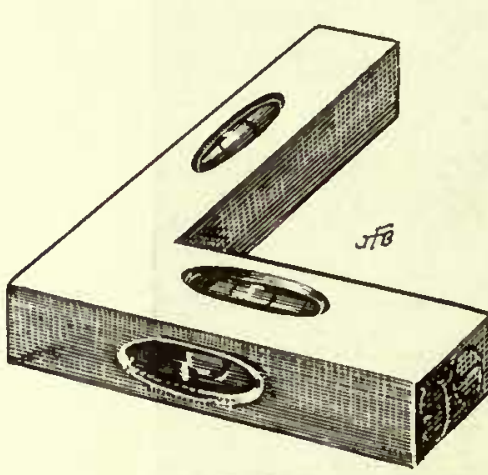

Fig. 130* front and rear bellows attached to its outside parts. The method by contact exposure is not very satisfactory unless the negative and the lantern-slide are of the same size. The box-method is a very good one. A box of this kind is very convenient, and may also be nsed for enlargements up to 5 or 6 times. The bellows-extension should be ample, so that various lenses may be accommodated and so that lantern-slides may be 11ade from large negatives if desired, $i . e$., the solid frannework or track on which the parts slide should be about 6 feet long, and the bellows-extension to eitler side of the middle piece slould be not less tlian 3 feet, exclusive of the woodwork at each end and in the middle. A very good apparatus of this sort is shown in plate $\mathbf{r} 7$. It is the Folmer \& Scllwing enlarging, reducing, and copying cannera, mounted on a plain wooden table of lowe construction, and the only defect I have discovered in it is that it has too sliort a bellows for use with lenses having a 12 -inch focus. It has a very neat device for obtaining a sharp focus and many other conveniences, and 11iglit just as well be made with a longer bellows. It is convenient to have a box which will take II by 14 plates. When making lanternslides the end of the box carrying the negative is pointed toward the window and is elevated a foot or more to secure uniform lighting. The writer has found the Voigtlaender collinear lens, series III, No. 6, very satisfactory for making lantern-slides and enlargenents. In plate $x$ the bellows-extension used when making lantern-slides from large negatives lies on the floor.

The time of exposure for lantern-slides varies greatly with quality of light and density of negatives, e. $g$., with stop 64 u. s. from $\mathrm{r} / 2$ second or less in bright light to fifteen minutes or more in very

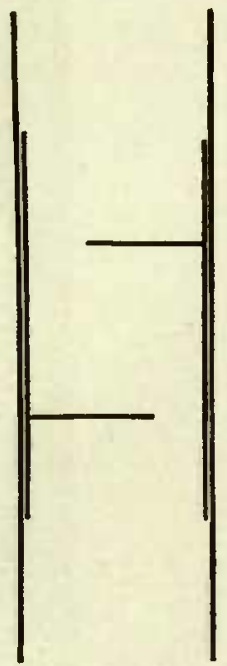

Fig. 131.† d11ll light with dense negatives. Lantern-slides should not be developed witlı pyro because it stains, and slould not be developed with metol-hydro because it often gives a foggy appearance if the contrasts in the negative are great or the exposure is a little too long. Hydrochinon gives very satisfactory slides.

*FIG. 130.-Cross-level, made by The L. S. Starrett Company, Athol, Mass. Nearly actual size. This is very convenient for use with cameras.

†FIG. 131.-Device for cutting out light in air-shaft of dark-room. Diameter, 12 inches. 
In lantern-slides one desires much detail and little density; it is customary, therefore, to develop only until there is a good surface inage. On no account must the development be pushed until the image slows through on the back. Even the densest portions must be translucent. Slides suitable for projection with very bright lights may prove too dense for dull ones. In making lantern-slides one must keep in mind the kind of light to be used in projection.

In making enlargenents, the cannera is lowered to the horizontal and pointed away from the window, and the object is lighted in part from above (skylight). To

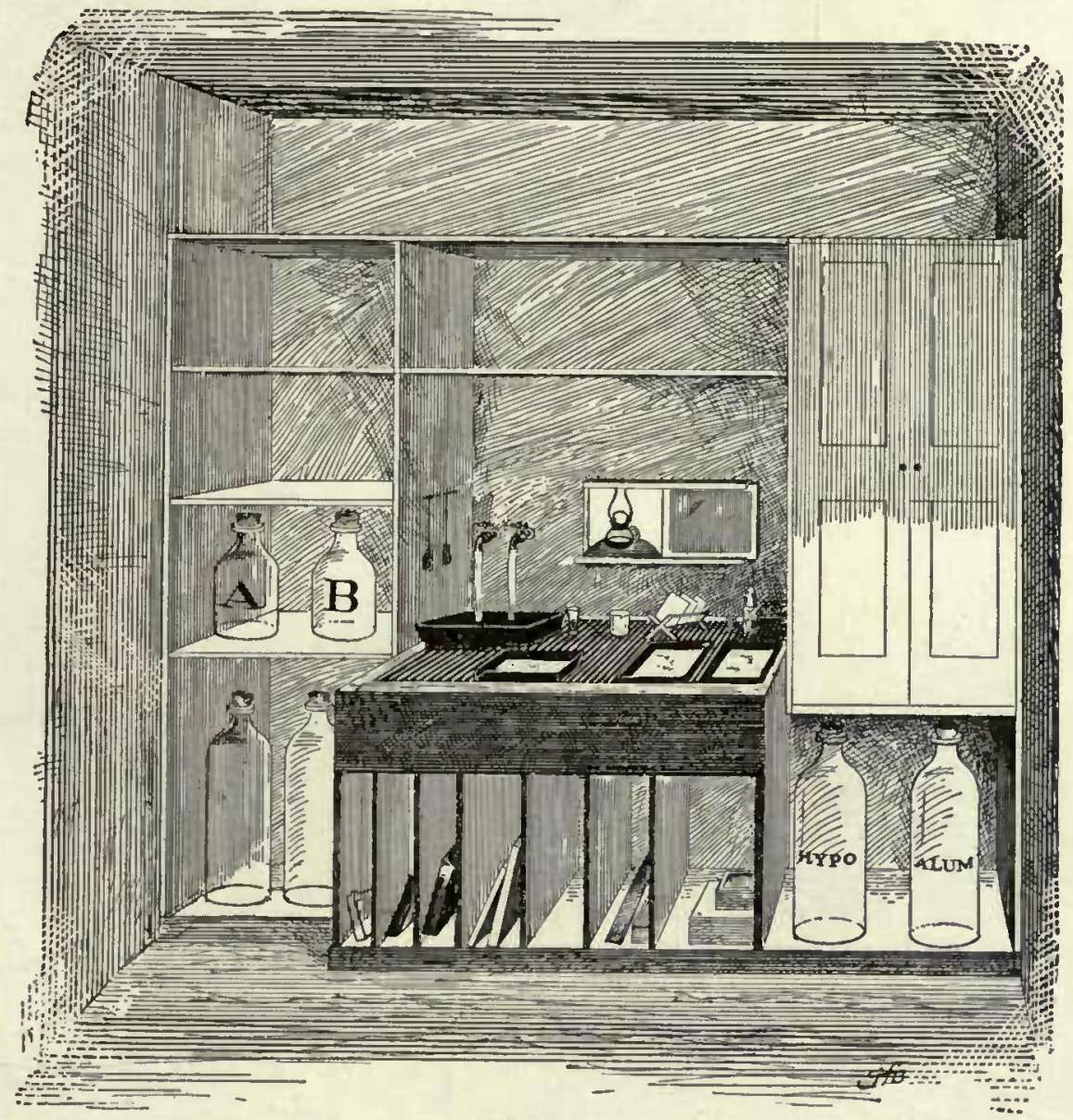

Fig. 132.*

facilitate shifts it is convenient to have the table-top (to which the camera-bed is screwed) turn freely on a central pivot, and the legs of the table should be mounted on casters so that it may be moved about easily. The table devised by the writer is shown in plate 17 . This was built by a carpenter and does well enough. In making enlargements the lens-board is removed from the interior and substituted for the kits in the front end of the camera; the ends of the wooden carrier (shown on first shelf of the cannera-table) are slid under the beveled cleats at the front end

*FIG. 132.-Side view of a convenient small dark-room, devised by Mr. Hubbard, 
of the table, and the map or other object to be enlarged is then pinned on a flat board in the right position in front of the lens, the board being held in place by the

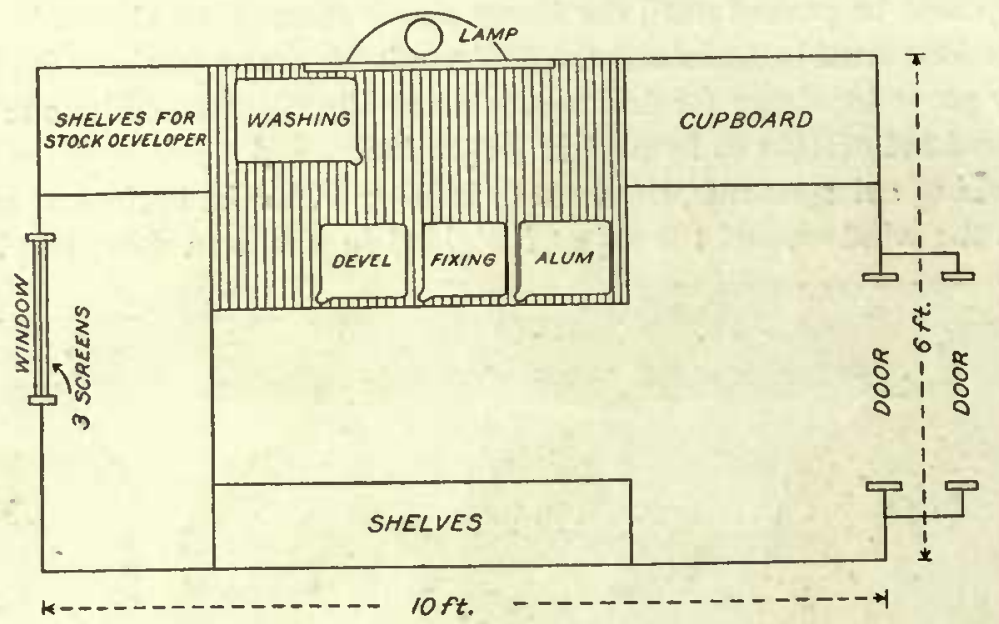

Fig. 133.*

carrier. The desired magnification is obtained by sliding the carrier in or out to a marked place previously determined.

When not made directly from the microscope, the histological drawings in this book have been made from photographic enlargements. For example, in fig. 72 a solio print or bromide print was made from the photomicrograph. This was then enlarged three or four times and from the resulting negative a salted-paper silver print or a blue print was made. A drawing was then made on this print with a fine-pointed pen and waterproof India ink. After careful inspection by the writer and sucli changes as were required to make the drawing correspond more nearly in all its details to the main lines of the photograph, the brown of the silver, or the blue of the iron salt, was rel11oved by a bath in water containing cyanide of potash. On reduction by the photoengraver many of the inequalities in the pen-work of sucl. drawings disappear and the pictures closely resemble the originals, whereas if they are drawn without enlargement, and engraved as drawn, the pen lines will in many cases liave a more or less ragged appearance.

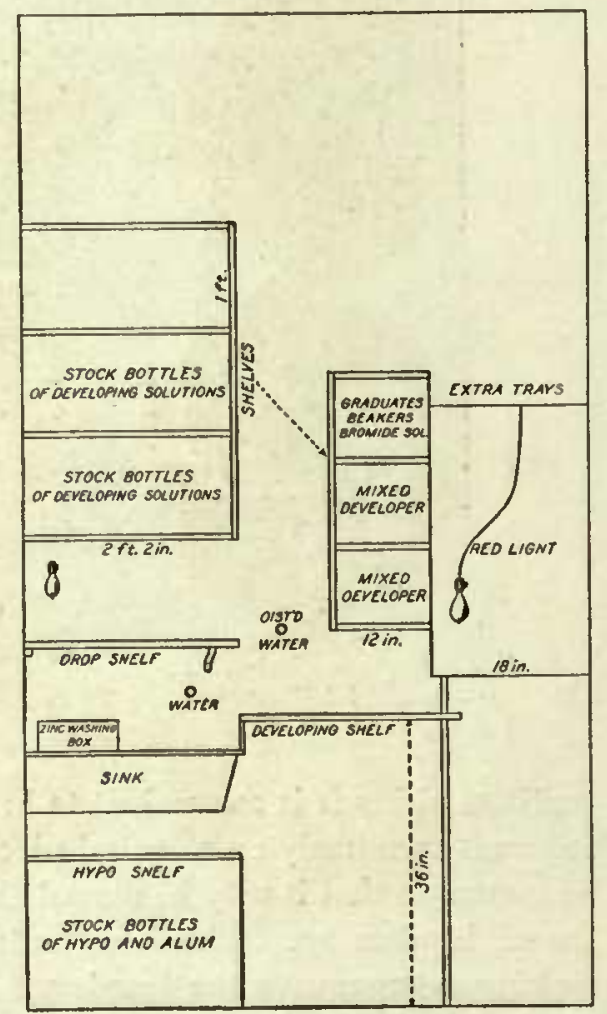

Fig. 134.†

*FIG. I33.-Top view of the room shown in fig. 132. All of the trays rest on triangular slats covering a deep sink. The screens are raised and lowered very easily by balanced weights.

†Fis. 134. - Side view of a small photographic dark-room in Laboratory of Plant Pathology. 
PLATE 19.

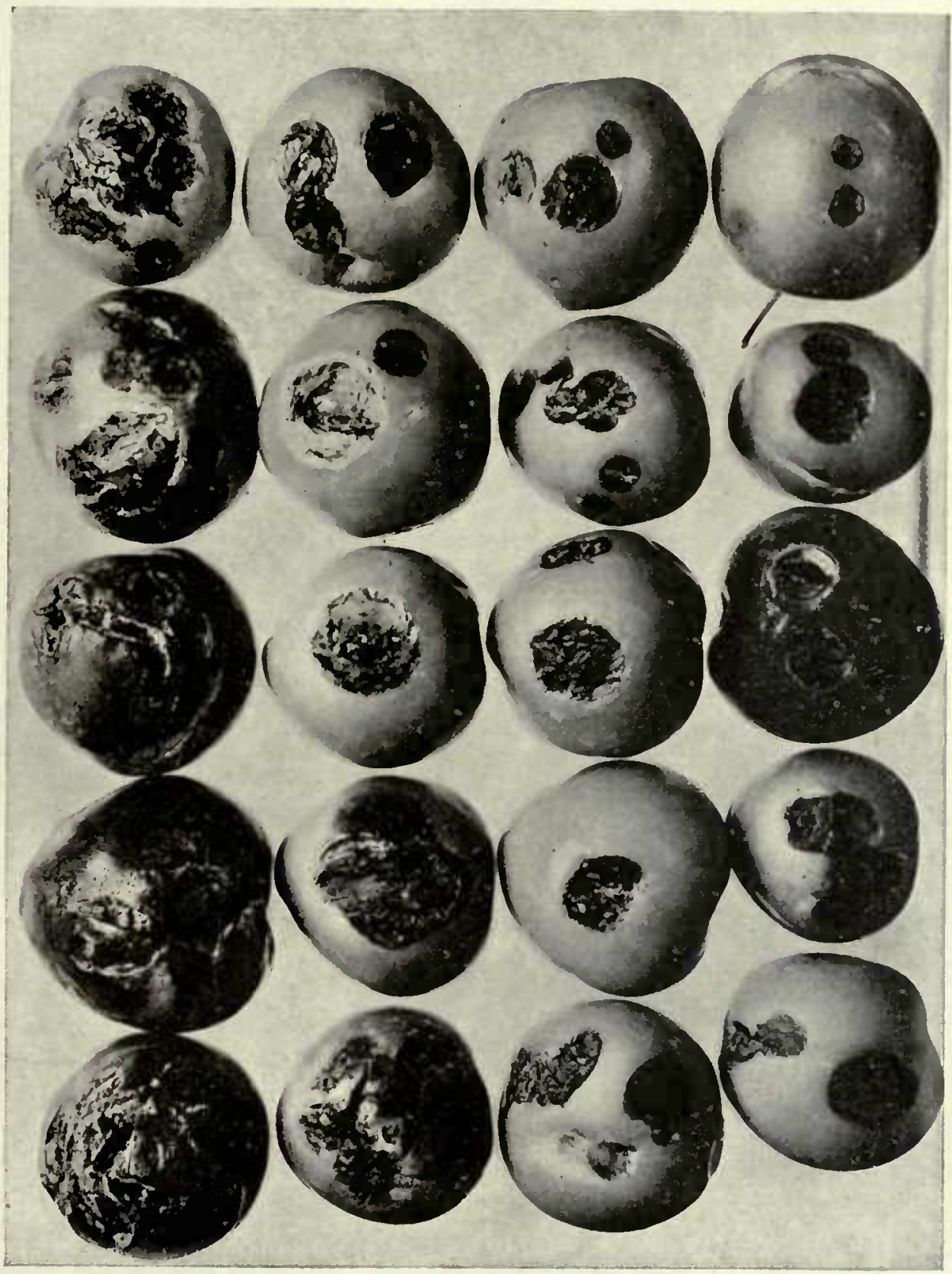

Bacterial black spot of the plum.

Spots about ax weeks old, except a very few on the two right-hand plums of the upper row. Fruits about one-half grown; collected July 24, 1902, from an orchard of Japanese plums in central Michigan. In this stage the plums (var. Hale) begin to creck open and are attacked occasionally by fungi (Monilis, etc.). Some tufts of Monilia may be seen on the outer, left-hand fruit, second row from the bottom. Early stages of this disewe are shown in figs. 70, 71, and 72 . 



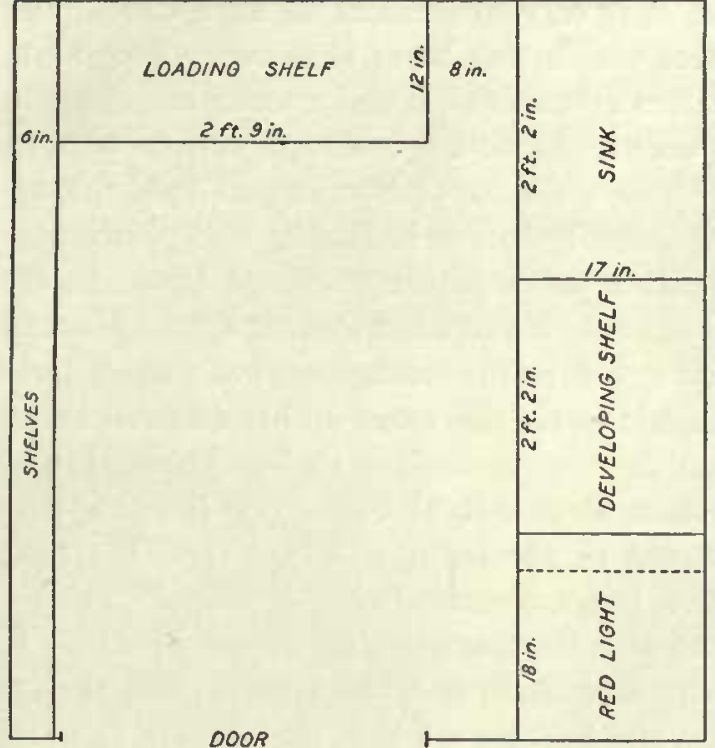

Fig. 135.*

The very convenient lieavy camera shown in fig. I24 may also be used for natural-size work, arranged as slowu in fig. I 29. In this connection the Starrett cross-level shown in fig. I 30 will be found very convenient for leveling the back of the camera.

Very excellent cameras are made by the Century Camera Company. Their Long-focus Century Grand leaves little to be desired in the way of a convenient, perfect-working instrument.

The dark-room for development is an important subject. The chamber must be light-tight. At the sane time it ought to be roomy and well ventilated. If the room is small and in use nuch of the time, some means of removing the foul air becomes inperative. The writer accomplishes this by an electric fan placed in the moutl of an air-shaft which extends from the ceiling to 6 or 8 feet above the roof. These shafts are cylindrical, I foot in dian1eter, made of heavy sheetiron and surmounted by a broad, wushroon - shaped cap. The interior is painted a dead black, and as an additional precaution against the entrance of light it carries a sleeve of the form shown in fig. $13 \mathrm{r}$. This effectually cuts out light. The air is pu111ped out so rapidly by a device of this sort that not the least inconvenience is experienced in working all day in a very sinall rooin.

If only one or two persons

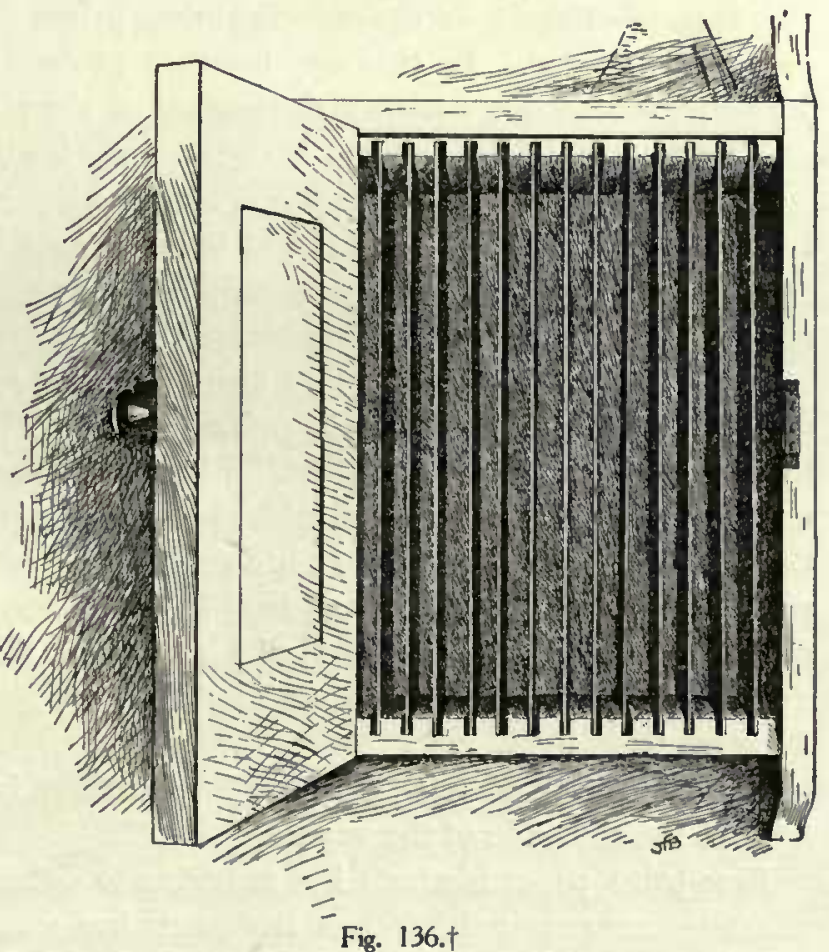

*FIc. 135.-Diagram of small dark-room shown in fig. I34. Standing in the middle, a man can touch the walls in either direction. In the ceiling is a foot-wide pipe extending 6 feet beyond the roof and capped with a hroad mushroom top. In the lower end of this pipe is an electric fan, which pumps foul air out of the room. Light is prevented from entering by partial cross-septa projecting from opposite sides of the air-shaft, and also by blacking its inner surface.

+Fic. 136.-Wall case for preserving from dust and scratches the enameled iron plates used for squeegeeing silver prints. 
of good habits are to use the dark-room, it is very convenient to have developing dishes and fixing trays on the same shelf, which 111ay be of slats over a deep sink, as in figs. ${ }^{32}$ and $\mathrm{I} 33$. With some shelves over this sink and a water-tap above it, everytling is in reacli withont noving about. If, on the contrary, various persons are to work in the dark-roon, some of then students with n11formed liabits, some of them older workers with incorrigibly slovenly habits, including a disposition to spill hypo over everytling; then some different arrangen1ent 1nust be 111ade, the sodium liyposulphite trays especially being kept on a separate slielf at a good distance from the developing shelf. Figs. I 34 and I 35 show the arrangentent of a small darkroom devised by the writer for photographic work, the space at his disposal being very linited. The air-shaft is in the ceiling over the loading slielf. Artificial light is furnislıed by two r6-candle power Edison electric-light bulbs, one hanging near the wall above the sink, the other inclosed in the red-light box. Over the ruby glass there is placed a sheet of orange-buff paper, commonly called post-office paper. The hypo trays are under the sink. The zinc box for washing negatives stands in the sink. Developers are mixed on the drop-shelf, and are kept on the shelves above it. The broninde bottle, graduates, and beakers are kept on the small shelves above the developing shelf. Large bottles of altum solution, liypo solution, etc., are stored under the hypo slielf.

Enameled plates for squeegeeing silver prints may be stored when not in use as shown in fig. I36. In this way they are protected from dust and scratches. To prevent prints from sticking the surface of the plates is occasionally rubbed with paraffiu dissolved in xylol, and is then polished with a soft clean cloth.

Some memoranda on pliotographic developers will be found under Formula. In addition to what has been said there a few lints on salted silver-paper, blueprint paper, and bromide-papers may be of service to those who wish to use these methods as preliminary to pen-and-ink drawing.

All papers designed for this use should possess a smooth surface suitable for pen-and-iuk work, and sensitive papers of this quality may be had of various dealers by specifying just what is desired. Blue-print paper and salted silver-paper may be made for one's self. It is preferable, however, to purchase the former, and to make the latter or to buy it fresl, as it does not keep well. Directions for making the plain silver-paper may be found in "The Figures, Facts, aud Formulæ of Photography and Guide to their Practical Use," by H. S. Ward, N. Y., Tenuant \& Ward, I 903; and in "The Photo Miniature," Vol. II, No. 22, "Albumen and Plain Paper Printing."

All sensitive papers placed in the printing frame shonld have the coated side next to the filn1-side of the negative.

Blue-print paper is much less sensitive to light than solio paper, and long solar printings are required. When the paper has assumed a deep-bronzy appearance it may be assumed to be sufficiently printed. A few trials will give the necessary experience. Blue-prints are developed by simply washing them in several clianges of pure water, taking care that the coated surface is wetted thoroughly from the start, $i . e$., freed from air-bubbles. No fixing is required. 
PLATE 20.

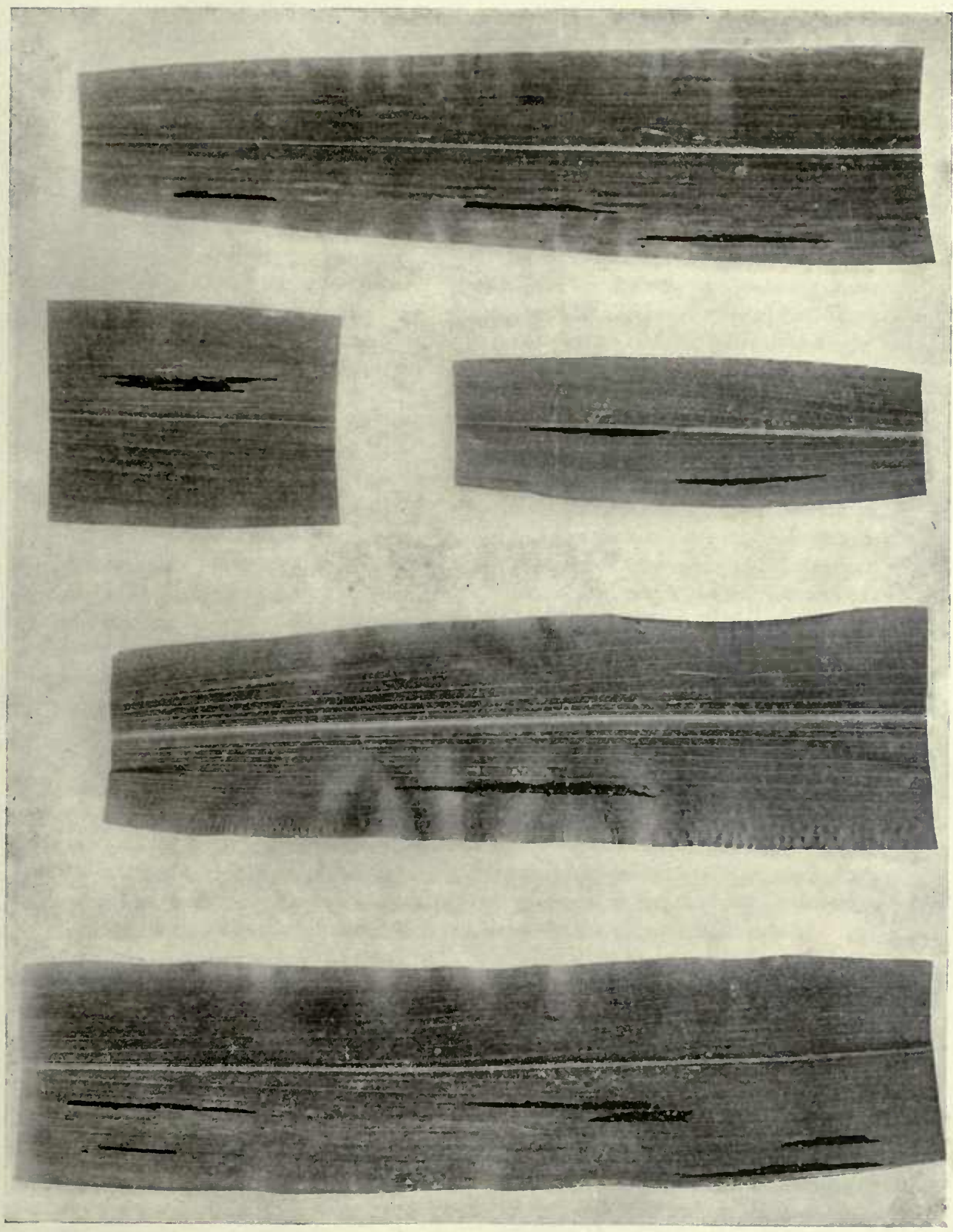

Bacterial disease of broomcorn. (Hothouse, U. S. Department of Agriculture, spring of 1905.)

Divense not complicated by aphides. The signs convist of gradually elongating red or red-brown stripes on a green background. In later stages the stripes coalesce and the leavea shrivel. Under surface of diseased areas often covered by red exusts-the dried-down, bacterial ooze from interior of leaves. The infections were by way of the stomath and these ppots ate about six weeks old. 

Salted silver-paper also requires a rather long printing with sunlight. When properly printed the paper is washed in a bath of salt-water, rinsed in several changes of pure water, and fixed in a weak solution of hypo ( $1: 15)$.

Bromide-prints under the negative are usually made by exposing the paper to artificial light at a standard distance, say 9 inches or 12 inches. By always exposing at a given distance and to a light of uniforn intensity two variable factors are excluded, and one tlien has to take into account only the quality of the paper and the density of the negative. It is usually economical, especially for beginners, to test the density of the negative in advance by exposing, for various periods, narrow strips of the sensitive paper laid across the negative so as to include dense and thin portions. These strips are then developed, and if none of them have been properly exposed, a second trial is made. When the right exposure has been learned, the print is made. A little experience enables one to judge quite correctly as to the proper exposure by simply looking through a negative. No very definite rules can be given for length of exposure; this depends so much on distance from the light and brightness of the flame. With velox paper and an ordinary flat gasflame at a distance of 9 inches the writer's negatives usually require from I 5 seconds to 2 minutes. With a Welsbach light or with thin negatives the time would be shorter. At a distance of 18 inches from the light the time would, of course, be quadrupled. Directions for the employment of special developers usually accompany each maker's paper. The writer has found ortol (p. I4I) a very good developer for velox paper, and prefers it to metol-hydro. Velox-prints are developed in weak artificial liglit (gas turned low); they are rinsed from the developing solution by passing quickly through a bath of pure water; they are then fixed in hypo, and washed for at least one-lialf hour in running water. The writer pins the prints to a smooth board and floats these in a batli-tub or clean sink, film-side down. Most of the curling may be avoided by drying the prints, film-side down, on mosquitonetting stretched on a wooden-frame.

The yellowing of prints is often due to the fact that they were not properly fixed; the lrypo solution was weak, or the time of exposure to it was not sufficient.

All pen-and-ink drawings on such photographic prints must be made with waterproof India ink, after which the plotographic part is bleached out by exposure for a few minutes in water containing cyanide of potash ( $1: 500$, more or less). The drawing; should be exposed in this bath only as long as necessary. If any part of the print refuses to bleach, it should be moistened with iodine potassium iodide and returued to the cyanide bath. It is then passed through pure water and dried face up on blotting paper in a place free from dust.

SOME MILFSTONES IN THE PROGRESS OF BACTERIOLOGY.

The development of bacteriology can not be separated from advances in human and animal patlology. Physicians and surgeons have made most of the brilliant discoveries or have led the way to thein. Chemists and plyysicists have assisted. With a few slining exceptions, botanists have had comparatively little to do witl the advancement of this science. Bacteriological inquiry has been an incentive to 
the improvement of various kinds of apparatus, notably the microscope, and it has derived corresponding advantages from the nse of these improved instruments of research. We owe, in particular, a great debt to the German physicist Abbe, whose discovery of the Jena glass made possible the superb modern apochromatic objective.

Anong the multitude of workers in animal pathology and bacteriology during the last thirty-five years certain men tower far above the rest, their contribitions to science having been more conspicuous and their inprint on their generation more lasting. If France is mentioned, we think at once of Pasteur, Davaine, Duclaux, Metchuikoff, Chamberland, Roux, Nocard, and Chauveau. In Germany we think of Virchow, Cohn, Colnuhein, Kocl, Weigert, Nicolaier, Eberth, Gaffky, Hueppe, Flügge, Fraenkel, Pfeiffer, Behring, Ehrlich, and many others; in Japan, of Kitasato and Shiga; in the United States, of Welch, Sternberg, Theobald Smith, Nuttall, Councilman, and a host of brilliant younger men, many of whom received their training under Welch in the Johns Hopkins Pathological Laboratory. England, from which one might have expected so much, has contributed comparatively little, owing probably to the laws in force in that country respecting animal experimentation, laws framed with the intention of doing a kindness to the lower animals, but working, on account of their interference with the pathologist, a distinct detriment both to men and animals, the aim of all animal pathological inquiry being the alleviation of human and animal suffering. In passing we should not forget, however, the contributions of 'Tyndall and Lister, the one a physicist, the other a surgeon.

Undoubtedly bacteriology owes very much to Louis Pasteur. France has had many great sons, none greater than he. His refutation of the doctrine of spontaneous generation cleared the air of many misconceptions and laid the foundations for exact experimentation. His demonstration of the nature of pébrine and flacherie, two destructive diseases of silk worms, brought again into vivid light the assumption that the origin of a great variety of human and animal diseases should be sought in the activities of microscopic organisms. His studies of anthrax and other diseases of warm-blooded animals confirmed this suspicion and set a great many persons thinking and working. His investigations of the problens connected with fermentation were similarly fertile in discovery and in singgestion.

The publication of Robert Koch's great paper on tuberculosis in I 884 marked another distinct advance. The same inemorable year Koch published in full his discovery of the cause of Asiatic cholera, only a brief announcement of it having been made in 1883 . The whole world was interested, and from this time on experimenters began to multiply in every civilized land, boards of health, universities, and private citizens vying with each other in the establishment of laboratories for the study of these minute organisms endowed with so much power for good or evil. Koch's investigations in South Africa bring us down to recent times, where the perspective is not so good. To sum up very briefly, omitting many things, the following are some of the milestones:

I. Overthrow of the doctrine of spontaneous generation.

2. Discovery that putrescible fluids (exclusive of inilk) will not decay after boiling, if protected from the bacteria of the air by means of cotton-plugs. 
3. Pasteur's studies of fermentations ; discovery of anaerobic organisms.

4. Pasteur's studies of pébrine, flacherie, antlırax, chicken-cholera, and rabies.

5. Cohn's system of classification.

6. Cohn's discovery of endospore-bearing organisms resistant to heat.

7. Introduction of anilin stains and photomicrograply.

8. Tyudall's discontinnous moist sterilization.

9. Lister's antiseptic surgery.

IO. Lister's dilntion method for obtaining pure cultures. Ascribed also to Naegeli.

xx. Miquel's discovery of thermoplilic bacteria.

x2. Discovery of root-tubercles of Leguminosæ by Woronin, and subsequent papers by Beyerinck, Hellriegel \& Wilfarth, et al.

3. Discovery of bacterial diseases in plants by Burrill, Prillieux, and Wakker.

x4. General introduction of Kocli's poured-plate method for obtaining pure cultures.

x. Koch's discovery of the "comma bacillus," the cause of Asiatic cholera.

16. Paper on tuberculosis by Koch in Mitth. a. d. Kaiserlichen Gesundheitsant, Bd. II.

I7. Use of synthetic media, of pressure filters, of fermentation tubes, and of other anaerobic apparatus.

r8. Introduction of apochromatic objectives.

9. Eberth and Gaffky's discovery of the bacillus of typhoid fever; Nicolaier's discovery of the tetanus bacillus; Loeffler \& Schutz's discovery of the bacillus of glanders; Salmon \& Sinith's discovery of the hog-cholera bacillus; Yersin's and Kitasato's independent discovery of the bacillus of plague; Pfeiffer's discovery of the organism causing influenza; Shiga's discovery of the cause of tropical dysentery.

20. Winogradsky's stıdies of nitrifying organisıs.

2x. Hansen's studies of fermentation, nore especially yeasts.

22. Duclaux's, Greene's, and Brown \& Morris's stridy of enzymic actions.

23. Study of toxines and anti-toxines; general use of anti-diphtheritic serum.

24. Migula's attempt to determine the exact morphology of all known species.

25. Discovery of the cause of peripueumonia in cattle by Nocard \& Roux; organism so minnte as to be at the extreme limit of inicroscopic definition.

26. Profound specialization, resulting in distinct classes of bacteriologists, $e . g$., animal and plant bacteriologists, nilk bacteriologists, water bacteriologists, soil bacteriologists; and in special societies and journals, e.g., those devoted exclusively to the study of tuberculosis.

Beyond this field, but of extreme pathological interest, and worked out by the exact metlods of the bacteriologist, are Laveran's discovery of the protozoan causing malarial fevers and Theobald Smitli's discovery of the protozoan causing the bovine disease known as Texas fever, botl parasites of the red blood-corpiscles. More recently it has developed that these are not rare types of disease. On the contrary, many virulent diseases of man and the lower animals are now known or believed to be due to Tripanosomes or other Protozoans, and the literature on the subject is becoming voluminous. 


\section{NOMENClature, aNd Classifications.}

The nomenclature of the bacteria is in a somewhat chaotic state, as might be expected of a science which has been cultivated so largely by medical men and so comparatively little by systematic botanists and zoologists. The writer therefore will venture a few remarks on this subject.

If an organism is distinct from any which has been described, so as to be regarded as a new species or spoken about as a distinct thing, then it should be given a specific Latin name and not designated by a figure or a letter of the alphabet. Bacillus No. I, 2, or 3 , or A, B, C, is proper enough for private memoranda while an investigation is incomplete, but when it is finished and ready for publication these designations should give place to scientific names.

Naturalists everywhere are in agreement that the scientific name of a living thing should consist of two words only-the name of the genus, followed by the name of the species, after which is usually added the name of the author, or, if a transposition has been made from one genus to another, the name of the original describer is put into a parenthesis, followed by that of the transferrer outside of the parenthesis. All polynomials, of which there are now many, are to be regarded as nomina excludenda. For example, Bacillus coli communis should give place to $B$. coli, and such names as Bacillus membranaceus amethystinus mobilis, Bacillus argenteo phosphorescens liquefaciens, Bacillus pyogenes foetidus liquefaciens, should yield to something shorter and more in conformity with modern views of nomenclature. More than I 70 trinomial names are to be found in the last edition of Flïgge's Mikroorganismen, and very few, if any, of them were given with the distinct idea that they represent varieties of other organisms. The liabit of giving trinomial or quadrinomial names should be abandoned, and as far as possible binomial names should be substituted for those already in literature.

In the period antedating Koch's discovery of the poured-plate method, when there was no very satisfactory way of separating one organism from anotlier so as to have pure cultures, the descriptions were necessarily vague. They were usually drawn from mixed cultures, and very brief descriptions were supposed to be ample. The result is that many of the names which have come down from this period are nomina nuda, or semi-nuda, $i . e_{.}$, it is impossible to associate them with any known organism for the very good reason that they were not founded on any one organism, but on mixtures now indeterminable, or were too imperfectly characterized. Generally speaking, such names should be abandoned. The only safe rule and the only just one is to discard all specific names which do not carry with them an exact statement or description, sufficient to associate the name beyond doubt with a particular organism. It is not sufficient description of an organism to say that it is the cause of a disease, unless the author has proved it to be such according to the well-recognized rules of pathology. In order that his name shall hold, an author must have carefully described the disease and must have proved in some way the pathogenic nature of his organism, or else he must have given a fairly correct description of the morphology and physiology (cultural characters) of the organism, so that it can be detected anywhere. Just how much shall constitute a sufficient description must depend on circumstances. A few lines might be sufficient if the description 
were exact and of such a character as to definitely indicate a particular organism as the one intended. Many pages would be insufficient if the description is vague and contradictory and does not enable the scientific public to fix upon a particular organism as the one intended. The careful work of subsequent investigators may sometimes lead an author to say that he 111eant to designate such or such organisms by lis names, but if he really described something different or made no intelligible descriptions, then his names can only be regarded as equivalent to nomina nuda and should never be substituted for later ones given after careful study and description of the organism. Any otlier course puts a premium on bad work. In case of the ligher plants and animals, preserved specimens will often serve to correct a faulty description and to indicate clearly the object to which the nanne was applied. Cultures of particular bacteria kept alive by means of frequent transfers to fresh culture-media will also serve the same purpose when they are able to run the gauntlet of extermination by other organisus accidentally introduced during some one of the many transfers, and when they have not varied too greatly from the original type as a result of changed environinent, but dead and dry organisıns, in most cases, offer only a most dubious and uncertain means of identification. Who, for exanple, would undertake to deternine what is included under the name Bacterium termo in von Thue1nen's dried collection, No. Iooo? The name Bacterium gummis affords a good exan11ple of what the writer has in mind. Bacillus vascularum solani, Bacillus caulivorus, Bacillus gossypina, and Micrococcus pellucidus are also examples of names given unaccompanied by any proper description of the organism. Many additional ones n1ight be cited. There is no lack. To found, for example, a new species of rabbit on the observation that a small jumping animal about the size and shape of a rabbit had congregated in certain turnip fields and caused great damage and apparently lad destroyed no other plants would only serve to provoke a smile or to raise a doubt as to the autlior's mental condition, and yet descriptions equally worthless are not at all uncommon in systematic bacteriology. The Micrococcus pellucidus, although published quite recently and in the Comptes Rendus of the French Acadeny, is not described any better. "I find it quite impossible," says Mr. Stoddert, " to identify many species from published descriptions." Numerous complaints of this sort, made in recent years by well-trained and competent men, sufficiently indicate the necessity of a thoroughgoing reform.

Various inore or less arbitrary dates have been assumed by zoologists and botanists as the proper beginning of species priority, none of which can be used in bacteriology. In the opinion of the writer the only proper starting point is from the time when bacteriologists were first able to make and easily maintain pure cultures of any given organism, namely, from the discovery of the poured-plate method of isolation in the year I88I. Nearly all species characterization prior to this time is a cloudland of uncertainty, and while it may be possible fifty or a hundred years from now, when the whole field of bacteriology, as we now understand it, shall have been thoroughly worked over, to decide by the doctrine of exclusion, with some degree of probability, what was meant by certain old names, nothing whatever can to-day be made out of the description accompanying these names. And here I wish to register a protest against anything of this nature ever being done. If, in his own generation, a name can not be associated beyond doubt 
with a particular organism by means of an author's description or figures or collected specimens, then this name should disappear, never to be revived. Societies of bacteriologists should unite in the near future on some authoritative date for the beginning of species priority, so that some sort of stability may be guaranteed to the nomenclature of the future.

In the way of generic nomenclature there is not much of value prior to Cohn's first great paper in the year $\mathrm{r} 872$. It seems perhaps rather commonplace reading now, but it really marked a great advance and was the result of twenty years of diligent inquiry. Inasmuch as there is no present agreement among bacteriologists as to the limits of common genera, the same genus name being used with very different meanings by different writers, it appears worth while to discuss the subject of genera at soine length.

At the outset three principal inquiries arise. First, what character or congeries of characters shall be considered of generic value; second, what generic names shall be used; third, what meaning shall be attached to these names?

In the description of species it is necessary to draw very largely upon physiological characters, but it will not be disputed, I think (certainly not by naturalists), that genera ought to be founded, if possible, entirely upon morphological characters, in confornity with the usages of other branches of natural history. Physiological characteristics may be used to help out our description of sub-generic groups, such as the yellow Bacterium (Pseudomonas) group, the green-fluorescent Bacterium (Pseudomonas) group, the hog-cholera group, the hay-bacillus group, the Proteus group, the Tyrothrix group, the Urobacillus group, etc., but morphology appears to be sufficient to distinguish the genera.

Quite dissimilar organisms are still put by many writers under the same genus name, but the tendency to carefully discriminate is on the increase, and before many years, it is safe to say, writers on bacteria will be using generic names with a definite morphological meaning. Certain it is that we can not go on much longer calling any rod-shaped organisin Bacillus or Bacterium interchangeably, or putting it into the one genus or the other according as we happen or do not happen to find it producing endospores, or growing as a short rod or as a filament. Some light may come from considering with what meaning such generic terms were originally used. Matters would also be much simplified by accepting 1872, the date of the appearance of Cohn's first great paper, as the proper date for the beginning of generic nomenclature of the bacteria, using only such earlier names as lie accepted, emending his conception of these genera in such ways as experience has shown to be necessary, and adding new names from time to time as new genera are discovered. If some date is not settled upon in the near future, the11 we may expect an attempt to substitute certain names which liave not been at all used for the last thirty years, i.e., since bacteriology becane a science, for those which are now in connmon use. The confusion which would result from an attempt of this sort and the utter uselessness of making such a change are sufficient grounds for desiring an authoritative expression of opinion on the part of organized bodies of men cultivating this branch of science before we are precipitated into any such confusion. The question raised is this: Shall we abandon nodern generic names given to definite, well-known, and easily recognizable organisms for old names given before there was any science 
of bacteriology, not now in use, and most of which can not be attached witl certainty to any specific organisn, or to any definite groun of organisus?

From time to time, as new discoveries have been made, our views as to what should be considered generic characters have undergone decided inodifications, as everyone knows who is familiar with the various writings on systematic bacteriology, especially those which have been the most widely read and have exerted the most influence. A full discussion of all the various problems of generic nomenclature is not, however, contemplated in this connection. It is safe to predict that no systen now extant can be looked upon as a finality, since we know as yet too little about these numerous and variable organisms to devise an altogether consistent systein. Classifications are conveniences, nothing more. Some conform more nearly than others to the observed facts, but none are perfect or, from the nature of the case, can ever be final. What the future may have in store no one can tell. There will undoubtedly be many surprising discoveries, and recent attempts at classification may then appear very crude. Our concern, however, is chiefly with the present and with knowledge as it appears to-day.

On the whole, the classification of Migula, which was proposed in October, r 894 , and is ontlined at length and applied to most of the well-recognized forms, in his beantiful great work, "System der Bakterien," appeals to me most strongly. Up to this time the writer has followed this system in his own publications and will continue to do so, with certain modifications, until some distinctly better system makes its appearance. This system is based on the flagella and is much more workable tlian one based on spores, or on a combination of these two characters. The presence or absence of flagella and their position on the body are used by Migula as generic characters.

In 1895 Dr. Alfred Fisclier also proponnded a new system of classification based on spores and flagella. This system was republished in 1897 , with material modifications, in his "Vorlesungen über Bakterien," and is modified still further in the second edition of that work. In the non-twisted, rod-shaped bacteria use is made of the flagella to separate the subfamilies, while the generic cliaracters are derived from certain phenomena incident to spore-formation. The following table of 7 genera, taken from his first paper, shows this system at a glance:

FisCIIER'S TABELL,ARISCHE UFBERSICHT DER BACILLACEEN.

\begin{tabular}{|c|c|c|c|c|c|}
\hline \multirow{2}{*}{ Sub-families. } & \multirow{2}{*}{ Flagella. } & \multicolumn{3}{|c|}{ Shape of rods coutaining endospores. } & \multirow{2}{*}{ Arthrospores. } \\
\hline & & Cylindrlc. & Spindle-form. & Clavate. & \\
\hline Bacilleī..... & None... & Bacillus..... & Paracloster.. & Paraplectrum... & Arthrobacter. \\
\hline Bactriniei... & $\begin{array}{l}\text { One polar } \\
\text { flagellum. }\end{array}$ & Bactrinium.. & Clostrinium.. & Plectrinium..... & Arthrobactrinium. \\
\hline Bactrillei... & $\begin{array}{l}\text { Polar fla- } \\
\text { gella tuft. }\end{array}$ & Bactrillum... & Clostrillum.. & Plectrillum..... & Arthrobactrillum. \\
\hline Bactridieī... & $\begin{array}{l}\text { Dif } f \text { us e } \\
\text { flagella. }\end{array}$ & Bactridium.. & Clostridium. . & $\begin{array}{c}\text { Plectridium } \\
\text { Diplectridium. }\end{array}$ & Arthrobactridium. \\
\hline
\end{tabular}


Concerning this classification it should be pointed out that large groups of bacteria are omitted altogether, namely, those which produce neither endospores nor arthrospores. This, so far as we yet know, includes nearly all the plant parasites. About one-half of the genera were hypothetical at the time the paper was published, $i . e$, not founded on any organism, as I have already pointed out in another place.* The question of whether an endospore-bearing rod is or is not swollen around the spore is often difficult to determine, and as Migula and Lehmann \& Neumann have pointed out, the endospore-bearing rods in some species may be either cylindric or spindle-form, or bear the spores in the middle or at one end. The whole question of the existence of arthrospores is still a matter of doubt. Closely-related forms, and even the same species, may possess one or several polar flagella. The genus Bacillus was founded by Cohn on Bacillus subtilis, which is now known to have peritrichiate flagella, Bacillus ulna, also actively motile, and $B$. anthracis, which is non-motile. Inasmuch as Cohn's studies were 1nade chiefly on $B$. subtilis, he having never studied $B$. anthracis, but only including it as a sort of aftertlought, for the sake of completeness, and because Bacillus subtilis is the first one described, it seens only proper that the term Bacillus should be restricted to motile forms resembling the hay bacillus, $i . e$., those having diffuse flagella, and should not be transferred to the non-motile forms. For the hay bacillus and similar forms Dr. Fischer has used the name Bactridium. This name, however, is inadunissible because preoccupied and that, too, whether bacteria be considered as plants or animals. Bactridium has been used as a genus name seven tines, as follows :

Bactridium Kunze, I8I7: For fungi, I I species of which are recognized in Saccardo's Sylloge Fungoruu1.

Bactriditu1n Salisb., used in 1839 as a sectional name under Erica (DC. Prod.), and also in 1889 by Drude in Engler \& Prantl's Die Natiir. Pflanzenfamilien. It is said by Baillon to be a synonym of Syringodea Benth. Bentha11 reduced Don's genus Syringodea to a section of Erica.

Bactridium LeConte, I86r: Col., p. 86 MS.; Bactridium Sauss., I863, Orthop. M. Scudder : Genera in Zoology.

Bacteridium Davaine, I868: For the organism causing anthrax.

Bactridium Schroeter, 1872 : For Micrococcus prodigiosus and various other pigment-bearing bacteria, most of which have since been included under Bacillus.

Bactridium Fischer, I895: For Bacillus subtilis, B. megaterium, B. typhosus, etc.; B. typhosus, however, being non-sporiferous, so far as known, has logically no place in Fischer's original classification, as already pointed out, since the mere fact of the absence of endospores does not presuppose the existence of arthrospores. The same remark applies to Bacillus amylovorus and to many other species.

Dr. Fischer himself knew of the existence of Kunze's genus Bactridium, and refers to it, but he does not appear to have knowil of Davaine's use of the word for the anthrax organism. He thinks that Kunze's "rare, little-know11 fungi" are so different that there will be 110 confinsion, and insists on using tlie word with an entirely different meaning for the most curious of all reasons, viz, "nm die Harmonie

\footnotetext{
${ }^{*}$ Review in Am, Naturalist.
} 
der Nomenclature nicht zu stören." The only possible ground on which such use conld be defended is that bacteria are so different from plants and animals that duplication of generic names is not a matter of any cousequence. If this were so, then he should, nevertheless, according to all recognized rules of nomenclature, have used the word witl a different concept, since the first use of Bacteridiun in this group was to designate a non-110tile organism. Davaine nsed this word long ago in a perfectly plain and legitimate way to separate the non-motile from the motile forms, and the organism, wlich he studied most carefully as the type of his new genus, is that wlicl was only some years afterwards designated Bacillus anthracis, namely, in 1872 , when Colnn forned his new genus Bacillns. If the genus Bacteridium is to stand at all as a bacterial genus, it must be 11 sed for Bacillus anthracis and its congeners, and it is an eminently proper name for these organisms, provided bacteriologists can bring themselves to think, with Fischer, that this name is not too close to the fungons genus Bactridium Knnze on the one hand or to the animal genera on the other, which have priority. The writer does not share this opinion. There would seem to be also an older name than Dr. Fischer's Plectrinium for monotrichiate bacteria having the spore borne in a swollen end, viz, Trécul's Urocephalum. This, according to Trécul, was a motile bacterinun coloring deep blue with iodine. Trécul describes it as 0.02 mm. long, "à queue flexueuse," with distinct spore formation at one end which was enlarged. The subfamily name Bactridei is also open to objection becanse preoccupied. There is a genus of palms, Bactris, and in 1889 Drude, in "Die Natürlichen Pflanzenfanilien," used the sibtribal name Bactrideae, which is the same word as Bactridei.

Dr. Fisclier lias not helped matters by the modifications introduced into his "Vorlesungen" as the result of criticism, since he has destroyed the logical consistency of his system by including sporiferous and non-sporiferous forms under the same genus name.

\section{MIGULA'S CLASSIFICATION OF THE BACTERIA.}

The bacteria are phycochrom-free schizomycetous plants with division in one, two, or three directions of space ; reproduction by vegetative multiplication. Resting stages in the form of endospores are prodnced in many sorts. Motility due to flagella occurs in sonte genera. In Beggiatoa and Spirochaeta the organs of notion are unknown.

\section{Order EUBACTERIA.}

Celis without any "Centralkörper" and free from sulphur and bacteriopurpurin; colorless or faintly colored, also chlorophyll-green.

\section{Family COCCACEAE Zopl emend. Mig.}

Cells globose in a free state; in stages of division often somewhat elliptical. Division in one, two, or three directions of space without previous elongation of cell. If the cells remain united after division, they are frequently flattened at points of coliesion. In all Coccaceae with cells large enough for observation septation takes place in the globose state before there is any elongation perpendicular to plane of division. Only a few species are motile. 
Streptococcus Billroth.

Cells globose and without organs of motion. Division in only one direction of space. When the cells remain united after division, moniliform chains are produced, or diplococcus forms, but the latter also occur in other genera of Coccaceae. Doubtful if any spore formation.

Micrococcus (Hallier) Cohn.

Cells globose in a free state. Division in two directions of space without previous elongation of cell. No organs of motion. Endospore formation not positively demonstrated and probably wanting. When the cells remain together after division Merismopaedia-like plates may be formed, in which case the contiguous cell-walls may be flattened.

\section{Sarcina Goodsir.}

Cells globose, in a free state. Division in three directions perpendicular to each other. No organs of motion. Spore formation doubtful. If the cells remain united after division, bale-like constricted packets are formed; frequently these do not appear, as the nutrient medium has the greatest influence on the form of the cell-unions.

Planococcus Migula.

Cells globose but usually adhering in twos or fours with points of contact flattened. Division in two directions of space, as in Micrococcus. Motile by means of one or two long, wavy-bent flagella. Spore formation unknown.

Planosarcina Migula.

Free cells globose. Division in three directions of space, as in Sarcina. Motile by means of long or short flagella. Apparently only one flagellum to each cell. No endospores. Usually the cells remain united after division as diplococci or tetracocci, but seldom in the form of packets.

\section{Family BACTERIACEAE.}

Cells longer or shorter cylindric, straight, or at least never spirally twisted. Division in one direction only, viz, perpendicular to long axis, and only after a preliminary elongation of the rod. In some species the rods separate early; in others they remain united for a considerable time as longer or shorter threads. A single cell, so far as known, does not immediately break up into two daughter cells when the first septum is formed, but remains as a single rod until additional septa are laid down. In some species the cells may be very short, so as to superficially resemble Streptococci, but an exact study of the cell-division enables one to distinguish with certainty.

Bacterium Ehrenberg (char. emend.).

Cells cylindric, longer or shorter, often forming threads of considerable length. Without organs of motion. Endospore formation occurs in many species, but appears to be entirely wanting in others. In many they may yet be discovered when the organisms are exposed to suitable environments.

Bacillus Cohn (char. emend.).

Cells straight, rod-shaped to ovoid, longer or shorter, sometimes united into quite long threads. Motile by means of wavy-bent flagella which are scattered over the whole body. Endospore formation frequent. In most species motility occurs only during a definite period of development, which is very brief in some species and very long in others.

Pseudomonas Migula.

Cells cylindric, shorter or longer, sometimes forming threads. Motile by means of polar flagella. The number of flagella on a pole varies from i to ro; most frequently it is 1 , or 3 to 6 . Endospore formation certainly occurs in some sorts, but is rare. 
A separation into two genera does not appear to be desirable at the present time. No such difference exists inside this genus as there is between the gellus Microspira, which only exceptionally has more than one flagellum on the pole, and the genus Spirillum, which has many polar flagella. Between the one-flagellate and manyflagellate forms there are all sorts of transitions in the genus Pseudomonas. Possibly the boundary between Pseudomonas and Microspira is artificial. Slight crooking of the rods, especially in stained preparations, has been observed in many species of Pseudomonas, and it is not always possible to decide whether a one-flagellate form belongs to this genus or to Microspira. Ordinarily, a decision may be reached by observing the shape of the threads or chains, those of Pseudomonas never being twisted into the form of a screw.

\section{Family SPIRILLACEAE (Screwbacteria).}

Cells spirally wound or representing a portion of the turn of a spiral, in which latter case the entire spiral is visible only when several cells remain united. Endospore formation established for some species, but rare. Apparently, in some of the larger species resting forms are also produced by the breaking up of the rods into short segments which envelop themselves in a gelatinous membrane. Usually motile. Division only in one direction of space perpendicular to the long axis.

Spirosoma Migula.

Cells generally rather large, spirally bent, rigid, and without organs of motion. Cells single, free, or united into small gelatinous families.

(1) Subgenus Eusprosoma: Cells single or united into a spirally twisted thread. Free, that is, not inclosed in any gelatinous envelope.

(2) Subgenus Myconostoc: Cells single or united into spiral threads, which are surrounded by a roundish general envelope.

Microspira Schröter.

Cells bent like a comma or sausage, rigid, single or several united, in which latter case screws or S-shaped figures are produced. Motile by means of I wavy-bent polar flagellum (rarely 2 or 3 flagella). The flagellum is usually not much longer than the cell. Endospore formation has thus far not been demonstrated. Many authors do not distinguish between this genus and the next.

Spirillum Ehrenberg.

Cells rigid, rods of various thicknesses, length, and pitch of the spiral, forming either long screws or only portions of a turn. Cells motile by means of a tuft of polar flagella ( 5 to 20), which are mostly half circular, rarely wavy-bent. These flagella occur on one or both poles. Their number varies greatly and is difficult to determine, since in stained preparations several are often united into a common strand. Endospore formation has been observed in some species. There are many undescribed species.

Spirochaeta Ehrenberg.

Cells thin, mostly quite long, motile and flexible, winding snake-like, but also moving in the manner of a screw. Organs of motion unknown. Endospore formation not observed.

Nearly related to the Algal genus Spirulina, but colorless and not segmented into single cells.

\section{Family CHLAMYDOBACTERIACEAE.}

Cells cylindric, united into threads which are surrounded by a sheath. Reproduction by means of motile or non-motile conidia which arise directly from the vegetative cells, and without passing through any resting stage grow into new threads. 


\section{Chlamydothrix Migula.}

Cells cylindric, non-motile, arranged in unbranched threads, with a sheath of varying thickness. Frequently the septation of the threads is only demonstrable after the use of reagents. Reproduction by means of non-motile, roundish or ovoid conidia, which arise directly from the vegetative cells. Syn .: Streptothrix (Cohn) Mig., Leptothrix Kütz. exp:, and Gallionella Ehrenberg exp.

Crenothrix Cohn.

Cells united into unbranched filaments, attached, and gradually enlarging toward the free end, $i . e .$, with a distinction between base and apex. Sheath rather thick. In iron waters the old and empty sheaths are permeated by ironoxidhydrate. Cells cylindric or flat discoidal. Multiplication by non-motile (mostly roundish) conidia, which arise from the vegetative cells by division and rounding off. For this purpose the cells of the thicker threads divide in tliree directions of space, those of the thinner threads only perpendicularly to the long axis of the thread. The conidia are discharged and germinate immediately, often on the sheath of the mother-thread. Only one species known.

Phragmidiothrix Engler.

Cells cylindric, later discoidal, forming threads soo $\mu$ long and 3 to $12 \mu$ thick, with a very delicate, scarcely visible sheath. Multiplication by non-motile conidia, which arise from the vegetative cell by division in three directions of space and rounding off. Perhaps to be united with Crenothrix, if the projections observed by Engler are not branches but epiphytes. Only one sort known.

Sphaerotilus Kützing ( 1833 ).

Cells cylindric, enveloped in sheaths, forming dichotomously branched threads with no differentiation into base and apex. Multiplication by means of conidia, which swarm out of the sheath, attach themselves anywhere, and immediately grow out into new threads. The conidia possess a tuft of flagella inserted sidewise under one pole.*

Genera, the systematic position of which is doubtful : Spiromonas Perty ; Spirodiscus Ehrenberg; Achromatium Schewiakoff; Newskia Famintzin; Streblothrichia Guiguard.

\section{Order THIOBACTERIA.}

Cells without any "Centralkörper," but with sulphur inclusions. Colorless, or pigmented rose, red, or violet by bacteriopurpurin; never green.

\section{Family BEGGIATOACEAE.}

Filamentous bacteria, destitute of bacteriopurpurin. Division of cells in one direction of space, viz, perpendicular to the long axis.

Thiothrix Winogradsky.

Threads attached, not uniformly thick, enveloped in a delicate sheath which is not easily demonstrable, non-motile, contents containing sulphur granules. The threads produce rod-shaped conidia at their end. These conidia, which are self-motile by means of a slow, creeping motion, attach themselves by one end to any sort of substratum, extrude a slime-cushion at the base, bend over ordinarily in their middle to a nearly right angle and grow into a new thread. Habitat, hot sulphur springs.

\section{Beggiatoa Trevisan.}

Threads destitute of a sheath, formed of flat discoidal cells, free, i. e., not attached. Multiplication by folding and separation of the threads. Motile by means of an

\footnotetext{
* Streptothrix and Cladothrix are omitted from the second volume, the species, so far as they represent bacteria, being distributed in other genera. C. dichotoma becomes Sphcerotilus dichotomus.
} 
undulating membrane, as in Oscillaria. The organism creeps along, but at the same time rotates around the long axis, mostly with a swinging of one or both free ends. Habitat, hot sulphur springs and other fluids in which hydrogen sulphide is developed. No reliable method is yet known for the separation of the species. The number and size of the included sulphur-granules are not of specific value. They depend on the amount of hydrogen sulphide in the water.

\section{Family RHODOBACTERIACEAE.}

Cell-contents rose, red, or violet, from the presence of bacteriopurpurin. Sulphur granules are also included.

Classification still very artificial, owing to imperfect knowledge. Author follows Winogradsky.

\section{(I) Subfamily THIOCAPSACEAE.}

Cells united into families. Division of the cells in three directions of space.

Thiocystis Winogradsky.

Families small, compact, enveloped singly or several together in a gelatinous cyst, capable of swarming. When the families have reached a definite size they escape from the gelatinous cyst, the latter either swelling aud softening uniformly or at some particular spot. The escaped cells either pass into the swarm stage or unite into a larger fused complex of families, the individual cells of which separate and swim away only after a long time, and by means of much vigorous struggling.

Thiocapsa Winogradsky.

Non-swarming, globose cells spread out upon the substratum in flat families, which are loosely enveloped in a common gelatin. The membrane is split by the growth of the family, and the cells are separated as if by the swelling of an intermediate substance.

Thiosarcina Winogradsky.

Non-swarming cells arranged in packet-shaped families, corresponding to the genus Sarcina in the Eubacteriaceae.

\section{(II) Subfamily LAMPROCYSTACEAE.}

Cells united into families. Divisions of the cells, first in three and then in two directions of space.

Lamprocystis Schröter.

Families at first solid, then globose-hollow, becoming perforated net-form; cells finally separating into small groups which are capable of swarming.

(III) Subfamily THIOPEDIACEAE.

Cells united into families. Divisions in two directions of space.

Thiopedia Winogradsky.

Fanilies tabular, formed of cells arranged in fours and capable of swarming.

(IV) Subfamily AMOEBOBACTERIACEAE.

Cells united into families. Division in one direction of space.

Amoebobacter Winogradsky.

Cells connected by plasma threads. Families amoboid motile. The cell families slowly change form, the cells drawing together into a heap or spreading out widely, thus bringing about a change in the shape of the whole family. In a resting condition a comnon gelatin is extruded, the surface of which becomes a.firm membrane. 
Thiothece Winogradsky.

Families inclosed in a thick gelatinous cyst. Cells capable of swarming and very loosely embedded in a common gelatin. When the swarm stage supervenes, the cells lie more loosely, the gelatin is swollen, and the cells swarm out singly and rather irregularly.

Thiodictyon Winogradsky.

Families consisting of rod-shaped cells having their ends united into a net. Out of an originally compact mass of rods there gradually results from rearrangement a Hydrodictyon-like cell-union, which, under unfavorable conditions, nay again draw together into a compact mass of rods. The multiplication of the families results from division or by loosening of slowly motile small cell-colonies.

Thiopolycoccus Winogradsky.

Families solid, non-motile, consisting of small cells closely pressed together. Multiplication of the colonies by the breaking up of the surface into numerous short shreds and lobes which continue to split up into smaller heaps.

(V) Subfamily CHROMATIACEAE.

Cells free, capable of swarming at any time.

Chromatium Perty.

Cells moderately thick, cylindric-elliptical or elliptical. Polar flagella.

Rhabdochromatium Winogradsky.

Cells rod-shaped or spindle-form, with flagella on the poles.

Thiospirillum.

Cells spirally twisted.

To the preceding may be added a third order, Myxobacteriaceæ, which is not discussed critically by Migula and is not adequately described in any of the textbooks. The following general characters are taken from the papers of Dr. Roland Thaxter, to whom we owe our knowledge of these curious and interesting organisms. The most recent paper is by Erwin Baur, Myxobakterien-Studien, Arcliv für Protistenkunde, V Bd., I Heft, pp. 92-I2I, I pl.

\section{MYXOBACTERIACEAE}

Motile, rod-like organisms, multiplying by fission, secreting a gelatinous base, and forming pseudoplasmodium-like aggregations before passing into a more or less highly developed cyst-producing, resting state, in which the rods may become encysted in groups without modification, or may be converted into spore-masses. The vegetative rods, which vary little in size and form in the different genera and species, are typically elongate, sometimes reaching i $5 \mu$ in length. Cell-division follows an elongation and nearly medium constriction of the rods, which, except at the moment of division, are always separate; never united in chains. A slow, sliding locomotion and a Beggiatoa-like, bending motion is characteristic of the active rods. Organs of motion have not been detected. In all species, with one exception, the rods, when seen in masses, are more or less distinctly reddish. A distinct, firm, hyaline, gelatinous base is secreted by the colony as it extends itself, over which the individuals may move or in which they become embedded.

The vegetative period, in artificial cultures, usually lasts about a week, or even two weeks, but in nature the production of cysts must be more rapid. Common in moist situations on dung, decaying wood, fungi, lichens, etc. According to Bauer they grow best at $30^{\circ} \mathrm{C}$. 
In forms like Myxococcus, in which the rods are somewhat scattered, the first preparation for spore-production as seen under the microscope consists in the appearance of groups of rods moving with a circular tendency, in which the more central individuals soon become converted into spores. The formation of a cystophore, when it occurs, results from the basal constriction of a papillate mass of rods which projects from the surface of the colony. In the encysted condition there are two classesone in which the individuals thus encysted show little or no modification from the rod-like vegetative state, the other in which they are converted into definite spores. They, however, seem to run into one another.

The species have been arranged under three genera, as follows:

Chondromyces B. \& C.

Rods forming free cysts, in which they remain unmodified. Cysts various, sessile, or borne on a more or less highly developed cystophore.

Polyangium Lk. (Myxobacter and Cystobacter syn.).

Rods forming large, rounded cysts, one or more free within a gelatinous matrix raised above the substratum.

Myxococcus Thaxter.

Rods slender, swarming together after a vegetative period to form definite, more or less encysted, sessile or stalked masses of coccus-like spores.

That which appears least defensible in Migula's classification is his use of the word Bacterium for the anthrax organism and similar non-motile bacteria. If this generic name is to be retained, it should be used somewhat as Elnrenberg used it, viz, for motile organisms, and should not be given to entirely different non-motile forms. We have the right to set aside so much of Ehrenberg's description as does not correspond to facts, but not inore. We do not know exactly what Elurenberg had in mind, it is true, but it certainly was not non-motile forms of the type of the anthrax organism.

Provided one goes back of Cohn's time ( 1872 ), which the writer is not disposed to do in case of the bacteria, the one species by which the generic name Bacterium must stand or fall is Bacterium triloculare Elirenberg. In size and shape, as described and figured, it agrees very well witl some of the larger species of Pseudomonas Migula. If we can trust Ehrenberg's distinct statements and his plain figure, it was provided, like most species of Pseudomonas, with one polar flagellum. Elirenberg also figures and describes it as trilocular or triarticulate. He may have been wrong in including it anong his Vibrionides and in figuring and describing it as possessed of a polar flagellum, an organ difficult to 111ake ont in unstained material and with the crude microscopes in use in his day, but, while we bear this in mind, we must not forget that the person who was using these microscopes was no ordinary observer, but a man with remarkable eyesight and with a genius for observations of this kind. Moreover, the tri-locularity which he observed may have been simply the organism in early stages of division, which is the more likely, since lie states that he saw it divide, and because in his specimens from Berlin he sometimes observed four septa and sometimes ouly two. Ehrenberg's description of the genus Bacterium, taken as a whole, is of course worthless for purposes of modern classification, our ideas of generic values being entirely different from his. A few things only come out of the rubbish heap of this early writing in a service- 
able condition. The organism was a short rod, multiplying by cross-septation, possibly also by 111eans of spores, colorless, sluggishly motile, 110ving, it is said, by 11eans of one polar flagellin, and occnrring abundantly in water containing rotten vegetation, where bacteria would be likely to abound. It should also be noted that it did not take up colored particles, such as indigo or carninine, when placed in water containing these substances. If the word Bacterium is used, it should be in conformity to these facts, or supposed facts, and may be so used, I think, nntil they are shown to be erroneous.

The 1natter is simplified, however, if we start with Colin's use of the word Bacterium in the year 1872 . The Bacteriun of Cohn is a certain Bacterium. termo. While we are not able to tie down Cohn's 11se of this nane to a particular species, it appears that we can do it quite definitely to a group of 111orphologically similar species. Much discredit has been thrown on Bacterium termo in modern times, and it has been left out of many classificatious. However, if one exanines into the matter, there is 110 reasonable doubt as to what Coln had in mind. His Bacterium termo was a small schizomycetous organism capable of growing freely in Cohn's nutrient solution, containing acid potassium phospliate and ammonium tartrate. It produced therein short rods (single, in pairs, or fonrs joined end to end) and roundish-lobed (kugelige-traubige) white zooglœx, together with a greenish 1

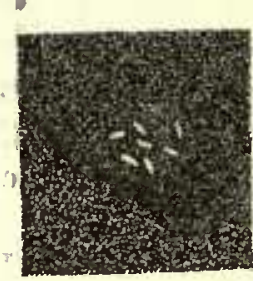

Fig. 137.* fuorescence. This is Cohn's statement and de Bary's. It did not appear in boiled fluids, $i$. e., was destitute of endospores (Cohn), and the motile rods were killed by a short exposure to $58^{\circ} \mathrm{C}$. (Schroeter). In other words, it was a non-sporiferons greenfuorescent organism possessed of a single polar flagellum, or, in some cases perhaps, provided with paired or triple polar flagella. If we start witl Cohr1's classification in the year 1872, we may keep the name Bacterium for schizonycetous organisms of this type, and at the same time we shall not be doing any violence to the older use of the word by Ehrenberg, who figures and describes this kind of an organism. This the writer proposes to do, substitnting Bacteriu11 (Cohn emend.) for Pseudomonas Migula and for more recent names proposed by others. Cohn's description, be it understood, is worthless for the most part, but his nanne Bacterium (B. termo) is usable beause it can be attached to a definite kind of organism. To show that Cohn's use of this word and the writer's use of it do not conflict with former usage, Ehrenberg's descriptions and figures of Bacterium are here reproduced frow1 the expensive and not readily accessible publications in which they appeared.

The organisin described as Bacterium triloculare by Ehrenberg is slown in figs. 137 and 138 , and Ehrenberg's account is sum11narized as follows:

The genus Bacterium was founded by C. G. Elirenberg in 1828 , and was characterized by him in the Symbolæ Physicæ, Aninnalia evertebrata. The book in which this description occurs is an unpaged folio. On the second page of the text proper, in a list of species found "In Oasi Iovis Hamınonis Siwae" this genus

*FIg. 137.-Bacterium triloculare. From Ehrenberg's Symbolæ Physica. Animalia cvertebrata. Decas prima. Berlin, I828. Plate II, fig. 6. 
is first mentioned as follows: "4. Bacteriun triloculare n.g." The second mention of the name is on the fourth page in a list of "Genera et Species, in Europe a me nond1111 visa.". The genus is described ou the sixth page as follows:

BaCterrum, Novum Genus, Familia Vibrionionum. Character Generis : Corpus polygastricum? auenterum? nudum, oblongum, fusiforme aut filiforme, rectum, monomorphum (contractione nunquam dilatatum1), parnm flexile (nec aperte undatum), transverse in multas partes sponte dividuum. hyalinum.

$B$. triloculare nov. spec.: distincte triloculare s. triarticulatum, subfusiforme,

Phytozoa Tab. II. Libyca fig. 6.

Animalculum $\mathrm{I} / 300$ lineae longum, corpore tereti. Articuli s. septa interna divisionem instantem multiplicem transversam indicare videntur.' Mobile sed pigrum animalculum.

In Oasi Iovis Hammonis Siwae observatum, praeterea nullibi.

Bacterii Generis physiologia hucusque obscura. Cibo colorato ventriculos replere hae formae respuunt ideoque ad Polygastrica non nisi dubitanter et interim collocantur. tillans.

Bacterium simplex vide Monas simplex. Bacterium scintillans vide Monas scin-

In general, Ehrenberg's figures are excellent where he could see anything to draw; but the seven figures of $B$. triloculare are very small (white on a darkigray background), and one can make nothing out of them beyond the fact that they are minute bodies, 3 or 4 times as long as broad and with two indistinct septa.' At the foot of the plate their length is said to be $\frac{1}{250}$ of a "linie." The figures are more or less rounded at the ends and show no constrictions at the septa.

In 1830 , in his "Beiträge" (see Bibliog., V), Ehrenberg has the following on the genius Bacterium:

Phytozoa. Classis I Polygastrica. A. Anentera. Ordo I Nuda. Family I Gynnica. Corpore non ciliato, oreciliato nudove (p. 37). Sectio II. V'brionia. Elongata, in se nunquam contracta. Sub-section $c$ : Corpore oblongo, fusiformi aut filiformi (tereti aut triquetro nec quadrangulo) aperte undatum non flexili, nec spirali :

BACTERIUM. nov. Gen:-Haec genera, Oscillatories valde affinia, ore nutriri nondum vidi. i species (p. 38 ).

In another place the following species are mentioned, without description, as belonging to this new genus: Bacterium cylindric, B. deses, B. Enchelys, B. fuscum, $B$. monas, $B$. punctum, $B$. termo, B. tremulans. The number in was apparently completed by the three others, $B$. triloculare, $B$. simplex, and $B$. scintillans, not liere nnentioned. In this paper Elirenberg made use of the subsequently oft-quoted expression: "Die Milchstrasse der Kleinsten Organization gelıt durcl die Gattungen Monas, Vibrio, Bacterium, Bodo." This idea appears to have inpressed hin greatly, for he repeats it in his "Infusionsthierchen."

In 1832 , in Elirenberg's "Geographische Verbreitung," a paper which was read January 10, r828, and written apparently before either of the preceding, but not printed until 1832 , three species of Bacterium are nentioned, $B$. simplex, B. triloculare, $B$. scintillans, all as new species, but there is no description of the genus or reference to any description. 
In $\mathrm{I} 832$, Ehrenberg again returns to Bacterium in a paper, "Ueber die Eintwickelung," etc. In this paper six species are included in the genus Bacterium, but four of thein he now regarded as doubtful:

Gattung XII Bacterium E., Gliederstäbchen.

$\ddagger$ ) deutliche Gliederung.

1. B. articulatum E., Perlenschnurgliederstäbchen.

[Descript.] Bewegung zitternd. Berlin.

2. B. triloculare H. und E., dreifächriges Gliederstäbchen.

\#) undeutliche Gliederung.

3. B. ? Enchelys E.

4. B. ? punctum E.

5. B. ? tremulans $\mathrm{E}$.

6. B. ? termo E.

In 1838 , in his magnificent work, "Die Infusionsthierchen," Ehrenberg gives additional information respecting the genus Bacterium. It is there described as follows:

Die quergetheilten gehören $z u$ den Zitterthierchen (Vibrionien), den längsgetheilten zu den Stabthierchen (Bacillarien) (p. 2).

Vierte Familie: Zitterthierchen (Vibrionia, Vibrionides).

Character: Animalia filiformia, distincte aut verismiliter polygastrica, anentera, nuda, gymnica, corpore Monadinorum uniformi, divisione spontanea imperfecta (transversa), catenatim consociata, hinc filiformia.

Charactère: Animaux filiformes, distinctement ou vraisemblablement polygastrique, sans canal alimentaire, sans carapace, sans appendices, à corps uniforme des Monadines, se réunissant par division spontanée imparfaite (transversale) en chaines filiformes (p. 73).

Zitterthierchen sind Monadinen, welche, durch queere unvollkommene selbsttheilung, bewegte Gliederfäden bilden (p. 74).

This fanily contained five genera: Bacterium, Vibrio, Spirocliaeta, Spirillum, and Spirodiscus.

\section{BACTERIOM.}

Character: Animal e familia Vibrioniorum, divisione spontanea in catenam filiformem rigidulam abiens.

Charactère: Animal de la famille des Vibrionides, prenant par la division spontanée la forme d'un fil articule raide (p. 75).

Ehrenberg's Bacterium was a motile organism, and he also saw, or thouglit he saw, an organ of motion, and carefully figured it.

Ich habe auch bei der stärksten Art und Gattung Bacterium ein Bewegungsorgan als einfachen wirbelnden Rüssell erkant (p. 74).

Besonders erfreulich war mir der deutliche Wirbel am Vordertheil der kleinen Körper im farbigen Wasser, und eine angestrengte Untersuchung brachte mir sogar einen einfachen fadenartigen kurzen Rüssel zu directer Anschauung. Bei den grössten Formen [of $B$. triloculare] hatte der Rüssel $1 / 3$ der Körperlänge, bei den kleinen die Hälfte. Die Bewegung der Thierchen war zitternd und um die Längsaxe wälzend (p. 76).

In this species he never saw more than 5 nor less than 2 or 3 septa. He never succeeded in making them take up stains, such as indigo, carmine, and india ink. "Vom Fortpflanzungsverhältniss sind nur Ei-? Körnchen und Selbsttheilung, ein 
rein thierischer Cliaracter, erkannt" (p. 74). At this time his genus was reduced to one species, that with wlich he started out, viz, B. triloculare.

Ganz sicher ist nur eine Art der Gattung (p. 75).

Von den im Jahre 1828 anfgeführten 3 Arten ist nur $B$. triloculare als Stamm verblieben, die beiden andern, $B$. scintillans und simplex, sind unter diesen Namen zur Gattung Monas gestellt (p. 77).

In the Vibrionides stress is laid on the incomplete self-division by which they form motile jointed threads (bewegte Gliederfaden) (p. 74). Bacterium is non-flexile (unbiegsam); Vibrio is flexile (schlangenformig biegsam) (p. 75). Bacterium can only swin straight ahead. There is a more decided "Einschnürung und grösseren Isolirung der Einzelthiere" in Vibrio than in Bacterium. In both genera division takes place at a right angle to the long axis.

Bacterium triloculare (fig. I38) consisted of oval corpuscles developing into short cylinders with rounded ends, 2 to 5 times as long as broad (usually 3 times), having as many transverse rays [septa]. It was found in 1820 in swamp water in the oasis of Jupiter Ammon, in Libya. In I83 1 , near Berlin, Ehrenberg found a supposedly similar organism which he named Bacterium articulatum. Subsequently

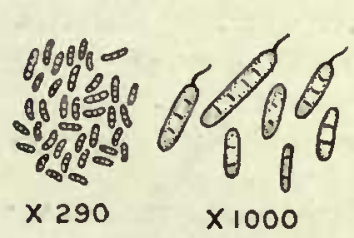

Fig. 138.* he says he rediscovered this organism in standing, "modrigen" water in a glass in his room, and finding what he considered to be transition forns, he abandoned the latter name and united all of these organisms, whatever they may have been, under the name of $B$. triloculare. The statements about the flagellum, and the figures of 1838 , appear to have been drawn wholly from the Berlin forms, supposed to be identical with the African ones. The organisus were colorless and non-flexile and self-division was observed. Contents very finely granular. Sluggishly motile, but "zahlreich und deutlich durcheinander falırend." The size of the African form is said to be $\frac{1}{300}$ linie; the Berlin forms were $\frac{1}{400}$ to $\frac{1}{192}$ linie. The single "Thierchen" in the Berlin form was one-fifth as long, $i . e_{.}, \frac{1}{900}$ linie. Ehrenberg's figures represent a magnification of $\times 290$ and $\times 1,000$ and are much better than those of $B$. triloculare in the earlier work. They show a transversely 2 to 5 septate, rodshaped organism, with rounded extremities, and bearing one polar flagellum about one-third the length of the body. There are no paired rods, or constrictions at any of the septa, but some of the rods are slightly curved. The shape and septation of the figures is slightly suggestive of some of the drawings of de Bary's Bacillus megaterium (Pilze Mycet. u. Bact., fig. I94). They also look somewhat like some of the involution forms of Bacillus hortulanus (Phil. Tr. Royal Soc., Series B, vol. I9I, pl. I6). Both of these organisw1s, however, have peritrichiate flagella. The flagellum resembles that on species of Vibrio.

Cohn's drawings of Bacterium termo are shown in fig. 139 , copied from his "Beiträge" (Bd. I, Heft 2, Tafel III). Cohn did not consider motility of any generic value, and consequently paid no attention to organs of motion. Dallinger \& Drys-

*FIG. 138.-Ehrenberg's Bactcrium triloculare, showing flagella. From Die Infusionsthierchen, Plate V, fig. I, I, 2. 
dale's conception of this organism, at a time when the air was full of talk of Cohn's researches, is shown in fig. I40. Dallinger \& Drysdale's drawings were made from

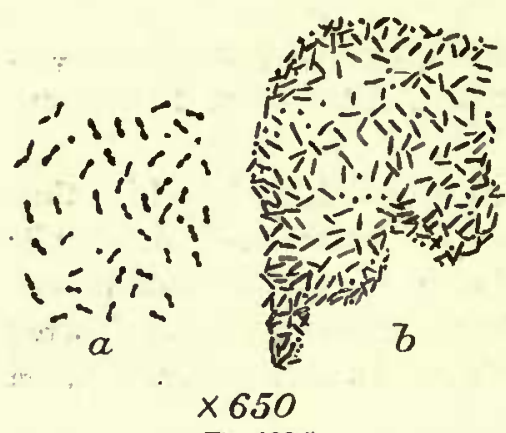

Fig. 139.* unstained material, and there is no donbt that these expert microscopists actually saw what they figured, viz, a sclizomycetous organism provided with one polar flagellunn and belonging to the family Bacteriacex. Dallinger afterwards carefully measured the diameter of the flagellum many times over in unstained nuaterial, grown in Cohn's fluid.

As bearing on the question whether Elirenberg could see the flagellum of an unstained bacterium with the microscopes at his disposal, it is interesting to note Dallinger's statenent that Koch could not see the unstained flagellum of Bacterium termo because he used "low-angled glasses, which are incompetent to that demonstration." Another remark of Dallinger is also pertinent. "I have learued," he says, "from experience that there is as great a diversity in different individuals in the sensitiveness of the retina as there is in sensitiveness of the olfactory or auditory nerves."

The writer's own conception of Bacterium termo is shown in fig. I4I. These organisms are green-fluorescent species cultivated in Cohn's solution, from water into which beans had been thrown in the manner described by Cohn. The very distiuct flagella were stained by Löwit's method. The particular species from which this was obtained did not liquefy gelatin.

To the writer, then, the genus Bacterium is Bacterium

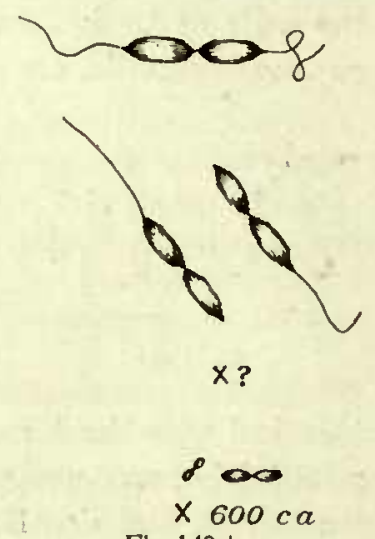

Fig. $140 . \dagger$ (Colm emend.), and is based on the morphology of the green-fluorescent organisurs,

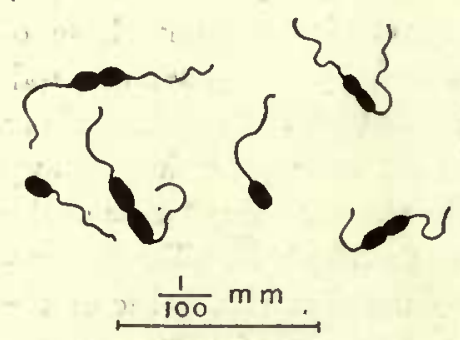

Fig. 141. capable of growing in Cohn's nutrient solution and called by him Bacterium termo. $\S$ It corresponds to Migula's genus Psendomonas, for which name it should be substituted as a proper generic name for straight or sliglitly curved Bacteriacer, notile by means of one to several polar flagella. It includes 111ost of the yellow bacteria and all of the green-fluorescent bacteria (vide Migula's system, Bd. II, p. 875).

*FIG. I39.-Bacterium termo: $a$, motile form; $b$, zoogloex. After Cohn. Untersuchungen über Bakterien. Beiträge z. Biol. d. Pflanzen, Bd. I, Heft 2, Plate III.

†FIG. I40.-Dallinger and Drysdale's conception of Bacterium termo. See Dallinger and Drysdale "On the Existence of Flagella in B. termo." Monthly Micros. Jour., Sept. I; 1875, Plate CXIII, p. 105, figs. 6 and 7.

$\ddagger$ FIG. I4I. - The writer's conception of Cohn's Bacteritum termo. Organism obtained by throwing beans into water and then making a transfer from the green-fluorescent liquid to Cohn's solution. Stained by Löwit's method. $\times 2000$.

\$These organisms have no necessary connection with Bacterium termo Ehrenberg or with Monas termo Müller. We shall never know what these were. 
We have therefore the following:

Bacterium (Cohn emend.).

Type: The one-flagellate, green-fluorescent schizomycetes, capable of growing in Cohn's nutrient solution. To these should be added all the morphologically similar, non-fluorescent and yellow species.

Synonym: Pseudomonas Migula.

Among others the following plant parasites belong here:
Bacterium campestre (Painmel),
B. pruni (Erw. Sm.),
B. hyacinthi Wakker,
B. vascularum (Cobb),
B. phaseoli (Eirw. Sin.),
B. juglandis (Pierce),
B. Stewarti (Erw. Sm.),
B. malvacearum (Erw. Sm.).

These clianges leave no generic name for the anthrax organism and other nonmotile forms.

The writer would like to name the anthrax organism and related forms in lionor of the distinguished man who first pointed out the generic significance of non-motility in this organism, but who infortunately selected for it the preoccupied name of Bacteridiun. There is, however, already a genus Davainea in helminthology, and it does not seem wise to make another, even in botany. Bacteria are now classed as plants, but we do not know what may finally be done with them. It remains, therefore, to adopt some old name, if an unobjectionable one can be found, and if not, to devise some entirely new name for the non-1notile bacteria. There are several old names not now in use, e.g., Metalacter and Melanella, but so far as I have been able to determine, none of them were given to organisms at all resembling the anthrax organism, and for one reason or another all must be rejected. I therefore propose the name Aplanobacter (from Greek words meaning withont motion and $a$ rod), and shall wse it as the generic name for the anthrax organism called Bacteridium by Davaine, Bacillus by Colın and Fischer, and Bacterium by Mignla. Under A planobacter I include all non-motile forms morphologically similar to the anthrax organism (Bacillus anthracis Cohn), the latter, however, being taken as the type of the genus:

A planobacter nov. gen. nom.

An unattached, non-motile, rod-shaped organism, destitute of chlorophyll and multiplying by fission, sometimes forming threads of considerable length. The type of the genus, in the family Bacteriacex, is that organism causing anthrax and most commonly known in literature as Bacillus anthracis Cohn.

For the present non-sporiferous forms, resembling Aplanobacter anthracis, are also included nnder this genus, but if it sliall be decided, later on, that the difference between sporiferons and non-sporiferous forms is of generic significance, then the latter may be excluded. This genus, as now understood, inclindes Aplanobacter anthracis (Colm) and many otlier non-111otile species called Bacillus in most books, but Bacterium by Migula. For a list of the species see Bacterium (p. 279) in Bd. II of Migula's "Systen." A few species there given are now known to be motile.

Forms related to Bacillus tuberculosis Koch and Bacillus leprae Hansen do not seem to belong with the antlyax organism, and some name must be found for these. 
L,ehmann \& Neumann have suggested Mycobacterium, and we may use this name without in any way committing ourselves as to the significance of the branching forms. I would include also under it Bacillus diphtherice Loeffler (Corynebacterium L. \& N.). The writer has not inquired critically as to whether this is the earliest available name for this group, but that of Sclerothrix, given by Metclnikoff in $\mathrm{I} 888$, is twice preoccupied, and that of Cocothrix, given by Lutz in I886, is too near the earlier Cocothrichium Link. In r889, in Saccardo's Sylloge Fungorum, De-Toni and Trevisan included these organisms under the genus Pacinia 'Trevisan, but 'Trevisan's original draft of this genus included only vibrios, his type being the organism causing Asiatic cholera.

Another difficulty is to decide what name shall be used for the cause of Asiatic cholera and its relatives. The majority, perhaps, of pathologists and bacteriologists use the genus name Vibrio. They understand by it small spirally bent organisms common in water and possessed of one polar flagellum or rarely of several such organs, the Vibrio cholerce being taken as the type. Others call most of these organisms Vibrio, but speak of Spirillum cholera. Others use the two names Vibrio and Spirillum interchangeably. Others try to escape the difficulty by avoiding Latin names altogether, speaking in the same article indifferently of "the cholera vibrio," "the cholera bacterium," and "the cholera bacillus." This is the case frequently in the recent big monograph by Kolle \& Wassermann. A few persons, following Migula, have used Schroeter's name, Microspira, given in I886. Microspira is inadmissible, according to strict rules of priority, because Trevisan's name Pacinia is one year earlier (1885). Trevisan's genus, although badly defined, following Zopf's ideas of pleomorphism, is tied hard and fast to the cholera organism. Apparently this name was given without any personal acquaintance with the organism named, but according to current rules of nomenclature this makes no difference. The choice, therefore, is between Pacinia and Vibrio, the one tied fast to a known species, but not used by working pathologists or bacteriologists since it was coined, so far as my reading goes, the other in common use, but a floating name-that is, one which can not be used for bacteria, and at the same time tied to any definite species or group of species included in the original draft of the genus.

Müller's genus Vibrio was published in 1773 in his "Vermium terrestrium et fluviatilium." It contained I 5 species-bacteria, eel-worms, etc. Otler things were also afterward put into it by Mïller, e.g., diatoms. We will be content with the first draft of the genus. It is described as follows: "Vibrio. Most simple, inconspicuous, terete, elongate worms." The first species is described as follows: Vibrio lineola.

Vibrio linear, hard to see. Danish, Stræg-strækkeren. A most minute animal, almost exceeding in smallness Monas termo and 30 times less than Vibrio bacillus and entirely different. A trembling motion of myriads of oblong and obscure points is seen in a single drop, or with the highest magnification undulatory movements. In infusions of vegetables it almost fills the substance of the water after many days.

'The second species, $V$. bacillus, first obtained from liay infusions, is described at a little greater lengtl, but not any better. The third species is a inixture of nematodes. The first two species are bacteria. One other species of sclizomycete is described, viz, Vibrio undula. This last, or what was supposed to be it, together 
with Vibrio spirillum, a subsequent addition by Müller, was removed by Elırenberg to form his genus Spirillum, which we still retain. The eel-worms were removed to form the genus Anguillula, and the other infusoria were variously distributed. Only the first two species of the original genus remained in Coln's time, and neither one was used by him. Cohn used Vibrio rugula, one of Müller's additions, for the first species under his emended genns Vibrio, but this has now been put by Migula into Spirillu111. 'The only other member of Colnn's genus Vibrio (emend.), V. serpens, is still less like the cholera organisin. Ehrenberg's figure of Vibrio lineola Müller (Infusionstl1.) shows crooked little organisms not nnlike what we now call vibrios.

As a general proposition the writer believes that if a genus name is to be retained one should be able to tie it to some definite type-species, and it ought to be a species put into a genus when it was first published, and not one put in after the genus has been emended out of all recognition. Of course, nothing can be done with Müller's, or Colnn's, genus description of Vibrio. If the name is to be retained for any organisms whatsoever, the description must be made over and the name anchored to a known species. Ordinarily such a name should be discarded. Under the circumstances, we may perhaps strain a point, make over the genus description in toto, and use the name Vibrio, as many pathologists have done, for Kocli's comma bacillus and related forms. Logically, perliaps, we should adopt the strange Pacinia; for convenience sake we may continue to use the familiar Vibrio. The name Vibrio is not used by helminthologists or algologists, and, if we connect it to the first species described by Müller under the genus, we may anchor the name to any small motile species, without fear that subsequent researches will require changes to be made. This may be done, because the description of Müller's Vibrio lineola, the first species, is so imperfect that identification is out of question; the name can never be attached to any morplologically definite organism or group of organisms different from the cholera vibrio, even the gelatinization of the water after many days being probably enough dne to other bacteria. The writer follows Lafar (rst ed.), Alfred Fischer, Lehmann \& Neumann, et al., and would write:

Vibrio (Müller, Cohn, emend.).*

Type of the genus, Koch's comma bacillus.

Synonyms.-Spirillum cholera-asiatica Koch; Microspira comma Schroeter; Pacinia cholere-asiatica Trevisan.

Kendall has criticized Migula's use of the word Pseudomonas on the ground that he has combined under it two distinct groups of the family Bacteriacere, the monotrichiate and the lophotrichiate forms, and because the name implies, he says, a relation to "pseudomonads." The second criticism implies that to be teuable a name must conform etymologically to all the facts in the case. This is a misconception. No one is warranted in setting aside a generic or specific name simply because it seems inappropriate. It is not inappropriate, however, since the first species in Müller's genus Monas was undoubtedly founded on small bacteria of some sort. As to the first criticism, that lies also against my use of Bacterium and requires a word. This criticism appears to me not well taken, since in the Bacteriaceæ, as Migula first pointed out, there is no such sharp distinction

\footnotetext{
*According to Fischer, I903, and Lehmann \& Neumann, I896, this emendation was made by Loeffer.
} 
between the monotrichiate and the lophotrichiate forms as there seems to be among the Spirillacer. Within the limits of the sane species, and on the same cover-slip, forms may occur with one flagellum and others with two or more (see fig. I5, which is not the only one I might offer). The name Psendomonas is of earlier date than Fischer's or Kendall's equivalents, has priority, and can 11 t be set aside on the gronnds named. If the reader is not satisfied with the reasons I have given for substituting the earlier name Bacterium, then he shonld-continue to use the name Pseudomonas.

For the present, therefore, I follow Migula's classification, except in so far as relates to his use of the words Microspira, Pseudomonas, and Bacterium.

The following mames should be rejected:

Acromatium.

Actinobacter.

Actinomyces.

Aërobacter.

Aethylbacillus.

Amylobacter.

Arthrobacter.

Arthrobactridium.

Arthrobactrillum.

Arthrobactrium.

Ascobacillus.

Ascobacterium.

Ascococcus.

Astasia.

Astrobacter.

Azotobacter.

Babesia.

Bacteridium.

Bacteriopsis.

Bactrillum.

Bactrinium.

Bollingera.

Botryomyces.

Cenoniesia.

Chromatium.

Clathrocystis.

Clostridium.

Clostrillum.

Clostrinium.

Coccos.

Cocobacillus.

Cocobacteria.

Cocothrix.

Cohnia.

Cornilia.

Corynebacterium.

Cryptococcus.

Cystobacter.

Dicoccia.
Diplectridium.

Diplobacteria.

Diplococcus.

Discomyces.

Dispora.

Erebonema.

Erythrobacillus.

Erythroconis.

Fenobacter.

Gaffkya.

Gallionella.

Gliabacteria. .

Gliacoccus.

Glischrobacterium.

Gonococcus.

Granulobacter.

Gummibacillus.

Hæmatococcus.

Halibacterium.

Helicomonas.

Helobacteria.

Hyalococcus.

Iodococcus.

Klebsiella.

Kurthia.

Lactobacter.

Lampropedia.

Leptothrix.

Leucocystis.

Leuconostoc.

Lineola.

Macrococcus.

Megabacterium.

Megacoccus.

Melanella.

Meningococcus.

Merismopedia.

Mesobacterium.

Mesococcus.
Metallacter.

Microbacterinm.

Microhaloa.

Microphyta.

Microsphæra.

Microspora.

Microsporon.

Microzoa.

Microzyma.

Monas.

Monobacteria.

Monococcus.

Mycoderma.

Myconostoc.

Mycothece.

Mycothrix.

Neisseria.

Newskia.

Nitrobacter.

Nitrosococcus.

Nitrosomonas.

Nocardia.

Nosema.

Octopsis.

Ophidomonas.

Pacinia:

Paracloster.

Paraplectrun.

Pasteurella.

Pasteuria.

Pediococcus.

Perroncitoa.

Petalococcus.

Photobacillus.

Photobacterium.

Photospirillum.

Plectridium.

Pleurococcus.

Pneumobacillus.
Pneumococcus.

Pollendra.

Proteobacter.

Proteus.

Rhabdomonas.

Rhizobium.

Saccharobacillus.

Saccharobacter.

Schinzia.

Schuetzia.

Sclerothrix.

Sphærococcus.

Sphærotilus.

Spirobacillus.

Spirodiscus.

Spiromonas.

Spirulina.

Sporonenia.

Streblothrichia.

Streptobacillus.

Streptobacteria.

Streptothrix.

'Tetracoccus.

Thermoactinomyces.

Thermobacillus.

-Thermobacterinm.

Thioderma.

Thiosphæra.

Thiosphærion.

Torula.

Tyrothrix.

Ulvina.

Urobacillus.

Urobacter.

Urocephalum.

Urococcus.

Urosarcina.

Zooglœea.

Zopfiella. 
PLATE 21.

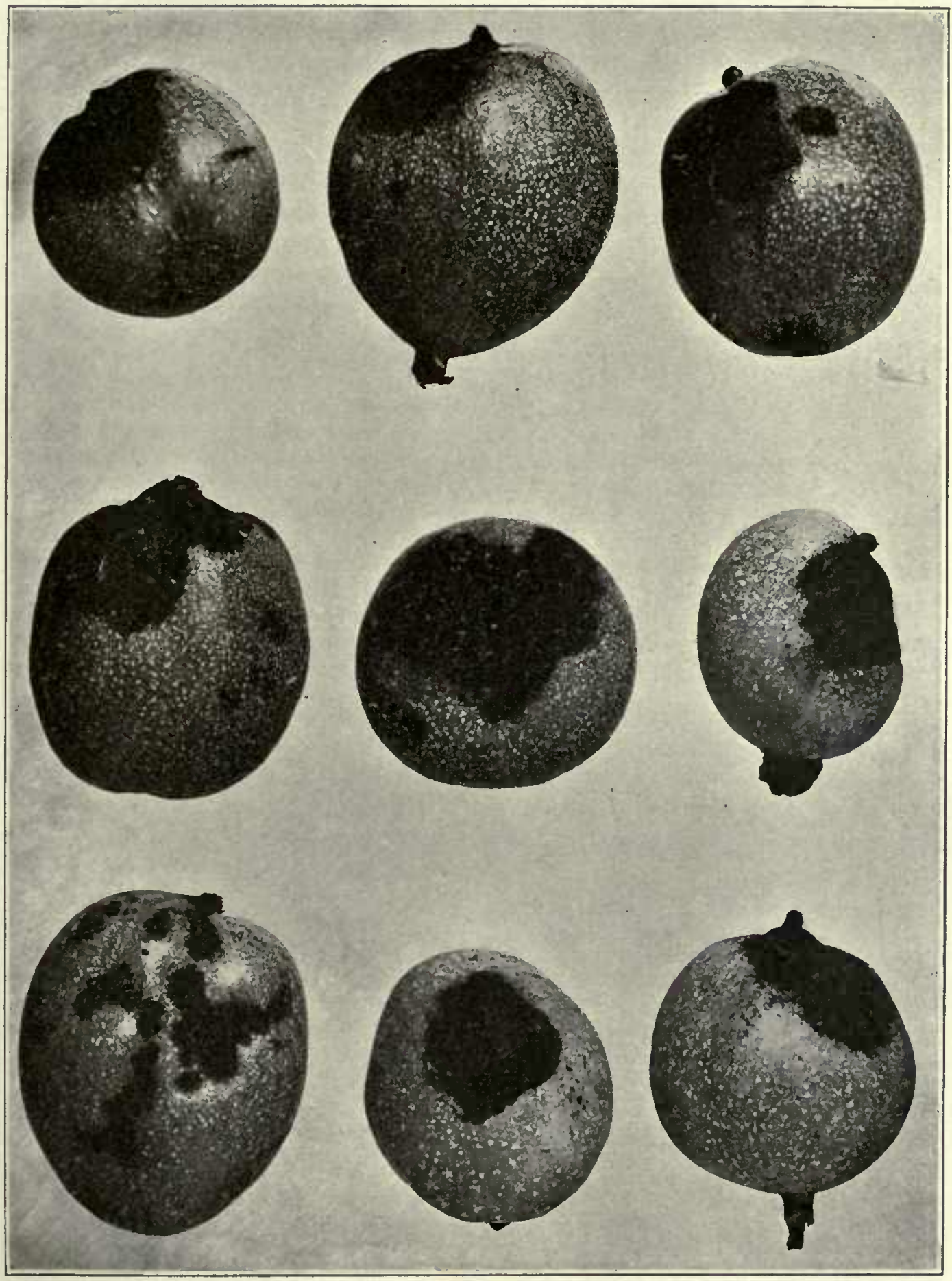

\section{Walnut disease.}

Bacterial black spot of the Persian walnut (Juglans regia), more commonly knowa as the English walnut. Half-developed green fruits from an orchard in California, showing the badly spotted epicarp; spots due to Bacterium juglandis (Pierce). Leaves and shoots are also subject to this disease, which has bocome serioun in Southern California, where large quantities of these nuts are grown for market. The attacked parts are conspicuously blackened as if charred. The numerous unall white spots show the location of groups of alomata. Iafection takes place readily through unbroken tisues. 

A very few of the preceding may perhaps some time make good their claim to be considered as independent genera. Many of these names are preoccupied in this group or in other groups; some represent mixtures; others, purely physiological genera; but sone of them nuay be used witlin the limits of genera to designate special physiological groups whenever sucl use leads to clearness of understanding.

Naegeli, Beyerinck, and Winogradsky lave studied especially the food require111ents of bacteria. Many others have, of course, contributed. Alfred Fischer has given a good summary in the second edition (p. 96) of his "Vorlesungen." Following tliis, and considering them especially with reference to their nitrogen-nutrition, the bacteria nuay be classified into seveu groups :

I. Paratrophic bacteria. The obligate parasites, capable of growing only on substrata similar in composition to the fluids of the host.

2. Peptone-bacteria. Organisms requiring peptones or albumoses.

3. Amido-bacteria. Organisms which also grow well when their nitrogen food is restricted to amido-bodies-asparagin, leucin, etc. - but not able to use ammonia.

4. Ammonia-bacteria. Able to take nitrogen from ammonia compounds.

5. Nitrobacteria. The denitrifying organisms. They require organic carbon con1pounds.

6. Nitrous and nitrate bacteria. The saltpeter-bacteria. Nitrates, nitrites, or ammonia-compounds furnish the necessary nitrogen. The carbon dioxide of the air serves as their carbon-food.

7. Nitrogen-bacteria. Organisms able to assimilate free nitrogen, but only in the presence of organic carbon compounds.

In I 895 Wyatt Johnston suggested that all the important cliaracteristics of a species miglit be recorded by numbers arranged in a definite order. Gage \& Plielps and Kendall afterward made use of the Dewey numeral system. By this means the leading features of a hundred or of five hundred organisms might be recorded on a single page, so as to be very easily compared. Chester has modified this system for application within the genus as follows:

$\begin{array}{rlll}\text { I00. } & \text { Endospores produced. } & 0.002 & \text { Acid without gas from saccharose. } \\ \text { 200. } & \text { Endospores not produced. } & .003 & \text { No acid from saccharose. } \\ \text { 10. } & \text { Aerobic and facultative anaerobic. } & .0001 & \text { Nitrates reduced. } \\ \text { 20. } & \text { Anaerobic. } & .0002 & \text { Nitrates not reduced. } \\ \text { I. } & \text { Gelatin liquefied. } & .00001 & \text { Fluorescent. } \\ 2 . & \text { Gelatin not liquefied. } & .00002 & \text { Violet chromogens. } \\ 0.1 & \text { Acid and gas from dextrose. } & .00003 & \text { Blue chromogens. } \\ .2 & \text { Acid without gas from dextrose. } & .00004 & \text { Green chromogens. } \\ .3 & \text { No acid from dextrose. } & .00005 & \text { Yellow chromogens. } \\ .01 & \text { Acid and gas from lactose. } & .00006 & \text { Orange chromogens. } \\ .02 & \text { Acid without gas from lactose. } & .00007 & \text { Red chromogens. } \\ .03 & \text { No acid from lactose. } & .00008 & \text { Brown chromogens. } \\ .001 & \text { Acid and gas from saccharose. } & .00000 & \text { Non-chromogenic. }\end{array}$

According to this scheme the formula for Bacillus coli and Bacterium campestre would be respectively B. 2I2.I I I IO and Bact. 2II.333 I5. Sucli a system adinits of indefinite extension, and the reader can see at a glance that, if well worked ont so as to include all the n11ore inportant facts; it wonld be invaluable for unification of 11ethods and for quick, easy reference. Each gronp of digits should include as 
many facts as possible. Kendall, for instance, under the gelatin group has also included action on dextrose as follows :

\begin{tabular}{|c|c|c|c|}
\hline & $\begin{array}{l}\text { Liquefaction of } \\
\text { gelatin. }\end{array}$ & $\begin{array}{l}\text { Fermentation of } \\
\text { dextrose, gas } \\
\text { production. }\end{array}$ & $\begin{array}{c}\text { Acid } \\
\text { production. }\end{array}$ \\
\hline I. & Negative. & Negative. & Negative. \\
\hline 2. & Negative. & Positive. & Positive. \\
\hline 3. & Negative. & Negative. & Positive. \\
\hline 4. & Positive. & Negative. & Negative. \\
\hline 5. & Positive. & Positive. & Positive. \\
\hline 6. & Positive. & Negative. & Positive. \\
\hline 7. & Unknown. & Negative. & Negative. \\
\hline 8. & Unknown. & Positive. & Positive. \\
\hline 9. & Unknown. & Negative. & Positive. \\
\hline
\end{tabular}

The subject is now in the hands of a committee of the Society of Allerican Bacteriologists for consideration and recommendation, and criticisms are desired. They may be sent to Prof. F. D. Chester, Wilmington, Del.; Prof. F. P. Gorhan, Providence, R. I., or to Erwin F. Sinith, Washington, D. C.

\section{Val,ue of Morphological, Characters.}

Ebb and flow, growth and change, this is the order of the world. Living things conform to a certain set of conditions and we say they are constant in structure and function because the conditions are fairly constant; change the environnent too much and they are destroyed; change it essentially, ever so little, and the animal or plant begins at once to respond to it. This is especially true of simple ninicellular forms. We can not, then, expect more than a moderate annount of constancy in these low forms of life. If under slight changes of environment they are fairly constant morphologically, it is all that we can expect, and in interpreting all descriptions we must inake due allowance for these slight changes which an anthor may not have observed.

There have bee11 two extreme views respecting the 1110rphology of the bacteria. Béchann, Hallier, Billroth, and Zopf stand for one extreme; Koch's earlier views for the other. To Hallier bacteria were only the developed plastids (protoplasmic granules) of fungi, and under widely different forms we might have the san1e organism functioning at one time as a harmless mold and at another as a micrococcus, causing the dreaded cholera or some other human or aninnal disease. Béchamp's microzymas were granules or fundamental elements more minute than the plant or animal cell, granules out of which all life developed and which persisted in other forms after the death of the cells. To Billroth all ordinary forms of bacteria, however dissimilar they might appear, were but stages of one nnique species, viz, his Coccobacteria septica. Zopf did not carry his doctrine so far, but taught pleomorphisin as a fundamental characteristic of the bacteria. To-day an organism might be a Micrococcus, tomorrow a Bacterium or a Bacillns. Koch, on the other hand, insisted on the fixity of forms. To him a bacillus was always the same thing, and the views of the polymorphists were explained as the result of errors in technique, the confounding of entirely different things. Koch's own methods were exact and his views had 


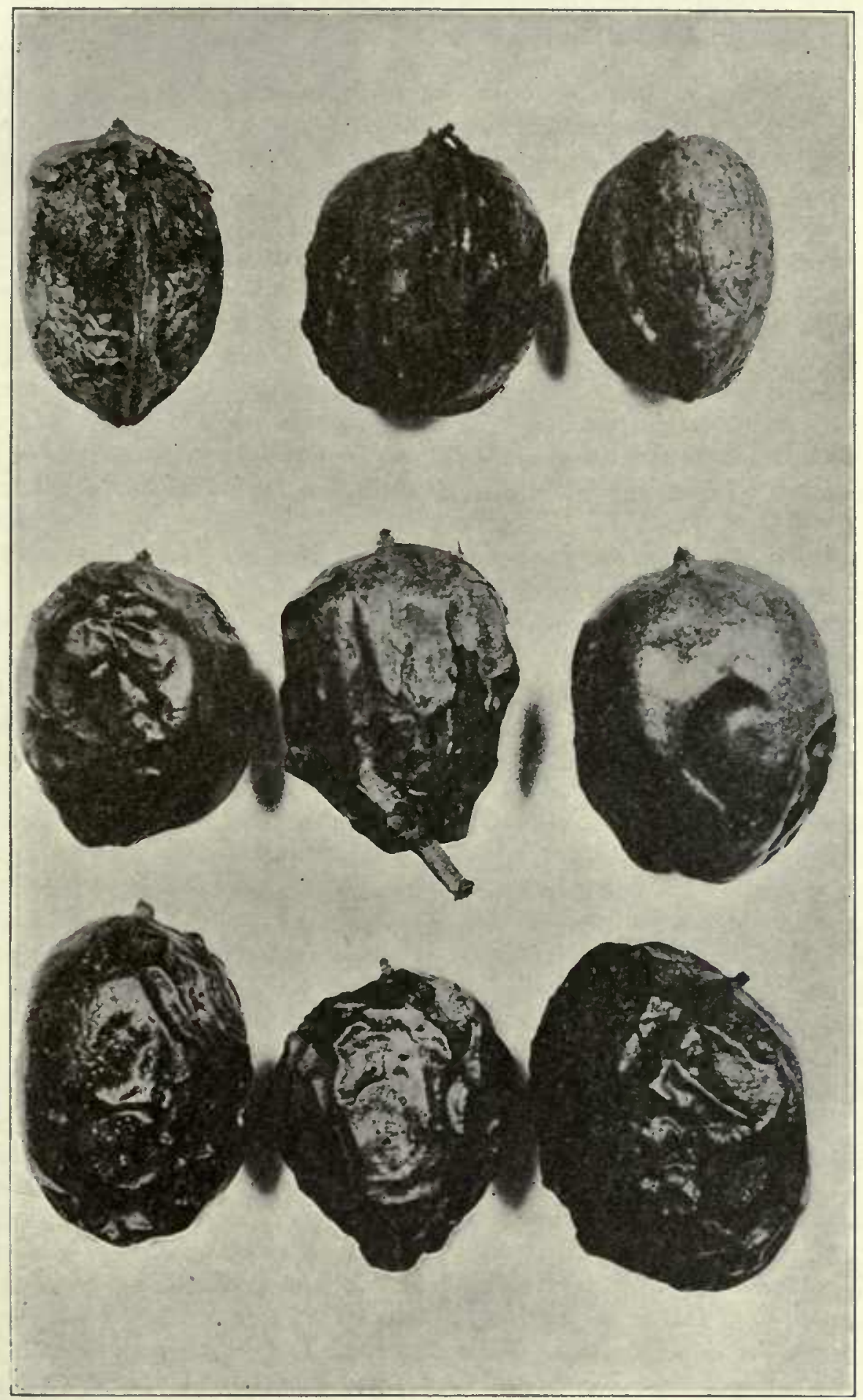

Bacterial black spot of the walnut.

A late atage of the divease on the nuts. Photograph by Pierce. Mr. Pieree, who discovered the eause of this dixease, has demonstrated 50 per cent of the loseres preveotable by spraying, and is now endeavoving to obtain revistant varieties by hybridizing and selection. The sum of $\$ 20,000$ was offered by the walnut growers of Califomia some time ago for a satiffactory remedy, and recently the legislature of California has appropriated a considerable sum for its investigation. 

enornous weight, since lie depended not on mere assertion, but pointed out many errors of fact and many flaws in the reasoning of lis antagonists.

To-day the majority of bacteriologists hold a sort of middle ground. Very few are willing to accept the views of the old polymorphists, but there is a spirit of rational inquiry abroad. We know that bacteria are much more responsive to changed environment than was supposed by Koch and his followers in the eighties, and we are prepared to believe anything respecting their origin and their polymorplism which can gain the suffrage of the great body of critical workers who now cultivate this field, and who at once begin to investigate from all sides any new and strange statement. Duplication of work, so called, is not waste of time.* If sharp criticism abound, so much the better. In this way we shall gradually reach a clearer understanding of these organisms. Meanwhile, let each one cultivate his own little field as best he inay, and, above all, let him be very sure of his facts before he publishes.

There can be no doubt that the same organism sometimes exists as a long filament in whicls no septa are visible and at other times as a short or nearly isodiametric rod, but we are not thereby compelled to consider the short form as a Micrococcus, i. e., as something very different from the long form. Physical conditions probably have inuch to do with bringing about these differences. Respecting the meaning of the branched forms, described by so many writers, the author is in doubt and can only wait for more light. Several hypotheses are open : (I) The bacteria, as now understood, are not a homogeneous group, but consist of many organisms of dissimilar origin and differing morphologically, which will be gradually separated out and put into their proper places, just as the Oosporas (Streptothrices) liave already been removed, leaving as Eu-bacteria a genuine residuum of inorphologically similar forms ; (2) the bacteria do not any of them represent a natural group, but are stages of various higher forms, just as certain cells, multiplying indefinitely in yeast form, are now known to be conidial stages of the higher fungi (smuts, mucors); (3) the branched forms, whicli come mostly in old cultures, or in other crowded conditions where the organisms are subject to the injurious action of their ow1 by-products (root-tubercles of Leguminosæ, lung-tubercles, etc.), are to be regarded simply as involution or degeneration forms, and not ligher stages of development; (4) the branchings are incomplete longitudinal fissions favored by special chemical or physical conditions. Time will show where the truth lies.

No harn will come to any one if all of these perplexing questions are not settled definitely within his own generation.

So far as can be judged from structure the bacteria appeared in early geologic ages (in coprolites, decaying bones, tree-trunks, etc.) in forms closely resembling those now existing, but we have very little definite information as to their origin. Probably they are related to the lower algxe and of as ancient origin. On relationship of the bacteria to Algæ, Fungi, Flagellata, and Myxomycetes, see Migula's remarks on the systematic position of the bacteria, in his "System," part I, page 237.

* Karl Pearson has recently stated that 50 per cent of the scientific work of the 19th century will have to be junked as worthless. In bacteriology 75 per cent would be nearer the truth. 


\section{Value of Cultural, Characters.}

Of what worth are the cultural characters commonly mentioned in descriptive bacteriology? Mucli depends on the proper answer to this question. There are indoubtedly two extreme views, neither of which is correct. One investigator would maintain that no dependence can be placed on them; another seems to liave no suspicion of any source of uncertainty. The truth undoubtedly lies somewhere between the two. That great progress in bacteriology has come from their use must be admitted by all. To cast doubt on everything already done is only to bring chaos back again. It is wise to make haste slowly. No necessity exists for making a rubbish heap of the past before beginning one's own work. Old metlods should be tried repeatedly, scrutinized from every standpoint, and only abandoned when they have yielded all that can be obtained from them, or when there is something distinctly better to take their place. New methods should be liailed with enthusiasm only in so far as they have actually made good their claim to be genuine improvements. A great deal of writing on bacteriology is worthless because not based on well-considered and properly conducted experiments. Hypotheses ad libitum, the more the better; but let us not forget to test each one in the crucible of experiment, and generally before publishing, rather than after. In other words, give to the world only the well-established facts. As a means toward arriving at the truth, let eacli person not only experiment as carefully as possible, but let him set down all the steps in his procedure, so that others may repeat his experiments. Many misapprehensions and supposed contradictions arise from the fact that workers are led to believe they have exactly duplicated another man's work when they lave done nothing of the kind. The temperature at which they have worked has been different, or some other physical or chenical condition, important but not recognized or not recorded by the first writer, has been unlike, and the results are not the same. Bacteria are not so simple as they appear. While monotonous morphologically they are complex in their multitudinous physiological activities, and are extremely apt to vary under a slightly changed environment. When we repeat an experiment we must know, therefore, whether we have preserved substantially the former environment. If we have not, then it should not surprise us if the results are somewhat different from those we anticipated.

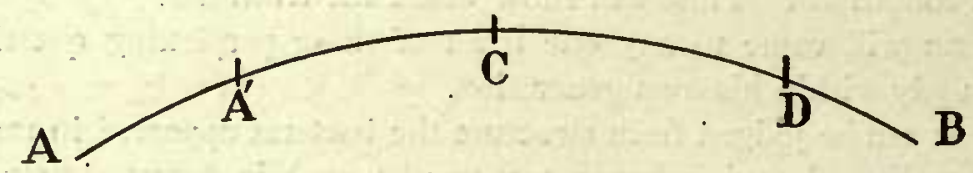

A very frequent sonrce of error in interpreting descriptions consists in not making sufficient allowance for changes due to slight variations in the culture-media. I can perhaps inake my meaning plainer in the following way: Let the curve A B represent all the variations in color and appearance of a given organism on a given medium, e.g., steamed potato. Now, if a worker describes his organism from a 


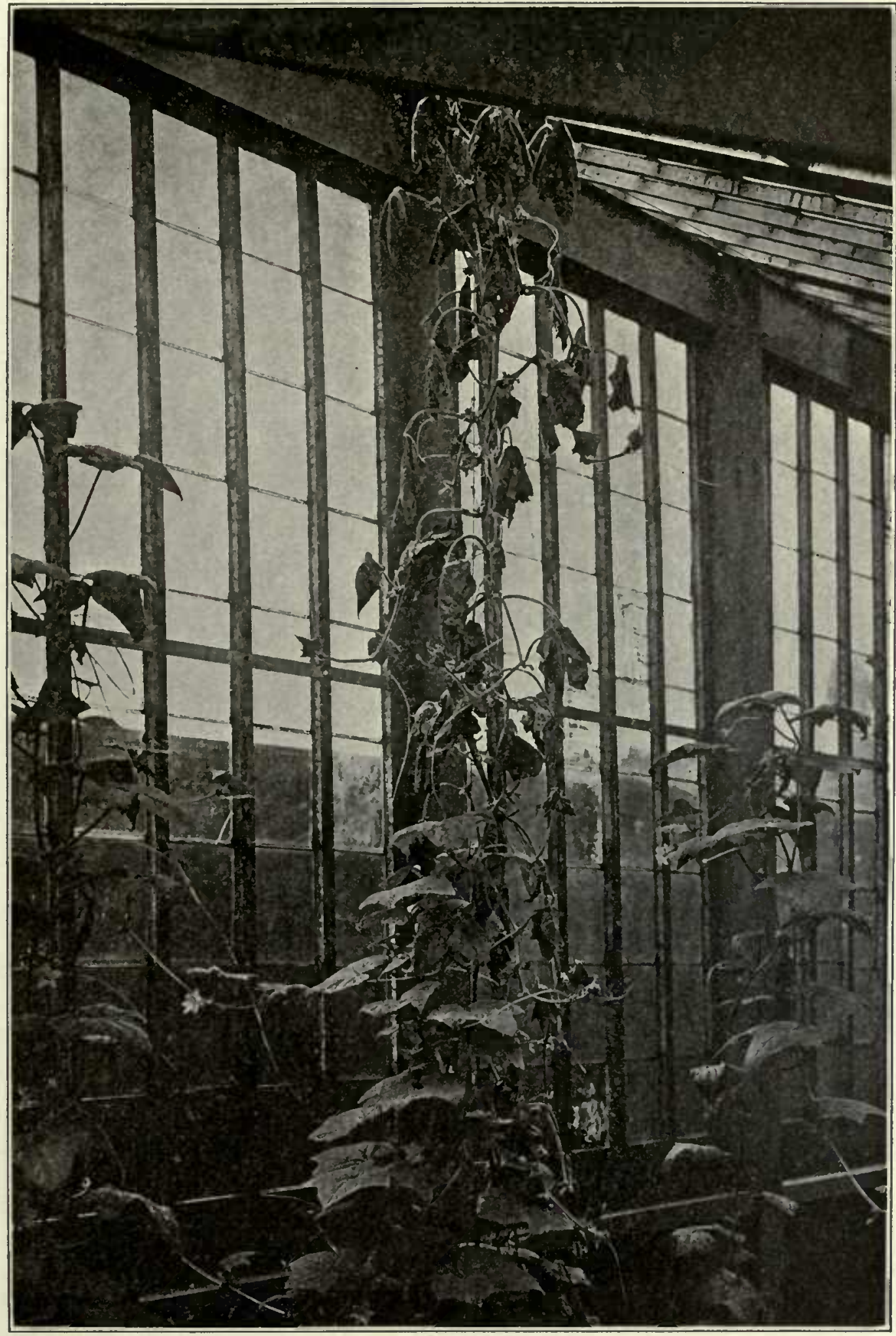

Bacterial wilt of the cucumber.

(Introduced to illustrate transmisaion of the disease by insects). The central plant (variety Long green) wat inoculated on June 17 wilh Bacillus tracheiphilus by the striped cucumber-beetle (Diabrotica vittata). As a result the gnawed leaves first wilted and then the whole upper part of the plant, the vascular bundles being occluded by the sticky white slime of this bacillus. Photographed July I, 1905. About I-14 natura size. The entire plant was dead about two weeks later. 

few cultures, he will thein ii all probability have covered only a fraction of the curve $A$ B, let us say between C and D, and not the whole curve of growtl. If, now, another worker should happen to experinent with potatoes capable of giving rise in the organism to phenomena represented by that part of the curve lying between $\mathrm{A}$ and $\mathrm{A}^{\prime}$, he wonld get sonnewhat different results and yet this wonld not prove steamed potato to be a worthless culture-medium. The only real facts in the supposed case are that neither person has experimented sufficiently to draw up a proper description of the characteristics of the given organism on potato. Let us suppose we have to do with a yellow organism, e.g., Bacterium phaseoli and that $\mathrm{A}^{\prime}$ to $\mathrm{A}^{\prime}$ represents a pale yellow growth, with no graying of the potato, while D to $B$ repre-

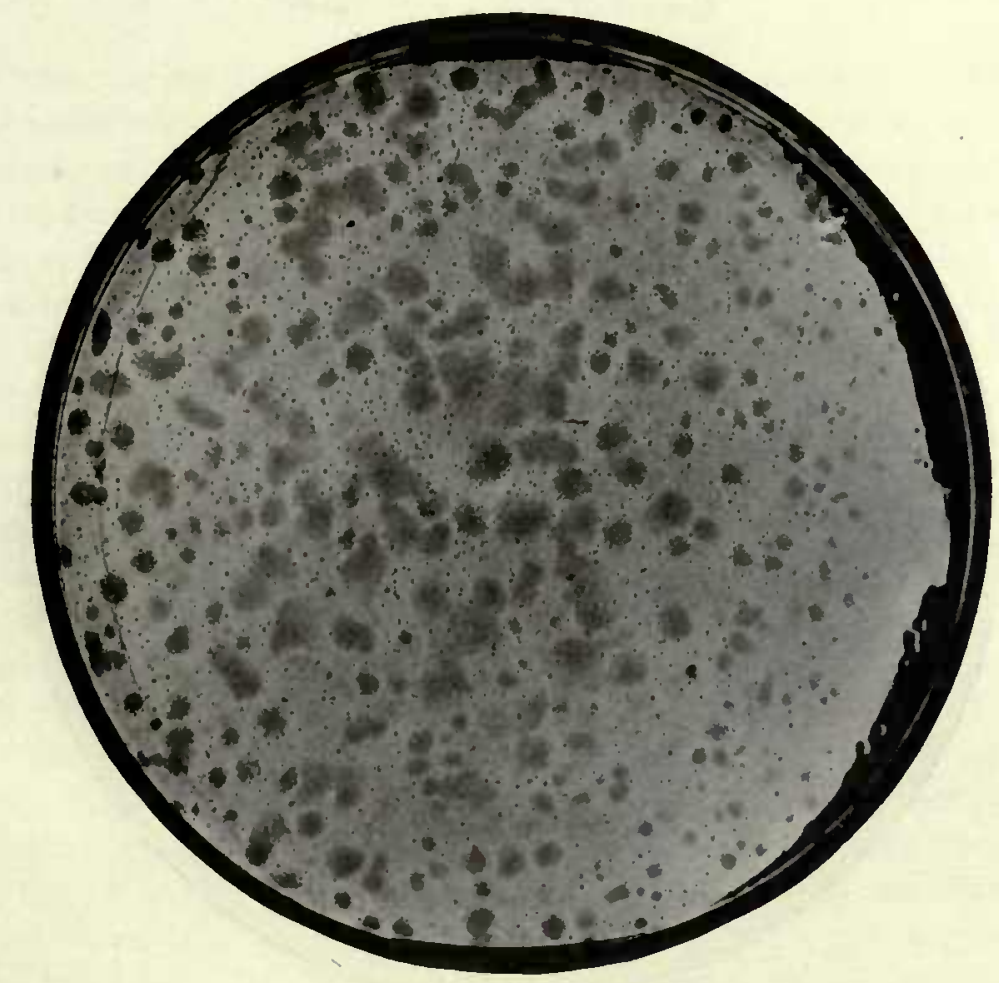

Fig. 142.*

sents a very deep yellow growth, with very decided graying of the potato. The cultures look like different organisms, but they are not. The descriptions would differ. Neither account alone would form a proper description of the behavior of this organism on potato, but there should be rather a combination of the two and of all internediate stages, viz-Potato: Color varying from pale to deep yellow, flesh of the potato usually grayed, but sometimes remaining unchanged, etc. The saine remarks apply to other non-synthetic media.

*FIG. I42.-Iris-rhizome rot. A dense sowing of the organism in an agar-plate culture after 45 hours at $25^{\circ} \mathrm{C}$. The buried colonies small. Not van Hall's organism, which, as received from Král of Prague, is non-pathogenic in my hands. 
In case of agar and gelatin there are numerous variations due to inadvertent changes in the culture-medium, especially if this is made by students. The media sliould be made by coinpetent, experienced persons, and then the descriptions of the behavior of the organisin on it should be broad enough to include slight differences in the aspect of the colonies, streaks, and stabs, which often depend on chenical and physical conditions within the control of the experimenter, $c . g$., on the water-content, on age of the 111ediun1, an1ount of moisture in surface-layers, kind of peptone, kind of gelatin, length of exposure and degree of heat during sterilization, etc. The dense or thin sowing of the plate may sometimes nuake a very decided difference in the aspect of the colonies. Fig. I42 shows a densely-

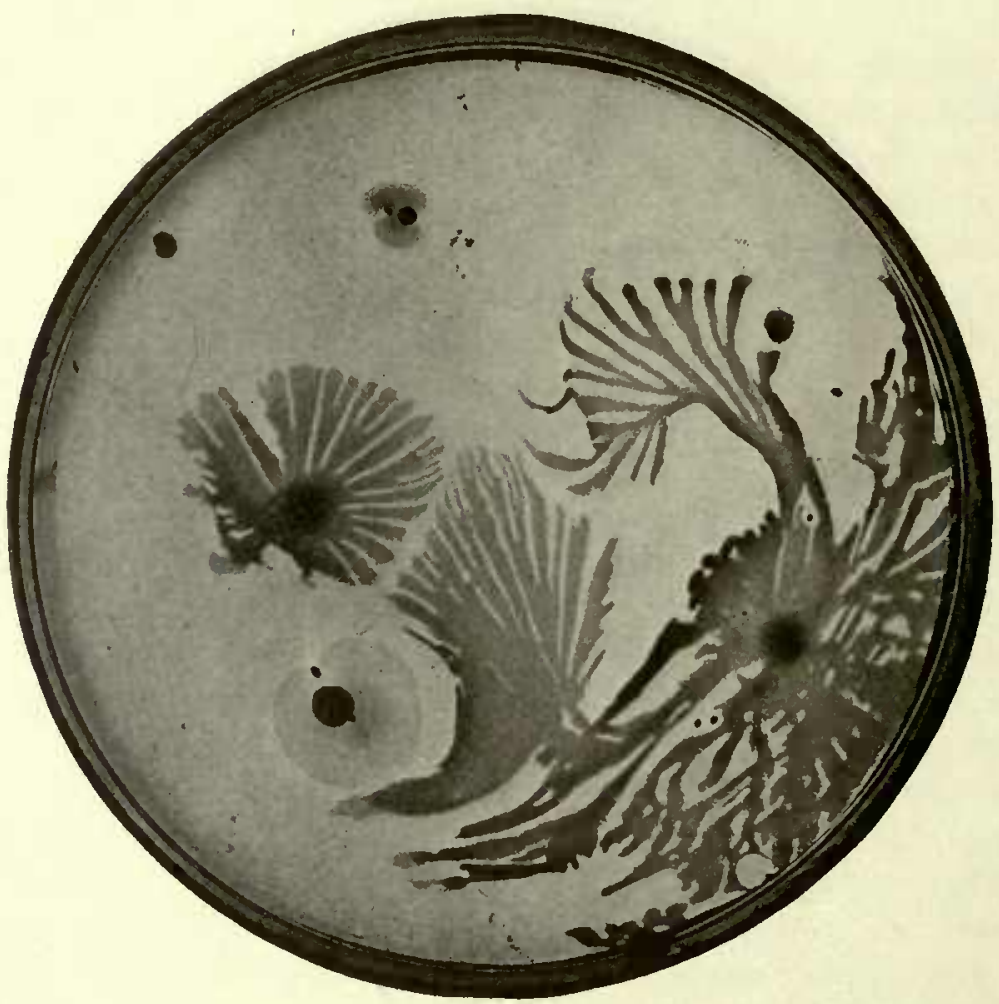

Fig. 143.*

sown plate, the colonies round or roundish. Fig. I43 shows the same organism, and from the same set of plates, but thinly sown and two days older. Here the colonies are radiate. In case of Bacillus aroidece when grown on agar-plates, near the maximum and minimum temperature limits, the surface-colonies are round even after many days, but they are promptly and strongly radiate when grown at or near the optimum temperature (see figs. I44, I45). When very thin sowings of this organism were exposed to the high temperature, the colonies were also round. It occurred to the writer that the round colonies obtained on the agar-plates exposed in the thermostat at $37^{\circ} \mathrm{C}$. might be due to physical changes in the surface

*FIG. 143.-Iris-rhizome rot. The same as 142 , but sown thinly and kept for 4 days at $25^{\circ} \mathrm{C}$. 
layers of the agar, $i . e$., to rapid loss of water, and experiments have shown this to be the case. Two sets of Petri-disli poured plates were made, inoculating from the sanne culture. One set was exposed in the open tliermostat at $37^{\circ} \mathrm{C}$, and these developed round colonies, similar to those shown in fig. I44. The otlier set was inclosed in the sanue thermostat, but inside of a closed glass vessel containing water. The colonies on these grew in radiating form, the same as in a third set of plates exposed at $30^{\circ} \mathrm{C}$. This does not account, however, for the appearance of circular colonies at low temperatures. After twelve days' exposure in an ice-box the writer obtained the same result as Townsend; the colonies were not radiate, but looked like those shown in fig. I44.

\section{UNDERGRADUATE WORK.}

As a rule, the results of this kind of investigation are to be distrusted. The freslı ambition of students and their deliglitful eagerness to take up hard problens are sources of great pleasure to every good teacher. At the same time such students must be held back rather than unged on, since for the most part they are still unfitted to do independent work, especially that which involves the drawing of general conclusions from a variety of experiments. The ordinary training of botanical and zoological laboratories will not fit the student for specialization in pathology and bacteriology. Skill in this sort of work must be obtained from consorting with the professional patlologist and bacteriologist. In general, at the present time a well-equipped modern laboratory devoted to animal pathology is a 1n11ch better place for the plant bacteriologist to learn inethods than even our best-equipped botanical laboratories. One of two alternatives is open to the anbitious student. Either he 1nust subnit to a long and rigorons conrse of elementary study in a bacteriological laboratory, under a competent and critical teacher, or else he must be content to pick up the general principles of the science ont of books and jonnals, with much blundering and stumbling in the first years of his study. During this nursery period, if he is jealous of his own reputation, he will not publish much. My experience has led me to disconnt very liberally the conclusions of student investigators, and I consider those students very unfortunate whose teachers urge them into precocious publication. In many cases nothing could be 111ore dannaging to their own reputation as scientific inquirers, or more injurious to the progress of science. Bad papers also react upon the teachers of such students, who can not by any shift evade responsibility. My advice to teachers is to discourage all students who do not show inarked aptitude, and to give to those who do show signal ability the best possible training in methods of work, but to discourage them from undertaking difficult pieces of original investigation. The only alternative is for the teacher to follow their work step by step and assume joint responsibility for it in the end. Even this latter course is sometimes risky, as the history of science shows very conclusively.

After a year or two of careful work on methods, under the watchful supervision of a good teacher, the bright student will have learned how to avoid many of the pitfalls which beset his way, and, if he has acquired a proper training in other directions, such as general botany, modern physics, chemistry, the modern languages, 
etc., he nuy be trusted to 11ndertake some original researcli. Even when once on liis feet as an investigator, n11y advice to lim would be: Try every conclusion repeatedly and n11ake haste slowly. When he becomes uneasy at delays, let hin reflect that one really good paper does much to set an unknown worker on his feet among scientific men, whereas one or two hastily written, poor papers will injure his reputation as an investigator more than half a dozen good papers subsequently published will suffice to repair. Moreover, in this age of enormously 11111tiplied publication it is impossible to read everything, and consequently if a writer wishes to attract attention he must have a commanding grasp of his subject; 111ust present

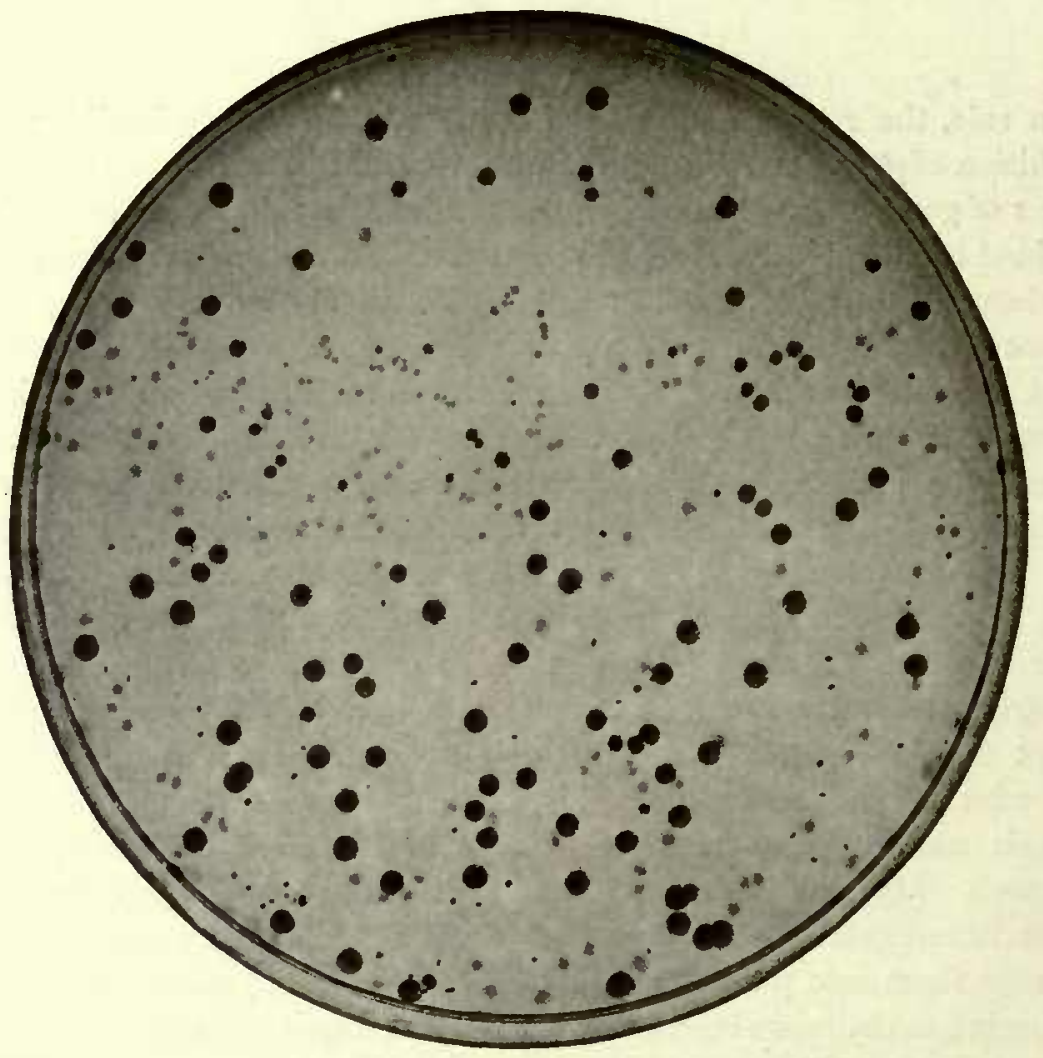

Fig. 144.*

its leading featnres in a clear, interesting style; must be as brief as the importance of his subject will warrant, otherwise his words are certain to be overwlielned and lost; and, finally, must publish in a proper place, i.e., not in some obscure "'Transactions" or in some local journal witl a small circulation. When ready to pubiish, stop and do your work all over again with more care. This is my advice to beginners. In the course of such general revision the chances are that many statements will require correction or modification, and some may have to be omitted altogether.

*FIG. I44.-Colonies of Bacillus aroideae, circular when grown on an agar plate at $37^{\circ}$ to $38^{\circ} \mathrm{C}$., $i$. e., at a temperature near the maximum. Photograph by Townsend. 
In any event, the student must have a considerable body of knowledge, gained by actual experiment, before his judginent is worth mucl. In the beginning he is apt to depend too much on the constancy of organisms and is certain to be misled by names. To illustrate: To hin all agar is agar and all gelatin is gelatin. Not so, perliaps, to the organisin with which he is experimenting. Slight differences in the composition of a culture-medinn sometimes make considerable difference in the growth and general appearance of the bacteria, and this must be taken into acconnt. After the student lias passed this stage of development he can interpret lis results nunch better. If, then, on some culture-medium he obtains results slightly

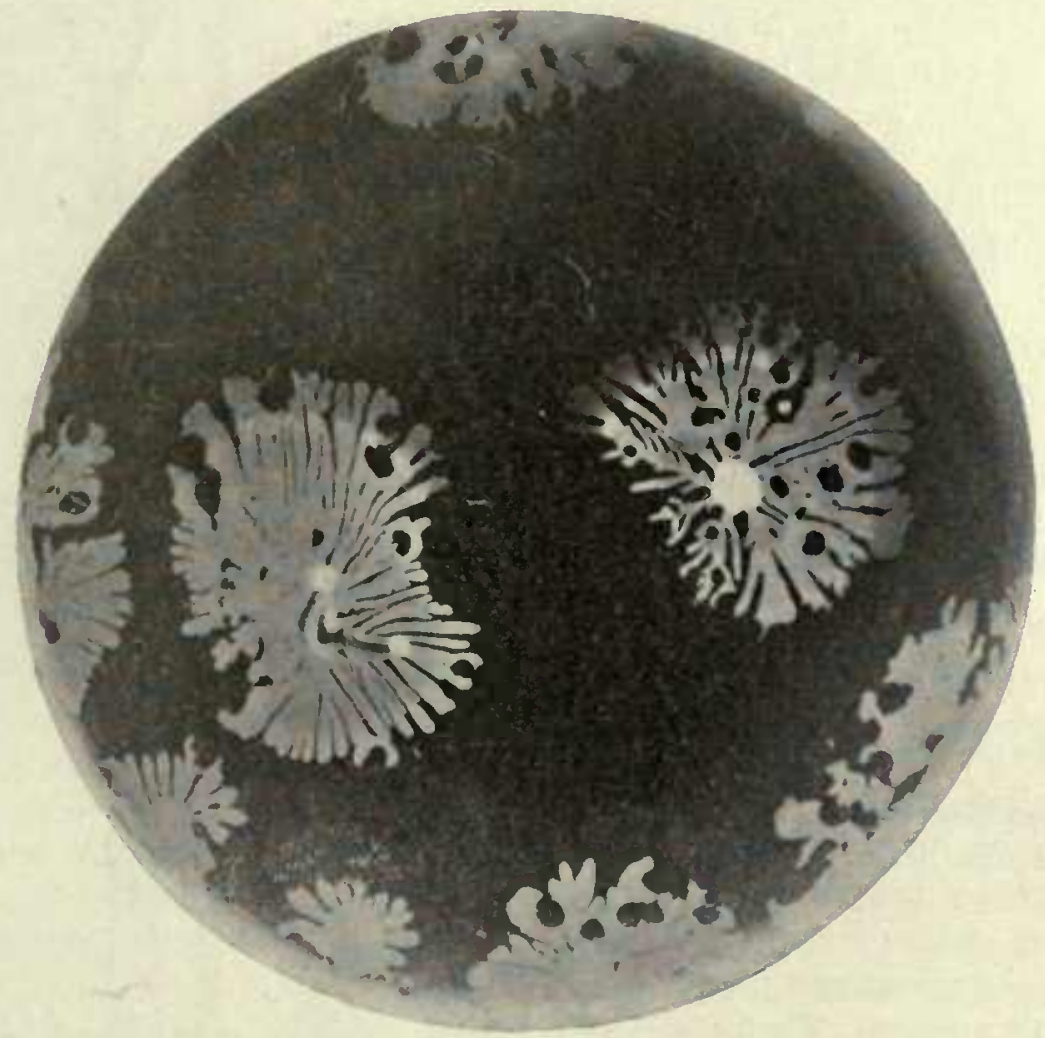

Fig. 145.*

different from those already published by some author, he is not inimediately driven to suppose (I) that he has a new species, or (2) that the earlier writer was in manifest error. Other lyypotheses now lie open to him. He is dealing with a living and variable organism, and perhaps the conditions in his experinent are not precisely like those to which it was subjected by the previous experimenter. It nuay also be an organism which has already varied into many races having slightly different peculiarities. Only when full weight has been given to these possibilities is he entitled to fall back on the others. On the other hand, however, he must not

Frc. 145.-Colonies of Bacillus aroideae, radiate-fimbriate when grown on an agar plate at $25^{\circ} \mathrm{C}$. Photograph by Townsend. 
escape Scylla only to fall into Charybdis. It may be that his organism varies in all sorts of ways, but he is by no means to assume this. Every liypothesis must be tried in the redncing fire of exact experinent.

Probably the best acquirement a student can get from his years of training is a spirit of self-distrust leading to habitnal cantion in the drawing of conclusions and the making of general statements. Sucli a spirit will preserve him from many foolish statements and will enable him to serve his generation to the best of his ability. He will not go far, however, withont a tremendons earnestness, an indomitable energy, directed in proper cliannels. L,et him concentrate this energy, the most priceless of all human attributes, and attack specific problems, one after another or a few at a time; not all at once. Honesty, industry, and self-reliance, tempered with the self-distrust already mentioned, will then carry him very far on the road he desires to go. Finally, the student should remember that the ideal man of science, and to a large extent also the actual man of science, is a modest man, always inclined to be cantions, always willing to revise his conclusions in the light of fresh evidence, generally plain-spoken, always an enemy of shans, and never offended by frank and honest criticism, preferring the white light of truth to the plandits of the multitude.

\section{A Final, Caution.}

Probably more mistakes arise from failure to carefully clieck np the work behind one than from any other source. What is meant by this can be explained in a few words, by n11eans of a series of examples.

(I) I nake subcultures from a poured-plate colony. The first subculture is on slant agar, the second is from the agar into beef-broth, the third is from the beef-broth into potato-broth, and from the latter I propose to inoculate a plant. The in-

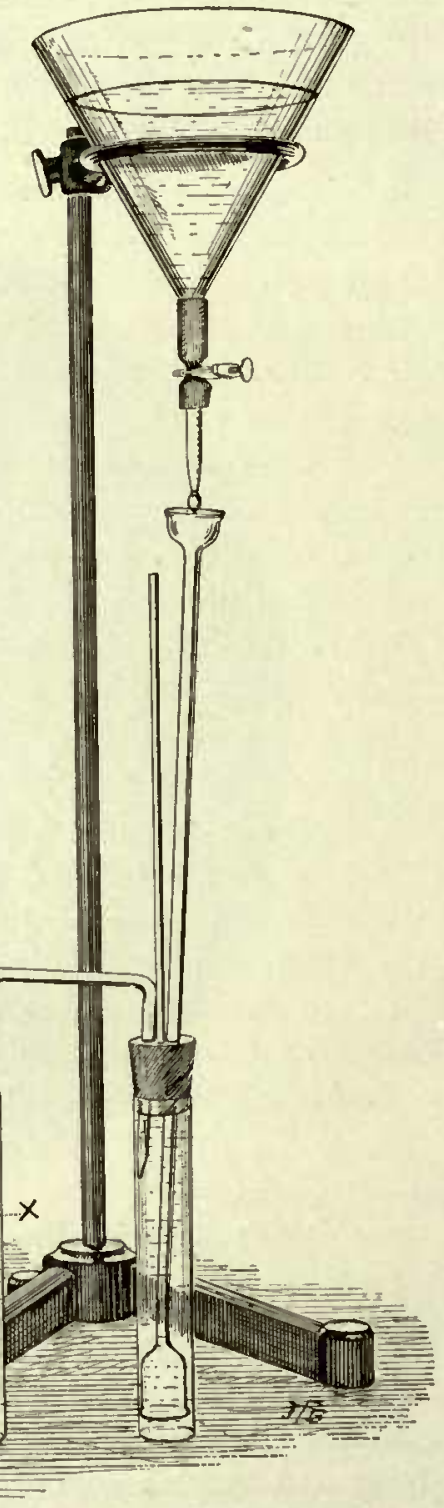

Fig. 146.*

*FrG. I46.-Apparatus for removing water from tissues with a minimum of injury. The specimen is placed on the wire carrier at $\mathrm{X}$ in water. The tube at the right also contains water. Alcohol (95 per cent) is then poured into the funnel and allowed to pass into the apparatus drop by drop. Its perfect diffusion through the water is obtained by making the basal ends of the carrying tubes flaring or funnel-shaped. By gaging the time between drops the alcohol may be substituted for the water, slowly or rapidly, in any desired time. About one-third actual size. 
ference is that this tube of potato-broth, which is only the third remove from the colony, contains a pure culture of the organism with which I started, but simple observations of the tube, even when coupled with a very firm persuasion, do not assure me that such is the fact. I clieck the inference by making plate-cultures and find in the tube either $(a)$ only the original organism; $(b)$ a mixture of two or more organisns; $(c)$ a pure culture of some wholly different organism, which entered during one of the transfers as an accidental contanination and has crowded out the original organisın.

(2) A plant is inoculated fronu a solid culture or fluid culture of a supposed parasite, and becomes diseased. The inference is that the inoculated organism has caused the disease. I clieck this inference by making plate-cultures from the interior of the diseased tissnes and find (a) great numbers of the inoculated organisn in pure culture and capable of again producing the disease, which I determine by actual experiment; (b) a mixtmre of organisns; (c) sonne wholly different organism; $(d)$ no bacteria whatever.

(3) Fermentation-tubes of cane-sugar bouillon inoculated with a supposedly pure culture soon show clouding in the closed end, with an abundant production of gas and acid. The inference is that these phenonnena are due to the presence of this particular organism. I clieck this inference by making plate-cultures and find $(a)$ a pure culture of the original organisn; $(b)$ only an intruder; $(c)$ a 1nixture of two organisms, in whicl case both may break up the sigar in the manner described, or only one of them.

(4) Drops of fluid containing a supposedly pure culture are dried on sterile cover-glasses and subsequently put into sterile beef-broth, which becomes clouded. The inference is that the organisin in question has resisted the drying. I check this inference by making plate-cultures from the fluid and find $(a)$ a pure culture of the right organism; $(b)$ a pure culture of some intruder.

(5) The thermal death-point of an organism is tested by inocnlating tubes of beef-bonillon and exposing them to a given temperature in the manner already described. Subsequently the bonillon clouds or does not cloud, as the case may be. The inferences are that the organism is killed or is not killed by the exposure. The first inference is checked by laving at the same time inoculated other tubes of the same bouillon, which liave been kept at room-temperatures, and whicl $(a)$ do not cloud, showing either that the bouillon itself inlibits growth or that only dead organisins were inserted, i. e., those from too old a culture; or $(b)$ wlich cloud readily, slowing that failure to grow in the exposed tubes is actually, as it was presumptively, attributable to the tenperature of the water-batl. I check the second inference by making poured plates from the clouded tubes and find $(a)$ pure cultures of the right organism; $(b)$ pure cultures of some intruder.

(6) A plant, whicl we will designate as A, is subject in the field to a certain disease, and this disease is readily reproduced under experimental conditions, using pure cultures of a given microorganisn1. A related plant, which we designate as $\mathrm{B}$, is subject in the field to a similar disease. A microscopic exanination shows similar lesions associated with a morphologically similar organism, and Petri-dish 
poured plates indicate the presence of a physiologically similar organism in both plants. The first inference is that the two diseases are caused by the same organism. A test-experiment is now instituted, viz, one or two varieties of $B$ are inoculated with the organism obtained from $A$, but these do not contract the disease. An easy second inference now is that we are dealing with two distinct diseases. This 1nay be perfectly correct, but it is not established by the experiment. Owing to an oversight, plants of A were not inoculated at the sanne time and in the same manner as B, to serve as checks, and consequently we are not assured as to the virulent nature of our culture-it may have been dead, or non-virulent, or the wrong organisi1. Check-plants should have been inoculated. Assuming, lowever, that this was done, and that A promptly contracted the disease while $B$ remained unaffected, it is not yet certain that the disease in the two plants is due to different organisms. The question of individual and varietal resistance to disease may have entered to complicate results. To eliminate this possible source of error a greater number of varieties of $B$ should be tested with a larger number of individuals in each variety. Cross-inoculations should also be made, $i . e$., nunnerous varieties and individuals of $\mathrm{A}$ should be inoculated with the organism isolated from $B$.

Enough has been said to show the ordinary method of work. All inferences should be carefully confirmed by frequent poured-plate cultures in Petri dishes, by cultivations on the media which have been found to give most characteristic results, and, finally, by frequent inoculations into the host-plants. In case of unexpected or striking results it is always safe to determine whether they can not be obtained in the absence of the assumed cause.

These methods involve an alnost endless anount of drudgery, but they are fundamental to any large success in the domain of pathology, and those who are desirous of winning a shining reputation without nuch labor are advised to cultivate some easier science. For those who are really in earnest, who do not mind hard work, and who have acquired the requisite training, no ficld affords greater opportunity for brilliant and useful work than that of plant pathology. 


\section{FORMULÆ.}

When not stated the solids are reckoned in grans and the fluids in cubic centineters. Water is understood when no particular solvent is mentioned.

\section{STAINS.}

\section{GENERAL, AND MISCELLANEOUS.}

\author{
Alcoholic Solutions of Anilin Stains.
}

These should be saturated solutions, made preferably with Grübler's stains and absolute alcohol. In well-stoppered bottles they keep indefinitely.

\section{Watery Solutions of Anilin Dyes.}

These do not keep long and must be made up fresh each time. If made directly from the dry powder or crystals, rather than from the alcoholic solution, the resulting fluid should be passed througls filter paper before using. Watery solutions are usually made by adding the alcoholic solution to distilled water in any strength desired. Usually a few drops of the alcoholic solution to 5 or ro cc. of water is sufficient.

\section{Anilin Water.}

Anilin water is made by shaking thoroughly one part of anilin in 20 parts of distilled water and filtering it clear by passing one or more times through filter paper moistened with water. It should be prepared fresh each time. Anilin, known also as anilin oil, is a colorless, oilylooking fluid. It oxidizes to a brown color if exposed to the air, and it should thercfore be kept in a close-stoppered bottle in the dark. The brown fuid is still usable, at least for some purposes.

\section{Ziehl's Carbol-Fuchsin.}

Fuchsin (basic) $\ldots \ldots \ldots \ldots \ldots \ldots$, I

Absolute alcohol................... Io

Carbolic acid (5 per cent sol. in water) $\ldots . \ldots \ldots \ldots \ldots \ldots \ldots . .100$

The fuchsin should first be dissolved in the alcohol and then the two fluids mixed. A powcrful and much-used stain.

\section{Ehrlich's Anilin-Water Gentian Violet.}

Alcoholic solution of gentian violet (saturated) $\ldots \ldots \ldots \ldots \ldots \ldots, \quad 5$

Anilin water.................. I00

This should be used as soon as prepared. It does not keep well.
Flexner's Anilin Gentian Violet.

Anilin oil.................... 2

Alcohol, 95 per cent.............. 5

Saturated alcoholic (absolute) solution of gentian violet............ 8

Distilled water................ 80

Mix well and filter.

Ehrlich-Weigert Anilin Methyl Violet.

Alcoholic solution of methyl violet (saturated) ............... II

Absolute alcohol................. Io

Anilin water................... I00

Does not keep well.

\section{Anilin Fuchsin.}

Prepared in the same way as Ehrlich's anilin gentian violet.

Ziehl-Nielson's Stain.

Used chiefly as a means for identifying tuberculosis. The cover-glass bearing the specimen is floated for 3 to 7 minutes on carbol-fuchsin which is heated until steam begins to appear. It is then washed in distilled water, plunged into to per cent nitric or sulphuric acid long enough to decolorize (a very short time). It is then passed through 60 per cent alcohol for a few seconds (just long enough to remove the stain from the background), washed thoroughly in watcr, dried, and mounted in balsam. The cover-glass preparation may be obtained also by dropping some of the stain upon it and holding it over the flame. This method is more economical of stain and time and less mussy than the preceding.

\section{Friedlaender's Stain.}

This has been used so far mostly for identifying the tubercle organism in sputum. It is made as follows: A few drops of carbol-fuchsin are placed on the prepared cover (which has been gently flamed) and heated over a flame until the fluid steams. The cover is then washed in distilled water, and plunged for a half 
minute or so into acid alcohol (c. p. nitric acid 5 cc., 80 per cent alcohol $100 \mathrm{cc}$.). It is then washed in water, stained about 5 minutes (for contrast) in an aqueous solution of methylene blue, dried, and mounted in cedar oil or balsam.

Loeffler's Alkaline Methylene Blue.

Alcoholic solution of methylene

blue (saturated)............. 30

$\left.\begin{array}{l}\text { Caustic potash....... I I } \\ \text { Distilled water..... I0,000 }\end{array}\right\} \ldots$. I00

This fluid retains its valuable properties for a considerable time and is an excellent stain.

Kühne's Carbol-Methylene Blue.

(I) Methylene blue............. 1.5

Absolute alcohol............. 10,0

(2) After triturating the above in an agate or porcelain mortar, or in a watch glass, add gradually $100 \mathrm{cc}$. of water containing 5 per cent carbolic acid. Methylene blue is not the same as methyl blue. (See Pregl, Bibliog., XIV.)

\section{Gran's Stain.}

This is a method of differential bleaching after a stain. The cover-glass preparations or sections are passed from absolute alcohol into Ehrlich's anilin gentian violet or into a watery solution of methyl violet, where they remain I to 3 minutes, except tubercle bacilli preparations, which remain commonly i2 to 24 hours (Gram). They are then placed for I to $3 \mathrm{~min}$ utes (occasionally 5 minutes) in iodine potassium iodide water (iodine crystals $\mathbf{r}$, potassic iodide 2 , water 300 ), with or without first washing lightly in alcohol. In this they remain $r$ to 3 minutes. They are then placed in absolute alcohol until sufficiently bleached, after which they are cleared in clove oil and mounted in Canada balsam. By this method the stain is removed from some kinds of bacteria and not from others.

Too much confidence must not be placed in this method, since in some cases the removal or non-removal of the stain from the organism depends on the length of exposure to the iodine water. It would be better, therefore, to expose all for the same period, $e . g ., 2$ minutes.

\section{Gabbett's Stain.}

Used mostly for tubercle bacteria in sputum. Stain first with carbol-fuchsin, then place the cover-glass for $I$ to 2 minutes in acid methylene blue (methylene blue 2 grams, 25 per cent sulphuric acid water roo cc.). When washed in water and dried it may be mounted in cedar oil or in balsam. The ordinary bacteria of sputum are decolorized; the tubercle organism retains the red stain.

The Ehrlich-Weigert Stain.

Used for detecting the tubercle-organism in sputum. The prepared cover is floated face down on anilin methyl violet, which is heated until steam rises. After 2 to 5 minutes on this hot stain plunge for a few seconds into acidulated water (I part nitric acid, 3 parts distilled water), then wash for a few scconds in 60 per cent alcohol, and afterward thoroughly in water. For a contrast stain the cover may be placed for 5 minutes in a saturated aqueous solution of vesuvin. It is then washed in water, dried, and mounted in balsam.

Bacteria which hold the stain after such treatment are sometimes called "acid-fast" bacteria.

Flemming's Triple Stain.

The slide is first placed in ( $I$ ).

(I) Safranin O (saturated alcoholic solution) $\ldots \ldots \ldots \ldots \ldots \ldots \ldots \ldots$

Distilled water.............. 50

Anilin water................ 5

After washing in water, it then goes into (2).

(2) Saturated aqueous solution of gentian violet.............. 50

It is then washed in water and passed into (3).

(3) Aqueous solution of orange G, strong or weak (generally about one-half saturated).

The slide is then washed quickly in 95 per cent alcohol, dehydrated, cleared, and mounted.

\section{Pregl's Method.}

(See '9r Pregl, Bibliog., XIV.)

$$
\text { Nicolle's Methods. }
$$

(See '95 Nicolle, Bibliog., XIV.)

$$
\text { Benda's Iron Haematoxylin. }
$$

Mordant the sections for several hours in I part of the following ferric solution* diluted with 2 parts of water:

Ferrous sulphate.............. 80

Water ........................ 40

Sulphuric acid................. 15

Nitric acid................... I8

This aolution, known to the German Pharmacopoeia as Llquor ferri sulphurici oxydati aud to tle U. S. P. as Liq. f. tersulphatis or aol. persulphate of iron, keeps indefinitely. It is made as follows: IIeat in a flask on a water-bath until fluid is brown and clear, and a drop diluted with water is no longer colored blue by potassiun ferricyauide, evaporate in a tared porcelain capsule to 100 parts, add a little water and evaporate agaln. Repeat the dilution and evaporation untll the hot fluid is free from the odor of nitrlc acid. Finally dilute to a weight of I60 parts. 
Wash the sections in distilled water and then in tap-water. Stain (until very black) in water containing I per cent hacmatoxylin. Differenliate in 30 per cent acetic-acid water with careful watching, or in more dilute acid, or in very dilute ( $1: 20$ ) liquor ferri, if it is to be followed by acid fuchsin as a contrast stain. (Verhandl. d. Anat. Gessellsch., I893, Jena, Gustav Fischer.)

Heidenhain's Iron Haematoxylin.

Mordant the sections from one-half hour to 12 hours in a 2.5 per cent watery solution of iron alum (ammonio-ferric sulphate $\left(\mathrm{NH}_{4}\right)_{2} \quad \mathrm{Fe}_{2}$ $\left(\mathrm{SO}_{4}\right)_{*}$ dissolved cold). This salt comes in violet crystals. Yellow or grcen crystals should be rejected. Rinse well in water. Stain in water containing 0.5 per cent of hacmatoxylin. Rinse, expose again to the iron-alum solution, watching the differentiation under the microscope, the examination being made in tap-water. When properly differentiated wash 15 to 45 minutes in running water. Dehydrate, clear only with xylol, and mount in xylol balsain. The mordant does not keep indefinitely, but is said to retain its properties for some time (Dodge).
Schaffner's Safranin Picro-nigrosin.

The slides are stained for a few minutes in anilin-safranin made as follows:

(I) Anilin water............. 50

Saturated alcoholic (95 per cent) solution of safranin... 50

Rinse quickly in water. They are then stained in (2).

(2) Distilled water............ I00

Picric acid thoroughly dissolved in the above.............. I

Then add nigrosin.......... I

Rinse in water, wash rapidly in 95 per cent alcoliol, dehydrate, and mount in balsam.

\section{Malachite Green.}

For plant tissues, as well as animal tissues, this may be used as a contrast stain, following carbol-fuchsin. It is dissolved in anilin ( $1: 1000$ ) and used fresh; gencrally the exposure to it should be for only a very brief period, i. e., I to 3 minutes. If not fresh, much longer exposures are required.

\section{CLEANING COVER-GLASSFS FOR FLAGELIA STAINS.}

Van Ermengen recommends boiling in a mixture of water IOO cc., concentrated sulphuric acid $60 \mathrm{cc}$, potassium bichromate 60 grams. The covers are afterward thoroughly wasled, first in water and then in absolute alcohol. They are set on edge and dried under a bell-jar.

Loeffler recommends heating covers in concentrated sulphuric acid. They are then wasled in distilled water and put into alcohol-anmonia, from which they are wiped with a very clean linen cloth.

Covers cleaned in the ordinary way may be freed from fat by passing then through a Bunsen flame inmediately before using.

\section{FLAGEILA STAINING.}

There is no easy road to success. Some of the common stones of stumbling are (I) oily or otherwise dirty covers; (2) cultures unsuited either by age or by composition of the nnedium; (3) the casting off of flagella on dilution or during the slow drying of the fluid on the cover; (4) an uneven or too copious distribution of the organisms on the cover; (5) imperfect mordanting; (6) excessive mordanting; (7) understaining; (8) overstaining; (9) precipitates on the cover-glass during some stage in the process.

If clean covers are used, if the bacteria are derived from young moist agar cultures, if a very small quantity of sucli culture is put into a large drop of well aerated water, or, better, into a test-tube or watch-glass containing 5 or ro cc. of water, and a tiny quantity of this dilution is taken on a platinun needle and deftly swept over the whole cover; or if the needle is touched to the bacterial fluid and then touched 
to one or nnore parts of a large drop of water on the cover, wlich is then put into the thermostat, so that it shall dry quickly and yet allow time for various rods to swin free from the tangle of their fellows; if the mordanting is thorough, but not excessive, and, finally, if there is no unforeseen mishap in the subsequent staining, good preparations of many organisms are easily secured. Others have given the writer much trouble (Bacillus amylovorus is one of the worst), and the only conclusion he has been able to reach is that the bacteria vary greatly in their response to flagella stains. Sometimes well-cleaned covers give trouble and then the surface of the glass itself is at fault (V.A. Moore), and covers of another origin shonld be tried.

Young agar cultures are usually preferred, $i . e$. , those not over twenty-four hours old, but good results may occasionally be obtained from much older cultures and also from other media. In case flagella are to be stained from fluid cultures by ordinary methods, the medinm in which the organism is grown must be very dilute, and there must usually be an additional extensive dilution on the cover, or before putting thereon, to avoid a dense ground stain. Bonillon contains too many fine particles, but Zettnow has found a way to stain frown bonillon (Bibliog., XII).

Recently the writer has obtained very good results with several organisms by growing them for some days in Io cc. of distilled water to which 2 or 3 drops of Uschinsky's solution was added. Covers were prepared directly from this solution. Others have reported good success by transfer of agar-grown organisms to considerable water in a watcli-glass or test-tube and incubating this in the thermostat for some hours before preparation of the covers. Others have reconinended the use of filtered, sterile, hydrant water instead of distilled water. Nearly every worker has solne favorite stain. The writer prefers Van Eirnengem's.

\section{Loefler's Flagella Stain.}

(1) Mordant:

Solution of tannin (20 per cent in water).... 10 Saturated (cold) aqueous solution of ferrous sulphate* ....................... 5 Saturated alcoholic solution of basic fuchsin. I

(2) Stain: Carbol-fuchsin.

(3) Corrective solutions: (a) I per cent solu. tion of caustic soda; (b) a sulphuric-acid solution of equivalent strength.

\section{A. Moore's Flagella Stain.}

This is a slight modification of Loeffler's. (I) Mordant:

Tannic acid (20 per cent in water)......... ro

Ferrous sulphate (cold saturated water solu-

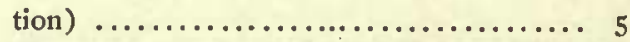

Basic fuchsin (saturated alcoholic solution). I

(2) Stain: Ziehl's carbol fuchsin.

Use the mordant fresh, and filter each time before using. Fix the film on the cover-glass by passing it quickly face up twice through the open flame, or by exposing for 5 or 10 minutes to a temperature of $120^{\circ}$ to $140^{\circ} \mathrm{C}$, the better way. A few cubic centimeters of the mordant are now placed in a wide test-tube ( $I$ inch), the cover is lowered into it, and the mordant is heated over a flame until steam rises. It is then removed from the flame and the cover is allowed to remain in the hot fluid 5 or 10 minutes, with occasional gentle shaking, after which it is drawn to the mouth of the tilted tube by means of a hooked platinum wire set into a glass rod. After thoroughly rinsing under the tap or in a fine stream of water the cover is lowered into the stain (held in another wide test-tube), where it is heated until steam rises (I to 3 minutes). One should know from beginning to end which side of cover bears the bacterial film. The cover is drawn to mouth of tube by means of a hooked platinum wire. Sometimes I per cent sol. $\mathrm{NaOH}$ ( $\mathrm{I} / 2 \mathrm{cc}$.) may be added to mordant with advantage.

\footnotetext{
"The iron oxide may be removed from the solution of fertous sulphate by passing it through a filter paper. Selected crystals should be used.
} 


\section{Fischer's Flagella Stain.}

This is a slight modification of Dr. Cörner's, which is itself a modification of Loeffler's.

(I) Mordant:

Dry tannin................... 2

Water .........................20 20

Solution ferrous sulphate $(1: 2) \ldots 4$

Concentrated alcoholic solution basic

fuchsin ................... I

Filter. This mordant will keep for several weeks. Drop it on the cover and heat over a gentle flame until steam rises; then continue onehalf minute longer without boiling. Wash. Treatment with alcohol is unnecessary.

(2) Stain: Place on the cover a few drops of concentrated watery solution of basic fuchsin. Heat slowly, so that steam rises after about I minute. Then expose for one-half minute longer, so that the stain boils up once or twice. Wash, dry, and mount. Fischer says tannin absorbs moisture readily, and advises keeping it in a desiccator.

\section{Bunge's Flagella Stain.}

(I) Mordant:

Tannin 20, water I00........... 30

Liquor ferri sesquichlorati........ I

Water ..................... 20

Saturated watery solution basic fuchsin $\ldots \ldots \ldots \ldots \ldots \ldots \ldots \ldots$

This must ripen some weeks by exposure to the air in a flask loosely plugged with cotton.

(2) Stain: Carbol-fuchsin.

Expose to the filtered mordant 5 minutes, using heat if necessary. Wash and stain.

\section{Van Ermengem's Flagella Stain.}

This is made as follows:

(I) Mordant:

Osmic acid ( 2 per cent water solution) .................... 50

Tarnin ( 10 to 25 per cent in water).. 100

Four drops of glacial acetic acid may be added to this.

(2) Silver bath: 0.25 to 0.5 per cent nitrate of silver dissolved in distilled water in a very clean bottle.

(3) Reducing and strengthening bath:

Gallic acid.................. 5

T'annin ...................... 3

Fused sodium acetate (somc books say fused potassium acetate).... I0

Distilled water................ 350

The flamed cover-glass (it may be unflamed)

is first covercd with the mordant for one-half hour, or if in a thermostat at $50^{\circ} \mathrm{C}$. for 5 or 10 minutes. The mordant is then carefully removed by thorough washing in water, alcohol (some say absolute alcohol), and water. The cover (film side up) is now put into the silver bath (a few cubic centimeters in a small, perfectly clean beaker or watch-glass) for a few seconds, during which it is gently agitated. Without rinsing, it is put next into a few cubic centimeters of the reducing solution and gently agitated until the fluid begins to blacken. It is then washed in water and examined. If not stained deeply enough the cover is returned to the silver bath, then once more passed through the reducing bath. It is finally dried and mounted in balsam. All the dishes must be scrupulously clean. The fluids must not be contaminated by the fingers nor by dipping iron or steel instruments into them.

Kuntze has suggested some improvements. (See Centralb. f. Bakt., I Abt., Bd. XXXII, 1902, pp. 555-56́o.)

\section{Pitfield's Flagella Stain.}

\section{(1) Mordant:}

Tannic acid, to per cent aq. sol...... Io

Corrosive sublimate, sat. aq. sol..... 5

Alum, sat. aq. sol............. 5

Carbol-fuchsin............... 5

Heat on cover until steam rises; keep at this temperature I minute; then wash, dry, and stain.

(2) Stain:

Alum, sat. (cold) aq. sol.......... 10

Gentian violet, sat. alc. sol........ 2

Kendall, in Journ. Applied Micr., Vol. V, 1902 , p. 1836 , says this has proved a very satisfactory stain to himself and his associates.

Another formula is given as follows:

(I) Saturated (cold) aqueous solution of alum ........................ 10

Saturated alcoholic solution of gentian violet $\ldots \ldots \ldots \ldots \ldots \ldots \ldots \ldots \ldots \ldots$ I

(2) Tannic acid (tannin) ............... I Distilled water................... Io

A mixture of these two fluids is put on the flamed cover, which is held over the flame and gently heated until nearly ready to boil. The cover is then put aside for 1 minute, after which it is washed in water, dried, and mounted in balsam. If the mixed mordant-stain is filtered before using, it is best to stain a sccond time for a moment in anilin-water gentian violet. 


\section{Löwit's Flagella Stain.}

Löwit's modification of Loeffler's flagella stain consists in substituting a copper-tannin mordant for one of iron-tannin. It is made as follows:

(I) Mordant:

Distilled water............... ro

Tannin ................... 2.5

Dissolve and filter through two thicknesses of filter paper, then add:

Saturated solution copper sulphate... 5

Saturated alc. sol. basic fuchsin...... I

Filter as before.

Covers are exposed to this mordant 20 seconds to 3 minutes without heating. Wash thoroughly.

(2) Stain: Expose cover to Ehrlich's anilin water gentian violet I to 5 minutes. Wash thoroughly in water, and if this is not sufficient plunge for a moment into 50 per cent alcohol or into acid alcohol ( 1 drop of 0.3 per cent $\mathrm{HCl}$ alcohol in 3 to $4 \mathrm{cc}$. of 60 per cent alcohol). The mordant and stain must be made up each time. If the mordant has been in use for some hours so that an oxidation film has formed on its surface, it is well to stop and remove this by filtration.

\section{Sclavo's Filagella Stain.}

Sclavo exposes some minutes in the mordant (tannin I, water 5O, alcohol 50); washes in aq. dest.; exposes some minutes in 50 per cent phospho-tungstic acid; washes carefully in aq. dest.; stains 3 to 5 minutes in gently warmed anilin-water fuchsin; washes, dries, and mounts in Canada balsam. Some kinds are not stained by this method.

\section{Bowhill's Flagella Stain.}

This author used two solutions made as follows:

(I) Orcein $\ldots \ldots \ldots \ldots \ldots \ldots \ldots \ldots$,

Absolute alcohol.............. 50

Distilled water.............. 40

(2) Tannic acid (tannin)......... 8

Distilled water (hot).......... 40

Equal parts of ( $\mathrm{I}$ ) and (2) are mixed and filtered. Bacteria from a fresh agar culture are suspended in boiled distilled water. This suspension is allowed to stand 5 minutes. Drops are taken and spread and dried on clean covers, which are then taken in the fingers and fixed over the flame. They are now floated, film down, on the mordant (gently warmed) for from Io to 15 minutes, then washed in water and dried.
Ehrlich's anilin-water gentian violet is now dropped on the cover, and this is heated over the flame until steam appears. The preparation is then washed, dried, and mounted in xylol balsam.

Subsequently Bowhill modified the above as follows, using the orcein itself as a stain:

(I) Saturated solution of orcein (allowed to ripen about ro days).

(2) 20 per cent solution of tannin dissolved in hot water.

The stain is prepared by taking of No. I, I5 cc.; No. 2, $10 \mathrm{cc}$; and distilled water, $30 \mathrm{cc}$. After mixing, the fluid should be filtered. Subsequent bleaching of the preparation should be avoided. (Hyg. Rundsch., VIII Jahrg., I8g8, pp. II and 105.)

Hinterberger's Method for Flagella.

(See 'oo Hinterberger, Bibliog., XII.)

Night Blue Stain for Flagella.

('See '99 Morton, Bibliog., XII.)

Zettnow's Method for Flagella.

Zettnow fixes with formalin, mordants with tartrate of antimony and tannin, and stains with gold or silver.

The fixing is done by taking bacteria from a fresh agar or bouillon culture and adding them to water. They are then killed by the addition of 4 per cent formalin. The fixed bacteria settle after a day or two, when the sediment containing them is pipetted out and washed, first in I per cent formalin water and finally in pure water. The cloudy water is spread and dried on clean covers, and when these have been fixed by gentle heat they are ready for the mordant. The mordant is made as folows:

(I) Tannin $\ldots \ldots \ldots \ldots \ldots \ldots \ldots \ldots \ldots \ldots \ldots \ldots \ldots$

Distilled water............... 100

Flask and heat to $35^{\circ}$ or $40^{\circ} \mathrm{C}$. in the waterbath.

(2) A solution of tartrate of antimony (I gram dissolved in water in a test-tube) is added drop by drop to solution (I), with shaking until the precipitate which forms is not redissolved. It is then filtered. The filtered mordant should be strongly opalescent, but not cloudy or opaque to transmitted light. This is said to be a permanent universal mordant, and one wlich does not cause precipitates on the cover. It is used hot $\left(70^{\circ}\right.$ to $80^{\circ} \mathrm{C}$.) for 5 or Io minites. The cover is then washed and gilded or silvered. Afterward the image may be intensified if desired. 
The gold method consists of placing on the mordanted cover 4 or 5 drops of an aqueous solution of neutral gold chloride (I : 2000). This is then heatcd until steam is given off frecly. If the mordanting has been sufficient there will be a deposit of metallic gold on the bacteria.

\section{Hugh Williams' Method.}

(Copied from Mallory \& Wright's Pathological Technique.)

This is a modification of van Eirmengem's method along the lines of the modification of Hinterberger and others. It has been adopted by Dr. Hugh Williams after a large experience with various methods in the laboratory of the Massachusetts General Hospital.

The method is capable of giving black bacteria and flagella, with little or no precipitate. The method is as follows:

(I) Cover the cover-glass with a mordant consisting of-

Alumnol,* I per cent solution... I part

Osmic acid, 2 per cent solution.. I part

Tannin, 20 per cent solution.... 3 parts

Shake the mixture, add three drops of glacial acetic acid, and again shake.

(2) Apply the mordant less than one minute without heating. Wash thoroughly in water.

(3) Cover the preparation, during about I minute, with a I per cent solution of silver nitrate to which sufficient ammonium hydroxid has been added to keep the silver in solution. $f$

(4) Wash in water.

(5) Wash with 0.6 per cent solution of sodium chlorid.

(6) Flood the preparation with a 30 per cent solution of ammonium hydroxid, and immediately wash in water.

(7) Apply a few drops of Ortol photographic developer. (The directions for making up this developer come with the Ortol.)

(8) Wash in water.

(9) Cover with a I per cent solution of gold clilorid during a few seconds.

(so) Wash in water and apply Ortol developer for a few seconds.

(II) Wash in water and cover with a I per cent solution of mercuric chlorid for a few seconds.

(12) Wasl in water.

(I3) Apply Ortol developer for a few seconds.
(14) Wash in water and repeat the application of chlorid of gold, the washing, and the application of the developer two or more times. Bctween the various applications of the chlorid of gold the preparation should be inspected with a high, dry lens to determine the progress of the staining. This is readily done by placing the cover-glass, charged side upward, on a slide. In this way the process of impregnation with gold may be controlled; for the flagella, if stained, may be easily seen with the high-power dry lens.

The preparation is very conveniently held during the process in cover-glass forceps. The washing is best done in a small stream of water from a faucet. The various solutions are conveniently applied from dropping-bottles.

It will be secn that the process consists essentially in the impregnation of the flagella with silver, followed by intensification, in the photographic sense, with mercury and gold. The object of the application of the sodium chlorid and ammonia is to remove the excess of silver compounds which adhere to the surface of the coverglass in spite of washing. This excess of silver compounds is chiefly responsible for the precipitates which appear on the preparation after the intensification. In spite of the application of the sodium chlorid and ammonia solutions, some precipitate will occur if the intensification is pushed too far. On this acount it is advisable to observe the progress of the intensification under the microscope, as above indicated.

Although this method may appear complicated, in practice it requires but a few minutes to stain a preparation.

\section{Duckwall's Method.}

Strcaks are made on 2 per cent agar in Petri dishes from young growths in bouillon. Suspensions are made in water according to nature of organism, the motile bacteria being divided into six groups for staining purposes. Pigments and slime are removed by shaking with chloroform. Cover-glasses must be absolutely clean. Mordant must be used only when fresh; dye must be fresh and used warm (Loeffler's stain); streaks on cover-glass should not be confluent. Fix witlout. injury to flagella; stain without overleating; wash in alcohol and water without breaking film; clear in xylol; mount in xylol balsam without previous examination. For details respecting method of making suspensions see The Canner and Dried Fruit Packer, Vol. XX, Feb. I6, I905, p. 23.

*Farhwerke vorm, Meister I,uclus n, Brïning, Höchst a. M., Germany.

+Wotkers in the Bureau of Animai Industry U. S. Depariment of Agricullure state that too great an excess of ammonia In the ailver nitrate may interfere witli tle working of the method. 


\section{CAPSULE STAINS.}

Ribbert's Method of Staining Capsules.

Water ...................... I00

Alcohol .................... 50

Glacial acetic acid.......... 12.5

Warm and add dahlia to saturation. The covers are barely touched to this stain, and are then washed in water. The cover may then be mounted in glycerin or balsam. The stain keeps well. If the cover is left on the stain too long the capsule becomes deep blue and can not be distinguished from the body of the organism.

\section{Friedlaender's Capsule Stain.}

(See '85 Friedlaender, Bibliog., XIII.)

Richard Muir's Capsule Stain.

\section{(I) Mordant :}

Mercuric chloride (sat. aq. sol.)...... 2

Tannin (20 per cent in water)......2

Potash alum (sat. aq. sol.)......... 5

The dried films are mordanted 2 minutes. They are then washed in water, in alcohol, and again in water.

(2) Stain: Carbol-fuchsin 2 to 3 minutes, with gentle heat.

Wash with water; re-mordant 2 to 3 minutes; wash again with water.

(3) Counter-stain: Methylene blue (sat. aq. sol.) 2 minutes. Bleach in methyl alcohol, clear in $x y l o l$.
Welch's Capsule Stain.

Fix in glacial acetic acid. After a few seconds pour off the acid and flood with anilinwater gentian violet; repeat this operation until all acid is removed; wash and examine in salt solution ( 0.85 to 2 per cent).

\section{Kaufmann's Method.}

Stain 2 hours at $35^{\circ} \mathrm{C}$. in Loeffler's methylene blue; wash in water containing caustic potash or soda ( $\mathrm{I}: \mathrm{r} 500$ ), dry; expose 2 minutes in $\mathrm{I} / 2$ per cent silver nitrate; wash again in the alkaline water; counterstain 30 seconds in basic fuchsin water ( $1 \mathrm{cc}$. sat. alc. sol. in $20 \mathrm{cc}$. aq. dest.); expose again to the alkaline water (seconds); dry and mount. Best adapted to demonstration of capsules in fresh tissues. The bacterial body is blue and the capsule red.

Moore's Night-blue Capsule Stain.

(See '99 Moore, Bibliog., XIII.)

\section{Boni's Method.}

Mix white of I egg, glycerin $50 \mathrm{cc}$, formalin 2 drops; shake well and filter. The bacteria are placed in a drop of this fluid, spread, and heated until the glycerin has entirely evaporated. Stain 20 to 30 seconds in carbol-fuchsin, wash in water, dry and counterstain 4 to 6 minutes in Loeffler's methylene blue, wash in water, dry, and mount in Canada balsam. The background is red, body of organism blue, and periphery colorless. (See 'oo Boni, Bibliog., XIII.)

\section{SPORE STAINS.}

\section{Hauser's Spore Stain.}

Pass cover-glass quickly three times through flame. Drop on carbol-fuchsin and heat for 5 minutes over flame, renewing the stain as it boils away. Nearly decolorize in dilute sulphuric or acetic acid ( 5 per cent). Wash very thoroughly. Counterstain with a dilute watery solution of methylene blue or with Loeffler's methylene blue (Festschrift für Zenker).

$$
\text { Möller's Spore Stain. }
$$

(See '91 Moeller, Bibliog., XI.)

$$
\text { Neisser's Spore Stain. }
$$

The cover is floated on hot anilin-fuchsin for an hour. The temperature should be near the boiling point. The cover-glass is then washed in water and decolorized in acid alcohol ( $\mathrm{I}$ part hydrochloric acid, 3 parts alcohol). Care must be taken not to expose to the acid alcohol too long; otherwise the color will be removed from the spores also. The cover is now stained for contrast in a saturated aqueous solution of methylene blue.

\section{Fiocca's Spore Stain.}

The prepared cover is placed in a watch-glass or test-tube containing $20 \mathrm{cc}$. of ro per cent ammonia (water solution) and Io to 20 drops of alkalin methylene blue or other alkalin solution of anilin color. Then the fluid is heated to the giving off of steam and left for 3 to I5 minutes. It is now passed for a moment (?) through 20 per cent nitric or sulphuric acid, then thoroughly washed in water and stained for contrast, if desired, in an aqueous solution of vesuvin, malachite green, or safranin (saturated?). (See '93, Fiocca, Bibliog., XI.)

(For other methods, e. g., Foth's, Klein's, Aujeszky's, see Bibliog., XI.) 


\section{Non-Synthetic Culturf; Media.}

\section{Standard Peptonized Beef-Bonillon.}

Standard peptonized beef-bouillon is made as follows: To 500 grams of finely minced lean beef add I,000 cc. of distilled water. The soluble parts may be removed from the meat by allowing the water to stand on it for 24 hours in the ice-chest or for I hour in the water bath at $55^{\circ} \mathrm{C}$. The writer prefers the second method. Then boil for 60 minutes either in the steamer or in a covercd dish. Filter through a clean cloth, using pressure (meat-press), cool, and remove fat by filtering through $S$. \& $S$. filter paper; make up to $\mathrm{r}, 000 \mathrm{cc}$. by addition of more water; then add I per cent Witte's peptonum siccum and 0.5 per cent c. p. sodium chloride. Steam one-half hour, filter, cool, titrate, add required alkali, steam again for one-half hour, filter, pipette into tubes or flasks, and autoclave or heat for a minimum time in the steamer. Plugs should be well made and fit tightly; glassware should be scrupulously clean. For some purposes both the peptone and the salt may be omitted. A greenisl bouillon indicates insufficient boiling, and will usually throw down some additional vexatious precipitate when lieated in the test-tubes. Other meats may be substituted for beef, and other peptones for Witte's. Meat-extracts are not rccommended. Such extracts usually contain resistant spores. Media which luave been steamed, or boiled in an open dish, are better for many bacteria than those which have been sterilized in the autoclave.

(For additional observations on proper sterilization see Culture Media, p. 29.)

\section{Dunhan's Solution.}

Distilled water............... I,000

Witte's peptonum siccum........ I0

C. P. sodium chloride......... 5

First recommended by Dr. Ed. K. Dunham, of New York.

\section{Standard Nutrient Agar.}

To $1,000 \mathrm{cc}$. of standard beef-bouillon add ro grams of agar-flour, stcam one-half hour, cool to $58^{\circ} \mathrm{C}$. ; add whites of two eggs (beaten thoroughly and neutralized to litmus by dilute hydrochloric acid) and thoroughly mix with the bouillon; steam I hour, filter hot through S. \& S. paper which has been thoroughly warmed with boiling distilled water. Use two or three funnels. That which remains unfiltered after a rcasonable time must be rcheated and put through a fresh filter papcr. Sometimes all can be got through a second filter paper without reheating. Some advise filtering in the autoclave or in the steamer, but the writcr has not found that necessary, and in recent years has also abandoned the hot-water funnel.

Clear agar may be obtained also by filtering through absorbent cotton, and some prefer this to filter paper.

In preparing agar from the "slender kanten" or the "square kanten," snip fine, soak in the bouillon I5 minutes, and then heat on the sand bath I hour at $110^{\circ} \mathrm{C}$. or in the autoclave 45 minutes at $105^{\circ} \mathrm{C}$. From this point proceed as before.

Long heatings in the autoclave at $110^{\circ} \mathrm{C}$, or shorter heatings at higher tempcratures, are apt to brown the agar, and should be avoided carefully, as this renders the medium less serviceable for the growth of bacteria. Agar which has been properly superheated filters readily. One per cent agar made from the agar-flour does not require to be heated on the sand-bath or in the autoclave, but filters satisfactorily after steaming for an hour at $100^{\circ} \mathrm{C}$.

After the agar has been tubed it may be sterilized, if it does not contain sugars, by one steaming in the autoclave for Io minutes at $110^{\circ}$ $\mathrm{C}$, or by short steamings in the steam sterilizer at $100^{\circ} \mathrm{C}$. on three successive days.

To those who are dependent on the agar-strips and do not have access to an atoclave, Schutz's method may be recommended as very good. The writer formerly made large use of this. It consists in heating the agar very hot in a minimum quantity of water or bouillon before adding the bulk of the fluid. (See p. 34 and Bibliog., XVI.)

Agar which has been soaked in 5 per cent acetic acid for an hour or two before adding it to the bouillon also enters into solution thoroughly and filters well after a short boiling. The acid must first be removed completely by washing in running water for some hours under a mosquito-net or a piece of gauze.

Unfiltered agar docs well enough for certain fungi, and for lazy people, but the agar used for delicate work in bacteriology should be as clear as the bouillon from which it is made., $i$. $e$, perfectly free from cloudiness and precipitates. Sufficient caustic soda is usually added to the agar to render it +15 of Fuller's scale. Other degrees are uscful, c. g., + Io, o, - ro, etc. 


\section{Litmus Lactose Agar.}

To I,000 cc. of ordinary agar, preferably that made up with bouillon free from muscle-sugar, add io grams of c. p. lactose and $20 \mathrm{cc}$. of a saturated (water) solution of c. p. (lime-free) blue litmus.

\section{Hesse and Niedner's Nutrient Agar for Water Bacteria.}

Distilled water.............. 980

Nährstoff Heyden (an albumose) 7.5

Agar-agar ............... 12.5

This agar is said to be the most suitable medium for the bacteriological examination of water. It gives a much larger number of colonies than ordinary agar. It requires no neutralizing. The poured plates are counted, according to Dr. Robin, on the gth or Ioth day. Chromogenic species are brilliantly colored. (Zeitschr. f. Hygiene, Bd. XXIX, pp. 454-462. See also Am. Jour. Pharm.,. Vol. LXXVI, p. II2.)

\section{Glycerin Agar.}

To each $\mathrm{I}, 000 \mathrm{cc}$. of ordinary agar add $50 \mathrm{cc}$. of Schering's c. p. twice-distilled glycerin.

\section{Standard Nutrient Gelatin.}

To $\mathrm{I}, 000 \mathrm{cc}$. of sterile standard peptonized beef-bouillon add 100 grams of best quality gelatin. Soak 2 hours at room-temperature. Then steam 5 minutes, cool, titrate, add the necessary alkali, steam 30 minutes, filter through $\mathrm{S}$. \& S. paper washed with sterile boiling hot water, tube at once, and heat in the steamer on three successive days 15 minutes, Io minutes, and $5 \mathrm{~min}$ utes, respectively, at $100^{\circ} \mathrm{C}$. Do not autoclave, and carefully avoid long heatings in the steamer. Have all the glassware sterile and the fluids sterile and sufficiently boiled to begin with. Very acid gelatin should be avoided. The very best English, French, and German gelatins should be used. + Io or + 15 is a good degree of alkalinity for many purposes. Zero of Fuller's scale is also useful. See remarks on gelatin (p. 3o).

\begin{tabular}{|c|c|}
\hline (See p. 48. ) & Blood Serum. \\
\hline (See p. 4I.) & Plant Juices. \\
\hline
\end{tabular}

(See page 39.)

(See p. 46.)

\section{Litmus Milk.}

Litmus milk is prepared from fresh milk which has been passed through a separator (centrifuge), or from milk which has stood 18 or 20 hours at $20^{\circ} \mathrm{C}$. and has had the cream removed by skimming and filtration. To each $100 \mathrm{cc}$. of this milk is added $2 \mathrm{cc}$. of a saturated solution of high-grade, lime-free, blue litmus (litmus I gram, water $15 \mathrm{cc}$ ). This gives a lavender color of just the right degrec, which reddens distinctly under the action of acids, and blues with the development of alkalies. The milk selected should not titrate more than + I6 with phenolphthalein and caustic soda. A good quality often gives + to to +14 . High readings denote the excessive multiplication of lactic acid bacteria. Such milks frequently coagulate on steaming, and are not suitable for culture-media. After adding the litmus water the milk should be pipetted in $10 \mathrm{cc}$. portions into cotton-plugged test-tubes and heated in streaming steam ( $100^{\circ}$ C.) for 15 minutes on each of 4 successive days.

This is a very useful culture medium. Every organism should be tested in it. All milk used for culture media slould be centrifuged, if possible, immediately after milking, and secured at once for the laboratory. Three stcamings are then sufficient. Milk offered for sale in cities is frequently more than 48 hours old and often contains from $3,000,0000$ to $6,000,000$ bacteria per cubic centimeter. Such milk is not fit for laboratory use.

\section{Nutrient Starch Jelly.}

The writer makes this as follows: To Io $\mathrm{cc}$. portions of modified Uschinsky's solution, or of the ordinary solution (glycerin omitted or not, as desired), is added I gram of clean aseptic potato starch. This. is rubbed up in the slanted fluid. The test-tubes are then very tightly plugged to avoid loss of water and placed carefully in a blood-scrum oven or in the top of an Arnold stcam sterilizer with the vents open, where they are heated for 2 hours on each of 5 successive days at $85^{\circ} \mathrm{C}$, to $93^{\circ} \mathrm{C}$. If water is lost during the heating it must be made up, using a sterile pipette. Potato starch is prepared in the laboratory (p. 50) with care in the washing and drying, so as to avoid retention of other substances than starch and the multiplication of resistant (spore-bearing) bacteria, which interfere with the sterilization. (See Proc. Am. Asso. Adv. Sci., I8g8, Vol. XLVII, p. 4II.) 


\section{Sinthetic Culture Media.}

Pasteut's Culture Fluid.

Ammonium tartrate........... Io

Ashes of yeast.............. Io

Rock candy................ I00

Distilled water.............. I,000

Dissolve cold.

Naegeli's Nutrient Solution.

Calcium chloride............ o.I

Magnesium sulphate......... .2

Dipotassium phosphate......... I.0

Ammonium tartrate.......... 10.0

Distilled water.............. I,, 000.0

Cohn's Nutrient Solution.

Distilled water............. $1,000.0$

Acid potassium phosphate.... 5.0

Magnesium sulphate......... 5.0

Neutral ammonium tartrate.... I0.0

Potassium chloride.......... 0.5

(De Bary, p. 86, Vorles. ï. Bact., 2 Auflage.) Raulin's Culture-Fluid.

Distilled water........... $1,500.00$

Granulated cane sugar....... 70.00

Tartaric acid............. 4.00

Ammonium nitrate......... $\quad 4.00$

Ammonium phosphate........ $\quad .60$

Potassium carbonate......... .6

Magnesium carbonate........ $\quad .40$

Ammonium sulphate........ $\quad .25$

Zinc sulphate.............. .07

Ferrous sulphate.......... .0. .07

Potassium silicate........... .07

Prazmowski's Culture-Fluid.

Dipotassium phosphate........ 5.0

Magnesium sulphate......... 5.0

Ammonium carbonate........ 5.0

Calcium chloride........... $\quad .5$

Distilled water.............. I,000.0

Dissolve cold. Any desired sugar may be added for the carbon food.

\section{Adolf Mayer's Culture-Fluid.}

(Unters. ii. d. alc. Gähr., I87o.)

Magnesium sulphate.......... 10.0

Ammonium nitrate.......... I5.0

Tri-basic calcium phosphate.... .I

Potassium phosphate......... I0.0

Distilled water............. r,000.0

Dissolve cold and add sugar. Add sodium chloride ( 3 per cent) if it is to be used for luminous bacteria, and an excess of pure carbonate of lime if acid-forming bacteria are to be grown.
Uschinsky's Solution.

Distilled water.............. I,000

Glycerin ................ 30 to 40

Sodium chloride............ 5 to 7

Calcium chloride............... o. I

Magnesium sulphate......... 0.3 to 0.4

Dipotassium phosphate....... 2 to 2.5

Ammonium lactate...........6 6 to 7

Sodium asparaginate......... 3 to 4

\section{Modified Uschinsky's Solution.}

The modified Uschinsky recommended by the writer for use with starch jelly is made as follows:

Distilled water........... r,000.000

Ammonium lactate......... $\quad 5.000$

Sodium asparaginate....... 2.500

Sodium sulphate.......... 2.500

Sodium chloride.......... 2.500

Dipotassium phosphate..... $\quad 2.500$

Calcium chloride.......... .oro

Magnesium sulphate........ .010

Fraenkel and Voges' Solution.

(Hygienische Rundschau, Bd. IV, I894, p. 769.)

Water ................... 1,000

Sodium chloride............. 5

Dipotassium phosphate* ....... 2

Ammonium lactate............ 6

Sodium asparaginate.......... 4

This paper also discusses Uschinsky's solution.

Fermi's Culture-Fluid.

Distilled water............. I,000.0

Magnesium sulphate.......... .2

Acid potassium phosphate......

Ammonium phosphate........ 10.0

Glycerin ................. 45.0

This may be added to agar in place of peptonized beef-broth (De Schweinitz) or to silicate jelly, in which case the volume of water must be reduced (see Silicate Jelly, p. 36).

Moore's 'Culture-Medium for Leguminous Roottubercle Bacilli.

(For ficld use.)

The dried culture (on cotton) is thrown into clean water containing: Cane-sugar, I; c. p. monopotassium phosphate, o.I ; c. p. magnesium sulphate, o.or per cent. After 24 hours add Merck's pure dibasic ammonium phosphate to amount of 0.5 per cent. Seeds are drenched with this fuid at end of another day, dried in sliade, and planted. 


\section{Maassen's Culture-Filuid.}

Malic acid................. 7

Distilled water................ 100

Neutralize to litmus exactly with 7 per cent potassium hydrate. Make up to $\mathrm{I}, 000 \mathrm{cc}$. with distilled water and add:

Asparagin ................. I0.0

Secondary sodium phosphate.... 5.0

Magnesium sulphate.......... 2.5

Sodium hydrate.............. 2.5

When dissolved add 0.01 gram of calcium chloride.

To this may then be added grape-sugar or any other carbon food desired.

\section{Proskaner and Beck's Culture-Fluid.}

Distilled water............ I,000.00

Commercial ammonium car-

bonate ............... 3.50

Primary potassium phosphate.. $\quad$ I.50

Magnesium sulphate......... 2.50

Glycerin ............... $\quad 15.00$

\section{Mackensie's Culture-Fluid.}

Acid ammonium tartrate....... I.5.

Bipotassium phosphate........ 2.5

Potassium sulphate........... 1.5

Sodium chloride............ $\quad .5$

Glucose ................ 5.0

Lactose ................ 5.0

Glycerin ................ I5.0

Water .................. I, 000.0

This is rendered alkalin to phenolphthalein with normal soda solution.

Culture-Medium for Luminous Bacteria.

(Molisch., l. c. p. 87.)

Water ................. 1,000.000

Gelatin ................. I00.000

Sugar ................. 20.000

Peptone ................ 10.000

Dipotassium phosphate...... .250

Magnesium sulphate....... .250

Enough sodium hydroxid to render the medium feebly alkalin. On this substratum the bacteria grow feebly and are not luminous until sodium chloride or some equivalent substance is added (usually 3 per cent). Then they grow well and become luminous.

\section{Winogradsky-Sleskin Silicate Jelly.}

Ammonium sulphate.......... 0.40

Magnesium sulphate......... .05

Potassium phosphate.......... . .

Sodium carbonate.......... $0.60-.90$

Calcium chloride............. Trace

Silicate jelly.............. I00.00

The salts are dissolved separately in the least possible water, and added to the dialyzed acid.

(For further observations on silicate jelly see p. 36.)

Nitrogen-free M cdium for Bacteria.

Triple-distilled water........ I,000.000

Cane-sugar .............. $\quad 5.000$

Monopotassium phosphate... $\quad 2.000$

Magnesium sulphate........ . . 100

Sodium chloride.......... $\quad .500$

All chemically pure, in scrupulously clean flasks. The water should be freshly distilled, kept in glass-stoppered bottles, and tested frequently with Nessler's solution for presence of ammonia.

Giltay \& Aberson's Culture-Mcdium for Denitrifying Organisms.

Distilled water.............. I,000.0

Potassium nitrate........... 2.0

Asparagin ................ I.o

Magnesium sulphate......... 2.0

Citric acid.............. $\quad 5.0$

Monopotassium pliosphate..... 2.0

Calcium chloride............ .2

Ferric chloride........... 2 gtts,

The acid should be nentralized by the addition of potassium hydrate.

This medium is a modification of that of Gayon and Dupetit, less nitrate being used and the neutralization being made with potash instead of ammonia. In preparing this fluid the asparagin and the nitrate of potash are dissolved in $250 \mathrm{cc}$. of water; the other substances are dissolved in $500 \mathrm{cc}$. of water, and after the citric acid has been neutralized the two fluids are mixed, cooled to $15^{\circ} \mathrm{C}$., and sufficient water added to make I liter. When the nitrate of potash and the asparagin are dissolved along with the other salts a decomposition occurs, and the liquid is browned from the presence of nitrous acid, which should be avoided. Some carbonate of lime is also added to the culture fluid. Instead of asparagin, 2 grams of dextrose 
may be added. If the latter is used the fluid must not contain the least excess of potassa; otherwise when it is sterilized there will be more or less humification. (Recherches sur un mode de dénitrification, etc. Archives néerlandaises des Sci. Ex. et Nat., Tome XXV, I892, pp. 34136r.)

\section{Winogradsky's Culture-Medium for Nitrogen- Assimilating Soil-Bacteria.}

Twice-distilled water........ 1,000.00

Potassium phosphate........ 1.00

Magnesium sulphate......... 0.50

Sodium chloride.......... or to 0.02

Iron sulphate............ . or to .02

Manganese sulphate...... . Or to .02

Dextrose ............ 20 to 40

To this should be added a small quantity of pure calcium carbonate, 30 or 40 grams per liter is sufficient. The carbonate is freshly washed in boiling water and added in paste or dried rapidly and preserved in flasks with groundglass stoppers. It is recommended that the second distillation of the water be made with carbonate of soda and that pure salts be obtained by repeated crystallizations. It is probable that inonopotassium phosphate is meant by phosphat de patasse. (Recherches sur l'assimilation de l'azote libre de l'atmosphère par les microbes, Archives des Science Biologiques, Tome III, p. 304, St. Pétersburg, 1895.)

\section{Beycrinck's Agar for Cultivation of the Nitrite Bacteria.}

Ordinary agar is added to distilled water, heated until it passes into solution, and poured into Erlenmeyer's flasks, where it is left to solidify. When cold the flasks are filled with distilled water (not neccssarily sterile) and set away. After scveral changes of water and the lapse of one or two weeks the soluble organic substances will have been absorbed out of the agar, and to it may now be added the inorganic llutrient substances desired, after which it is sterilized. Along with the nutrient substances some pure precipitated calcium carbonate should be added. The sterile agar may then be solidified in Petri dishes, test-tubes, etc. Beyerinck considers this medium better for isolation of the nitrite ferment than the silicate jelly. Hydrogen ammonium sodium phosphate $\left(\mathrm{NH}_{4} \mathrm{Na}-\right.$ $\mathrm{HPO}_{4}+{ }_{4} \mathrm{H}_{2} \mathrm{O}$ ) is recommended as the best one of the ammonium salts for addition to the agar, bccause, upon cooking, the agar is not attacked, and consequently additional soluble substances are not liberated from it. (Beyerinck: Kulturversuche mit Amöber auf festem Substrate. Centralb. f. Bakt., I Abt., Bd. XIX, I8g6, pp. 257-267.)

\section{Winogradsky's Nutrient Agar for Isolation of Nitrate Bacteria.}

Tap-water ................ 1,000

Agar (thoroughly washed)...... 15

Di-potassium phosphate......... 0.05

Fused sodium carbonate......... I

Sodium nitrite (Merck)......... 2

(Centralb. f. Bakt., 2 Abt., Bd. V, I899, pp. 537-549.)

Winogradsky \& Onélianski's Fluid CultureMedium for Isalating the Nitrate Bacteria fram Soils.

Distilled water.............. I,000.0

Magnesium sulphate.......... .3

Ferrous sulphate........... 4

Sodium chloride............ .5

Di-potassium phosphate....... $\quad .5$

Fused sodium carbonate....... I. I.

Sodium nitrite (Merck)....... I.o

Transfers through a series of flasks are necessary in order to isolate the organism. (Centralb. f. Bakt., 2 A bt., Bd. V, I899, pp. 537-549.)

Winogradsky \& Omélianski's Fluid CultureMedium for Isolating the Nitrite Bacteria fram Soils.

Distilled water............. I,000.0

Ferrous sulphate............. 4

Magnesium sulphate......... $\quad .5$

Di-potassium phosphate....... I.O

Sodium chloride.......... 2.0

Ammonium sulphate......... $\quad 2.0$

The cultures are made in broad-bottomed flasks in 50 cubic centimeters of the fluid, to each of which about $1 / 2$ gram of magncsium carbonate is added. It is necessary to transfer through a serses of flasks in order to obtain pure cultures. If the organism does not grow well on the start, additional ammonium sulplate may be added, viz, I cubic centimeter of a 10 per cent solution to each flask. (Centralb. f. Bakt., 2 Abt., Bd. V., 1899, pp. 537-549.)

Dubois' Fluid Mediun for Luminous Bacteria.

(See '93 Dubois, Bibliog., XXVII.)

Kuntze's Medium for Bacillus Prodigiosus.

(See 'oo Kuntze, Bibliog., XXIII.) 
Omélianski's Magnesia-Gypsum Blocks for the Cultivation of Nitrifying Organisms.

One per cent carbonate of magnesia is uniformly mixed with gypsum and water added to it, stirring until it becomes of the consistency of sour cream, when it is poured upon plateglass and spread out. As soon as the mass becomes of a doughy consistency and is ready to harden, it is cut into circular blocks for Petri dishes and into strips for test-tubes. The circular pieces may be cut with a Petri dish of a size a little smaller than the dishes it is intended to use. As soon as the gypsum has hardened thoroughly the blocks are pried loose from the plate glass, placed bottom up in the dishes (so as to give a smooth surface), and enough of the above (nitrite) culture-medium added to half cover the block. This is then autoclaved and additional stcrile culture-media added from time to time as necessary, being careful not to wet the inoculated surface of the block. The sowings are made on the smooth surface of the block and the dishes are kept in a thermostat at $25^{\circ}$ to $30^{\circ} \mathrm{C}$. Colonies begin to be visible in 4 to 5 days. In 10 to 14 days many colonies are 0.25 to 0.50 millimeter in diameter. (Centralb. f. Bakt., 2 Abt., Bd. V, 1899, p. 652.)

\section{MISCELLANEOUS.}

\section{Distilled Water.}

\section{(See page 124.)}

\section{Chromic Acid Clcaning Mixture.}

This is made by pouring I gallon or more of concentrated crude sulphuric acid into an equal volume of a saturated aqueous solution of potassium bichromate. It should be done in a large enameled iron kettle, the acid being added slowly at intervals, with frequent stirring, so as to keep the mixture below the boiling point. An excess of the sulphuric acid should be avoided. Pure water should be used for dissolving the potassium bichromate, and under no circumstances should this solution be poured into the acid, since steam might be gencrated and dangerous splutterings occur. The resulting chromic acid is very injurious to the skin and should be used with care. At $15^{\circ} \mathrm{C}$. each Io parts by weight of water will dissolve about I part of the potassium salt. The chromic acid mixture is said to explode violently when brought into contact with certain substances, e. g., alcohol, glycerin.

\section{Fluid for Softening Hard Tissues.}

Frequently grains of cereals and other hard tissues may be softened for cutting on the microtome with slant stroke by soaking from 3 to 6 months in equal parts of alcohol and glycerin.

$$
\text { Unguentum resinae. }
$$

(See Bibliog., XVII, 'oo, Bulloch.)

Darwin's Wax-Mixture.

This consists of vaseline 50 parts, beeswax 35 parts, meited together. Then stir in of powdered resin 15 parts. If a stiffer mixture is de- sired, add more wax up to 50 parts (see Darwin \& Acton, Plant Physiology, p. 3, foot note).

Pencils for Writing on Glass.

(See page III.)

$$
\text { Pyrogallol Developer. }
$$

(Much used in Laboratory of Plant Pathology.)

(I) Alkali :

Carbonate of potash

(cryst.)*........ I I $1 / 2$ ounces, or 46.5 grams

Carbonate of soda

(cryst.)*........ 2 ounces, or 62 grams Distilled water..... I2 $1 / 2$ ounces, or $375 \mathrm{cc}$.

(2) Pyro:

Sulphite of soda

(cryst.)*...... 4 ounces, or 124 grams Citric acid.......6.60 grains, ur 3.9 grams Bromide of potash.. 40 grains, or 2.6 grams Distilled water..... I2 $\frac{1}{2} 2$ ounces, or 375 cc. Pyrogallic acid..... I ounce, or 31 grams

The pyrogallol should be addec last of all, and the nearly filled bottle closed at once.

For a normal developer take 2 drams of No. I, add 2 drams of No. 2 , and make up to 4 ounces with distilled water. Reduce the amount of alkali to one-fourth dram or less in case of much overexposed plates. In case of cxposures likely to exhibit too great contrasts reduce the pyro. Always begin development with one-fourth of the alkali, unless the exposure is known to be correct. Both solutions should be kept in glassstoppered bottles.

Bottles containing alkali should have the inside of the neck and the ground surface of the stopper wiped dry before replacing; then the latter will not stick.

*In case anlyydrous salts are employed, use one.half as much. 
Ortol Developer.

(See pp. I40-I4I.)

Pyro Developer for Dry Plates.

(Recommended by S. G. Lofft.)

(I) Water ......... Io oz., or $300 \mathrm{cc}$.

Citric acid...... Io grains, or 6.46 grams

Pyrogallic acid... I oz., or 3I grams

(2) Sodium sulphite

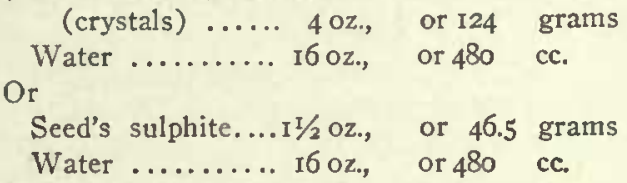

(3) Sodium carbonate

(crystals) ..... 4 oz., or I24 grams Or

Water ......... $16 \mathrm{oz}$, or 480 cc.

Seed's carbonate.. 2 oz., or 62 grams

Water ......... 16 oz., or $480 \mathrm{cc}$.

To develop take-

Water ........... 40z., or 120 cc.

No. I ........... 2 drams, or $7.5 \mathrm{cc}$.

No. $2 \ldots \ldots \ldots \ldots \ldots$. $1 / 2$ oz., or $\mathrm{I}_{5} \mathrm{cc}$.

No. $3 \ldots \ldots \ldots \ldots \ldots .1 / 20 z$, or $\mathrm{I}_{5} \mathrm{cc}$.

For underexposures dilute and change frequently to fresh developer.

For overexposures use old developer or restrain with a few drops of Io per cent potassium bromide.

\section{Lantern-slide Develuper.}

(Used in Laboratory of Plant Pathology.)

Distilled watcr...............cc.. 900

Carbonate of soda (cryst.) grams. . 39

Sulphite of soda (cryst.)...grams.. 39

Hydrochinon .............grams. . I3

Add the hydrochinon after solution of the soda salts, and put at once into a glass-stoppered bottle. For use take 3 ounces of above and 3 ounces of distilled watcr, to which add 5 drops of a ro per cent solution of bromide of potassium. If properly cxposed the image should appear in 30 to 60 seconds, and the development should be over in 3 or 4 minutes. Good for a dozen or more properly exposed slides.

\section{Zettnow's Copper-chrom-filter.}

Dry, pure, copper nitrate......... I60

Purc chromic acid............. I4

Distilled water............... 250

This may be diluted further with water if desired.

In case there is difficulty in preparing the above, a solution, stated by Zettnow to be nearly as useful, consists of-
Sulphate of copper............. I75

Bichromate of potash........... I7

Water ..................... I,000

(Centralb. f. Bakt., IV Bd., I888, p. 51.)

Neuhaus says, water 500 to $I, 000$, and also 2 cubic centimeters of sulphuric acid. This solution extinguishes all the blue and violet rays.

Toning Bath for Solio Paper.

(A) Hyposulphite of soda... 8 ounces Potash alum (crystals).. 6 ounces Cane sugar ........... 2 ounces Water .............. 80 ounces

Dissolve cold, then add 2 ounces of borax which has been dissolved in $8 \mathrm{oz}$. of hot water. Let stand 12 hours, and then decant.

(B) Pure chloride of gold.. 7.5 grains Acetate of lead.......64 grains Distilled water........ 8 ounces

This solution must not be filtered and must be shaken thoroughly each time before using.

Solio paper should be printed about one-third darker than it is desired to have the pictures. When the prints are ready they are placed facc down in a toning mixture made of stock $\mathrm{A}, 8$ ounces, and stock B, I ounce, taking care that the entire surface of each print is uniformly wetted. They are allowed to remain in this bath, with constant movement by means of the fingers, until the desired color is obtained (usually about 5 minutes). The prints are now immersed in salt water $(1: 32)$ for 5 minutes. They are then exposed for 15 minutes to the fixing bath, consisting of-

Hyposulphite of soda..... I ounce

Sulphite of soda (crystals) 60 grains

Borax ............... $1 / 2$ ounce

Water ................ 20 ounces

The prints are finally washed for from $I$ to 2 hours in running cold water. The toning bath should not be cooler than $40^{\circ}$ or warmer than $60^{\circ} \mathrm{F}$.

\section{A New Test for Iridol.}

Herter \& Foster have recently described what is stated to be a rapid and accurate method of determining indol, adapted either for colorimetric or gravimetric determinations. To slightly alkaline solutions naphthoquinon sodium monosulfonate is added. A blue crystalline compound, di-indyl naphtho-ketone mono-sulfonate is produccd. This is slightly soluble in water, but is readily soluble in chloroform, its solution being red. (Science, n. s., Vol. XXI, I905, p. 987.) 


\section{FIXING FLUIDS.}

\section{Absolute Alcohol.}

Expose 24 hours or more. Very useful for fixing bacteria in tissues, as it prevents their diffusion. It causes, however, considerable shrinkage of the tissues, and the nuclei are often difficult to stain, and are usually distorted. Bacteria fixed in this way stain well in Ziehl's carbol-fuch sin.

Picric Acid in Hot Absolute Alcohol.

(See p. 8.)

Mercuric Chloride in Hot Absolute Alcohol.

(See p. 8.)

\section{Acetic Alcohol with Mercuric Chloride.}

Absolute alcohol................ I

Glacial acetic acid............... I

Chloroform .................. I

Add mercuric chloride until saturated. Wash with alcohol or with alcohol containing tincture of iodine. One of the most rapid fixatives known.

\section{Acetic Alcohol (Carnoy's Fluid.)}

Glacial acetic acid.............. I

Absolute alcohol................ 3

Expose 24 hours or more and wash in alcohol. This solution preserves the chromatic and cyto- plasmic structures better than alcohol alone, and shrinks the tissues much less. Tissues fixed in this solution take most of the coal-tar stains better also. It has very great penetrating power, which makes it very useful in fixing large pieces of tissue.

Chromo-aceto-osmic Acid (Flemming's Fluids).

A. Stronger solution-

I per cent chromic acid......... I5

2 per cent osmic acid.......... 4

Glacial acetic acid............. I

B. Weaker solution-

I per cent chromic acid........ 25

1 per cent osmic acid............ ro

I per cent acetic acid............ Io

Water .................... 55

Expose 12 to 48 hours and wash in running water. This is probably the most valuable of all the fixing fluids for preserving exactly all the cell structures; and material fixed in it takes the coal-tar stains unusually well. It has very slight penetration, and therefore the tissues should be cut into pieces not more than 2 millimeters thick. It should be kept in glass-stoppered hottles, and should be made fresh every 6 months or less.

For additional formulæ consult the various standard text-books, especially Eyre's "Bacteriological Technique," wbere may be found, among others, the following:

Kitasato's glucose-formate-bouillon.

Iron-bouillon. Lead-bouillon.

Parietti's bouillon.

Carbolized bouillon.

Kitasato's glucose-formate-agar.

Gnarniari's agar-gelatin.

Carbolized agar.

Glycerine blood-serum.

Heiman's serum-agar.

Washbourn's blood-agar.

Urine-gelatin. Urine-agar.

Whey-agar.

Fish-gelatin.
Fish-bouillon.

Fish-agar.
Glycerinated potato.

Glycerine-potato-broth.

Elsner's potato-gelatin.

Goadby's potato-gelatin.

Beer-wort. Wort-gelatil.

Wort-agar. Wine-must.

Gasperini's wheat-broth.

Bread-paste. Milk-rice.

Pakes' iron-peptone-solution.

MacConkey's bile-salt-broth.

MacConkey's bile-salt-agar.

Sabouraud's French proof agar.

Blaxall's English proof agar. 
PLATE 24.
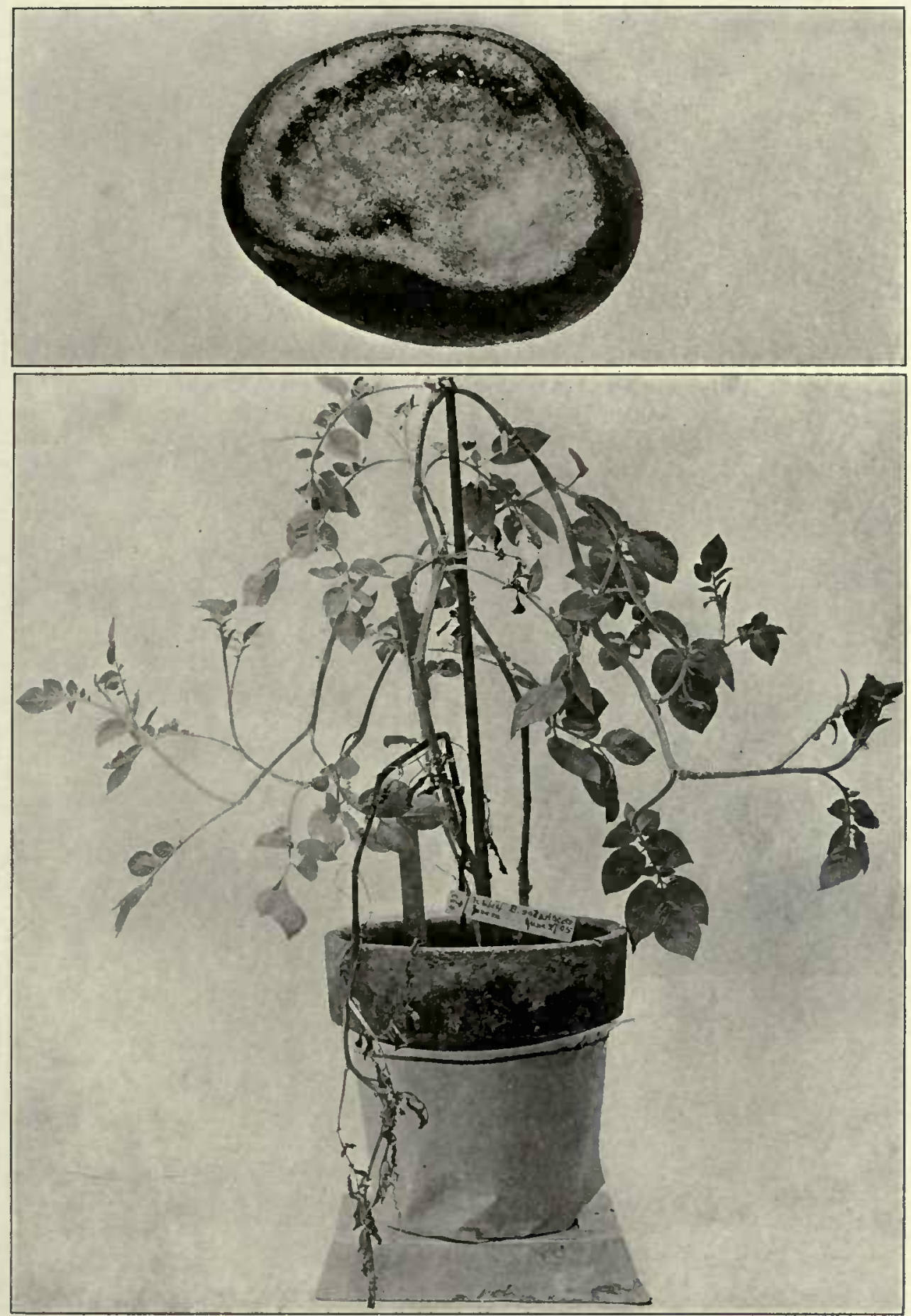

\section{Brown rot of the potato.}

Potato-tuber from Hastings, Florida, crop of 1905, sound externally, but browo-rotted in the vascular syztem, the bacteria having entered through the veswels of the underground stem. Bacterium solanacearum was plated out and subcultures were used to infect potted potatoplants. The plant ahown was inoculated on June 27, by delicate needle-pricks. Disease more advaoced on obe inoculated thoot than on the other; later this also shriveled. Tubes ostural size; pholographed May 29. Plaot about one-fifth natural size; pholographed July 15, 1905. 

PLATE 25.

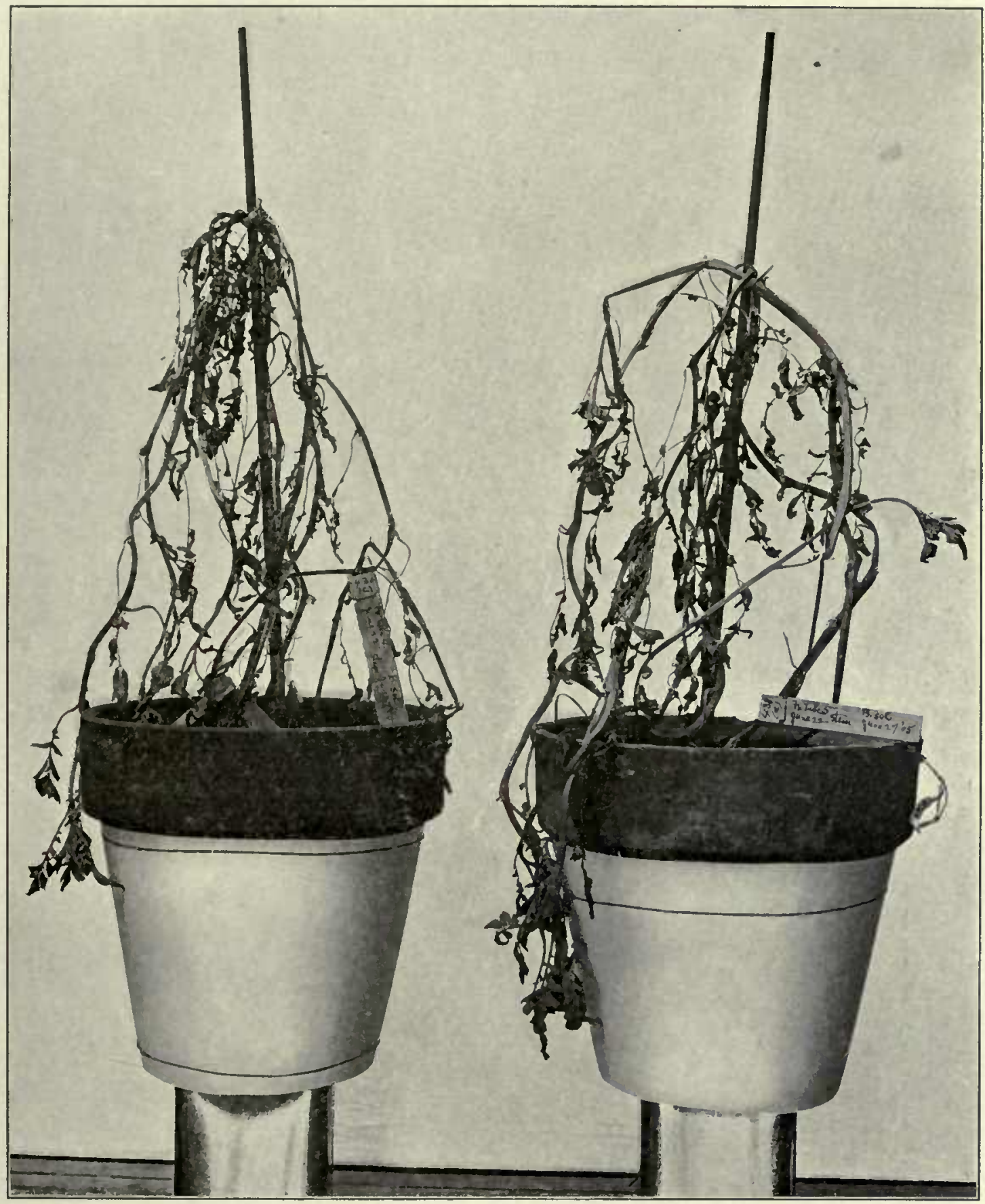

Early Rose potatoes destroyed by Bacterium solanacearum.

Plants inoculated at ume time, in same way, and from same source as plant shown in plate 24. About one-fourth natural nize. Progress of disease rather slow; no tubers were formed. All of the shoots dead or dying. Photographed August 3, 1905, i. e. at end of fifth week. 

PLATE 26.

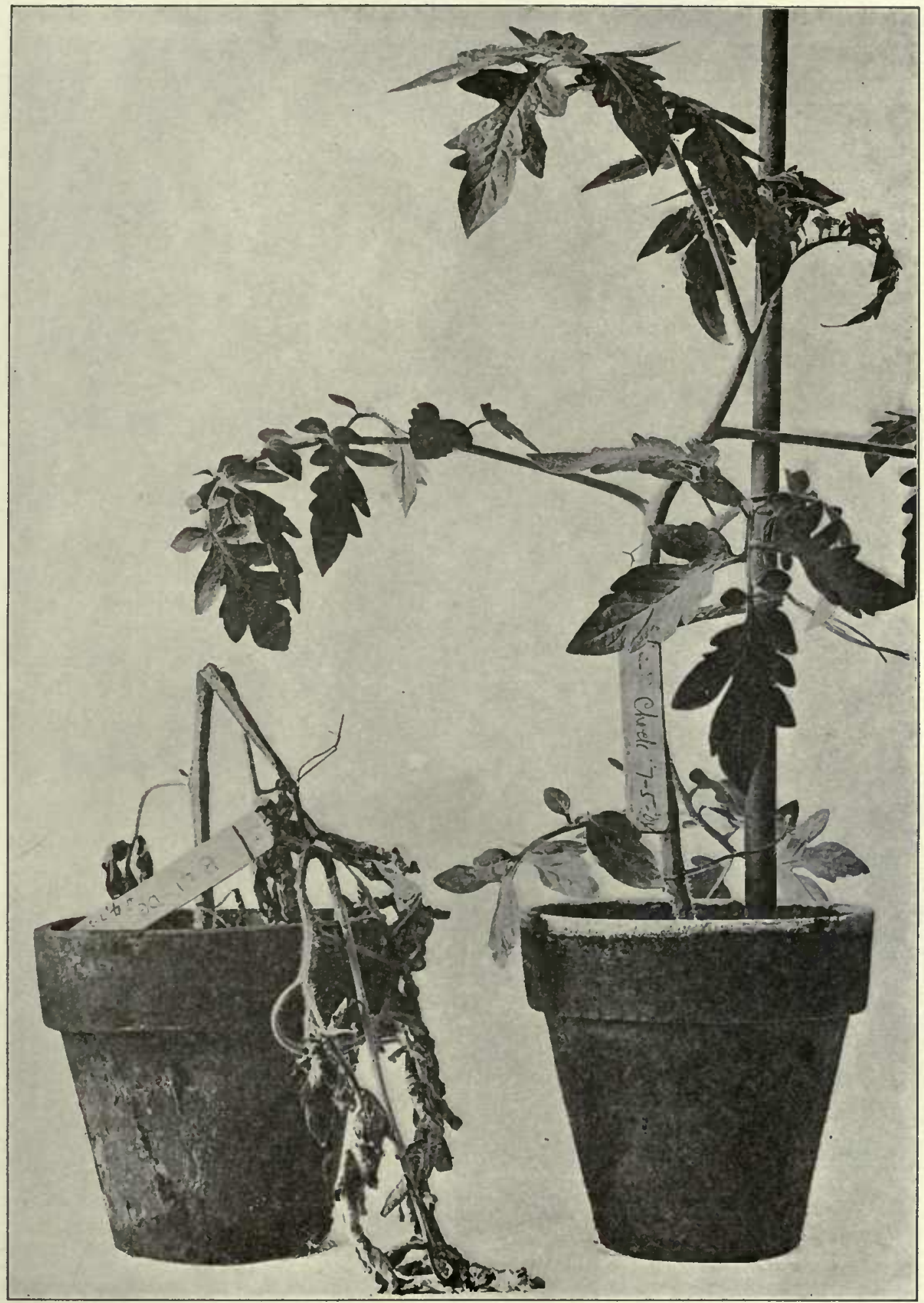

Effect of Bacterium solanacearum on a tomato-plant.

The left-hand plant was inoculated in the stem on July 5, by means of a few needle-pricks. The right-hand plant was pricked with a sterile needle. The infectious material was a subeulture from a poured-plate colony. This was obtained from the interioe of a potato-stem, naturally infected, in District of Columbia. Photosraphed July 11, 1904. About one-third natural size. 


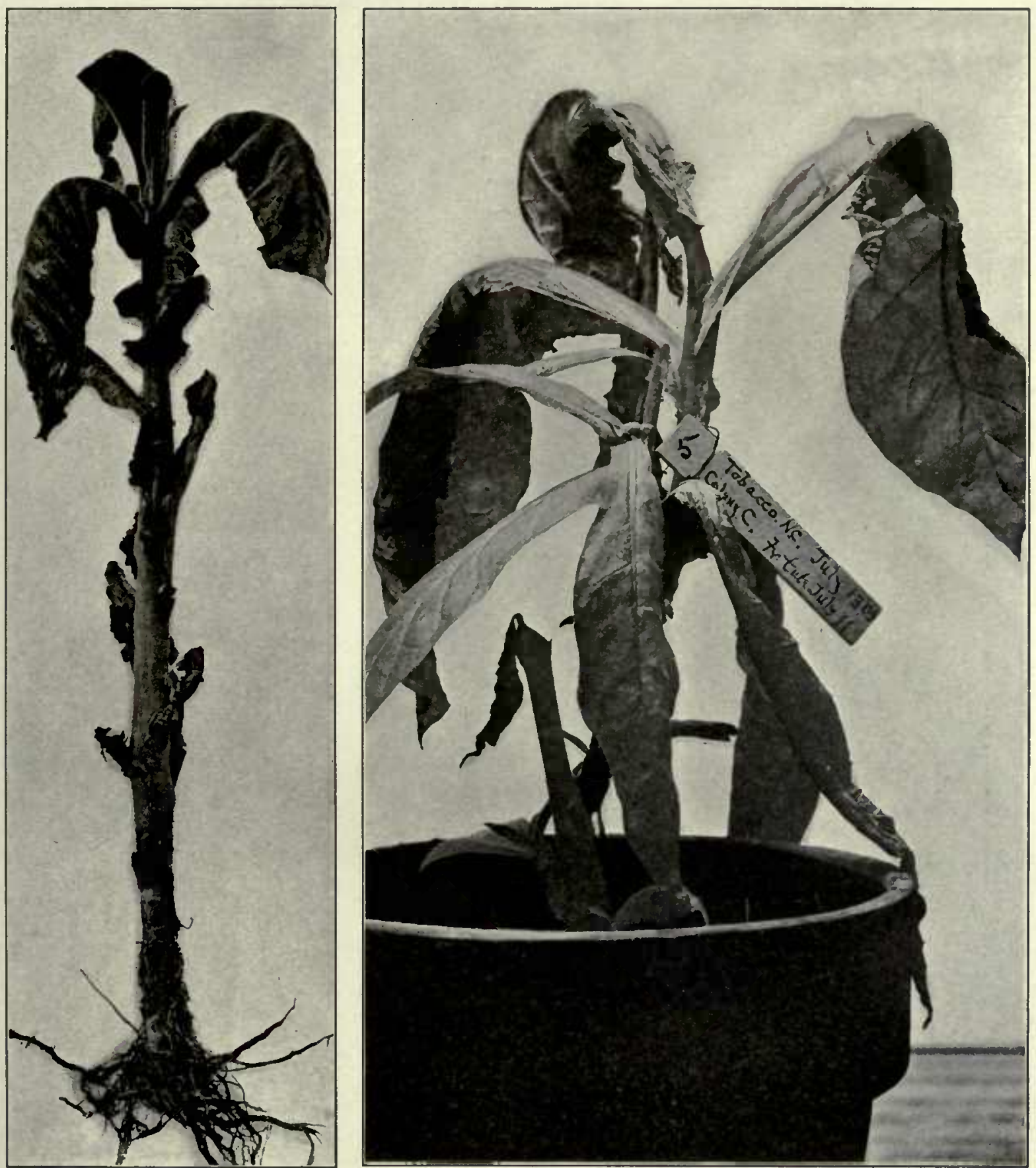

The Granville tobacco-wilt, a bacterial disease.

The left-hand plant wilted naturally in the field, was pruned, transplanted to the hothouse, recovered for a lew weeks, developed the leaves shown, and then wilted again. Photographed June 28; one-third natural size.

In this disease the vascular ring is browned and eavibies are formed in the stem. The bacterial slime is gray-white and abundant. Fungi were not present in the plants examined by me. Poured plates were made Irom the interior of several such slems, and these yielded practically pure cultures of one organism. A subculture from one of these colonies was ured to inoculate the right-hand plant. The needle-pricks were made on July 13,1905. Photogtaphed August 3; one-half natural size. Twelve plants were inoculated at this time and all contracted the disease. The rigns and lesions were the same as in the plants obtained from the field. The organism caussng this diverse is elocely related to Bact. solanacearum. 



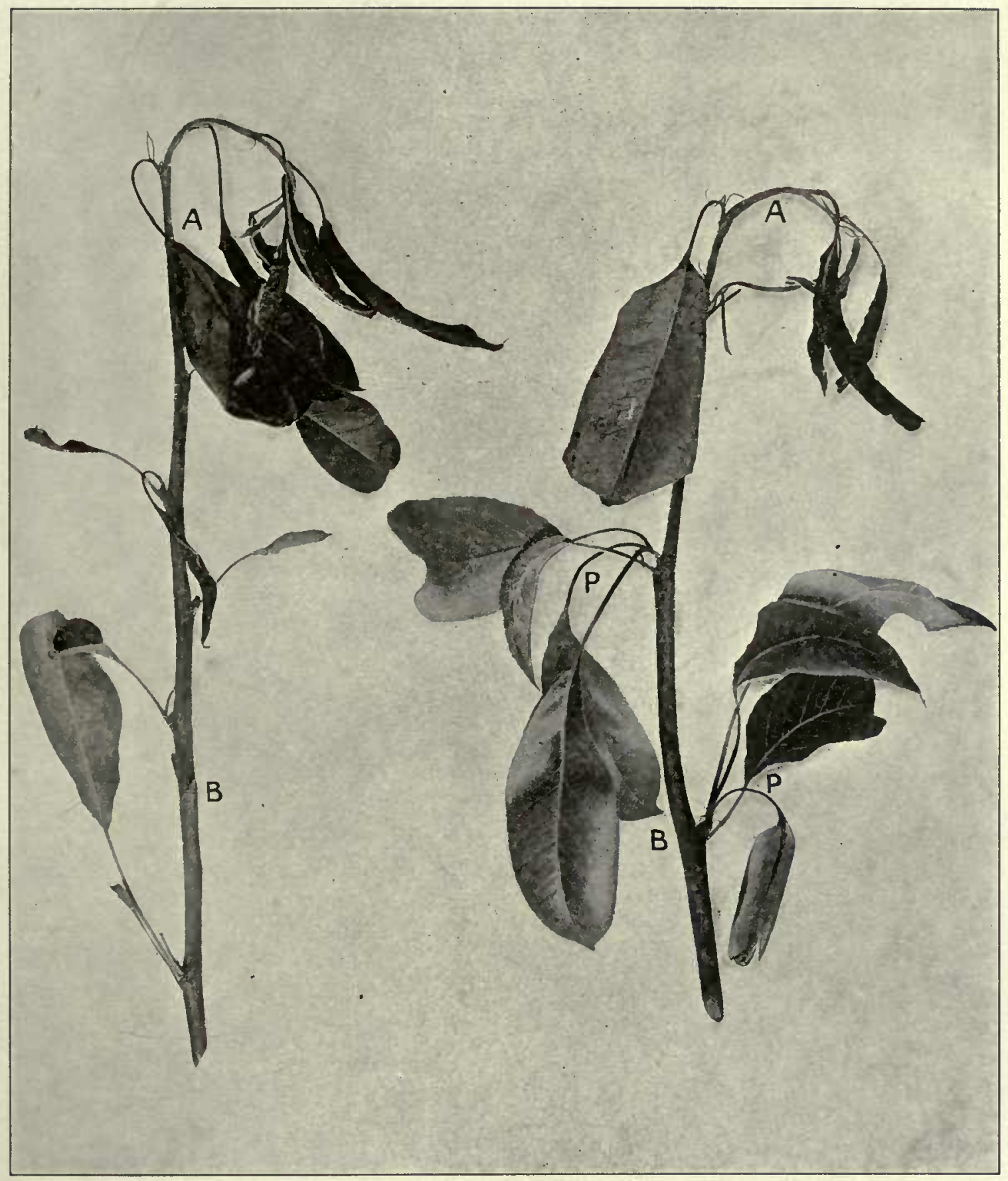

Pear-shoots blighted by Bacillus amylovorus.

Inoculations by needle-pricks on rapidly growing stems. The intectious material came from a green apple. The poured plates yielded practically pure cultures and the inoculations were made directly from colonies in these plates. Of 12 inoculations ( 8 shoots, 4 fruits) II were successful. Needle-pricks made July $10,1905$. Pholographed July 20. The lower leaves were still green; the lope ( $A$ and $A$ ) had ahriveled and browned; the bacteria had pased downward in the bark to points below $B$ and $B$, and they had also sun out into the petioles $(P$ and $P)$ and had browned them, but the blades of these leaves were still green. 

PLATE 29.

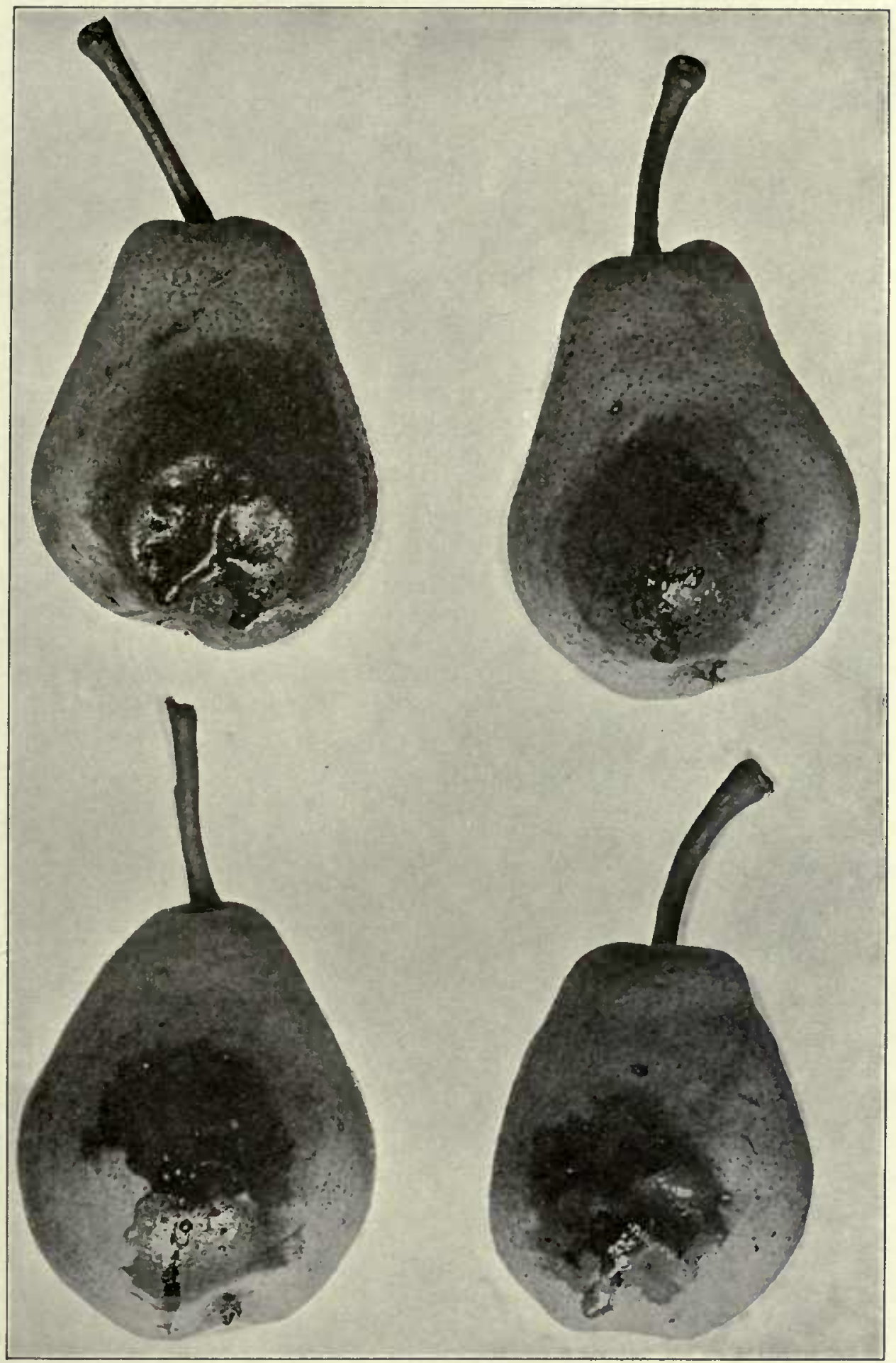

Green pears inoculated with Bacillus amylovorus.

These were inoculated from the same poured plate and at the same time as the shoots shown in plate 28, but the photographs were made two days earlier. The inoculations were by means of a few needle-punctures. The inoculated parts browned, softened, shriveled lightly, and were extruding bacterial alime from small cracks and fom many stomata. Beyood the browned aren there was a watersoaked area. The internal injury was extensive-in one fruit nearly the whole ioterior had softened and was occupied by the bacteria. These timues were filled with grayish bacterial slime to such an ecormous exteat that on handling them the fingers dripped with it. Inoculated July 10, 1905. Photographed July 18; about natural vize. Poured plates made from the interios of these fruits yielded pure cultures of $B$. amylovorus. 

PLATE 30.

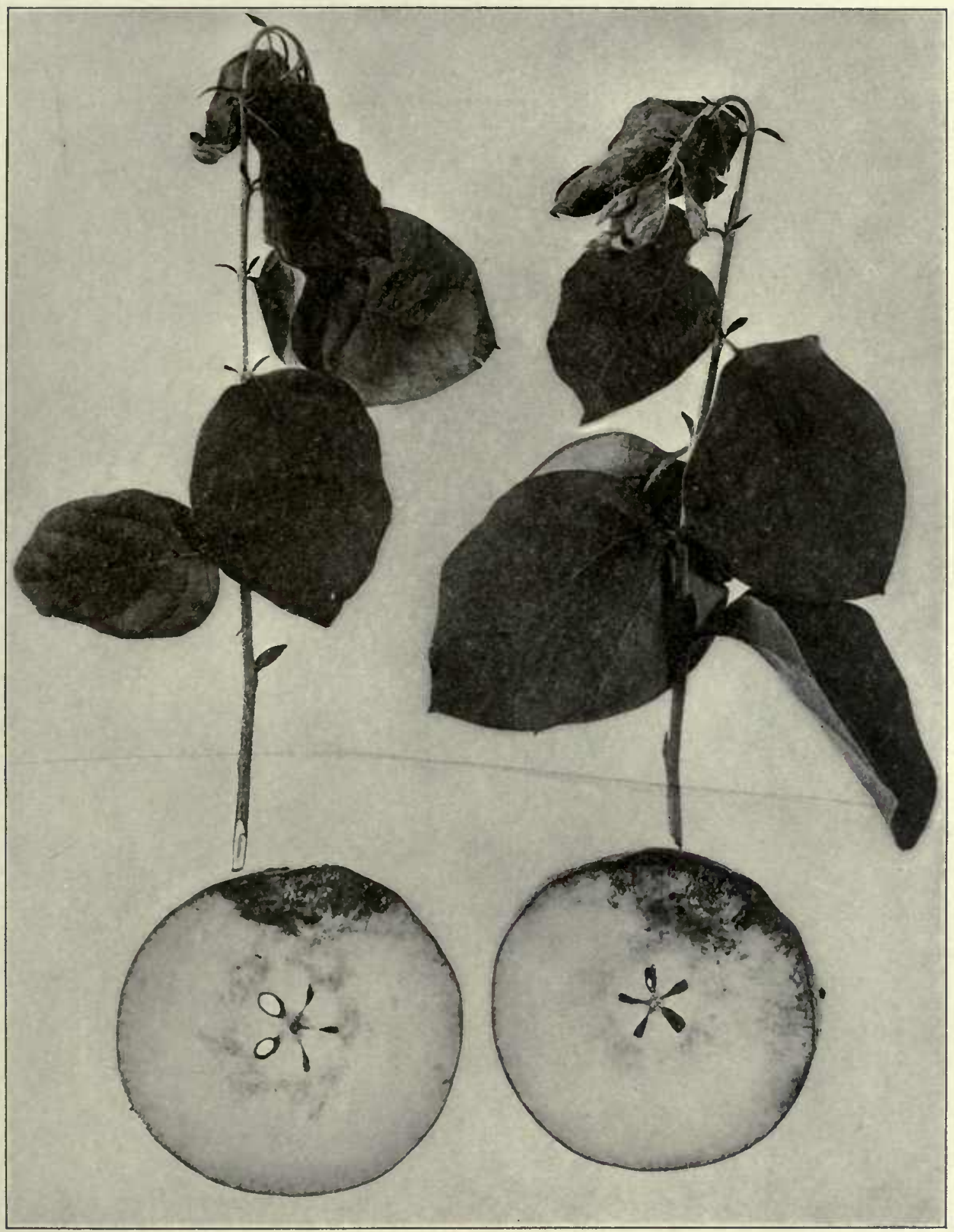

Blighted quince-shoots and pear-fruits.

Twelve inoculations were made and all were succesulu -8 quince-shoots and 4 pear-fruitu. None of the checks contracted the disease. The organisn was introduced by delicate needle-pricks. The subculture used was derived from a poured-plate colony obtained from the interior af one of the pean shown in plate 29. Owing, no doubt, to the riper and therefore less susceptible condition of the tisues, and possibly also to somewhal cooler weather, the dixintegration of the deeper timues of the fruits had not proceeded a far as in the pears inoculated on the same tree 10 days eatier; in those fruita frat inoculated the decay was from 5 ta 10 times as extensive on the 8 th day as in the second inoculations an the llih day. Inoculated July 20, 1905. Phatographed July 31. 

PLATE 31.

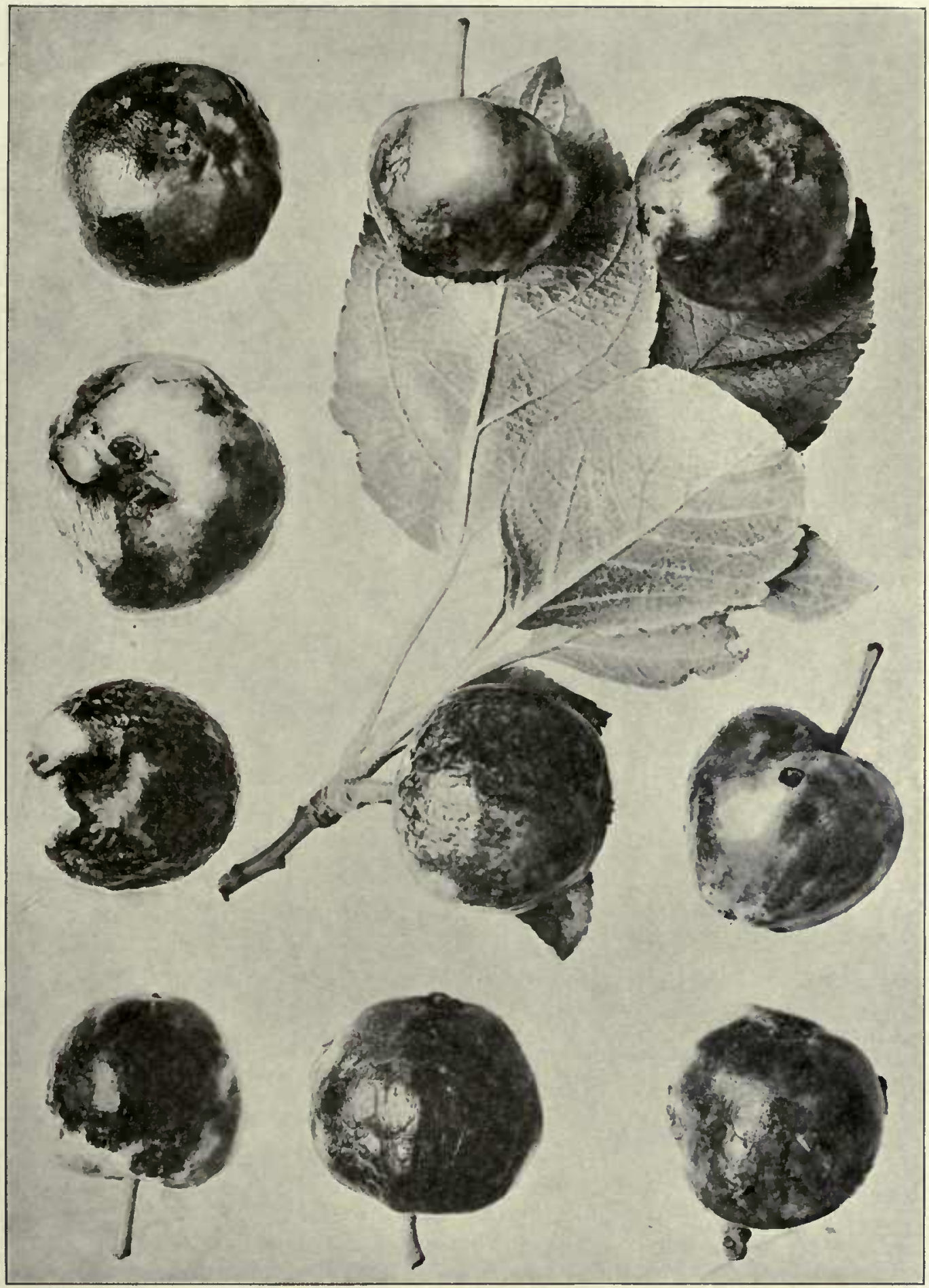

Small green apples blighted by Bacilius amylovorus.

One of these fruits furnished the bacteria used to inoculate the thoots and fruits shown in plates 28 and 29. The interior of these fruits was gorged with a gray-white bacterial alime. The surface was browned and ahriveling in many places and water-soaked in others. Bacteria were cozing from the darker parts. Every one of many fruits examined had been wounded by the curculio, and probably infection occurred in this manner. Arliogton Farm, Viuginia. Photographed June 30, 1905. 



\section{BIBLIOGRAPHY.}

\section{General Literature.}

As far as possible the references in this bibliography have been arranged chronologically so that the reader may see at a glance the historic development of the subject. In several cases logic has been sacrificed to convenience, e. g., in keeping the nitrifying and denitrifying bacteria separate from the group devoted to oxidation and reduction, the average reader, it was thought, being more likely to search for references to the nitrogen bacteria under the former than under the latter heading.

\section{Journals.}

Archiv für Hygiene. Munich and Leipsic. Verlag von R. Oldenbourg.

Beguis lu 1883. 5 I vols, to date.

Zeitschrift für wissenschaftliche Mikroskopie und für mikroskopische Technik. Braunschweig. Harald Bruhn.

Begun in 2884. 21 vols. to date.

Zeitschrift für Hygiene und Infectionskrankheiten. Leipsic. Veit und Comp.

Begun in 1886. 48 vois. to date.

Annales de l'Institut Pasteur. Paris, G. Masson et Cie. Begun in 1887. 18 vols. to date.

Centralblatt für Bakteriologie, Parasitenkunde und Infektionskrankheiten. I Abt. Medicinisch-hygienische Bakteriologie und tierische Parasitenkunde. Gustav Fischer, Jena.

Begun in 1887 under the titie, Centraib. f. Bakt., und Patgitenkunde, Title chauged and scope limited when the following pubilication was begur. 37 vols. to date.

Centralblatt für Bakteriologie, Parasitenkunde und Infektionskrankheiten. 2 Abt. Allgemeine landwirtschaftlich-technologische Bakteriologie, Gärungsphysiologie, Pflanzenpathologie und Pflanzenschutz. Gustav Fischer, Jena.

Begun in 1895. 12 rois. to date.

Annales de Micrographie, specialement consacrées à la Bactériologie, etc. Paris, Geo. Carré et C. Naud. Begun in 1888.

Zeitsclırift für Pflanzenkrankheiten. Paul Sorauer, editor. Verlag von Eugen Ulmer, Stuttgart.

Begun in 1891. Il vois, to date. Occasional articles only on bacteria.

The Journal of Pathology and Bacteriology. Edinburgh and London. Young J. Pentland. Begun in 1892. 9 vois. to date.

Journal of the American Public Health Association. The number for Octoher, 1895 , contains numerous valuable papers on bncteriology. The number for October, 1897 . contains report of a committee on the pollution of 1897, contains report of a cortes; also report of committee on disinfectants. Weport of meeting held October 3I-November 3 , 1899 . contains notes on the reaction at which the maximum tains notes on the reaction in liquid media; a paper on growth of bacterla occtrs ln fication of water bacteria, etc.
Tijdschrift over Plantenziekten. Onder redactie van Ritzema Bos en G. Staes. Gent. J. Vuylsteke.

- Begun in 1895. 7 parts have appeared. Only occasional papers on bacteria.

The Journal of Experimental Medicine. Now York, D. Appleton \& Co. Beguu in 1896 . Edited hy Wm. H. Weich, of Johna
Hopkins University. 6 vols. to date. Contains many papers of interest to persons who are not physiclans. Recently trausferted to the Rockefeller Institute under editorship of Simon Flexner.

Archives de Parasitologie. Paris, Geo. Carré et C. Naud.

Begun in 1898.8 vols, to date. Published sluce vol. 4 by Société d'editions scientifiques.

Joturnal of Applied Microscopy. Rochester, N. Y., Bausch and Lomb.

Begun in 1898 . 6 rols. Discontinued.

Archives des Sciences Biologiques. Publiées par l'Institut impérial de médecine expérimentale à St. Pétersbourg.

Valuahle. Begun in 1892 . Io volumes todate.

The Botanical Gazette. University of Chicago Press. Begun privately in 1875.38 vols, to date. Papers on bacteria only in secent volumes.

Journal of Hygiene, Cambridge, England. Edited by Nuttall.

Begun in 19o1. Published quarteriy by Camhridge Universlty Press, Warehouse Ave., Maria Lane, London, E. C. 4 vois. to date.

Journal of Medical Research. Edited by Harold C. Errnst, Boston, Mass.

7 vols. to date. This is a continuation of the Journal of the Boston Society of Medical Sciences.

Zeitschrift für Physikalische Ohemie, Stöchiometrie und Verwandtschaftslehre. Herausgegeben von Wilh. Ostwald und J. H. Van't Hoff, Leipzig. Verlag von Wilhelm Engelmann.

Ahout 45 vois. to date.

The Journal of Infectious Diseases. Founded by the Memorial Institute for Infectious diseases, Chicago.

Begun in Igo4. 
Bulletin de l'Institut Pasteur. Revues et analyses des travaux de microbiologie, médicine, biologie générale, physiologie, chimie biologique dans leurs rapports avec la bactériologic. Comité de redaction: G. Bertrand, A. Besredka, A. Borrel, C. Delezenne, A. Marie, F. Mesnil, de l'Institut Pasteur de Paris.

Begun in 1903.

II. Transactions, Beiträge, Jahresberichten, Festschriften, Etc.

('70-'92). Beiträge zur Biologie der Pflanzen. Edited by Ferdinand Cohn. Is Heften. (5 vols.) Breslau, I870-1892.

('86). Jahresbericht über die Fortschritte in der Lehre von den Pathogenen Mikroorganismen umfassend Bakterien, Pilze und Protozoën. Von P. Baumgarten. Braunschweig, Harald Bruhn, and more recently Leipzig, S. Hirzel.

Begun in 1886. First volume covers the year 1885. The last volume (18 Jahrgang) brings the literature references down to the close of 1902. Contains nothing ou piaut parasites, and the title is therefore misleading.

('86). Arbeiten aus dem Kaiserlichen Gesundheitsamte. Berlin, Verlag von Julius Springer.

Extremely valuable on account of the high quality of the papers, which deal mostly with animal diseases. The first two volumes were published as Mitteilungen, etc. Begun in 1886.

('92-'95). Beiträge zur Physiologie und Morphologie niederer Organismen. W. Zopf. 5 Heften. Leipsic, Arthur Felix, I892-I895.

('93). The Wilder Quarter-Century Book. Ithaca, N. Y., Comstock Pub. Co., 1893

contains several valuable papers.

Publications of the Division of Vegetable Physiology and Pathology, Bureau of Plant Industry, U. S. Department of Agriculture, Washington, D. C.

Frequently when editions are exhausted, copies may be procured at actual cost of printing by addressing the Bureau of Documents, Union Butlaing, Washington, D. C. The publications of the Department of Agriculgratis on application to the Secretary of Agriculture.

('94). KLEIN, L., und Migula, W. Arbeiten aus dem bacteriologischen Institut der technischen Hochschule zu Karlsruhe. Bd. I, II, III, Wiesbaden, O. Nemnich, I894-I903.

('o3). Contributions to medical research dedicated to Victor Clarence Vaughan by colleagues and former students of the department of medicine and surgery of the University of Michigan on the twenty-fifth anniversary of his doctorate. Ann Arbor, George Wahr, I903, pp. vI, 620 , with numerous plates and figures.

\section{Manuals.}

('80). Winter, Georg. Bacteria. In Die Pilze of Rabenhorst's Kryptogamenflora Deutschlands. I Abt., I884.

The volume was pubilshed in parts, the one on bacletia coming out at an earlydate (1880). Transi. by T. J. Burril as part of a paper entitled "The Bacteria," Springfield, I11., 1882. 11 tb Rep. I11. State Iudustrial Univ.

('83). Duclaux, E. Chimie biologique-Microbiologie. Paris, 1883, pp. vII, 908. This forms Tome Ix, first section, of Fremy's Encyclopédie Chimique.
('84). DE BARY, Anton. Vergleichende Morphologie und Biologie der Pilze Mycetozoen und Bacterien. Leipzig, Engelmann, I884, pp. XVI, 558. English translation by Garusey revised by Balfour in
1887 under title of " Comparative morphology a nd biology of the fungi mycetozoa and bacteria." Oxford, Clarendon Press.

('85). DÉ Bary, ANTon. Vorlesungen über Bacterien. Leipzig, Engelmann, I885, pp. vr, I46. There is an English trauslatiou by Garusey, revised by Batfour, oxford, 1887. The second German edition was published in 1887, Pp. VI, 158,20 figs. A third edition revised by Miqula, cortaining 186 pages and 41 figures, appeared in 1900 .

('86?). Schroeter, J. Schizomycetes. In Die Pilze Schlesiens, pp. I36-174. Breslau, J. U. Kern's Verlag.

The volume as a whole bears date of 1889 .

('87). LOFFFLER, FRIIDRICH. Vorlesungen über die geschichtliche Entwickelung der Lehre von den Bacterien. Erster Theil bis zum Jahre, I878, pp. XII, 252, with 3 plates and 37 text figures. Leipsic, F. C. W. Vogel, 1887.

('go). Baumgarten, P. Lehrbuch der pathologischen Mykologie, pp. IX, 973, 24. Braunschweig, Harald Bruhn, I89o.

('9o). Cornil, A. V., ET BabEs, V. Les bactéries et leur rôle dans l'étiologie, I'anatomie et l'histologie pathologique des maladies infectieuses. $3 \mathrm{~d}$ ed. 2 vols. Tome I, pp. vII, 582 . Tome II, pp. 608. Paris, Félix Alcan, I890.

('go). FraEnkel, CARI. Grundriss der Bakterienkunde. 3 d ed. pp. vir, 5I5. Berlin, August Hirschwald, I890.

An excellent book, but now requires tevision. There is an F, nglish translation by Linsley. New York: Wm. Wood \& Co., 1891.

('90). KRAMER, ERnST. Die Bakteriologie in ihren Beziehungen zur Landwirtschaft und den landwirtschaftlich - technischen Gewerben. Theil I. Die in der Landwirtschaft durch Bakterien bewirkten Vorgänge. Mit 36 Abbild. Wien, Verlag von Karl Gerolds Sohn, 189o. 8vo. I7I pp. II Theil. Die Bakterien in ihren Verhältnisse zu den landwirtschaftlichen-technischen Gewerben. 8vo. pp. VI, I78, with 79 figures. Vienna, Gerolds Sohn, I89I.

('9I). EISENBERG, JaMES. Bakteriologische Diagnostik. 3d ed. pp. xxxI, 509. Hamburg and Leipsic, Leopold Voss, isgr.

('9i). Hueppe, Ferdinand. Die Methoden der Bakterien-Forschung. Handbuch der gesammten Methoden der Mikrobiologie. 5 verbesserte Aufl. 8vo. pp. vIII, 495, with 2 lithographic plates and 68 wood cuts. Wiesbaden, C. W. Kreidel's Verlag, I89ı.

A French translation of an earlier edition, by Van Ermengem, entitied, Manuel tecbuique de microbiologie, was published at Paris in 1887.

('9i). Woodhead, German Sims. Bacteria and their products. London, Walter Scott, Ltd., I89I. I2mo. pp. XIII, 459, with 20 photomicrographs.

('92). StrRneERG, Geo. M. Manual of Bacteriology. pp. XII, 886. 8 plates and 268 figures in the text. 8vo. New York, Wm. Wood \& Co., I 892 . 
('94). Frankland, Percy, and Frankland, Mrs. G. C. Micro-organisms in water. London, Longmans, Green \& Co. pp. XI, 532, with figures, I804

('95). Аввотт, A. C. The principles of bacteriology. A practical manual for students and physicians. 3d ed. pp. XII, 493, with 98 figures, I7 of which are colored. Lea Brothers \& Co., Philadelphia, I895. Last (6th) ed. in I902, pp. XI, 641.

('95). ITZEROTT UND NIEMANN. Mikrophotographischer Atlas der Bakterienkunde. Mit i26 mikrophotographischen Abbildungen in Lichtdruck auf 2I Tafeln. Leipzig, Johann Ambrosius Barth (Arthur Meiner), r895.

('95). Kan'TIIACK AND DRYSDALE. Elementary practical bacteriology. pp. xxi1, I81, with 16 figures. 12mo. London and New York, Macmillan \& Co., 1895.

('95). FraENKEL, CarL und PFetFFE, Richard, Mikrophotographischer Atlas der Bakterienkunde. $2 \mathrm{~d}$ ed. Berlin, 1895 . Verlag von Aug. Hirschwald. 76 plates (I 56 figures) with descriptive text. 8vo.

('g6). HUEPPE, FERDINAND. Naturwissenschaftliche Einführung in die Bakteriologie. pp. vIII 268, with 28 wood cuts. Wiesbaden, C. W. Kreidel's Verlag, 1806.

English translation by Fydwin $O$. Jordan, entitled, The Principles of Bacteriology. The Opeu Court Pub. Co Chicago, 1899 .

('96). Lehmann, K. B., and Neumann, RudolPh. Bakteriologische Diagnostik. 2 vols. I2mo. Münohen, J. F. Lehmann, 1806. Theil $\mathrm{I}$. Atlas of 63 colored plates. Theil Ir, Text, which also includes some figures, pp. vir, 448 , and a folded sheet, giving a synopsis of some of the characters of 62 species.

There is an English edition in one volume, issued by Wm Wood \& Co in 187 The Cerman edition is a very useful book. The Fnglisl edition does not is a very useful book. The Englisli edition does not give the tion and description of species and the folded sheet.

('g6). FlutGGE, C. Die Mikroorganismen. Mit besonderer Berücksichtigung der Aetiologie der Infektionskrankheiten. 3 völlig umgearbeitete Aufl. 8vo. 2 vols. Bd. I. pp. xvi, 596, with 57 text figures. Bd. II. pp. XXII, 75I, with 153 text figures. Leipsic, F. C. W. Vogel, 1896 .

very useful.

('gó). STFRNBFR, GEo. M. Text-book of bacteriology. pp. XI, 693, with 9 heliotype and chromolithograph plates and 200 engravings. 8vo. New York, Wm. Wood \& Co., I8g6.

In the second revised edition (1901) there is a chapter In the second revised edition (1901) there is a chapter gether.

('96). Crookshank, Edgar M. Bacteriology and infective diseases. 4 th ed. pp. xxx, 715, with 22 plates and 273 wood engravings and photographs. Small 8vo. London, H. K. Lewis, I806.

('97). MaCE, E. Traité pratique de bactériologie. 3e ed. pp. virI, II44, with figures. Paris, J. B. Baillière et fils., 1897 .

4th ed. Paris, 1901, pp. viri, 1196, 338 figs. Much new matter added. A very useful book.

('97). Maliory, Frank Burr, and Wright, James Homer. Pathological technique. A practical manual for the pathological laboratory. pp. 397, with 105 illustrations. Philadelphia, W. B. Saunders, 1897. 2d ed. (with slight change of title), revised and enlarged. IgOI, pp. 432 , with I 37 illustrations. Compact and useful.

('97). Mrgula, W. System der Bakterien. Handbuch der Morphologie, Entwickelungsgeschichte und Systematik der Bakterien. I Bd. Allgemeiner Teil. 8vo. pp. virI, 368, with six plates, five of them from photomicrographs. Jena, Gustav Fischer, I897.

('97). FISCHER, ALFRED. Vorlesungen über Bakterien. 8 vo. pp. vIII, I86, with 28 figures. Jena, Gustav Fischer, 1897 .

For criticisms on that portion of this book which re lates to plant diseases, see Centralb. f Bakt. 2 Abt, is p. 271, 809, and 1901, 88, 128, 190. English translation in 1900 by A. Coppen-Jones, under title, Tbe structure and functions of bacteria. 2 German ed. in 1903.

('97-'03). Lafar, Franz. Technische Mykologie. Ein Handbuch der Gärungsphysiologie für technische Chemiker, NahrungsmittelChemiker, Gährungstechniker, Agrikulturchemiker, Pharmaceuten und Landwirte. Jena, Gustav Fischer, 1897-1903. I lith. and 158 text figs.

The first volume, devoted to the bacteria, contalus pp. $\mathrm{XII}, 362$. This was translated by Salter as 'rechnical Mycology, etc. London: Chas. Griffin \& Co., and Philadelphia : Lippincott, 1898 . A new ed. is being pnblished.

('g8). Duclaux, E. Traité de Microbiologie. T. I, Microbiologie général. Paris, Masson et Cie. I898. pp. III, 632, 6r text figures.

('98). Procedures recommended for the study of bacteria, with especial reference to greater uniformity in the description and differentiation of species. Being a report of a committee of American bacteriologists to the Committee on the Pollution of Water Supplies of the American Public Health Association. (Submitted at the meeting of the association in Philadelphia, Sept., I897.) Concord, N. H., The Rumford Press, 1898. pp. 47, with charts.

This pamphlet should be in every laboratory, and in the hands of every studeut.

('98). HEIM, L. Lehrbuch der Bakteriologie mit besonderer Berücksichtigung der bakteriologischen Untersuchung und Diagnostik. 2 Aufl., pp. xvir, 604. Stuttgart, Ferdinand Enke, 1898.

('98). Peinmain, T. H., and Moor, C. G.. Applied bacteriology. pp. $\mathrm{xV}, 464$, with text figures and 8 lithographic plates (the latter copied from Lehmann and Neumann), also folded plate, after Stoddard, showing 3 "halo cultures." 2d ed., 1898. London, Bailliere, Tindall \& Cox.

('oo). MOORE, Veranus A. Laboratory directions for beginners in bacteriology. Cornell University (Ithaca, N. Y.). $2 d$ ed., revised, 1900. Ginn \& Co., The Athenæum Press, Boston, Mass. pp. Xvi, I43.

('o). Migula, W. Specielle Systematik der Bakterien. 2 Bd. 8vo. pp. IX, I,068, with I8 tables from photomicrographs and 35 text figures. Jena, Gustav Fischer, I900. (Issued two months ahead of time.)

Thls book should be in every laboratory. No other general work deals as carefully with the morphology of the bacteria. It is designedly less complete in its treatment of cultural characters. 
('oo). Levy, ERnSt, AND Klemperer, Felix. Ellements of clinical bacteriology for physicians and students. Second enlarged and revised edition. Authorized translation by Augustus A. Eshner, Philadelphia. W. B. Saunders, 1900. pp. 44I, 92 figs.

('or). Aвbotr, A. C. The hygiene of transmissible diseases, their causation, mode of dissemination, and methods of prevention. W. B. Saunders \& Co., Philadelphia and London, Igor. $2 d$ ed. pp. 350 , with 46 ill. and oharts. Populat.

('Ot). Almouist, E., OCH Trolli-Peteresson, G. Mikroorganismerna i praktiska Lifvet Bakteriologiens utreckling och untidastandpunkt. 184 pp. 8vo. Stockholm, Igor.

('OI). Chester, Frederick D. A manual of determinative bacteriology. New York, The Macmillan Co.; London, Macmillan \& Co., Ltd., IgOI. pp. vi, 401 .

('OI). CONN, HERBERT W. Agricultural bacteriology. A study of the relation of bacteria to agriculture, with special reference to the bacteria in the soil, in water, in the dairy, in miscellaneotss farm products, and in plants and domestic animals. pp. vi, 4I2. Pluiladelphia, P. Blakiston's Son \& Co., Igor.

('or). Frost, WILLIAM D. A laboratory guide in elementary bacteriology. pp. virs, 205. Tracy, Gibbs \& Co., Madison, Wis., Igor.

('o2). International catalogue of scientific literature. First annual issue. R. Bacteriology. Published for the International Council by the Roy. Soc. of London, vol. virr, I902 (December), London, Harrison \& Sons, 45 St. Martin's Lane.

At least one additional volume has beeu published.

('02). Bowhill, Thomas. Manual of bacteriological technique and special bacteriology. 2d ed, revised and enlarged. New York, William Wood \& Co., I902. pp. XvI, 324, I36 figs.

('02). Eyre, J. W. H. The elements of bacteriological technique, a laboratory guide for the medical, dental, and technical student. 170 illustrations. Philadelphia and London, W. B. Saunders \& Co., I902. pp. 37I.

('o2?). Collection de planches murales destinées à l'enseignement de la bactériologie. Publiées par l'Institut Pasteur de Paris.

Cette collection touche comme principaux sujets ; charbon, touget, cholera des poules, prieumonie, lepre, supputation, peste, gonocoque, cholera, fievre typhoide, morve, tuberculose, lepre, actinomycose, diptherle, tetauos, etc. et les maladies a protozoalres: coccidies, paludusme, maladie de la mouche tse-tse, trypanosomes, etc. Conditions de la publication. La collection comprend actuellement 65 planches du format $80 \times 62$ centimettes, couleurs sur papier toile très fort, munies d'oelllets permettant de les suspendre sur denx pitons et reuuies, dans un carton dispose spécialement à cet effet. File est accompagnee d'un texte explicatif rédigé en trois langues (français, allemand, anglais). Prix: 250 francs (port
sus). Les planches ne sont pas vendues separement.

(-). Park, Wilitam H. Bacteriology in Medicine and Surgery. Lea Brothers \& Co., New York. I2mo., 688 pages, with 87 illustrations in black and colors, and 2 colored plates.

('O2). Roger, G. H. Les maladies infectieuses. Paris, Masson et Cie, 1902, T. I, pp. xrv, 664; T. II, pp. 665-I,520; av. II7 fig.
('02). Matzuschita, TEïsi. Bacteriologische Diagnostik. Zum Gebrauche in den bacteriologischen Laboratorien und zum Selbstunterrichte. Für Aerzte, Tierärzte roıd Botaniker. Jena (G. Fischer), Ig02, pp. Xvir, 692, mit I Taf.

('O2). HEWLETT, RICHARD T. A Manual of Bacteriology, Clinical and Applied, 2d Edition. London (Churchill), I902, p. 533, with 20 plates.

('O2-'04). KolLE, W., UND WASSERMAN, A., unter Mitwirkung von 54 Fachmänner. Handbuch der pathogenen Mikroorganismen. Jena, Gustav Fischer. Begun in 1902. 20 Lieferungen to Sept., I904.

Four latge volumes, with an atlas containing 288 photographs. Motrographic in chatacter.

('03). Sternbirg, Gro. M. Infection and immunity, with special reference to the prevention of infectious diseases. G. P. Putnam's Sons, New York and London, 1903. pp. Ix, 293. Populat.

('o3). Frankland, Mrs. Percy. Bacteria in daily life. Longmans, Green \& Co., London, New York, and Bombay, 1903. pp. 216. No illustrations.

Populat.

('O3). Williams, HL'RBERT U. A manual of bacteriology. Ninety-nine illustrations. 30 ed., revised and enlarged. Philadelphia, P. Blakiston's Son \& Co., 1903. pp. Xv, 35I.

('O3). MCFARLAND, JOSEPH. A text-book upon the pathogenic bacteria for students of medicine and physicians. With 153 illustrations, a number of them in colors. $4^{\text {th }}$ ed., rewritten and enlarged. W. B. Saunders \& Co., Philadelphia, New York, and London, I903. pp. 629.

('o3). Muir, Robert, and Ritchie, James. Manual of bacteriology. Am. ed. (with additions). revised and edited from the third English ed. by Norman MacLeod Harris. I70 illustrations. Macmillan Co., New York. Macmillan \& Co., Ltd, Iondon, 1903. pp. Xx, 565 .

An excellent book.

IV. Physical, Chemical, Zoological, and Botanical Works of Special Use to the Plant Pathologist.

('6r). Graham, Thomas. Liquid diffusion applied to analysis. Philos. Trans. of the Roy. Soc., London, vol. I5I, pt. I, I861. pp. 183-224. 3 figs.

Interesting loug paper, in which the making of silicate jeliy is described.

('83). Molisch, HaNS. Ueber d. Mikrochem. Nachw. v. Nitraten u. Nitriten in d. Pfanze mittelst Diphenylamin oder Brucin. Berichte der Deutschen Botanischen Gesellschaft, 1883. pp. 150-I55. See also Bot. Centralb., Bd. XIV, I883, pp. 355-356.

('84). GautiÉ, Armand. Traité de chimie appliquée à la physiologie et à l'hygiene. Paris, I884. Not seen. 
('84). DF, VRIES, Huco. Over eene methode om in planten-sappen gebanden zuren te befolen. Maaudblad voor Natuurwetenschappen, No. 9, 1884. Rev, in Botan. Centralb., Bd. Xxiv, p. 249.

Thls author gives a method of estimatlng the quantity of acid in plauts wheo not free, i. e., when united with
bases.

('84). Mol,, J. W. Eene nieuwe mikrochemische looizuurreactie. Maandblad voor Natuurwetenschappen, 1884. Rev. in Bot. Centralb. Bd. Xxiv, p. 250.

Best method (micro-chemical) of detecting taunin in cells. Jle soaks small pieces of tissue in saturated solu tion (7 per cent) acetate of copper 8-10 days and longer will not injure. Then they are sectioned and treated for a few minutes with a drop of 0.5 per cent sol. iron acetate. Too long an exposure browns the cell walls. The sections are then washed in water, transferred to alcohol and finally mounted in glycerine or glycerine jelly. If the test cannot be made at ouce the specimens wil . If be injured by preserviog in alcohol after the souing in acetate of copper. The tannin-bearing cells become green or blue.

('85). Hanausek, T. F., and Pammer, L. Ueber die Löslichkeitsverhältnisse des Kautschuks. Zeitschrift des allg.- österr. ApothekerVereins, 1885, No. 31, pp. 486-488, with a table. Rev. in Bot. Centralb., Bd. xxv, 1886 p. 308.

Note on best aolveots for rubber.

('85). Strasburger, Ėd. Zur mikroskopischen Teohnik. Bot. Centralb., Bd. xxiv, 1885 pp. 156-157.

According to Strasburger, Faber's yellow pencils are the best for writiug on glass or porcelain. To fiud particular places in a preparation, he makes rings on the stage of the microscope to each side of the opening, asd, when the desired field is in view, corresponding ones on
the slide. The best method of making ean de Javelle is aid to be the following:

(a) Take 20 parts of 25 per cent chloride of lime (Chlorkalkes), stir up in 100 parts of water, and let staud for a

(b) Dissolve 15 parts of pure potash in 100 parts of

Add $b$ to $a$, and, after one to several days, filter and ise the filtrate. If lime still remains in the fluid, add a $\mathrm{few}$ drops of potash solotion and filter out precipitate.

('85). Leimann, O. Physikalische Technik. Specielle Anleitung zur Selbstanfertigung physikalischer Apparate. pp. xir, 416, with 882 wood cuts and 17 tables. Leipsic, Wm. Engelmann, 1885.

('85). Noli, F. Eau de Javelle, ein Aufhellungsund Lösungsmittel für Plasma. Botan. Centralb., Bd. xxi, 1885, pp. 377-380.

Author tello how to make and how to use eau de Javelle. Alcoholic material is best suited for treatment. Fresh protoplasm does not dissolve completely, but leaves detritus and granules. Strasburger, Ibid., Baud xxiv, p. 157 , says this is not eau de Javelle.

('85). KRAUS, C. Ueber amphotere Reaction der Pflanzen-Säfte. Botan. Centralb., Bd, xxuv, 1885, p. 287.

A. Meyer summarizes some of Kraus' results obtained from the pith parenchyma of twenty plants. Kraus claims that veutral litmus would not answer. He used red and blue litmus. Little pieces were thrown iato tbe sap aud left a long time. lie got both reactions.

('86). PFEFFer, W. Ueber Aufnahme von Anilinfarben in lebende Zellen. Untersuchungen a. d. Bot. Inst. zu Tuebingen, Leipzig, 1885́, Bd. II, Heft 2, pp. 179-329.

('86). BACimanN, E. Spektroscopische Untersuchugen von Pilzfarbstoffen. Plauen, 1886. Not seen.
('86). Shenstone, W. A. The methods of glass blowing for the use of physical and chemical students. pp. $x, 86$, with figures. 12mo. Rivingston's, Waterloo Place, London, 1886.

('89). BEIRENS, W., Kossei, A., UND SCHIEFFERDECKER, P. Das Mikroskop und die Methoden der mikroskopischen Untersuchungen. pp. VIII, 315, with 193 wood cuts. Braunschweig, Harald Bruhn, I889.

('go). Curtman, Charless O. Chemical reagents and the spectroscope. 12mo. pp. 256, with 12 plates. John L. Boland Book and Stationery Co., St. Louis, 1890 .

A useful little book.

('90). NickEL, Emil. Die Farbenreactionen der Kohlenstoffverbindungen. $2 d$ ed. pp. visI, 134. Berlin, Verlag von Hermann Peters, 1890.

('9J-'92). OstwaLd, W1LHFL, Lehrbuch der allgemeinen Chemie. Zweite gänzlich umgearbeitete Auflage. Leipzig, I891-I892. 2 Bd.

The fourth book of the aecond edition was trauslated

into Einglish by M. M. Pattisou Muir, under the title

"Solutions." Loudou, 28gr, ppo xili, 316, 8 vo.

('92). Trumble, Henry. The tannins. pp. I68. J. B. Lippincott Co., Philadelphia, I892.

('92). Z1MmERMANN, A. Die batanische Mikroteohnik. Ein Handbuch der Mikroskopischen Präparations- Reaktions- und Tinktionsmethoden. Mit 63 Abbild. im Text. Tübingen, 1892. pp. x, 278. English translation by James Ellis Humphrey. Henry Holt \& Co., New York, 1893 .

('03). LEA, A. Sheridan. The chemical basis of the animal body. New York, Macmillan \& Co. 1893. pp. 288. Forms Part $v$ of 6 th ed. of Foster's larger Physiology.

('93). Bender, Adole, und ERdMann, Hugo. Chemische Präparatenkunde. 2 vols. Bd. I. Anleitung zur Darstellung anorganischer Präparate, von Bender. pp. vill, 530, with 102 figures, 1893 . Bd. 11. Anleitung zur Darstellung organischer Präparate, von Erdman. pp. XI1, 610, with 4I figures. Stuttgart, Ferdinand Enke, 1894.

('93-95). SснмjDr, ERNST. Ausführliches Lehrbuch der Pharmaceutischen Chemie. Braunschweig, Fr. Vieweg \& Sohn. 3d ed. Inorg., 1893. Organic, 1895. pp. 648, vi. 4th ed., 1901. pp. XXxir1, 1,944.

('94). BEHRENS, H. A manual of microchemical analysis. With an introduotory chapter by John W. Judd. With 87 illustrations. pp. $\mathrm{xxv}, 246$. London and New York, Macmillan \& Co., 1894.

('94). Landolit und Bozrnstein. Physikalisch-chemische Tabellen. 2 d ed. pp. xi, 563. Berlin, Julius Springer, 1894 .

('94). The National Dispensatory. 5th ed. 1894. Lea Brothers \& Co., Philadelphia and New York. pp. VI11, 1903.

('94). Schulz, G., AND JUlrus, P. Systematic survey of the organic colouring matters. Translated fram the German and edited with extensive additions by Arthur G. Green. pp. viss, 205. London and New York, Macmillan \& Co., I894.

Very useful. 
('94). Lidronss, B. Ueber die Wirkungssphäre der Glycose u. Gerbstoff-Reagenten. Sep. Abdr. aus Lunds Univ. Arsskr. 'T. XxvirI, I4 pp. Rev. Bot. Centralb., I894, Bd. LIX, p. 28I.

Author says tannins give most of the protein reactions, and may thins lead iuvestigators to many wrong conclusions. The following test is given for grape sugar in plant tissues: The parts to be tested are soaked for some time in an alcoholic copper solution, and then brought to a boil over a water bath. This calises a precipitate of copper oxide (oxydul) in all of the cells wbich contained grape sugat. The alcoholic copper solution is made as follows : Add some acetic acid and glyceriu to an alcoholic solution of copper acetate. This is then mixed with an equal volume of alcoholic solution of caustic soda (Natronlösung). This mixture is as sensitive as Fehling'a solution, and is not reduced by various substances which reduce Fehling. A great number of soluble reducing substauces are removed by the alcohol from the plant cells, while the sugar remains behind.

Barfoed's reagent consists of acetate of copper disaolved in water and made acid by acetic acid. It is useful for detection of sugar in some cases where Fehling's solution is worthless, i. e., in the presence of Phloroglucin, Aesculin, Quercit, which reduce the latter. The former, on the contraty, is reduced by Hydrochinon and

'95). Cross and Bevan. Cellulose. An outline of the chemistry of the structural elements of plants, with reference to their natural history and industrial uses. pp. vI, 320, with 14 plates. London, Longmans, Green \& Co., 1895.

('95). MEYER, ARTHur. Untersuchungen über die Stärkekörner. 8vo. pp. xvI, 318, with 9 lithographic plates and 99 text figures. Jena, Gustav Fischer, 1895.

('95). von Lippman, E. O. Die Chemie der Zuckerarten. 8vo. Second edition. pp. XxvI, I,I74. Braunschweig, Fr. Vieweg u. Sohn, 1895 .

The third edition appeared in 1904 in two large volumes, pp, xxxviii, 2003 . Indispensable.

(c5). BEHRENS, H. Anleitung zur mikrochemischen Analyse der wichtigsten organischen Verbindungen. I Hft. Anthracenegruppe, Phenole, Chinone, Ketone, Aldehyde. pp. viII, 64, with 49 figures, I895. $2 \mathrm{Hft}$. Die wichtigsten Faserstoffe. pp. vIII, 108, with 18 figures in text and three colored plates. 1896. $3 \mathrm{Hft}$. Aromatische Amine. pp. vII, 135, with 77 figures, I896. 4 Hft. Karbamide, aliphatische Karbonsäuren, Aromatische Karbonsäuren. Hamburg and Leipsic, Leopold Voss, 1897.

very useful.

('96). Beyerinck, M. W. Kulturversuche mit Amöben auf festem Substrate. Centralb. f. Bakt., I Abt., Bd. XIX, pp. 257-267, 1896 .

('96). Comey, Arthur M. A Dictionary of Chemical Solubilities. Inorgantc. pp. XX, 515 Macmillan \& Co., London and New York, 1896.

('96). Merck's Index. An encyclopædia for the physician and the pharmacist; stating the names and synonyms; source or origin; chemical nature and formulas; physical form, appearance, and properties; melting and boiling points; solubilities; gravities and percentage strengths; physiological effects; therapeutic uses; modes of administration and application; regular and maxi- mum dosage; incompatibles; antidotes; special oautions; hints on keeping and handling; methods of testing; market values, etc., of the chemicals and drugs used in medicine, in chemistry, and in the arts. $2 \mathrm{~d}$ ed. Merck \& Co., New York, I8g6.

Very useful.

('96). LEFEVRE, LÉon. 'Traité des matières colorantes organiques artificielles, de leur préparation industrielle ot de leur applications. 2 vols. 8vo. pp. Xx, I,648, with 31 text figures and $26 \mathrm{t}$ dyed or printed samples of silk, wool, cotton, paper, and leather, prepared under the direction of the author especially for this edition. Paris, G. Masson, 1896 .

('97). DAVENPoRT, C. B. Experimental morphology. Part I. Effect of chemical and physical agents upon protoplasm, I897. The Macmillan Co., New York. pp. xIv, 280, 74 figs.

('97). MILLER, WALTER. Scientific Names of Latin and Greek Derivation. Proc. Calif. Acad. Sci. Zoology. Third Ser. Vol. I, No. 3, pp. 1I5-I43, 1897 .

('97). Schneider, A., AND Altschul, Julius. Reagents and reactions known by the names of their authors. Milwaukee, Wis., 1897. Pharm. Review Pub. Co.

Tbis book was first writteu by A. Schneider. The German edition was revised and enlarged by Julius Altschul. It was translated into English by Richard Fischer.

('97). Bausch, EDward. Manipulation of the microscope. Bausch and Lomb Optical Co., Rochester, N. Y. 3d ed. 200 pp. I897.

('97-04). PFEFFER, WILHELM. Pflanzenphysiologie. Ein Handbuch der Lehre vom Stoffwechsel und Kraftwechsel in der Pflanze. Bd. 1. Stoffwechsel. pp. $\mathrm{x}, 620$, mit 70 Holzschnitten. Leipzig, 1897. Bd. Ir, Kraftwechsel. 1 Hälfte, I90I, pp. 353, mit 31 Holzschnitten. II Hälfte, I904, pp. XI, 353-986, mit $60 \mathrm{Holz}-$ schnitten. Verlag von Wilhelm Engelmann. English translation by Alfred J. Ewart, Oxford, Clarendon Press. Vol. I, 1900. Vol. II ( Part I), 1903. Vol. III in preparation.

('98). BeHRENS, WiLHiLM. Tabellen zum Gebrauch bei mikroscopischen Arbeiten. Braunschweig, Harald Bruhn. pp. vir, 237. 3d ed., revised, 1898 .

Extremely useful.

('98). von Bungr, Gustav. Lehrbuch der physiologischen und pathologischen Chemie. In neunundzwanzig Vorlesungen für Aerzte und Studierende. 4 vermehrte und verbesserte Aufl. Leipzig, Verlag von F. C. W. Vogel, I898. pp. IV, 510.

English translation, from $4^{\text {th }}$ Germau ed, by Starling. London, 1902.

('98). SchrofDer von der Kolk, J. L. C. Kurze Anleitung zur mikroscopischen Krystalbestimmung. pp. 60 , with text figures. Wiesbaden, C. W. Kreidel's Verlag, I8g8. 
('98-'03). Allen, AlFred H. Commercial organic analysis. A treatise on the modes of assaying the various organic chemicals and products cinployed in the arts, manufactures, medicine, etc., with concise methods for the detection of impurities, adulterations, etc. $8 \mathrm{vo}$. Vol. x. Alcohols, neutral alcoholic derivatives, etc. ethers, vegetable acids, starch, s"1gars, etc. 3d ed., 1898, pp. xii, 557

Vol. 1I, Part x. Fixed oils and fats, glycerol, explosives, etc. 3 d ed., 1899 , pp. $x, 387$.

Vol.11, Part 11. Hydrocarbons, mineral olls, lubricants, benzenes, naphthalenes and derivatives, creosotes, pbe-

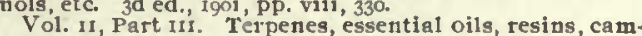
phors, etc. 3d ed. preparing.

Vol, 111, Patt 1. Taunins, dyes, and coloring matters. $3 d$ ed.,enlarged and rewritten. Illustrated. $1000, p p$. xvi 589 .

Vol. III, Part II. The amines, hydrazines and derivatives, pyridine bases, the antipyretics, etc. Vegetable alkaloids, tea, coffee, $\operatorname{cocos}$, etc. 8 vo, $2 \mathrm{~d}$ ed., 1892 , pp. viii, 584

Vol, 111, Part 111, Vegetable alkaloids, non-basic vegetable bitter principles. Anjmal bases, animal acids, cyanogen compounds, etc. 2d ed, 8 vo., 1806 pp. xil, 508

Vol. iv. 'The protelds and albuminous principlea. ed., 1898, pp. $x i, 584$.

('99). Coir , AlFred I. Indicators and test papers, their source, preparation, application, and tests for sensitiveness, etc. New York, John Wilcy \& Sons; London, Chapman \& Hall, Ltd., I899. pp. IX, 249.

Very useful.

('99). The Dispensatory of the United States of America. I8th ed., I899. Philadelphia, J. B. Lippincott Company, pp. XL, $, \mathrm{I}, 999$.

('g9). BenRENS, H. Anleitung zur mikrochemischen Analyse. pp. XI, 242, with 96 figures. 2d ed. Hamburg and Leipsic, Voss, I899.

('OO). SchOENICIIEN, WALTER, UND KALBERLAH, ALFRED. B. Eyferth's Einfachste Lebensformen des Tier- und Pflanzenreiches. Naturgeschichte der mikroskopischen Süsswasserbewohner. 3 vollständig netubearbeitete und vermehrte Auf. Mit über 700 Abbildungen auf I6 Tafeln in Lichtdruck rach Zeichnungen von Dr. A. Kalberlah. Braunschweig, Verlag von Benno Goeritz, I900. pp. viII, 556.

('oo). Sutron, Francis. A systematic handbook of volumetric analysis. 8th ed., enlarged and improved, Ig00. pp. XI, 640, with figures. London, J. and A. Churchill.

This book should be in every laboratory.

('oo). VAN Rijn, J. J. L. Die Glykoside chemische Monographie der Pflanzenglykoside, nebst systematischer Darstellung der künstlichen Glykoside. Gebrïder Borntraeger, Berlin, I000. pp. XVI, 5 II.

('oo). Behrens, H. Mikrochemische Technik. Hamburg u. Leipzig, Leopold Voss, rgoo. pp viII, 68 .

('OO). BUECHL, Max. Die Diastasen, 1900.

Not seen.

('or). GAGE, S. H. The Microscope. An introduction to microscopic methods and to histology. 8th ed., revised, I90I. pp. Iv, 299 with over two hundred figures. Comstock Publishing Co., Ithaca, N. Y.

Deserves a place lu every laboratory.
('OI). Coblentz, Virgil. A manual of volumetric analysis, treating on the subjects of indicators, test-papers, alkalimetry, acidimetry, analysis by oxidation and reduction, iodometry, assay processes for drugs with the titrimetric estimation of alkalolds, estlmation of phenol, sugar, tables of atomic and molecular weights. P. Blakiston's Son \& Co., Philadelphia, 1901. pp. virr, I8r.

('O1). LEE, ARTHUR Bolles. The Microtomist's Vade-Mecum, a handbook of the methods of microscopic anatomy. 5th rev. ed. Philadelphia, P. Blakiston's Son \& Co., rgor. pp. XIV, 532.

Very useful. French ed by Lee and Henneguy. Paris, Octave Doin, 1902

('OI). Cross, C. F., ANd Bevan, E. J. Researches on cellulose, I895-I900. Longmans, Green \& Co., London, New York, and Bombay, I90I. pp. viI, 180 .

('OI). HaNaUSEK, T. F. Lehrbuch der technischen Mikroskopie. With 256 text figures. Stuttgart, Ferdinand Enke, Igor. pp. x, 456.

('ol). Rawson, Christopiter, Gardiner, Wal,Ter M., AND LAYCOCK, W. F. A dictionary of dyes, mordants, and other compounds used in dyeing and calico printing. London, Chas. Griffin \& Co., Ltd.; Philadelphia, J. B. Lippincott Co., I9or. pp. 37z.

('o2). Omélianski, W. Ueber die Gärung der cellulose. Centralb. f. Bakt., 2 Abt., Bd. virI, Nos. 7-13, pp. 193-201, 225-231, 257-263, 289294, 32I-326, 353-36I, 385-39I, I text fig. and I plate. Jena, I902.

Omelianski finds two morphologically similar bacteria capable of fermenting pure cellulose (Swedish filter paper) in mineral solutions with chalk. Both grow anaerobically, and beat spores in a swollen terminal part. One called the hydrogen ferment breakg up cellulose with the formation or hydrogen, carbou dioxide, acetic acid, and butyric acid. The other, calied the marsh-gas ferment. breaks up cellulose witb the formation of marsh-gas, cultures were made by the selective method, by whlch means most of the accompanying forms were crowded out. The hydrogen ferment was isolated from the methane ferment by heating the material used for the first transfer (irom the methane-yielding ferment for 15 minutes at $70^{\circ}$, the subsequently inocnlated flasks then gave only the bydrogen fermentation. The organism of the latter was isolated pure on potato but only after many trials and with feeble growth and weak ferment powers. The methane bacterium waa no obtained pure in colonies. Nelther organism colored blue with iodine. The experiments were begun in 1894 and carried through a long series of years, involving an enormous amount of painataking labor.

('o2). Mann, Gustav. Physiological histology. Methods and theory. pp. xv, 488. Oxford, The Clarendon Press, Ig02.

('O2). HOEBER, Rudolf. Physikalisohe chemie der Zelle und der Gewebe. Wilhelm Engelmann, Leipzig, Ig02, pp. XII, 344, with 21 fg.

('o3). KUESTER, ERNST. Pathologische Pflanzenanatomie. Verlag von Gustav Fischer, Jena, I903, pp. viI, 312, with I2I figures.

('o3). Daven port, Charles Benedict. Experimental Morphology. Part II. Effects of Chemical and Physical Agents upon Growth. 8vo. The Macmillan Co., New York. 
('o3). Peirce, George James. A Text-Book of Plant Physiology. Henry Holt \& Co., New York, I903, PD. VI, $29 \mathrm{I}$.

('o3). Cohn, AlFred I. Tests and reagents, chemical and microscopical, known by their author's names, together with an index of subjeots. Ist ed. 383 pp. New York, John Wiley \& Sons; London, Chapman \& Hall, Ltd., 1903.

('o3). von Fuerth, Orro. Vergleichende chemische Physiologie der niederen Tiere. Jena, Gustav Fischer, 1903. pp. xIv, 670.

('O4). NuTYTALI, GEORGE H. F. Blood immunity and blood relationship; a demonstration of certion blood-relationships amongst animals by means of the precipitin test for blood. pp. XII, 444. Cambridge (England) University Press, I904.

\section{Books and Papers of More or Less General Interest.}

('28). Ehrenterrg, C. G. Symbolæ physicæ, seu icones et descriptiones animalium evertebratorum sepositis insectis quæ ex itinere per Africam Borealem et Asiam Occidentalem Friderici Guilelmi Hemprich et Christiani Godofredi Ehrenberg medicinæ et chirurgiæ doctorum studio novæ aut illustratæ redierunt percensuit et regis iussu et impensis edidit Dr. C. G. Ehrenberg. Decas prima. Berolini ex Officina Academica Venditur a mittlero MDCcCXXVIII.

('30). EHRENBERG, C. G. Beiträge zur Kenntnis der Organisation der Infusorien, etc. Printed I3 Aug., 1830, as part of Abhandl. d. K. Akad. d. Wissensch. zu Berlin. Physic. Klasse for the year 1830. As a whole the volume bears date of 1832 .

('32). EHRENBERG, C. G. Die geographische Verbreitung der Infusionsthierchen in NordAfrika und West-Asien, etc. Abhandl. d. K. Akad. d. Wissensch. zu Berlin. Physik. Klasse. For the year 1829 . Printed I832.

('32). EHRENBERG, C. G. Ueber die Entwickelung und Lebensdauer der Infusionsthiere, otc. Abhandl. d. K. Akad. d. Wissensch. zu Berlin, 1831. Printed January, 1832.

('38). EHRENBERG, C. G. Die Infusionsthierchen als vollkommene Organismen. Ein Blick in das tiefere organische I,eben der Natur, von Christian Gottfried Ehrenberg zu Berlin. Nebst einem Atlas von vierundsechszig colorirten Kupfertafeln gezeichnet vom Verfasser. Leipzig, Verlag von Leopold Voss, 1838. pp. 548, folio.

('40). HENLE, J. Pathologische Untersuchungen. Berlin, August Hirschwald. pp. vi, 274. I840.

('54). SchroedER, H., und von Dusch, Th. Ueber Filtration der Luft in Beziehung auf Fäulniss und Gährung. Annalen der Chemie und Pharmacie, Bd. Lxxxix (Neue Reihe, Bd XIII), Heft 1. pp. 232-243, Heidelberg, 1854. Fixtremely interesting historically. These authors were the first to show that boiled beef bouillon and similar easily putresclble fluids could be preserved indefinitely if protected from the floating matter of the air by means of cotton plugs. Boiled milk, on the contrary. decayed as certainly under the cotton as when exposed directly to the air, for reasons unknowu to thetu. T'be exact nature of this floating matter of the air was not determined. That remained for Pasteur to work out aome years later by means of many ingeuious experlments.
('54). Cohn, Firdinand. Untersuchungen über die Entwicklungsgeschichte der mikroscopischen Algen und Pilze. Der Akademie ïbergeben den I Mai, I853. Nov. Act. Acad. Cres. Leop.-Carol. Naturæ Curiosorum. Vol. XXIV, Pars I, I854. pp. 103-256, 6 plates. Breslat and Bonn.

('59). Schroede, H. Ueber Filtration der Luft in Beziehıng auf Fäulniss, Gährung und Krystallisation. Annalen der Chemie und Pharmacie, Bd. CIx (Neue Reihe Bd. XxxIII), Hift. I, pp. 35-52, 1859. Leipzig und Heidelberg.

('60). PASTEUR, Louis.. Expériences relatives aux générations dites spontanées. C. R. des sé. de l'Acad. des Sci., Paris, 1860. pp. 303-307.

('62). Pasteur, Louis. Mémoire sur les corpuscles organisés qui existent dans l'atmosphère. Examen de la doctrine des générations spontanées. Ann. de Chimie et Physique, I862. 3 série, T. LXIv, pp. 5-IIo.

('65). Davaine, C. Sur l'existence et la recherche des bactéridies dans la pustule maligne. C. $\mathrm{R}$. d. sé. et mém. de la société de biol. for I864, p. 93-94 (comptes rendus part). Paris, I865.

('68). Roberts, W. Chandler. On the occurrence of organic appearances in colloid silica obtained by dialysis. Journ. of the Chem. Soc. of London. New serries, vol. vi, 1868, pp. 274-276, 2 figs. of fungi.

Roberts appears to have been the first to observe the growth of organisms on silicate jelly.

('72). СонN, F. Untersuchungen über Bacterien. Cohn's Beitr. zur Biol. der Pflanzen, Bd. J. 2 Hft. 1872. pp. 127-224. I plate.

('73). LISTER, JOSEPH. A further contribution to the natural history of Bacteria and the germ theory of fermentative changes. Quarterly Journal of Microscopical Science. I873. Vol. xill. pp. 380-408.

('73). Pasteur, Louis. Etudes sur le vin, ses maladies, causes qui les provoquent, procédés nouveaux pour le conserver et pour le vieillir. Deuxième édition revue et augmentée. Avec 32 planches imprimées en couleur et 25 gravures dans le texte. Paris, I873. F. Savy. pp. IV, 344.

('76). PAsteur, Louis. Etudes sur la bière, ses maladies, causes qui les provoquent, procédé pour la rendre inaltérable, avec une théorie nouvelle de la fermentation. I2 plates, 85 text figures. Paris, 1876. Gauthier-Villars. pp. vitr, 387.

('77). voN NAEGel, C. Die niederen Pilze in ihren Beziehungen zu den Infectionskrankheiten und der Gesundheitspflege. München. R. Oldenbourg, 1877. pp. XxxII, 285.

('78). LiSTER, JOSEPH. On the lactic fermentation and its bearing on pathology. Transactions of the Pathological Society of London. 1878. Vol. xxix, pp. 425-467.

('79). Nencki, M., U. Giacoso, P. Giebt es Bacterien oder deren Keime in den Organen gesunder lebender Thiere? Journ. f. Prakt. Chem., I879. Bd. xx, p. 34-44.

('82). Motr, F. W., ANd Horsley, V. H. On the existence of bacteria, or their antecedents, in thealthy tissues. Journ. of Physiol., vol. III, I880-I882. pp. 188-194. 
('82). Engrimann, Th. W. Zur Biologie der Schizomyceten. Bot. Zeitung, 1882, col. 32I-325 and 337-34I.

('84). MetschnikoFr, E. Ueber die Beziehung der Phagocyten zu Milzbrandbacillen. Archiv f. patholog. Anat. u. Physiologie is. f. Klin. Med., Bd. LXXIX, 1884. pp. 502-526. 2 plates.

('86). Bolton, MEAdE. Ueber das Verhalten verschiedener Bacterienarten im Trinkwasser. Ztschr. f. Hyg. Bd. I, I886. pp. 76-II4.

('86). ABBE, E. Ueber Verbesserunget des Mikro skops mit Hilfe neuer Arten optischen Glases. Sitzungsber. der medicin,-naturw. Gesellschaft zu Jena, i886. Also a separate, 24 pp. 8vo.

('88). SoYKA, J., Und BANdLER, A. Die Entwickelung von (pathogenen) Spaltpilzen unter dem wechselseitigen Einfluss ihrer Zersetzungsprodukte. Fortsohr. d. Med. Bd. vi I888. pp. 769-773.

Treats of growth of bacteria in media exhausted for other organisms.

('88). Banti, Guido. Sulla distruzione dei batterii nell'organismo. A rch. per lo sc. med., I888. Vol. XII, pp. I9I-22I, with 2 pp. of bibliography, I plate.

('89). VignaI, WILLIAM. Contribution à l'étude des Bactériacées. Le mesentericus vulgatus. Paris, I889.

('9o). KOCH, R. Ueber bakteriologisohe Forschung. Berlin, 1890 , Verlag von August Hirschwald. pp. I5.

('93). Dixon, H. H. On the germination of sceds in the absence of bacteria. Sai. Trans. Roy. Dublin Soc., vol. v, series II, I893-I806. pp. $\mathrm{I}-4$. Review in Rev. Sci., I894, pp. $437-438$

('94). Kocrs, W. Giebt es ein Zellleben ohne Mikroorganismen? Biol. Centralb., I894. No. 14, pp. 48I-49I.

Answer, yes. Plants are grown from sterllized seeds and kept fourteen mouths without contact with bacteria. Plims refused to decay when the surface had been ster-

('94). Frankland. Die Bakteriologie in einigen ihrer Beziehungen zur chemischen Wissenschaft. Centralb. f. Bakt., Bd. $x v, 1894$, pp. IOI-II2.

('95). WARD, H. Marshali. On the biology of Bacillus ramosus, a schizomycete of the River Thames. Proc. Royal Soc. of London, vol. IVIII, I895. 8vo. p. 265 . Also a separate.

('95). PFEFFER, W. Ueber Ellection organischer Nährstoffe. Pringsheim's Jahrbücher, Bd. XXVIII, I895, pp. 205-268.

('95). Achard, Ch., ET Phulp1N, E. Contribution a l'étude de l'envahissement des organes par les microbes pendant l'agonie et après la mort. Arch. de méd. exper. Tome vin, I895, pp. 25-47.

('95). BECO, L. Etude sur la pénétration des microbes intestinaux dans la circulation générale pendant la vie. Ann. de l'Inst. Pasteur, T. IX, I895, pp. I99-209.

('95-'96). NuTTAII, GEORGE H. F., UND TIIJERFELDER, H. Thierisches Leben ohne Bakterien im Verdauungskanal. Ztschr. f. physiol. Chem. Bd. XXI, I895, pp. I09-12I, und Bd. XXII, Hft. I, 1896 , pp. $62-73$.
('96). LuNT, JoSEPH. On Bacillus mesentericus niger (a new potato bacillus). Centralb. $f$. Bakt. 2. Abt., Bd. II, 1896. pp. 572-573.

Motile, liquefies gelatin rapidly, produces endospores copiously, blackens potato, curdles milk witb aubsequent solution of the curd, converts potato stareb into gugar i. e., there is no iodine reactlon after a time, but a copious reduction of Pehling's solution.

('98). Sanareili, G. Das myxomatogene Virus. Beitrag zum Studium der Krankheitserreger ausserhalb des Sichtbaren. Centralb. f. Bakt., XXIII Bd., 1898, pp. 865-873.

Author thinks it improbable that there are unorganized causes of infection, and that therefore certain infectious diseases must be due to organisms too small to be visible to the human eye, even when helped by the best optical appliances.

('99). Oméliansky, V. Sur la culture des microbes nitrificateurs du sol. Arch. d. Sci. biol. St. Pétersb. Tome vir, No. 4, 1899 , pp. 29I-302.

('99). SruRgrs, W. C. A soil bacillus of the type of de Bary's B. megaterium. Phil. Tr. Roy. Soc. of London. Series B, vol. Igr, pp. 147-169. pl. 14-16, B. 172. London, 1899.

Otganism described as Bacillus bortulanus.

('oo). HoF, A. C. Untersuchungen über die Topik der Alkalivertheilung in pflanzlichen Geweben. Botanisches Centralb., Bd. LXXXII, No. 9, XXI Jahrg., No. 35, I900, pp. 273-280.

('oo). Smirt, R. GREIG. The (bacterial) clouding of white wine. Proceedings of the I,innean Society of New South Wales, Igoo. Part 4, Oct. 31. pp. 650-658. Also a separate.

('oo). Jordan, Éwin O. Some observations upon the bacterial self-purification of streams. Jour. Exp. Med., vol. v, pp. 27I to 3I4. Dec., igoo. I plate.

('oo). FORD, WM. W. Varieties of colon bacilli isolated from man. Montreal Medical Journal, Nov., rgoo. pp. 835-844. Also a separate, Io pp. Bibliography of I4 titles.

('oo). SмIтн, ТнE, Овод. Adaptation of pathogenic bacteria to different species of animals. Phila. Med. Journ., May 5, Ig0o. Vol. v., pp. I,OI8-I,022.

('OI). FISCHER, ALFRED. Ueber Protoplasmastruktur. Antwort an O. Buetschli. Archiv f. Entwickelungsm. d. Org., I90I, Bd. XIII, pp. I-33.

('02). JoEST, ERNST. Unbekannte Infektionsstoffe. Centralb. f. Bakt., Abt. I, Bd. xxxI, Originale, 1902, pp. 36r-384, pp. 410-422. Bibliog. of 58 citations.

('o3). Ford, W. W. The classification and distribution of the intestinal bacteria in man. Studies from the Royal Victoria Hospital, Montreal, vol. I, No. 5 (Pathology II), May, Ig03, 95 pp.

('o3). Winslow, C. E. A., and Nibecker, C. P. The significance of bacteriological methods in sanitary water analysis. Technology Quarterly of Mass. Institute of Technology, vol. XVI, No. 3, Sept., I903, pp. 227-239. Also a separate.

('04). Phillips, Orvilis P. A comparative study of the cytology and movements of the Cyanophyceae (Plates xxIII-xxv, pp. 237-335. Bibliog. Trans. and Proc. Bot. Soc. Pennsylvania, Vol. I, No. 3, 1004.

Finds short cillia on side walls of Cyanophycer. 


\section{Important Books and Papers on Special} Human and Animal Diseases.

('63). Davaine, C. Recherches sur les infusoires du sang dans la maladie connue sous le nom de sang de rate. C. $\mathrm{R}$. des sé. de l'Acad. des sci., I 863 , T. LVII, pp. 220-223, 35I-353, 386387 .

This and many other papers on anthrax are reprinted

in "l'Oeuvre de Davaine," Paris, 1889, I vol. 8vo.

('64). Davaine, C. Nouvelles recherches sur la maladie du sang de rate considérée au point de vue de sa nature. C. $R$. des sé. et mém. de la soc. d. biol. for I863, Paris, I864, pp. 193-202.

('70). PASTEUR, Lous. Etudes sur la maladie des vers à soie, moyen pratique assuré de la combattre et d'en prévenir le retour. Tome I. La pébrine et la flacherie, pp. XII, 322, illustrated, and Tome II, Notes et documents, pp. 327, Paris, I870. GauthierVillars.

('76). Косн, RoBerT. Aetiologie der Milzbrandkrankheit begründet auf die Entwicklungsgeschichte des Bacillus anthracis. Cohn's Beiträge 2. Biol. đ. Pflanzen. Bd. II, p. 277, Breslau, I876.

('77). PASTEUR, L. Etiologie des maladies charbonneuses. Archives Vétér. 'T. II, Paris, I877, pp. 668-67I.

('80). Pasteur, Chamberland ét Roux. Sur l'étiologie du charbon. Archives Vétér. T.V., Paris, 1880, pp. 548-557.

('80). Pasteur, Louis. Sur les maladies virulentes, et en particulier sur la maladie appelee vulgairement choléra des poules. C. R. des sé de l'Acad. des sci. 'T. Xc, I880, pp. 230-248.

('8I). Koch, Rober' Zur Aetiologie des Milzbrandes. Mitteil. a. d. K. Gesundheitsamte. .Bd. I, I88I, pp. 49-79.

('82). LOEFFler UND SchulTz. Vorläufige Mitheilung über die Arbeiten des K. Gesundheitsamtes, welche zur Entdeckung des Bacillus der Rotzkrankheit geführt haben. Deutsch. med. Wochenschr. Bd. viIr, I882, pp. 707708.

On the bacillus of glanders. See Vol. CXV, New Sydenham Society for an English transiation.

('83). EBERTH, C. J. Der Typhusbacillus und die intestinale Infection. Vortrag 226, Volkmann's Sammel. Klin. Vorträge. Innere Med. No. 77 , pp. 2,033-2,050, with 2 figs. Leipzig. Breitkopf und Härtel, I883. Bibliography of 13 titles.

(83). FEHLEISEN. Die Aetiologie des Erysipels. Verlag von Theodor Fischer. Berlin, I883, pp. 38 .

('84). Pasteur, Chamberland et Roux. Sur la rage. C. R. des sé. de l'Acad. des Sci. T. XcvirI, Paris, I884, pp. I229-I231.

Earlier papers will be found in the same journal,

T. XCVIII, p. 457; T. XCV, p. 1187, and T. XcII, p. 1259 .

('84). LOEFFLER, FRIÉDRICH. Untersuchungen über die Bedeutung der Mikroorganismen für die Entstehung der Diphtherie beim Menschen, bei der Taube und beim Kalbe. Mitteil. a. d. K. Gesundheitsamte. Bd. II, I884, pp. 42I-499.

('84). GAFFKY. Zur Aetiologie des Abdominaltyphus. Mittheil. a. d. K. Gesundheitsamte, Bd. II, I884, pp. $372-420$.
('84). Косн, RoBERT. Die Aetiologie der Tuberkulose. Mitteil. a. d. K. Gesundheitsamte, Bd. II, I884, pp. I-88, with to plates.

See Vol. CXV, New Sydenham Soclety for English translation. This paper should be read by every student who desires to know how a good piece of investigation is conducted.

('84). Nicolaier, AR'Trur. Ueber infectiösen Tetanurs. Deutsche med. Wochenschr., I884. Bd. $x$, pp. $842-844$.

('84). Koch, RoBER'T. Vortrag über die Cholera. Berliner klin. Wochenschr. Nos. 31 and 32 pp. 477-483 and 493-503. Deutsche med. Wochenschir. Nos. 32 and $32 a$, I884, pp. 499507 and 519-523. Reprinted also in Fortschr. der Medicin, Bd. II, Beilage, Heft I6, I884, pp. I2I-I34 and Heft I7, pp. I4I-I68.

Describes the " comma bacillus," now generally recognized to be the cause of Asiatic chiolera.

('84). Косн, R. Ueber die Cholerabakterien. Deut. Med. Wochenschr., Bd. x, I884, pp. 725-728.

('84). Chauveau, A., et Arloing, S. Etude expérimentale sur la septicémie gangréneuse. Bull. de l'Acad. de méd., Paris, 6 mai, I884, 2e série, T. XI1I, pp. 604-6i5.

('85). Nicolaier, Arthur. Beiträge zur Aetiologie des Wundstarrkrampfes. Inaugural-Dissertation, Göttingen, I885, W. Fr. Kaestner, pp. 3I.

('87). NOCARD ers Roux. Sur la culture du bacille de la tuberculose. Annales de l'Inst. Pasteur, T. I., I887, pp. I9-29.

('88-'oo). Roux, E., ET Y Y ERSIN, A. Contribution à l'étude de la diphthérie. Ann. l'Inst. Pasteur. Ier mémoire, Tome II, I888, pp. 62966I. 2e mémoire, Tome IIr, 1889. pp. 273288. 3e mémoire, Tome Iv, 1890, pp. 385-426.

('89). Berring. Beiträge zur Aetiologie des Milzbrandes. Ztschr. f. Hyg., Bd. VII, I889, pp. I7 I-I 85.

('89). Kitasato, S. Ueber den Tetanus bacillus. Ztschr. f. Hygiene, Bd. vil, I889, pp. 225234, I plate.

('80). Hog cholera. Its history, nature, and treatment, as determined by the inquiries and investigations of the Burean of Animal Industry, U. S. Dept. Agric. Gov't. Pr. Office, Washington, D. C., I889, pp. I97, pl. I6.

Bulletin prepared in great part by Dr. Theobald Smith.

('oo). SMrth, Theodald. On the influence of slight modifications of cuiture media on the growth of bacteria as illustrated by the glanders bacillus. Journal of Comparative Medicine and Veterinary Archives, vol. xI, pp. I58-I6r.

('gI). KiTasato, S. Experimentelle Untersuchungen über das Tetanusgift. Zeitschr. f. Hyg., Bd. $x$, I 891, pp. 267-305.

('or). Smitir, Tribobald. Special report on the cause and prevention of swine plague. Bureau of Animal Industry, U. S. Dept. of Agriculture. Bull. 6, I89I, pp. I66, I2 plates.

('ar). Smitri, Theobald. Zur Kenntniss des hogcholerabacillus. Centralb. f. Bakt., Bd. IX, pp. 253-257, 307-3II, and 339-343.

('92). PFEIFrER, R. Vorlänfige Mittlieilungen über die Erreger der Influenza. Dent. med. Wochenschr., Bd. Xviri, I892, p. 28.

('93). Behring. Die Geschichte der Diphtherie. Leipzig, I893.

Not seen. 
('93). Brieger, Ludwig, and Cohn, Georg. Untersuchungen über das Tetanusgift. Zeitschr. f. Hyg., Bd. Xv, pp. I-IO, 1893 .

As small a quantity of the tetanus poison as $0.000,23$ gram would be a lethal dose for a man weighiog 70 kilos. This is an inference based on experiments wlth mice.

('93). Moore, VERANus A. Observations on the morphology, biology, and pathogenic properties of twenty-eight streptococci found in the investigation of animal diseases. Bureau of Animal Industry, U. S. Dept. of Agriculture, Bull. No. 3,1893 , pp. 9-30.

('93). Moore, V. A. Pathogenic and toxicogenic bacteria in the upper air passages of domesticated animals. Bulletin No. 3, Bureau of Animal Industry, U. S. Dept. Agric., I893, pp. 38-48.

('93). PFEIFFER, R. Die Aetiologie der Influenza. Zeitschr. f. Hyg., Bd. XIIr, I893, pp. 357-386, 8 plates.

('94). Novy, F. G. Ein neuer anaërober Bacillus des malignen Oedems. Zeitschr. f. Hyg., Bd. XVII, I894, pp. 209-233, 2 heliotype plates from photomicrographs by Dr. Pfeiffer.

('94). Kitasato, S. The bacillus of bubonic plague. The Lancet, London, I894 (II), pp. 428-430.

('95). Sieber-Schoumow, MмE. N. O. Contribution à l'étude des poissons venimeux. Sur le Bacillus piscicidus agilis, microbe pathogène pour les poissons. Arch. d. sci. biol., Tome III, I895, St. Pétersb., pp. 226-256, I colored plate, 7 figs.

Author lsolated from dying fish and from the water of the reservoir contaluing the sick fish, its inflow and outtlow pipes, an anaerobic, gas forming ( $\mathrm{CO}_{2}$ ), motile, short organism (Bacillus piscicidux agilis), pathogenic to cold-blooded animals, especially fish and frogs. Ot garism cosgulates milk and grows readily $8 t 37.5^{\circ} \mathrm{C}$. It was killed by a hesting (5-10 min.) iu river water at 68-70 C., and agar or gelatin culturea yjelded the cholera red reaction with hydrochloric acid. The organism is also toxic to white mice, guinea pigs, rabbits, and dogs, but not to pigeous.

('98). Shiga, Kiyoshi. Ueber den Erreger der Dysenterie in Japan. Centralb. f. Bakt., I Abt., Bd. XXIII, I898, pp. 599-600.

('98). SMITH, THEOBALD. A comparative study of bovine tubercle bacilli and of human bacilli from sputum. The Jour. of Exper. Med., vol. III, I898, pp. 45I-5II.

('g8). L,OFFFL,ER. Benicht der Commission zur Etrforschung der Maul- und Klauenseuche bei dem Institut für Infektionskrankheiten in Berlin. Erstattet an den Cultusminister von dem Vorsitzenden der Commission, Berlin, Aug. 12, 1898. Deutsche mediz. Wochenschr., I898, No. 35, pp. 562-564. Also a separate. Reprinted in Centralb. f. Bakt., I Abt., Bd. xxrv, I8g8, pp. 569-574.

Organism passes through a Chamberland filter, and is invisible.

('98). Petruschky, J. Ueber Massenausscheidung von Typhusbacillen durch den Urin von Typhus-Rekonvalescenten und die epidemiologische Bedeutung dieser Thatsache. Centr. f. Bakt. I Abt., Bd. xxıı, I898, pp. 577-583.

('98). Nocard, Ed., et L ECLAINChe, E. Les maladies microbiennes des animaux. 3d ed. I903. Tome I, pp. II, 668; Tome, II, pp. 645. Paris, Masson et Cie.
('98). Nocard Et Roux. Le microbe de la péripneumonie. Bulletin de la Soc. Central de Méd. Vétérinaire. Recueil de Méd. Vétérinaire Annexe, Paris. Nouvelle sér., T. I6. Mar. 24, I898, pp. 213-233. See also the Veterinary Journal, London, vol. XLvII, pp. 147-I52.

Authors describe as the cause of pleuro-pneumonia in cattle an orgauism of very small aize, not visible clearly eveu after staining. The serum from diseased foci is extremely virulent, but $\mathrm{jt}$ is impossible to cultivate anything from this serum by any of the ordiuary methods. Many bacteriologists have tried and failed, iucludiog Nocard and Roux. These authors foally succeeded in cultivating it in bouillon in collodion sacks. The bouil lon was inoculated with a little of the virulent serum and the sacks were then placed in the peritoneum of rabbits, where they were sllowed to remalo some weeks subject to osmosis. The organism clouds the bouillon slightly, and is visible under high magnifications, in brigbt light, as innumerable, minute, bright, mobile points. This bouillon is capable of reproducing the dis ease but is free from bacteria cultivable on ordinary media. Check sacks iocubated in the peritoneum gave no such result, veither did sacks inoculated with healed virus. Collodion sack cultures lacubated in the perltoneal cavity of animals were first used (?) by Metchaikoff Roux and Salimbeni in their study of the toxin and antl. toxio of cholera.

The authors finally succeeded in cultivating this or ganism oulside of the animal body, by nsing a special boullon and a special agat (see Les maladies microbleanes des animaux, I903, T. I., p. 450). "Virulent albuminous liquids, pulmonary serum not diluted, or the Martin serum bouilion filtered through Chamberland or Berkefeld bongies, gives a sterile filtrate. On the contrary, after dilutiou of the same liquids in a non-albu. minous medium, the microbe passes through the Berte. feld a ad the Chamberland bougie. Under these conditions the filtration eaables one to obtain without difficulty a characteristic pure culture, even from inpure products."

('98). Nocard ett Roux. Le microbe de la péripneumonie. Ann. de l'Inst. Pasteur, I8g8, T. XII, pp. 240-262.

('99). GELPKE, THEODOR. Bacterium septatum und dessen Beziehungen zur 'Gruppe der Diphtherienbacterien ( $B$. diphtheriae [Klebs-Löffler], B. pseudodiphtheriticum [Löffer] und B. xerosis). Arb. a. d. Bact. Institut der techn. Hochschule zu Karlsruhe, II Bd., 2 Hefte, I899, pp. 71-148. 5 plates (40 photomicrographs) and 4 charts. Bibliog. of 45 titles.

('O). WELCH, WILLIAM H. Morbid conditions caused by the Bacillus aerogenes capsulatus. Phila. Med. Journ., vol. vi, I900, pp. 202-2I6.

('o). Fle EXNER, Simon. On the etiology of tropical dysentery. Phila. Med. Journ., vol. vi, I900, pp. 4I4-424. The autbor calls special atteution to Sbiga's results.
Flexner studied this disease in the Phillppines. He says "That the bacillus is ideotical with tbe organism obtalned by Shiga jut the epidemic of dysentery which prevalled in Japan, there can be no reasonable doubt. In vailed in Japan, there can be no reasonable doubt. In
morphological, cultural, a od pathogenic characteristics morphological, cultural, aod pathogenic,

('oo). Gormam, F. P. The gas-bubble disease of fish and its cause. U. S. Fish Commission, Bull. for I899, pp. 33-37, I900, Washington.

('o). Smith, R. GREjG. A new bacillus pathogenic t. fish. Proceedings, Linnean Soc., New South Wales for Igoo. Sydney, I90I, vol. XXv, pp. I22-I30. Two heliotype plates.

This is named Bacillus piscidus bipolatis, in allusion to the bipolar germlnation of its apores. The organlsm is motile, and lique fies gelatin. 
('oo). SMITH, R. Greig. A fish disease from George's River. Proc. Linnean Soc., New South Wales for I900. Sydney, I901, vol. $\mathrm{xxv}, \mathrm{pp} .605-609$.

('99-'oo). Moschcowitz, Alexis V. Tetanus. A study of the nature, excitant, lesions, symptomatology, and treatment of the disease, with a critical summary of the results of serum therapy. Studies from the Dept. of Pathology of the College of Physicians and Surgeons, Columbia University, New York. Vol. vII, 88 pp. A bibliography of 337 titles. I899-1900.

('or). Schultz, N. K. De la vitalité du microbe de la peste bubonique dans les cultures. Arch. des Sci. Biol. publiées par l'Inst. Impérial de Méd. Exper. à St. Pétersbourg. T. viri, No. 4, I90I, pp. 373-389. I plate.

Organlsm not sporiferous. Author made various tests from old cultures kept in sealed tubes of bouillon, and concludes that under favorahle conditions the pest bacillus may preserve its vitality and virulence for four years. In its most modified form,
of very small round grains.

('or). Tartakowsky, G., et Dchounkowsky. Du microbe de la péripneumonie des boeufs. Arch. des sci. biol. publiées par l'inst. impér. de méd. expér. à S.t. Pétersbourg. T. vin, Ig0I, pp. 44I-460, 6 figs.

Confirms the work of Nocard and Roux.

('02). MARSH, M. C. Bacteritum truttre, a new species of bacterium pathogenic to trout. Science, n. s., vol. Xvi, No. 409, pp. 706-707, Oct. 3I, I902. Also a separate.

This organism hrowns nutrient agar. Its thermal death point is said to be $42^{\circ} \mathrm{C}$.

('o2). Shiga, K. Weitere Studien über den Dysenteriebacillus. Zeitschr. f. Hyg. Bd. XLI, I902, pp. 355-368.

('o2). Moor E, V. A. The pathology and differential diagnosis of infectious diseases of animals. Ithaca, N. Y., 1902. pp. XIV, 380. 73 figs. 8 plates.

('O2). KосH, RoBERT. An address on the transference of bovine tuberculosis to man. Brit. Med. Jour., London, 1902, vol. 2, pp. I,885r,889.

('o3). Marsh, M. C. A more complete description of Bacterium truttre. Bull. U. S. Fish Commission for 1902. Washington, Govt. Printing Office, I903, pp. 4II-4I5, with two plates. Also a separate.

Grows well in media which is neutral or +5 , but there is little or no growth when the acidity is +15. Growth is also inhibited by an alkalinity of -5 . Gelatir and blood serum are liquefied. There is no growth on potato unless it is first neutralized; then there is a scanty white growth. Milk is not coagulated, but it becomes fairly transparent after two weeks. It does not ferment glucose, lactose or saccbarose. It reduces nitrates to uitrites and to ammonia. It is vot clearly mobile It does not pro. duce indol or phenol. The optimum temperature is at or neat $20^{\circ} \mathrm{C}$. It is actively pathogenle to trout, especially or near trout, in which the discase was first observed.

('O3). Monfallet, D. Bibliographie abrégée des infeotions. Paris et Santiago (Chili), Ch. Goffi, éditeur, 1903, pp. 1-65.

About 1900 classified references to papers on human and animal diseases of a communicable nature.

('04). REMIINGER, P. Les travaux récent sur la rage. Bull. de l'Inst. Pasteur, I904, T. It, pp. 753764.
"We have shown that if one filters au emulsiou of rabies virus through a Berkefeld $V$ bougie and then centrifuges the filtrate, the upper layers are deprived of viruleuce, but the virulence is kept in the lower layers. Barratt hus obtained the same results with an unfiltered emulsiou of a rabid brain."

('04). FleXNer, Simon, Holt, L. EMMeTt, and assistants. Bacteriological and Clinical Studies of the Diarrheal Diseases of Infancy, with Reference to the Bacillus Dysenterize (Shiga). Studies from the Rockefeller Institute for Medical Research, New York. Vol. II, I904, pp. 7-202.

\section{VI1. Predisposition, Conditions Favoring Infection} or Immunity.

('80). Chauveau. See xxil.

('8I). LOEFFIER, FRIEDRICF. Zur Immunitätsfrage. Mitth. a. d. K. Gesundheitsamte. Bd. I, I881, pp. 134-I87. Also a separate, 54 pp.

('87). MetchnikofF. See XXI.

('88). NuTTali. See XXXviII.

('88). NutTati. See XXI.

('88). FiuEGGe, C. Studien über die Abschwächung virulenter Bakterien und die erworbenc Immunität. Zeitsch. f. Hygiene. 1888. Bd. Iv, pp. 208-230.

('89). BuchNer. See XXI.

('89). Nissen. See XXI.

('9o). LEHMANN. See XXI

('or). Ogata. See XXI.

('9r). BUCHNER, HANS. Ueber Immunität, deren natïrliches Vorkommen und künstliche Erretgung. Münch. Med. Wochenschr. I891, 38 Jahrg., pp. 551-554, 574-579.

('04). EHritch and WassermanN. See Xxi.

('OI). Huepre, Ferdinand. Perlsucht und Tuberculose. Berliner klin. Wochenschrift, Igor, No. 34, pp. 876-878. Also a separate, pp. Io.

('OI). ZaBolotNY, D. Recherches sur la peste. 2 mém. Expériences d'inoculation, d'immunisation et de traitement des animaux. Arch des Sci. Biol. publiées par l'Inst. Impérial de Med. Exper. à St. Pétersbourg. T. vIII, No. 4, I90I, pp. 390-427. 2 plates.

('or). METCHNIKoFF, Elite. L'immunité dans les maladies infectieuses. Paris (Masson), I90I, pp. Ix, 600, av. fig. German trans. by Julius Meyer. Jena (Fischer), I902, pp. XI, 456.

Not seen.

('o2). Ammon, Orro. Theoretische Betrachtungen iiber Ansteckung und Disposition. Arch. f. Hyg. Bd. XLII, Ig02, pp. 289-305.

('02-'04). KOLIE, and Wasserman. See III.

V111, Symbiosis, Antagonism.

('8I). KERN, EDWARD. Ueber ein neues Milchfcrment aus dem Kaukasus. Bull. de la Soc. Imp. d. Nat. de Moscou, Tome Livi, pp. I4I177, 2 d part (No. 3), 2 plates, I88I.

Kephir. Dispora caucasica, nov. gen. and n. sp. Plates good.

'84). KranniIals, H. Ueber das Kumys-ähnliche getränk "Kephir" und ueber den "Kephir"pilz. Deutsch. Archiv. f. klin. med. Bd. Xxxv, pp. I8-37, I plate. Bibliography of 18 titles. 
('84). Struve, Heinrich. Ueber Kephir. Ber. d. deutsch. chem. Gesellsch. Bd. Xvir, i884, pp. 3I4-3I6 and I,364-I,368.

('87). METCINIKOFl. See XXI.

('87. GARRÉ, C. Ujeber Antagonisten unter den Bacterien. Correspondenzbl. f. Schweizer. Aerzte, Jahrg. xvir, I887, pp. 385-392.

('88). NUTTALL. See XXI.

('88). DE FREUDENREICH, E. De l'antagonisme des bactéries et de l'immunité qu'il confère aux nilieux de culture. Ann. de 1'Inst. Pasteur, T. II, 1888, pp. 200-206.

('88). Dubors. See Xxvir.

('88). Hfricourt. Des associations microbiennes. Rev. de méd., T. -, I888, pp. -

Not seen.

('88). Sirotinin. Ueber die entwicklungshemmenden Stoffwechselproducte der Bacterien und die sog. Retentionshypothese. Zeitsch. f. Hyg. Bd. IV, I888, pp. 262-290.

('89). Beyminck, M. W. Sur le kéfir. Arch. néer. des sci. ex. et nat., T. xxiII, I889, pp. 428444. I fig.

('89). RoGERS, G. H. Quelques effets des associations microbiennes. C. R. hebd. d. sé. et mém. de la soc. de. biol., ig janvier, I889, Paris, sé. 9, T. I, pp. 35-38.

Two bacleria, inoffensive to a given animal, may be come pathogenic when inoculaled together.

('go). BragovestchensKY, N. Sur l'antagonisme entre les bacilles du charbon et ceux du pus bleu. Ann. de l'Institut Pasteur, T. Iv, 1890, pp. 689-715.

('9I). Mix, Cirarles L. On a kephir-like yeast found in the United States. Proc. Amer. Acad. of Arts and Sciences, I89I, n. s. vol. XVIII, PP. IO2-II4.

('93). WArd, H. Marshali, The ginger-beer plant, and the organisms composing it. A contribution to the study of fermentation-yeasts and bacteria. Pliil. Trans. Roy. Soc. (B) for I892. London, I893, vol. I83, pp. I25 to 197, Pl. 6.

('94). Galtris, V. Nouvelle recherches sur l'influences des associations bactériennes. Exaltation de la virulence de certain microbes. Accroissement de la receptivité. $C . R$. des sé. de l'Acad. d. sci., T. cxvill, I894, pp. I,00I-I,004.

(' 96 ?). von FREUDENREICII, EDUARD. Bakteriologische Untersuchnngen ïber den Kefir. Landw. Jahrbuch d. Schweiz, I896. Bd. x, pp. I-20. 2 text figs, and I heliotype plate.

('97). von FrEudenREIci, Fd. Bakteriologische Untcrsuchungen über den Kefir. Centralb. f Bakt., 2 Abt. Bd. III, 1897, pp. 47-54, 2 figs.; $87-95,135-141$.

('oo). Krause. See xv.

\section{Carriers of Infection.}

('88). AlESSI, GUISEPPE. Sulla trasmissibilità dei germi infettivi mediante le deiezioni delle mosche. Arch. per lo sci. med. Vol. XII, Torino, I888, pp. 279-202.

('9r). W WAIT, M. B. Results from recent investigations in pear blight. Proc. Am. Asso. Adv. Sci., 40th meeting, Salem, I892.

Mr. Waite obtained his first resuils in 1841 , and called attention to them al the Wrshington meeting of the $\mathrm{Am}$. Asso. Adv. Sci. that aummer.
('94). Yersen, La peste bubonique à Hong-Kong. Ann. de l'Inst. Pasteur. T. viII, I894, pD. $662-667$.

The pest is carried by rats.

('95). Smitis, ERwin F. Bacillus tracheiphilus, etc. Centralb. f. Bakt.,etc. 2 Abt. I Bd., I895, p. 365 .

The disease is spread by beetles.

('96). SMITH, ERwin F. A bacterial disease of the tomato, egg plant, and Irish potato. Washington, 1896, p. 22 , and P1. II, fig. 3 .

Disease communicated by beetlea.

('97). Marpmann. See xlix.

('97). SMITh, ERwin F. Pseudomonas campestris (Pammel). The cause of a brown rot in cruciferous plants. Centralb. f. Bakt. 2 Abt., Bd. III, P. 409-4IO.

Disease communicated by siugs and by larvæ of the cabbage bulterfly.

('98). Simond, P. L. La propagation de la peste. Ann. de l'Inst. Pasteur, T. XII, I898, pp. 625-687. 5 figs.

('98). NuTtal, George H. F. Zur Aufklārung der Rolle, welche stechende Insekten bei der Verbrcitung von Infektionskrankheiten spielen. Centralb. f. Bakt., Bd. Xxirr, I Abt., I898, pp. 625-635.

('99). Nu'Ttall, G. H. F. On the rôle of insects, arachnids, and myriapods as canriers in the spread of bacterial and parasitic diseases of man and animals. Johns Hopkins Hosp. Repts., vol viII, No. I-2, pp. I-I54. 3 plates. Bibliography of 366 titles.

Noticed in Nature, Dec. 14,1899 .

('oo). Galit-Valerto, Bruno. Les puces des rats et des souris jouent-elles un rôle important dans la transmission de la peste bubonique à l'homme? Centralb. f. Bakt., I Abt., Bd. XXVII, I900, pp. I-4. 3 figs.

('O2). Galit-VALERIo, BRUno.. The part played by the fleas of rats and mice in the transmission of bubonic plague. Jour. Trop. Med., Londan, vol. v, 1902, pp. 33-36.

('04). BREnNer, W. Die Scliwarzfäule des Kohls. Centralb. f. Bakt. 2 Abt. Bd. xiI, p. 729.

Disease said to be communicated by aphides.

X. General Morphology of the Bacteria. Cytology.

('74). BiLlRoTII, THEODoR. Untersuchungen über die Vegetationsformen von Cocco-bacteria septica und den Antheil welchen sie an der Entstehung und Verbreitung der accidentellen Wundkrankheiten haben. Berlin, I874. Verlag von Georg Reimer. Quarto, pp. xIV, 244. 5 plates.

('77). BILLROTH, TH., AND EHRLICH, F. Untersuchungen über Coccobacteria septica. Archiv. f. klinische chir. Bd. xx, pp. 403433, I pl., Berlin, 1877 .

('78). HALLIER, ËRST. Die Plastiden der niederen Pflanzen, ihre selbststāndige Entwickelung, ihr Eindringen in die Gewebe, und ihre verherende Wirkung. Leipzig., I878, pp. 92, 4 plates.

('82). Zopr, W. Zur Morphologie der Spaltpflanzen. Spaltpilze und Spaltalgen, Leipsic, I882, pp. vi, 74. Verlag von Veit and Comp. 7 plates. 
('86). Hueppe, FERdinand, Die Formen der Bakterien und ihre Beziehungen zu den Gattungen und Anten. I886. pp. VIII, 152, 24 figs. Wiesbaden. C. W. Kreidel's Verlag.

('88). Pom mer, Gustav. Ein Beitrag zur Kenntniss der fadenbildenden Bakterien. Mitth. bot. Inst. Graz, Jena, I888, pp. 93-I I2. I plate. Bacillus brassicæe, a sporiferous form, isolated from an imperfectly sterilized decoction of cabbage leaf.

('89). MEт́chñкоFF, Eı. Contributions à l'étude du pléomorphisme des baotéries. Ann. de l'Inst. Pasteur, T. III, I889, pp. 6I-68. I plate.

(89). ERnst, Paul. Ueber Kern-und Sporenbildung in Bakterien. Zeitschr. f. Hyg. Bd. v, 1889, pp. 428-486. 2 plates.

('80). BABES, VIctor. U.eber isolirt färbbare Antheile von Bakterien. Zeitsohr. f. Hyg. Bd. v, I889, pp. I73-Igo. I plate.

('89). Winogradsky, S. Pléomorphisme des bactéries. Ann. de l'Inst. Pasteur, T. II I, I889, pp. 249-264.

('89). METCHNIKoFF, E.L. Nate sur le pléomorphisme des bactéries. Ann. de l'Inst. Pasteur, T. III, I889, pp. 265-267.

('go). Almouist, E. Untersuchungen über einige Bakteriengattungen mit Mycelien. Zeitsch. f. Hyg. Bd. viII, I890, Heft 2, pp. I89-197.

('oo). Bürschli, O. Ueber den Bau der Bakterien und Verwandter Organismen. Leipzig, C. F. Winter, I890, pp. 37. I pl.

Maintains the existence in the bacteria of a body corresponding to a cell nucleus.

('oI). FamintziN, A. Eine neue Bakterienform, Newskia ramosa. Bulletin de l'Acad. de St. Pétersbourg. Nouvelle série (II), I891, T. XXXIV, p. 48 I.

Not seen.

('OI). DANGEARD. See XXIII.

('gi). Protopopofr. Sur la question de la structure des bactéries. Ann. de l'Inst, Pasteur, I89I, Tome v, p. 332-336.

('9I). Zitrinow, E. Ueber den Bau der Bakterien. Centralb. f. Bakt. x Bd., I891, pp. 689-694 I Tafel.

('92). ZukaI, Hugo. Ueber den Zellinhalt der Schizophyten. Ber. d. deutsch. bot. Gesellsch. $\mathrm{X}, \mathrm{I} 892$, pp. 5I-55.

('92). Sjombring, Nils. Ueber Kerne und Theilungen bei den Bakterien. Centralb. f. Bakt., XI Bd., I892, pp. 65-68, with I colored Tafel.

"In the bacterial body there may be demonstrated consequents in other cells, two components $-v$ ucleus sequently, as in other cells, two components - a disand cell-bod"

('92). Thaxter, Rorand. On the Myxobacteriacex, a new order of Schizomycetes. Botanical Gazette, vol. xvir, No. I2, pp. 389-406. Pls. XXII-XXV, I892.

('g2). Sauvageat, C., et Radais. Sur les genres Cladothrix, Streptothrix, Aotinomyces, et description de deux Streptothrix nouveau. Ann.de l'Inst. Pasteur. 'T. VI, I892, pp. 242273. I plate.

('92). FoERSTER, F. Ueber eine merkwürdige Erscheinung bei Chromatium Okenii Ehrbg. sp. Centralb. f. Bakt., XI Bd., I892, pp: 257-264, mit I taf. (colored).

Author'a figures show curlous bands or bridges connecting the bacterial cells sidewise as well as end to end.
('92). Trambusti, A., and Galeo'tut, G. Neuer Beitrag zum Studium der inneren Struktur der Bakterien. Centralb. f. Bakt., XI Bd., I892, pp. 717-722, mit I Taf. (colored).

('92). KLEIN, E. Zur Geschichte des Pleomorphismus des Tuberculoseerregers. Centralb. f. Bakt., XII Bd., 1892, pp. 905-906.

('02). BuÉrschLI, O Untersuchungen über mikroskopische Schäume und das Protoplasma. 4to, mit 6 lithogr. Taf. u. 23 Fig. im Text, so wie einem Atlas von I9 Mikrophotographieen. Leipzig, I892. Rev. in Centralb. f. Bakt., Bd. XIII, I893, pp. $436-438$.

Again maintains the existence in bacteria of a Centralkoerper corresponding to a nucleus, and points out that Alfred Fischer's criticism of his former statements has uo substantial basis. See especially pp. 75 to 79 .

('94). Beyerinck, M. W. Ueber die Natur der Fäden der Papilionaceenknöllchen. Centralb. f. Bakt., Bd. Xv, I894, pp. 728-732.

('94). IlkEWICz, W. Ueber die Kerne der Milzbrandsporen. Centralb. f. Bakt., Bd. xv, 1894, pp. 26r-267, mit I Figur.

('95). Ward, H. Marshal.4. The formation of bacterial colonies. Annals of Botany, vol. IX, I 895 , pp. 653-657.

('95). WARD, H. Marshali. A false bacterium. Annals of Botany, vol. IX, I895, pp. 657-658.

('95). Wager, Harold. Preliminary nate upon the structure of bacterial cells. Annals of Botany, vol. IX, I805, pp. 659-66I.

('95). ICoppen-Jones, A. Ueber die Morphologie und systematische Stellung des Tuberkelpilzes und über die Kolbenbildung bei Aktinomykose und Tuberkulose. Centralb. f. Bakt., XVII Bd., I895, pp. I-I6 and 70-76, with I plate.

('95). BRUns, Hayo. Ein Beitrag zur Pleomorphie der Tuberkelbacillen. Centralb. f. Bakt., XVII Bd., I 895 , pp. 817-826, with 8 figs.

('95). LuBINSKI, Ws. Zur Kultivierungsmethode, Biologie und Morphologie der Tuberkelbacillen. Centralb. f. Bakt., xvir Bd., I895, pp. I25-I 28 .

('95). BABEs, V. Beobaohtungen über die metachromatischen Körperchen, Sporenbildung, Verzweigung. Kolben-und Kapselbildung pathogener Bakterien. Zeitschr. f. Hyg. Bd. $\mathrm{xx}, 1895, \mathrm{pp} .412-437,2$ plates.

Fig. I $8 e$ of Table XI is particularly instructive. This shows a true bramchiug in the anthrax organism, but it is confined to the capsule.

('g6). Coppen-Jones, A. Ueber die Nomenclatur des sog. "Tuberkelbacillus." Centralb. f. Bakt., I Abt., Bd. xx, I806, No. I0-Ix, pp. 393-395.

('06). KANTHACK, A. A. Ueber verzweigte Diphtheriebacillen. Centralb. f, Bkt., $\mathrm{xx}$ Bd., 1896, pp. 296-297.

('96). ZETrNow. Bilder von Spirillum undula mnajus bei freiwilligem Absterben. Centralb. f Bakt., XIX Bd., 1806, pp. I77-I80, with I plate, I6 figs.

('97). ThaxTER, Rouand. Contributions from the Cryptogamic Laboratory of Harvard University. xxxix. Further Observations on the Myxobacteriaceae. Botanical Gazette, vol, XXIIr, No. 6, r897, pp. 393-4Ir, 2 plates.

('97). Marpmann, G. Zur Morphologie und Biologie des Tuberkelbacillus. Centralb. f. Bakt., xxII Bd., I 897 , pp. 582-586, with I plate. 
('97). JonAan-Or,Sen, Olav. Zur Pleomorphismusfrage. Centralb. f. Bakt., 2 A.bt., Bd. I11, 189\%, pp. 273-28.4, 2 plates.

linds branching forms.

('97). KurT. Die Streptothrixform des Rotlaufbacillus. Centralb. f. Bakt., xxı Bd., I897, pp. $726-732$, with 4 figs.

('g8). Schultz. See x xxvili.

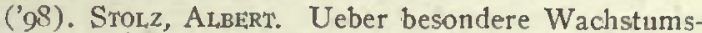
formen bei Pneumo- und Streptokokken Centralb. f. Bakt., xxıv Bd., I898, pp. 337343, with 6 figs.

rigures look like involution forms.

('98). Zifmann, Hans. Eine Methode der Doppelfärbung bei Flagellaten, Pilzen, Spirillen und Bakterien, sowie bei einigen Amöber. Centralb. f. Bakt., xxıv Bd., I898, pp. 945955, I plate.

The author's figures show the body of tbe spirilinm blue enclosing I-5 c8rmiu colored granules.

(98). Ruzicka, Vhad. Zur Frage von der inneren Struktur der Mikroorganismen. Centralb. f Bakt., XXIII Bd., I898, pp. 305-307, with plate.

Finds granules, which take stains, in bacterial body reserves conclusions as to their nsture, but thinks they are not pleomorphic or degeneration phenomena.

('gS). Grassberger, R. Zur Frage der Scheinfädenbildung in Influenzaculturen. Centralb. f. Bakt., XxiII Bd., I898, pp. 353-364, with I plate and 4 text figs.

('98). Burchard, Grorg. Beiträge zur Morphologie und Entwickelungs-Geschichte der Bacte rien. Arb. a. d. Bact. Institut der tech. Hochschule zu Karlsruhe, "I Bd., I Heft, 1898, pp. $1-64,2$ pl.

Twenty new species sre described-Bacterium pituitans, B. perittomaticum, B. flexile, B. turgescens, B. brachy'sporum, B, implectans, B petroselini, B. sngulkns, Bacillis goniosporus, B. pectocutis, B. pancicutis, B cylind rosporus, B. leptodermis, B. bipolaris, B. loxosils, B. myxodens, B. arnoraciae, B. Idosus, B. loxosporus. B. cnrsot.

('98). Wagner, A. Coli- und Typhusbakterien sind einkernige Zellen. Centralb. f. Bakt., xxi11 Bd., 1898, pp. 433-438, and pp. 489-492, with 2 plates and 6 figs.

('08). Craig, Ciiarles F. The branched form of the bacillus tuberculosis in sputum. The Journ. of Exp. Med., vol. I11, 1898, pp. 363-37o, I plate.

Author thinks it is prenature to sepstate $B$. tubercuA uthor thinks it is premature to sepstate B. tubercu-
losis from the bacteria on account of this phenomenon.

('99). SchulzE, Otro. Untersuchungen ïber die Strahlenpilz formen des Tuberculoseerregers. Zeitschr. f. Hyg. Bd. xxxi, 1899, pp. 153I86, I plate.

('99). Galli-Valerio, Bruno. Contribution à l'étude de la morphologie du Bacillus mallei Centralb. f. Bakt., xxv Bd., I899, pp. I77180 , with 5 figs.

Autbor fuds branched forms in boullon and on agar.

(99). Berestenw, N. Zur Frage der Klassifikation und systematischen Stellung der Strahlenpilze. Centralb. ff Bakt. Xxvi, I 899, p. 300

('99). MoËLler, ALFRED. Eïn neuer säure- und alkoholfester Bacillus aus der Tuberkelbacillengruppe, welcher echte Verzweigungsformen bildet. Centralb. f. Bakt., Bd. xxv, I899, pp 369-373, with I plate.
('99). Spirig, W. Die Streptothrix (Actinomyces) Natur des Diphtheriebacillus. Centralb. f. Bakt., xxvi Bd., 1899, pp. 540-541.

('99). Lubarsch, O. Zur Kenntniss der Strahlenpilze. Zeitschr. f. Hyg. Bd. XxxI, 1899, pp. 187-220, I plate.

('99). Marx, Huco. Zur Morphologie des Rotzbacillus. Centralb. f. Bakt., XXv Bd., 1899 , pp. 274-278, with 4 figs., showing branched forms.

('99). Muehlschlegel, A. Ein Beitrag zur Morphologie und Entwickelungsgeschichte der Bakterien nach Studien an drei Körnerbacillen. Arb. a. d. kaiserl. Gesundheitsamte, Bd. Xv, Heft. I, pp. I31-152, I899. I plate pantly colored. Rev. in Centralb. f. Bakt., xxv Bd., I899, p. 771 .

73 titles cited under litersture.

('oo). Fininberg. Ueber den Bau der Bakterien. Central.b. f. Bakt., xxvı Bd., 1900, pp. 417426 , with 5 plates.

Author believes he has demonstrated the existence of a nucleus in the bacteria by means of Roms nowskl's ataining method (a mixture of methylene blue and eosin). The plasma stains bIue; the nucleus, which may be small or which may fil nearly the whote bactertal body, stains red or red-brown.

('o). ZerTTNow. Romanowski's Färbung bei Bakterien. Centralb. f. Bakt., xxvil Bd., 1900, pp. $803-805$.

Says Dr. Feinberg's papers contribute "nichts Neues "

('o). Nakanishi, K. Vorläufige Mitteilungen über eine neue Färbungsmethode zur Darstellung des feineren Baues der Bakterien. Mïnch. med. Wochenschr., 1900, No. 6. Rev. in Centralb. f. Bakt., xxvir Bd., 1900, pp. 547549.

"All bacteria in their young stage, when they have grown under favorable conditions, are one-nucleate
short cells."

('o). Skschivan, T. Zur Morphologie des Pestbakteriums. Centralb. f. Bakt., xxvıII Bd., I900, pp. 289-292, with 4 text figs.

Finds v'shaped and branched forms.

('oo). Marx, Hugo, and Woithe, Friedrich. Morphologische Untersuchungen zur Biologie der Bakterien. Centralb. f. Bakt., xxviri $\mathrm{Bd}$, I900, pp. I-II, 33-39,65-69, and 97-III, with 3 plates.

('co). Galli-VAlerio, Bruno. Seconde contribution à l'étude de la morphologie du B. mallei. Centralb. f. Bakt., XxviI Bd., J900, pp. 353359 , with 26 figs.

('o1). MEYER, ARThur. Ueber die Verzweigung der Bakterien. Centralb. f. Bakt., I Abt., xxx Bd., I 901, No. 2, pp. 49-60, 2 plates.

('OI). ROSENFELD. See XV.

('OI). ReICIIENBACH, H. Ueber Verzweigung bei Spirillen. Centralb. f. Bakt, I Abt., Bd. xxıx, I90I, pp. 553-557. I heliotype plate.

Many of tbe spirffla are shown with distinct brsnches.

('o2). Buetscili, Orro. Bemerkungen über Cyanophyceen und Bacteriaceen. Archiv. f. Protistenkunde, Bd. I, Heft. I. Jena, Gustav Fischer, I902. pp. 41-58, I plate.

On the nature of the " Centralkoerpet."

('O2). ERRERA, Lteo. Sur une bactérie de grandes dimensions: Spirillum colossus. Recueil de l'Inst. botanique (Univ.de Bruxelles), $T$. v, 1902, pp. 347-357. Also a separate. 
('O2). LOEB, L. M. On branching forms of certain bacteria. Jour. of Med. Research. Vol. vIII, IgO2 (n. s., vol. III), pp. 4I5-423. The
cillus.

he author finds branching forms in the typhoid ba-

('o2). HeFFFran, Mary. An unusual bacterial grouping. Centralb. f. Bakt., 2 Abt., viII Bd., I902, pp. 689-699. Also a separate, (with 5 figures in the text).

B. rosaceus metalloides forms rosette-like groupings in liquid media and on some solid media.

('O2). Matzuschita, Trīsi. Beobachtungen über den merkwürdigen Teilungsprocess bei einem proteusartigen Luftbacillus. (Vorl. Mitteilung). Centralb. f. Bakt., Abt. 2, Bd. Ix, I902, pp. 257-260, mit I Taf.

('o3). Hill, H. W., and Rickards, B. R. Notes on Morphology. I. "Snapping" as characteristic of the diphtheroid group. II. Branching of the organism of actinomycosis. Am. Pub. Healtil Ass'n. Proc. 3ath Ann. meeting at New Orleans, Dec. 9-12, 1902, Columbus, Ohio, 1903. Also a separate, 4 pp., 2 figs.

('O3). Wolbach, S. B., and ERnst, Harold C. Observations on the morphology of Bacillus tuberculosis from human and bovine sources. Jour. of Med. Research, Ig03, vol. x, No. 3, pp. 313-333. I3 plates. Also a separate.

('04). Thaxter, Roland. Contributions from the cryptogamic laboratory of Harvard University, Lvr, Notes on the Myxobacteriaceae. Bot. Gaz., June, 1904, vol. Xxxvir, pp. 405$4 \mathrm{I} 6$, with 2 plates.

Cystobacter becomes Polyangium.

('04). Lepeschinin, W. W. Zur Kenntniss der Erblichkeit bei den einzelligen Organismen. Die Verzweigung und Mycelbildung bei einer Bakterie (Bacillus Berestnewi n. sp.) Centralblatt f. Bakt., 2 Abt., I904, Bd. X1I, pp. 64I-648, and Bd. XIII, pp. I3-22, 20 figs.

Describes a branched form.

\section{Spores.}

[See also some papers under $\mathrm{X}, \mathrm{XV}$, and XXXIV.]

('7ó). Cohn, Fírdinand. Untersuchungen über Bacterien. Beiträge zur Biologie der Pflanzen, Bd. II, Heft 2, 1876, pp. 249-276.

('84). Buchner, H. Ueber das Verhalten der Spaltpilz-Sporen zu den Anilinfarbstoffen. Aertzliche Intelligenzbl., Jahrg. xxxI, I884, pp. 370.

('87). LEHMANN, K. B. Ueber die Sporenbildung bei Milzbrand. Münch. med. Wochenschr., I887, pp. 485-488, No. 26.

('88). Prazmowski, A. Ueber Sporenbildung bei den Bakterien. Verhand. d. k. k. Akad. d. Wissenschaften in Krakau. Math.-naturw. Sektion, Bd. XvmI, I888, p. 35, I Tafel.

Author thinks existence of "arthrospores" is not proved.

('88). Globig. See xxxin and xxxiv.

('88). GrubER. See xxxiIt.

('88). BuCHNER, H. Ueber die vermeintlichen Sporen der Typhusbacillen. Centralb. f. Bakt., I888, Bd. IV, pp. 385-390.
('89). KLEIN, LUDWIG. Ueber einen neuen Typus der Sporenbildung bei den endosporen Bacterien. Ber. d. deutsoh. Botan. Gesellsch., $\mathrm{Bd}$., vil, 1889, pp. (57)-(72). I plate.

Five spore-bearing bacilli are described. The spores are green. 1n one filamentous-septate species the spores generally occur in pairs, with a septum between, i, e, the pole of one segment, and in the negative pole of its felpole

('9I). FISChER, Sce XL.

('9I). MoklleR, H. Ueber eine neue Methode der Sporenfärbung. Centralb. f. Bakt., Bd. x, 189i, pp. 273-277.

The author summarizes his method as follows: "The air-dried cover glass preparation is passed through the flame three times and put into absolute alcohol for two minutes; then two minutes in chloroform; then washed witl water one-half to two minutes. It is subsequently plunged into 5 per cent chromic acid and again thoroughly washed in water, after which carbol-fuchsin is dropped upon it and warmed over the flame to boiling for 6 seconds. The carbol-fuchsin is then poured off, the cover-glass plunged into 5 per cent sulphuric acid until it is bleached, and then thoroughly washed in water. The watery solution of methylen blue or malachite green is then allowed to act upon it for 30 seconds, after which it is washed off. The spores should then be visible as a dark red iu a beautiful green or blue bacterial body."

('91). Cramer, E. Die Ursache der Resistenz der Sporen gegen trockene Hitze. Arch. f. Hygiene, I89I, Bd. XIII, pp. 7I-II2.

Resistance is due to extreme drytuess of the spores, and to the fact that all their water is hygroscopic water, which evaporates quickly iu dry air, leaving presumably pure water-free albuinen.

('92). Fотн. Zur Frage der Sporenfärbung. Centralb. f. Bakt., XI Bd., I892, pp. 272-278.

Does not find Moellet's chromic a cid method universally applicable. Anthor soinetiuses substitutes chloriodid zinc. He has also found hydrogen peroxide very useful. He also uses auiliu water fuchsin. A pure, colorless, toluidin free anilin may be had from Joh. Wolff, in Breslau. In case of anthrax spores, the proper time of exposlau. is cas mlnutes with chroric acld 2 to $21 / 2$ minutes ure is $11 / 2$ minutes with chromic acld 2 to $2 / 3$ minutes with concentrated cliorzinc lodide solution, and 3 miuhe obtained the best results with $\mathrm{H}_{2} \mathrm{O}_{2}$.

('93). Fiocca, R. Ueber eine neue Methode der Sporenfärbung. Centralb. f. Bakt., xIv, I893, No. I, pp. 8-9.

Cover-glass preparations are plunged 3 to 15 miuutes (mostly 3 to 5 minutes) into steaming hot water containng 10 per cent arnmonia water, to which has also been added 10 to 20 drops of some alcoholic anilin solutiou. Covers thus treated are then plunged for a moment into water containing 20 per cent sulphuric ot sittic acid, and are subsequeutly exposed to a contrast stain. The stains ecommended are gentian violet, fuchsin, methylene blue and safranin; the contrast stains are vesuvin, chrysoidin, methylene blue, malacliit green or safranin. The preparations are said to be clear and satisfactory.

('93). Physalix. See xxxim.

('94). ERrst, PaUl. Färbungsversuche an Sporen mit Hilfe der Maceration. Centralb. f. Bakt., B.d. Xvi, I $894, \mathrm{pp}$. I82- I84.

('95). Miquel, P., and LatTrRaye, E. De la résistance des spores des bactéries aux temperatures humides égales et superieures à I00 degrees. Ann. de micrographie. Tome vir, I895, p. I10, I58, 205. Rev. in Centralb. f. Bakt., XIx Bd., I896, pp. 360-362.

('95). BUNGE, R. Ueber Sporenbildung bei Bakterien. Fortschr. d. Med., Bd. xIII, I895, No. 20 and $2 \mathrm{I}$. Rev. in Centralb. f. Bakt., Xvir Bd., 1895 , p. 718 . 
('96). Schre,raer, Osivald. Ueber die physiologischen Bedingungen der endogenen Sporenbildung bei Bacillus anthracis, subtilis, und tumescens. Centralb. f. Bakt., xx Bd., 1896 , 353-374 and 429-437.

Forty-five papers cited at close of this article.

('96). BuCunter, H. Ueber die plyysiologischen Bedingungen der Sporenbildung beim Milzbrandbacillus. Centralb. f. Bakt., $\mathrm{xx}$ Bd., 1896, pp. 806-807.

('98). Catrerina, G. Ricerche sull'intima struttura delle spore dei batteri. Separate from Atti d. Soc. veneto-trentina, vol. III, Fasc. 2, Padova, 1898 , jo pages, with I plate. Rev. in Centralb. f, Bakt., xxvi Bd., 1899, pp. 35-36. Some evidence in favor of existence of a nucleus.

('98). Migulı, W. Der Keimgehalt und die Widerstandsfähigkeit der Bakterien der animalen Lymphe. Arb. a. d. Bact. Institut der tech. Hochschule zu Karlsruhe, II Bd., I Heft, I898, pp. $65-72$.

('98). Aujtszky, Al,adar. Eine einfache Sporenfärbungsmethode. Centralb. f. Bakt., XxIII Bd., 1898, pp. 329-33I.

The unfixed covers are placed in a boiling lot $1 / 2$ per cent solution of $\mathrm{HCl}$ for 3 to 4 minutes, then washed in water, dried, fixed, aud stained with hot carbol fuchsin (three times over flame). Covers are then cooled, bleached in 4 to 5 per cent silphnric acid, and counterstained to 2 minutes in malachit green or methylene blue.

('99). Stepinanidis, Philopimin. Ueber den Einfluss des Nährstoffgehaltes von Nährböden auf die Raschheit der Sporenbildung und die Zahl und Resistenz der gebildeten Sporen. Arch. f. Hyg., Bd. Xxxv, 1899, pp. I-10. Review in Centralb. f. Bakt., xxvi Bd., 1899, p. 568.

In a poor substratum authrax spores were formed more rapidly but in less numbers than in a rich medium. Toward heat the spores from the rich and poor media behaved alike.

('99). Ku, EiN, Ar.ex. Eine einfache Methode zur Sporenfärbung. Centralb. f. Bakt., xxv Bd., 1899, pp. 376-379.

Klein's modification consista in staining the spores before they have dried. In a watch glass he makea a spore emulsion in phys. salt solution. To this is added an equal volume of filtered carbol fuchsin. This is then gently beated over the open flame for slx minutes, i.e. until steam rises. Covers are now prepared and the bacterial layer fixed by pasaing twice tbrough the fiame. The covers are then passed through 1 pet cent $\mathrm{H}_{2} \mathrm{SO}_{4}$ for I to 2 secouds, washed in water and counterstained 3 to 4 minutes in alcoholic methylene blue solution diluted with water.

('99). Dannappert. See $\mathrm{xxxi11}$

('oo). Sмiтн, R. GREIG. The double staining of spores and bacilli. Proceedings of the Linnean Socioty of New South Wales, 1900, Part 3, June 27, pp. 394-397. Also a separate (issued Nov. 22, 1900 )

('o2). Scilaudinn, Färirz. Beiträge zur Kenntnis der Bakterien und verwandter Organismen. J. Bacillus bütchlii, Arch. f. Protistenkunde, Bd. I, 1902, pp. 306-343, I plate. Bibliography of 24 ititles.

This very large, slow-moving otganism was isolated from the intestinal tract of a cockroach, Periplaueta from the

orientalis. spora caucasica, is constantly disporous. $\mathrm{B}$. buetchlii was spora caucasica, is constantly is porous. B, huetchi1 was
selected for study of its inner structure, on account of its selected for study of its inuer structure, on account of its
large size. The membrave did not give the cellulose telarge size.
action.
Seventy-three figures are given, illustrating inner structure, stages in the formation of the sporea (one in each pole of the rod), polar germination of the spores, etc. The otganism is 24 to $80 \mu$ long by 3 to $6 \mu$ broad, mostly 50 to $60 \mu \times 4$ to $5 \mu$. The bacillus is flagellate, after the manner of $\mathrm{B}$. subtilis.

\section{X11. Flagella.}

('38). EIIRENBERG. See v.

('72). Coun . See v.

('75). Dallinger, W. H., and Drysdale, J. J. On the existence of flagella in Baoterium termo. The Monthly Microscopical Journal, Sept. I, 1875, pp. 105-108.

('76). Warming, Eúg. Om nogle ved Danmarks Kyster levende Bakterier. Kjöbenhavn, 1876.

('77). Kocir. See I,

('78). Dalilinger, W. H. On the measurement of the diameter of the flagella of Bacterium termo: a contribution to the question of the "Ultimate limit of vision" with our present lenses. Journ. Roy. Micros. Soc., vol. I, 1878, pp. 169-175, 2 plates.

From the mean value of 200 measurements (50 with each of 1 high-power objectives) Dallinger concludes that the diameter of the unstained fiagellum of $B$. termo, iu round numbers, is one-two hundred and four thousandth (1-204000) of an iuch. This is equal to about one-eighth microu.

(79). van Tieghem, Pinlippe Edouard Leon. Sur les prétendus cils des bactéries. Bull. de la Société Botanique de France, 1879, T. Xxv, pp. $37-45$.

Van Tieghetn maintained that the flagella were moved from within the body of the bacterium, they themselve being inert gelatinous organs, and not vibratile cilia

('89). IOEFFLER, F. Eine neue Methode zum Farben der Mikroorganismen, im besonderen ihrer Wimperluare und Geisseln. Centralb. f Bakt., vi Bd., I889, No. 8-9, pp. 209-224, mit 8 Photognammen.

('89). TRENKMANN. Die Färbung der Geisseln von Spirillen und Bacillen. Centralb. f. Bakt. vi Bd., Oct. 15, 1889, No. 16-17, pp. 433-436.

('ga). Messita. See Livi.

('oO). LOEFFLR, F. Weitere Untersuchungen über die Beizu11g und Färbung der Geisseln bei den Bakterien. Centralb. f. Bakt., Bd. vis, 1890, pp. 625-639.

('9o). TRENKMAnN. Die Färbung der Geisseln von Spirillen und Bacillen. 11. Mitth. Centralb. f. Bakt., 1890, Bd. vin, No. 13, pp. 385-389.

Covers on which the bacterial film is dried without heat are put for 6 to 12 hours in water containing 2 per cent tanniu and 0.5 to 0.25 of one per cent hydrochloric acid. They are subsequently washed for one hour in fodine water, and then stained $/ 2$ hont in weak gentian violet anilin water, inade as follows: Into a test tube holding $25 \mathrm{cc}$. put a iew drops of concent rated alcoholic golution of gentian violet and add to cc, of distilfed water. Then pour out about one-half of this and fill up with anilit a teebly-stained background.

('91). Humprrey, J. E. Notes on Technique. II. Bot. Gazette, 1891, pp. 71-73.

Cilia of zoospores of algx and fungi are stained very readily and sharply "iu a drop of moderately strong solution (in 90 per cent alcohol) of Haustein's rosanillinviolet, composed of equal parts of fuchsin and methyl vlolet," after first fixing themi in a conple of drops of I per cent osmic acid solution. 
('92). Strauss, I. Sur un procédé de coloration à l'état vivant des cils ou flagella de certaines bactéries mobiles. C. R. de la Soc. de biologie, 18g2, No. 23, pp. 542-543. Also Bull. Méd., I892, p. I,003.

('93). Scravo. Di un rapido processo per le colorazione delle ciglia di alcuni microorganismi. Ministera dell'intern. Laboratori scientifica della direzione di Santa-Roma.

Rev. in Centralb. f. Bakt. Bd. xv. p. 507, 1893 .

('93). Nicol, E, M., Morax, V. Technique de la coloration des cils, etc. Ann. de l'Inst. Pasteur, T. vir, 1893, No. 7, pp. 554-561.

('93). Moors, V. A. On the character of flagella on the Bacillus choleræsuis, B. coli communis, and the B.typhi abdominalis. Wilder Quarter Century Book, Ithaca, N. Y., I893, pp. 339-363.

('93). van ERMgNGem, E. Nouvelle méthode de coloration des cils des bactéries. Trav. du Lab. d. Hygiène et de Bact. de l'Univ. de Gand, T. I., 1. 3, 1893 .

Original not seen. A very good method. Reviewed in Zeitscht. f. Wissensch. Mikr. Bd, XI. 1894, pp. 98-99, and in Aun. de Micrographie, T. v., r893, pp. 394-395.

('94). Hessert, W. Geisselfärbung ohne Beize. Centralb. f. Bakt., Bd. xvi, I894, No. 8-9, pp. 346-347.

See also $\mathrm{A}$ simpie stain for ciliated bacteria. Chicago Med. Recorder, 1894, pp. 240-242.

('94). BunGr, R. Ueber Geisselfärbung von Bakterien. Fortschr. d. Medizin, Bd. XII, I894, No. 12, pp. $462-464$.

('94). Bunge, R. Zur Kenntniss der Geisseltragenden Bakterien. Ibid., No. 17, pp. 653-670.

('94). Bunge, R. Weitere Mittheilungen ïber Geisselfärbung. Fortschr. d. Mediz., Bd. XII, I894, pp. 929-935.

('95). MoorE, Veranus A. On the nature of the flagella and their value in the systematic classification of the bacteria. Jour. Am. Pub. Health Asso., Oct., I895, Ann. vol. xx, p.p. 432-444, 3 plates.

('95). FERRIER Considérations générales sur le pléomorphisme des cils vibratiles de quelques bactéries mobiles.-Archives de médicine expérimentale et d'anatomie pathologique. Paris, Série 1. T. vir, I895, pp. 58-75. I plate.

('96). LoEwit, N. Zur Morphologie der Bakterien. Centralb. f. Bakt., XIX Bd., I896, pp. 673686 , with I plate.

('96). Kanthack, A. A., and Conner. , T. W. The flagella of the tetanus bacillus, and other contributions to the morphology of the tetanus bacillus. Jour. Path, and Bact., IV, 1896-97, pp. 452-459.

('g8). Bowнrц, Tr. Eine neue Methode der Bakterien-Geisselfärbung bei Gebrauch einer Oreeinbeize. Hyg. Rundschau, 1898, No. I. Rev. in Centralb. f. Bakt., xxir Bd., I898, pp. $667-668$.

('98). Strphens, J. W. Van Ermengem's method of staining flagella; a modification. The Lanicet, I898, Oct. I. Rev. in Centralb. f. Bakt., Xxv Bd., I899, p. 392.

Substitutes for nitrate of silver a 2 per cent largin solution. The flagellac are said to be cleaner and more distinct.
('99). WELckr, E Eine neue Methode der Geisselfärbung. Arcl. f. klin. Chir., Bd. LIX, 1899, Heft. I, pp. I29-143. Rev. in Centralb. f.

Bakt., Bd. Xxvi, I899, pp. 520-521.

A silver process of about the same complexity as that of van Ermengem.

('99). Zetrinow. Ueber Geisselfärbung bei Bakterien. Zeitschr. f. Hyg., Bd. xxx. I Heft., March, I899, pp. 95-106.

Discusses van Frmengem's silver method, and gives a gold method which is said to be better.

('99). Morion, N. Flagella staining. Trans. Jenner Inst., London, vol. I. 2 series, pp. 242-243, 1899.

Tap water is recommended for dilutions. A 24-hour agar surface growth furnishes the bacteria. They are agar siltace growt finte of this sterilized water in a allowed to diff use in a two of this is then placed on the watch glass. A drop or two of this is then placed on withclean slide or cover and spread as widely as possible without use of the needle. The excess is absorbed by blotting paper. The dried film is not fixed by heat. The stais consists of tantic acid 1 gram, potash alum gram, due tilled water $40 \mathrm{cc}$. To this is added 0.5 gram of night blue dissolved in $20 \mathrm{cc}$. of absolute alcoliol. The copious precipitate which results is carefully removed by filtration. The fluid is then ready for 11 se. Stain 2 minutes. The flagella are blue, the body of the organism is not stained. ,onger exposures cause precipitates. Connterstain for the body by exposure for 1 or 2 minutes to anilin-water geutian violet. "I consider that the application of heat and the spreading of the film with the "1

('oO). HINTERBERGER, A. Eine Modifikation des Geisselfärbungsverfahrens nach van Eirmengem. Centralb. f. Bakt., Bd. xxvir, No. 16-17, 1900, pp. 597-605, I plate and I fig.

('or). Wiltiams, Hugr. Flagella stain. See Pathological technique, by Mallory and Wright. Second E.d., I90I. pp. I04-106. W. B. Saunders \& Co., Philadelphia and London.

('02). MEYTR, ARTHUR. Kurze Mitteilung über die Begeisselung der Bakterien. Centralb. f. Bakt., Abt. I, Bd. xxxI, Originale, I902, pp. 737-739.

\section{XII1. Capsules.}

('78). CiENkowsKI. Untersuchung über die Gallertbildungen des Zuckerrübensaftes. Resumé allemand du mémoire russe, Charkow, 1878. Not seen.

('85). RibBik'T. Zur Farbung der Pneumoniekokken. Deutsche med. Wochenschr., 11 Jahrg., 1885 , p. 136.

Gives a method for staining capsules.

('85). FrimplaEnder, C. Ueber Pneumonie-Micrococcen. Fortsch. d. Med., Bd. III, I885, pp. 9I-93.

Replies to criticism of Gerunain Sée, and gives his metbod of staining the capsule.

('85). Frisdraender, C. Notiz, die Färbung der Kapselmicrococcen betreffend. Fortsch. d. Medicin, Bd. III, I885, No. 23, pp. 757-760.

The authot's plan for staining capsules is as follows: Pass the dried covers three times throngh the flame, and Pass the dried covers three times throngh the flarne, and then expose from one to several minutes in 1 per cent acetic acid water. Remove from the cover by blowing tbrongh a glass tube drawn to a point and dry in air quickly. Thet expose in a saturated solution of aniliti water gentiau violet for a very few seconds, wash in water and examue. The exposure to the gentian violet shonld ing the interior protoplasm. 
('92). LIESENBERG, C., U. ZOPF, W. Ueber den sogenannten Froschlaichpilz (Leuconostoc) der europäischen Rübenzucker- und der javanischen Rolizzuckerfabriken. Zopf's Beitraege, Hft. I, I 892 , pp. I-29, with 2 plates, and Hft. II, I892, pp. I-2. Rev. in Am. Nat., March, 1897 , p. 228.

('92). WELCH, WM. H. A gas-producing bacillus (B. aerogenes capsulatus, nov. spec.) capable of rapid development in the blood-vessels after death. Bull. Johns Hopkins Hospital, vol. 3, No. 24, July-August, I892, pp. 8I-9I. Also a separate.

('94). Koch, AlFred, and Hosazus, Hans. Ueber einen neuen Froschlaich der Zuckerfabriken. Centralb. f. Bakt., Bd. Xvi, I894, pp. 225228, mit I fig.

Describes a branching gelatinous organism as Bact. pedlculatum. The branching is due to a termiual splitting or one-sided development of the capsule.

('95). Srrm, A. Ueber die in den Produkten der Zuckerfabrikation auftretenden Bakterien. Centralb. f. Bakt., 2 Abt., Bd. I, 1895, pp. 277-283.

('96). WrLDE, MAX. Ueber den Bacillins pneumonia Friedländer's und verwandte Bakterien. Inaugural Dissertattion, Bonn, I 896, pp. 74. Bibliography of 89 titles. Printed by Carl Georgi.

('96). Fricke, CARI。 Ueber den sogenannten Bacillus mucosus capsulatus. Zeitschr. f. Hyg., Bd. XXIII, I896, pp. 380-45I, with a bibliography of 25 titles.

('98). Pane, N. Ueber die Genesis der Kapseln des Pneumococcus. Centralb. f. Bakt., xxiv Bd., I8g8, pp. 289-294, with 2 figs.

The capsule is the swollen onter part of the bacterium.

('98). Kaufmans. Eine neue Methode zur Färbung von Bakterienkapsein. Hyg. Rundschau, I898, No. I8. Abstr. Centralb. f. Bakt., I Abt., Bd. xxv, p. 32.

('g9). WARd, See XLVII.

('99). Moore, A. Capsule staining. Trans. Jenner Inst., $2 \mathrm{~d}$ ser., pp. $244,1899$.

Recommends a contrast staln for the capsule. The preparation is first fixed with dilute acetic acid, then stained in carbol fuchsin for about 1 minute, washed in distilled water and dried. It is then stalned, wlth or without gentle heat, in night blue for 1 or 2 minutes. washed and dried. The uight blue solutiou Is Morton's modification of McCrorie's staln. (See Morton, Flagella staintug.) By this metlod the capsule is stalned blue and the body dark red.

('99). Strong, Lawrence Watson. Ueber die Kapselbacilien. Centralb. f. Bakt., xxy Bd., I899, pp. 49-52.

('o). Boni, Icılio. Methode zur Darstellung einer "Kapsel" bei allen Bakterienarten. Centralb. f. Bakt., xxviı Bd., 1900, pp. 705-707.

('oi). Ward. See xlviI.

('oI). BonI, I. Ricerche stulla capsula dei batteri. Giorn. Soc. ital. igiene, Milano, vol xxı1, I901, pp. 417-430.

(02). Smith, R. GReig. An Ascobacterium from the sugar-cane, with notes upon the nature of the slime (Bacterium sacoliari, n. sp.) Proceedings of Linnean Soc. of New South Wales, vol. XxviI, 1902, part I, pp. I37-145. I plate. Also a separate (issued Aug. 22, 1902). See also Centralb. f. Bakt., 2 Abt., Bd. IX, p. 806.

\section{Stains and Staining Methods.}

(See also XI, XII, sad XIII.)

('-). EHrLich. Beiträge zur Kenntniss der Anilinfärbungen und ihrer Verwendung in der mikroskopischen Technik. Arch. f. mikr. Anat. Bd. xIII, p. 263.

('75). WEIGER'. Färbung von Bakterien. Ber. über d. Sitzungen d. schlesischen Gesellsch. f. vaterl. Cultur, ro Dec., 1875.

('77). KocH. See LV.

('8I). WEIGERT. Zur technik der mikroskop. Bakterienuntersuchungen. Virch. Archiv. Bd. I.XXXIV, I88I, p. 275.

('82). EHRLICH. Färbung der Tuberkelbacillen. Verhdlgn. d. Ver. f. i. Med., I Mai, 1882 D. med. Woch., 1882, p. 269.

('82). ZIEHL. Zur Färbung des Tuberkelbacillus. Deutsche med. Wochenschr., I882, No. 33 p. 45 I.

('82). SzYSzYLowicz, J. Das Corallin als mikrochemisches Reagens in d. Pflanzenhistologie, R. i. S. Ak. Krakau, T. X, I883, pp. 97-I I4. Not seen. Rev. Bot. Centralb., I886, Bd xxvir, p. 5I. See also Bot. Centralb., Bd. XII, I882, p. I 39 .

This substance should be dissolved in godium carbouate. It is used as a test for slime derived from starch. which staius diffusely purple or rose. After stainlug, the preparation should be subjected to hot alcohol, which removes the staiu from all but the starch graing and slime derived therefrom. Gum slime and cellulose slime are bleached, the former even iu cold alcohol. Pure gum

('83). ZIEHL. Zur Lehre von den Tuberkelbacillen, insbesondere ïber deren Bedeutung für Diagnose und Prognose. Deutsche med. Wochenschr., 1883, p. 62.

('84). Koch. See vi.

('84). LOEFFLER. See VI.

('84). Gram, C. Ueber die isolirte Färbung der Schizomyceten in Schnitt-und Trockenpräparaten. Fortsohr. d. Med., Bd. II, No. 6,1884, pp. $185-I 89$.

('86). PFEFFE, W. Ueber Aufnahme von Anilinfarben in lebende Zellen. Untersuchungen a. d. bot. Inst. Tübingen, II, p. $179,1886$.

('87). Unna. Die Rosaniline und Pararosaniline, eine bacteriologische Farbenstudie. Dermatologischen Studien. Heft 4, pp. 9-73. Hamburg, Voss, 1887.

('87). KÜHNE. Ueber ein combinirtes Universalverfahren, Spaltpilze im thierischen Gevebe nachzuweisen. Dermatol. Studien, herausgeg. von Unna. Heft 6. Hamburg, I. Voss, 1887.

('87). HEIM, L. Die Neuerungen auf dem Gebiete der bakteriologischen Untersuchungsmethoden seit dem Jahre, I887, I. Farbungsmethoden. Centralb. f. Bakt., X Bd., 189I, pp. 260-265, 288-296, and 323-328

('88). KuEHNE, H. Praktische Anleitung zum mikroskopischen Nachweis der Bakterien im thierischen Gewebe. Leipzig (Günthers), I888, pp. I5-23, Methylentlaumethode.

(88). Unna, P. G. Die Entwicklung der Bakterienfärbung. Eine historisch-kritische Uebersioht. Centralb. f. Bakt., I888, n Bd., pp. 22-26; also pp. 6I-63, 93-99, I20-I25, I 53I58, I89-195, $218-221,254-259,285-291,312-$ $320,345-348$.

At the end 71 papers on this subject are mentioned by 
('9I). Prégr, Fritz. Ueber eine neue Karbolmethylenblau-Method. Centralb. f. Bakt., x Bd., I801, pp. 826-829.

Pregl finds the following method of staiuing sections on slides satisfactory: "Exposure for one-half to one milute to carbol methylen blue, sometimes with the aid of heat; second, brief washiug in water; third, bleachiug in 50 per ceut alcohol until the section has become pale blue passing into greenish; fourth, removal of the water by means of absolute alcohol; fifth, clearing in xylol

Kuchne's carbol methylen blue is made as follows: 1.5 grins. methylew bl ue, 10 grins. absol ute alcohol, 100 gra ms pet cent carbolic-acid water. The alcohol is poured ove the methylen blue; the carbolated water is then added an rubbed up tboroughly with it. If only a small quantity is needed from time to time, it is better to make it up in less amounts, as, with time, the staivitug power of the solution decreases.

('92). KuEHNE, H. Das Malachitgrün als Ausziehungsfarbe. Centralb. f. Bakt., XI Bd., I892, pp. $756-758$.

Anthor finds malacbit green dissolved in aniliu oil very useful for treatment of sections staiued in carbol-fuchslu, etc. The bacteria stand out distiuctly deep red on blulsh background. See paper for details.

('93). Nicolite, E'T Cantacuzène, J. Propriétés colorantes de l'oxychlorure de ruthénium anmoniacal. Anr. de l'Inst. Pasteur, T. viI, pp. 33I-334.

('95). UnNA, P. G. Ueber Verwendung von Anilinmischungen zur tinktoriellen Isolierung von Gewebselementen. Monatshefte f. prakt. Dermatologie, Bd. XXI, 1895. Rev. in Centralb. f. Bakt., I Abt., Xx Bd., I8g6, p. 406.

('95). Nicol LE, M. Pratique des colorations microbiennes, Méthode de Gram modifiée et méthode directe. Ann. de l'Inst. Pasteur, T. IX, I895, No. 9. Rev. in Centralb. f. Bakt., xviII Bd., I895, p. 552.

Catbol violet is substituted for anilin violet. Fxcess of color is temoved with alcohol-aceton.

('97). SEMENOWICZ, W., UND MARzINOWSKY, E. Ueber ein besonderes Verfahren zur Färbung der Bakterien im Deckglaspräparate und in Schnitten. Centralb. f. Bakt., XXI Bd., 1897, pp. 874-876.

('OO). DREYER, GEORGES. Bakterienfärbung in gleichzeitig nach van Gieson's Methode behandelten Schnitten. Centralb. f. Bakt., I Abt., xxvil Bd., 1900, pp. 534-535.

Can be used fot differential staining of animal tissues with bacterla in them, provided the 1atter are such as stain by Gram's method.

('oo). J,E Doux. Bemerkungen zu dem Artikel des Herrn M. Dorset: "A new stain for Bacillus tuberculosis." Centralb. f. Bakt., I Abt., XXVII Bd., Igoo, p. 616.

Dorsett recommended Sudan III for staining the B. tuberculosls. Le Doux says he bas tried tbis repeatedly with entitely negative results.

('a2). Livinson, JA. B. Ueber Färbung des Fettes und der fettigen Degeneration der geformten Elemente in flüssigen und halbfiüssigen Medien mit Sudan 11I. Wratsch. St. Petersberg, 1902, Bd. I, pp. 1,208-1,209. (Russian.)

('o2). GrimmE, ARnor,D. Die wichtigsten Methoden der Bakterienfärbung in ihrer Wirkung auf die Membran, den Protoplasten und die Einschlüsse der Bakterienzelle. Centralb. f. Bakt., Abt. 1, Bd. XxxII, Originale, 1902, pp. I-16, pp. 81-90, pp. I6I-18o, pp. 24I-255, pp. 32I-327, with 2 plates. Bibliog. of 78 titles.

\section{Morphological and Physiological Changes Due to Changed Environment.}

(87). ScHort'ELIUS. Untersuchungen über den Microc. prodigiosus. Festschr. f. Kölliker, Leipzig, 1887. Not seen.

This author ohtaiued pigmeuted and uon-pigmented races of Baciltus prodigiosus.

('89). Beirring. Beiträge zur Aetiologie des Milzbrandes. vI. Ueber asporogenen Milzbrand. Zeitschr. f. Hyg., I889, Bd. viI, pp. I7I-I76. Author describes method of obtaining Aplanobacter Bacillus) anthracis without spores.

('go). Sмгін. See vi.

('9o). Roux, E. Bactéridie charbonneuse asporogène. Ann. de l'Inst. Pasteur, T. IV, I8go, pp. 25-34

('92). Nencki, M. Ueber Mischkulturen. Centralb. f. Bakt., XI Bd., I802, pp, 225-228.

('02). Adami, J. G. On the variability of bacteria and the development of races. Med. Chronicle, vol. xVI, I8g2, No. 6, pp. 366-38g. Also a reprint from Med. Chronicle, Sept., I892, 8vo., 26 pp., Manchester (John Heywood), I 802

('92). Charrin, A., et Phisalix. Abolition nersistante de la fonction chromogène du Bacillus pyocyaneus.-C. R. des sé. de l'Acad. des Sci., Paris, 1892. T. cxiv, pp. 1,565-1,568.

('93). SANDER. Ueber das Wachstum von Tuberkelbacillen auf pflanzlichen Nährböden. Arch. f. Hyg., Bd. Xvi, Heft 3, I893, pp. 238-3II.

At $38^{\circ}-39^{\circ} \mathrm{C}$. (not at $22-23^{\circ} \mathrm{C}$ ), this anthor induced the organism of tuberculosls to grow on a variety of vegetable substances, i. e., potato, carrot, kohlrabi, macaroni, etc. A11 were cooked.

('93). Stoney, G. Suggestion as to a possible source of the energy required for the life of bacilli, and as to the cause of their small size. Proc. Roy. Soc., Dublin. Vol, viII, Pt. I, pp. 154-I56. Dublin, I893.

Views of a physicist.

('94). Surmont, H., Ex Arnould, E. Recherches sur la production du bacille du charbon asporogène. Ann. de l'Inst. Pasteur, T. vilI, 1894 , pp. $817-832$.

('94). URY, JAKoB. Ueber die Schwankungen des Bacterium coli commune in morphologischer und kultureller Beziehung. (Inaug. Diss.) 8vo., 47 pp., Strassburg i. E., I894 Rev. in Centralb. f. Bakt., Bd. Xvi, I894, pp. 579-581.

('94). Smith, Theobald. Modification, temporary and permanent, of the physiological characters of bacteria in mixed cultures. Tirans. Assoc. Amer. Physicians, Phila., I894, pp 85-109.

('94). Dieudonné, A. Beiträge zur Kenntnis der Anpassungsfähigkeit der Bakterien an ursprünglich ungünstige Temperaturverhältnisse. Arbeiten aus dem kaisenl. Gesundheitsamte, Bd. Ix, 1894, pp. 492-508, Berlin, I894 (Julius Springer). Also a separate. Rev. in Centralb. f. Bakt., Bd. XvI, I891, pp. 965-967.

('95). Davenport, C. B, and Castle, W. E. On the acclimatization of organisms to high temperatures. Archiv. f. Entwickelungsmechanik der Organismen, Bd. II, Heft 2, I895, pp. 227-249. Bibliography of 3 pages.

Organisms become acclimatized to ligh temperature by loslug water from their protoplasm. 
('97). Рескнam, Adfiaide Ward.. The influence of environment upon the biological processes of the various members of the colon group of bacilli. Jour. of Exper. Medicine, 1897, Sept., pp. 549-59I.

('97). AuERBACH, WilHelm. Ursache der Hemmung der Gelatine-Verflïssigung durch Bacterien durch Zuckerzusatz. Arch. f. Hygiene, Bd. XxxI, I897, pp. 3II-3I8.

('g8). Ficker, Martin. Ueber Lebensdawer und Absterben von pathogenen Keimen. (Habilitationsschrift.) Leipzig, Veit \& Comp, I898. Rev. in Centralb. f. Bakt., xxvı Bd., I900, p. 685.

Sorts of glass used for loolding culture medis have a distiuct infuence on certain bacteria by reason of substances dissolved ont of it.

('98). Ruzicka, Syanislav. Experimentelle Studien über die Variabilität wichtiger Charaktere des $B$. pyocyaneus und des $B$. fluorescens liquefaciens. Centralb. f. Bakt., xxiv Bd. I898, pp. II-I7.

('98). NiEDFRKorn, ERminio. Vergleiohende Untersuchung über die versohiedenen Variotäten des Bacillus pyocyaneus und des Bacillus fluorescens liquefaciens. (Inaug. Diss.) Freiburg. Switzerland, 1898 . Rev. in Centralb. f. Bakt., xxviI Bd., 1900, pp. 749-750.

('98). London, E. S. Le microbiomètre et son application à l'étude des phénomènes d'inanition chez les bactéries. Arch. des sci. biol. publiées par l'inst. imp. de méd. expér. à St. Pétersburg, 'T. vi, 1898, pp. 71-80.

The bacteria experimented on endured starvation only 49 to 88 drys.

('99). HeLLSTRoEM, F. E. Zur Kenntnis der Einwirkung kleiner Glukosemengen auf die Vitalität der Bakterien. Centralb. f. Bakt., xxv Bd., 1899, pp. 170-180 and 217-223.

Fiven small quantities of grape sugar proved harmful in case of acid-forming bacteria.

('99). Madsen, TH. Einige Bemerkungen zu dem Aufsaltz von F. E. Hellström zur Kenntnis der Einwirkung kleiner Glukosemengen auf die vitalität der Bakterien. Centralb, f. Bakt., xxv Bd., 1899, pp. 712-713.

('99). Tomasczewski, E,con. Ueber das Wachstum der Tuberkelbacillen auf kantoffelhaltigen Nährböden. Zeitschr. f. Hyg. Bd. XxxII, I899, Heft 2, p. 247.

('oo). Kohlarugce. See Xlvi.

('oo). Smith, Theobald. Variation among pathogenic bacteria. Jour. Bost. Soc. Med. Sci., vol. IV, No. 5, 1900, pp. 95-109.

('oo). EMM Mrich, Rudol, morphologischen Veränderungen der Milzbrandbacillen bei ihrer Aufiösung durch Pyocyanase. Centralb. f. Bakt., xxvil Bd., I900, pp. 776-787, with I colored plate.

('o). Krause, PaUl. Beiträge zur Kenntnis des Bacillus pyocyaneus. Centralb. f. Bakt., XxviI Bd., I 900, pp. 769-775.

Cousider effect of electricity (Tesla stream); pigment formation when in symbiosis with streptococel; behavior in lyydrogen, carbon dloxide, illuminatlug gss, hyvior in lydrogen, carbon dloxide, 111 minating gas,
drogen sulphld; in vacuo; 11 ature of the plgments.

('o). Sмттн, T11 Éobald. Die Bedeutung von Varietäten bei pathogenen Bakterien. Centralb. f. Bakt., xxvıI Bd., 1900, pp. 676-677. ('oo). Matzuschita, Teisis. Ueber die Veränderlichkeit der Eigenschaft des Bacillus anthracis, Gelatine zu verflussigen. Centralb. f. Bakt., xxviII Bd., 1900, pp. 303-304.

('oo). Matzuschita, Teïsi. Die Einwirkung des Kochsalzgehaltes des Nahrbodens auf die Wuchsform der Mikroorganismen. Zeits. f. Hyg., 1900, Bd. xxxv, p. 495.

('o1). RosenFelD, A. Ueber die Involutionsformen einiger pestähnlicher Bakterien auf Koohsalzagar. Centralb. f. Bakt., I Abt., Bd. xxx, 1901, pp. 641-653.

('02). Smitri, THEOBald. The relation between bovine and human tuberculosis. The Medical News, New York, vol. Ixxx, Feb. 22, 1902, pp. 342-346. Also a separate, pp. I4.

('02). L.tPouTRE, L. Recherches sur la transformation expérimentale de bactéries banales en races parasites des plantes. Annales de l'inst. Pasteur, T. XVI, 1902, pp. 304-312.

('O4). MAASSEN, AlBERT Die teratologischen Wuchsformen (Involutionsformen) der Bakterien und ihre Bedeutung als diagnostisches Hilfsmittel. Arbeiten a. d. Kaiserlichen Gesundheitsamte, Berlin, Io04, Bd. XXI, Heft 3, pp. $385-400$, pl. $x$ to xv.

\section{Culture-Media.}

('59). Payen. Sur la gélose et les nids de salangane. C. R. des sé. de l'Acad. des sci., Paris, T. XLIX, I7 Oct., 1859, pp. 521-530.

According to Payen, agar-agar has the following average composition: Carbon, 42.770 ; hydrogen, 5.775; oxygen, 51.445; total, 100.000 .

('82). NAEGELI, C. v. Untersuchungen ueber Niedere Pilze. a. d. Pflanzenphys. Inst. i. Muenche11. 1882, pp. 1-285.

('86). Guilligbeau, A., et DE FreudenREich, Ë. Préparation des gelées à base d'agar-agar. Archiv. des sci. phys, ot nat., ze Période, T $\mathrm{xv}$, Genève 1886, pp. 466-468.

This autlior describes a method of making agar with. out filtering. Cook for a quarter of an hour a water solution of agar ( 2 per cent), salt 0.5 per cent, and peptone I pet cent. This is alkaline; neutrallze. Add an equal qusntity of boulllon prepared the day before. This bouillou containa salt and peptone in the same proportion ( 1 kilo. of meat for 2 litres of water). Cook lu the autoclave for two hours at a teinperatuoe of $120^{\circ}$ to $125^{\circ} \mathrm{C}$. Do not pass $130^{\circ}$, as agar chauges color. Remove and let stand. After 4 to 5 hours one has in the upper part of the flask a limpid liquid with all lmpurities at the bottom. During this time the temperature must be kept above $42^{\circ}$. Decaut and sterilize at $110^{\circ} \mathrm{C}$.

('86). Miquit, P. "De la culture des bactéries" in Septième Mémoire sur les organismes microscopique de l'air et dex eaux. Annuaire de l'observ. à Montsouris pour 1885. See especially pp. $569-570$

This deals with use of Fucus crispus as basis for a solid culture-medium.

('87). ScIIotrelius, M. Einige Neuerungen an bacteriologischen Apparaten. 2 Vollständig klarer Agar-Nährboden. Centralb. f. Bakt., 1887, II Bd., pp. I00-I0I.

Agar is aosked about five minutes in 2 per cent hydro. chloric acid and then washed in frequent changes of water. Five to ten per cent of this a rer is ences water. Five to ten per cent of this agar is then macerated over night lu bounion at room temperature; cooked peptone and aalt added; neutralized with carbonate of filter paper. 
('87). Dal Pozzo, D. Das Eiweiss der Kiebitzeier als Nälurboden für Mikroorganismen. Med. Jahrb. Jahrg., r887, pp. 523-529.

('87). Аввот', A. C. An improvement in the method of preparing blood serum for use in bacteriology. Medical News, I887, vol. I, p. 207. Rev. in Centralb. f. Bakt., iा Bd., I887, pp. 424-425.

('87). RAskiN, M. Zur Zïchtung der pathogenen Mikroorganismen auf aus Milch bereiteten festen und durchsichtigen Nährböden, St. Petersburger med. Wochenschr, XII Jahrg., 1887, pp. 357-36o.

('88). vON FREUDENREICH, E. Zur Bereitung des Agar-Agar. Centralb. f. Bakt., I888, II I Bd., pp. 797-798.

Recommends filtering nutrient agar in the autociave at about $10^{\circ} \mathrm{C}$. Time required 30 to 60 minutes.

('88). VAN PUTEREN. Ueber die Herstellung von festen Nährboden aus Miloh zu Mikroorganismen Kulturen. (Russian.) I888.

('88). HUEPPE, FERDINAND, Ueber die Verwendung von-Ëiern zu Kulturzwecken. Centralb. f. Bakt., I888, IV Bd., pp. 80-8I.

Cultures are made in the uncooked eggs after shaking and proper surface sterilization.

('88). Roux, E. De la culture sur pomme de terre Ann. de 1'Inst. Pasteur, T. 11, I888, pp. 28-30, 2 figs.

('89). PETrI, R. J. Ueber den Gehalt der Nährgelatine an Salpetersäure. Centralb. f. Bakt., v Bd., I 889 , pp. $457-460$.

Commercial gelatin generally contains nitrates in considerable quantities.

('89). VOIGTLAENDER, FELIX. Ueber die Diffusion in Agargallerte. Zeitschr. f. Physik. Chemie., Bd. I I I, 1889, pp. 3I6-335.

A study of some of the physical properties of agar The rate of diffusion of many acids and other substances was determined. The conclusions are:

1. The diffusion in agat jelly from watery solutions is not disturbed by the process of imbibition.

2. The validity of Flck's law for dilute solutions was amply demonstrated.

3. The rapidity $\mathrm{c} f$ diffusion of a substance in different concentrations of the agar jelly is the same. The diffusion constants observed in the jelly are like those of water or greater or less.

greater or less. With the of the temperature the constant does not
4. Whe increase in linear relation, but the amount of the salt which enters in increases.

('80). REIN, J. J. The industries of Japan; together with an account of its agriculture, forestry, arts, and commerce; from travels and researches undertaken at the cost of the Prussian Government; with 44 illustrations and 3 maps. London, Hudder \& Stoughton, 27 Paternoster Row, I889, pp. XII, 570. 2 d revised German edition, Ig05.

The cartilaginous Floridex, particularly species and varieties of Gigartineæ, Caulacantheæ, Gelide, Sphærococcex and Tylocarpee, are distinguished for their high proportion of pararabin, and furnish, with boiling wate prep-jelly. They are gathered in great quantity on al the costs of the Malay Archipelago and the waters of China and Japan, aud are utllized in part direct as food, partly in the preparation of algæ-glue, Jap. Fu-nori, or pargy and diled, and when further prepared, are designated by the Malay word Agar-Agar i. e., vegetable. This name whes oringly applicd to Gigartina (Eucheuma) isiformis, G. spinosa, and G, tenax, which is collected near sin, spor example, in rreat massea, and shipped to China The Chinese use them not only for food but make of them Hai-Thao a transparent glue, wlth which they stiffen silk and other stuffs, and also fill up the iuterstices of coarse clothes for the manufacture of lanterns.
('89). Perri, R. J. Nachtrag zu "Ueber den Gehalt der Nährgelatine an Salpetersäure." Centralb. f. Bakt., v Bd., I889, pp. 679-680.

('go). KUEHNE, W. Kieselsäure als Nährboden für Organismen. Zeitsohr. f. Biol. Neue Folge, Bd. Ix, Der ganzen Reihe, Bd. Xxvir, 1890, pp. 172-I79.

('go). Tischutkin, N. Eine vereinfachte Methode der Bereitung von Fleisch-Pepton-Agar. Wratsch., I890, No. 8, pD. I77-178. Reviewed in Centralb. f. Bakt., Bd. IX, p. 208, I 89 I.

The crude agar-agar is first exposed for 15 miuntes iu acetic-acid water (5 glacial acid, 100 water).

('9I). SchuLTz, N. K. Zur Frage von der Bereitung einiger Nährsubstrate. Centralb. f. Bakt., $x$ Bd., I89I, pp. 52-64.

('9i). Slessin, P. Die Kieselsaüre Gallerte als Nährsubstrat. Centralb. f. Bakt., Bd. x, I8gI, pp. 209-213.

('9I). Marpmans. Mittheilungen aus der Praxis. I, Ersatz für Agar; 2, Ersatz für Gelatine. Centralb. f. Bakt., x Bd., I89I, pp. I22-124.

('92). Phitri, R., und MAAszen, AlBERT. Ueber die Bereitung von Nährbouillon für bakteriologische Zwecke. Arbeiten aus d. kaiserl. Gesundheitsamte, Bd. viII, No. 2, I892, pp. 3I I-3I4.

('92). LoEw, O. Ueber einen Bacillus, welcher Ameisensäure und Formaldehyd assimiliren kann. Centralb. f. Bakt., XII B.d., I892, pp. $462-465$.

('92). DE LAGERHEIM, G. Macaroni als fester Nährboden. Centralb. f. Bakt., xI Bd., I892, pp. $147-148$.

Author states that cultures of chromogenic bacteria on macaroni stand out from the background very distinctly and are very instructive. The whitest macaroni should be selected. It is cut into pieces $4.5 \mathrm{~cm}$. 1ong. These are put into test tubes and covered $\mathrm{I} \mathrm{cm}$. Over with water and cooked for 15 minutes. The water is then carefully poured off and the media aterilized in streaming steam in the

92). SEILER, F. Influence de la composition de la gelatine nutritive sur le dévéloppement des colonies microbriennes. Schweizerische Wochenschr. :f. Chemie u. Pharm., I8g2, pp. $26 \mathrm{I}-263$

('92). Schutz, J. Q. A rapid method of making nutrient agar. Bull. Johns Hopkins Hospital,vol. III, July-A ugust, I892, p. 92.

A useful and easy method.

('93). Uschinsky. Ueber eine eiweissfreie Nährlösung für pathogene Bakterien, nebst einigen Bemerkungen über Tetanusgift. Centralb. f. Bakt., Bd. xiv, i893, No. ro, pp. 316-319.

('93). NastiukorF. Ueber Nährböden aus Eigelb für Bakterienkulturen. Wratsch., I893, No. 33 and 34. Rev, in Central.b. f. Bakt., XviI Bd., I895, pp. 492-493.

('93). HESSE, W. Ueber den Einfluss der Alkalescenz des Nährbodens auf das Wachsthum der Bakterien. Zeitschr. f. Hygiene, Bd. $x v$, I893, pp. I83-19I. 3 plates.

('94). FraEnkeL, C. Beiträge zur Kenntniss des Bakterienwachsthums auf eiweissfreien Nährlösungen. Hyg. Rundschau, Jahrg. IV, I894, pp. $769-776$. 
('94). Wescher, F. Die Bereitung eines festen undurchsiohtigen Nährbodens für Bakterien aus Hülnnereiern. Centralb. f. allg. Path. u. patl. Anat., Bd. v, I894, pp. 57-59.

Fggs are shaken untif the yolks and whites are thoroughly mixed. They are then boiled hard. The shell is now removed, the egg cut into suitable pieces, put into media is said to give very characteristic growths with many bacteria.

('95). Turro, R. Ueber Stroptokokkenzüchtung auf sauren Nährböden. Centralb. f. Bakt., Bd. XVII, I Abt., I895, pp. 865-874.

('95). Sendivick ANd PRESCOTT. See Xlvi.

('95). ElLSNER. Untersuchungen über eleotives Wachsthum der Bacterium coli-Arten und des Typhusbacillus und dessen diagnostiche Verwerthbarkeit. Zejtschr. f. Hyg., Bd. XXI, I895, pp. 25-31.

(95). Smitir, Tilzobal, Ueber die Bedeutung des Zuckers in Kulturmedien für Bakterien. Centralb. f. Bakt., xviu Bd., I895, pp. I-9.

('95). Bleisch, Max. See xvit.

('95). Haegler, Cari, S. Zur Agarbereitung. Centralh. f. Bakt., XviI Bd., I895, pp. 558-560, with 2 figs.

Advises centrifuging to clear the agar.

('95). Deycke, G. Die Benutzung von Alkalialbuminaten zur Herstelluıg von Nährböden. Centralb. f. Bakt., XviI Bd., I895, pp. 24I245.

('95). Fuller, GEo. W. On the proper reaction of nutrient media for bacterial cultivation. Jour. Am. Pub. Health Asso., Oct., 1895, vol $\mathrm{xx}$.

A very useful paper. It is recommended for geveral reading.

('05). HEIM, L. Zur Bereitungsweise von Nahrmitteln. Centralb. f. Bakt., XviI Bd., I895, pp. 190-195, I plot.

('95). Zupnik, Lăo. Zur Agarbereitung. Centralb. f. Bakt., xvir Bd., 1895, p. 202 . Review in Bot. Centralb., Bd. Lxv, I896, p. 52.

Author obtains clear agar by filtering it through a thin layer of a hsorbent cotton, placed funnel-form iu the hot water filter, wet with hot distilled water aud pressed in place witli the fingers. The bonillon anust be clear to start with. The agar powder is then added and cooked I hour in streaming steam.

('95). MAassen, Albert. Die organischon Säuren als Nährstoffe und ihre Zersetzbarkeit rlurcl die Bakterien. Arb. a. d. kaiserl. Gesundlieitsamte, Bd. xI, Zweites Heft, I895, pp. 340-4II.

('06). Capaldi, Achille. Zur Verwendung des Eidatters als Nahrbodenzusatz. Centralb. f. Bakt., $\mathrm{xx} \mathrm{Bd.,} \mathrm{1896,} \mathrm{pp.} \mathrm{800-803.}$

('97). HESSE. See XI,VI.

('97). Marpmann. See xhix.

('97). Forster, J. Nāhrgolatine mit hohem Sclımelzpunkte. Centralb. f. Bakt., XXII Bd., 1897, pp. 34I-343.

By careful minimizing of heat the atuthor obtains sterlle nutrient gelatin nelting at $29^{\circ}-30^{\circ} \mathrm{C}$.

('97). Stondart, F. Walt,is. New method of separating the typhoid bacillus from the bacillus ooli communis, with notes on some tests for the typhoid bacillus in pure cultures. University Callege, Bristol. The Jour. of Pathology and Bacteriology, IV, I896-97, p. 429.
('97). BokoRny, Tн. Grenze der wirksamen Verdünnung von Nährstoffen bei Algen und Pilzen. Bio. Centralb. June 15, 1897, pp. 417-426.

Author states that 0.002 per cent peptone serves no fonger as a nutrient for bacteria, but o.oro per ceut does.

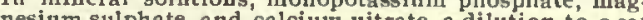
per cent still we, per cent solutions, becteria appented.

('97). London, E. S. Schnelle und leichte Methode zur Bereitung des Nähragars. Centralb. f. Bakt., xxi Bd., I897, pp. 686-687.

('97). Hiss, Philip Hanson. On a method of isolating and identifying bacillus typhosus, based on a study of bacillus typhosus and members of the colon group in semi-solid culture media. Jour. Exp. Med., vol. I1, 1897, pp. 677-700.

('98). SMith, Erkwin F. Potato as a culture-medium with some notes on a synthesized substitute. Proc. Am. Asso. Adv. Sci., Vol. Xrvir, I898, p. 4 I I. Also a separate. Centralb. f. Bakt., 2 Abt. Bd. $v$, IO2.

('98). Bokorvv, TH. Sources of Carbon for Bacteria. See table by Bokorny in his Lehrbuch der Pflanzenphysiologie, pp. 56-59. Paul Parey, Berlin, I8g8.

('98). GiEsENHAGEN, K. Eine Vorrichtung zum Filtrieren von Nähragar. Centralb. f. Bakt, xxiv Bd, I898, pp. 501-502.

('99). Yokote, T. Ueber die Darstellung von Nähragar. Centralb. f. Bakt., xxv Bd., I8g9, pp. 379-380.

Author heats his filtered bonillon, to which agar has been added, for I honr on a sand bath, after which it filters readily if the sand temperature has been above $110^{\circ}$

C. It will not filter satisfactorily if lower temperatures are used.

('99). BuIESENER. Ueber Gelatinekulturen im Brütschrank. Zeitsahr. f. Hyg., Bd. Xxxil, Heft I, I 899. Rev. in Centralb. f. Bakt., XXvir Bd., 1900, pp. $472-473$.

Author preparea a gelatin which remains solid at 27-30 $0^{\circ} \mathrm{C}$.

('99). CESARIS-DEMEL. Ueber das verschiedene Verhalten einige Mikroorganismen in einem gefärbten Nähr-Mittel. Centralb. f. Bakt., XXvi Bd., 1899, pp. 529-540, with 2 plates.

The medium recommended is liver broth with tincture of litmus. This aerves, it is said, to differentiate certain species.

( 0 ). Glaessner, Paul. Ueber die Verwertbarkeit einiger neuer Eiweisspräparate zu Kultur$z$ wecken. Centralb. f. Bakt., xxvir Bd., I90o, pp. 724-732.

Comparative tests of somatose, nutrose, etc.

('02). YENDO, K. Uses of marine Algx in Japan. Postelsia, St. Paul, Minn., 1902, pp. 3-18. 3 plates and 3 Japanese prints.

Gelidium cornenm (Japanese Ten-gusa) furnishea the agar-agar of com merce.

('O2). Whipple, GEORGE C. On the physical properties of gelatin, with reference to its use in culture media. Technology Quanterly. Boston, Mass., vol. xv, pp. 127-r60. Also a separate.

('o4). GaGe, Stephen DE M., and Adams, George O. Studies of media for the quantitative estimation of baateria in water and sewage. Jour. of Infectious Diseases, vol. I, No. 2, 1904, pp. 358-377. Also a separate. 
('04). HEssE, Gustav. Beiträge zur Herstellung von Nährböden und zur Bakterienzüchitung. Ztschr. f. Hyg., 1904, Bd. XLVI, pp. 1-22. Discusses effect of adding various acids and alkalies, effect of heat on reaction, ise of insoluble glass, etc. Most of the methods advised are already in use in ivany laboratories in the United States.

XVII. Methods or Work, Apparatus, Etc.

('73). KLEBS, E. Beitraege zur Kenntniss der Micrococcen. Arch. f. exp. Path. u. Pharmakol., I873, Bd. I, pp. 3I-64, with 4 plates.

Klebs here outlines his fractional method of culture. see espectally pp. 46-47.

('77). Косн. See ц, .

('78). LISTER, JoSEPH. On the lactic fermentation and its bearings on pathology. Trans. Path. Soc. of Irondon, I878, vol. XXIX, pp. 425-467. Lister's dilution method for obtaining pure cultures is here described. See especially page 445 et seq.

('8I). Koch, RoBERT. Zur Untersuchung von pathogenen Organismen. Mittheil. a. d. kaiserdichen Gesundheitsamte, Bd. I, I881. Berlin, pp. I-48, I 4 plates.

In thia paper Koch outlined his now unlversally nsed method of obtalning pure cultures (colonles) on solid media, viz: by use of gelatine for streaks and poured plates. See pp. 24 and following, especially page 27 . In I881, or earlier, Buchner diluted bis anthrax fluid until it was assumed that the quantity used to inoculate each flask contained only one organism (p. 19).

('83). КосH, RoBerT. Ueber die Milzbrandimpfung, eine Entgegnung auf den von Pasteur in Genf gehaltenen Vortrag. Kassel und Berlin, Theodor Fischer, I882. The same in French. Theo. Fischer, I883.

The celebrated Koch "rnles of procedure" are given in this paper.

('84). Hoffmann, F. W. Einfacher Einbettungsapparat. Zoologisoher Anzeiger, vII Jahrg., I884, No. 157-184, Leipzig, pp. 230-232, I fig. Makes use of a vacuum to hasten the infiltration of paraffin.

('84). ERrera. Sur l'emploi de l'encre de Chine en Microscopie. Bull. Soc. Belge d. Microscop. I884.

Not seeu. The ink is used to form a coutrasting background.

('86). von Esmarch, ERwin. Ueber eine Modifikation des Koch'schen Plattenverfahrens zur Isolierung und zum quantitativen Nachweis von Mikroorganismen.-Zeitsch. f. Hygiene, I886, Bd. I, pp. 293-30I, 3 figs.

The inethod of roll cultures is here described.

('87). PETrI, R. J. Eine kleine Modification des Koch'schen Plattenverfahrens. Central.b. $f$. Bakt., I Bd., I887, No. 9, pp. 279-280.

Description of the now everywhere common Petridishes.

('87). Esmarci. See xxxil.

('80). BEYERINCK, M. W. L'auxanographie ou la méthode de l'hydrodiffusion dans la gélatine appliquée aux recherches microbiologiques. Arch. néerlandaises de sci. ex. et nat., I889, T. XxIII, pp. 367-372.

('go). KUEBLER. Untersuchungen über die Brauchbarkeit der "Filtres sans pression, Systeme Chamberland-Pasteur." Zeitschr. f. Hyg., Bd. vIII, I890, pp. 48-54
('gI). NUTTALL, GEORGE H. F. A method for the estimation of the actual number of Tubercle bacilli in tuberculous sputum. With a note on the general application of the method to bacteriology. Bull. of the Johns Hopkins Hospital, vol. II, I891, pp. 67-76.

By use of this method flasks or tubes of media can be inoculated, it is said, with predetermined exact numinoculated, it is

('9r). BUJwID, O. Eine einfache Filtervorrichtung zum Filtriren sterilisirter Flüssigkeit. Centralb. f. Bakt., IX Bd., I89I, pp. 4-5, mit I Abbildung.

('9i). Gabritschewsky, G. Zur Technik der bakteriologischen Untersuchungen, I. Graduirte Kapillarpipetten zum Abmessen sehr kleiner Filüssigkeitsmengen. Centralb. f. Bakt., $\mathrm{x}$ Bd., I89I, pp. 248-250, mit 2 figs.

('9I). NoRDTMEYER, H. Ueber Wasserfiltration durch Filter aus gebrannter Infusorienerde.Zeitsch. f. Hygiene, I89I, Bd. x, pp. I45I54, I fig.

('91). Sмiтh, Theobald. Kleine bakteriologische Mittheilungen. Centralb. f. Bakt., x Bd., I89I, pp. I77-I86, mit 2 figs.

First two notes relate to apparatus; the second, to his inside-out method of filtering througl chamberland bougies (figired).

('9I). KNaUer, FrIEDRICH. Eine bewährte Methode zur Reinigung gebrauchter Objektträger und Deckgläschen. Centralb, f. Bakt., Bd. $\mathrm{x}, \mathrm{I} 89 \mathrm{I}, \mathrm{pp} .8-9$. Evew old stuck-together slides are said to be cleaned
perfectly by boiling 30 minutes in to per cent lysol, with perfectly by boiling 30 minutes in to per cent lysol, with occasional stirring. They shonld then be Aooded with tap water, and finally wiped with a soft, cleall, onl-free even by 15 minutes boiling in 5 per cent lysol solution a perfect cleaning of the glass."

('9I). Altmann, P. Thermoregulator neuer Konstruktion. Centralb. f. Bakt., IX Bd., I89I, p. 79I-792.

('OI). BEYERINCK, M. W. Die Kapillarhebermikroskopirtropfenflasche. Centralb. f. Bakt., IX Bd., I891, pp. 589-590, mit I Abbildung.

An easily constructed useful water flask, furnishing drops of auy slze (see fig. 16) or a fine stream.

('92). HASWELL, WM. A. On a simple method of substituting strong alcohol for a watery solution in the preparation of specimens. Proc. Linn. Soc. N. S. W., vol. vi, for 1891, pp. $433-436$, I fig. Sydney, 1892 .

This method was worked out 10 years later, indepen. dently, in my laboratory, by Deane B. Swingle, who had lis paper and drawings ready for publicatlon when this earlier paperwas discovered. Swlngle's device, which is a considerable tinprovement on Haswell's, is shown in Fig. I46. By means of the expanded base of the Inner tube a quite equable diffusion of the alcobol is secured.

('02). Giltay, E., U. ABERson, J. H. Methode zur Prüfung von Filtereinrichtungen wie die Chamberland-Bougies. Centrailb. f. Bakt., I892, Bd. XII, pp. 92-95, I fig.

('92). v. FREUDENREICH, ED. Ueber die Durchlässigkeit der Chamberland'schen Filter für Bakterien. Centralb. f. Bakt., XII Bd., I892, pp. 240-247.

The author's experiments lead to the couclusion that the Chamberland flter cannot be used safely more than a the Chamberland filter cannot be used sa fely inore than a week for the conth 
('02). Smirit, Theobald, and MOORE, V. A. Zur Prüfung der Pasteur-Ohamberland Filter. Centralb. f. Bakt., xil Bd., 1892, pp. 628-629, mit I Abbildung.

('92). AltmanN, P. Ein nener Thermoregulator für Petroleumheizung bci Thermostaten Centrall. f. Bakt., xuI Bd., I8g2, pp. 654-655, mit 2 figs.

('92). Arlojng, G. De l'influence des filtres minéraux sur les liquides contenant des substances d'origine microbienne. C. R. des sé. de l'Acad. des sci., T. cxiv, r892, pp. J,455-1,457.

('92). DE FreudenREich. De la perméabilité des filtres Chamberland à l'égard des bactéries. Annales de Micrographie, 1892, Tome IV pp. 559-568.

('92). Holm, Just Chir. Sur les méthodes de culture pure et spécialment sur la culture sur plaques de $\mathbf{M}$. Koch et la limite des erreurs de cette méthode. Meddelelser fra Carlsberg Iab. Tredie Bind. Andet Hefte. Kjobenhavn, I892, pp. I-23. Danish edition, Tredie Bind, Forste Hefte, 189I, pp. I-32.

('92). Nencki and Zawadzki. See Xlvir.

('92). Ar,Tmann, P. Neue Mikrogaslampen als Sicherheitsbrenner. Centralb. f. Bakt., xI Bd., 1892 , pp. $786-787,3$ figs.

('93). ZETTNow. Reinigung von neuen Deckgläsern. Centralib. f. Bakt., Bd. XIv, I893, pp. 63-64.

The last traces of fat are best removed from cosers by burning. The clean covers are placed on an 8 to $10 \mathrm{~cm}$. square piece of shect iron, which is then heated for a few minutes in the open flame of a Bunsen burner.

('93). SchEPILEWKy, E. A. Ein Regulator zum Thermostaten mit Wasserheizung. Centralb. f. Bakt., Bd. xiv, I893, pp. 131-138, mit I fig.

(93). Gruber, Max. Gesichtspunkte für die Prüfung und Belunteilung van Wasserfiltern. Centralb. f. Bakt., Bd. xıv, 1893. pp. $488-493$.

('93). Kirchiner, Martin. Gesiohtspunkte für die Prüfung und Beunteilung von Wasserfiltern. (Entgegnung auf die gleichnamige Arbeit von Prof, Max Gruber in Wien). Centralb. f. Bakt., Bd. xiv, 1893, pp. 516-527.

('93). Brunner, G., and Zawadzki, A. Zählplatte zu den Petri'schen Schalen. Centralb f. Bakt., Bd. xiv, 1893, pp. 6,6-618, mit I fig.

A method is giveu for dividing a clrcle $10 \mathrm{~cm}$. in diameter into 64 equal parts. The circles aud sections are to be in white ink on black paper.

(93). SchoEFER, Hans. Ueber das Verhalten von pathagenen Keimen in Kleinfiltern. Centralb. f. Bakt., Bd. xIv, J893, pp. 685-693.

('93). LAFAR, FrANz. Eine neue Zählvorrichtung für Plattenkulturen in Petrischalen. Zeitsoh. f. Nahrungsmitteluntersuchung u. S. w., Wien, I893, No. 24, p. 429. Rev. in Centralb. f. Bakt., Bd. xv, I894, pp. 33I-333, mit I fig.

(94). LOIFFLER, F. Eine sterilisirbare Injectionsspritze. Centralb. t. Bakt., Bd. XvI, I894, pp. 729-731.

To be had from wittig, instrument maker in Grelfs. wald, Geruany.

('94). Houston, A. C. Note on a simple apparatus for collecting samples of water for bacteriological purposes, at different depths from the surface. Jour. of Path. and Bact., vol. II, 1894, pp. 496-497, I fig.
('94). VALL,IN, E. Le régénération par agents chimiques des filtres Chamberland. Revue d'hygiène ett de police sanitaire, I894, No. 11, p. 946. Rev. in Centralb. f. Bakt., XVII Bd., 1895, pp. 496-497.

Author recommends a godium bisulphite solution (1:zo) for cleaning filters.

('94). Kuprianow, J. Zur Methodik der keimfreien Gewinnung des Blutserums. Centralb. f Bakt., xv Bd., 1894, pp. 458-462, I fig.

Describes and figures a device for filling test tubes with exact amounts of fuid culture media.

('94). Funck, ERNST. Zur Frage der Reinigung der Deckgläser. Centralb. f. Bakt., Bd. xvi, 1894, pp. II 3-II4.

A uthor cleans alides and covers which have been used with oil, Canada balsam, staius, etc., by first placing then for a time in turpeutine, geparating the covers from the slides as fat as possible. They are then put into a broad beaker, covered with hydrochloric acid, to which is added a few grams (2 to $3 \mathrm{knife}$-points) of chlorate of potash This is then covered with a glass plate and heated on water bath for a lew minutes. The glasses are the washed ly hot water. Equal parts of goda, talcum, aud sieved sawdust are now added with water enough to make a thick fluid mlxture, which is now heated for one half hour on the water bath, with frequent shaking ol the contents of the beaker. The glasses are then washed agaln in hot water, to which a little hydrochloric acid has been added, especially, in case some calcium carbouate has been deposited on the glass. Finally, wash in hot water or ethyl alcohol and dry with a soft cloth.

('94). van HEST, J. J. Bakterienluftfilter und Bakterienluftfilterversohluss. Centralb. f. Bakt., Bd. Xvi, 1894, pp. 435-147, also pp. 495-499, mit 11 figs.

('95). KNauss, K. Eine einfache Vorrichtung zum Abfüllen von je to $\mathrm{ccm}$. Nährsubstanz. Centralb. f. Bakt., xvıI Bd., 1895, pp. 878879, with I fig.

('95). Bantr, G. Eine einfache Methode die Bakterien auf dem Agar und dem Blutserum zu isolieren. Centralb. f. Bakt., Xviı Bd., 1895, pp. 556-557.

Agar is slanted, in broad tubes (diam. 2-3 cm). The material contalulug tbe bacteria is diluted to the proper amount wlth aterile bouillour water is then inoculated by needle or queutly thted iver the by allowed to drain back again.

('95). BlEIsch, MAX. Ein Apparat zur Gewinnung klaren Agars ohne Filtration. Centralb. $\mathrm{f}$. Bakt., xvir Bd., 1895, p.p. 360-362.

('95). LodE, ALors. Eine automatische Abfüllburette fïr Nährlösungen und Heilserum. Centralb. f. Bakt., xvנj Bd., 1895, pp. 53-54, with 3 figs.

('95). Brunner, Conrad. Notiz zur Methode der Isolierung von Bakterien anf Agarplatten im Reagensglase. Centralb. f. Bakt., xvıı Bd., J895, p. 59.

('95). BuJwId, O. Bemerkungen über die Filtration bakterienhaltiger Flüssigkeiten. Centralb. f. Bakt., xvIII Bd., 1895, pp. 332-333.

Considers the Chamberland a less fragile and safer filter than the Berkefeld.

('95). ABEI, RUDOL.F. Ein Halter für Objektträger und Deckgläschen. Centralb. f. Bakt., xvirI Bd., pp. 782-783, with I fig.

('g6). MELnIKow-RasweDENKow, M. Ueber die Einstellung des d'Arsonvalschen Thermostaten. Centralb. f. Bakt., Xjx Bd., I8g6, pp. 709-712, with I fig.

('96). CzAPLEWSKJ. Bakteriologische Notizen. Centralb. f. Bakt., Bd. xx, 1896, pp. 307-313.

Sixteen notes on methods of work. 
('96). KRETz, Richard. Eine handliche und leicht sterilisierbare Abfüllvorrichtung für Kulturflüssigkeiten. Centralb. f. Baktt., XIX Bd., I896, pp. 73-74, with I fig.

('97). VAN't' HoFF, H. J. Eine schnellere und quantitativ bessere Methode der bakteriologischen Plattenzählung. Centralb. f. Bakt., XxI Bd., I897, pp. 73I-733, with I fig.

Pours a suitable dilution of the bacteria on surface of gelatin or agar, and spreads fluid as widely as possible.

('97). Bolley, H. L. An apparatus for the bacteriological sampling of well waters. Centralb. f. Bakt., XXII Bd., I897, pp. 288-290, with I fig.

('97). KASPAREK, ThEODOR. Ein Vacuum-Apparat zum A.bdamp fen von Kulturen mit Ehmann'scher Wasserheizung. Centralb. f. Bakt., XXII Bd., I897, pp. 6-7, with I fig.

('97). KISCHENSKY, D. Ein Verfahren zur schnellen mikroskopischen Untersuchung auf Bakterien in Deckglas- und ObjektträgerPräparatem. Centralb. f. Bakt., XXI Bd., I897, pp. 876-877.

('97). Sмiтн, Тнеовад. Ueber Fehlerquellen bei Prüfung der Gas- und Säurebildung bei Bakterien und deren Vermeidung. Centralb. f. Bakt., XxII Bd., I897, pp. 45-49.

('97). Novy, F. G. Neue Apparate zum Filtrieren und zum Sterilisieren durch Dampf. Centralb. f. Bakt., XXII Bd., I 897 , pp. 337-340, with 3 figs.

('97). Schuermayer, B. Eine Abänderung des automatischen Gasabschlusses beim Verlöschen der Flammen an Brütschränken. Centralb. f. Bakt., XxI Bd., I897, pp. 40040 I, with I fig.

('97). RoBERTSON, Sigismund. Ueber Objektträgerund Deckglashalter. Centralib. f. Bakt., XxI $\mathrm{Bd}$., I897, pp. 589-591, with 2 figs.

('98). Piorkowski. Ein neuer theizbarer l'ärbetisoh. Deutsch. med. Wochenschr., I898, No. 20. Rev, in Centrall. f. Bakt., xxrv Bd., I898, pp. 902-903, I fig.

('98). Smith, THEobald. One of the conditions under which discontinuous sterilization may be ineffective. Journal of Experimental Medicine, vol III, I898. Rev. in Centralb. f. Bakt., XXvi Bd., I809, p. 585.

('98). Novy, F. G. Ein neuer Thermoregulator Centralb. f. Bakt., xxIII Bd., I898, pp. I,054I, 056, with 2 figs.

Made by Greiner and Friedrichs, Stuetzerbach, Thuringia, Germany.

('98). Murrill, Paul. Ein wirksamer Gasdruckregulator. Centralb. f. Bakt., XXIII Bd., I 898 , pp. I,056-1,059, with 2 figs.

('g9). KERN, FERDINAND. Eine automaltische Messpipette für keimfreie Flüssigkeiten. Centralb. f. Bakt., xxv Bd., I899, pp. 75-77, with I fig.

('99). Novy, F. G. Collodium Sacs. See his book entitled Laboratory work in bacteriology, pp. 496-50I.

('oo). Bulloch, Wilidam. A simple apparatus for obitaining plate cultures or surface growths of obligate anaërobes. Centralb. $f$. Bakt., Xxvir Bd., I900, pp. I40-I42, with I fig.

A ththor uses the unguentum resinze of the British Pharmacopoia as a lnteing material. This consists of resin in powder 200 grams, or 8 ounces: yellow beeswax 200 grams, or 8 ontices : olive oil 200 grams, or 8 onnces, and lard 150 gratua, or 6 ounces. Melt together with gentle heat the resin and wax, add the other ingredients, strain through muslin, and cool with stirring.
('Oo). WRIGHT, JAMES H. A simple method for anaërobic cultivation in fluid media. Centralb. f. Bakt., XXviI Bd., I900, pp. 74-75, with I fig.

('oo). Striwart, C. Balfour. Apparatus for heating cultures to separate spore-bearing microorganisms. Centralb. f. Bakt., xxvir Bd., 1900, pp. 366-367, with I fig.

This is a modification of Meyer's hot-air bath.

('oo). PEtRI, R. J. Eine einfaohe Vorrichtung zum Abfüllen der Nährgelatine. Centralb. f. Bakt., xxviI, Bd., I900, pp. 525-526, I fig.

('oo). Nutrali, George H. F. Ein Apparat zur Herstellung von Rollkulturen. Centralb. $f$. Bakt., XXvir Bd., 1900, pp. 605-609, with 2 figs.

('oo). Piorkowski. Ein Apparat zur Ermittelung von Desinfektionswirkungen. Centralb. $f$ Bakt., XxvII Bd., I900, pp. 609-6Io, with I fig.

('oo). EPSTEIN, Stanislaus. Ein neuer Thermoregulator. Centralb. f. Bakt., Xxviri Bd., I900, pp. 503-504, with I fig.

('o). PETRI, R. J. Ein neuer Reagenzglasständer für Kulturen. Centralb. f. Bakt., XxvıII Bd., I 900, pp. 747-748, with I fig.

('oo). Sмith, R. GREIG. The measurement of bacteria. Proceedings Linmean Soc., New South Wales for I900, Sydurey, I901, vol. Xxv, pp. 533-536. Three figures in text. Also a separate (issued Nov. 22, 1900).

('oo). Petri, R. J. Neue verbesserte GelatineSollälchen (verbesserte Petri-Schālchen). Centralb. f.. Bakt., xxviII Bd., I900, pp. 7982 , with 3 text figs.

This Petri-dish has a cover of yellow brown glass, of stich a form that when they are piled one above the other all are protected from the action of the violet rays of the spectrun. These are made in two forms by Paul Altmann, Berlin.

('oo). Peirri, R. J. Neue anaërobe Gelatine-Schä1chen-Kultur (verbesserte Petri-Schälchen). Centralb. f. Bakt., xxviII Bd., I900, pp. I96I99, with 2 text figs.

('oo). WRIGHT, J. H. A simple method of cultivating anaërobic bacteria. Jour. Boston Soc. Med. Sci., vol. v, I900, pp. I I4-II5.

The plug is pushed part way down the test-tube containing the culture. The cotton is then partly saturated with strong pyroganic acid whter (equal bulks of wate atd acid). Sodium hydrate solution ( $\mathrm{NaOH}, 2$ water) is then pipetted on, and the tube immediately plugged air tight with a soft rubbet stopper. The medis shonld con tain I per cent glucose. It should be fresh, and its resction not more acid than +15 . It may be used for fluids, or roll cultures, and other forms.

('o2). Hil., HrbBért' Winstow. "Hanging block" preparations for the microscopic observation of developing bacteria. Journal of Med. Research, Boston, vol. vir, 1902 (new ser., vol. II), pp. 202-212, 3 figs. Also a separate.

('o2). WHERRY, WM. B. Experiments on the permeability of the Berkefeld filter and the Pasteur-Chamberland bougie to bacteria of small size. Jour. of Med. Research, vol. viII (n. s., vol. III), I902, pp. 322-328, I fig.

('O2). KaLLERMAN, KARL. A method for fixing and sectioning bacterial colonies, fungous mycelium, etc. Jour. App. Micro., vol. v, 1902, p. I,980. Also a separate.

('O2). Kellerman, Karl F. An improved method for making collodion tubes for dialyzing. Jour. App. Micro., vol. v, Ig02, p, 2,038. 
("02). Carnot, Paul, eit Garnier, Marcel. Sur la technique des cultures en tubes de sable Paris, C. R. soc. biol., T. LIV, I902, pp. 748750.

('O2). Carnot, Paul, ét Garnier, Marceir De l'emploi des tubes de sable comme méthode générale d'étude, d'isolement et de sélection des microorganismes mobiles. Paris, C. R. soc. biol., T. LIV, I902, pp. $860-863$.

(o2). RaGaud, Cl. Nouveau bain de paraffine à cluaufage et régulation électriques. J. anat. pliysiol., Paris, T. xxxvIII, I902, pp. I932I 4 , av. fig.

('o2). GRIJNs, G. Eine einfache Vorrichtung, um zu verhindern, dass beim Gebrauch des Brütapparates für konstante niedrige Temperatur, System Lautenschläger (Katalog No. 60, No. II7), wenn das Eis im Behälter ausgeht, das ungekiuhlte Wasser in den kalten Sohrank fiesst. Centralb. f. Bakt. Abt. I, Bd. XXXI, Originale, I9O2, pp. 430-432.

('02). Harris, Norman MacliEod. Concerning an improved method of making collodium sacs. Centralb. f. Bakt., Abt. I, Bd. Xxxir, Originale, I902, pp. 74-80.

Dr. II arris makes his sacs around gelatin capsules.

('03). Gorsline, Citartess S. On the preparation and use of collodium sacs. Vaughan Quarter Century Book, Ig03, pp. 390-394. Ann Arbor, Mich., George Wahr.

('o3). Winslow, C. E. A., And Nibecketr, C. P. The significance of bacteriological methods in sanitary water analysis. Technology Quarterly, vol. XvI, I903, pp. 227-239. Also a separate.

('04). REMLINGER, P. Le passage du virus rabique à travers les filtres. 2 e mém. Ann. de l'Inst. Pasteur, T. xvill, 1904, pp. 150-164.

('04). Rcport of the [English] committee appointed to consider the standardisation of methods for the bacterioscopic examination of water. Journal of State Medicine, August, I907. See also Chemical News, vol. xc, Oct. 7 , I904, pp. I77-I79.

Distilled-water agar and distilied-water geiatln are recommended for use along with nutrient agat and gelatin. In the search for $B$. coli the committee recommends eitber the glucose-formate broth of Pakes or the
bile-salt brotli of MacConkey.

XVIII. Special Means of Differentiating Bacteria. ('84). Gram. See xiv.

('87). von RozSAIIEGYI, A. Ueber das Züchten von Bakterien in gefärbter Nährgelatine. Centralb. f. Bakt., II Bd., I 887, No. I4, pp. $418-424$. A tuthor added various aubstancea to his cuiture media, e. . . fuchsin, methylen blue, gentian violet, vesnvin, etc. Different bacteria behave very differentiy as respecls growth, absorption of pigment, and change of color in
the pigment. Organisms may be differenlated in this way.

('88). Buywid, O. Neue Methode zilm Diagnosticiren und Isoliren der Cholerabakterien. Centralb. f. Bakt., 1888, iv Bd., pp. 494-496.

In' 24 hours, in 2 per cent feebly alkaline peptone solittion al $37^{\circ} \mathrm{C}$, the cholera organism gives a fitue purple-red color on adding IICl. On longer ctiltivation other organisms give the sane reaction. This depends on tie formation of indoi and a trace of vitrite. ('go). Petruscil kx, Johannes. Die Farbenreaktion bakterieller Stoff wechselprodukte auf I ackmus als Beitrag zur Charakteristik und als Mittel zur Unterscheidung von Bakterienarten. Centralb. f. Bakt., viI Bd., I890, pp. I-8 and 49-53.

('92). Bujwid, Opo. Eine neue biologische Reaktion für die Cholerabakterien. Centralb. f. Bakt., XII Bd., I892, pp. 595-596.

('92). BEYERINCK, M. W. Notiz über die. Cholerarothreaktion. Centralb. f. Bakt., xII Bd., I892, pp. 715-718.

('93). Schir, Formalin zur Diagnose des Ty.phusbacillus. Centralb. f. Bakt., Bd. xIv, 1893, pp. 717-718.

The typhoid organism will not grow in bouillon containing as littie formalin as 1:15,000. B. coll develops

vigorously with as much formalin as $1: 3000$

('93). Mathews, Albert P. On Wurtz's Mothod for the Differentiation of Bacillus ityphi abdominalis from Bacillus coli communis, and its application to the examination of contaminated drinking water. Teohnology Quarterly, vol. vI, 1893, pp. 24I-25I.

Litmus lactose gelatin or agar is reddened by $B$. coli and is unchanged or made deeper blue by $B$. typhosus. Aul hor tesis suspicious water by poured plates. Afer 14 hours at $37.5^{\circ} \mathrm{C}$. all blue colonies resembling typhoid are lested further, i. e., in milk, geiatin, boulion, nitrate sointion, and sugar media.

('93). Gorini, Konstantin. Anmerkung • ïber die Cholerarotreaktion. Centralb. f. Bakt., Bd. XIII, 1893, pp. 790-792. A good peptone for this purpose must be white, without The water solution must be clear colorless warming. slightiy alkaline, foamy on shaking It must neutrai or let reaction with Fehling's change on boilting. It must surention, which does not Griesz reagent, and fintly utes with Diphenylanine, a faint but distiuct narrow, cleat bluc ring.

('94). Schneider, Paur. Die Bedeutung der Bakterienfarbstoffe für die Unterscheidung der Arten. (Inaug. Diss.) 8vo., 46 pp., 2 Taf., Basel, I894. Rev. in Centralb. f. Bakt., Bd Xvr, 1894 , p. 633. See also Arbeiten a.d. bakt. Institut Karlsruhe I, 1894.

('94). Marpmann. Zur Unterscheidung des Bacillus typhi abdominalis vom Bacillus coli commune. Centralb. f. Bakt., Bd. xvi, I804, pp. $817-820$.

Uses various "chromo agars" for differentiating bacterla, i. e., agar with fuchsin, malachit green, nigrosin and indolin. Sodium bisnlpbit must be nsed wilh the the first two.

('94). LunkEwICz, M. Eine Farbenreaktion auf die salpetrige Säure der Kulturen der Cholerabacillen und einiger anderer Bakterien.

Centralb. f. Bakt., Bd. xvi, 1894, pp. 945-949. Describes the preparations of the Griess-Ilosvay reagent.

('94). ABEL, Rudolr. Ueber die Brauchbarkeit der von Schild angegebenen Formalinprobe zur Differential-Diagnose des Typhus bacillus. Centralb. f. Bakt., Bd. xvi, 1894, pp. I,04II,046.

Finds some bacteria more tolerant of formalin that was atated by Schild. It is not a satisfactory melhod for separating typhoid bacili from $\mathrm{B}$. coli. 
('95). Mackensie, J. J. Opening discussion on "What new methods can be suggested for the separation of bacteria into groups, and for the identification of species." Jour. Am. Pub. Health Asso., Oct., I895, Ann. vol. xx, pp. 419-431.

Notes on synthetic media.

('07). Stoddart. See xvi.

('97). Hiss. See xvi.

('98). Houston, A. C. Note on four micro-organisms isolated from the mud of the river Thames, which resemble Bacillus typhosus. Centralib. f. Bakt., XXIV Bd., I898, pp. 518525, colored diagram.

('g8). FERMi. See xxxvi.

('98). Rothberger, C. Julius. Differential diagnostische Untersuchungen mit gefärbten Nährböden. Centralb. f. Bakt., XxIv Bd., 1898, pp. 513-518.

With neutral red (Toluidin red) in agar B. coli is said to cause a cleariug of the color and a very decided fluorescence. B. typhi leaves the medium unchanged. Tbe best method is said to be to add 3 to 4 drops of a concentrated water solution to to cc. of fluid agar, and then 1 cc. of a 24 -hour old bouillon culture. In agar stained with safranin, B. coli reduces the color: B. typhi does
not. Dead cultures of $B$. coli (cultures heated 2 hours at $78^{\circ} \mathrm{C}$.) did not produce these changes.

('98). Pacinotri, G., and Muniecki, J. L'albume d'uovo colorito in verde-cupo dal caffè crudo, come mezzo diagnostico di sviluppi batterici. Gazz. degli ospedali e della cliniche, I8g8, No. 3I. Rev. in Centralb. f. Bakt., Xxv Bd., I899, p. 257.

('g9.) RothberGER, C. Juluus. Differential diagnostische Untersuchungen mit gefärbten Nährböden. II, Mitteilung. Centralb. f. Bakt., Xxv Bd., I809, pp. I5-17 and 69-75.

Author tested the effect of various bscteria on 35 anilin dyes, 13 of which proved useful in agar media. The loss of color in methylen blue, safranin, Toluidin bine, or seille extract and indigo carmin is due to reduction pro cesses. In case of the itdi
changed to dark green.

('o). ScHEFFLER, W. Das Neutralrot als Hilifsmittel zur Diagnose des Bacterium coli. Centralb. f. Bakt., xxvili Bd., 1900, pp. 199-205.

Author says B. coli in neutral red, grape sugar agar Author sarly in 24 to 8 hours a beautiful green fluor givea regularly ises : fluid agar, $100 \mathrm{cc}$., grape sugar, 0.3 gram ; concentrated watery solution of neutral red, Icc

('O1). Hoeischer, Walter. Ueber die Differenz der histologischen Wirkung von Tuberkelbacillen und anderen diesen ähnlichen säurefesten Bacillen (Grasbacillus II Moeller Butterbacillus Petri-Rabinowitsch Thimotheebacillus Möller). Münchener med. Wochenschr., Bd. XLVIII, I90I, pp. $\mathrm{I}, 483-\mathrm{I}, 484$.

('02). Hiss, Phillip Hanson, Jr. New and simple media for the differentiation of the colonies of typhoid, colon, and allied bacilli. 'The Journal of Medical Research, June, I902, vol. viII, pp. 148-167. Also a separate. 2 plates.

Author describes a simple solid medium in which buried colonies of the typhoid bacillus send out threadformed radiations, while those of B. coli, etc., do not bear any fringing threads. This medium, used in Petridish poured plates, consists of distilled water 1,000, agar 15. gelatin 15, dextrose 10, Liebig's extract meat 5 , sodium chloride 5 .
('02). Fitz Geral, Mabel Puretoy, and Dreyer, GEORGES. The unreliability of the neutral red method, as generally employed for the differentiation of $\mathrm{B}$. typhosus and $\mathrm{B}$ coli. Festsksrift ved Indvielsen af Statens Seruminstitut. Kjöbenhavn, 1902, pp. I-39.

('o2). Buxton, B. H. A comparative study of the bacilli intermediate between B. coli communis and B. typhosus. Jour. Med. Res. I I (n. s.), pp. 20I-230, 3 plates.

Bibliography of 16 titles.

('o3). Gage, Stephen DeM., and Phelps, Earle $B$. Notes on B. coli and allied forms, with special reference to the neutral-red reaction. Proceedings of the Thirtieth Annual Meeting, American Public Health Assn., New Orleans, I,a., Dec., 1902. Pub. Columbus, Ohio, Igo3, vol xxvili, pp. 402-412. Also a separate, pp. 11.

('o3). SchueDER. Zum Nachweis der Typhusbakterien im Wasser. Zeitschr. f. Hyg., Bd. XLII, I903, pp. 317-326.

Describes differential methods.

('04). Stokes, Wilialam Royal. A simple test for the routine detection of the colon bacillus in drinking water. Jour. of Infectious Diseases, vol. I, I904, pp. 34I-347. I plate.

Neutral red reaction.

\section{Aerobism, Anaerobism.}

(See also various citations under $X X$.)

('6I). PASTEUR, LoUis. Animalcules infusoires vivant sans gaz oxygène libre et déterminant des fermentations.-C. $R$. des sé. de l'Acad. des sci., Paris, I86i, 'T. I.II, pp. 344-347.

('63). PASTEUR, Louis. Nouvel exemple de fermentation déterminée par des animalcules infusoires pouvant vivre sans oxygène libre, et en dehors de tout contaot avec l'air de l'atmosphère.-C. R., des sé. de l'Acad. des sci., Paris, I863, T. LVI, pp. 4I6-42I.

('63). PAsteur, Louis. Recherches sur la putréfaction. C. R. des sé. de l'Acad. des sci., Paris, I 863, 'T. I,VI, pp. I,I89-I, 194 .

" Je propose avec toute sorte de scripules ces mots youveaux aerobiea et anaerabes pout indiquer l'existence de deux classes d'êtres inferieures, les uns ivcapable de vivre en dehors de la présence du gaz oxygène libre, les autres pouvant se multiplier à l'infini eu dehors du con tsct de ce gaz."

('8o). BuCHNER. Ueber die Lebensfähigkeit der Spaltpilze bei fehlenden Sauerstoff, 1880 . Not seen.

('85). HEsse, W. UND R. Ueber Zuchtung der Bacillen des malignen Oedems. Detitsche med. Wochenschrift, I885, 11 Jahrg., pp. 214-215.

Describes a method of cultivating s naerobic orgau isms by sowing them in deep masses of solid media.

('86). Liborrus, PaUl. Beiträge zur Kentniss d. Sauerstoffbedürfnisses der Bakterien. Zeitschr. f. Hyg., Bd. I, I886, pp. I I5-I77.

According to review by Zimmerman in liot. Centralb. Bd. XXVIII, 1886, p. 198, author found but little more oxygen lu layers of agar buried $3 \mathrm{~cm}$. aud over under addi tional agar than in vessels in which air was expelled by
hydrogen, etc. He used "Indigotinloesung" as a test. 
('87). Roux, E. Sur la culture des microbes anaërobies. Ann. de l'Inst. Pasteur, Bd. I, I 887 , pp. 49-62.

('SS). Bucinfrr, Hans. Eine nete Methode zur Kultur anaërober Mikroorganismen. Centralb. f. Bakt., 1888, iv Bd., pp. 149-i 5 r.

The pyrogallic acid method. If I gram pyrogallol and $10 \mathrm{cc}$, 10 per cent potasll water are used for esch $100 \mathrm{cc}$, air space, all oxyget is removed in 24 hours at $37^{\circ} \mathrm{C}$. The use of this inixture liberates small quautities of carbonic oxide, which is less in quantity in proportion as the absorption of the oxygen is tapid Buchuer observed the injurious influence of this gas ou the bacteris with which he experimented.

('S8). Frafnkel, CarL. Ueber die Kultur anaërober Mikroorganismen. Centralb. f. Bakt., t888, II I Bd., pp. 735-740 and 763-768. I fig.

('89). Fraenker. See xxxvij.

('89). Frankland, Prrcy. On the influence of carbonic anhydride or other gases on the development of micro-organisms. Proc. Roy. Soc., vol. XL, 1889 , pp. 292-30t. See also Zeitsch. f. Hygiene, Bd. vi, i 889, pp. I3-22.

The other gases tested were liydrogen, carbonic oxide and nitrous oxide. IIydrogen had the least deletertous effect on the organisms tested, which were B. pyocyaueus, Koch's comma bacillus, and Finkler's spirillnu.

('go). Smitir. See $x x$.

('go). Poroff. Sce xlvirt.

('92). OслтA, M. Einfache Baktenienkultur mit verschiedenen Gasen. Centralb. f. Bakt. XI Bd., 1892, pp. 621-623, mit I fig.

Ogata's method, which is essentially that prevlousiy described by Heim, consists in softening the upper part of a test tube in the flame and drawing it ont so that the row is thmus. This part should be just below by a nat lug that is lu the uper one third of the tube cotoun of glass tubing is 110 w pluged at oule cotton and is drawn cotton, and is drawn out into a capillary tube, which must be loug enough to reach down iato the bot tom o the cultire medinm. The hroken end of this tube is now toliclied to the desired cultire and passed iuto the test inbe. The cotton-plugged end of the glass tube is now attached to a rubber tube connected with the gas apparatus. After the gas has buhbled throngh the medinm or a sufficient time, the capillary tuhe is removed, and the test tube is inmedlately sealed in the open flame by further constriction of the isthmus and a complete rinoval of the upper part of the test tube.

Fluid cultures may also be made in such tubes by preparing the isthmus before the tubes are filled with the medium.

('92). Herm, L. Zur Originalmittheilung von Ogata: "Einfache Bakterienkultur mit verschiedenen Gasen." Bd. XI, p. 621. Centralh. f. Bakt., XI, I892, p. 800 .

('92). van Senus, A. H. C. Zur Kenntniss der Kultur anaērober Bakterien. Centralb. f. Bakt., хт Bd., I892, pp. I44-ז45.

('93). Novv, F. G. Die Kultur anaërober Bakterien. Centralb. f. Bakt., Bd. XIv, I893, pp. 581600,2 figs.

The "Novy jars" ate hete figured aud described and 49 references to literatute are giveu at the end of the atticle.

('Đ3). BEYYR1NCK, M. W. Ueber Atmungsfiguren boweglicher Bakterien. Centralb. f. Bakt. Bd. xsv, I893, pp. 827-845, mit r Tafel.

('93). Smitil. See $\mathrm{xx}$.

('94). NiCOlaiER. Bemerkung zu der Arbeit voll Prof. F. G. Novy: "Die Kultur anaërober Bakterien" (Centralb. f. Bakt., Bd. xıv, I803). Centralb. f. Bakt., Bd. xv, I894, p. 227.
('94). Smiтh, ThEorald. Further observations on the fermentation tube, with special reference to anaërobiosis, reduction, and gas production (abstract). Proc. Am. Ass. A. Sci. 42, Madison Meeting, 1893, Salem, 1894, p. $26 \%$.

('94). Engrimann, TH. W. Die Erscheinungsweise der Sauerstoffausscheidung chromophyllhaltiger Zellen im Lioht bei Anwendung der Bacterienmethode. Verhand. d. Kon. Akad. van Wetenschappen te Amsterdam ( 2 te sectie, deel III; No. 11, I894), pp. IO, Iv, with a folded plate, also a reprint, $17 \mathrm{pp}$. Gives a bibliography of 61 titles. See also Onderzoekingen Physiol. Laborat. Utreclit, IV Reeks, II I deel., 1895 .

('94). Lubinski, WSEwolod. Zur Methodik der Kultur anaërober Bakterien. Centralb. f. Bakt., Bd. Xvi, ז894, pp. 20-25, mit 4 figs.

('94). Novy, F. G. Die Plattenkultur anaërober Baleterien. Centralb. f. Bakt., Bd. Xvı, 1894, pp. 566-571, with 3 figs.

('94). Arsins. Eine Methode zur Plattenkultur der Anaëroben. Centralb. f. Bakt., Bd. xv, I 894 , pp. I5-17. The author makes his cultures iu ordinary exsiccators
having ground glass covers.

('95). Schмidr, Ad. Eine einfache Methode zur Züchtung anaërober Kulturen in flüssigen Nährböden. Centralb. f. Bakt., xviI Bd., 1895, pp. 460-46r, r fig.

('95). Braatz, Egbert. Einiges über die Anaērobiose. Centralb. f. Bakt., xvir Bd., I895, pp. 737-742, with I fig.

('95). KEDRowsKI, W. Ueber die Bedingungen, unter welchen anaërobe Bakterien auch bei Gegenwart von Sauerstoff existiren können. Zeitschr. f. Hyg., Bd. xx, 1895, pp. 358-375.

They do this best when mixed wlth gerobes, but the absorption of the oxygen is not so important as Pasteur supposed. The author belleves that the aerobes excrete some special substance favorable to the growth of the anaerobes. This substance he did not determine.

('95). Gerstner, R. Beiträge zur Kentniss obligatanaërober Bakterienarten. Arbeiten aus dem Bakteriologischen Institut der Technischen Hoohschule zu Carlsruhe, Bd. I, I895. H. 2, pp. I48-I83, with 2 Taf.

('96). Kasparek, Theodor. Ein einfacher Luftabschluss flüssiger Nährböden beim Kultivieren anaêrober Bakterien. Centralb. f. Bakt., xx Bd., 1896, pp. 536-537, 2 figs.

('96). Durham, HerRert E. On a self-acting means of cultivating anaerobic microbes. Jour. Patlı. and Bact., vol. rI I, 1896, pp. 23I-236.

('97). BEck, M. Zur Züchtung anaërober Kulturen. Centralb. f. Bakt., Xxi Bd., I\$97, pp. 343345 , with 2 figs.

('98). Scholiz, W. Ueber das Wachstum anaërober Bakterien bei ungehindertem Luftzutritt. Zeitschr. f. Hyg., Bd. Xxvir, I8g8, pp. 132142. Review in Centralb. f. Bakt., Xxrv Bd., 1808, p. 932.

('98). FERRAN, J. Ueber das aërobische Verhalten des Tetanusbacillus. Centralb. f. Bakt., XXTV Bd., T898, pp. 28-29.

Thinks his experiments show tetanus bacillus is not a strict anaerobe, but only a facultative anaerobe. 
('98) KLEIN, ALEX. Ein Apparat zur bequemen Herstellung von anacroben Plattenkulturen. Central.b. f. Bakt., xxıv Bd., 1898, pp. 96797 I, 2 figs.

The reviewer has not had that trouble with Novy's apparatus complained of by Mr. Klein. 'The autlior's siphon arrangement for uixing the potash water with the pyrogaliol after exhaustion of the air appears to be very good.

('98). Ferran, J. Ueber die Verwendung des Acetylens bei der Kultur anaërober Bakterien. Centralb .f. Bakt., xxiv Bd., 1898, p. 29.

('98). Zupnik, LEo. Ueber cine neue Methode anaërober Ziichtung. Centralb. f. Bakt., XXIv Bd., I898, pp. 267-270, with I fig.

('98). Oprescu. Zur Teohnik der Anaërobenkultur. Hyg. Rundsohat, I898, No. 2. Rev. in Centralb. f. Bakt., Xxin Bd., I898, p. 668.

('08). UCKE, AlEXANDER. Ein Beitrag zur Kenntnis der Anaëroben. Centralb. f. Bakt., xxir Bd., 1898, pp. 996-1,00I.

('08). Trinkmann. Das Wachstum der anaëroben Bakterien. Centralb. f. Bakt., Xxuı Bd., 1898, pp. I,038-1,043 and $1,087-1,090$.

('98). Marpmann. Eine nelue Methode zur Herstellung von anaëroben Rollglaskulturen mit Gelatine ader Agar. Centralb. f. Bakt., XxiII Bd., I898, pp. 1,090-I,09I.

('g8). Erstein, Stanislaus. Apparat zur Kultur anaërober Bakterien. Centralb. f. Bakt. XXIv Bd., I8g8, pp. 266-267, I fig.

('g9). KABRHEL, Gustav. Zur Frage der Züchtung anaërober Bakterien. Centralb. f. Bakt. xxv Bd., I890, pp. 555-56I, with I fig.

As an oxygen indicator author uses methylene blue in sugar gelatin.

('og). Smith, Throbaln. Some devices for the cultivation of anaerobic bacteria in fluid media without the use of inert gases. Jour. Bost. Soc. Med. Sci., I899, pp. 340-343. Also a separate, 4 pp.

('oo). Epstejn, Stanislaus. Ein vereinfachtes Verfahren zur Züchtung anaërober Bakterien in Doppelschalen. Centralb. f. Bakt., xxviu Bd., 1900 , p. 443 , with I fig.

(on). Perri. See xvil.

('oo). Krause. See xv.

('oo). Bullock. See xvil.

('oo). WrJgirt. See xVIJ.

('02). OMf́t,IANSKI, W. Ein einfacher Apparat zur Kultur von Anaëroben im Reagenzglase. Centralb. f. Bakt., Abt. 2, Bd. viII, I902, pp. 7II-7I4.

XX. Fermentations, Gas-Formation, Enzymes, Etc. (See also XiX and XLVIII.)

('57). Pasteur, L. Mémoire sur le fermentation appelée lactique. C. $R$. des sé. de l'Acad. des sci., T. XLV, 1857, pp. 9I3-916.

('77). VINES, S. H. On the digestive ferment of Nepenthes. Journ. Linn. Soc. (Bot.), vol. $\mathrm{xv}, 1877$, pp. $427-4,3 \mathrm{I}$.

('79). v. NAEGELI, CARL WILHLLM. Theorie der Gärung. Ein Beitrag zur Molecularphysiologie. München, I879, pp. IV, I56.

('79). Prazmowski, A. Zur Entwicklungsgeschichte und Fermentwirkung einiger. BacterienArten. Vorläufige Mittheilung. Bot. Zeitung, Bd. xxxviI, No. 26, col. 409-424, 1879.
('79). van TiEginm, P. F. L. Sur la fermentation de la cellulose.-Bull. de la Société Bot. de France, I879, T. XXvI, pp. 25-30.

('82). MAYER, ADOLF. Die Lehre von den diemischen Fermenten oder Enzymologie. pp. VI, 124. Heidelberg, I882.

('82). Béchamp, A. Sur les microzymas comme cause dé la décomposition de l'eau oxygénée par les tissus des animaux et des végétaux. C. $R$. des sé. de l'Acad. des isci., Paris, T. XCIV, pp. $1,653-1,656$.

('82). BERT, B., ET REGN $\triangle R D$, P. Action de l'eau oxycénée sur les matières organiques et les fermentations. C. R. des sé. de l'Acad. des sci. Paris, T. Xciv, pp. I,383-I,386. Jour. de Pharm. et de Chimie, T. VI, 5 série, I882, pp. I4-17.

('82). WorrmanN, J. Untersuchungen über das diastatische Ferment der Bacterien. Zeitschr. f. physiol. chem., Bd. vi, pp. 287-329, I882. Also Jour. Chem. Soc., Xuiv, pp. 930-938, I883.

('82). Marcano, V. Fermentation directe de la féctile. Mécanisme de cette métamorphose. C. R. des sé. de l'Acad. des Sci., Paris. T. $\mathrm{XCV}, 1882$, pp. $856-859$.

('83). BÉchamp, A. Les microzymas dans leurs rapports avec l'hétérogénie, l'histogénie, la physiologie et la pathologie, pp. XXXvıI, 992, with 3 pl. Paris, I883.

Prior to $188_{3}$ Réchamp isolated from yeast an enzyme capable of inverting cane sugar. See pp. 69 et seq.

('83). Vigna, A. Ueber Bakteriengährung des Glycerins. Ber. d. deutsch. chem. Gesells., xvi, pp. I,438-1,439; Gazz. Chim. Ital., vol. XIII, pp. 293-296, I883.

('83). TAPPEINER, H. Ueber Cellulosegährungen. Ber. d. deutsch. chem. Gesclls., Bd. xvi, 1883, pp. I,734-I,740.

('83). TAPPEINER, H. Ueber die Sumpfgasgährung im Schlamme der Teiche, Sümpfe und Kloaken. Ber. d. deutsch. chem. Gesells., Bd. Xvi, I883, pp. I,740-1,744.

('86). Hoppe-SEYLER, FELIX. Ueber Gährung der Cellulose mit Bildung von Methan und Kohlensäure. Zeitschr. f. physiolog. Chemic., I886, Bd. X, pp. 20I-2I7 and 40I-440.

('89). KRAMER, ERNST. Studicn über schleimige Gährung. Sitzungsb. d. k. Ak. d. Wissenschaften. Math.-natturw. Classc, Bd. xcvirs, s889, iv Hft., Abt. I I b. Chemie, pp. 358-396. Wien.

An interesting paper.

('89). Frankland, Percy F., and Fox, J. J. On a pure fermentation of mannite and glycerinc. Proc. Royal Soc, I.ond., I889, vol. XLVI, pp. 345-357.

('89). Curtman, Ciras. O. Naohweis der Glycose durch Safranin. Pharmaceutische Rundsohat, Bd. viI, I 889 , p. I32.

('89). Tischutkin, N. Dic Rolle der Baktericn hei der Veränderung der Eiweissstoffe auf den Blättern von Pinguicula. Ber. d. deutsch. bot. Gessellsclı., Bd. vir, IS89, pp. 346-355.

('go). Sclavo, Acilli, E', und Gosio, B. Ueber eine neue Gärung ider Stärke. Staz. sperim. agrar, ital., I890, vol. XIX, p. 540. 
('9o). REINITZER, FR. Uober die wahre Natur des Gummifernientes. Zeitschr. f. physiol. Chemie, Bd. xrv, 1800 , pp. 453-470.

This autior states that Wiesner's ferment, which changes cellinlose into gum and slime, does not exist. Nickel, of Berlin, has come to the same conclusion iudepende11ty. (See 13ot. Centralb., 1800 , Bd. XLIII, p. 118), The "orcin salzsäure " reaction of Reichl ia a furfurol reaction.

('Do). SmITH, ThEodald. Das Gährungskölbchen in der Bakteriologie. Centralb. f. Bakt., vII Bd., 1800, pp. 502-506, mit I Abbildung.

('90). SMITH, TH EOBALD. Einige Bemerkungen über Säure- und Alkalibildung bei Bakterien. Centralb. f. Bakt., Bd. viri, 1890, pp. 389-39I.

(go). Ferrm, Claudio. Die Lreim und Fibrin lösenden und die diastätisohen Fermente der Mikroorganismen. Centralb. f. Bakt., VII Bd., 1890 , pp. $460-474$.

('9o). Dubois, R. Sur le prétendu pouvoir digestif du liquide de l'urne des Nepenthes, C. R. des sé. de l'Acad. des Soi. T. cxi, i890, pp. 315-317.

Maintains that the observed restilts are not due to any pepsin-like body secreted by the plant, bnt to the action of intruding bacteria, and concludes that the Nepentbes are not csrnivotous.

('9I). HÉRY. Sur une fermentation visqueuse de l'encre.-Annales de Micrographie, I891, T. IV, pp. 13-2r.

('9I). FFrRI, CiAUdio. Weitere Untersuchungen über die tryptischen Enzyme der Mikroorganismen. Centralb. f. Bakt., x Bd., I89I, pp. $401-408$.

('9I). RiTSERT. Bakteriologische Untersuchungen über das Sohleimigwerden der Infusa. Ber. d. pharm. Gesellsch., I Bd., 1891, pp. 389399. Rev. in Centralb. f. Bakt., I892, XI, pp. 730-733.

('gI). SuciISLAND, E. Ueber Tabaksfermentationen. Ber. d. d. bot. Gescllsch., Bd. IX, I89I, pp. 79-8I.

('9I). BEY EINCK, M. W. Verfahren zum Nachweise der Säureabsonderung bei Mikrobien. Centralb. f. Bakt., ix Bd., 1891, pp. 781-786.

This method consists in usiug with gelatin or aggr, for plate-cultures, etc., a solid opaque substance which is converted into a soluble, transparent substance in the presence of acid.. For thils purpose Beyerinck adds to the culture-medium a amall amount of water in which a very finely divided carhouate of lime has been shaken up. This makes a white opaque plate. Colovies which secrete acids are soon surrounded by a transparent dif. fusion field. Other carbonates may be used, e. $g$, zinc carbonate. This mcthod may also be used for the demonstration of alkall production.

('9i). Tiscirutrin, N. P. Ueber die Rolle der Mikroorganismels bei der E,rnälirung der insektenfressenden Phanzen. Arbeit. d. St. Potersburg naturf. Gesell., vol. for I890, Sect. d. Bot. pp. 33-37, S.t. Petersburg, I891. Ahs. in Bot. Centralb., Bd. L, 1892, p. 304.

(92). Cons, H. W. Isolirung eines "Lab" fermentes aus Bakterienkulturen. Centralb. f. Bakt., Bd. XII, I892, pp. 223-227.

('92?). FRankLand and FrEIV. The fermentation of calcium glycerate by the Bacillus ethaceticus. Trans. Roy. Cliem. Soc., 189r. Rev. in Centralb. f. Bakt., XII Bd., 1802, p. 724.

('92). Franki,and, P., and MacGrigor, J. Fermentation of arabinose with the Bacillus cthaceticus. Trans. Cliem. Soc., I892. Rev, in Centralb. f. Bakt., XII Bd., 1892, p. 725.

('92). Frankland, P. F., and FRew, W. A pure fermentation of mannitol and dulcitol. Trans. Chem. Soc, i892, pp. 254-27\%.
('92). Frankland, P. F., and Lumspen, J. S. Decomposition of mannitol and dextrose by the Bacillus ethaceticus. Trans. Chem. Soc., 1892, pp. $432-444$.

('92). Fermi, Claudio. Beitrag zum Studium der von den Mikroorganismen abgesonderten diastätischen und Inversionsfermente. Centralb. If. Bakt., xII Bd., I892, pp. 713-715.

of 62 bacteria investigated, 20 were acid producera, 2 inverted cane sugar, 24 developed a proteol ytic enzym, 20 a

('92). Tischutkin, N. Ueber die Rolle der Microorganismen bei der Errnährung insektenfressender Pflanzen. Acta Horti Petropolitanie, Bd. XII, St. Petersburg, I892, pp. I-I9. Abstract in Bot. Centralb., Bd. LiII, I893, p. 322.

('92). Frankland, P. F. Cantor lectures on recent contributions to the chemistry of baoteriology of the fermentation industries, gr. 8vo., 31 pp. London, W. S. Trounce, I892.

Not seen.

('93). HildE,BRANDT, H. Weiteres über hydrolytische Fermente, etc. Arch. f. path. Anat. u. Physiol., Bd. Cxxxı, I893, pp. 5-39.

('93). GowBEL. Pflanzenbiologisohe Schilderungen II, 1893, p. 186.

Criticises views of Dubois and Tischutkin.

('93). HAPP. Bakteriologische und chemische Untersuchungen über die schleimige Gärung, p. 31 , these inaugurale. Berlin, 1893 .

Not seen. Describes Micrococcus gummosus,

('93). Cavazzani, Emil. Zur Kenntnis der diastatischen Wirkung der Bakterien. Centralb. f. Bakt., Bd. XIII, I893, pp. 587-589.

('93). PÉrte, A. Sur la formation des acides lactiques isomériques par l'action des miorobes sur les substances hydrocarbonées. Ann. de l'Inst. Pasteur, T. vIr, I893, pp. 737-750.

('93). HessE, W. U.eber die gasförmigen Stoffwechselproducte beim Waohsthum der Bakterien. Zeitschr. f. Hyg., Bd. xv, 1893, pp. 17-37.

('93). Smith, ThEobald. The fermentation tube with special reference to anaerobiosis and gas production among bacteria. Wilder Quarter Century Book, Ithaca, N. Y., 1893, pp. 187-232.

('93). Frankland, P., and MacGregor, J. Sarcolactic acid obtained by the fermentation of inactive Iactic acid. Trans. Chem. Soc., London, 1893, pp. I,028-1,035.

('93). GRIM BerT, L. Fermentation anaérobie produite par le Bacillus orthobutylicus. ses variations sous certaines influences biologiques. Ann. de l'Inst. Pasteur, T. vir, I893, pp. 353-402.

('93). GreEN, J. R. On Vegetable Ferments. Annals of Botany, I893. Vol. vir, pp. 83-137.

('94). Ferrmi, Claudio, and Perrossi, Leone. Ueber die Enzyme. Centralb. f. Bakt., Bd. xv, 1894, pp. 229-234.

('94). Firmi Und Pernossi. Ueber die Enzyme. Zeitschr. f. Hyg., Bd. xv11, 1894, pp. 83-127.

Studies of the action of hest, ligbt, and various chemical substances on various enzy mes.

('94). Wood, JosEPH T. Fermentation in the leather industry. Journal of the Society of Chemical Industry, 1894, vol. xirr, pip. 218-222. 
('94). Gotrstein, Apoly. Ueber die Zerlegung des Wasserstoffsuperoxyds durch die Zellen, mit Bemerkungen über eine makroskopische Reaktion für Bakterien. Vinohow's Archiv., Bd. cxxxiII, p. 296. Rev. in Centralb. $f$. Bakt., Bd. XVI, I804, pp. 518-519.

('94). TimpE, HermanN. Ueber die Beziehungen der Phosphate und des Kiaseins zur Milchsäuregärung. Die landwirtschaft. Versuchsstat., Bd. XL.II, I894, pp. 223-238.

('94). LASER, Hugo. Die makroskopische Wasseruntersuchung idunch Anwendung von Wasserstoffsuperoxyd. Centralb. f. Bakt., Bd. XVI, I894, pp. I80-I 82 .

This substance, which causes liberation of oxygen from $\mathrm{H}_{2} \mathrm{O}_{2}$ is said to be nuclein. Author failed to confirm Gottstein's results. (Virchow's Archiv., Bd. exxxmin, Heft 2.)

('94). Grefe, J. R. The influence of light on diastase. Abstr. of a paper read before the British Assoc. at Oxford, Aug., I894. Ann. of Bot., vol. vIII, I894, pp. 370-373.

('94). Gosıo, B. Ueber Links-Milchsäure bildende Vibrionen. Arch. f. Hyg., Bd. XxI, I894, pp. II4-I22.

('94). MACFAyden ANd Blaxall. See Xxxiv.

('95). BAIER, EDUARD. Ueber Buttersäuregährung. Centralb. f. Bakt., 2 Abt., Bd. I, I895, pP. $84-87$ and 1 I 8 -I 20 .

('95). OMÉlanski, V. Sur la fermentation de la cellulose. C. R. des sé. de l'Acad. des sci., T. cXXI, I895, pp. 653-655.

(95). JotRgENSEN ALFRED. Les microorganismes de la fermentation. Traduit par Paul Freund. 8 vo., 318 pp., 56 illst., Paris (Soc. d'éditions scientifiques), I895. Microorganisms and Fermentation. English translation bv Alex. K. Miller and A. E. Lennholm. Third edition completely revised, with 83 illustrations. pp. XIII, 318. London, Macmillan \& Co., Ltd. New York, The Macmillan Co., I900. There is also German translation whioh has reached the 3 d ed. Berlin, I892.

orig., in Danish, not seen.

('95). Gosio, B. Zersetzungen zuckerhaltigen Nährmateriales durch den Vibrio choleræ asiaticæ Koch. Arch. f. Hyg., Bd. Xxil, I895, pp. I-27.

('95). Fermi und Montesano. Die von den Mikroben bedingte Inversion des Rohrzuckers. Centralb. f. Bakt., 2 Abt., Bd. I, I895, No. I3-I4, pp. 482-487, No. I5-I6, pp. 542-556.

The author used Nylander's and Rubner-Penzolde's reactions. Fehling's solution was not used, because it is not to be trusted in the presence of albumen.

(95). BEYRINCK, M. W. Ueber Nachweis und Verbreitung der Glukase, das Enzym der Maltose. Centralb. f. Bakt., 2 Abt., Bd. I, I895, pp. 22I-229, pp. 265-27I, and pp. 329-342.

('g6). Bourouelot, EMIL. Les ferments solubles (diastases-enzymes). pp. viII, 220. 8vo. Paris, Société d'éditions scientifiques, 1806 .

('g6). PFEFFer, W. Ueber regulatorische Bildung von Diastase. Ber. u. d. Verhandl. d. K. sach. Gesellsch. d. Wissenschaften zu Leipzig. Mathematisch-Physik. Classe, 1896, pp. 5I3-5I8. Also a separate.

('07). BuchNer, H. Die Bedeutung der activen löslichen Zellprodukte für den Ohemismus der Zelle. München. med. Wochenschr. 1897, No. 12, pp. 299-302.
('97). BUCHNER, ED. Alkoholische Gärung olne Hefezellen. Ber. d. deutsch. chem. Gesellsoh., I897, Jahrg. xxx, pp. II7-I 24 and I,II0-I,I13. See also Ibid., Jahrg. XXXI, p. 568-574.

" Fine Trennung der Gährwirkung von den lebenden Ilefezellen ist bisher nicht geluugen." (XXX, p. 117.)

('97). VinEs, S. H. The proteolytic enzyme of Nepenthes. Annals of Botany, vol. XI, 1897 , pp. $563-584$.

('98). PREscot1, S. C., ANd UNDERWOad, W. LYMAN. Contributions to our knowledge of microorganisms and sterilizing processes in the canning industries. II The souring of canned sweet corn. Tech. Quarterly, vol. XI, No. I, I8g8, 6 plates. Also a separate, $30 \mathrm{pp}$.

('99). Omícianski, V. Sur la fermentation de la cellulose. Aroh. des sci. biol. publiées par l'inst. imp, de méd. expér. à St. Pétershourg, T. VII, pp. 4II-434. I heliotype plate.

('99). Fermi, Claudio, and Buscaglioni. Die proteolytischen Enzyme im Pflanzenreiche. Centralb. f. Bakt., 2te Abt., Bd. v, I899, No. I, 1p. 24-27; No. 2, pp. 63-66; No. 3, pp. 91-95; No. 4, pp. 125-134; and No. 5, pp. I4.5-I58.

('o9). Duchaux, E. Traité de microbiologie. 'Tome II. Diastases, toxines et venins. Paris, Masson et 'Cie, I899, pp. II I, 768, large 8vo. The best treatise in French.

('o9). SACII ARoFF, N. Einige ergänzende Angaben zur Mitteilung: "Ueber den Chemismus der Wirkung der Enzyme und der bakteriaiden Stoffe." Centralb. f. Bakt., xxv Bd., I899, pp. 346-350.

('99). BULLER, A. H. R. Die Wirkung von Bakterien auf tote Zellen. Inaugural. Dissertation. Univ. of Leipsic, pp. 47. Leipsic, I899.

('99). BREDIG, G., und MULLLER V. BERNECK, R. Ueber Platinkatalyse und die chemische Dynamik des Wasserstoffsuperoxyds. Zeitschr. für Physikalische Chemie., Bd. xxxI, I899, pp. 258-353, 3 text figs.

In many ways plattnum black behaves like an enzyue.

('99). BuchneR, E., UND RAPP, R. Alcoholische Gährung ohne Hefezellen. Ber. d. deutsch. chem. Gesellsch., Jahrg. xxx (I897), 2,668; Jahrg. XXXI (I898), 209, I,084, I,090, I,53I ; Jahrg. XXXII (I899), I27-I37.

('99). GREen, J. Reynolds. The soluble ferments and fermentation. pp. XIII, 480. Cambridge (England), at the University Press, I899. 2d ed., IgoI, pp. xv, 5I2, with a bibliography of 806 titles.

An excelleut book, and the only complete, authoritative one in English.

('oo). Duclaux, E. Traité de microbiologie. Tome III. Fermentation alcoolique. Paris, I900, pp. III, 760, 84 text figures, 8vo. Masson et Cie.

('o). TurRo, R. Zur Bakterienverdauung. Centralb. f. Bakt., xxvili Bd., 1900, pp. I73-I77.

('oo). Morgenroth, J. Zur Kenntnis der Labenzyme und ihrer Antikörper. Centralb. f. Bakt., XXvir Bd., 1900, pp. 72I-724.

('or). ScIIOENE, ÁlBERT. Die Mikroorganismen in den Säften der Zuckerfabriken. Berlin, Zs. Ver. D. Zuckerind., Bd. LI, Igor, techn. TI, pp. $453-468$. 
('OI). Boufrard, A. Les maladies microbiennes des vins. Fermentation alcoolique; maladies microbiennes; carre des vins; hygiène des vins; traitcment des vins malades. Nancy, I90I, 12mo., avec 6 planches et fig. Not seetl.

('oI). Duclaux, E. Traité de microbiologie. Tome IV. Fermentations variées des diverses substances ternaires. Paris, Masson et Cie., I90I, pp. III, 768, 45 text figures. Valuable.

('o1). Gessarn, C. Etudes sur la tyrosinase. Ann. de l'Inst. Pasteur, T. xv, IgoI, pp. 593-6I4.

('or). BE,IJERNCK, M. W. Anhäufungsversuche mit Ureumbakterien. Ureumspaltung duroh Urease und durch Katabolismus. Centralb. f. Bakt., Bd. viI, I90I, pp. 33-6r, with I plate and 4 figures.

('o2). Rollv. Weiterer Beitrag zur Alkali- und Säurcproduktion der Bakterien. Arch. f. IHyg., Bd. XL1, 1902, pp. 406-412.

('o2). Schreiber, KARL. Fettzersetzung durch Mikroorganismen. Arch. $\mathfrak{i}$. Fyg., Bd, XLI, 1902, pp. 328-347.

('02). SMith, R. GREIG. The gum fermentation of sugar cane juice. Proc. Linnean Soc., N So. Wales, for the year rooI, Sydney, 1902. Vol. xxvr, Pt. I, pp. 589-625, I plate. Also a separate.

('o2). Smith, R. Greig. The deterioration of raw and refined sugar crystals in bulk. The acid fermentation of raw sugar crystals. Proc. Linn. Soc. of New South Wales, for Igor, Pt. 4, pp. 674-683, 684, Sydney, I902. Also a separate (issued May 20, 1902).

('O2). OMLilanskI, W. Sur la fermentation forménique de la cellulose. Arch. des sci. biol. publiées par d'inst. imp. de méd. expér. à St. Pétersbourg, T. IX, I902, pp. 25I-278, I heliatype plate.

('o2). Filifront, JEAN. Enzymes and their applications. English translation by Samuel C. Prescott, vol I. The enzymes of the carbohydrates. The oxidases. New York, John Wiley \& Sons; London, Chapman \& Hall, Ltd., I902, pp. XI, 322.

('o2). Salvam URA, S. On the liquefaction of mannan by microbes. Bulletin of the College of Agriculture, Tokyo Imperial University, vol. v, No. 2, 1902, pp. 259-262. Also a separate.

('O2). Weiss, Richarb. Uber die Baktcrienflora der Sauern Gährung einiger Nahrungs-und Genussmittl. Arb. a. d. Bact. Institut der tech. Hochschule zu Karlsruhe, Ir Bd., 3 Heft, 1902, pp. I63-269.

Forty-eight new species are described: Streptococcus citreus, $S$, maximus, Micrococcus pulcher, M. regulatis, M. irregularis, M. umbilicatus, M. tuinimus, M. gummo sus, M. tu ucilagineus, M. vulgaris, $\mathbf{M}$. piliformis, $\mathbf{M}$ expressts, M. granulatus, M. subluteus, M. tener, M glandulosus, $M$. vesicosus, $M$. mucilaginosus, $M$. fulvus, lacillus fortissimus, B. opacus, B, splraus, B. fuliglnosus, B. eminans, B. ventricosus, B. citricus, B. odoratus, $B$. anygdaloidcs, B. robustus, B. tuberosts, B. globulosis, 13. fungosus, B. Alavesceus, B. gracilesceus, Bacteriut ariosum, B. spinosum, B. crenatum, B, plicativum, B. brevissimum, B. ramificans, B. gibbosum, B. gracillimun, B. squamatum, B. utiforme, B. insulsum, B, subcitrinum, B. gratulostum, Pseudomonas iactica, Ps. Listeri.

('o2). Gran, H. H. Studien über Meeresbakterien. 2. Ueber dic Hydrolyse des Agar-Agars durch ein neues Enzym, die Gelase. Bergens Mus. Aarb., 1902, No. 2, p. 16.
('O3). KELLERMAN, KARL. The effects of various chemical agents upon the starch-oonverting power of taka diastase. Bulletin Torrey Botanical Club, vol. xxx, 1903, pp. 56-70. Also a separate.

('o3). Vinss, S. H. Proteolytic enzymes in plants. Annals of Botany, vol. xvil, Jan., I903, pp. 237-264.

('03). SMITH, R. GREIG. A gum (levan) bacterium from a saccharine exudate of Eucalyptus Stuartiana. Proc. Linnean Soc., N. So. Wales, vol. xxvir, for the year 1902, pp. 230236. I plate. Sydney, I902-'o3.

('o3). Liprmann, E. O. von. Zur Nomenklatur der Enzyıne, Berichte d. deutsch. Chem. Gesellschaft, 1903, Bd. xxxvi, p. 33 I.

\section{Ptomaines, Toxins, Antitoxıns, Serums, Phagocytosis, etc.}

('86). BnïGGR. Untersuchungen über Ptamaine. Beriin, 1886. Traduction par Roussy et Winter as Microbes, ptonuanes ot maladies. Paris, 1887, pp. XII, 235.

('87). MFitch NikoFr, Elis. Sur la lutte des cellules de l'organisme contre l'invasion des micrabes. Ann. de l'Inst. Pasteur, T. I, I887, pp. 321-336.

('88). NutTald, Geo. Experimente über die bacterienfeindlichen Einflüss des thierisohen Körpers. Zeitschr. f. Hyg., Bd. Iv, I888, pp. 353-394.

('88). GAE'RTNER. Ueber die Fleischvergiftung in Krankenhauser und den Erreger derselben. Jena, I888.

Not seew.

('89). Nissen, F. Zur Kenntniss der Bacterienvernichtenden Eigenschafit des Blutes. Zeitsohr. f. Hyg., Bd. vı, 1889, pp. 487-520.

('89). Buchner, H. Ueber die baoterientödtende Wirkung ides zellenfreien Blutserums. Centralb. f. Bakt., Bd. v, I889, pp. $817-823$; and Bd. vi, I889, pp. I-II.

('go). Brifgrr, L., U. FraEnkel, CarL. Untersuchungen über Bacteriengifte. Berl. klin. Wochenschr., B.d. XxvII, I890, No. II, pp. 24I-2.46; No. 12, pp. 268-27I.

('go). Linmann. Ueber die pilztödtende Wirkung des frischen Harns des gesunden Menschen. Centralb. f. Bakt., Bd. vir, I890, pp. 457-460.

('go). Jacquemart, F. Ĺes ptomaines, histoire et caractères chimiques, mémoire couronné par la Société royale des sciences médicales et naturelles de Bruxelles. Jour, de méd. de chir. et de pharm., Bruxelles, I890, No. 18. Rev. in Centralb. f. Bakt., IX Bd., I89I, pp. IO7-IIO.

('go). Carbonf, Tito. Ueber die von Proteus vulgaris crzeugten Gifte. Centralb. f. Bakt., I89o, Bd. viII, pp. 768-773.

('go). Lewandowski, A. Ueber Indol- und Phenolbildung durch Bakterien. Deutsohe mediz. Wochenschrft, Bd. XVI, I890, p. I,I86.

('go). Gabritchevsky, G. .Sur les propriétés chimiotactiques des leucocytes. Ann. de l'Inst. Pasteur, T. IV, I89o, pp. 346-362.

('gr). Ogata, M. Üeber die bacterienfeindliche Substanz des Blutes. Centralb. f. Bakt., Bd. IX, I891, pp. 597-602. 
('91). TrapeznikofF. Du sort des spores de microbes dans l'organisme animal. Ann. de 1'Inst. Pasteur, T. v, I891, pp. 362-394, 2 plates.

('94). EHRlich, P., UNd WassermanN, A. Ueber die Gewinnung der Diphtherie-antitoxine aus Blutserum und Milch immunisirter Thiere. Zeitsah. f. Hyg., Bd. XviIr, I894, pp. 239-250.

('95). BRIEGER, L. Weitere Erfahrungen über Bakterietigifte. Zeitsoh. f. Hyg., Bd. XIX, I895, pP. IOI-II2.

('06). BRIEGER UND BOER. Ueber Antitoxine und Toxine. Zeitsch. f. Hyg., I8g6, Bd. xxI, pp. 259-268.

('06). GAUTIER, ARMAND. Les toxines microbientres et animales, I896, pp. viI, 6I7. Soc. d'éditions scientifiques, Paris.

('96). EHRLich, P. Die statliche controle des Diphtherie serums. Berl. klin. Wochenschr., Bd. XXXIII, I8g6, pp. 44I-443.

('g6) VAughaN, Victor C., aNd Novy, FreDr. G. Ptomains, leucomains, toxins, and antitoxins. 3d ed. Lea Bros. \& Co., Philadelphia and New York, I896, pp. x, 604.

Contains a bibliograpliy of several hundred titles. The th ed. was issued in 1902, witli the following tille: Cellular toxins or the chemical factors in the causation of disease. Same publishers. Pp. vill. 495.

('96). Metchnikona, Eit., Roux, E., ET TAURELliSALIMBENI. Toxitne et antitoxine cholérique. Ann. de l'Inst. Pasteur, T. X, I896, pp. 257282.

('97). Smith, Thiobat, A modification of the method for determining the production of indol by bacteria. Jour. Exper. Med., vol. II, I897, pp. 543-547.

('oo). BorDÉr, J. I,es sérums hémolytiques, leurs antitoxines of les théories des sérums cytolytiques. Ann. de 1'Inst. Pasteur, 1900, T. XIV, pp. 257-206.

('o). MEтch de l'Inst. Pasteur, T. xIv, pp. 369-377, 1900.

(') . Fischer, AlFrED. Die Empfindliohkeit der Bakterienzelle und das baktcricide Serum. Zeitsohr. f. Hyg., Bd. Xxxv, Ig00, pp. I -58 , I plate.

('oi). Zabolotiny. See vit.

('OI). BORDET, J., ET GENGOU, O. Recherches sur la coagulation du sang et les sérums anticoagulants. Aun. de 1'Inst. Pasteur, T. Xv, I90I, Pp. I 29-I 44 .

('OI) BORDET, J., ET GENGOU, O. Sur l'existence de substances sensibilisatrices dans la plupart des sérums antimicrobiens. Ann. de l'Inst Pasteur, I00I, T. XV, pp. 289-302.

('or). BorDEr, J. Sur le mode d'action des sérums cyitolytiques ot sur l'unité de l'alexine dans un même sérum. Ann. de l'Inst. Pasteur, T. $x v$, I90I, pp. 303-318.

('or). Gruber, Max. Zur Theorie der Antikörper. I. Ueber die Antitoxin-Immunität. II. Ueher Bakteriolyse und Hacmolyse. Münchener med. Wochenschr., Bd. XIVIII, I90I pp. I,827-I,830, pp. I880-I884, pp. I,924-I,986 Not seen.

('02). MARX, E. Die experimentelle Diagnostik, Serumtherapie und Prophylaxe der Infectionskrankheiten. [Bibliothek v. Coler, Bd. XI.] Berlin (A. Hirschwald), Ig02, pp. VII, 206, mit 2 Taf.
('04). WASSERMANN, A. Inmune sera, haemolysins, cytatoxins, and precipitins. English translation by Charles Bolduan. New York, John Wiley \& Sons; London, Chapman \& Hall, 1904, pp. Ix, 77.

\section{Attenuation, Virulence.}

('80). Pasteur, Louis. De l'atténuation du virus du choléra des poules. C. R. des sé. de l'Acad. des sci., T. XCr, I880, pp. 673-680.

('80). Chauveau, A. Des causes qui peuvent faire varier les résultats de l'inoculation charbonneuse sur les moutons algériens. Influence des quantités des agents infectants. Applications à la théorie de l'immunité. C. R. 'des sé de l'Acad. des sci., 'T. $x \mathrm{xC}_{\text {, }} \mathbf{1 8 8 0}$, pp. I, 526-I, 530 .

('8I). PASTEUR, I,ouis. Le vaccin ides oharbon. C. $R$. des sé. de l'Acad. des sci., T. Xcri, I88I, pp. 666-668.

('8i). Pasteur, Chamberland, ex Roux. De l'atténuation des virus et de leur retour à la virulence. C. R. des sé. de l'Acad. des sci., T. XCIT, I88I, pp. $429-435$.

('8i ). Cin Auveau, A. De l'atténuation des effets des inoculations virulentes par l'emploi de très petites quantités de virus. C. R. des sé. de 'Acad. des sci., T. XcII, I88I, pp. 844-848.

('83). Chamberland Ét Roux. Sur l'atténuation de la bactéridie charbonncuse et de ses germes sous l'influence des substances antiseptiques. C. R. des sé. de l'Acad. des sci., T. Xcvi, 1883, Paris, pp. I,4IO-I,4I2.

(87). METCHNIKOFE, EILE Sur l'attenuation des bactéridies charbonneuses dans le sang des moutons réfractaires. Ann. de 1'Inst. Pasteur, T. I, I887, pp. 42-44.

('89). Macḱ. See XxIII.

('o3). D'Arsonval, and Citarrin. Sec xxxir.

('94). Roger. See xxxiI.

(95). KLEPZOFF. See XXXIII.

('03). FunRmann, Franz. Ueber Virulenzsteigerung eines Stammes des Vibrio Cholerae asiaticae. Sitzungsber. d. kaiserl. Akad. d. Wissensch. Mathematisch-Naturwissensch. Klasse., Bd. cxiI, Heft. viri, Abt. III, I903. pp. $267-284$. With Bibliography of 15 titles.

XXIII. Pigments. Green Bacteria.

('73). LANKESTER, E. RAY. On a peach-coloured bacterium, Bacterium rubescens, n. s. Quart. Jour. Micro. Sci., 1873, vol. xiIr, n. S., pp. 408-425. 2 plates (colored).

('80). VAN TIEGHEM, PH. Observations sut des bactériacées vertes, sur des phycochromacées blanches, et sur les affinités de ces deux familles. Bull de la Soc. Bot. de France, Tome xxviI, I880, pp. I74-I79.

('82). EngrimanN, TH. W. Zur Biologie der Schizomyoeten. Bot. Zeitung, 40 Jahrg. I882, col. 32I-325 and 337-34I.

Describes a green organism as Bacterium chlorinum. It is believed to cantain chlorophyl1.

('87). Schortreilus. See xv.

('87). Prove, Oskar. Micrococcus oohroleucus eine neue chromogene Spalt pilzform. Beitr. zur Biol. der Pflanzen., Bd. IV, Hft. 3, 1887, pp. 409-439, I plate. 
('89). MAcÉ. Sur la récupération de la vitalité des cultures de bactéries par passages sur ccrtains milieux. Soc. des sc. de Nancy pour I888, Series II, T. IX, Fasc. xxII, pp. xxIx$\mathrm{x} \times \mathrm{x}$ and $79-83$, Paris, 1889 .

The medium used was potato. Bacteria which havelost their power to form pigment on ggar or to iufeet frogs will often regsin these functious if eultivated for a time on potato.

('89). Zopr, W. Ueber Pilzfarbstoffe. Iv. Vorkommen einer Lipochroms bei Spaltpilzen. Bot. Zeitung, Bd. XLvis, I889, col. 89-92.

('89). Zopk, W. Ueber das mikrochemischen Verhaliten von Fettfarbstoffen und Fettfarbstoffhaltigen Organen. Zeitschr. f. wissensch. Mikroskopie, I889, Bd. vi, pp. I72-I77.

('89). Scuiblateuder, D. Ein Bacillus mit brauner Verfärbung der Gelatine. Allgemeincn Wiener medicinischen Zeitung, Jahrg. XXXIV, I889, pp. I7I-172, Wien, I889. Also a separate, 7 pp.

This organisur liquefies geiatin. It was isolated from spoiled eggs.

('90). BEJIR, P. Ueber eine nicht mehr farbstoffbildende Rasse des Bacillus der blauen Milch. Centralb. f. Bakt., Bd. viri, r890, pp. $485-487$.

('go). ClaAsSEn, HeinR. Ueber einen indigoblauen Farbstoff erzeugenden Bacillus aus Wasser. Centralb. f. Bakt., Bd. vis, I800, pp. 13-I7.

('91). Dangeard, P. A. Contribution à l'étude des Bactériacées vertes (Eubacillus gen. nov.). Le Botaniste, Sér. I I, I89I, fasc. 4, pp. 15II60, avec. planche. Also C. $R$. des sé. de l'Acad. des soi., T. cxir, I80I, pp. 25I-253. Review in Centralb. f. Bakt., x Bd., I89I, pp. 745-747. Daugeard found his green spore-bearing organism
(Fubacillus multispotus) on the walls of a culture flask (F,ubacillus multispotus) on the walls of a culture flask
ised for the growt used for the growt ho fresh-water alga, where it made a felt of very loug slender flexible filameuts. He states that it contains chlotophyll distributed through the protoplasin. The sporiferous filameuts may be bravehed. The spores are a distiuet green. Its liabitat is

fresh-water alge in the vieinity of Caen, France. Tollowing forms described by Klein: Bacillus de Baryfollowing forms, described by Klein: Bacillus de Baryanus, B. Solmsii, B. Peronjella, B. maerosporus, and B. limosus, all of which are sporiferons, the spores being blue-grcen. These
with chlorophyl1.

('9I). Stater, Charles. On a red pigment forming organism, Bacillus corallinus. The Ouarterly Jour. of Microsc. Sci., I89I, vol. 32, n. s., No. cxxvir, pp. 409-416, I plate.

The author says budding and branched forms ocent in liquid media.

('OI). BEYYRINCK, M. W. La biologie d'une bactérie pigmentaire. Archives néerlandaises, T. XXv, I89I, Livr., 3I4. See also Die Lebensgeschichte einer Pigmentbakterie. Bot. Zeitung, I89I, Nos. $43,45,46$, and 47 , colunms 705-712, 74I-752, 757-770, and 773781 , with I plate.

Thls paper describes the morphology and blology of Bacilins cyaneofuscus, which was first found eausing damage to the glne of a gelatin factory and afterwards in other places. "Th's microbe is also the canse, or at lesst one of the caures, of a deterioration quite frequent in Holland cheeses, especially those known as ' $\mathrm{d} d \mathrm{sm}$, change which under the uane of 'bluelug, is tnich ciresded by makers of these product,"

rhis organism belongs to the chromoparous group of pigment-forming bacteria, 1 c. it is itself colorless but pigment-forming bacteria, 1 . c., it is itself colorless, but excres the pigment. The first forin of the pignent is pears as solid-hlue splierites, mixed in with the baeteria.
('91). Overbeck, A. Zur Kenntniss der Fettfarbstoff-Produktion bei Spaltpilzen. Nova Acta d. K. Leop. Carol. Deutschen Akad. d. Naturf., Bd. Lv, No. 7, pp. 399-416. I plate. Halle, I89I. Also a separate.

('9I). BEIJERINCK, M. W. De Levensgeschiedenis eener Pigmentbacterie. Versl en Mededeel. der koninkl. Akad. van Wetensch. Afdeeling Naturkunde, 3 Reeks, 8 Deel, I89I, pp. (307)- (3I5)

Paper deals with Bacillus cyaneofuscus.

('9I). Gessard, C. Des races du bacille pyocyanique. Ann. de l'Inst. Pasteur, T. v, I89I, pp. 65-78. Organlsm produces two piguients : (a) Pyoeyanin (b) fluoresciue, and probably a third.

('91). ZopF, W. Ueber Ausscheidung von Fettfarbstoffen (Lipodiromen) seitens gewisser Spaltpilze. Ber. d. deutsoh. bot. Gesellsch., Bd. IX, pp. 22-28, 189 I.

('92). GeSSARD, C. Sur la fonction fluorescigène des microbes. Ann. de l'Inst. Pasteur. T. VI, I892, pp. $801-823$.

('92). Charrin E'T Pitysalitx. See xv.

('92). RoHrER. Ueber die Pigmentbildung des Bacillus pyocyaneus. Centralb. f. Bakt., X1 Bd., 1892, pp. 327-335.

('92). OKADA, K. Ueber einen rothen Farbstoff erzeugenden Bacillus (Bacillus rubellus) aus Fussbodenstaub. Centrallb f. Bakt, XI Bd., I892, pp. I-4, mit I colored Taf.

('93). ERNST, Harold C. The Bacillus pyocyaneus pericarditidis. The American Journal of the Medical Sciences, I893, October, No. 258, pp. 396-402. Rev. in Centralb. f. Bakt. Bd. XV, 1894 , p. 559.

This organism is motile by tneaus of a polat flageilum and the writer has chauged the name to Bacterium pericarditjdis (Erust). It produces no pigment soluble in chloroform.

('93). Voces, O. Ueber einige im Wasser vorkoinmende Pigmentbakterien. Centralb. f. Bakt., Bd. XIv, I893, pp. 30I-315.

An account of Bncillus coeruleus and other biue or violet pigment-forming orggnisms.

('93). D'Arsonval and CiIARrin. See Xxxir.

('94). Borodoni-UHFríndZZI. See XlviI.

('94). TersSIER, P. J. Etude des propriétés chromogènes permanentes ou facultatives de certains microbes pathogènes oul saprophytes cultivés sur l'albumine de l'œuf ooagulé. Arch. de méd. expérim. et d'anatomie pathologique, Tome vI, 1894. No. 2, pp. 315-327.

(94). Guignard fit Sauvageau. Sur un nouvea microbe chromogène, de Bacillus chlororaphis. C. R. des sé. et mém. de la Soc. de Biol., Paris, sé. $\mathrm{x}$, T. T, 22 Dec., I894, pp. $841-843$.

('95). Schneider, Paul. Die Bedeutung der Bacterienfärbstoffe für die Unterscheidung der Anten. Arbeiten aus dem bakt. Institut der Technischen Hochschule zu Karlsruhe. Bd. I, H.ft. 2, I805, pp. 20I-232, I fig. and I Tafel.

Conclusions : (1) Distinguisbable in part by diverse behavior in solvents. (2) The an me organism, under lik conditions, always prodices the same pugment. (3) Two sorts 111ay produce the same pigment. (4) Most of those sorts which produce apparently the same pigment, and are much alike in other ways, may be distinguished easily by the differeut resctious of the pigments.

('95). Dangeard, P. A. Observations sur le groupe des baotéries vertes. Ann. de micrographie, I895. T. viI, pp. 67-60.

Considers Bact. viride, van Tieghem, to helong to the alga. 
('95). Thum , K. Beiträge zur Biologie der fluorescirenden Bakterien. Arbeiten aus dem Bakt. Inst. der Technischen Hochschule zu Carlsruhe, Bd. I, 1895, pp. 291-377.

The following summary of the most important results is introduced in exterso, owing to the difficulty of procuring the original paper:

1. All fluorescent bacteria show in alkaline gelatin, first a sky-blue, later a moss-green fluorescence, and with the latter a yellowing of the substratum. Old cultures, with the exception of those of Bacillus finorescens putidus, are orange-red, with a dark-green fluorescence.

2. All these colors are due to one yellow pigment, a concentrated watery solution of which is orange yellow, a ditute one yellow. Both fluids are blue fluorescent, but, upon the addition of au alkali, become, according to the concentration, dark-green or unoss-green fluorescent.

3. All species produce the same pigment.

4. All are alkali formers. The production of ammonia in mauy species is considerable, and it is due to the preseoce of this alkali that the blue fluorescence gives place to the green.

5. The view of Naegeli, Ledderhose, and Kunz of the formation of a leuco-pigment, and their attempt to trace back the different colorings to oxidation phenonena, has not been confirmed.

6. Bacillus pyocyaneus Ernst, contrary to the view of the other investigators, forms only oue pigment.

7. Iu potato cultures and on acid gelatin, the same coloriug matter is produced as in alkaline media. The green finorescence is, in every case, cansed by the action of the ammonia. 8 . The a and $\beta$ forms of Bacillus pyocyaneus differ only in the pioment iormed. The a form is a rood the $\beta$ form a poor allalion a poor alkali producer. When am ture of the $\beta$ form, jt resembles a culture of the a form. 9. When an acid producer and a fluoresceut form are grown together in the same culture, the yellow

appears northally, but there is no flnorescence. Io. All species have the power of oxidizing grape sugar with the production

11. The addition of sodium formate to the ordinary wutieut gelatin causes an increased ammonia produc1utric

12. In hydrochinon gelatin all species produce a brown. ish-red color due to the action of ammonia on the hydrochinon. This may, under certain clrcumstances, be nsed as a tesi for ammonia.

13. The behavior of the different species in media contalulng different organic substances is so characteristic that it may serve as a valuable means of differentiating related species. Ammonium succinate, or asparagis, affords good nourishment for all species.

14. According to the aource of the carbon or nitrogen. the same orgauism is an abundant or scanty alkali producer; e,g., Bacillus pyocyaneus Erust is a poor alkali former in nutricut gelatin, but a good ove in a mmonium succivate.

15. Fach organism shows manifestations of life only when it comes in contact with the oxygen of the ait. Hence, only there do we find pigment and formation of ammonia.

16. For the formation of the pigmeut, calcium chloride is entirely unessential, but magnesium sulfate and potaslum phosphate are of the greatest importance. Gessard's view, that only phosphoric acid is absolutely necessary. is erroneous thes phoric acid is absolut ely necessary, is erroveous, nor may it ever be concluded thace it due to absence of phosfates.

17. The substitution of calcium for magnesium, and vice versa, does not influence the development of the different apecies, but in the formation of the pigment, calclum can not take the place of magnesium.

18. The blue color of a finid culture of Bacilius pyocyanens, in the absence of phosphoric acid, is never caused by pyocyanln, as Gessard assumed, but is referable only to refraction phenomena.

I9. The least anount of potassinm pliosfate or maguesium gulfate is sufficient for the formatiou of the fluoregcent pioment. Where in such nutrient solutions, mostly blue fluorescence is to be observed there has been a decreased amount of ammouia produced because of the small supply of wutrient salts in the solution.

2o. Bacterium syncyaneum has the power oi forming 20. Bacterium syncyanen has the power oi forming fwo plgments a the former agrees, The latter varies from steei-biue to bro

21. The fluorescence of the $\beta$ form of Bacterium syncyaneum nay be produced by cultivating it in ammonium cyaneum nay be produced by cultivating it i
lactate and transferring to uutrient gelatin.
('96). BIEL, WILHELM. Ueber einen schwarzes Pigmentbildenden Kartoffelbacillus. Centralb. f. Bakt., 2 Abt., Bd. II, I896, pp. 137-I40.

('96). ScheUrLen. Geschichtliche und experimentelle Studien über den Prodigiosus. Archiv. f. Hyg., 1896, Bd. xxvi, pp. 1-31.

('96). Gorini, C. Ueber die schwarzen pigmentbildenden Bakterien. Centraib. f. Bakt., I Abt., Bd. $\mathrm{xx}, 1896$, p. 94.

('97). EWART, A. J. Bacteria with assimilatory pigments, found in the tropics. Annals of Botany, vol. XI, 1897, pp. 486-487.

Author found seven greenisl bacteria in water at Buitenzorg, Java, showing a faint evolution of oxygen when exposed to light. These were B. chilotininn and streptococcus varians, two forms closely resembling van Tieg hem's B. virens and Bact. viride; a alother large bacillis, somewhat resembling vau Tieghem's B. virens, and two Spirilla. The red Bacterium photometricum, which is common in Java, gives, on treatment with hot alcoho be identical with chlorophyli.

('97). Thiry, G. Contribution à l'étude du polychromisme bactérien. Bacille et Cladothrix polychromes; cristaux colorés. Arch. de physiol., 1897, No. 2, pp. 284-288.

('97). NeumanN, Rudolf. Studien über die VariaWilität der Farbstoffbildung bei Mikrococcus pyogenes $\alpha$ aureus (Staphylococcus pyogenes aureus) und einigen anderen Spaltpilzen. Arch. f. Hyg., Bd. Xxx, I897, pp. I-31. I table.

"Die eine Race kanu also aus der anderen entstelicu und in eige andere ïbergeführt werden."

('98). Ward, H. Marsin ali. A violet bacillus from the River Thaines. Annals of Botany, vol XII, I 898 , pp. 59-74. One double plate in color.

('08). NiEDERKORN. See xy.

('98). Ruzicka. See xv.

(99). JoRdan, EDWIN O. The production of fluorescent pigment by bacteria. Botanical Gazette, vol. XXVII, pp. 19-36, 1899.

('99). JoRdan, E. O. Bacillus pyocyaneus and its pigments. Jour. Exper. Med., vol. Iv, Nos. 5 and 6,1899 , pp. 627-647.

('go). Boland, G. W. Ueber Pyocyanin den blauen Farbstoff des Bacillus pyocyaneus. Centralb. f. Bakt., XXv Bd., I899, pp. 897-902, with I curve.

Very probably $\mathrm{B}$. pyocyancus forns two pigments.

('oo). Tinry, Grorges. Bacille polychrome et Actinomyces mordoré. Recherches biologiques sur les bactéries bleues at violettes. Polychromisme. Corps bactériens et cristaux colorés. Matière colorante cristallisée Travaux du lab. d'hyg. et de l'inst. sérothérapique de l'Unjver. de Nancy. Paris, J. B. Ballière et fils, 1900, pp. viII, I54, 7 plates.

Contains also a bibliography of I4I titles on pigmentforming bacteria.

('). KunTZE, W. Ein Beitrag zur Kenntnis der Bedingungen der Farbstoffbildung des Bacillus prodigiosus. Zeitschr. f. Hyg., Bd. xxxiv, Hft. I, 1900, pp. I69-184. Rev. in Centralb. f. Bakt., xxviri Bd., I900, pp. 602-604

With a solution made up of 100 parts pure water, I to 2 asparagin, 2 to $4 \mathrm{c}$. $\mathrm{p}$ grape sugar, and 0.2 dipotassium phosphate, the author obtained a fairly good growth B. prodlgiosus without color. With the same solution and a grape sugar not quite pite, there was always a formation of pigmeut. The wato or on adding a trace of $(0,001)$ of MgSO 4 . This substance coutaminated the sugar fitst used. 
('oo). Krause. See xv.

('oo). Chamot, E. M., ANd Thiry, G. Studies on chromogenic bacteria. I. Notes on the pigment of Bacillus polychromogenes. Bot. Gaz., vol. Xxx, I900, pp. 378-393. I6 figs. Also a separate.

('oI). GesSARD, C. Variété mélanogène du bacille pyocyanique. Ann. de l'Inst. Pasteur, T. XV, I90I, pp. 8I7-83I.

('o2). Gessard, C. Essai sur la biologie du bacille pyocyanique. Ann. Inst. Pasteur, Paris, T. XVI, I902, pp. 3I3-330.

('02). Perrow N. Uber einen neuen roten Farbstoff-bildenden Bacillus. Arb. a d. Bact. Institut der techn. Hochschule zu Karlsruhe, II Bd., 3 Heft, I902, pp. 27I-29I, with I plate. Describes Bacillus subkilieusis.

('a2). LoEw, O., and KozA1, Y. Ueber Ernährungsverhältnisse beim Bacillus prodigiosus. Bull. of the College of Agric., Tokyo Imperial Univ., vol. v, 1902, No. 2, pp. 137-141. Also a separate.

A favorable medium for production of pigment and bacteriolylic enzyme is composed of peploue 1 per cent, sodium acelate 0.2 per cent, and asparagiu 0.2 per cent in
waler.

('o3). Marsh. See vi.

('O3). Papenhausen, Hubert. Uber die Bedingungen der Farbstoffbildung bei den Bakterien. Arb. a. d. Bact. Inst. der tech. Hoclischule zu Karlsruhe, III Bd., I Heft, I903, pp. 43-79. Bibliog. of 20 titles.

Twenty-1 wo species experimented upon. Oxygen is rery necessary for the production of the pigments. The other conditions for oplim um production of pirment vary greatly in differeut species.

('o4). Hetrferan, Mary. A comparative and experimental study of bacilli producing red pigment. A dissertation submitted to the faculties of the Graduate Schools of Arts, Literature and Science, in candidacy for the degree of Doctor of Philosophy. The University of Chicago. Printed in Jena by Gustav Fischer, I904, pp. 55. Bibliog. of 77 titles.

('04). LEONARD, ETHEL, L. Bacterium cyaneum: A new cliromogenic organism. The Johns Hopkins Hospital Bulletin, vol. xv, I904, pp. $398-400$

\section{Reduction and Oxidation.}

(87). Spina, A. Bacteriologische Versuche mit gefänbten Nährsubstanzen. Centralb. f. Bakt., II Bd., Jena, I887, Nos. 2-3, pp. 7I-75. Reductiou processes of bacteria in presence of nethylen blue, etc.

('87). CaHEN, Fritz. Ueber das Reduktionsvermögen der Bakterien. Zeitschr. f. Hyg. Bd. II, I887, pp. 386-396.

('9I). Winogradsky. See XXV.

('91). Fermi, Claudio, and Montesano, Giuseppe. Ueber die Dekomposition des Amygdalins durch Mikroorganismen. Centraib. f. Bakt., Bd. $x v$, I894, pp. 722-727.

('96). Smith, ThEomal, Reduktionserscheinungen boi Bakterien und ihre Beziehungen zur Bakterienzelle, nebst Bemerkungen über Reduktionserscheinungen in stcriler Bouillon. Centralb. f. Bakt., XIX Bd., I896, pp. I8I-I87.
('99). MUELLER, FRIEDR. Uober reduzierende Eigenschaften von Bakterien. Centralb. f. Bakt. Xxvi Bd., I899, pp. 5I-63.

The pigment need must be soluble in water, and must uot poison lie bacteria. Author usea melhyleve blue and filmus. Under literature, ix papers are cited.

('99). ROTHBERGER. See XVIII.

('99). MuELLER, FRIEDRICH. Ueber das Reduktionsvermögen der Bakterien. Centralb. f. Bakt., Xxvi Bd., I899, pp. 8oI-8I9.

Author used methylene blue, litmus, indigo-carmin and rosanilin acetale in various media wilh many orgauisms.

('oi). Gran. See xxv.

('o2). Cathcart, Eiduard, und Hahn, Martin. Ueber die reduzierenden Wirkungen der Bakterien. Arch. Hyg., München, Bd. xu,rv, Ig02, pp. 295-32I.

('O2). EmmerLing, Oscar. Die Zersetzung stickstofffreier organischer Substanzen durch Bakterien. Braunschweig ( $F$. Vieweg \& \$.), I902, pp. IX, I4I, mit 7 Taf.

Not seen.

('o3). van Detden, A. Beitrag zur Kenntniss der Sulfatreduction durch Bacterien. Centralb. f. Bakt., 2 Abt., XI Bd., 1903, pp. 8I-94 and II3-I I9, I heliatype pl.

\section{Nitrifying and Denitrifying Organisms, Use of Free Nitrogen.}

('66). Woronin. Ueber die bei der Sohwarzerle und der gewöhnlichen Lupine auftretenden Wurzelanschwellungen. Mémoires de l'Acad. imp. St. Pétersb., 7 Serie, T. x, 1866. See also Ann. des sci. nat. Bot., 5 sé., T. vir, pp. $73-86$, I plate.

('77). Schlozsing, TH., ET MuznTz, A. Sur la nitrification par les ferments organisés. C $R$. des sé. de l'Acad. des sci., Paris, 1877 , T. LXXXIV, p. $30 \mathrm{I}$; and T. LXXXV, p. I,0I8.

('79). Scirioesing, TH., ET Muentz, A. Recherches sur la nitrification. C. R. des sé. de l'Acad. des sci., Paris, T. LXXXix, 1879, pp. $891-894$ and $\mathrm{I}, 074-\mathrm{I}, 077$

('82). Déneran e't Maquenne. Sur la réduction des nitrates dans la terre arable. C. R. des sé. de l'Acad. des sci., I882, T. xcv, pp. $691-$ $693,732-734,854-856$.

('82). DupertT, G., ext Gayon, U. Sur la fermentation des nitrates. C. R. des sé. de l'Acad. des sci., T. Xcv, pp, 6 $44-646$, Paris, I882.

('82). DUPETTT, G., ET Gayon, U. Sur la transformation des nitrates en nitrites. $C . R$ des sé. de l'Acad. des sci., T. XCV, Paris, 1882, pp. I,365-I,367.

('83). Dupetit, G., ET Gayon, U. Quelques-unes des conditions les plus favorables à la fermentation des nitrates. Mém. de la soc. des sci. physiques et naturelles de Bordeaux, 2 sé., T. v, I883, Extr. Procès-verbaux sé. du 23 nov., I882, pp. III-IV.

('83). Springer, A. Reduction of nitrates by ferments. Am. Chem. Jour., vol. Iv, pp. 452$453, \mathrm{I} 883$

('86). Gayon ET DUPETTT. Recherches sur la réduction des nitrates par les infiniments petits., I886. Paris,? Publisher? 
('86). Munro, J. H. M. The formation and destruction of nitrates and nitrites in artificial solutions, and in river and well waters. Jour. Chem. Soc. Trans., London, I886, vol. XI,IX, pp. 632-68r.

('88). BEyerjnck. Die Bakterien der Papilionaceenknöllohen. Bot. Zeitung, Jahrg. XI,VI, I888, col. 725-735, 74I-750, 757-77 I, 781-790, $797-804,2$ plates. Review in Centralb. $f$. Bakt., Bd. v, I889, pp. 804-805.

('88). HELIRIEGEI, H., UND WILFARTI, H. Untersuchungen über die Stickstoffnahrung der Gramineen und Leguminosen, 1888. Beilageheft zn der Zeitsahr. d. Vereins f. d. Rübenzucker-Industrie d. Deutschen Reichs. Berlin, pp. 234, with 6 plates.

('9o). Frankland, PerRcy F. The nitrifying process and its specific ferment, Pt. I. Phil. Trans. Roy. Soc., Lond., vol. 181 B., 1890, pp. 107128 .

('go). Winogradsky, S. Recherches sur les organismes de lá nitrification. Ann. de l'Inst. Pasteur, T. IV, r8go, pp. 2r3-23r, 257-275, and $760-771$.

Nitromonas can live on purely inorganic matters, although destitute of chloroph yll. His "vitratferment" consists of pear-shaped rods, which do not exceed $1 / 2 \mu$ in length, and are 13/3 to 2 times less in breadth. The "nitritorganismus" is 4 to 5 times larget than the "nitratbildner," and has a roundish form.

('go). LaURENT, EM. Expériences sur la réduction des nitrates par les végétaux. Ann. de l'Inst. Pasteur, T. Iv, pp. 722-744, 1890.

('9I). Gilitay, E., Und AbERSON, J. H. Recherches sur un mode de dénitrification et sur le schizomycète qui la produit. Archives néerlandaises des sci. ex. et nat., I89r, T. $\mathrm{xxv}$, pp. 34I-36I, I plate.

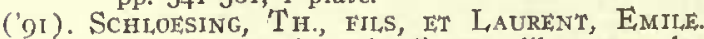
Sur la fxation de l'azote libre par les plantes. C. R. des sé. de d'Acad. des sci. Paris, I89I, T. CXuIJ, pp. 776-778 and $1,059-$ I,060, I802, T. CXV, pp. 659-66I and 732-735.

('gr). Winogradsky, S. Recherches sur les organismes de la unitrification. Ann. de l'Inst. Pasteur, T. v, I891, pp. 92-100 and 577-616.

Winogradsky's fourth and fifth memoirs on nitrifying bacteria. The fourth deais with the question of solid media suited to theit culture, and describes the making of silicate jelly. The fifth deals with the formation and the oxidation of uitrites in the nitrification.

('or). Beiterinck, M. W. Over ophooping van atmospherische stikstof in culturen van Bacillus radicicola. Versl. en Mededeel. der Koninkl. Akad. van Wetensch. zu Amsterdam, Afd. Natuurkunde, II I, 8, 189r, pp. (460)-(475), I text fig. Abstract in Koch's Jahresb., III Bd., p. 205.

('92). Winogradsky, S. Contributions à la morphologie des organismes de la nitrification. Arch. id. sci. biol. publiées par l'Institut Impérial de méd. expér. à St. Pétersbourg, Tome r, r892, p. 108. Reviewed in Ann. de l'Iist. Pasteur, T. vi, I892, pp. 458-462.

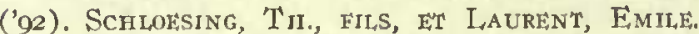
Recherches sur la fixation de l'azote libre par les plantes. Ann. de l'Inst. Pasteur, 1892, T. vi, pp. 65-Ir 5 .

('02). BERTHFLor. Nouvelle recherches sur la fixation de l'azote par les microbes. C. R. des sé de l'Acad. des sei., 1892, T. Cxv, pp. 569-574.
('93). BERTHELor. Recherches nouvelles sur les nicroorganismes fixateurs ic l'azate. C. R. des sé. de l'Acad. des sci., Paris, 1803, 'T. CXVi, pp. 842-849.

(94). Duclaux, E. Sur la fixation de l'azote atmosphérique. Revue critique. Ann. de l'Inst. Pasteur, I894, 'T. viII, pp. 728-736.

('94). Wrnogradsicy, S. Sur l'assimilation de l'azote gazeux de l'atmosphere par les microbes. C. R. des sé. de l'Acad des sci., Paris, T. cxvr, r893, p. I,385, and T. cxvir, I894, Feh. 12, p. 353. Rev. in Centralb. f. Bakt., Bd. XVI, I894, pp. I29-I30.

('95). Wrinogradsky, S. Recherches sur l'assimilation de l'azote libre de l'atmosphère par les microbes. Arch. des sci. biol. pub. par d'Institut. imperial de médeoine expérimentale à St. Pétersbourg, Tome II I, No. 4, I 895 , pp. 297-352.

A very interesting and valuable paper.

('96). Winogradsky, S. Zur Mikrobiologie des nitrifikationsprozesses. Centralb. f. Bakt., 2 Abt., Bd. Ir, I8g6, pp. 415-428.

('97). Maź. Fixation de l'azote libre par le bacille des nodosités des légumineuses. A111. de l'Inst. Pasteur, 'T. XI, I897, pp. 44-54.

The second and thitd menoirs are continned in the Annales for 1898, under the title, "Les microbes des Antuales for 1898, under the
uodosites des legumineuses."

('98). Konvalewski, S. Beiträge zur Frage über dic Assimilierung von freiem Stickstoff seitens der Bakterien. Russ. Arch. f. Pathol. Bd. vi, I8g8, p. 25I. Rev. in Centralb. f. Bakt., Xxv Bd., I899, pp. 771-772.

('98). Mazé. Les microbes des nodosités des légunıineuses. Ann. de l'Inst. Pastenr, T. Xi1, 1898. Second memoir, pp. I-25, I fig. Third memoir, pp. 128-155, 2 plates.

The second mentoir deals with the physiology of the organism. The third menoir deals with the morphology of the root-tubercle organisin. Maze says it is pathogenic for certain animals. In the animal body it is said to become nearly ronnd, to be much reduced in dianeter, and to have a tendency to grow in chains.

('g9). Omélaninsy, V. Sur la nitrification de l'azote organique. Arch des sci. biol publiées par l'inst. imp. de méd. expér. à St. Pétersbourg, T. vIr, I899, pp. 272-290.

('g9). Omél,iansky, V. Sur la culture des microbes nitrificateurs du sol. Arch. des sci. biol. publiées par l'inst. imp. de méd. expér. à St. Pétersbourg, T. v11, I899, pp. 291-302.

(99). Winogradsky U. OMÉliansky. Ueber den Einflus der organischen Substanzen auf die Arbeit der nitrificierenden Mikrobien. Centralb. f. Bakt., 2 Abt., Bd. vi, I899, p. 329.

('og). Winogradsky, S., ET OMćlitansKy, V. L'influence des substances organiques sur le travail des microbes nitrificaten.rs. Arch. des sci. biol. publićes par l'inst. imp. de méd. expér. à St. Pétersbourg, T. vir, 1899, pp. 233-27 I.

('oo). KRUtGer, W., AND Schnerdewind, W. Utsache und Bedeutung der Salpeter-Zersetzung im Boden. Landwirtschaftliche Jahrbücher. Ztschr. f. wiss. Landwirtschaft, Berlin, 1900, Bd Xxix, pp. $747-770,2$ plates

('or). BriJferinck, M. W. Ueber oligonitropliile Mikroben. Centralb. f. Bakt., etc., Bd. vir, rgor, pp. 56i-582, with I heliotype plate.

Describes A zotobacter. 
('o1). Gran, H. H. Studien über Meeresbakterien. 1. Reduction von Nitraten und Nitriten. Rergens Museums Aarbog, I90I, No. 10, pp. 23.

Three new specles are described: Bacillus repens, $D$. trivialis, $\mathbf{3}$. Heusenii.

('OI). MaAssein, Albert. Die Zerzetzung der Nitrate und der Nitrite durch die Bakterien. Ein Beitrag zum Kreislauf des Stickstoffs in der Natur. Arbeit. a. d. K. Gesundheitsamt., Bd. XVIII, 190I, pp. 2 I-77.

('02). Moore, Geo. T. Bacteria and the Nitrogen Problem. Yearbook Dept. Agric., 1902, pp. 333-342, 6 plates. Also a separate.

Pure cultures of the root-tubercle orgauism are absorbed on collon, which is then dried, wrapped in tin foil. and thins distributed to the agriciltingst to throw the colton into a pail of water, to which is added small packages of uutrient salts. After 48 hours inous seeds are tben drenched with it, and sown after dry-

('O2). SMITH, R. GREIG. Nates on Vibrio denitrificans, Sewerin. Proc. Linnean Soc., New South Wales, for the year 1901. Sydney, 1902, vol. Xxv1, Pt. I, pp. 118-121. I plate.

('02). Omélianski, W. Kleinere Mitteilungen über Nitrifikationsmikroben. I. Die Kultur des Nitritbildners auf Papierscheiben. II. Wird schweflige innd phosphorige Säure durch Nitrobacter oxydiert? III. Scheiden die Nitritmikroben eine Oxydase aus? Centralb. Bakt., Abt. 2, Bd. vir, I902, pp. 785787; Bd. Ix, 1902, pp. 63-6́5, pp. I13-117, mit I Taf.

('O2). BejJerinck, M. IV., und VAN DeLDEN, A. Ueber dic Assimilation des freien Stickstoffs durch Bacterien. Centralb. Bakt., Abt. 2, Bd. IX, 1902, pp. 3-43.

('02). BunleERT, H. Untersuchungen über die Arteinheit der Knöllchenbakterien der Leguminosen und über die landwirtschaftliche $\mathrm{Bc}$ cleutung dieser Frage. Habilitationsschr. Halle (Druck v. Wischan u. Wettengel), 1902, p. 55. Centralb. Bakt., Abt. 2, Bd. IX, 1902, pp, 148-153, 226-240, and 273-285.

('O2). HILT NER, L. Ueber dic Impfung der Leguminosen mit Reinkulturen. D. landw. Presse, Berlin, Bd. Xxix, 1902, pp. I19-120.

('O2). Nobre, Friedrich, UND Rich'TER, L. Ueber den Einfluss des Nitratstickstoffs und der Humussubstanzen auf den Impfungserfolg bei Leguminosen. Landw. Versuchstat., Berlin, Bd. LVI, I902, pp. 44I-448.

('O3). BERSTEXN, P. Úber einige in den Kulturen zur Reinzüchtung der Nitratbildner regelmässig auftretende Bakterienarten. Arb. a.d. Bact. Inst. der tech. Hochschule zu Karlsrulue, III Bd., I Heft, 1903, pp. 8I-100.

The following new species are described: Bacterium comes, B, modestum, D, debile and Ps, inmicola. None of these species will grow in media entirely free from or these species

('O3). BENECKE, W., UND KEUTNER, J. Ueber stickstoffinindende Bakterien aus der Ostsec. Ber. d. deutsch. bot. Gesellsoh., Bd. Xxi, Heft 6, pp. 333-346, Berlin, Ig03, 4 text figs.

('05). MOORF, GForgr. T. Soil Inoculation for Legumes. Bureat1 of Plant Industry, U. S. Department of Agriculture, Bull. 7I, Jan. 23, 1905, pp. 72, pl. 9.

\section{Use of Free Carbon Dioxide.}

('87). Hufpre, Frirdinand. Ueber Chlorophyllwirkung chlorophyllfreier Pflanzen. Tageblatt der 60 versammlung deutscher Naturforscher u. Aerzte in Wiesbaden, I887, pp. 244-2.45.

('go). Winogradsky U. OMf́liansky. See Xxv.

('o2). Nathansohn. See li.

('O3). BEIJERINCK, M. W., UND VAN DELDEN, A Ueber eine farblose Bakterie, deren Kohlenstoffnahrung aus der atmosphärischen Luft herrïhrt. Centralb. f. Bakt., 2 Abt., Bd. $x$, No. 2, 1903, pp. 33-47. See also Versl. Wis. Nat. Afd. K. Acad. Wet., Bd. xI, 1903, pp. 450-465 (Dutch); and Proc. Sci. K. Acad. Wet., Bd. v, 1903, pp. 398-4I3 (English), Ainsterdan.

"We will use the name Bactllus oligocarbophilue to desiguate a colorless bacterium whose carbon needs, in the dark as well as in the light, are satisfied by a not yet exactly known carbon compound, or compounds, of the air, onit of which compound this organism must also cre ate the necessary energy for its life proceases." It is stated that this substance is not carbon dioxide.

('O4). BEIJERINCK, M. W. Ueber die Bakterien, welche sich im Dunkeln mit Kohlensäure als Kohlenstoffquelle ernähren können. Centralb. f. Bakt., 2 Abt., XI Bd., I904, No. 20-22, pp. 593-599.

\section{XXVI1. Luminous Bacteria.}

('75). PFLuegre, E. Beiträge zur Lehre von der Respiration. Sec. 5. Die Phosphorescenz der lebendigen Organismen und itire Bedeutung für die Principien der Respiration. Pflüger's Archiv, 1875, Bd. x, pp. 275-300.

('80). Lassar, O. Die Micrococcen der Phosphorescenz. Pflüger's Arch. f. die gesam. Physiol. I880, Bd. XXI, pp. 104-108.

('85). Nuefch. Ueber leuchtende Bacterien. Bâle, 1885.

Not seen.

('87). FischER. Bakteriologische Untersuchungen auf einer Reise nach Westindien, It Ueber einen lichtentwickelnden, im Meerwasser gefundenen Spaltpilz. Zeitschr. f.Hyg. Bd. II, 1887, pp. 54-92, and Nachtrag, pp. 92-95.

('87). Forster, J. Ueber cinige Eigensohaften leuchtender Bakterien. Centralb. f. Bakt., Bd I I, I887, pp. 337-340.

('87). KaIz, Oscar. Preliminary remarks on phosphorescent bacteria from sea-water. Proc. Litun. Soc., New South Wales, vol. 11, Pt. I1, 1887, pp. 33I-336.

('87). Duclaux. Sur les microbes phosphorescents. Revue critique. Ann. de l'Inst. Pasteur, T. I, 1887, pp. 489-492.

('88). Dubors, R. Sur le rôle de la symbiose dhez certains animaux marins lumineux. C. $R$. des sé. de l'Acad. des sci., T. cvir, Paris, I888, pp. 502-504.

('88). Fischér, B. Ueber einen neuen lichtentwickelnden Bacillus. Centralb. f. Bakt., 1888, I11 Bd., pp. 105-108, and pp. 137-I4I.

('89). BEYERINCK, M. W. Le photobacterium luminosum, bactérie lumineuse de la mer dı nord. Arch. néer. des sci. ex. et nat., T. xx111, 1889, pp. 401-415. 
('89). BeYERINCK, M. W. Ies bactéries lumineuses dans leurs raports avec l'oxygène. Arch. néer. des sci. ex. et nat., T. XxIIr, I889, pp. 416-427.

('89). Giard, A., unn Brliet, A. Observations sur la maladie phosphorescente des Talitres et autres Crustacés. C. R. de la Soc. de biol., 1889, Tome 1, pp. 593-597.

('89). I.EHMANN, K. B. Studien über Bacterium phosphorescens Fischer. Centralb. f. Bakt., $\checkmark$ Bd., I889, pp. 785-791.

('go). Giarn, A. Nouvelles reoherohes sur les bactérjes lumineuses pathogènes. C. $R$. de la Soc. de biol., I89o, Tome I I, pp. 188-191.

('9o). BEIJERINCK, M. W. Over jichtvoedsel en plastisch voedsel van lichtbacteriën. Versl. en Meded. d. Kon. Akad. v. Wetenschappen, Aft. Natururk. Derde Reeks, Deel vir, I89o, pp. 239-302. I text figure.

('go). Bri, Et, A. Contribution à l'étude de la morphologie et du développement des bactériacées. Bull. scientifique de la France et de la Belgique, publié par Giard, T. XxI, I890, p. I-289, plates 9. Bibliography of 662 titiles. Also a separate.

The bacterinm of inminons sand fleas is described in a note on p. 144 as Bacterium Giardi Billet.

('gr). BeymRINCK, M. W. Sur l'aliment photogène et l'aliment plastique des bactéries lumineuses. Arch. néerl. des sci. ex. et nat., T. XXIV, 1891, pp. 369-442.

('91). Katz, Oscar. Zur Kenntniss der Leuchtbakterien. Centralb. f. Bakt., I89I, IX Bd., pp. 157-163, 199-204, 229-234, 258-264, 3II-316, 343-349.

('92). RUSSELL, H. L. Impfungsversuche mit Giard's pathogenem Ireuchtbacillus. Centralb. f. Bakt., XI Bd., I892, pp. 557-559.

Author obtained no conciusive evidence as to the pathogenic nature of this organism.

('92). E1jkmann, C. Lichtgevende Bacteriën. Geneeskundig Tijdschriftvoor NederlandschIndië. Deel xxxır, Aflevering 4, Batavia en Noordwijk, 1892, pp. I09-115. Also a separate. Rev. in Centralb. f. Bakt., XII Bd., 1892 , pp. 656-657.

('93). Dumors, Raphaer. Extinction de la luminosité du Photobacterium sarcophilum par la lumière. C. R. des sé. et mém. de la soc. de Biologie, Paris, I893, 9 sér., T. v, pp. I60I6I.

This organism was isolated from the luminous flesh of a dead rabbit. It was cultivable in a synthetic medium made as follows: Ordinary water, 100; asparagine, I glycerin, 1 ; potassium phosphate, 0.10 ; sea salt, 3. After some months in this medium the luminosity diminished. Exposed to the light for some days, at about to ${ }^{\circ} \mathrm{C}$., the culture takes on a fine orange yellow color, becomes opaque, and loses its l11minosity except at the edges. Transfers may be made from this yellow growth readily, but the resulting cultures are not luminous. In the dark, however, such cultures return after some days to their orginal transparent color, and again become luminous.

('95). KUTSCHER. Zur Phosphorescens der Elbvibrionen. Centralb. f. Bakt., Xvirr Bd., 1895 , p. 424.

('98). Frankland, Percy. The action of bacteria on the photographic plate. Centralb. f. Bakt. xxiv B.d., I898, pp. 609-612.

Only the luminous sorts are able to act through glass. The action of non luminous species is probably dive "to the evolution of volatile chemical substances." The latter exposures were long-several days.
('99). HENNEBERG, W. Leuchtbakterien als Krankheitserreger bei Schwammücken. Centralb. f. Bakt., Xxv Bd., 1899, pp. 649-650.

('99). Barnard, J. E. Photogenic Bacteria. Trans. of the Jenner Inst., London, 1899, second series, pp. 81-112. 2 plates.

"Spectroscopically the light emitted by the photogenic organisms examined by me is confined to a very small portion of the visible spectrum; never extending into the ultra-violet or infra-red. Visually it only includes the green and blue, and photographically it extends very slightly further into the violet. The economic value of such a light source is obvious, and it is a matter of great practic

The writer experinented with 13 species.

('O2). MCKENNEY, R. E. B. Observations on the conditions of light production in luminous bacteria. Proc. of Biol. Soc. of Wash., Nov. 20, 1902, vol. xi, pp. 213-234. Also a separate. Bibliog. of 35 titles.

('o2). Barnard, J. E., and Macfadyen, Allan. On Luminous Bacteria. Annals of Botany, vol. XVI, Dec., 1902, pp. 587-588.

('03). Molisch, Hans. Vienna Acad. Sci., 1903. Luminous baoteria for Safety Lamp. Science, 1903, p. 7 rg.

Paper read, but not yet printed. Note in Science made from a Renter's telegram.

('o4). GoriIAM, F. P. See a preliminary note in Centralb. f. Bakt., 2 Abt.,

\section{Hydrogen Sulphide and Otherwise Unclassified By-Products.}

('79). Mroues, P. De la fermentation sulfhydriqute. Bull. de la Soc. ohim., T. Xxxir, 1879, p. J27-131.

('89). Hor,SchEWNIKOFF. Ueber die Bildung von Schwefelwasserstoff durch Bakterien. Fortschr. d. Med., I889, Bd. vir, pp. 201-213.

('9I). NENCKI, M. Di.e isomeren Milohsäuren als Erkennungsmittel ainzelner Spaltpilzarten. Centralb. f. Bakt., Bd. Ix, I89I, pp. 301-306.

('91-'93). RAY-PAIl,HADE. Reoherches expérimentales sur le philothion. Paris, I891. Le philathion et le soufre. Assoc. franc. pour l'av. des sci., Congrès de Besançon, 1893. Part I, pp. I93, 250, and 302.

('92). SommaruGa, E. Ueber Stoffwechselproducte von Mikroorganismen. Zeitschr. f. Hyg., Bd. XII, 1892, pp. 273-297.

('92). Pe'tri, R. J., U. MAAsSEN, A. U.eber die Bildung von Schwefelwasserstoff durch die Krankheitserregenden Bakterien unter besonderer Berücksichtigung des Schweinerothlaufs. Veröffent. d. k. Gesundheitsamtes, XVI Jahrg., I802, p. II9.

('93). STAGNITTA-BALISTRERI. Die Verbreitung der Schwefelwasserstoffbildung unter den Bakterien. Arch. für Hyg., Bd. XvI, I893, pp. 10-34.

For demonstration of sulphuretted hydrogen in gelatin the anthor adds iron saccharate, tartrate, or acetate to the gelatin. For fluids he uses lead acetate paper.

('93). Rubner. Ueber den Modus der Schwefelwasserstoffbildung bei Bakterien. Arch. f. Hyg., Bd. Xvi, I893, pp. 53-72.

('93). RuBNER. Die Wanderungen des Schwefels im Stoffwechsel der Bakterien. Arch. f. Hyg., 1893, Bd. xvi, pp. 78-100. 
('93). Petri, R. J., und Maassen, Albert. Beiträge zur Biologie der krankheitserregenden Bakterien ins besondere über die Bildung von Sohwefelwasserstoff durch dieselben unter vornehmlicher Berücksichtigung des Schweinerothlaufs. Arbeiten aus dem Kaiserl. Gesundheitsamte, Bd. vil, I893, pp. 318-356. Many parasitic and aaprophytic forms have been tested. All produce sulphuretted hydrogen when cultivated in presence of suitable sulphur compounds, i. c., such as are loosely bound. The reductiou of litum us and indigo in solid cultures is ascribed to this gas. It is believed that all bacteria are capable of producing it, and that the dis tinction into producers and non-prod
etied lydrogen in ust be abandored.

('93). Petri, R. J., und MaAssen, Albert. Weitere Beiträge zur Schwefelwasserstoffbildung aërober Bakterien und kurze Angaben über Merkaptanbildung derselben. Arbeiten aus dem Kaiserlichen Gesundheitsamte, Bd. virr, I893, pp. 490-506.

('93). RubNER, M. Ueber das Vorkommen von Mercaptan. Arohiv. f. Hyg., 5893, Bd. XIx, pp. I36-193.

('94). WENZELL, W. T. A contribution to the knowledge of bacteriologic chemistry. Jour. Am. Med. Asso., I894, vol. XXIIJ, pp. 90I903.

('96). Duchaux, E. Sur les odeurs de putréfaction. Revue critique Anı. de l'Inst. Pasteur, T. $x, \mathrm{I} 896 . \mathrm{pp} .59$ to 64 .

('97). Morris, Max. Studien über die Produktion von Schwefelwasserstoff, Indol und Merkaptan bei Bakterien. Aroh. f. Hyg., xxx Bd., I897, pp. 304-3I I.

Mercaptan was demonstrated by use of "isatiuschwefelsäure," which is colored green by this substavce.

('O2). Banning, Friedrich. Zur Kenntuiss der Oxalsäurebildung durch Bakterien. Centralb. f. Bakt., Abt. 2, Bd. vili, 1902, pp. 520-525, pp. 556-567, mit 1 Taf.

\section{Action of Light on Bacteria.}

('77). Downes And Br,unt. Researches on the effect of light upon bacteria and other organisms. Proc. Roy. Soc., vol. xxvi, No. 184, 1877, 6 Doc., pp. 488-500. Iondon.

Downes and Blunt determined germicidal action to be associated chiefly with the actinicrays of the spectrum.

('78). DOWNES AND BLUNT. On the influence of light upan protoplasm. Proc. Roy. Soc., vol. XXviII, No. I9I, I878, i9 Dec., pp. 199-212.

('78). Tyndal, J. Note on the influence exercised by light on organic infusions. Proc. Roy. Soc., London, val. xxviri, pp. 212-217. Nature, vol. XIX, I879, p. 210.

Negative results. Used flasks, and organisms grew after exposure to sunlight.

('SI). TYNDALL, JOHN. On the arrestation of infusorial life by solar light. Br. asso. for the advancement of sci. Rep., 388I, pp. 450-45 I. Nature, vol. xxiv, p. 466 , i88I.

Tyndall's results were due to the way in which he experilnented, $i$. e., with flask cultures.

('82). FNGELMANN, Tir. W. Bacterium photometricum. Fin Beitrag zur vergleichenden physiologie des Licht- und Farbensinnes. Onderzoekingen gedaan in het Physiologisch Laboratorium der Utrechtsohe Hoogeschool, Derde Reeks, viI, Aflev. It, 1882, pp. 252290, I plate.
('84). Downes, A., and Blunt, T. P. The influence of dight on baoteria. Trans. Roy. Soc, Victoria, vol. $\mathrm{xx}, \mathrm{pp} . \mathrm{I}-2,1884$.

Reply to Jamiesou.

('85). Duclaux, E. Influence de la Jumière du soleil sur la vitalité des germes de microbes. C. R. des sé. de l'Acad. des sci. T. C., I885, pp. I I9-12I.

('85). DuCL,Aux, E. Influence de la lumière du soleil sur la vitalité des nnicrococcus. C. $R$. des sé. de l'Acad. des sci., Paris, T. cI, I885, pp. 395-397.

('86). ARLOING, S. Influence de la lumière blanohe et de ses rayons constituants sur le dévéloppement et les propriétés du Bacillus anthracis: Arch. de physiol. normale et pathol., I886, 3 sér., T. vir, pp. 209-235.

('86). Straus, I. Note sur l'action de la lumière solaire sur les spores du Bacillus anthracis. C. R. des sé. ot mém. de la soc. de Biologie. Paris, 8 sé., T'. II I, I886, pp. 473-474.

(86). Downes, Arthur. On the action of sunlight on Micro-organisms with a demonstration of the influence of diffused light.-Proceedings of the R. Sooicty, London, 1886, vol. XI, pp. I4-22.

('87). Duchaux, E. Aotion de la lumière sur les microbes. Ann. de l'Inst. Pasteur, I887, T I, pp. 88-92.

('87). Roux, E. De l'action de la lumière et de l'air sur les spores de la bactéridic du charbon. Ann. de l'Inst. Pasteur, T. I, I887, pp. 445452.

('88). Engelmann, Th. W. Die Purpurbakterien und ihre Beziehungen zum Lichte. Bot. Zeitung, I888, Jahrgang xLvI, col. $66 \mathrm{I}, 677$, 693 , and 709

('88). ENGELMANN, Tis. W. Ueber Bacteriopurpurin und seine physiologische Bedeutung. Pflüger's Archiv., I888, Bd. XLII, pp. I83-186.

('80). RAUM, Johannes. Der gegenwärtige Stand unserer Kenntnisse über den Einfluss des Lichtes auf Bacterien und auf den thierischen Organismus. Zeit. f. Hyg., Bd. vi, 3889, pp. 312-368.

This paper contains a bibiiography of 7 pagea.

('89). Pansini, S. Dell'azione della luce solare sui microorganismi. Revista d'igiene practica e sperimentale, Napoli, I889, pp. 69-IoI. Reviewv in Ann. de Micr., 1890, p. 516.

('go). SAverio. L'influenza della temperatura sull' azione microbicida della luce. Anı1, dell' Inst. d'ig. di Roma.

Not seen.

('go). Janowskr, TII. Zur Biologie der Typhusbacillen. Centralb. f. Bakt., vis Bd., 1890, pp. I67-I72, I93-I99, 230-234, and 262-266.

Discusses the actiou of suvlight.

('91). GFISLER, F. K. On the action of light on bacteria. (Russian.) Wratsch, I891, No. 36, pp. 793-797

Not seen.

('92). Momon's. See xxxv.

('92). Korluar, E. Zur Frage über den Einfluss des Lichtes auf Bakterien. Wratsch, I802, Nos. 39 and 40. Rev. in Centralb. f. Bakt., XII Bd., 3892 , p. 836 . Also in Ann. de l'Inst. Pasteur, T. VII, 1893, p. 430. 
('92). Cirmlewsky. Zur Frage über die Wirkung des Sonnen- und elektrischen Lichtes auf die Eiterbakterien. Wratsch, I892, No. 20. Reviewed in Centralb. f. Bakt., Bd. Xı, pp. 174-175, I 892

('92). GrisLE, THEODOR. Zur Frage über die Wirkung des Lichtes auf Bakterien. Centralb. f. Bakt., XI Bd., I892, pp. I61-173.

('92). Buch NER, H. Ueber den Einfluss des Lichtes auf Bakterien. Centralb. f. Bakt., xi Bd., I 892, pp. $78 \mathrm{r}-783$.

Deals with question of effect of light on bacteria suspended in water. "The result of all these experiments points to tbe conclusion that light exerts a powerful dis. infecting influence upon the named bacterial sorts when these are suspended in water." The experiments were made on typhoid bacilli, $B$. coll communis, $B$. pyocyaneus, cholera vibrios, and various bacteria of decay.

('92). Buchner, H. Ueber den Einfluss des Lichtes auf Bakterien. I I Mitth. Centralb. f. Bakt., Bd. X11, I892, Heft 7-8, pp. 217-2I9, I fig.

Author obtained bacterlal letters and figures on agar and gelatin platea by eovering a part and exposing to sunshine. Light passed through wate active bactericldal powers.

('03). Buchner, H. Ueber den Einfluss des Lichtes auf Bakterien und über die Selbstreinigung der Flüsse. Anch. f. Hyg., Bd. XviI, I893. pp. 179-204.

('93). Richardson, ARTHur. The action of light in preventing putrefactive decomposition; and in the formation of hydrogen peroxide in organic liquids. Jour. Chem. Soc., Transaotions, London, 1893, vol. LXIII, pp. 1,109I, I30.

('97). D'ARCY, R. F., AND HARDY, W. B. Note on the oxidizing powers of different regions of the spectrum in relation to the bactericidal action of light and air. Jour. of Physiol. 1804-95, vol. XVII, pp. 390-393.

('94). Ward, H. Marshall. The Action of light on bacteria. Phil. 'Trans. Royal Soc, Lond. vol. I85 ( I804), pp. 96I-986. Also a separate. 4to., 25 pp., I plate. See also Revuc Sci., 1894 .

('94). FISCIIER, BERNil ARD. Die Bakterien des Meeres nach den Untersuchungen der Planktonexpedition unter gleichzeitiger Berïcksichtigung einiger älterer und neuerer Untersuchungen. Centralb. f. Bakt., Bd. xv, 1804, pp. 657-666.

Shows that aunlight tends to reduce number of bacteria in upper layers of the sea. There are always more bacteria in upper layers of the sea at sintise than in the afternoon. There are also in the daytime a great many anete a a depth of 10 meters than neat the sutface. The depth to which the bactericidal action of the sunllght penetrates depends on its intensity, duration of action, clearness of the water, etc. It prohahly reaches down several meters. Cultures of various water bacteria were killed 11 a short time when exposcd to the midday sun in A ugust, the sun's rays being first passed through one-half meter of sea water.

('94). DiEudonné, A. Beiträge zur Beurteilung der Einwirkung des Liohtes auf Bakterien Anbeiten a. d. Kaiserl. Gesundheitsamte, Bd. IX, I894, Heft 2, pp. 405-413. Rev. in Centralb. f. Bakt., xviI Bd., 1895 , pp. 646-647.

The red end of the spectrum (between the lines $D$ and F) has no injurlous effect. In the green (between linses $\mathrm{F}$, and $\mathrm{F})$ there is a distinct iuhibiting action. In the blue violet and ultra-volet the hactericidal action is inost of teria. Bncteria inoculated in plates al ready exposed tc the light grew which has had the heat rays removed by hiltialog action.
('94). Difudonne, A. Ueber die Bedeutung des Wasserstoffsuperoxyds für die bakterientödtende Kraft des Liohtes. Arbeiteı aus dem kais. Gesundheits-Amt., Bd. 1X, 1894, pp. 537-540.

Ascribes bactericidal effect of light in great part to the formation of hydrogen peroxide in the culture-medium.

('94). Engeimann. See xix.

('94). d'Arsonval and Charrin. See xxxi11.

('96). BЕск, M., U. Schultz, -P. Ueber die Einwirkung sogen. monochromatischen Jichtes auf die Bacterienentwicklung. Zeitsehr. f. Hyg., Bd. XXIII, I896, pp. 490-496.

('go). Kedzior, Laurenz. Ueber den Einfluss des Sonnenlichtes auf Bakterien. Arch. f. Hyg., Bd. xxxvi, 1899 , pp. 323-334. Rev. in Centralb. f. Bakt., Bd. xxvir, I900, pp. 203 and 759.

Sunllght also destroys in an atmosphere of lydtogen. although less actively.

('oi). Simoncini, G, B., E Viola, D. L'influenze dell'innaffiamento sul contenuto batterico delle polveri di strada. Ann. d'igiene sper., Roma, vol. XI, I901, pp. 373-392.

Bibliog. of 21 titles. The bactericidal action of light was greater on the moistened dust of the street than on the dry dust.

\section{Effect of Electricity.}

('OI). SPILKER, W., UND GOTTSTEIN, A. Ueber die Vernichtung von Mikroorganismen dureh die Induktionselektricität. Centralb. $f$ Bakt., IX Bd., I89I, pp. 77-88.

('91). Finkm, Claudio. Ueber die Reinigung der Abwãsser durch Elektricität. Areh. für Hyg., Bd. XIIt, 189I, pp. 207-228.

('93). KRUEGER, S. Ueber den Einfluss des constanten elektrischen Stromes auf Wachsthum der Bakterien. Zeitschr. f. klin. med., Bd xxII, 1893, pp. I91-207.

Krueger's conclusions are: The inhibition or destruction of the bacteria is due to the libetation of ions in the fliid.

('03). Burci, E. E Frascani, V. Contributo allo studio dell'azione battericida della corrente continua.-Atti della Soc. Tose. di Scienze nat. Pisa. Mem., vol. xil, I893, pp. 99-119.

('94). d'Arsonval and Cimarrin. See XXxir.

('06). FrienenNThal, H. Ueber den Einfluss des elektrischen Stromes auf Bakterien. Kritisches Referat. Centralb. f. Bakt., xix Bd., I806, pp. 319-324.

('96). Gorrstrin, A. Ueber den Einfluss des elektrischen Stromes auf Bakterien. Centralb. f. Bakt., XIX Bd., I806, pp. 602-605.

('06). Frie,Dentital, H. Ueber den Einfluss des Induktionselektrizität auf Bakterien. Kritisches Referat. Centralb. f. Bakt., xx Bd., I 806, pp. 505-508.

('06). Marmitr, I. A. Les toxines et l'électricité Ann. de l'Inst. Pasteur, T. X, I8g6, pp. 469480.

('99). Thinle. Hermann, und Wol,F, Kurt. Ueber die Einwirkung des elektrischen Stranses anf Bakterien. Centralb. f. Bakt., xxv Bd., I899, pp. 650-655, with I fig.

Results all negative.

('oo). Krause, See xv. 
('ot). Strekti, Hirmann. Untersuchungen ïber dic baktericide Wirkung des Hochspannungsfunkenliohtes nebst Angabe einer Methode zur besseren Ausnützung der baktericiden Kraft des Voltabogenlichtes. D. med. Wochenschr., Berlin, Bd. Xxvir, 190I, pp. 69-72, pp. $87-89$.

('o1). Ullmann, Joinannes. Ueber die Einwirkung elektrisclien Bogenlichts auf Mikroorganisnuen in Gegenwart von fluoreszierenden Stoffen. Diss. München (Druck v. M. Eirnst), 190I, p. 17.

\section{Action on Bacteria of Roentgen Rays, Ra- dium Rays, Etc.}

('06). WıTtLIN, J. Les rayons Röntgen exercent-ils tme action quelconque sur les bacteries? Ann. de micro., T. virl, I8g6, pp. 514-515.

Author fiuds that the Roeutgen rays have vo effect upon bacteria.

('g6). Minck, F. Zur Frage ïber die Einwirkung der Röntgen'schen Strahlen auf Bakterien und ihre eventuelle therapeutische Verwendbarkeit. Münchener mediz. Woohenschrift. I896, Bd. XLIII, pp. IOI-I02 and p. 202.

Autliot obtained only negative results.

('97). Potr, Francis. Concerning the action of Xrays on cultivation of tubercle Bacillus. The Lancet, London, vol. II, for 1897 (55th year), pp. 1,314-1,315.

The tubercle bacillus was not affected by $X$-rays.

('97). Brarse, ET SAmbuc. De l'action des rayons X sur de Pyocyaneus et la bactéridie charbonneuse C. R des sé. et mém. de la soc, de biol., T. Iv, Ioe série, I897, pp. 689-692.

Little or no effect on these organisms.

('97). Beauregard em Guichard. Action des rayons $\mathrm{X}$ sur certains charactères biologique des microbes. $C$. $R$. des sé. et mém. de la soc. de biol., T. Iv, Ioe série, 1897, pp. 803-804.

The bacteria are mucli less sensitive than higher organisins.

('OS). RIEDER, HERMANN. Wirkung der Röntgenstrahlen auf Bakterien. Münch. med. Wochenschr., 45 Jahrg., 1808, pp. IOI-IO4, 2 text figures (exposed agar plates).

Contrary to the statements of various other experimenters, this writer says that he obtained positive germi-
cldal tesults on sevel pathogenic organisms by exposures cidal results on sevel pathogenic organisms by exposures
lasting from 45 minutes to 1 hourt. The earlier literature is cited. Voltohm's apparatus was used. The photograplis sliow the center of the agar Petrl-dish cultures graplis slow the center of
cleared of bacterisl colonies.

('98). Wolfenden, Norris, and Forbes-Ross, F. W. A preliminary note on the action of the Roentgen rays upon the growth and activity of hacteria and micro-organisms. The I ancet, London, June 25, 1898, pp. 1,752$\mathrm{I}, 753$.

Bacilins prodigiosis on potato was exposed to the rays for one hour on several occasions. Growth was much greater than in the control tubes, aud more pigunent was greater
('98). RIEDER, H. Weitere Mittheilung über dic Wirkung der Röntgenstrahlen auf Bacterien sowie auf die menschliche Haut. Münch. med. Wochenschr., 45 Jahrg., I898, pp. 773774.

('or). CASParI, W. Ueber die bacterienschädigende Wirkung der Becquerelstrahlen. Nach in Gemeinschaft mit Priv. Doc. Dr. Aschkinass ausgeführten Versuchen. Arch. ital. biol., Turin, T. Xxxvi, I90I, p. 130.

('o2). Rieder, Hermann. Nochmals die bakterientödtende Wirkung der Röntgenstrahlen. Münchener med. Wochenschr., Bd. XLIX, 1902, pp. 402-406.

('o4). PREScorT, S. C. The effect of radium rays on the colon bacillus, the diphtheria bacillus and yeast. Science, n. s., vol. Xx, Aug. I9, 1904, pp. 246-248.

"Radium rays have uo effect upon fresh cultures of B. coli, B. diplitheria, or Saccharom yces cerevisize at a dis tance of one centimeter where the time of exposure is less than go minutes.

\section{Effect of High Pressure on Bacteria.}

('75). BERT, P. Influence de l'air comprimé sur les fermentations. C. R. des sé. de l'Acad. des sci., Paris, 1875. T. LXXX, pp. I,579-1,582.

('77). BERT, P. De l'emploi de l'oxygène à haute tension comme procédé d'investigation physiologique; des venins et des virus. C. R. des sé. de l'Acad. des sci., Paris, $1877, T$. Lxxxıv, pp. 1,130-1,133.

('91). Scilaffer et de, FreudenReicir. De la résistance des bactéries aux hautes pressions combinées avec une élévation de la température. Annales de Microg., T. IV, I89I, pp. 105-119.

Milk subjected to a pressure of many atmospheres $\left(7^{8}-90\right)$ for several hours at $45^{\circ}$ to $63^{\circ} \mathrm{C}$ was not sterilized. High pressure for a week also failed to sterilize it.

('03). D'Arsonval e't Charrin. Pression et microbes. Ira semaine médicale, I893, T. XIII, p. 251. Rev. in Centralb. f. Bakt., Bd. XIv, $1893, p$. 64. See also C. R. des sé et mém. de ìa soc. de Biol., Paris, 20 mai, I893, pp. 532-533.

B. pyocyancus, in fresh bouillon cultures, was subjected to a pressure of 50 atmospheres under carbon dioxide, All were dead inside of 24 hours. Hiven two hours' exposure interfered with the reproductive fintiotion, i. e., lessened the uumber of organisms capable of producing colonies, and iu cultures made after four hours' pressure only and iu cultures made after four hours pressure only traces of ability to form pigment remained. In culture made after six hours exposure there was no formation of pigineut, and generally no colouies when aown upon ('94). D'Arsonval and Charrin. See xxxill.

('94). Roger, Action des hautes pressions sur les microbes. C. R. des sé. de l'Acad. des sci., T. cxix, Paris, p. 963.

Pressures of 1,000 to 3,000 atmospheres were tried with, o11 destroying the bacteria. Certain functions, however wete destroyed, e. $g$. , pathogenicity.

('97). Malfitano, G. Sul coinportamento dei microorganismi all'azione dei gasi compressi. Boll. della Soc medico-chirurgica di Pavia, 1897. Rev. in Centralb. f. Bakt., xxin Bd., 1898, pp. 233-236. 
XXXIII. Action of Heat and Cold on Bacteria.

('75). EIDAM, EiduARD. Die Einwirkung verschiedener temperaturen und des Eintrocknens auf die Entwicklung von Bacterium termo Duj. Cohn's Beiträge z. Biol. d. Pflanzen, Bd. I, Heft 3, pp. 208-224, Breslau, 1875.

('77). Frisch, A. Ueber den Einfluss niederer Temperaturen auf die Lebensfähigkeit der Bacterien. Sitzungsber. der K. Acad. der Wissensch. Wien. Math.-natur.-wissenschaften Classe, Mai, 1877 , Bd. LXxv, I I Abt., pp. 257-269.

('77). Tyndali, Join. On theat as a germicide when discontinuously applied. Proc. Roy. Soc., London, vol. Xxv, I877, No. I78, pp. 569-570.

('79). ChAMBERLAND, CH. Résjstance des germes des certains organismes à la température de IOO degrés; conditions de leur dévéloppement. C. R. des sé. de I'Acad. des sci., T. IXXXViII, I879, pp. 659-66I.

('82). LEBEEDFF, A. Contribution à l'étude de l'action de la chaleur et de la dessication sur la virulence des liquides septique et sur les l'onganismes inférieurs. Arohives de Physiol. normale et Path., Ser. II, T. x, pp. I75-204, I882.

('84). PICTE'T, R., ET Yung, E. De l'action du froid isur les microbes. C. R. des sé. de l'Acad. des sci., T. Xcvil, I884, pp. 747-749.

('87). Prudden. See Xlvi.

('87). Esmarch, E. Der Henneberg'sche Desinfector. Zeitschr. f. Hyg., Bd. II, I887, pp. 342-368.

('88). GLOBIG. Ueber einen Kartoffel-Bacillus mit ungewöhnlich widerstandsfähigen Sporen. Zeitschr. f. Hyg., Bd. I I I, I888, pp. 322-332.

('88). Gruber, Max. Notiz über die Widerstandfähigkeit der Sporen von Bacillus subtilis gegen Wasserdampf von $100^{\circ} \mathrm{C}$. Centralb. f. Bakt., I 888, Bd. II I, pp. 576-577.

In six tubes of hay infusion iuoculated with spores of B. subtilis, seaied by heating neck in flame, and then steaned $1 / 2$ hour, there was an abuudant growth of the hay hacillus in 36 hours at $37^{\circ}$ C. Subseq nently 21 samhay hacillus in 36 hours at 370 . Subseqnently 21 sam-
ples of spores, dried on silk threads and exposed to ples of spotes, dried on silk threads and exposed to
streaming steam lot $2 \frac{1}{2}$ hours, in Thursfield's apparstus, grew readily : in 24 hours, at $35^{\circ} \mathrm{C}$., there was a most luxgrew readily; in 24 .
uriant vegetation.

('88). FischER, B. Bakterienwachstum bei $0^{\circ} \mathrm{C}$. Centralb. f. Bakt., Bd. Iv, I888, pp. 89-92.

('go). Lustig, Alexander. Ein rother Bacillus im Flusswasser. Centralb. f. Bakt., Bd. virI, I89o, p. $33-40$.

Instig isolated a motile bacillus from river water, which grew from room-tem perature (probably $15^{\circ} \mathrm{C}$ ) to $60^{\circ} \mathrm{C}$.

('92). Forster, J. Ueber die Entwickelung von Bakterien bei niederen Temperaturen. Centralis. f. Bakt., xII B.d., I892, pp. 43I-436.

The kinds of bacteria ahle to grow at $0^{\circ}$ are not very unmerots, but seem to be widely distributed, especially in water and on the aurface and in the intestinal tract of fresh-water fish aud salt-water fish.

('93). Pictet, Raour. De l'emploi méthodique des basses températures en biologie. Archiv. d. sci. phys. et nat., зe Période, T. $\mathrm{xxx}, \mathrm{pp}$. 293-314, Genève, I893.

Experiments with higher animais and plants, infusoria, microbes, diatoms. With these two latter, excessive and prolonged cold gave negative resilts. They were subjected to a temperature of minus $200^{\circ}$.
('93). Prysarix. Influence de la chaleur sur la propriété sporogène du Bacillus anthracis. Abolition persistante de cette fonction par hérédité des charactères acquis. Arch. de physiol. nonmale et path., Paris, I893, T. v, sér. 5, pp. 2I7-225.

('94). D'Arsonval, E'T Cirarrin. Influence des agents cosmiques (électricité, pression, lumièrc froid, ozone, etc.) sur l'évolution de la cellule bactérienne. Arch. de physiol. normalc et path., I894, T. vI, series 5, pp. 335-342.

('94). Watdo and Walsi,. See XIVIII.

('94). Havemann. Ueber das Wachsthum von Mikroorganismen bei Eisschranktemperatur. (Inaug. Diss.) 8vo., 2 I pp., Rostock, I894. Not seen.

('95). STERNBERG, GEORGE M. What shall be the methods followed in determining the relation of bacteria to tcmperature? Jour. Am Public Health Asso. Ann. vol. Xx, I895, pp. 4II-4I4.

('95). KLEPZOFF, Const. Zur Frage über den Einfluss niederer Temperaturen auf die vegetativen Formen des Bacillus anthracis. Centralb. f. Bakt., xvir Bd., I895, pp. 289-295.

Exposure to intense cold (avcrage $-24^{\circ} \mathrm{C}$ ) for 12 dsys killed the anthrax organism iu blood aud various orgats. Fxposire for 25 days (at $-1^{\circ}$ to $-24^{\circ} \mathrm{C}$, a verage $-10.40^{\circ}$ C.) killed agar cultures. The colonies in ggar plates became less and less numerous as time passed No sp
were preseut. Loug exposure reduced the virulence.

('95). Miquíl, P., etT LatTrRave. De la résistance des spores des bactéries aux températures humides égales et supérieures à $100^{\circ}$. Ann. de micr., T. VII, I895, pp. I IO-I 22, I58-I70, and 205-2I8.

('99). Dannapper, Max. In wie weit ist die höherc Widerstandsfähigkeit der Baktoriensporen ein allgemeines Charakiteristikum derselben gegenijber den vegetativen Spaltpilzformen? 8vo., pp. 27, Konigsberg, i. Pr., 1899, von E. Karg u. R. Manneck.

Some spores are said to show only a stight resistance to steam at $99^{\circ} \mathrm{C}$. Of 25 species obtained from soils, decay-
ing mixtures, milk, butter, etc., and said to be sporiferous, all but three were destroyed by exposire to sterm st olis, all bitt three were destroyed by exposire to ster m st $99^{\circ}$. for 10 minutes and all but 8 by exposure for 5 mintites while 4 were killed by exposure fot as short a time as 15 , seconds, and two others by exposure for 1 miuute. The names of these organisius are not given, so that the experiments cannot be duplicated, and in most cases it is not stated that the sporiferous nature of these bacteria was settled definitely by seeing the spores germinate. It is possible, therefore, that some of the extremely sensitive forms were not actually spore-bearing, but only gave microscopic appearances, which were interpreted ss sucls. It is possible, also, that the spores were tested hefore they were fully matured. Only two of the very seusitive forms were examined critically, owitng, it is said, to lack of tine, and of one of these seusitive forms it is said: "A direct observation of the germination was not undertaken hecause tlie spore nature of the culture appeared unquestionable." Even heating for 1 to 3 minutes at $75^{\circ}$ to $80^{\circ} \mathrm{C}$ destroyed this orgatism. Gertuluation of the other was observed. The maximum temperature which could he endured in this case, for I minute, was $75^{\circ} \mathrm{C}$. Both were green spores. Both were double staiued by Moeller's

('99). RAvinet, M. P. The resistance of bacteria to cold. New York Medioal News, vol. LXIIV, I899. Also a separate, 5 pp. Rev. in Centralb. f. Bakt., xxviri Bd., I900, p. 75 I.

Tests in liquid air: B. diphtheria was alive at end of 30 minutes, B. typhi and $B$. prodigiostus at the end of 60 minutes, B. typhi and $\mathrm{B}$. prodigios 
('09). Snitu, Turobald. The thermal death point of lubercle bacilli in milk and some other fluids. Journal of Experimental Med., vol. Iv, I899, pp. 217-233. Rev. in Centralb. f. Bakt., Xxvi11 Bd., I900, p. 409.

When embedded in the film on the surface of milk, Dr. Si11 th found the tubercie organlsm resisted a temperature of $60^{\circ} \mathrm{C}$. for an hour.

('g). Kasansky, M. W. Die Einwirkung der Winterkälte auf die Pest- und Diphtheriebacillen. Centralb. f. Bakt., xxv Bd., I899, pp. 122-124.

These organisms withstood exposure for 6 mouths to severe temperatures. They were frozen all of the time for the first five months. From December 4 to 28 , aud agaiu from February 13 to Marcli , the maximum tem. perature was $-10^{\circ}$ to $-23.4^{\circ} \mathrm{C}$, and the minimum was $-14^{\circ}$ to $-33.8^{\circ} \mathrm{C}$.

(s9). LEVIN. See XitII.

(99). Mironesco, Thenonor G. Ueber eine besondere Art der Beeinflüssung von Mikroorganismen durch die Temperatur. Hygien. Rundschau, Jahrg. 1x, 1899, pp. 961-964. Rev. in Centralb. f. Bakt., xxviI Bd., 1900, p. 86.

('oo). Meyre, J. Ueber Einwirkung flüssiger Luft auf Bakterien. Centralb. f. Bakt., xxvin Bd., 1900, pp. 594-595.

Anthrax spores and Staphylococcus pyog. aureus were tested. The exposure to the liquid air varied from seconds to 15 minutes. Neither organism was killed. The temperature of 1 iquid air is $-190^{\circ}$ to $-220^{\circ} \mathrm{C}$, accord ing to Spiess, and $-182^{\circ}$ to $-192^{\circ} \mathrm{C}$. according to Mac
fadyen

('oO). Sedgwick, IV. T., and Winslow, C. E. A Experimental and statistical studies on the infucnce of cold upon the bacillus of typhoid fever, and its distribution. Jour. Bost. Soc. Med. Sci., vol. iv, No. 7, I900, pp. I8I-182. See also Centralb. f. Bakt., xxviı Bd., 1900, p. 684 .

30 to 60 per cent of the bacilli were destroyed in water during the first bour of treezing. After exposure for two weeks 99 per cent were destroyed. "The last two or three germs per thousand appear to be very resistant, som remainiug a ter twelve weeks of freezing. The four race used showed constant individual differences in thelt sus. ceptibility to cold. Alternate Ireezing atd thawiog wa tested and found only slightly more destructire than coutinnons freeziug." As several races of typhoid organism were tested, we may infer that ice fa not very likely to communicate typhoid fever.

('oo). Park, WM. Hallock. A few experiments upon the effects of low temperature and freezing on typhoid bacilli. Jour. Bost. Soc. Med. Sci., vol. Iv, No. 8, 1900, pp. 213-216.

Cultures were used from twenty different cases of typhoid fever. They behaved when frozen mnch as Sedg wick and Winslow'a. On the average, at the end of twelve weeks' freezing only 0.05 of one per cent remained alive, i ce, 1,250 per cubic centimeter as g gaiust $2,560,410$ per cubic centineter at the beginuing.

"At twelve weeks the bacilli in the ice from vine sonrces are all dead. Two more show po growth in 1 ce The others contain from 80 to 11,000 in each cc of ice. Only one, howerer contains orer t,000 (culture When typhoid bacilit are in feces, freezlng dues 9 . When typhos bacin exert so much of au effect. Thus typhold and colon bacilli, originally 37,000 to a foopful of feces, wite stil 12,000 at the eud of tive weeks exposure to a temperature ranging daily between zero and $28^{\circ}$ F., and typhold bacilias well as colon were still abundant in the feces at ilve wecka. It is a dificult matter to say for just how long a pertod lce made from infected water remains dav gerous. The bacilli, even when few in number, are often vigorous and fully virulent, and, so far as $1 \mathrm{am}$ a ware, we are 1guorant as to the number of bacilli tequired to start frozen the less the number of pathogenic bacteria whlch remain alive in it."
('oI). Park, W. H. Duration of life of typhoid bacilli, derived from twenty different sources, in ice. Abstract of paper read at $2 \mathrm{~d}$ meeting Soc. Am. Bacteriologists, Dec., I90o. Centralb. f. Bakt., I Abt., Bd. xxix, IgoI, pp. 441-445.

This describes the completion of an experimeut already reported upon in part (see above). At the eud of the twenty-second week of exposure the bacllli were dead in all the cultures of eacb onle of the tweuty races tested by
freezing.

('oI). D'Arsonval. La pression osmotique et son ròle de défense contre le froid dans la cellule vivante. C. $R$. des sé. de l'Acad des sci., Paris, I901, T. cxxxIII, pp. 84-86.

The fluid in the bacteria is probably not solidified, if the cell is not ruptured, owing to the enormous osmotic pressure in those small organisms. By lowering the os motic teusion the author thinks that any cell may be killed by cold.

('o2). Schmidt-Nieisen. Sigval. Ueber einige psychrophile Mikroorganismen und ihr Vorkommen. Centralb. Bakt., Abt. 2, Bd. Ix, 1902, pp. I45-147.

('O2). Macfadyen, Allen, and Rowland, Sydney. On the suspension of dife at low temperatures. Abstract of paper read before Section $\mathrm{K}$ of the British Association, Belfast, 1902. Annals of Botany, vol. xvi, 1902, pp. 589-590.

Various bacterial orgauisms were exposed from 20 hours to 7 days at $-190^{\circ} \mathrm{C}$. "These exposures did not produce any appreciable impairment in the vitality of the organ isms, etc." Also to hours at $-252^{\circ} \mathrm{C}$. the tem perature of jiquidliydrogen had no appreciable effect on the vitality of the micro-organisms tested. Bacillus typhosua, B. coll communis, Staphylococcus pyogenes anrens and a Sach aromycete grew after exposure to liquid air for six mouths. "In no instance conld any impairment of tbe vitality of the orgavisms be detected."

The objection to these statements is that quantitative determivations appeat unt to have been made, at least here is no mention ot any. The writer of this review oblaiped a decided diminution of the numbet of viable bacteria in several species by exposure to liquid air for 20

('02). Macfadyen, Alien. On the influence of the prolonged action of the temperature of liquid ait on micro-organisms, and on the effect of mechanical trituration at the temperature of liquid air on photogenic bacteria. I.ondon, Proc. R. Soc., vol. LXXI, No. 468, Oct., I902, pp. 76-77.

"The above experiments slow that a prolonged exposure of six months to a temperature of about no appreciable effect on the vitality of mictoThe organisms tested were $B$. Iy munts. Stuphylococcus pynoenes arreus, and s cnm-

The triturated bacteria lost their luminosity.

('o5). Smith and Swingre. See p. 83.

\section{Thermophilic Bacteria}

(73). Mrquel, P. Title? Bull. de la statistique municipale de Paris, Décembre, 1879 .

Not seen.

He discovered in the water of the Selne an immobile, rod-shaped Schizomycete capable of living and developing at the tempersture of $70^{\circ} \mathrm{C}$.

('81). van Tifigiem, PH. Sur des bactériacées vivant à la température de $74^{\circ} \mathrm{C}$. Bull. Sac. bot. de France, T. 28, I881, pp. 35-36.

This autbor cultivated several species of thermophilic bacteria at $70^{\circ} \mathrm{C}$., and aome at higher tem peratures.

('81). Miquen. Thermobacteria. Anntaire de l'Observatoire de Montsouris, pour I881, p. 464 
('S6). CérTes, A., ET Garrigou. De la présence constante de micro-organismes dans les eaux de Luchon, recueillies au griffon à la température de $64^{\circ}$, et de leur action sur la production de la barégine. C. R. des sé. de l'Acad, des sci., T. crII, 1886, pp. 703-706.

('88). GLoBig. Ueber Bakterien-Wachsthum bei 50 bis $70^{\circ}$. Zeitschr. f. Hyg., Bd. II I, 1888, pp. 204-32i. Rev. in Centralb. f. Bakt., Bd. III, 1888 , pp. $366-368$.

Globig obtained 30 sorts of bacteria which grew on potato st $58^{\circ} \mathrm{C}$. At $68^{\circ}$ only a few of them eontinued to

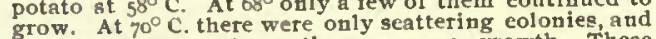
at higher temperatures there was no growth. These orgauisms were not pathogenic to mice. As a rule, growth began at sbout $50^{\circ} \mathrm{C}$., i.e., about 13 degrees above blood-heat. One would not gtow at $37^{\circ} \mathrm{C}$. or $50^{\circ} \mathrm{C}$, but grew at $60^{\circ}$. One grew all the way from $15^{\circ}$ or $20^{\circ}$. to thes or sewage. Most were bacilli (rods).

('88). Mrouel, P. Monographie d'un bacille vivant à au-delà de $70^{\circ}$ centigrades. Ann. de micro., 1888, T. I, pp. 3-10.

This organism will vot grow at temperatures 11 det $40^{\circ}$,

) COHN, FERDINAND Ueber Wärmeerzeugung durch Schimmelpilze und Bakterien. Vortrag., Breslau, 1890.

('93). Cons, F. Ueber thermogene Bakterien. Ber. d. Deutsch. bot. Gesellsch., Bd. XI, I893, Gen. Versamlungs-Heft, pp. 66-69.

Cohn found that when eotton wool waste was moistened, it reaehed a temperature of $67.2^{\circ} \mathrm{C}$. in 24 to $3^{6}$ hours, and then slowly eooled ( 6 days) to the air-temperature. When the same waste was sterilized there was no rise in temperature.

('94). Machadyen, Allan, and Blaxall, Frank R. Thermophilic bacteria. Journal of Pathology and Bacteriology, vol. III, 1894, pp. 87-99. See also Br. Med. Jour., No. I,760, I894, p. 644 .

These authors obtained from garden soil an abundant growth of thermophllie bacteria on agat at $60^{\circ}$ to $65^{\circ} \mathrm{C}$, They also isolated these organisms from feces, sewage, sea-water, dirt of London streets, Thames water, Thames mud, atraw, surface soil, and soll 5 feet 4 inehes down. These thermophilic bacteria are, therefore, most widely distributed. There were quite a variety of species - at least twenty. All were baeilli ; all were spore-bearing. Sonte were aetively motile. Active motility eontinued for thre weeks in oue hanging drop. The colonies developed very rapidly in agat-plates. Fifteen sorts were tested as fol lows: None of them grew at $22^{\circ}$ or at $37^{\circ} \mathrm{C}$. Morse-dutg organisms grew at $40^{\circ}$ to $42^{\circ} \mathrm{C}$. Six sorts grew slowly at $50^{\circ}$ to $52^{\circ} \mathrm{C}$, and more sbuudantly at $60^{\circ}$ to $65^{\circ} \mathrm{C}$. Two grew first at $56^{\circ}$, and four refused to RTow at $56^{\circ}$, but grew when the temperature was raised to $60^{\circ} \mathrm{C}$. None would grow at $75^{\circ}$. The lower limit of growth for nearly all was $50^{\circ}$ C. and the upper near $75^{\circ} \mathrm{C}$. Boiling for ten minutes did not destroy these organisms. The optimum tem perature for growth is said to be $60^{\circ}$ to $65^{\circ} \mathrm{C}$. These organisus dld not ferment sugars and did not thrive on substrata eontaining sugars, these substance

Ouery: How do these organisms exist in a climate as eold as that of Edinburg?

('95). Rabinowitsch, Lxdia. Ueber die thermophilen Bakterien. Zeitschr. f. Hyg., Bd. xx, 1895, pp. I54-164. Leipsic.

These thermophilic organisms were found in snow, in earth, in the dust of a street in Berlin. They were very abundant in the water of the Spree (7,000 to 8,000 per cubic centimeter). They are abundant in the dung of horses and cowa, and also more or less so in the excrement of goats, tabbits, guluea pigs, dogs, mice, doves, hens, ducks, partots. They oeeur in the whole digestive tract ot man, and are found in certain fish, frogs, and some other eold blooded animals. Miss R. also found them abundant in germinating bs rleyin a brewery. They oceuralso in milk. even after it is boiled. She isolated and studied 8 species. All produced spores. None were pathogenic to miee or dores. The highest temperature at whieh any of them would orow was $75^{\circ} \mathrm{C}$, and growth at this high temper ture was slight. There was an abundant growth at $58^{\circ}$ to $68^{\circ} \mathrm{C}$, and the optimum is said to be $60^{\circ}$ to $70^{\circ}$. They are very resistant to moist heat and also to dry heat. They were not killed by exposure to streaming steau for 5 to hours. While growing best at high temperatures, these organisins can grow slowly facultative-anaerobically at $33^{\circ}$ to $40^{\circ} \mathrm{C}$., and the a uthor thinks that they multiply in side warm-blooded animals. Slie found the temperature of dung piles as high as $62^{\circ}$ to $66^{\circ} \mathrm{C}$.

('95). KarLiNSKY, JUS'YYN. Zur Kenntniss der Baciterien der Thermalquellen. Hygienische Rundschau, r895, Bd v, pp. 685-689.

('o6). Trich, M. Beitrag zur Kenntniss thermophiler Bacterien. Hygienische Rundschau, I896, Bd. vi, No. 22, pp. 1,094-I,095.

('98). LAXA, O. Ueber einen thermophilen Bacillus aus Zucker-Fabriksproducten. Vorläufige Mittheilung. Zeitschr. f. Zuckerindustric in Böhmen, Bd. xxır, I8g8, p. 376 . Not seen.

('98). OpREscu. Studien ïber thermophile Bakterien. Arch. f. Hyg., Bd. xxxirr, 1898, p. 164. Rev. in Centralb. f. Bakt., Bd. Xxv, I899, p. 360.

('g9). Tsiklinsky, Mlti. Sur les microbes thermophiles des sources thermales. Ann. de l'Inst. Pasteur, T. Xir, r899, pp. 788-795 Bibliog. of 13 titles.

The author isolated five thermophilic organisms from hot springs. One form grew readily at $70^{\circ} \mathrm{C}$.

('99). Michaél,is, GroRg. Beiträge zur Kenntniss der thermophilen Bakterien. Arch. f. Hyg. B.d. xxxvi, Hf.t. 3, I899, pp. 285-293. Rev. in Centralb. f. Bakt., xxvij Bd., 1900, p. 537

Describes and names four new thermophilic organisms. All have three speeific names, and one has fonr, to-wit Bacterium thermophilus aquatilis liquefaciens aerobins.

('99). CAMBIER. Thermophilic bacteria as ferments, action on glucose. Rev. de phys. et de chim. 1899 , p. 223.

Not seen.

('02). Russel, H. L., and Hastings, E. G. A Micrococcus, the thermal death limit of which is $76^{\circ}$ C. Centralb. f. Bakt., 2 Abt., Bd. vi11, 1902, pp. 339-342, I plate.

('o3). SETCHELL, WM. A. The upper temperature limits of life. Science, n. s., vol. Xvir, 1903, pp. 934-937.

Hot springs were studied in three localities in California and in Yellowstone National Park. Author found only Cyanophyceæe and Bacteria in strictly thermal waters. The Cyanophycero were found at $65^{\circ}$ to $68^{\circ} \mathrm{C}$., aud sparingly up to $75^{\circ}$ to $77^{\circ} \mathrm{C}$. The baeteria were abundaut at $70^{\circ}$ to $71^{\circ}$, a nd oceurred in considerable quautity at $82^{\circ} \mathrm{C}$. and $89^{\circ} \mathrm{C}$. "The temperature of $89^{\circ} \mathrm{C}$. is the highest at whieh 1 have been able to find any organisms living." Care was taken to determine the temperstures in the exact plas of vations.

\section{Resistance to Dry Air.}

('75). EIDAM, See XxxIIT.

('92). Momont, I. Action de la dessication, de l'air, et de la lumière sur la bactéridie charbonncuse filamenteuse. Ann. de 1'Inst. Pastelir, 1892, T. VI, Pp. 2I-3I.

('03). Swan, ALLEN P. On the resisting vitality of the spores of Bacillus megaterium to the oondition of dryness. Annals of Botany, vol. vII, p. 153-I54, 1893. 
('94). Walliczé, HéinRich. Die Resistenz des Bacterium coli commune gegen Eintrocknung. Centralb. f. Bakt., Bd. xv, 1894, pp. 9.9-950.

B. coll proved quite sensitive to dry air. The writer of this abstract has found great differences among bacteris e. g. B. tracheiphilus was killed by a few minutes' exposure ou cover-glisses, while Bact. hyacinthi lived uuder similar conditions for more than a montl. Jones fonnd his Bacillus carotovorus to be even more sensitive that B. tracheiphilus, See following citatlous.

(95). Smrth, Friwin F. Bacillus traclieiphilıs, ete. Centralb. f. Bakt., 2 Abt., Bd. I, p. 370.

(97). Miouer, P. Sur la longévité des germes des bactéries dans les poussières et dans le sol. Ann. de micr., 1897, T. IX, pp. 199-207 and 251-259.

('o1). Jones, I. R. A soft rot of the carrot, etc. 13th Ann. Rep. Vt. Agric. Exp. Sta. for 1000 Burlington, Vt., 1901. See p. 328 for reference to this subject.

('or). SuITIr, ERIvis F. The cultural characters of Ps. hyacinthi, otc. Bull. 28, Div. Veg. Phys. and Path., U. S. Dep. Agr., Washington, D. C., 190r, p. 145 .

XXXVI. Action of Acids and Alkalies.

('86). Aввотт, A. C. The gernicidal value of some of the vegetable acids. The Medical News, Phila., 1886, 9 Jan., pp. 33-34.

('92). DezinRUECK, M. Ueber das Verhalten der Cholerabacillen auf frischen Früchten, einigen Genuss- und Nahrungsmitteln. Sonderabdruck aus den Veröffentlichungen des Kaiserlichen Gesundheitsamte, 1892 , No. 42, vom Ig October, Berlin. Verlag von Julius Springer, 1892, pp. 812-824.

The per cent of malic acid in many fruits is given. This varies from 0.13 (certain pears) to 2.65 (ted currants). In the feebly actd fruits, the choleta brcilli were dead inside of 3 to 7 days : in the the tarter fruits they retained their vitality only for a period measured by hours. Usually they were dead in from 1 to 6 hours.

('g2). Schlueter, G. Das Wachstum der Bakterien auf saurem Nährboden. Centralb. f. Bakt., Bd. XI, I 892, pp. 589-598.

A dozen different bacteria were tested in "ordinary nu. trient gelatin" snd in fisb glue, with addition of lartic acid, alum, tartaric acid, citric acid, acetic acid, and hyacid, alum, tartaric acid, citric acid, acetic acid, and hyas I per cent of lactic acid, or I per cent tartaric acid but theit growth was slow and usually feeble. Severa grew feebly in the presence of $1 / 2$ per cent alum. Six grew abundantly it gelatin acidified with citric acid,so that $8 \mathrm{cc}$. of the gelatin required for its neutralization $4 \mathrm{cc}$. of sodium carbonate water of the strength 5.3:1000 In fish glue coutaining 0.15 per cent acetic acid, several grew, but only feebly. Six grew in fish glue contsining 0.075 per cent hydrochloric acid. The anthrax organism grew hetter with 0,2 per cent alum than on a veutral

('93). Hrsse, W. Ueber den Einfluss der Alkalescenz des Nährbodens auf das Wachsthum der Bakterien. Zeitschr. f. Hyg., Bd. xv, 1893, pp. 183-191.

('93). Voges, O. Ueber das Wachstum der Cholerabacillen anf Kartoffeln. Centralb. f. Bakt., Bd. XIII, I893, pp. 543-550.

Organism woula not grow 011 potalo as ordinatily prepared lut grew well at $37^{\circ} \mathrm{C}$. (and more slowly at $20^{\circ}$ on pared.jut grew we ad at the addition of a to 3 perits wete obtsined 1de. Nearly as good resuts wete obtained with $1 / 4$ to $1 / 2$ per cent sodium carbonate solution. Growth was also solution.
('97). DeEleman, M. Der Finfluss der Reaktion des Nährbodens auf das Bakterienwachstum. Arbeit. aus dem Kaiserl. Gesundheitsamte, Bd. xHI, 1897, Heft 3. Rev. in Centralb. E. Bakt., xxı Bd., 1897, pp. 355-356.

('98). Fermi, Craudio. Die Mineral- und organischen Säuren, die Alkali, die Alkaloide, das Jodkali und das arsensäure Kali zur Differenzierung der Mikroorganismen. Centralb. f. Bakt., Bd. xxil, 1898, pp. 208-217 and 266-273.

of the plant acids, oxalic was found to be the most deleterious to the Schizomycetes. The conclusions are giren on p. 266 et seq.

\section{XXXVIl. Agglutination and Precipitation.}

('g6). Widal, FERnAnd. Séro-diagnostic de la fièvre typhoide. Bull. et mém. de la soc. méd. des hôp. de Paris, 26 juin, 1896, pp. 56!-566.

('97). Widal, F., ex Sicard, A. Etudes sur le sérodiagnostic et sur la reaction agglutinante chez les typhiques. Ann. de l'Inst. Pasteur, T. $x 1,1897$, pp. $353-432$.

('97). FLEXNLR, S. A recently discovered property of the blood serum in animals immune from certain diseases, and its application to the diagnosis of those diseases in human beings. Science (n. s.), vol. v, pp. 193-194, 1897.

('97). Malvoz, E. Reoherches sur l'agglutination du Bacillus typhosus par des substances chimique. Ann. de l'Inst. Pasteur, T. XI, 1897, pp. 582-590.

('98). Nicol, L, Chardiss. Recherches sur la substance agglutinée. Ann. de l'Inst. Pasteur, T. XII, I898, pp. 161-191.

('99). Bordert, JulEs. Le méchanisme de l'agglutination. Ann. de l'Inst. Pasteur, T. XIIr, 1899 , pp. 225-250.

('99). KraUs, R. Ein Beitrag zur Kenntniss des Mechanismus der agglutination. Wiener Klin. Wochenschr. 1899, Jahrg. XIr, pp. I-4.

('99). Gruber. Zur Theorie der Agglutination. Münch. med. Wochenschr., I899, No. 41 . Rev. in Centralb. f. Bakt., xxvur Bd., I900, pp. 285-286.

('99). Sabrazès etT Brengues. Agglutinines chimiques. C. R. de la Soc, de biol., I899, No. 35. p. 930. Rev. in Centralb. f. Bakt., xxvir Bd., 1900, p. 756.

('o). Zrkes. Ueber das Ausschleudern von Mikroorganismen unter Zuhilfenahme von Fällungsmitteln. Oesterr. Chemiker-Zeitung, 1900 , No. 2. Rev. in Centralb. f. Bakt., Xxvir Bd., 1900, p. 628.

('o). SmIth, R. GREIG. The flocculation of bacteria. The mechanism of agglutination. Proceedings of Linn. Soc. of New South Wales, Ig00, Pant I, pp. 65-74, 75-83. Also a separate (issued Aug. 8, rooo).

('oo). Durham, Herbert E. Some theoretical considerations upon the nature of agglutinins, together with furtlier observations upon Bacillus typhi abdominalis, Bacillus enteritidis, Bacillus coli communis, Bacillus lactis aerogenes, and some other bacilli of allied character. Jour. of Exp. Med., vol. v, pp. 353-388. 
('or). WILSON, RoBERT J. Observations contributing to precision in the use of the Widal test for typhoid. N. Y. Univ. Bull, of the Med. Sci., vol. I, No. 2, 1901, pp. 87-02.

('or). Dodge, Charles Wright. A short method for the Widal test. Jour. of Applied Micro., vol. IV, Igor, p. 1,565. Also a separate.

('02). Neurem, F. Ueber die Agglutination der Pneumokokken und über die Theorieen der Agglutination. Zeitschr. f. Hyg., I902, Bd. $\mathrm{XL}, \mathrm{pp} \cdot 54-72$.

('O2). EISENBERG, Philipp, UND VOLK, RichaRd Untersuchungen über Agglutination. Zeitsch. f. Hyg., I902, Bd. XL, pp. I55-195.

Bibliog. of 56 titles.

('o2). Joos, A. Untersuchungen über den Mechanismus der Agglutination. Zeitsch. f. Hyg., 1902, Bd. XL, pp. 203-230.

('O2). SMITH, R. GRE'r. Funther remarks upon the mechanism of agglutination. Proc. Linnean Soc. of New South Wales, vol. xxvir, 1902. Part I, pp. 66-72. Also a separate (issued Aug. 22, 1902)

('o3). FiLXNER, SiMON. An aspect of modern pathology. Science, n. s., vol. xvirI, No. 444, I903, pp. 3-15.

\section{XXXVI1I. Antiseptics and Germicides.} (See also XXXVI.)

('7O). LISTER, JOSEPH. On the effects of the antiseptic system of treatment upon the salubrity of a surgical hospital. Edinburgh, Edmonston and Douglas, I870, pp. I9.

(74). Davaine, C. Recherches relatives à l'action des substances antiseptiques sur le virus de la septicémie. Gaz. med. de Paris, 1874, p. 44. Reprinted in l'Oeuvre de Davaine, Paris, I880.

(75). Lewin, L. Das Thymol ein Antisepticum und Antifermentativum. Virchow's Archiv. Bd. LXv, 1875, pp. 164-I89. Polli's Annali di chimica applicata alla med. Milano, vol. LXII, 1876, pp. 321-324.

('77). Polsi, G. Sulle proprietà antifermentative dell'acido boracico e sue applicazioni alla terapia. Mem. Ist. Lomb., vol. xull, pp. 453468. Journ. de Pharm., et de chimie, 'T' XXVI, I877, 4 sé., pp. 77-79.

('79). Bover, V. Ueber die antiseptischen Eigenschaften der Pyrogallussäure. Journ. f. prakt. Chem. Neue Folge, Bd. xıx, pp 445-46I, I879.

('8o). Pavesi, C. Del solfato di potassa, e specialmente della sua proprietá antisettica, antifermentativa. Polli. Annali, vol Lxxi, serie 3a, I880, pp. I10-1 I5.

(8o). Endemann, H. Boracic acid as a preservative. Chem. News, vol, Xit , pp. I52-153, I880.

('80). Schwartz, Nicolai. Ueber das Verhalten einiger Antiseptica zu Tabacksinfusbacterien. Pharm. Zeitschr. f. Russland, Bd. XIx, I880, pp. 610-625, 641-658, 673-685.

Tested chloroform and found it of little worth. Experiments were made with 40 substances. The tabulat summary is on pp. 684-685. Picric acid heads the list for efficlency.

('80). Regnard, Paul. Influence de l'eau oxygéluée sur la fermentation. Gaz. méd. de Paris, T. Ir, 6 ser., 1880 , p. 358.

('81). Chappuis, E. Action de l'ozone sur les germes contenus dans l'air. Bull. de la Soc cluim. de Paris, I sém., n. s., T. xxxv, Paris, I88I, p. 290.

('8I). BARNES, J. B. The antiseptic properties of cinnamic acid. Pharmacent. Jour. and Transactions, vol. xir, pp. $477-478,188$ I.

('8I). JALAN DE IA Crorx, N. Das Verhalten der Bakterien des Fleischwassers gegen einige Antiseptica. Arch. f. exper. pathol. u. pharm., I881, Bd. X111, pp. 175-255. Ber. d. deutsch chem. Gesellsch., Bd. XIV, pp. 2,8352,838 .

('8I). Gosselin, L., ET Bergeron, A. Recherches sur la valeur antiseptique de certaines substances et en particulier de la solution alcoolique de Gaultheria. Arch. gén. de méd., Paris, I88I, vol. I, vili, sé., T. 7 (misprinted 6), I47 vol. de la collection, pp. 16-29.

('82). Bert, P., et Regnard, P. Aotion de l'eau oxygénée sur les matières organique et les fermentations. C. R. des sé. de l'Acad. des sci., T. Xciv, 1882, pp. 1.383-1.386.

('82). Burce, V. Sur l'action désinfectante et antiseptique du cuivre. C. $R$. des sé. de l'acad. des sci., T. xcv, 1882, pp. 862-864.

Workers in copper escape both cholera and typhoid fever. It is sald that there has not been a single death from either disease in the Sociéte de Bonaccord (copper, bronze and brass workers) siuce its establishment i11 1819.

("82). SchIFFERDCKER, P. Ueber eine neue Injectionsmasse zur Conservirung der Leichen für den Präparirsaal. Arch. f. Anat. u. Entwickelungsgesch., 1882, pp. 197-198.

('82). Vulpian. Ettudes expérimentales relatives à l'action que peut exercer le permanganate de potasse sur les renins, les virus et les maladies zymotiques. C. R. des sé. de l'Acad. des sci., T. Xcıv, I882, pp. 613-617. Jour. de Pharm. et de Chimie, T. vi, 5 série, I882, pp. I00-104.

(86). Unna, P. G. Ichthyol und Resorcin als Repräsentaten der Gruppe reduzierender Heilmittel. Hamburg, I886. Unna's Dermatologische Studien, 2 Heft, pp. I-85.

(89). Nưtal, Geo. Experimente über die bakterienfeindlichen Einflüsse des thierischen Körpers. Zeitsclar. f. Hyg., Bd. Iv, I888, pp. 353-394, I plate.

('88). SALKowSKr, E. Ueber die antiseptische Wirkung des Chloroformwassers. Deutsche medioin. Wochenschrift, I888, Bd. xIV, pp. 3093 II.

('88). LoEw, O. Physiologische notizen über Formaldehyd. München. med. Wochenschr., 1888, Bd. xxxv, pp. 412-413. Physiol. Ges. München ( $\mathrm{I}-6)$, I888, pp. 39-41. Rev. in Ch. Centralb., I889, I,X Jahrg., Bd. I, p. 90. ('89). BEHRING. Ueber Quecksilhersuhlimat in eiveisshalitigen Flüssigkeiten. Centralh. f. Bakt., I888, Bd. II 1, pp. 27-30 and 64-66.

('89). Fraenket, CarL. Die Einwirkung der Kohlensäure auf die Lebensthätigkeit der Mikroorganismen. Zeitsch. f. Hyg., Bd. v, I889, pp. 332-362.

('go). AlteHOEFER. Ueher die Desinfectionskraft von Wasserstoffsuperoxyd auf Wasser. Centralb. f. Bakt., I8go, Bd. vin, pp. I29-137.

('go). KirchneR, M. Untersuchungen über der Einwirkung des Chloroforms auf die Bakterien. Zeitschr. f. Hyg., Bd. viII, pp. 465-488, I89o. 
('go). Sonntag, Hermann. Ueber die Bedeutung des Ozons als Desinficiens, Zeitschr. für Hyg., I89o, Bd. viII, pp. 95-I 36.

('9I). T'izzoni, Guido, u. Catrani, G. Ueber die Widerstandsfähigkeit der Tetanusbacillen gegen physikatische und chemische Einwirk11ngen. Archiv. f. exper. Path. u. Pharm., I89i, Bd. xxvili, pp. 4I-60.

(9I). Frori, ICh, O. Ueber das Ozon, dessen Herstellung anf elektrischem Wege und dessen technisolne Anwendungen, insbesondere in der Gesundheitstechnik. GesundsheitsIngenieur, I891, No. I6, pp. 543-55I.

(91). Froelich, O. Ueber das Ozon, dessen Herstellung auf elektrischem Wege und dessen technische Anwendungen. Electrotechnische Zeitschr., i89 I, I2 Jahrg., pp. 340-344.

Contaius ahort paragraph on physiological action of ozone. Bacteria living in water are killed " sämmtlich," No experiments with pathogenic bacteria. It is still question whether bacteria in the air arekilled.

('91). GFrlach, Val. Ueber Lysol. Zeitschr. f. Hyg., Bd. x, 1891, pp. I67-196. Also a separate.

Lysol is more active than carbolic acid or creolin. The hands may be disiufected In a I per cent. solntion without soap. Surgical instruments may be sterilized in $1 / 4$ per cent golution without the least injury. Walls may be disinfected in a 3 per cent solution. It is to man the least poisonous of the antiseptics of its class.

('9I). Fischer. See XI.

('S2). Schlueter, See xxxvi.

('52). Richter, $\mathrm{CH}_{\mathrm{H}}$. De l'action de quelques sels métaliques sur la fermentation lactique. C $R$. des sé. de l'Acad. des sci., T. cxiv, 1892, pp. I,494-I,496.

('s2). OHhMUELLer. Ueber die Einwirkung des Ozons auf Bakterien. Arbeiten aus dem Kaiserl. Gesundheitsamte, Bd. vil, I802, Heft I, pp. 229-25I.

Ozone In water is less effective as a germicide in proportion as the water contains more and more dead organic matter. It is not adapted to the disinfectlon of rootuls.

('92). Delbrueck. See xxxyi.

(92). HAMMER, HANS. Ueber die desinficirende Wirkung der Kresole und die Herstellung nentraler wässriger Kresollösungen. II Mittheilung, Arch. f. Hyg., Bd. XIV, I892, pp. II6-134.

('92). Aronsohn, Hans. Ueber die antiseptischen Eigenschaften des Formaldehyde. Berl. klin. Wochenschr., 1892, Bd. Xxix, No. 30, pp. 749-75I

('92). Berlioz, F., and Tril,Lat, F. Sur les propriétés des vapeurs du formal ou aldélyyde formique. C. R. des sé. de l'Acad. des sci., 1892, T. cxv, pp. 290-292.

('92). HANKin, E. L'action bactéricide des eaux de la Jumna et du Gange sur le microbe du choléra. Ann. de l'Inst. Pasteur, T. X, Pp. $511-523$.

Cholera does not descend the rivers In India. Bacteria are invch rater in these rivers than in European rivers. Tlie filtered, unboiled river water has a decided bactericidal action on the cholera organisu. When boiled the water lost 1 ts germicidal property.

('93). ve Christmas, J. Sur la valeur antiseptique de l'ozone. Ann. de l'Inst. Pasteur, T. VII, I 893. pp. 776-780.

(93). Scililit. See xvili.

('o3). Vogrs. See xxxvi. ('s3). Green. Ueber den Werth der Kuplersalze als Desinfektionsmittel. Zeitschr. f. Hyg., Bd. XIII, I893, pp. 495-51I.

States that copper salts have considerable value as germicides, especially the soluble ones. Cuprum bichloratum is considered most valuable. This is the only copper salt that is suffciently active in solutious containing much albumen. For the treatment of wounds, bichlorate is much beiter than copper sulphate.

('93). Loew, Oskar. Ein natürliches System der Giftwirkungen. München, I 803 , Wolff und Lüneburg, pp. viıI, I36. Rev. in Centrall). f. Bakt., I893, Bd. xiv, p. 234.

('93). Gruber, Max. Ueber die Löslichkeit der Kresole in Wasser und ïber die Verwendung ilırer wässrigen Lösungen zur Desinfektion. Arch. f. Hyg., Bd. xvil, I893, pp. 618-625.

('94). Dieudonné. See Xxix.

('94). D'Arsonval, et Charrin, See xxxili.

('94). ABEL. See xvili.

('94). Miguel. De la désinfection des poussières sèches des appartements; and Contribution nouvelle à l'étude de la désinfection par les vapeurs d'aldéhyde formique. Ann. de micr., T. VI, I894. See pages $257,305,396$, 520,588 , and $62 \mathrm{I}$.

('94). PotTEvin, Henri. Recherches sur le pouvoir antiseptique de l'aldéliyde formique. Ann. de l'Inst. Pasteur, T. vili, I894, pp. 796-810.

('94). Bolton, MEadE. The effect of various metals on the growth of certain bacteria. Intermat. Med. Mag., December, I894, pp. 812-822. Also a separate. Reviewed in Am. Nat., Oct., I 895 , p. 933.

('94). Scriroiv, P. F. Ueber den Einfluss des Wasserstoffsuperoxydes auf einige pathogene Mikroorganismen. St. Petersb. med. Wochenschr., I894. No. 6. Rev. in Centralb. f. Bakt., Bd. xvi, 189.4, pp. 42-43.

Cliolera bacteria were destroyed in 3 minntes in 1:200; in 1:300 they were alive after i houtr. Typhoid ba. cilli, in 1:roo to 1:200, were killed in 10 minutes; in 1:1000, after 1 honr. Anthrax spores, in 14 per ceut solution were killed in less than 3 miuutes; a 2 per cent solution killed them in less than oue hour: $a$ I per cent solution did not kill in 1 hour. Staphylococcus pyogen. anreus, from cul. tures I day old, was killed in $1: 100$ in less than $10 \mathrm{~min}$ utes $;$ in 1:200 it required more than 15 mlnutes. Diplococcus pnenmonia does not grow in boullon to which hydrogen peroxide has been added in $1: 10,000$ to $1: 18,000$. Solutious of $1: 200$ destroyed a one-day old culture in 15
minutes.

(94). WalliczeK, Heinrich. Die baktericiden Eigenschaften der Gerbsäure ('Tamnin der Apotheken). Centralb. f. Bakt., Bd. xv, I 894, pp. 89 I-894.

Tables sliowlng effect of various per cents of tannin on

B. coli, B. antliracls, and Staphylococcus aureus.

('95). BURCKharD, G. Zwei Beiträge zur Kenntnis der Formalinwirkung. Centralb. f. Bakt., XviII Bd., I895, pp. 257-264.

Twenty titles are cited at the end of this paper.

(95). VAN ERMENGEM, E. De la stérilization des eaux par l'ozone. Ann. de l'Inst. Pasteur, T. Ix, 1895, pp. 673-709. Rev. in Centrall. f. Bakt., Bd. Xix, I 806 , pp. 836-838, 2 figs.

Van Ermengem's report is favorable.

(95). Schepilewsky, Eugen. Formaldehyd als Desinfektionsmittel. (Dissert.) St. Petersburg, I805. (Russisch.) Rev, in Centralh. f. Bakt., Bd. xIx, I896, pp. 794-796. 
('05). Goriansky, G. J. Sur la désinfection des crachats phtisiques et des cultures tuberculeuses par les solutions alcalines de goudron et de vinaigre de bois. Arch. des sci. biol., pub. par l'Inst. imp. de méd. exp. à St. Pétersburg, Tome 3, I895, pp. 148-166.

Wood-vinegar is a very euergetic disinfectant. Iu quantity equal to the volume of spitinm, aud acting for hoitrs, it was found entirely efficient. Exposure of 4 honirs is not stficieut in some cases to destroy B. tub stroyed by exposure for I hour to this acid.

('95). D'Arsonval. Sur la production de l'ozone concentré et sur ses effets bactéricides. C. $\mathrm{R}$. des sé. et mém. de la soc. de ibiol., Paris, Io sé., T. II, I895, pp. 500-502.

The writer's experiments were negative, and he is very skeptical as to germicidal power of ozone.

('95). Fischer. See Xt.

('96). WALTER, K. Zur Bedeutung des Formalins, bezw. Formaldehyde als Desinfektionsmittel. Zeitsch.r. f. Hyg., Bd. Xxi, I896, pp. 42I-45I. Rev. in Centralb. f. Bakt., XX Bd., I896, p. 280.

('97). Iwanofe, W. A. Zur Frage über das Eindringen der Formalindämpfe in die organischen Gewebe Centralb. f. Bakt, XxII $\mathrm{Bd}$., ז897, pp. 50-58.

Formalin vapor did not penetrate rapidly into the depths of tle tissues tested (livers of rabbits and guinea pigs).

('97). WEYLAND, J. Desinfektionswirkung und Eiweissfällung chemischer Körper. Centralb. f. Bakt., xxI Bd., I897, pp. 798-802.

('97). Fugrbringer und FrEyhan. Neue Untersurchungen über die Desinfektion der Hände. Deutsche med. Wochenschr., 1897, No. 6. Rev. in Centralb. f. Bakt., Xxi Bd., r897, pp. 708-7 10.

Authors recommend alcohol. A 2 per cent solution of Anthors recommend alcohol. A 2 per cent solution of
mercuric chloride is still better. Both may be used, the latter preceded by the former.

('97). Podgorny, K. M. Effect of iodine on pathogenic bacteria. Thesis of St. Petersburg, No. 36,1897, pp. 74 .

('97). Schumburg. Ein neues Verfahren zur Herstellung keimfreien Trinkwassers. Dettsch med. Wochenschr., Bd. xxIII, I897, No. Io pp. I 45-I46.

Bromide treatment.

('98). Minervini, Rafaer. Ueber die baktericide Wirkung des Alkohols. Zeitschr. f. Hyg., Bd. XXIx, I898, pp. I I7-T48. Bibliography of 18 titles.

Ethyl alcohol has only a weak bactericidal action. It is most active iu conceutrations of 50 to 70 per cent. Alcoholic solutions of antiseptic substances are less active than water solutions.

('98). Schultz, N. De l'action des antiseptiques sur le bac. pestis hominis et de la désinfection id'effects et de locaux contaminés par la peste bubonique. Arch. des sci. biol. publiées par 1'inst. impér. de méd. expér. à St. Petersbourg, T. vi, 1898, pp. 397-426, i plate.

The appearance of the bacteria subjected to the anttseptics, as shown on the plate, strongly suggests the ap pearance of organtsms in old cultures, viz.: involition forms, and the two phenomeua may be due to the same canse, the involution forus arising from the larmful ac tion of products excreted by the bacteria, or arising from the action of substauces developed in the media as the resint of bacterial occupation.
('98). FluEgGE, C. Die Wohnungsdesinfektion durch Formaldehyd. Zeitschr. f. Hyg., Bd. XxIx, I 898, pp. 276-308.

('98). Firmi. See xxxvi.

('99). Popork, S. P. Vergleichende Studien über die desinfizierende Wirkung reiner Sublimatlösungen und Kombinationen derselben anit anderen Desinficientien. (Diss.) St. Petersburg, I898. Rev. in Centralb. f. Bakt., Xxv Bd., T899, pp. 33I-332.

The power of i per cent sol. mercuric chloride is increased very decidedly by addition of 1 per cent hydrocreased very decidedy by addition of 1 per cent hydrochloric acid, or 1 per cent phenol, and by the addition of 2 per cent phenol a still more effective mixture is obtained. Addition of 1 to 2 per cent $\mathrm{NaCl}$ weakened the ganisnis, but increased it on others.

('o8). Lucas-Championnièré. Sur la valeur antiseptique de l'eat oxygénée. Bull. de l'acad. de méd., I 898 , T. XL, série 3, Paris, pp. 599$6 \pm 7$.

('gg). Marmier ett Abraham. I a stérilisation industrielle des eaux potables par l'ozone. Rev. d'hyg. et de Police Sanitaire, Paris, 1899, T. XXI, pp. 540-554.

Great things are clained for this metlod. Only some specimens of Bacillus subtilis are said to have escaped destruction, aud of these only one individual for each $15 \mathrm{cc}$. of water treated with a concentration of ozone equal to $6 \mathrm{milligrams}$ per litre of air.

('99). Stadlek, EDUard. Ueber die Einwirkung von Kochsalz auf Bakterien, die bei den sogenannten Fleischvergiftungen eine Rolle spielen. Arch. f. Hyg., Bd. xxxv, r899, pp. 40-82. Rev. in Centralib. f. Bakt., xxvi Bd., I899, p. $4 \mathrm{IT}$.

B. coli, B. morbificans bovis, aud B. euteritidis grew iu bouillon with 7 per cent sodium chloride. During the first 2 to 3 days they were injured, hut after that they made a juxuriant growth. The toleration limit for B. coli aud B. enteritidis is between 7 and 8 per cent of $\mathrm{NaCl}$, aud that of B. morbificans bovis between 8 and 10 per cent. The more sensitive to salt, e. g. Ps. hyacinthi was restrained more seusitive
by I. 5 per cent.

('g9). Buiss, C. L., AND Novy, Fr. G. Aotion of formaldehyde on enzymes and on certain proteids. The Jour. Exp. Medicine, vol. IV, I899, pp. 47-80.

('99). WeyL, TH. Keimfreies Trinkwasser mittels Ozon. Centralb. f. Bakt., Xxvi Bd., I899, pp. I5-32, with I fig.

"Ozone is a specific bacterial poisou." It is recontmended for sterilizing drinking water.

('99). КосH, E., AND Fuchs, G. Ueber den antibaktericllen Wert des Acrolein. Centralb. f. Bakt., xxvi Bd., I899, pp. 560-563.

Acrolein is a substance related to formaldeliyd. In 0.25 to 0.5 per cent solutions it proved more effective than form aldehyd on a number of nou-sporiferous organisus.

('99). Calmetre, A. Rapport sur la stérilization industrielle des eaux potables par l'ozone. Ann. de l'Inst. Pasteur, 1899, 'T. Xiri, pp. 344-357.

A favorable report on sterilization of water by ozone by a committee, of which Calmette was secretary. They recommended the system of Marmier and Abraham fo the city of Lille.

('99). RouX ET CALMETTE. Sterilization of water by ozone. Rapport présénté à la municipalité de Lille, février, r 899 .

Not seen. 
('09). Marpanan. Dic baktericide Wirkung des Fluornatriums und der Nachweis desselben in Nahrungsmitteln. Centralb. f. Bakt., Bd. $\mathrm{XXv}, \mathrm{I} 899$, pp. 309-3I I.

Considers sodium fuoride a valuable disinfectant for all bacteria in nutrient medla. Sodinm fuoride is sald to be scarcely more harmful to man tlian common salt. growth of bacteria without lessening that of the yeast.

('oo). Orro. Sterilization of water by ozone. Bulle. tin de la Société des ingénieurs civils de France, février, 1900.

('Ol). Mayer, EUgen, UND Wolpert, Heinrich. Beiträgc zur Wolungsdesinfektion durch Formaldehyd: I. Die zweckmässigste Form des Verdampfungsapparats. I I. Einfluss der Temperatur auf die Desinfektionswirkung. III. Verstärkung der Desinfektionswirkung durch künstliche Luftmischung (Vorl. Mitt.). Hyg. Rdsch., Berlin, XI Jahrg., I90I, pp. $153-158$.

('o1). SMutu, ERwin F. Growth of bacteria in the presence of cliloroform and thymol. Sciencc, n. s., vol. XIII, p. 327, March 1, Igor. See also Jour. Boston Soc. Med. Sci., vol. v, p. 375, and Centralb. f. Bakt., Igor, I Abt., Bd. Xxix, pp. 445-446.

('or). Hess, Orro. Der Formaldehyd. Seine Darstellung, Eigenschaften, und seine Verwendung als Konservierungs-therapeutisches und Desinfektionsmittel mit besonderer Berijcksichtigung der Wohnungsdesinfection. Marburg, N. G. Elwert, 2 Aufl, Igor, pp. IV, I29.

('o2). Rouly. Zur Analyse der Borax- und Borsäurewirkung bei Fäulnissvorgängen, netost Studien über Alkali- und Säureptoduktion der Fäulnissbakterien. Arch. f. Hyg., Bd. XLI, 1902, pp. 348-405.

('02). Prescotr, SAMuer C. Antisepties and their use in the preservation of food. Technology Quarterly. Vol. xv, 1902, pp. 335-342.

('O2). Hill HibBert W. AND Rickards, Burt R Notes on formaldehyd. Proc. Am. Pub. Health Asso., 3oth Ann. Meeting, New Orleans, Dec., Igo2. Also a separate, pp. I2.

('02). SchUEDER. Eintgegnung auf die Schumburg' sche Arbeit: "Das Wasserreinigungsverfahren mit Brom" und die Arbeit von A. Pfuhl: "Zu den Schüder'schen Prüfungsversuchen des Bromverfahrens nach Schumburg." Zeitsch. f. Hyg., Bd. Xxxix, 1902, pp. 532-539.

('O2). Schumburg, Wilhelm. Zu der Schüder'schen Entgeguung bezüglich des Bromverfahrens zur Trinkwasser-Reinigung. Zeitsch. f. Hyg., Bd. XL, 1902, pp. 199-202.

('o2). GREEN, A. B. The disinfectant action of chloroform and various other substances on the specific and extrancous micro-organisms of vaccine. Rep. Med. Off. Loc. Gov., London, 1902, p. 639-663.

('02). ENAGES, EUGEN. Das Schumburg'sche Verfuhren der Trinkwasserreinigung mittels Brom. Centralb. f. Bakt., Abt. I, Bd. xxxs, Originale, 1902, pp. 65I-670.

('02). Konrídr, DÁNIEL. Ueber die baktericide Wirkung der Seifen. Arch. f. Hyg., Bd. XLIV, I902, Pp. 101-I12.

Recommends a resorcin soap.
('O2). MAYer, EUgen, UND Wolpert, Heinrich. Ueber die Verfahren und Ápparate, zur Entwicklung volr Formaldehyd für die Zwecke der Wohnungsdesinfektion. Arch. f. Hyg., Bd. XLIIS, I902, pp. I57-169.

('02). CoHn, ERNST. Ueber den antiseptischen Wert des Argentum colloïdale Credé und seine Wirkung bei Infektion. Diss. Königsberg i. Pr. (Druck v. M. Hiller), 1902, p. 57.

('o3). RickARDS, BURT RANSOM. A comparison of some of the more common liquid disinfectants. Jotrr. Mass. Asso, of Boards of Health, vol xim, No. 3, Oct., 1903, pp. 70-76.

('o3). Freer, PAUL C., AND Novy, Fredr. G. On the organic peroxides. Vaughan Quarter Century Book, pp. 63-127. Ann Arbor, 1903.

"Acetyl and benzoyl hydrogen peroxides are extremely germlcidal, and easily rank with the most active dislufectants. " * IIydrogen peroxide is considerably weaker than these organlc peroxides. The activity of the peracids and of liydrogen peroxide is not due to active oxygen, but is probably due to the acid ions."

('o3). RrDeal, Samuer. Disinfection and the preservation of food, together with an account of the chemical substances used as antiseptics and preservatives. 3d cd., London, Sanitary Pub. Co., Ltd.; New York, John Wiley \& Sons, 1903, pp. 494.

('o4). KonRÁDI, DANIÉ, Weitere Untersuchungen ueber die bakterizide Wirkung der Seifen. Centralb. f. Bakt., I Abt., Originale, xxxvi Bd., 1904, pp. I $51-160$.

St. Laceleau soap is actively bactericidal,

('05). Kraemer, Henry. The Oligodynamic Action of Copper Foil on Certain Intestinal Organisms. Proc. Am. Phil. Soc., vol. XLIX, pp. 5I-65. Phila., 1905. Also a separate.

XXX1X. Chemotropism, Thermotropism, Geotropism, Contact-Irritation, Etc.

(84). PFEFFER, W. Lokomotorische Richtungsbewegungen durch chemische Reize. Untersuchungen aus dem bot. Institut Tiibingen, I Bd., 1884, pp. 363-482.

The chapter on Spaltpilze begins on p. 449 .

('86). Duboss, R. Influence du magnétisme sur l'orientation des colonies microbiennes. C. $\mathrm{R}$ des sé. et mém. de la soc, de biol., Paris, I 886,8 sé., T. III, pp. 127-128.

('88). PFEFFER, W. Uebcr chemotaktisclie Bewegungen von Bakterien, Flagellaten und Volvocineen. Untersuch. a. d. bot. Inst. zu Tübingen, I888, Bd. II, Heft 3, pp. 582-66r.

('go)'. Ali-CoHen, CH. H. Die Chemotaxis als Hülfsmittel der bakteriologischen Forschung. Centralb. f. Bakt., vin Bd., 1890, pp. I6I-167.

('93). Boyce AND Evans. Upon the action of gravity on Baoterium Zopfii. Communication made to the Royal Society, Feb., 1893. Rev. in Centralb. f. Bakt., Bd. $x v$, I894, pp. 568-569.

('93). Roтu, A. Ueber das Verhalten beweglicher Mikroorganismen in strömenden Flüssigkeiten. Deutsch. med. Wochenschr., r893, No. 15, pp. 351-352.

In streaming fluids tlis anthor observed in motile bac teria a decided tendency to move against the current.

('94). Miyoshi, Manabu. Ueber Chemotropismus der Pilze. Botanisclie Zeitung, 1894, Hft. I, col. I-28, with I table.

Deals only with fungi. 
(94). BeYrerinck, M. W. Ueber Thermotaxis bei Bakterium Zopfii. Centralb. f. Bakt., Bd. XV, 1894, p. 799.

Refers to thernotaxis the movemenls of the threads of Bact. Zopfii, which Boyce and Evans supposed to be die to geotropism.

('ol). Jennings, H. S., And Crosby, J. H. Studies on reactions to stimuli in utuicellular organisms. vil. The manner in which bacteria react to stimuli, especially to chemical stimuli. A.m. Jour. of Physiol., vol. vi, Igor, pp. 31-37. Also a separate.

The movement of unicellular organisms toward or away from chemical substances is said to be due to a "motor reflex" comparable to that of the ciliate infusoria, and get to cherable to that or the ciliate in at

('or). Rothert, W. Beobachtungen und Betrachtungen über tactische Reizerscheinungen. Flora oder Allgemeine Botanische Zeitung, 88 Bd., 190I, Hft. 11 I, pp. 371-421.

('o2). Clark, Judson F. On the toxic properties of some copper compounds with special reference to Bordeaux mixture. Botanical Gazette. vol. Xxxili, 1902, pp. 26-48, 7 figs.

Coulroverts Miyoshi on cheanorop sm.

('O3). RoTHERT, W. Ueber die Wirkung des Aethers und Chloroforms auf die Reizbewegungen der Mikroorganismen. Jahrb. f. Wiss. Bot., Bd. $\mathrm{XXXIX}, 1903$, pp. 1-70

The variability in sensitiveness of the same organism at different times was most disturbing. "Material which to-day is strikingly chemotactic or phototactic may be to-morrow unusable. Especially striking and perplexing was the behavior of Spirillum undula, this classical object for clemotaxis and osnotaxis, with which Pfeffer made his celebrated investigations, and with which in former years I confirned the experiments of Pfeffer.

\section{Osmatic Pressures.}

('91). Wladimiroff, Alexander. Osmotische Versuche an lebenden Bakterien. Zeitschr. f. physikalische Chem., Bd. v1I, 1891, pp. 529543.

('9I ). Wradimiroff, Alexander. Biologische Studien at1 Bakterien. 1. Uber das Verhalten beweglicher Bakterien in Lösungen von Neutralsalzen. Zeitschr. f. Hyg., 1891, Bd. X, pp. 89-1 Io.

('91). Fischer, Alfired. Die Plasmolyse der Bakterien. Ber, über die Verhandlungen d. K sächs. Ges. d. Wissenschaften. Mathem.phys. Classe, Leipzig, I89I, Bd. XIIII, pp. 52-74, I plate.

Plasmolysis was either definitely established or rendered extremely presumptive (snaller forms) for $17 \mathrm{kinds}$ of bacteria. The concentralion which induced it varied in most cases from 0.5 to 5 per cent. In a few cases the least concentration which would ind uce plasmolysis was not determined. Generally strengths of 1 to 2 per cent sodium chloride were sufficient. "Die untere Grenze liegt fast fiir alle Bacterien bei I per cent oder 0.75 per cent NaCl."

(95). Fischar, AlfRED. Neue Beobachtungen über Plasmolyse der Bakterien in Untersuchungen über Bakterien. Jahrb. f. wissensch. Bot., Berlin, I895, Bd. xxvir, pp. $1-34$.

('or). d'Arsonval. See xxxir.

\section{Chemical Analysis of Bacteria.}

('79). Nencki, M., und Schaffer, F. Ueber die ohemische Zusammensetzung der Fäulnissbakterien. Jour. f. Praktische Chemie, tueue Folge, Bd. xx, I879, pp. 443-466, I fig., I plate, Also a separate.

('8I). SchaFFER, F. Zur kenntniss des Mykoproteins. Journal f. Prak. Chemie, neue Folge, Bd. XXIII, I88I, pp. 302-304.

('86). Brown, Adrian J. On an acetic ferment which forms cellulose. Journal Chem. Soc. Trans., London, vol. XLIX, pp. 432-439.

(87). Brown, Adrian J. Note on the cellulose formed by Bacterium xylinum. Journ. Chem. Soc., London, Trans., vol. r, I, 1887 , p. 643.

('87). Vincenzi, Livio. Ueber die chemischen Bestandteile der Spaltpilze. Zeitschr. f. physiolog. Chemie, I887, Bd. x1, pp. 181-183.

('88). HAMMERSCHLAG. Ueber bacteriologischchemische Untersuchung der Tuberkelbacillen. Verhandlungen der Schweizerischen Naturf. Gesselsch, in Solathurn, August, 1888, 71 Jahresversammlutig, pp. 85-86.

('93). Cramer, E. Die Zusammensetzung der Bakterien in ihrer Abhängigkeit von dem Nährmaterial. Arch. f. Hyg., Bd. xvı, Heft 2, 1893, pp. $15 \mathrm{I}-195$.

('93). Nishimura, Toxosaku. Untersuchung ïber die chemische Zusammensetzung eines Wasserbacillus. Arch. f. Hyg., Bd. xvilI, 1893, pp. 318-333.

('93). DREYFUSS, IsidoR. Ueber das Vorkommen von Cellulose in Bacillen, Schimmel- und anderen Pilzen. Zeitschr. f. physiol. chem., Bd. XVIII, 1893, pp. 358-379. The conclision is that cellulose occurs in hay bacilli
and in pus bacilli.

('95). Cramer, E. Die Zusammensetzung der Cholerabacillen. Arch. f. Hyg., Bd. xxis, I895, pp. 167-190.

('98). de Schweinitz, E. A., and Dorset, Marion. The mineral constituents of the tubercle bacilli. Centralb. f. Bakt., Bd. Xxits, 1898 , pp. 993-995.

('O2). KRESLiNG, K. I. De la substance grasse des bacilles de la tuberculose. Arch. des sci. biol., publiées par l'inst. imp. de méd. expér. à St. Pétersbourg, T. 1X, 1902, pp. 359-376.

\section{Distribution of Bacteria-Geographical and Altitudinal.}

(Deserts, mountains, arctic regions, sea air, depths of the sea, deep wells, surface soils, air at the earth's surface, and at higher levels.)

('8I), Mrouer , P. Sur le dosage des bactéries dans les poussières et dans le sol. Bull. Soc. Bot. de France, i881, T. xxvin, sér. 3, pp. 44-5i.

('82). Tyndall, John. Essays on the floating-matter of the air in relation to putrefaction and infection. New York, D. Appleton \& Co., I882, pp. Xix, 338.

('83). Mıquel, P. Les organismes vivants de l'atmosphère, pp. virl, 3 ro. Paris, 1883. Gauthier-Villars. 
(83). Miquet, P. Nouvelles recherches sur les bactéries atmospliériques effectuées à l'observatoire de Montsouris. Ann. de l'observatoire de Montsouris pour l'an I883, pp. 39I-437.

('83). Mrque, P. De la pureté en microbes de l'air des montagnes et de quelques districts de la Suisse. La semaine médicale, 1883, pp. 274276.

("83). Giacosa, Piero. Studii sui corpuscoli organizzati dell'aria sulle alte montagne. Atti $R$. Accad. d. sci. di Torino, vol. xviII, pp. 263272, I883, I plate.

('84). DE FreudenREich, ED. Des microbes de l'air des montagnes. La semaine médicale, 11 septembre, I884, pp. 36I-362.

Relates to scarcity of bacteria in the alr at high altitudes. In the summer, iu the Bernese Alps, in four places tides. In the sur at altes of air vere aspirated witliout fulders, a total of 2700 The following The followitug sumer 2,900 meters high aud on 2,366 meters high, vegetatiou reaching nearly to the top. On the glacier 2,000 litres of air were aspirated in six por tions. Two of the sowings remained sterile. One gave a micrococcus, another B. subtilis, one after niote than 15 days gave a torula. and one a mold. "Il nous resterait bactéries pour 2,000 litres, soit un par nietre cube." In Bern the anthor says he obtains huludreds and thousand of bacteria per cubtc meter using the same delicate ilethods.

The experiments on the mountain yielded 8 bacterio

(84). DE FREUDENREICH, EDOUARD. Recherches sur les organismes vivants de l'air des hautes altitudes. Archiv. des sci. physiques et naturelles, ze Période, T. douziome, Genève, I884, pp. $365-387$.

Anthor shows that the purity of the air ou mountains is in uch greater than former writers have supposed.

('84). Miquel, P. Des organismes microscopique de l'air de la mer. La semaine médicale, I 884. pp. 90-92.

('84). Hesse, W. Ueber quantitative Bestimnung der in der Luft Enthaltenen Mikroorganismen. Mitth. a. d. K. Gesundheitsamte, Berlin, vol. II, I884, pp. I82-207.

('85). Mıquer, P. Septième mémoire sur les organismes microscopiques de l'air et des eaux. Annuaire de l'observatoire de Montsouris pour l'an I885, pp. 467-6II.

The part relating to nuicroorganisms in the sea-ai begins on p. 514. This subject is also treated in tlie report of the observatory for 1886 , pp. 535-550.

(86). BEuMER.. Zur Bakteriologie des Bodens. Deutsche med. Wochenschr., Bd. XII, I886, pp. 464-466.

('86). Fischer, B. Bakteriologische Untersuchungen auf einer Reise nach Westindien. Zeitschr. f. Hyg., Bd. I, I 886, pp, 42I-464.

This paper discusses the microorganisms and spores foind tin sea-air.

('86). ADAMETz, L,EPOLD. Untersuchungen über die niederen Pilze der Ackerkrume. Inaugural Dissertation, 78 pp., 2 Taf., Leipzig, 1886. Rev. in Centralb. f. Bakt., I887, Bd. I, pp. 8-IO.

('87). Petri, R. J. Zusammenfassender Bericht üher Nachweis und Bestimmung der pflanzlichen Microorganismen in der Luft. Centralb. f. Bakt., Bd. II, I887, pp. II $3-I_{1} 8$ und I5I-I58.
('87). Maggiora, A. Ricerche quantitative sui microorganismi del suolo con speciale riguardo, all'inquinazione del medesimo, Giornale della R. Accademia de medicina di Torino, I887, vol. Xxxv, Series 3, pp. I53-172.

(87). FraENKEL, CARL. Untersuchungen über das Vorkommen von Mikroorganismen in verschiedenen Bodenschichten. Zeitschr f Hyg., I887, Bd. I I, pp. 521-582.

('89). Reim ERs, JoHN. Ueber den Gehalt des Bodens an Bacterien. Zeitschr. f. Hyg., I889, Bd. VII, pp. 307-346.

('89). Rermers, John. Ueber den Gehalt des Bodens an Bacterien. Inaug. Dissert. Jena, I 880 , 8vo., 44 pp., Leipzig, Veit u. Comp. Reviewed in Centralb. f. Bakt., 1 Abt., Bd. $x$, I89I, p. 489.

"Die Zone dieser plötalicheu Keinıverminderıng liegt im Jenenser Boden-wie im Berliner-zwisclien I und 2 metres.'

('go). Kramer. See ili.

('gi). Manfredi. See xlini.

('93). Cristiant, H. Analyse bactériologique de l'air des hauteurs puisé pendant un voyage en ballon. Ann. de l'Inst. Pasteur, T. vir, pp. $665-67 \mathrm{I}$.

At elevations above the soil of 1,0co meters and upward the cultures remained sterile although in each cose litres of air was allowed to bubble through the culture media. Eveu at much lower levels the maje culture colonies are believed to have come frou the eartl ind rectly, 1. e., by way of the balloon.

('93). Duclaux, E. La distribution de la matière organique et des microbes dans le sol. Revue critique. Ann. de l'Inst. Paseur, T. VII, 1893, pp. 823-833.

('97). Moritz, Otro, und Neumann, R. O. Ueber einige hakteriologische Wasseruntersuchungen im Atlantischen Ozean. Centralb, f. Bakt. 2 Abt., Bd. XIII, Igo4, pp. 48I-489.

('99). LEvin. L,es microbes dans les régions arctiques. Ann. de l'Inst. Pasteur, T. XIII, I 899 , pp. $55^{8-567}$.

The arctic air was tested in twenty places, approxim. ately the same anlount being filtered at each place total of 21,600 litres of this fittered ait yielded three bacterial colonies and a few mold spores. The surface waters of the arctic also contain few bacteria. Ninety samples of water were taken from the sea at greatdepths ( $1, \infty 00$ to 3,000 metres). These samples also contained bacteria of several kinds but in Small uumbers. The teniperature at this depth is below zero centigrade. "Tont nn uionde de bactérfes existe à uue température qui descend jusqu'à $2^{\circ}$ an dessous de xéro."

('or). Gazert, Hans. Bakteriologische Aufgaben der deutschen Südpolar-Expedition. Petermanns geogr. Mitteil., Bd. XLvil, 1901, pp. I $53^{-1} 55$.

('OI). BELLI, C. M. Chemische, mikroskopische und hakteriologische Untersuchungen iber den Hagel. Hyg. Rdsch., Berlin, Bd, xi, IgoI, pp. I,I I I-I, 187 .

('02). Binor, JEAN. Etude bactériologique du massif du mont Blanc. Nature, Paris, (Ier semest.), Ig02, pp. 359-362, av. fig. C. $R$. des sé. de l'Acad. des sci., T. cxxxIV, I902, pp. 673-676. 
XL111. Soil-Organisms; Putrefactive Organisms.

('82). Tyndal, See Xi,il.

('86). Adametr. See Xlit.

('86). Bęumer. See Xrit.

('87). FRAENKEL. See Xlit.

('89). ReIMERS. See XLI1.

('9I). BerTHELot, M., LT ANDRÉ, G. Sur l'odeur propre de la terre. C. R. de sé. l'Acad. des sci., Paris, 1891, T. cxir, 598.

('9i). Manfredi, Luigi. Sulla contaminazione della superficie stradale nelle grandi città dal punto di vista dell'igienc e dell'ingegneria sanitaria. Recerche e studi fatti con specialc riguardo alla città di Napoli. Atti della R. Accad. delle sci. fis. e mat. di Napoli. 2a serie, vol. IV, I89I, appendice, No. 4, pp. I-79.

('93). Ducl,aux. See XliI.

('96). Duclaux. See xxvili.

('99). Levin. See xili.

('or). SMITh, R. GREIG. Bacteria and the disintegration of cement. Proc. Linn. Soc. of New Soutl Wales, vol. Xxvi, for the year IgoI, Part I, Sydney, I902, pp, 107-117. Also a separate (issued Aug. 13, I90I).

Disintegration not due to the bacteria.

('o2). Katayama, T. On the general occurrence of Bacillus methylicus in the soil. Bull. of the College of Agr., Tokyo Imperial Univ., vol. v, No. 2, 1902, pp. 255-258. Also a separate.

(O2). CHESTER, FREDERICK D. The bacteriological analysis of soils. Proc. 23d Ann. meeting of Soc. for Prom. Agric. Sci., 1902, pp. I73182. Also a separate.

('c2). ChESTER, FREDERICK D. Bacteria of the soil in their relation to agriculture. Bulletin No. 98, Dept. of Agric. of Pennsylvania, 1902, pp. 88, with plates. A bibliography of 105 titles.

('02). REMY, TH. Bodenbakteriologische Studien. Centralb. Bakt., Abt. 2, Bd. vilı, 1902, pp. 657-662, pp. 699-705, pp. 728-735, pp. 761-769.

('O4). Chester, Frederick D. Observations on an Injportant Group of Soil Bacteria. Organisms related to Bacillus subtilis. Fifteenth Annual Report of the Delawiare Dollege Agrl. Exp. Sta., for I903, Newark, Del., U. S. A. With 5 plates. Also a separate, pp. I-54. Copy of soparate received from author Octaber 15, 1904.

\section{Vinegar-Bacteria.}

('6r). Pasteur. Acetic fermentation due to bacteria. Ann. scient. de l'École normale supérieure, I86I. Not seen.

('68). Pasteir, Louis. Etudes sur le vinaigre, sa fabrication, ses maladies, moyens de les prévenir; nouvelles observations sur la conservation des vins par la chaleur. Paris, I868. Gauthicr-Villars, Imprimeur-Libraire. Victor Masson et Fils, Libraires, pp. viII, I Io.

('86). Brown. Sec XLI
('86). Brown, A. J. The cliemical actions of pure cultivations of Bacterium aceti. Jour. Chem. Soc. Trans., I886, vol. XI,IX, London, pp. 172-187.

('87). Brown, A. J. Further notes on the chemical action of Bacterium aceti. Jour. Chem. Soc., London, 1887, vol. I, T, Transactions, pp. 638642.

('93). HANSEN, EMIL Chr. Botanische Untersuchungen über Essigsäurebakterien. Ber. d. deutsch. bot. Gesellsch., Bd. XI, I803, pD. (69)-(73). Genoral Versammlungs-Heft.

(93). LAFAR, F. Physiologisclie studien über Essiggärung und Schnell-Essigfabrikation. Centralb. f. Bakt., I893, Bd. XIII, pp. 684-697. Bibliography of I 3 titles.

('-). HANSEN, E. C. Recherches sur les bactéries acétifiantes. Compt. rend. d. trav. du Lab. Carlsberg, T. I I, Liv. 3, pp. 182-2i6.

('94). Hansen, Emil, Ch. Recherches sur les bactéries acétifiantes. Ann. de micrographic, T. vI, I894. No. 8, pp. 385-395; No. 9, pp. 44I-470. Also a separatc, pp. 4I. I4 text figs.

('95). Lafar. Pliysiologische studien üher Essiggärung und Schnellessigfabrikation. Centralb. f. Bakt., 2 Abt., Bd. I, 1895, pp. I 29I50.

('97). LAFAR. See III.

('98). Beyerinck, M. W. Ueber die Arten der Essigbakterien. Centralb. f. Bakt., 2 Abt., Bd. IV, I898, pp. 209-2 I6.

('oo). HANSEN, EMIL, CH. Recherches sur les bactéries acétifiantes. (Troisième mémoire.) C. R. des travaux du laboratoire de Carlsberg, T. v, Ire Livraison, 1900, pp. 30-46, I fig. Also a separate. Copenhagen, I900.

XLV. Silage-Bacteria, Fermentation of Tobacco, of Indigo, Retting of Flax, of Sisal Hemp, Etc., Softening of Pickles, Sauerkraut, Etc.

(See also XX and XLIV.)

('87). Alvarez, E. Sur un nouveau microbe, déterminant la fermentation indigotique et la production de l'indigo bleu. $C$. $R$. des sé. de l'Acad. des sci., Paris, I887, T. cv, pp. 286289.

('89). Burril, , T. J. The biology of ensilage. Bull. Ag. Exp. St. Univ. of Ill., I889, No. vir, pp. 177-194.

('9r). Ar,BERT, FRIEDRICH. Untersuchungen über Grünpressfutter. Jahrb. d. deutscl. I, andwirtsch.-Gesellsch., Bd. VI, Tl. I, pp. I49250, Berlin, ז89r.

This author says bacteria exert a preponderant inflit. euce on the conrse of the fermentation.

('gi). Suchsland, Emil. Ueber Tabaksfermentation. Ber. d. deutsch. bot. Gesselsch., Bd. IX, Berlin, I89I, pp. 79-8I.

('94). VAN LOOKEREN-CAMPAGNE, C. J. Bericht über Indigo-Untersuchungen, ausgeführt an der Versuchs-Station zu Klatten auf Java. D. landw. Vers.-Stat., I894, Bd. XLIII, pp. 40I426. 
('95). Winogradsky, Sergus. Sur le rouissage du lin et son agent microbien. C. R. des sé, de l'Acarl. des sci., Paris, 1895, T. cxxI, pp. $742-745$.

A resume of the principal results of work done by Fribes in Wiuogradsky's taboratory.

1. Stems sterilized under water by a short heating at $100^{\circ}$, repeated three days in siccession, or by one lieating at $115^{\circ}$ for fifteen minutes, did not become retted.

2. Sterilized flax immersed in water and inoculated with auy one of the lo aerobic and anaerobic organisms, first isolated from the macerations by means of gelatin plates, did not muergo, even after several mouths, a commencement of retting, nor was any liberation of gas noticed. On the contrary-

3. If into tubes of water containing sterilized flax a sniall bit of straw of unsterilized flax was thrown a very active fermentation commenced at the end of 12 to 15 hours, and at the end of two or three days the retting was completed.

The specific organism was obtained for study from successive cultures upot steam-sterilized flax protected from the air by inmersion in deep tubes full of water, whose surface was covered by a layer of oll. After a long enongh series of re-sowing under these same conditions. the microscopic study of these cultures has remored all doubt abont the agent of this fermentation. It is found almost pure in the interior of the stem, and Fribes has succeeded in isolating it in a completely pure state by cultivating it, in the absence of air, upon slices of cooked potato rubbed with clialk. It is a bacillus relatively arge, forming spores in the terminal swellings (tadpole formi). In the young state its rods are from 1o to $15 \mu$ long swith a thickness of $0.8 \mu$ often one finds articulated filaments much longer: they become later a little thicker $(1 \mu)$, and form then ovoid swellings $3 \mu$ tong by $2 \mu$ thick : the ovoid spore which is formed there is $1.8 \mu$ by $1.2 \mu$. Sterilized flax was retted in pure cultures of this bacillns. and, after nudergoing the snccessive operations of grinding (dressing) peeling and combing, yielded a fine silky flax of light color but a little too much retted and without consistence.

In a general study of the bacteria of retting, Fribes dis. covered the following facts:

1. The bacilns ferments glucose, cane-sugar, milksugar, and starch, but only when the liquid contains peptone. With amanonia as the only source of nitrogen, the bacillus is absolutely void of actlon on these eminently fermentable substances.

2. Pectic matters, pectine, or pectic acid, extracted from fax, pears, carrots, white turnips, pure as they can be prepared, are decomposed, in presence of an an. mouiun salt as the sole nitrogenous food, with an extraordinary facility.

3. Cellulose, inder the form of Swedish filter paper, or as an amorphous precipitate, can absolutely not be attacked by this bacillus. Gun arabic is not fermented. 4. Vegetable substance, from Bax, white turnips, ex4. Vegetable substance, from fax, white turnips, ex alkaline, and submitted to fernentation by this bacillus. alkalime, and submitted to fermentation by this bacillus mated as pectic matter; also the loss of weight of the nated as pectic matter ; also the loss of weight of the iu pectic matter of the unfermented substance.

As a result of these studies Winogradsky concludes that the retting of flax may be considered as a pectic fermentation in the micro-biological sense of the word of which the bacillus described is the specific agent.

('96). Tolon Es, Giul.Jo. Ueber die Fermentation der Oliven und die Oxydation des Olivenöles. Atti R. Acad. dei Lincei Roma, se. v, Rendiconti, Classe sci. fis., matem. e nat., vol. v, Feb. 16 , 1806 , pp. 122-120.

Due to an enzyme. Not bacterial.

('06). VAN LOOKEREN-CAMPAGNE, C. J., U. VAN DER VEEN, P. J. Ueber Indigobildung aus Pflanzen der Gattung "Indigofera." D. landw. Vers.-Stat., 1896, Bd. XL,vi, pp, 249258.

('97). Conrad, Eugen. Bakteriologische und chemische studien über Sauerkrautgährung. Arch. f. Hyg, Bd. Xxix, I\&97, pp. 56-95. See also Zeitschr. f. Spiritusindustrie, $\mathrm{xx}$ Jahrg., 1897, No. 23, p. 188; No. 24, pp. 200-201.
The fermentation of the "Welsskraut" is attributed to Bacterium brassica acida, J,ehm. \& Conrad, uearly telated to Bacillus coli. This organism is motite, growa aerobically and anaerobically, produces acids, carbon dixoide, hydrogen and marsh gas. Gelatin is not lignefied The surface colonies are gray white to gray yellow on gelatin and agar, and are bright yellow ou potato. It ferments maltose, lactose and dextrose. Most of the acid is lactic acid.

('98). Breaudat, L. Sur le mode de formation de l'indigo dans les procédés d'extraction industriels. Fonctions disastasiques des plantes indigofères. C. R. des sé. de l'Acad. des sci., Paris, J898, 'T. cxxv11, pp. 769-771.

('98). MoI,1sch. Ueber die sogenannte Indigogährung und neue Indigopflanzen. Sitzungsber. d. k. Akad. der Wiss. in Wien, July, I898. Title only.

('g8). Prescott and Underwood. See xx.

('99). BrÉaudat. Nouvelles recherches sur les fonctions diastasiques des plantes indigofères. C. $\mathrm{R}$. des sé. de l'Acad. des sci., Paris, T. CXXvi1, I899, pp. I,478-1,480.

('og). VerRnouT, J. H. Onderzoek over bacteriën bij de fermentatie der tabak. Mededeelingen tuit s'Lands Plantentuin, xxxiv, Batavia, G. Kolff \& Co., 1899, p. 49,2 plates.

The fermentation of tobacco is ascribed to Bacitlus tabaci-fermentationis Vernhout.

('99). LoEw, Oscar. Curing and fermentation of cigar leaf tobacco. U. S. Dept. of Agric., Report No. 59, Div. Veg. Phys. \& Path., $34 \mathrm{pp}$.

('oo). Laew, Oscar. Sind Bakterien die Ursache der Tabakfermentation? Centralb. f. Bakt., 2 Abt., Bd. vi, 1900, Pp. I08-II2.

The fermentation is strictly enzymic, and bacteria are not concerned in it

('o). Loew, Oscar. Physiological Studies of Connecticut leaf tobacco. U. S. Dept. of Agric., Div. of Veg. Phys. \& Path., Igoo. Report 65. $57 \mathrm{pp}$.

('OO). BEIJERINCK. Verdere onderzoekingen over de indigovorming tuit weedl (Isatis tinctoria) Proc K Akad. Wetensch. Amsterdam, Deel IX, June 30, 1900, pp. 74-90. Abstr. in Bot. Zeitung, 2 Áht., vol. 58, 1900, col. 188-189.

The production of indigo blue is due to the action of the enzyme isatase upon tsatan. Isatan occurs in the protoplasm ; isatase occurs in the chromatophores. In the living cell the a uthor thinks reactions are prevented by the acidity of the cell-sap. He says :" The action of isatase upon isatan is possible only in "nentral or amplioteric and yery weakly acid solutious." A te
$48^{\circ}$ to $50^{\circ} \mathrm{C}$ is the optimum for this action."

('o1). Loew, Oscar. Catalase, a new enzym of general occurrence, with special reference to the tobacco plant. U. S. Dept. of Agric. Rep. 69, Div. Veg. Phys. \& Path., 1901, 47 pp.

('O1). Russel,L, H. L., AND Babcock, S. M. Concerning the theories of silage formation. Science, n. s., vol. XI1I, p. 328 , I901.

The conclusion reached is that bacteria do not play any very considerable role in the fermentation of silage.

('O1). Preyer, Axel. Ueber Kakaofermentation. Tropenpflanzer, Berlin, Bd. v, 1901, pp. 157173.

('o1). Schulte im Hore, A. Zur Kakao-Fermentation. Tropenpflanzer, Berlin, Igor, Bd. v, pp. 225-227. 
('02). Babcock, S. M., Und RusshLL, H. L. Die bei der Herstellung von Gärfutter (Silage) wirkenden Ursachen. Centralb. f. Bakt., Abt. 2, Bd. Ix, 1902, pp. $8 \mathrm{I}-88$.

('02). Hauman, L. Etude microbiologique et chimique du rouissage aérobie du lin. Ann. de l'Inst. Pasteur, T. xvi, 1902, pp. 379-385.

(02). Ba1L, Oskar. Untersuchung einiger bei fler Verwesung pflanzlicher Stoffe thätiger Sprosspilze. Centralb. f. Bakt., Abt. 2, Bd. vili, 1902, pp. 567-584.

('o3). Wehmer, C. Die Sauerkrautgärung. Centralb. f. Bakt., 2 Abt., Ig03, x Bd., pp. 625-629.

('04). Storrmer, K. Ueber die Wasserröste des Flachses. Centralblatt f. Bakt., 2 Abt., Bd. xil1, No. I-3, Sept., rgo4, pp. 35-45. Continued.

('o4). Beijerinck, M. W., and van Delden, A. "On the bacteria which are active in flax-retting." Koninklijke Akademje van Wetenschappen te Amsterdam. Proceedings of the Meeting of Jan. 30, Igo4. Pub. Feb. 25, 1904, pp. 462-48I, $\mathrm{I}$ plate. Also a separate.

('04). OmEliansk1, W. Die histologischen und chemischen Veränderungen der Leinstengel unter Einwirkurg der Mikroben der Pektinund Cellulosegärung. Centralb. f. Bakt., 2 Abt., XII Bd., Ico4, pp. 33-43, I plate.

('o4). WEнMER, C. Die Sauerkrautgaerung. Bericht des $V$. Internationalen Kongresses $f$. angewandte Chemie z:1 Berlin, 1903. Sekt VI, Bd. III, Berlin, 1904, p. 712. Also a scparate, $5 \mathrm{pp}$.

Obtains resulta decidedly different from Conrad. The ordinary sauerkraut fermentation is a mixed fermentation. Gas-deveiopment is due to a bottom yeast : acic production to a nou-liquefying, non-motile, non-gas

XLVI. Bacteria in Water and Ice; Dung-Bacteria. (See also XXXIII and XXXIV.)

(76). Warming. See xir.

('S6). FraENKEL, CarL. Ueber den Bakteriengehalt des Eises. Zeitschr. f. Hyg., Bd. I, I886, pp. 302-314.

('87). MACÉ. Sur quelques bactéries des eanx de boisson. Ann. d'hyg. publ. ot de méd. lég. avril, 1887. 3d series, T. Xvir, pp. 354-357.

(87). Prudden, T. Mitcheli. On Bacteria in and their relation to disease, with special reference to the ice supply of New York City. Med. Record, March 26 and April 8, I887, Nos. I3 and I4; also a separate, 6r pp. Reviewed in Centralh. f. Bakt., Bd. I, I887, pp. 650-652, and Ann. de J'Inst. Pasteur, T. T, I887, pp. 409-410.

Dr. Prudden tested the resistance of various bacteria to prolonged cold, In blocks of ice aud to repeated freezings and thawiugs. Proteus vulgaris and Bacillus prodigiosus did not grow after 51 days freezing. A slender liquefying bacillus from Croton water was killed in seven days. The following withstood freezing: Staplyylococcus pyogenes. (66 days): a fuorescent bacillus from ice (77 days); bacillus of typhoid fever (123 days) c11ltures made at intervals slowed less and less living, but all were not destroyed. Repeated freezings and thawings were more fatal to the typhoid hacillus than a coustant low tem perature. Five freezings and thawings at intervals of

(87). Bordoni-Ufrrfinuzzi, Guido. Die biologiselie Untersuchung des Eises in seiner Beziehtmg zur öffentlichen Gesundheitspflege. Centralb. f. Bakt., 1887, Bd. I1, pp. 489-497.
('88). Scrm mick, L. Eine Gletscherbakterie. Centralb. f. Bakt., 1888, Bd. IV, pp. 545-547.

A greeu fluoresceut organism was the com movest form. This was a short rod which liquefied gelatin.

(91). Viron, L. Du rôle des Schizophytes dans les réactions qui se passent clans les eaux distillées. Jour. de Pharm. et de Chim., I89r, T. xxun, series 5 , pp. 586-593.

('9r). Nordtmever. See XVir.

('94). LASER, See Xx.

('94). Houston. See xviI.

('94). Frankland, P., and Mrs. P. Micro-organisms in water. London, $1884, \mathrm{pp} . \mathrm{x} \tau, \mathbf{5 3 2}$.

(95). Sedgivick Und PREscont. On the influence of variations in the composition of nutrient gelatin upon the development of water bacteria. Am. Pub. Health Asso., vol. xx, 1895 pp. $450-458$. Rev. in Centralb. f. Bakt., xix Bd., 1896, p. 222.

('95). Rabinowitsch. See xxxiv.

('95). Smith, Theodald. Notes on bacillus coli communis and related forms; together with some suggestions concerning the bacteriological examination of drinking water. The Amer. Journal of the Med. Sci., Sept., 1895. Also a separate, pp. 20.

(95). Smith, Theobald. Ueber den Nachweis des Bacillus coli communis im Wasser. Centralb. f. Bakt., xvi1 Bd., 1895, pp. 494-495.

(95). Sevirin, S. A. Die im Miste vorkammenden Bakterien und deren physiologische Rolle bei der Zersetzung derselben. Centralb. f. Bakt., 2 Abt., Bd. I, I895, pp. 97-II4 and 799-817.

(97). HESSE, FRIEDR. Ueber die Verwendung von Nähragar-Agar zu Wasseruntersuchıngen. Centralb. f. Bakt., xxi Bd., 1897, pp. 932-937

Finds agar-media better than gelatin on account of number of liquefying organisms constantly present in
water.

(97). Kern, Heinrich. Beitrag zur Kenntniss der im Darme und Magen der Vögel vorkommenden Racterien. Arla. a. d. bact. Inst d. tech. Hochschule zu Karlsruhe, Bd. I, Heft IV, 1897 , pp. $379-532$.

Many bacteria are described at length.

(99). Ward, H. Marshal.r. Some Thames Bacteria. Annals of Botany, vol. XiI, I8g8, pp. 287-322. Two double plates in color.

This paper treats of ( 1 ) A short colorless bacterium

forming stearine-like colonies: type of Bacterinun ureae

(Jaksch): (2) A colorless capsuled coccus or bacterium

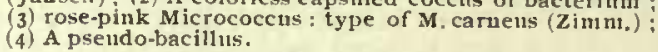

('99). Kasansky. See Xxxil.

('Sg). Fulter, George W., and Johnson, Grorge A. On the differentiation and classification of water bacteria. Jour. Exp. Med, vol. iv, 1899, pp. 609-626; also a separate.

('o). Kohrbrugge, J. H. F. Vibrion-Studien. I. Die Ubiquität choleraähnlicher Wasservibrionen. Centralb. f. Bakt., xxviII Bc., I900, pp. 721-726. II. Panmorphisnus und erbliche Variationen. Ibid, pp. 833-842.

('oo). Sedgwick and Winstow. See xxxili.

('or). PARK .See xxxilt.

('or). Horrocks, W. H. An introduction to the bacteriological examination of water. London, J. \& A. Cliurchill, 190r, pp. x, 300, 5 plates. 
('OI). Gage, Stephen DE M. Bacteriological Studies at the Iawrence Experiment Station, with special reference to the determination of $B$. coli. 33d An. Rep. St. Bd. of Health of Mass., for 1901, pp. 397-420. Also a separate, pp. 26.

(or). Migul, W. Compendium der bakteriologischen Wasseruntersuchung nebst vollstaendiger Uebersiclit der Trinkwasserbakterien. O. Nemnich, Wiesbaden, I90I, pp. viI, 440, with 2 plates.

Not seen.

('o2). Macfadyen. Sec Xxxili.

('o3). JoRDAN, EDWIN OAKEs. The kinds of Bacteria found in river water. Journal of Hygiene, vol. III, No. I, Igo3. Also a scparate, pp. I-27.

('O3). IMMENDORF, H. Ueber Stallmist-Bewahrung (Konservicrung) mit Cluemischen Mitteln. Berlin, Mitt. d. Landw. Ges., Bd. xvin, 1903. pp. 99-IOI.

('o3). Schueper. Sce xvil.

('o3). Winslow and Nimickera. See xvil.

('o4). Gage and Adams. See xvi.

('o4). STokes. See xvili.

\section{Milk-Bacteria; Butter-Bacteria ; Cheese-} Bacteria; Meat-Bacteria.

(8i). JalaAn de la Croix. See xxíniti.

('82). SChM IDT-MUenLheim. Untersuchungen über fadenziehende Milch. Pflüger's Archiv., I882, Bd. xxvil, pp. 490-510, I fig.

('84). HUEPrE, FERDINAND. Untersuchungen ïber die Zersetzungen der Milch durch Microorganismen. Mitth. a. d. K. Gesmundheitsante, Bd. II, Berlin, 1884, pp. 309-37I.

(89). MEnGE, Kari, Ueber rothe Milch. Centralb. f. Bakt., vi Bd., I889, pp. 596-602.

('89). Baginsky, ADOl, Rote Milch. Deutsche Medizinal-Zeitung, 1889, No. 9, pp. 106-107.

('89). Baginsky, Adol.F. Zuin Grotenfelt'schen Bacillus der roten Milch. Dentsche mediz. Wochenschrift, I889, Bd. xv, p. 212.

This orgauism was isolated from feces. It liquefied gelatin slowly and colored milk a dirty red or red-brown.

(9I). Cons, H. W. Ueber einen bittere Milch erzeugenden Micrococcus. Centralb. f. Bakt., IX Bd., 189i, pp. 653-655.

('91). Adamerz, L. Untersuclutingen über Bacillus lactis viscosus, einen weitverbreiteten milchwirthschaftliohen Schädling. Berliner landwirthschaftliche Jahrbücher, I89r, Bd. xx, pp. 185-207, I plate. Rev. in Centralb. f. Bakt., Ix Bd., I891, pp. 698-700.

(92). Nencki, L., et Zawadzki, J. Sur la sterilisation du lait. Arch. des Sci. Biol. publiées par L'institut Impérial de Med. Exp. à St. Pétersbourg, T. I, 1892, pp. 371-397.

Contains a bibliography of 50 uumbers.

(93). Duci,aux, E. Sur le rôle protectcur des microbes dans la crẻme et les fromages. Anlı. de l'Inst. Pasteur, T. vil, 1893, pp. 305-324.

(93). Bleisch, Max. Ueber bittere Mileh tind die Sterilisierung der Milch durch Erhitzen unter Luftabschluss. Zeitschr. f. Hyg., I893, Bd. xin, pp. 81-99.
(94). Bordoni-UfFreduzzi, Guido. Ein Fall von fuchsinähnlicher Bakterienfärbung des Fleisches. Hygien. Rundschat., 1894, Bd. Iv, pp. 12-14.

('94), v. KLECKI, VAlERIAN. Ueber einige aus ranziger Butter kultivierte Mikroorganismen. Centralb. f. Bakt., Bd. xv, I 894, pp. 354-362.

('94). Leichmann, G. Ueber eine schleimige Gärung der Milch. Landw. Ver.-Stat., Bd. XiıII, 1894, pp. 375-398. Rev. in Centralb. f. Bakt., Bd. XVI, I894, pp. 122-123.

('94). RusSELL, H. L. Outlines of dairy Bacteriology, pp. vi, i 86, I894. Pub. by author. Madison, Wisconsin.

('94). PAMMEL, L. H. An aromatic bacillus of cheese (Bacillus aromaticus 11. sp.). Extracts from the Iowa Agricultural Exp. Station, Bull. No. 2I, I 894 , pp. I-5. Rev. in Centralb. f. Bakt., Bd. xvi, I894, p. 128.

('G4). Weigmann, H., und Zirn, Gg. Ueber "seifige" Milch. Centralb. f. Bakt., Bd. xv, I894, pp. 463-470, mit 2 Abbildungen.

('94). Duclaux, EMIL.E. Le lait; études chimiques et microbiologiques. 2 tirage, augmenté de notes sur le rôle des microbes et sur les phosphates du lait. 376 pp., I2mo. Paris, J. B. Baillière \& fils., I 804 .

('94). HENRICI, H. Beitrag zur Bakterienflora des Käses. Arb. a. d. bact. Inst. d. tech. Hochschule z.1s Karlsruhe, Bd. I, Heft I, I894, pp. 1-1 10 .

('95). Rabinowitsch. See xxxiv.

('95). Jolles, Max, u. Winklefr. Ferdinand. Bakteriologische Studien ijber Margarin und Margarinproductes. Zcitschr. f. Hyg., Bd. $\mathrm{xx}, 1895, \mathrm{pp} .60-108$.

The bacterial content of margarin products is sligit in comparison with that of natural butter.

('95). Conn, H. W. Bacteria in the dairy. vi. Experiments in ripening cream with Bacillus No. 4I. 7 th Ann. Rep. of the Storrs Ag. Ex. Station for 1894 , pp. 57-68. Middletown, Conn., 1895 .

('g6). Conn, H. W. The relation of pure cultures to the acid, flavor, and aroma of butter. Centralib. f. Bakt., 2 Abt., Bd. I I, I8g6, pp. 409$4 \mathrm{I} 5$.

('97). ConN, H. IV. Butter aroma. Centralb. f. Bakt., 2 Abt., Bd. I I I, 1897, pp. 177-179.

('s9). MaAszen, AlBert. Fruohtätherbildende Bakterien. Arb. a. d. k. Gesundheitsamte, Bd. $x v$, Berlin, 1899, pp. 500-513, 3 pl. from photomicrographs.

The plates and text deal largely with Bacillus esterificaus, B. ester fluorescens and B. prapolleus. There are numerous references to literature.

('s9). Moore, V. A., ANd Ward, A. R. An inquiry concerning the source of gas and taint-producing bacteria in cheese curd. Bull. No. 158, Cornell Univ. Agr. Exp. Station, I899, pp. 22 I-237, I plate.

('c9). W ARd, Archibald R. Ropiness in milk and cream. Cormell Univ. Agr. Exp. Sta. Dairy Div. Bul. I65, r899, pp. 395-412, 4 figs.

Ropiness attributed to Bacillus lactisviscosus.

(99). Stadler. Sec Xxxvin.

('o). Wrber, A. Die Bakterien der sogenannten sterilisirten Milch des Handles ihre biologischen Eigenschaften, etc. Arb. a. d. k. Gesundheitsante, Bd. Xvir, 1900, pp. 108-155. With bibliography of 225 titles. 
('o1). Chodat, R., etr Hofman-Bang, N. O. I,es bactéries lactiques et leur importances dans la maturation du fromage. Ann. de l'Inst. Pasteur, T. Xv, 190I, pp. 36-48.

Discusses relation of tyrothrix to ripening of cheese.

('ol). WARD, Archibald R. Further observations upon ropiness in milk and cream. Cornell Univ. Agr. Exp. Sta. Dairy Div. Bull. 195, Ig01, pp. 29-39, 2 figs.

('OI). PARK, WM. HALrock. The great bacterial contamination of the milk of cities. Can it be lessened by the action of Health authorities? The Journ. of Hygiene, vot. J, IgoI pp. 391-406. See also N. Y. Unjv. Bulll. of the Med. Sci., vol. r, 190I, pp. 7I-86.

('O2). Fisch Fr, BERNHARD. Zur Aetiologic der sogenannten Fleisohvergiftungen. Zeitschr. f. Hyg., Bd. $\times x \times 1 x, 1902$, pp. 447-510, 2 plates. With a bibliography of 31 titles.

('02). EPSTERN, ST. Untersuchungen über die Reifung von Weichkäsen. Arch. f. Hyg., Bd. XLIJI, I902, pp. I-20.

('02). Conn, H. W., AND EsTen, W. M. The comparative growth of different species of bacteria in normal milk. Fourteenth Ann. Rep. Storrs Agr. Exp. Station, Storrs, Conn. Igor, pp. 13-80. Middletown, Conn., I902.

Relates to those bacterla occurrig uaturally iu milk and not to those introduced by the bacteriologist.

('o2). Gruber, Tr. Ueber einen die Milch rosafärbenden Bacillus. Bacillus Jactorubefaciens. Centralb. f. Bakt., Abt. 2, Bd. virr, I902, pp. 457-462.

('02). Gruber, Tir. Ueber eine in der Milch Rübengeruch und Rübengeschmack erzeugende Bakterie. Molk. Zeitung, Hildesheim, Bd. XVI, 1902, pp. 35I-353.

('o2). Harding, H. A., und Rogers, L. A. Rostflecken in Cheddarkäse. Centralb. f. Bakt. Alut. 2, Bd. vi11, I902, pp. 442-443.

Ascribed to Bacillus rudensis.

('O2). Richter, Albrecht P. F. Bakterielles Verhalten der Milch bei Boraxzusatz. Arch. f. Hyg., Bd. XLIII, I902, pp. I5I-I5t6.

('o2). GR1MM, MAX. Ueber einen neuen aromabildenden Bacillus nebst einigen Bemerkungen ïber Reinkulturen für Expontbutter. Centralb. f. Bakt., Abt. 2, Bd. viır, I902, pp. 584-590.

('O2). Rosam, A. Ueber Konservierung der Milch mittels Wasserstoff superoxyd. Centralb. f Bakt., Abt. 2, Bd. vilı, I902, pp. 739-744, pp. 769-774.

('o3). Harrison, F. C., and Cumming, M. The bacterial flora of freshly-drawn milk, Part iv. Journal of Applied Microscopy, vol. vi, 1003 , No. 2, p. 2,18I. Bibliography of 25 titles.

('o3). Swithindank, Harold, and Newman, George. Bacteriology of Milk. With special chapters by Dr. Newman on the spread of disease by milk and the control of the milk supply. With chromo-lithograplis, Woodbury typc reproductions of photographs of cultures and other illustrations of bacteria ancl of apparatus, and also charts illustrating epidemics, London, 1903, John Murray, pp $x x, 605$. ('o3). Conn, H. W., And Stocking, W. A., JR. Comparison of bacteria in strained and unstrained samples of milk. Rep't of Storrs Agr. Exp. Station, Conn., I902-3, pp. 33-37.

('o3). Conn, H. IV., ANd Strocking, W. A., JR. Series Ir. Strained and nnstrained milk preserved at $70^{\circ}$ and $50^{\circ}$. Rep't of Storrs Agr. Exp. Sta., Con11., 1902-3, pp. 38-51.

('o3). Conn, H. W., ANd Stocking, W. A., JR. Series 1II. Aseptic milk. Rep't of Storrs Agr. Exp. Station, Conn., I902-3, pp. 52-62.

('o3). Conn, H. W., and Esten, W. M. Qualitative analysis of bacteria in market milk. Rep't of Storrs Agr. Exp. Station, Conn., I902-3, pp. 63-9I.

('o3). ConN, H. W. Bacteria in freshly drawn milk. Rep't of Storrs Agr. Exp. Station, Conn., I002-3, pp. 92-98.

('o3). Cons, H. W. "The relation of temperature to the keeping property of milk." Storrs Agr. Exp. Station, Storrs, Conn. Bull. 26, Oct., I903, pp. 3-15.

The author's summary is as follows:

I. Variations in temperature luave a surprising infuence upon the rate of multiplication of bacteria. At $50^{\circ}$ these or thisms may multiply ouly 5-fold in 24 hours while at $70^{\circ}$ they may multiply 750 -fold.

while at $70^{\circ}$ they may multiply 750 -fold. 2. Temperatire has a great influence upon the keeping pody) will curdle in 18 hours, while the sane milk kept at $70^{\circ}$ will not curdle for 48 hours, and if kept at $50^{\circ} \mathrm{F}$. at $70^{\circ}$ will tot curdle for 48 homr, and if kept at $50^{\circ}$ F. without curdling for two weeks or more.

without curding for two weeks or niore. 3. So far as the keeping property of nilik is concerned, the wiatter of temperature ts of more significance th the original contamination of the milk with bacteria. 4. Milk preserved at $50^{\circ}$ or lower will keep sweet for a long time, but it becomes filled witl bacteria of a more unwholesome type than those that grow at higher tem be perfectly sweet.

('o3). Wil Hémy. Die Bakterienflora der Fleischextracte und einiger verwandter Präparate. Arb. a d. Bact. Inst. der techn. Hochschule zu Karlsruhe, IJI Bd., I Heft, I903, pp. I-42, with 3 plates ( 18 photomicrographs).

Most of the bacteria exist in form of spores. Twelve new species are described : Micrococcus carniphilns, Mr. marginatus, Streptococcus debllis, Bacterium fla reum, B. insulosum, Bacillus carniphilns, B. canaliculatus, B. car is, B. iutermittens, B. anthraciform is, $\mathbf{B}$. glaciform is B. micans, B. kaleidoscoplcus. B. carniphllus occurs in most ineat extracts. Other species found were: Bactevulgatus Flügre, B. cereus Frankland, B, laevis Frankland, and B, vegetus Kern.

\section{Bacteria in Bread.}

('85). LAURENT, EMILE. La bactéric de la fermentation panaire. Bull. de l'Acad. roy. de Belgique, 3 sér., T. $x$, I885, pp. 765-775.

('88). Arcangeli, G. Sulla fermentazione panaria Atti della Società toscana di scienze naturali residente in Pisa. Memorie. Pisa, I888, vol. IX, pp. 190-2I I. Bibliog. 29 titles.

(89). KRATSCHMER UND NIEMIIOWICZ. Ueber eine eigentïmliche Brotkrankheit. Wiener klinische Wochenschrift, I889, Bd. II, pp. 593594.

Authors ascribe the stringy bread to Bacillus mesentericus vulgatus Flïgge. They did not determine from what source the bread was infected, but state that the or ganlsm will not grow in acid dough or acid bread, but that it grows luxuriantly in feebly alkaline dough o bresd. 
('So). Pertrirs, W. L. Die Organismen des Sauerteiges und ihre Bedeutung für die Brotgährung. Bot. Zeitung, I889, Bd. XLVII, col. 405-4I9, 42 I-43I, 437-449.

(9o). Ufrelmann, J. Verdorbenes Brot. Centralb. f. Bakt., vir Bd., r89o, pp. 48I-485.

('go). Popoff, M. Sur un bacille anaérobie de la fermentation panairc. Ann. de l'Inst. Pasteur, i890, T. rv, pp. $674-676$.

('04). LEIrMANN, K. B. Ueber die Sauerteiggärung und die Beziehungen des Bacillus levans zum Bacillus coli communis. Centralb. f. Bakt., Bd. xv, 1894, pp. 350-354.

('94). Waldo, F. J., ANd Watsh, David. Does baking sterilize bread? The Lancet, London, 1894 (II), pp. g06-go8.

The general conclusion is that baking does not fully sterilize. The anthors cultivated numerons kinds of bacteria from the interior of baked loaves.

('97). Vogé, J. Beitrag zur Keuntniss des "fadenziehenden Brotes." Zeitschr. f. Hyg., Bd. xxvi, I897, pp. 398-4I6.

('99). Juckenack, Adolf. Beitrag zur Kenntniss des "fadenziehenden Brotes." Zeitschr. f. Untersuch. d. Nahrungs- und Genussmitteln, II Jahrg., I899, pp. 786-788.

('oo). Thomans, J. Beitrag zur Kenntniss des "fadenziehenden Brotes." Centralb. f. Bakt., 2 Abt., Bd. vi, 1900, pp. 740-743.

Stringy bread was found due to bacteria introduced with the flonr. The bacillus isolated by the anthor out of bread and two kinds of flour is called Bacillus panis viscosi (Vogel). Its cultural chatacters are given as follows :

follows: method, iquefies gelatin rapidly forms a dry gray-white growth on agar spreads widely and is wrinkied and graywhite on atato, grows in gry and is wrined and graygas-fortination, grows sapes gas-for on $40^{\circ}$ to $42^{\circ} \mathrm{C}$.

('or). Duclaux. Pain filant. See Traité, T. Iv, pp. 5I3-5I5.

('or). Beulshausen, Friedrich. Zur Kenntnis der Ursache des Klebrigwerdens von Brot. Diss. Rostock (Druck v. C. Hinstorff), 190I, p. 24.

('02). Michels, WolfGang. Zur Entstehung des fadenziehenden Brotes. Diss. Kiel. Königsberg i. Pr. (Durck v. Hantung), I902, p. I5.

('02). LEHMANN, K. B. Hygienische Untersuchungen üher Mehl und Brat. x. Neue Studien über die Acidität des Brotes, ilıre Ursachen und ilire beste Bestimmungs-methode. Arch. Hyg., München, Bd. XLIV, 1902, pp. 214-237.

\section{Iron-Bacteria.}

('88). Winogradsky, S. Ueber Eisenbacterien. Bot. Zeitung, 46 Jahrg., 1888, col. 261-270.

('92). Mol,Isch, Hans. Die Pflanze in ihrer Beziehung zum Eisen. Eine physiologische Studie. Jena, I892, Gustav Fischer, II9 pp., I table.

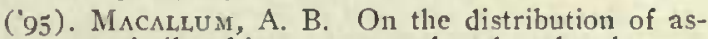
similated iron compounds, other than haemoglobin and haematins, in aninal and vegetable cells. Quarterly journal of microsc. science, $1895-96$, vol. Xxxvm, new series, No. 150 , pp. I75-274, with 3 plates.

The part relating to the bacteria begins on page 254 .
('97). Marpmann, G. Bakteriologische Mitteilungen. 1. Ueber einen netien Nährboden für Bakterien. II. Ueber ferrophile Bakterien. III. Ueber den Zusammenhang von pathogenen Bakterien mit Fliegen. Centralb. f. Bakt., Xx1I Bd., 1897, pp. 122-I32.

The new substratum is raw silk. Anthor has found a bacterium which stores iron in its cell-contents. nou-motile, $2-3 \times 0.8-2.0 \mu$ ends rounded form plum. black polar chromatophores and intermediate nles. Many cells are entirely black and opaque. piont is insoluble in alo and beuzine. It becounes bluisi nonla, and hleaclies with $\mathrm{HCl}$, giving of hydron phid. On adding ferricyanide of potash hydrogent stit with it the bacterig becone an intense arter $\mathbf{H C l}$, or tone-gelatin the organism was white but when ou pepof tron sulphate was added it became black.

('97). Mryoshi, Manabu. Ueber das massenhafte Vorkommen von Eisenbacterien in den Thermen von Ikao. Journ. of the Coll. of Science, Imperial Univ., Tokyo, Japan, vol. $\mathrm{x}$, Pt. 1 I, 1897 , pp. I39-142.

('97). Migula. See iII.

('97). Lafar. See iII.

('o4). Schorler, B. Beiträge zur kenntnis der Eisenbakterien. Centralb. f. Bakt., I904, Bd. XII, pp. $68 \mathrm{r}-695$.

\section{Sulphur-Bacteria.}

('86). Certés and Garrigou. See Xxxiv.

('87). Winogradsky, Sergius. Uober Schwefelbakterien. Bot. Zeitung, I887, Bd. XLv, col. $489,513,529,545,569,585,606$. 3 figs.

('88). Winogradsky, S. Sur la morphologie et la physiologie des sulf fobactéries. Beitr. z. Morphol. und Physiol. d. Bakterien., fasc. $\mathbf{r}$. Leipzig, 1888 .

Not seen.

(89). WimogradsKy, S. Recherches sur les sulfobactéries. Ann. de l'Inst. Pasteur, T. II I, I 889, pp. 49-60.

('89). DE Toni and Treivisan. Sulpluur bacteria. Sec Saccardo's Sylloge Fungorum, vol. 8, p. $x, 027$. Species granula sulphuris secernentes.

(93). ZELINsky, N. D. Ueber Schwefelwasserstoffgärung im Schwarzen Meere und den Limans von Odessa. Fortschr. d russ. chem. u. phys. Gesellsch., Bd. xxv, Part v, I893, pp. 298-303. (In Russiani.)

('95). YÉGounow, M. Sur les sulfo-bactéries des limans dodessa. Archiv. des sci. bio de l'Inst. impérial de méd. expér. de St. Péters. bourg, vol. II I, I895, pp. 38I-397. Rev. in Ann. de Micr., T. vIr, I895, pp. 281-282.

('95). BEYERINCK, M. W. Ueber Spirillum desulfuricans als Ursache von Sulfatreduction. Centralb. f. Bakt., 2 Abt., Bd. 1, I895, pp. 49-59 and 104-II4.

('97). Migula. See inf.

('97). Lafar. See it I.

('97). Mryosir, Manabu. Studien über Schwefelrasenbildung und die Schwefelbacterien der Thermen von Yumoto bei Nikko. Jour. College Sci., Imp. Univ. Tokyo, vol. x, Pt. 11, pp. 143-173, 1897, I plate. Rev. in The American Naturalist, vol. XXXI, 1808 , pp. 456-457.

('Or). Conn. See III. 
(o2). Nathansohn, Alexander. Ueber eine neue Gruppe von Schwefelbacterien und ihre Stoffwechsel. Mitt. a. d. zool. Stat. Neapel., Bd. xv, 1902, pp. 655-680.

('o3). Hinze, G. Thiophysa volutans, ein nenes Schwefel-Bacterium. Ber. der d. bot. Gesellsch., Bd. xxi, Hft. 6, July, 28, 1903, pp. 309-316.

('03). VAN DELDEN. See xxiv.

\section{L1. Bacteria in Prehistoric Times.}

(79). van Tieghem, Pri. Sur la fermentation butyrique (Bacillus amylobacter) à l'époque de la houille. C. R. des sé. de l'Acad. des sci., Paris, 1879, T. LXXX1X, pp. 1,102-1,104.

('95). Renaulit, B. Sur quelques bactéries des temps primaires. Bull. du Museum d'histoire naturelle, Paris, année I895, T $\mathrm{T}$, No. 4, pp. 168-172, 4 figs.

('05). Renault B. Sur quelques Bactéries due Dinantien $(\mathrm{Culm})$. C. R. des sé. de l'Acad. des Sci., Paris, T. cxx, 1895, pp. 162-164.

('95). Renault, B. Sur quelques micrococcus du Stéphanien, terrain houiller supérieur. C R. des sé. de l'Acad. des sci., Paris, T. exx, 1895, pp. 217-220.

(95). Renault, B. Sur quelques bactéries anciennes. Bull. du Mus. d'Hist. nat., Paris 1895, T. I, pp. 247-252, 6 figs.

('96). Renault, B. Sur quelques bactéries devoniennes, C. R. des sé. de l'Acad. des sci., Paris, T. cxxi1, I896, pp. I,226-I,227.

(96). Renault. Houille et Bacteriacées. Soc. d'nat. d'Autun, Bull. Ix, Autun, 1896, pp. 475-500, I pl.

('g6). Renault, B. Les bactériacées de la houille. C. R. des sé. de l'Acad. des sci., Paris, T. CXX111, 1896, pp. 953-955.

('96). RENault, B. Les Bactéries devoniennes et le genre Aporoxylon d'Unger. Bull. du Mus. d'Hist. nat., Paris, 1896, T. 11, pp. 201-203

('96). Renault, B. Notes sur quelques nouvelles bactéries fossiles. Bull. du Mus. d'Hist. nat., Paris, I806, T. 11, pp. 285-288, 4 figs.

('96). RenaulT, B. Recherches sur les bactériacées fossiles. Ann. des sci. nat. bot., virt série, T. 11, 1896, pp. 275-349, with 46 figures.

('96). Renault, BERNARD. Les bactéries dévonienne et le genre Aporoxylon d'Unger. Bull. d. 1. Soc. d'Hist. nat. d'Autun, T. 1x, I896, pp. [39-142, of the Procès-verbaux des sé.

('97). RenaulT, B. Les bactériacées des bogheads. C. R. des sé. de l'Acad des sci., Paris, T' CXX1v, 1897 , pp. 1,315-1,318.

('97). RenaulT, B. Les bactériacées et les bogheads à Pilas. Bull. d. MIus. d'Hist nat Paris, T. 111, I897, pp. 33-39, 4 figs.

(97). Renault, B. Les bactériacées des bogheads. Bull. d. Mus. d'Hist. nat., Paris, T. I11, I897, pp. 251-258, 6 figs.

('g7). Renault, Bernard. Bogheads et bactériacées, Soc. d'histoire naturelle d'Autun. x Bulletin, r897, pp. $433-469,18$ text figures.

("98). RENAULT, B. Les microorganismes des lignites. C. R. des sé. de l'Acad. des sci., Paris, T. cxxvi, 1898 , pp. $1,828-1,831$.
('98). RenaulT, B., Fit Rocie, A. Du mode de propagation des bactériacées dans les combustibles fossiles et du rôle qu'elles ont joué dans leur formation. Soc. d'histoire nat. d'Autun, IX Bull., 1898, pp. 133-147, in the Procès-Verbaux d. sé.

('oo). I,EMı Ère, L. Transformation des végétaux en combustibles fossiles. Essai sur le rôle des ferments. Congrès géologique international de I900, Paris, T. I, I901, pp. 502-520.

\section{L11. Preparation of Slides, Cultures, Etc., for Museums, \&c.}

(80). KaISER, EdUARD. Verfahren zur Herstelling einer tadellosen Glycerin-Gelatin. Bot. Centralb., Bd. 1, 1880, pp. 25-26.

I gram best French gelatin, 6 grams aq. dest.; soften 2 hours. Add 7 grams of c.p. glycerin and i gram of c. p. carbolic acid to each too grams of the preceding. Warm and stir 15 minutes. Filter through glass wool previously washed in distilled water.

('83). Grove, W. B. New methods of mounting for the microscope. (Hillhouse's snethod for glycerine mounting.) Midland Naturalist, vol. VI, 1883 , p. 166. Journal of the R. Microscop. Soc., London, August, 1883, p. 599.

According to Hillhouse, as reviewed by Dippel in Botan. Centralh. p. I59, Vol, XVI, I883, glycerin mounts are readily made tight by substituting Canada halsan dissolved in turpentine for ordinary cemeuts. Ring in ordinary way. Hillhouse says that a drop of glycerin on glass can be covered by a drop of balsam, and the latter will spread over it and adhere firmly to glass around it on all sides, inclosing it completely.

( 87$)$. SoYka, J. Ueber ein Verfahren, Danerpräparate von Reinkulturen auf festem Nälırboden herzustellen. Centralb. f. Bakt., 1887, Bd. 1, pp. 542-544.

('88). J ACOBJ, ËD. Härtung und Färbung von Plattenkulturen. Centralb. f. Bakt., 1888, 11 Bd., pp. 536-538.

('88). SoYKA, J., UND KRÁL, F. Vorschläge und Anleitungen zur Anlegung von bacteriologischen Museen. Zeitschr. f. Hyg., I 888 Bd. IV, pp. I 43-1 50 .

('89). KRÁL, Franz. Weitere Vorsclıläge und Anleitungen zur Anlegung von bakteriologischen Museen. Zeitschr. f. Hyg., Bd. v, I889, pp. 497-505.

('89). SснцLц. Kleine Beiträge zur bakteriologischen Technik. I. Konservirung von Platten- tınd Reagensglaskulturen. 6. Schimmelpilze hindert man im Waohsthum. Centralb. f. Bakt., 1889, v Bd., März I, No. 10, pp. 337340.

Cultures are covered for 24 hours with a fuid consisting of equal parts of alcohol and glycerin, to which has been added I part per 100 of a I per cent solution of mercuric chloride. Preparatious treated in this way are said to remain unchanged for years.

Camplor is said to hinder the growth of molds without interfering seriously with bacteria.

('g2). Dawson, Cnarles F. Eime Methode, Danerkulturen von Bakterien hermetisch zu verschliessen. Centralb. f. Bakt., XII Bd., 1892, pp. $720-72 T$. 
(93). Hauser, G. Ueber Verwendung des Formalins zur conservirung von Bacterienculturen. München. med. Wochenschr., I893. Bd. Xı. pp. 567-568. Rev. in Centralb. $f$. Bakt., Bd. Xrv, 1893 , p. 290.

Ten or fifteen drops of fresh formalln are put on filter paper and placed under the cover of the Petri-dish culture. This is then exposed to the vapor of formalin in a close room lined with wet filter paper, 15 drops of forma. lin being placed on cotton and introduced for each 1000 cc. of air space. As the formalin pessetrates the deeper layers of gelatin only slowly, a thin layer should be used for liquefying organisms. The formalin should be allowed to act for several days, and he renewed once or twice. The gelatin appears to be permanently disinfected, will not melt at any temperature, and is unclanged in appearance. To liave permanent preparations it is only necessary to keep them from drying out.

(9.3). Hauser, G. Weitere Mitteilungen ïber Verwendung des Formalins zur conservirung von Bacterienculturen. Mïnchen. med. Wochenschr.. I893, Bd. xL, pp. 655-656, No. 35. Rev. in Centralb. f. Bakt., Bd. xıv, 1893 , pp. $468-469$. Describes a nnethod of fixing aud mounting colonies
taken from gelatil plate cullures.

(94). Krueckmann, Emir. Eine Methode zur Herstellung bakteriologischer Museen und Konservierung von Bakterien. Centralb. f. Bakt., Bd. xv, 1894, pp. 851-857.

Fixes cultures with mercuric clyloride, etc., and pre. serves them in formalin, air-tight, in the dark.

('97). Pakes, W. C. C.. And Eyre, J. IV. Formalin as a preservative for cultivations of hacteria. Jour. of Path. and Bact., vol IV, I897, pp. 418-420. Also a separate, 3 pp.

('or). Conn, H. W. How can bacteria be satisfactorily preserved for museun specimens? Science, n. s., vol. xi11, I9oI, p. 326.

\section{Stock-Cultures, How Best Kept; Vitality on Media.}

('89). Czaplewski, E. Zur Anlage bakteriologischer Museen. Centralb. f. Bakt., vi Bd., 1889, pp. 409-411.

This method consists in limiting the amount of air which can reach the culture by saturating the npper part of the cottou plug with melted paraffirt. The chlef objec. tion to it is the increased difficulty of cleaning the discarded tubes.

(98). Lunt. On a convenient method of preserving living pure cultures of water bacteria. Rev. in Centralb. f. Bakt., xxı1 Bd., I8gs, pp. 795-796.

Certain water-bacteria ulay be kept alive for two years or more in sterile water, i. e. nutscls longer than in ordinary culture-media.

('oo). Bolley, Henry L. The duration of bacterial existence and [in ?] trial environments. Centralb. f. Bakt., 2 Abt., v1 Bd., I900, pp. $33-38$.

Reports getting a good growth of Bacillus anylovorus aud Bact. dianthi in agar and bouillon by transfers from aud Bact. diant lin agar and bouillon by transfers from cultures which had been hermetically sealed for 9 years. Tests of the pathogente
not to have been niade.

('01). Scilultz. Seevr.

\section{Color-Charts; Nomenclature of Colors.}

('86). Ridgway, Robert. Nomenclature of colors for naturalists. I95 water colors on ten plates, with rules for making the same and a general discussion of colors. Boston, Little, Brown \& Co., 1886.

Valuable, but out of print. Especially useful on account of the number of colors. Another edition in account of the

(94). Saccardo, P. A. Chromotaxia seli nomenclator colorum polyglottus additis speciminibus coloratis ad usum botanicorum et zoologorum. $2 \mathrm{~d}$ ed. Padua. Typis Seminarii, I894, 8vo., 22 pp., with two tables containing 50 colors.

A cheap and useful color scleme for botanists.

('95). Color chart under Spectrum, in the Standard Dictionary, Funk and Wagnalls, New York, 1895.

This may be had separately.

('95). Shutrléworth, E. B. Nomenclature of colors for bacteriologists. Jour. Am. Pub. Health Asso., Oct., I895, Annual vol. xx, pp. 403-407.

('98). Prang, Louis. The Prang standard of color. Popular ed., Boston, 1898. Folio.

('-). Chart of Spectrum Scales made from the Bradley colored papers. Milton Bradley Co., Springfield, Mass. A small sheet (about $3 \frac{1}{4} \times 7 \frac{1}{2}$ inches) with 90 colors. Also a large folded chart (IIx28 inclies).

Colors are briglit, but nust be carefully prolected from the light.

\section{Photography and Photomicrography.}

('77). Kocir, Rober't. Verfahren zur Untersuchungen, zum Conserviren nnd Photograpliren der Bacterien. Cohn's Beiträge, i I Bd., 3 Heft, Breslau, I877, pp. 399-434, with 24 photomicrographs on 3 plates.

('8r). Косн, R. Zur Untersichung von pathogenen Organismen. Mitth. aus dem Kais. Gesundheitsamte, Bd. I, 188I, pp. $r-48$.

The paper is illustrated by 84 bellotypes from photomi. crograplss.

('83). Sternberg, Geo. M. Photomicrograplis and how to make them; pp. xv, 204, with twenty plates of photomicrographs. James R. Osgood \& Co., Boston, I883.

('87). Crookshank, Edogar M. Photograplyy of bacteria. Illustrated with 86 photographs reproduced in autotype, pp. xIx, 64, Jondon, H. K. Lewis, 1887 .

('87). Roux, E. La photographie appliquée à l'étude des microbes. Ann. de l'Inst. Pastetrr, T. I, I887, pp. 209-225.

(88). ZETTNow, E. Das Kupfer-Chrom-Filter. Centralb. f. Bakt.. 1888. Bd. iv, pp. 51-52.

This light filter is well adapted to photographing bacieria, whether they are stained red, bine or violet.

This filter is made as follows : For use with surnlight 160 grams copper nitrate and 14 grams pure chromic acid diluted with water to $250 \mathrm{cc}$. Mlore couvenient to prepare and suitable for most purposes in a layer 1 to $2 \mathrm{~cm}$. thick is 175 grams sulphate of copper and 17 grams bichromate of potash dissolved in I litre of water. Tlie copper-chrom. filter transmits only a small portion of the spectrum. viz., those yellow-green rays which act most strougly upon erythrosin plates. For the concentrated solution these rays are from wave length 580 to 560 : more diluted from 590 to 545 . 
('88). NEUHAUSS, R. Verschicdenes über Microphotographie. Zeitschr. f. Mikr., Bd. v, pp. 484-486, I 888.

('go). Neuhauss, Richard. Lehrbuch der Mikrophotographic. pp. XI, 273, with 6r wood cuts, 4 autotypes, 2 collotype plates, and I photogravure. Braunschweig, Harald Bruhn, I8go.

A very useful book.

('go). Pringle, ANDREw. Practical photo-micrography; by the latest methods. The Scovill \& Adams Co., New York, I890, pp. I83, Ix, 42 figs. Frontispiece and 6 plates.

('9o to '99). Voger, H. W. Handbuch der Photographie. Vier Theile enthaltend die photographische Chemie, Optik, Praxis und Kunstlehre. Berlin. I Thicl., I89o, pp. Xvi, 35I, I2 plates; II Theil., I894, pp. XI, 367; I I Theil., A.bt. I, I807, pp. x, 3 I I, A.bt. I I, I899, pp. X, I59.

('99). The photo-miniature. Tennant and Ward, New York. Begun in 1899 .

A series of small, inexpensive volnmes, by various anthors, on various pliases of photograpliy. Some of them excellent. Abont 70 numbers up to beginning of 1905.

('99). Hubbard, J. G. Color screens as applied to photomicrography. Jour. Bost. Soc. Med. Sci., vol. II I, I899, pp. 297-30I.

('99). Wright, James H. Examples of the application of color screens to photomicrograply. Jour. Bost. Soc. Med. Sci., vol. II I, I899, pp. 302-307.

('OI). Abney, Sir William de Wiveleslie. A treatise on photography. Tenth ed. thoroughly revised, with I 34 illustrations. I ongmans, Green \& Co., 39 Paternoster Row, Iondon, New York, and Bombay, Igor, pp. XVII, 425 .

An excellent book, but subjects treated very briefly.

('O2). Walmsley, W. H. The A B C of photomicrography. pp. viI, I55. Tennant and Ward, New York, I902.

LVI. Methods and Systems of Classification. (See also III and X.)

('38). EHRENBERg. See v.

('4I). Dujardin, Fł́lix. Histoire naturelle des zoophytes, infusoires comprenant la physiologie et la classification. Paris, I84I.

('65). Davaine. See $v$

('65-67). Trteul, A. Urocephalım. C. R. des sé. de l'Acad. des sci., I865, T. LXI, p. I56 and 432. Ibid. I867, T. LXV, p. 513.

The form of bacterium with a spore at one end, which is swollen, was called Urocephalum by Trecul.

('72). Corn. Seev.

('79). TrEvisan. Introduzzione allo studio die bacteri. Atti d. Inst. Lombardo, I879.

('80). Winter. See III.

('8I). Zopf, W. Ueber den genetischen Zusammenhang von Spaltpilzformen. Monatsbericht d. Königl. preuss. Akad. d. Wissenschaften, Berlin, I881, pp. $277-284$, I plate. See also various editions of Zopf's "Spaltpilze."

('85) DE BARY. See III.
('85). KUENTSLER, J. De la position systématique des bactériacées. Jour. de nicr., T. IX, 1885 , pp. 295-307.

According to this author the bacteria are of animal origin, the nearest relatives being the Flagellata, especially the astomous forms. There are transition forsus.

('86?). Schrofiter. See iII.

('86). Hueppe, Ferdinand. Die Formen der Bakterien und ihre Beziehungen zu den Gattungen und Arten. With 24 wood-cuts. Wiesbaden, C. W. Kreidel's Verlag, I886, pp. VIII, I52.

('89). DE Toni And Trevisan. Sylloge Schizomycetarum. Forms a portion of vol. vIII of Saccardo's Sylloge Fungorum. Padua, I889, pp. 923-I,087.

Those volimes of Saccardo's Sylloge Fungorum which are out of print have been reproduced in fac-simile (zincography) by R. Friedländer and Sohn, Berlin.

('go). Messea, Az. Contribuzione allo studio delle ciglia dei batterii e proposta di una classificazione. Revista d'igiene e Sanità Pubblica, Anno I, I89o, pp. 5I3-528, I plate. Bibliography of In titles. Rev. in Centraib. f. Bakt., etc., Bd. IX, I8gI, pp. I06-10\%, and in Baumgarten's Jahresbericht, Bd. viI, p. 344.

The bacteria are classified as Gymnobacteria and Trichobacteria. The latter are s11bdivided into four groups: Monotricha (one polar flagellum), Lophotricha (a tuft at one pole), Amphitricha (one fiagellum at each end), and Peritriclia (flagella from various parts of the body). These names are not used in a generic sense.

('92). WARD, H. MARSIIALL. On the characters or marks employed for classifying the Schizomycetes. Annals of Botany, vol. 6, I 892 , p. IO3.

('94). Migul, W. Ueber ein neues System der Bakterien. Arbeiten aus dem Bakt. Institut der Technische Hochschule zu Karlsruhe, Bd. I, Hft. 2, I 894 , pp. 235-238.

('95). Migula, W. Schizomycetes. Engler and Prantl's Die Natïrlichen Pflanzenfamilien, Leipzig, Wilhelm E,ngelmann, I895.

('95). FisCHER, ALFRED. Untersuchungen über Bakterien. Jahrh. f. wissensch. Botanik, Bd xxvII, I895, Hft. I, pp. I-I63. 5 plates.

('96). MEz, Cari. Der heutige Stand der bakteriologischen Systematik. Botanisches Centralb., Bd. LXVIII, I896, pp. 203-2II.

('97). CHESTER, FREDERICK D. A preliminary arrangement of the species of the genus Bacterium. oth Ann. Rept. of the Delaware Coll. Agr. Exp. Sta., I897. Also a separate, pp. 93.

('97). Migula. See i i .

('97). Fischer. See i II.

('oo). Migula. See i I I.

('O2). Thaxter. See X.

('03). KENDAli, ARTiHUR I. A proposed classification and method of graphical tabulation of the characters of bacteria. Proc. Amer. Purb. Health Asso., Thirtieth annual meeting, held at New Orleans, La., Dec., I902, vol. Xxviri, pp. 48I-493. Also a separate, pp. 3-I5. Pub. I903.

('O3). FORD, WIL,IAM W. The elassification and distribution of the intestinal bacteria in man. Studies from the Royal Victoria Hospital, Montreal, vol. I, No. 5 (Pathology II), 1903, pp. 3-95. 3 tables. Also a separate. 
('03). Gage, Stephen de M., and Phelps, Earle B. On the classification and identification of bacteria, with a description of the card system in use at the Lawrence Exp. Station for Records of Species (Lawrence, Mass.). Proceedings of thirtieth annual meeting of American Public Health Assn., New Orleans, Ira., Dec., I902, vol. XxviIs, pp. 494505. Pub. Columbus, O., I903. Also a separate, pp. I2-23.

('04). Perkins, Roger G. Bacillus Mucosus Capsulatus. A study of the group and an attempt at classification of the varieties described. Jour. of Infectious Diseases, vol. I, No. I, I904, pp. 24I-267. Also a separate.

('05). Winslow, C. E. A., And Rogers, Anne F. A revision of the Coccaceae. Preliminary communication. From the Biological laboratories of the Massachusetts Institute of Technology. Science, n. s., Vol. XxI, I905, pp. $669-672$.

The 445 described forms are reduced to 31 types, Five genera are recnguized, vlz, Diplococcus and Streptococ. cus, belonging to the sub-family Paracoccacese, and Micrococcus, Sarcina and Ascococcus, belonging to the subfamily Metacoccaceac.

\section{Useful Catalogues.}

Catalogues and addresses of instrument makers, manufacturers of chemicals, etc. :

CARL ZFiss, Jena.

(I) Microscopes and microscopical accessories, 32 ed., I902.

(2) Photographic objectives and photo-optical appliances, roor.

(3) Catalogue of instruments and appliances for projection and photomicrography, fourth ed., I899.

ERNST LEITZ, Wetzlar.

Microscopes and accessory apparatus. Cat. 39. U.

S. Branch: Wm. Krafft, 80 East I8th st., near Broadway, New York.

Bauscir And Lomb, Rochester, N. Y.

(I) Optical apparatus, microscopes, photographic lenses.

(2) Chemical apparatus, bacteriological apparatus.

Eimer and Amend, New York.

Chemical and physical apparatus, I903. Am. agents for Zeiss.

Wirtall and Tatum, Philadelphia, New York, and Boston.

Glassware.

F. AND M. LAUTENSCHLAEGER, Berlin.

Cat. No. 6o. Bacteriologie, Chemie, Asepsis.

Maison Wirsneg (P. Lequeux), 64 Rue Gay-Lussac, Paris.

Catalogue des appareils de bactériologie et d'hygiènc.

M. Schanze, Leipzig.

Preisverzeichnis von Mikrotonie.

Dr. Hermann Rohrbeck, Berlin.

Brood-ovens, thermo-regulators, etc.

Dr. G. Gruebler and Co., Leipzig.

Preislisten von Farbstoffe und Reagentien.
Grübler's stains may be obtained in the U. S. from Wm. Krafft, 8o East I8th st., near Broadway, New York.

Koenigliohe Porzellan-Manufaotur, Berlin.

Preis-Verzeichniss, No. v. Geräthschaften zu chemischen und pharmaceutischen Zwecken. I Jan., I899.

Price list of chemical apparatus manufactured and sold by C. Gerhardt, Bonn am Rhein, Germany.

P. J. KIPP U. ZoHNEN, Delft, Netherlands. Makers of the Reinhold-Giltay microtome.

Dr. RoD. MUENCKE.

Catalog über chemische Apparate und Gerathschaften, I900, Berlin, N. W., Luisen-Strasse 58. Preis 5 mark. pp. 600 .

Dr. PETERs \& RosT.

(I) Preis-Liste über Apparate und Utensilien für elektrochemische und elektrolytische Arbeiten. Liste No. 29. Berlin, I900, pp. 48.

(2) Preis-Liste über Apparate und Utensilien fiir Bakteriologie, Hygiene. Mikroscopie. Reagentien, Farbstoffe, Nahrboden, Reinculturen, mikroscopische Präparate. Liste No. 30. Berlin, I900, pp. I23.

(3) Preis-Liste über chemische Apparate und Utensilien für wissenschaftliche und FabriksLaboratorien, Chemicalien. Reagentien, Normal-Lösungen. Liste No. 28. Berlin, I902, pp. 534.

(4) Preis-Liste über physikalische Apparate. Liste No. 37. Berlin, I902, pp. Iv, 383.

Max Kaehler and Martini, Berlin.

Chemical and Bacteriological Apparatus.

The above five catalogues or their equivalent may now be obtained from the following:

Vereinigte Fabriken für Laboratoriumsbedarf, ges. M. B. H., Chauseestr. 3. Berlin. N., formerly Max Kaehler \& Martini. Dr. Peters \& Rost. New York Office: Iaboratory and School Supply Co., 20-24 East 2oth street, New York.

EmiL Greiner, New York.

Bacteriological apparatıs. glassware, high-grade glass blowing. Very reliable.

Greiner \& Friedrichs, Stützerbach, Germany.

Glassware.

C. P. Gorkz.

Price list of double-anastigmat lenses and of the Goerz-Anschutz camera. Berlin-Friclenan, and 52 East Union Square, New York.

Former and Schwing, 407 Broome street, New York. High-grade cameras.

Hénry Heil Chemical Co., 298-312 S. Fourth street, St. Loulis, Mo.

Illustrated catalogue and price list of chemical and physical apparatus and instruments for laboratories, chemists, iron and steel works, smelters, assayers, mines, sugar refineries, schools, colleges, universities, etc.

Spencer Lens Co., Buffalo, N. Y.

Microscopes. Excellent lenses, especially lowpower apochromatics and a new $2 \mathrm{~mm}$. oil immersion achromatic. 
BeCKER, ChRISTIAN.

Price list of balances and weights of precision. Factory: New Rochelle, N. Y.; New York office: 7 Maiden Lane.

ThE KNY-SchEERER Co., 225-233 Fourth avenue, New York.

( I) Illustrated Catalogue of Surgical Instruments, I 902 , pp. I,VI, and pp. I,00I-I,06I, 2,00I-2,I40, $3,001-3,192,4,001-4,102$, and 5,00I-5, I80.

(2) Aseptic Surgical Furniture and General Hospital Supplies, 6 ed., 1902, pp. 232. Fully illustrated.

E. H. SARGENT, \& Co., I43 and I45 Lake street, Chicago.

Importers and makers of laboratory supplies, price list of apparatus, chemicals, reagents, tissue-stains, microscopical and bacteriological supplies, etc.

JAMES T. DougherTY, 409 and 4II W. Fifty-ninth street, New York.

Scientific apparatus. Sole United States agent for Carl Reichert, Vienna, Austria, microscopes, microtomes, and polarizing apparatus.

The VoigTlaender \& Son Optical Co., $137 \mathrm{~W}$. Twenty-third street, New York.

Collinear and telephoto lenses, porro prism binoct1lars, etc.

W ARNER \& SWASEy, Cleveland, Ohio.

Excellent binocular field glasses.

Charless J. Ross Co., i525 Fairmount avenue, Pliiladelphia, $\mathrm{Pa}$.

Excellent quality of drawing-board, heavily coated, so as to permit of any number of erasures. Recommended by Dr. Roland Thaxter and by the writer.

The Century Camira Co., Rochester, N. Y.

Excellent cameras embodying many convenient, time-saving devices.

Stanley Photographic Dry Plate Co.

Cheap dry-plates of good quality.

M. A. Seed Dry Plate Co., St. Louis, Mo.

Standard dry-plates. Non-curling films. Isochromatic, ordinary, and non-halation plates of good quality.

Hammer Dry Plate Co., St. Louis, Mo.

Both Seed and Hammer publish interesting little free handbooks on negative making, etc.
G. Cramer Dry Plate Co., St. Louis, Mo. New York Depot: 32 East Ioth street.

Cadett Spectrum Dry Plate Co., London, England. The Ilford Chromatic Plate Co., London, England. The $3^{\mathrm{T} / 4}$ by $4^{\mathrm{T} / 4}$ plates are highly recommended by Dr. Jeffrey for photomicrographic work. They cost 20 cents per dozen, exclusive of duty.

The EAstman KodaK Co., Rochester, N. Y.

Roll and cut films, Kodoid films, non-curling films, solio paper, velox paper, etc.

Willis and Chements, Philadelphia, Pa.

Platinatype paper.

Dr. J. C. MiLLER, Denver, Colo.

Blue-print papers of high grade, known as "French Satin, Jr."

G. GENNERT, 24 and 26 East I3th street, New York.

Hauff's Ortol developer, white glass for lanternslide covers, etc.

Mallinckrodt Chemical IVorkśs, St. Louis, Mo., and New York, N. Y.

Photographic chemicals of a high grade.

KéufFel \& Esseir Co., New York.

I27 Fulton street and 42 Ann street. Catalogue and price list of drawing materials and surveying instruments. Drawing paper of any quality desired converted into blue-print paper. Branches in Chicago, St. Louis, and San Francisco.

E. Schéring, manufacturing chemist, Berlin, Germany.

Král's Laboratory, Prag, Austro-Hungaty.

Der gegenwärtige Bestand der Král'schen Sammlung von Mikroorganismen, Oct., 1902. Král's Bacteriologisches Laboratorium, Prag. I. Kleiner Ring 11. Telegramm-Addresse: Král's Laboratorium.

Cultures of several hundred sorts of bacteria and of some fungi may be had from this laboratory. Authors are urged to send their new species to Král.

W. P. Stender, Leipzig, Gerichtsweg Io. Fabrik und Iager von Glasgegenstaenden zur Anfertigung mikroskopischer Praeparate, u. s. w.

EAGLE OXYGEN Co.

(See p. 8I.)

Defender Photo Supply Co., Rochester, N. Y.

Argo and other photographic papers. 


\begin{abstract}
A D D E N D .
Page 46, paragraph $b$, for "fat" read casein. The fluid lias a soapy feeling, but "saponification" also is probably not the proper term. What actually occurs is a matter for the chenist to deternine. The inoculated milk shows no cliange at first, but gradually becones intensely alkaline and clears synchronously, without coagulation or precipitation. By addition of acids, or concentrated solutions of sodiun cliloride, copper sulphate, etc., the transparent fluid may now be filled witl a white flocculence, which slowly settles to a bulky caseous precipitate, leaving a superuatant clear, pale whey. It usually requires a montl or six weeks for the inoculated milk to becone entirely transparent, but a similar transparency may be produced at once in clieck trubes of milk by adding a few drops of an1monia-water.

On testing cultures grown for a few days in " nitrate bouillon," as described on p. 63 , it liappens frequently that there is no nitrite reaction. It is then necessary to know whether nitrate is actnally present in the bouillon. Usually cultures of Bacillus coli, or some other known nitrate-reducing organism serve this purpose. If strcli cultures lave not been provided, the test for nitrates may be made with diphenylanin dissolved in strong sulplutic acid. On addition of a few drops of this reagent there is an innnediate, evanescent, deep-blue reaction if nitrates are present. The reagent is prepared by slowly dropping 90 cc. of c. p. sulplutric acid into Io cc. of pure water, after which I gram of diphenylanin is added, and the solution preserved in a glass-stoppered bottle.
\end{abstract}





\section{N D E X.}

Abbe camera ......................... 130

Abstracts, making of ................. I I4

Acclimatization to high temperatures....... 222

Acetic alcohol

as a fixing fluid.................... 202

with mercuric chloride.............. 202

Acetone, for use in fermentation-tubes...... 52

Acid-fast bacteria.................... I 88

Acid-forming bacteria, demonstration by plate

cultures ................... 51, 233

Acid gelatin, effect on growth........... 30

Acid,

hydrochloric, in culture-media.......... 98 oxalic, actively germicidal.............. 249

Acids,

action on enzymes................... 68

effect on bacteria................... 249

formation of, in milk-cultures.......... 46

method of estimating in plants, when not

free ...................... 207

spilled, neutralization of ................ I07

toleration of, by bacteria........... 70,249

vegetable, sensitiveness of bacteria to..... 69

Achromatium ...................... I62

Acrolëin, germicidal action of............ 252

Achromatic objectives,

disadvantages of.................... I40

with excellent definition .............. 265

Aërobe, Pasteur's definition of............230

Agar-agar,

combined with bouillon and sugars...... 33,51

commercial, source of............. 31, 225

composition of .................... 32, 223

cultures on, for flagella staining........ 20

filtration of ................... 33, 224, 225

glycerinated ................... 50, 196

litmus lactose..................... Ig6

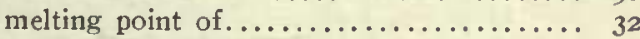

methods of making............ 223, 224, 225

nutrient, centrifuging of.............. 225

nutrient, temperature at whicl poured..... I05

per cent used for media.............. 35

rate of diffusion in. ................. 224

roll-cultures of ................... 36

softening of, by bacteria.............. 32

solidification of.................... 32

source of ........................ 3I

standard nutrient, preparation of...... 33, 195

sterilization of .................. 98, 99

variation on, of same organism........... I80

with neutral red................... 230

without nutrients.................... 229
A gar-block method for study of antagonism.

conism.. 73

Agar-plates, for detection of acid-forming colonies ....................... 5 I

Agfa-intensifier ................... 142

Air,

bacteria infrequent in Arctic........... 255

bacteria rare in upper strata of.......... 255

of mountains, bacteria rare in.......... 255

over the sea, bacteria rare in............. 255

Air-currents, danger of............. 103, 106

Air-shaft, for ventilation of dark-room...... 149

Albumen, egg,

Mayer's .......................... I I

preparation of, for culture-medium........ 48

Alcohol

as a fixing fluid................ 8, 202

ethyl, for use in fermentation-tubes....... 52

methyl, for usc in fermentation-tubes..... 52

weak germicidal action of ........... 252

Alkalies

action on enzymes................... 68

formation of, in cultures............. 6r

sensitiveness of bacteria to............ 69

toleration of, by bacteria............. 70

Alkaline methylene blue............... I 88

Amaryllis, inoculated with B. hyacinthi..... 66

Amido-bacteria ...................... I75

Amins, test for....................... 64

Ammonia-bacteria ..................... r75

Ammonia,

oxidation of, by bacteria.............. 64

test for........................ 64

Ammonium,

citrate, relation to pigment-production..... 65

lactate, relation to pigment-production..... 65 oxalate, solvent of middle lamella........ 67 salts, oxidation of, by bacteria.......... 64 salts, sterilization without loss of ammonia. $\quad 52$ succinate, rclation to pigment-production... 65

Amoebobacter ........................ 163

Anaërobe, Pasteur's definition of.......... 230

Anaërobes ....................... 5I

Arens' method of cultivating........... 231

Bucliner's method for growing........... 23I

Bulloch's method of obtaining............ 228

Heim's method................... 23I

Hesse's method..................... 230

Klein's apparatus for............... 232

on culture-media in hydrogen, etc........ 57

present in milk.................... 46

Wright's metlods of cultivating......... 228 
Anilin-dycs,

differential diagnosis with........... 230

watery solutions of .............. 187

Analin-dyes (basic),

affinity of bacteria for............... 27

use of, in vegretable tissues............ 29

Anilin fuchsin................... 187

Anilin gentian violet.................187

Anilin methyl violet................. 187

Anilin stains, alcololic solutions of ........ 187

Anilin-water ..................... 187

Animal-fuids for culture-media,

becf-broth ..................... 45

blood-serun ..................... 48

egg-albumen ................... 48

cgg-yolk ....................... 49

litmus-milk ................... 48,196

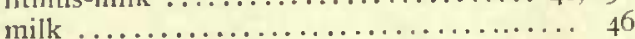

rice cooked in milk................ 48

Anschiitz, normal thermometers........... 78

Antagonistic action of bacteria.......... 73

Anthrax organism,

asporogenous ................... 222

behavior when injected into plants...... 89

branching in .................... 2 6 generic name for................. I7 I

Anthrax spores, substratum influences formation of ....................... 219

Antiseptics,

effect on form of bacteria............ 252

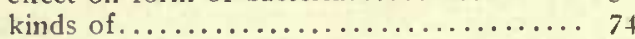

literature on .....................250

Aplanobacter, specics included under genus. . 17 I

Apochromatic objectives,

in photomicrography.................. I 39

recommended for bacteriological work.... 130

Spencer ........................ I40

Zeiss .......................... 130

Apparatus necessary in laboratory......... 95

Apple blight, due to B. amylovorus......... 202

Arnold steam-sterilizer................ 47

Arthrospores, disputed existence of. .. 21, 158, 218

Asparagin,

in fermentation-tubes................ 52

relation to pigment-production........... ó

Atkinson, method for photographing poured

plates ......................... 134

Aujeszky, spore-stain....................... 219

Autoclave, for sterilization of culture-media. 84,98

Bacillus,

Cohn's genus........................ 158

Fischer's genus........................ 157

in Migula's classification............... 160

Bacillus amylovorus,

absence of pigment in................ 65

distributed by insects................... 215

effect of direct stmlight on............ 72

enters plant through nectarics........... 92

flagella hard to stain................ 190

hosts of ......................... 87

nitrates not reduced by............... II3

non-sporiferous ....................... 158

useful for comparison.............. 29
Page.

Bacillus aroideae................... I15

hosts of ........................ 86

soft rot due to................... I15

stain produced by.................. 65

thermal relations of ................ 86

variation in shape of colonies at different

temperatures ................... Iso

Bacillus Bütchlii, imer structure of........ 219

Bacillus carotovorus,

soft rot due to................... 103

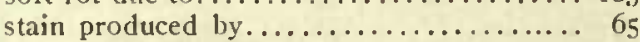

thermal relations of ................. 86

tissues occupied by ................ 5, 6

Bacillus coli,

effect of formalin on............... 229

how differentiated from B. amylovoriss. . 51, 113 method of differentiating from B. typhosus. 229 useful for comparison................. 29

vitality of ..................... 72

Bacillus denitrificans, sizc of ............ I8

Bacillus hortulanus, isolation of, by heat. 106, 211

Bacillus oleraceae, maximum temperature for. 86

Bacillus oligocarbophilıs............... 24I

Bacillus prodigiosus,

culture-media for............. 238, 239 for study of production of pignent....... 6 magnesium sulphate necessary for pigment. 238 pigmented and non-pigmented races of. . 64, 222,

peaction of color to acids and alkalies.... 238

Bacillus rosaceus metalloides, rosettc-like groupings .................... $2 \mathrm{I} 8$

Bacillus tracheiphilus,

absence of pignent in............... 65

action of block-tin on.................. 97

behavior in fermentation-tubcs.......... 53

hehavior toward acids and alkalies......... 70

distributed by insects............ 178, 215

effect of frezing on .................... 82

effect of sodium chloride on .......... 70

susceptibility to dry air................ 7 I

viscidity of .................... 20

Bacillus typhosus,

action of copper on...............74,97 bchavior when injected into living plants... 89

effect of formalin on............... 229

Hiss' special medium for differentiating... 230

non-sporiferous ................... 158

Wurtz's method of differentiating......... 229

Bacteria,

action on photographic plate.......... 242 amount of acid tolerated.............. 70 animal origin of .................. 264 bluc pigment forming, in cheese, etc....... 237 branched forms.......... 177, 217,218, 237 effect of chemicals on.............. 74,250 effect of freezing........... 79, 246, 247, 258 effect of gases on................ 58, 231

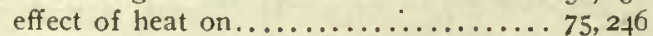
effect of ions on.................. 244 effect of light on.................. 71,243 effect of pressure on .............. 245 hanging-block cultures............... 22 
Bacteria-continued.

Page.

hanging-drop cultures.............. 22 in bread, baking does not destroy all...... 26r in milk.................... 196, 260 isolation from diseased tissues, methods of. II limits of size................... I 8 long vitality of ............. 72, 214, 263 monotonous morphology of........... 25 move against a strcam.............. 253 110n-nitrifying associated with nitrifying... 24I oxidation of ammonia and ammonium salts

hy ............................64 photographing in stained tissues...... 136, 140 prehistoric ....................252 presence in diseased tissues, how determined ....................... 10 rapidity of movement............... 26

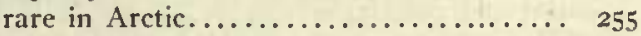
rare in mountain air............... 255 sensitiveness to acids................ 69 scnsitiveness to alkalies.............. 69 species found in meat-extracts.......... 260 thernal range of . . . . . . . . . . . 75, 246 toleration limit for sodium chloride... . 70, 252

Bacterial ash, alkaline............... 42

Bacterial disease communicated by beetles... 92, I 78,2 I 5

Bacterial soft rots, similarity of......... 8 Bacteriology,

milestones in progress of............ I5I prominent workers in............. I52

Bacteriosis of walnut............. 174, 176 prevention of .................. 93

Bacterium,

Cohn's genus.................... 166

Ehrenberg's genus................... I65

iron stored by................... 26 I plant parasites belonging to genus....... I7 I Migula's use of the word.......... 160, 165 substituted for Psendomonas......... I66, I 7 I triloculare .................. 165, I69

Bacterium campestre,

communicated by slugs, larvæ, etc.......2 25 effect of desiccation on................ 7 I cnters plant through water-pores. 92, 94, 102, I24 enzymes produced by................ 68 relation to soft white rots........... 73 tissues occupied by............ 7, I0, I I, 12 useful for comparison.............. 29

Bactcrium hyacinthi,

effect of desiccation on............ 7 I

effect on Amaryllis atamasco ............ 66

Bacterium malvacearum, leaf spots due to................. 95 stomatal infection................. 126

Bacterium pediculatum, branching of....... 22I

Bacterium phaseoli,

beans infected with, by way of stomata.... 92 effect of direct stmlight on........... 72 pigment of ................... I79

Bacterium pericarditidis, flagellum of ................... 237

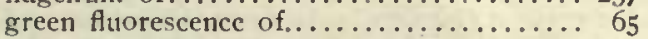

Bacterium pericarditidis-continued. viscidity in fluid culture-media......... 42 vitality of ..................... 72

Bacterium solanacearum, distributed by insects...............215 optimum temperature for.............. 86 plants inoculated with............ I7, 202 relation to soft white rots........... 73 stain produced by....................... 65

Bacterium syncyaneum, blue color of, in acid milk ...................... $6_{5}$

Bacterium syringae..............6.64, 66, I35

Bacterium Stewarti,

stock-cultures of, how best kept........ 72

tissues affected by.............. 4,90 Bacterium termo,

Cohn's and de Bary's account of......... I66 Dallinger \& Drysdale's conception of....... I70 flagella of.................20, 170, 219 Bacterium triloctulare, flagella of........ 20, 169 Bacterium vascularum, relation to red stain of sugar-cane....... 66 stock cultures of, how best kept.......... 72

Bactridium, as a genus name............. I5 Balsam, for mounting sections............ II9 Banti, isolations on slant media........... 227 Barfoed's reagent................... 208 Béchamp, views concerning morplology.... I76 Beef-bouillon,

proper sterilization of............... 98 standard peptonized................. 45, 195

Beetles, discase spread by........ 92, 178, 215 Beggiatoa ...................... I62 Bell-jars, for use in inoculations.......... 108 Benda's iron-haematoxylin............... I 88 Benzoic acid...................... 74 Beyerinck,

agar for detection of acid-forming colonies ................... 51, 233 agar for cultivation of nitrite bacteria...... 199 Bacillus oligocarbophilus............. 24I blue pigment bacteria in cheese........ 237 fermentation of indigo............. 257 Kapillarhebermikroscopirtropfenflasche.... 226 root-tubercle bacteria, study of........ I53

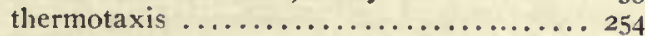
Bilirubin as a test for free oxygen.......... 57 Billroth, views concerning morphology...... 176 Birds, intestinal tract of, bacteria in......... 258 Blood-serum ...................... 48 Blue prints, making of, for drawing purposes. 150 Bokorny, amount of nutrients needed by bacteria ....................... 225

Bolley, on longevity of bacteria.......... 263

Boni's method of staining capst1les.......... 194 Bouillon,

cultures in, for flagella staining...... 20, 190 lead acetate in ................... 5 neutral red in.................. 5 I of varying degrees of alkalinity and acidity. 5I peptonized standard ................ 195 salted ....................... 5I stcrilization of .................. 99,99 
Bougie,

Berkefeld's, for filtration of culture-fluids. .

Chamberland's, for filtration of culturefluids ........................

Chamberland's, sterilization of, necessity for frequent................... 44

Bowhill's flagella stain............... 192

Boxes for sterilization of pipettes......... 4I

Branched forms.......23, 377, 215, 216, 217, 218 Bread,

Bactcria cause stringiness in. ....... 260, 26r

baking does not fully sterilize.......... 26r

Bredig und Müller, enzymic action of platinum black................... 234

Brenner, black rot of cabbage, communicated

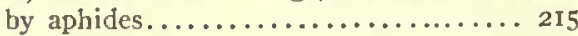

Bromide-prints ................... I5 I

Broomcorn,

natural infection in.............. 92, I50 red blotches and stripes, relation of bacteria

to $\ldots \ldots \ldots \ldots \ldots \ldots \ldots \ldots \ldots \ldots \ldots \ldots \ldots \ldots \ldots \ldots \ldots$

Brownian movement, deceptive nature of. . I0, 26 Brown pigment, bacteria producing. 65, 2 I I, 214,237 Brunner and Zawadzki, counting plate......227

Bubonic plague, nature of organism causing.. 2 I4 Bucliner,

effect of light on bacteria............244 method of growing anaërobes.......... 23I

Bujwid,

cholera red.......................220 comparison of Chamberland and Berkefeld filters .....................227

Bunge's flagella stain............... I9 I

Burcq, effect of metallic copper on bacteria... 250

Bütschli, nature of central body in bacteria. 2I6, 217

Butter, bacteria in.................. 259

Cabbage, natural infection in... 92, 93, 94, 102, 124

Cages for inoculation................. I08

Calcium carbonate, effect of, on longevity.... 6 6 I

Calcium chloride, effect on luminous bacteria. 60

Camera,

Abbe, for drawing................ I30

centering of horizontal............... I37

enlarging, reducing, and copying......... 146

photographing with horizontal........... I 37

Cankers produced by bacteria............ 8

Capillary drop flask............... 21, 226 Capsule,

branching caused by one-sided development

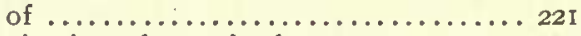

examination of unstained.............. I9

Friedlaender's stain...............220 methods of staining for demonstration of. 19, 194 Moore's contrast stain...............22 I

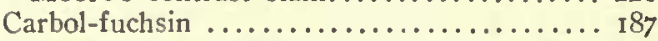

Carbol-methylene blue................. I88

Carbolic acid...................... 74 for sterilizing surface of diseased material.. I4 Carbon dioxide,

assimilation of, by bacteria............ 64 behavior in.................. 59, 223 cultures in, factors to be considered....... 59 gencration of................... 54,55
Carbon dioxide - continued.

Page.

removal of all oxygen from............. 57

test for, in fermentation-tubes......... 6 I

test for purity of .................. 55

washing of ...................... 55

Carbon monoxide, effect on bacteria........ 58

Carnoy's fixing fluid................. 202

Casein,

non-precipitated, clearing of.......... 267

precipitated, re-solution of.............. 46

separation of, in milk-cultures........4 46,67

Cavities produced by bacteria............ 8

Cell-nucleus ............... 216,217,219

Cellulose,

in bacteria................... 219,254

pure, fermented by bacteria...........209

Chains, occurrence of bacteria In......... 22

Chamberland autoclave................ 85

Chamberland filter,

cleaning of................. 45, 227

enzymes entangled in walls of.......... 68

penetration of, by bacteria.......... 45, 226

used in study of antagonism......... 73

Characters,

cultural, value of ................ 178

decimal systen of recording............ I75

morphological, value of............. I76

variation in, due to environment....... I82, I83

Check-plants,

importance of ................... 14, I86

proper behavior of............... 15, 16

Checking work, necessity for, and methods of. 184

Chemicals, for use in culture-media........ 97

Chemotropism ...................... 27

Chester,

decimal system.................. I75

terminology for description of colonies.... 30

Chlamydothrix .................... I62

Chloroform ........................ 250, 254

Chlorozinc-iodide,

use in staining anthrax spores........... 218

Chodat, lactic acid bacteria in cheese....... 260

Cholera vibrio,

cultivation on potato................ 249

destroyed by river waters in India.......... 25

effect of copper on................. 250

method of diagnosing and isolating....... 229

names for....................... I73

Chondromyces .................... 165

Chromatium ...................... I64

Chromatium Ökenii, cells connected sidewise. 2 I6

Chromic acid,

cleaning mixture....................200

use in staining spores............... 218

Chromo-aceto-osmic acid for fixing fluid.... 202

"Chromo-agars" for differentiation........229

Chromogens, medium for study of....... 48, 224

Chromoparous bacteria................ 237

Cladothrix .......................... 162

Classifications ..................... 154

Classification,

Migula's system.................. 159

Fischer's system................... 157 
Classification-continued.

water-bacteria .................... 203

Winslow \& Rogers................ 265 with reference to nitrogen-nutrition....... 175

Cleaning, glasswarc............ 100, 226, 227

Cleaning mixture, chronic acid.......... 200

Clostridium pasteurianum, separation by heat. 106

Cloth, impervious to light.............. I43

Clouding,

nature of, in culture-fluids............ 42

rapidity of, in culture-fluids........... 42

Coccaceae, revision of..................265

Coccobacteria septica................. I7ó

Coconut-water, as a culture-medium....... 4I

Cocothrix ..................... 172

Cohn,

Bacillus of ........................ 158

Bacterium of .................... I66

nutrient solution of ............... 197

rise of temperature in cotton-wool waste... 248

Collections, the nuking of............. II

Collodion,

sac-method for study of antagonism...... 73

sacks, preparation of, for dialyzing.... 37, 229

Colonies,

acid-forming, special agar for detection of. 5I

characters to be noted on solid media..... 29

counting of ...................... 36

effect of physical conditions on appearance of $\ldots \ldots \ldots \ldots \ldots \ldots \ldots \ldots \ldots \ldots \ldots \ldots \ldots \ldots \ldots \ldots \ldots \ldots \ldots \ldots$

measurement of.................... I15

photographing of ............... 134

Color-scales,

importance of .................... I09

kinds recommended.................. 263

Comma bacillus,

classification of .................. 173

Koch's paper on.................. 212

Conditions which are unfavorable, influence on cell-unions................ 22

Conrad, fermentation of sauerkraut........ 257

Constancy of characters............... 183

Contact-irritation .................. 27

Contamination, how to avoid............ I03

Contrôl-plants, proper behavior of....... I5, I6

Coplin's staining jar................... I I

Copper-chrom-filter .................. 20I

Copper salts, germicidal value of.........25I

Copper sulphate..................... 74

Corallin, test for slime derived from starch.. 22I

Cotton,

dry heating in bulk.............. 99, IOI

natural infection in................. 95

surgeons' absorbent, sterilization of........ I0I

waste, for laboratory use............. 107

Counting-plates, ruled................... 36,227

Cover-glasses, cleaning of............. 227

Cover-glass preparations................20, 28

Covers, discarded, care of............. 107

Cramer, resistance of spores to dry heat, cause of ....................... 218

Crenothrix ............................. 162

Cristiani, bacteria in upper air........... 255
Page.

Cross-inoculations . ................. 186

Cross-level ........................ 149

Crystals,

formation of, in milk-cultures........... 46

in old cultures..................... 66

prevent making thin sections........... 122

Cucumber, natural infection in......92, 178, 215

Cultural characters,

value of ....................... 178

variations in, due to environment..... I82, 183

Culture-fluids,

cold sterilization of .............44,52

examination of, before inoculation......... 42 growth in, characters of, to be noted..... 42 non-synthetic...................... 195 synthetic...................... 197

time required for clouding. ............ 42

Culture-media ......................223 agar-nutrient......................... 195 beef-broth.................. 45, 195 blood-serum ...................... 48 containing sugars, stcrilization of........ 98 cooked vegetables for.............. 40 Dunham's solution.................. 195 egg-albumen ..................... 48 egg-yolk ...................... 49 for iuminous bacteria.............6. 60,199 gelatin .................... 29, 196 hydrochloric acid in................. 98 litmus milk...................48, 196 milk ........................ 46 non-synthetic ................... 195 plant juices used as.................. 4I preparation and care of............. 97 protection from light................. 53 raw, preparation of ............... 4I record-book for...................... 109 silicate-jelly .................... 36, 198 special, for differential purposes......... 229 starch-jelly .................. 50, 196 sterilization of, in autoclave............ g8 storage of...................... 99 synthetic ........................ 197

titration of .................... 69

Culture-rooms ..................... I04

Cultures,

elective ......................... I06

involution forms in................. 23

method of keeping notes on............ II3

methods of testing purity............... $8_{4}, 185$ plate, stab and streak............. 29,30 preservation of, in museums............ 20 2 storage of stock............... 123, 263 treatment of spilled.................. 107

Cyanophyceae, cilia on side walls of.......2 211 Cystobacter ...................... 165, 218

Cytase ......................... 67

Dallinger, measurement of unstained flagella,

Dallinger \& Drysdale, Bacterium termo, fla-

170, 219 gella of...................... 20

Dangeard, green bacteria.............. 237

Dannappel, spores sensitive to heat......22, 246 
Dark-room

arrangement of................. I50

ventilation of .................. I49

d'Arsonval,

negative results with ozone........... 252

osmotic pressure of bacteria.......... 247

Darwin's wax-mixture.............. 200

Dawson, root-tubercles of legumes........ 64

Davenport \& Castlc, acclimatization to high temperatures ................. 222

Decimal system of recording characters..... I75

de Freudenreich,

bacteria in mountain air...............255

penetration of Chamberland filter by bacteria ....................... 226

Degeneration-forms ........... 23, 177, 252 de Koninck, gas-generator............. 54

de Lagerheim, macaroni as a culture-medium. 224

Delbrueck, acid fruits, effect on cholera organism .................... 249

Delphinium, bacterial disease of ........ 92, I 30

Denitrifying organisms, Giltay \& Aluerson's culture-medium for............... I98

Desiccation, effect of ........... 70, 248

Developer,

hydrochinon ............... I 46 , 201

lantern-slide ......................2OI

ortol ...................... I40

pyrogallol ...................200, 20I

Development of negatives............. I40

Dewar glasses, for liquid air............ 80

Dextrin for use in fermentation-tubes....... 52

Dialyzing, collodion sacks for.......... 37

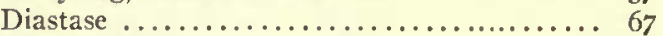

Diastasic action, medium for study of .... 50, 196

Dieudonné, part of spectrun harmful to bac-

teria ....................... 244

Differentiation of species.......25, 225, 220, 230

Dilution method for obtaining pure cultures.. 226

Diphenylamine-test for nitrates......... 267

Direct-infection experiments, value of ....... 9

Disease,

conditions favoring the spread of........ 93

geographical distribution of ........... 7

meaning of term................. 4

signs of ..................... 7

varietal resistance to ............ 93, I86

Disinfectants ..................... 74

for sterilizing surface of diseased material. If

literature of ................. 250

Disinfection of hands, wounds, floors, tables, etc. ...................... I07

Distilled water,

of a high degree of purity............. I 20

made in large quantities.................... I 24

made in small quantities................... I28

storage of ................... 126, 120

Distribution, gcographical ...............

Divided-plate method for study of antagonism

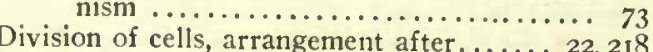

Downes \& Blunt, discover of light ................... 243
Page.

Drawings, on photographic prints.......... I5I

Dreyer, staining of bacteria in tissues....... 222

Dreyfuss, cellulose in bacteria............. 254

Dry air, sensitiveness of bacteria to.....7.7, 249

Dubois, fluid medium for luminous bacteria. 242

Duckwall, method of staining flagella....... 193

Dunham's solution................... 195

Eau de Javelle ..................... 207

Economic aspects,

conditions favoring spread of discasc...... gI methods of prevention............... 93 natural methods of infection.......... 9I need of statistics relating to plant diseases.. go

Egg-alhumen,

for culture-media................ 48

Mayer's ....................... I Ig

Eggs as a culture-medium...........224, 225

Egg-yolk, for culture-medium.......... 49

Ehrenberg,

Bacterium of . ............... I65-169

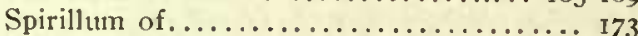

Ehrlich's anilin-water gentian violet......... I 87

Ehrlich-Weigert anilin methyl violet.... J 87, , 88

Elective culture.................... 106

Embedding, method of, for microtome-sections $\ldots \ldots \ldots \ldots \ldots \ldots \ldots \ldots \ldots \ldots$ I 8

Engelmann,

green bacteria.................... 236

photometric locteria............... 243

Enlargements, photographic........... I47

Environment

influence on cultural characters. I78, ı 82, I83, 222 response morphologically to change in. I76, 222

Enzymes,

filtering of $\ldots \ldots \ldots \ldots \ldots \ldots \ldots \ldots \ldots$

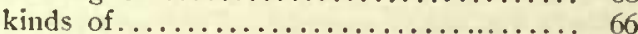

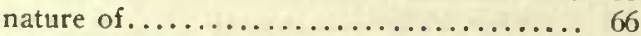

not injured by dry heat.............. 68

number produced by one organism....... 68

substances inhibiting action of.................... 68

thermal relations of ............ 67,233

Errera,

India ink in microscopy. ............ 226

spirillum of large size................ I9

Error, methods of guarding against.............. I $8_{4}$

Ether, sulphuric................ 74, 254

Euspirosoma ........................ I6

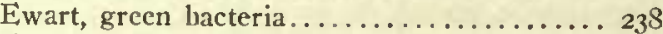

Ewell, anaërobic apparatus.................. 56

Exposure scales.................. I43

Exposure, time of,

for isochromatic plates ............. I43

for lantern slide.................. 146

for Petri-dish poured plates ........... I34

for photomicrographs.................. I4

for velox paper...................... I5

Faber's pencils for glass................. I Io

Farmer's reducing solution.......................... 142

Favorable influence of one organism on another $\ldots \ldots \ldots \ldots \ldots \ldots \ldots \ldots \ldots \ldots, 72,71$

Fehling's solution,

reaction of peptone with............. 229

when not usable............. 208, 234 
Page.

Feinberg, on cxistence of nucleus........217

Fermentation,

causes of ..................... 60

commercial importance of............. 60

determination of gases produced by....... $6 \mathrm{I}$

effect of calcium carbonate on.......... 6 I

isolation of products of ............ 6 I

litcrature of..................... 232

meaning of term................ 60

measurcment of volume of gas produced... 61

ohscrvations to be made on........... 6 I

of cellulose..................... 209

pectic .......................... 257

products of .................60, 6́

Fermentation-tubes,

absorption of air into closed end of...... 52

fluids to be used in................. 52

observations to be madc on cultures in.... 52

style preferred.................... 53

substances to be tested in............ 52

test for presence of air in closed end...... 54

wooden rack for................. 52

Fermented foods, bacteria of............. 235

Fernui,

concentrated solution for silicate-jelly... 39, 197

effect of acids, etc., on bacteria.......... 249

studies of ferment-bacteria............ 233

Fermi und Montcsano, reagent for sugar.... 234

Fcrmi und Pernossi, action of heat, light, ctc.,

on enzymes..............................

Ferran, aërobic behavior of tetanus........ 231

Ficker, glass, influence of substances dis-

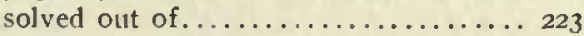

Filaments, bacteria in form of........... 22

Filters,

Berkefeld and Chamberland, for cold sterilization of fluids.................. 43

Zettnow's copper-clirom.............. 201

Filter-papers,

cnzymes held in meshes of............ 68

most convenient form of............. 34

reaction of ......................... 34

Filtration,

by means of compressed air, etc......... 44

inside-out method................. 43,226

of milk for culture-media............... 46

of nutrient-agar.................. 33-35

of thick fluids....................... 69

Fiocca's spore-stain.................. 194

Fischer, A.

classification of .................. 157

experiments on plasmolysis..........22, 254

flagclla-stain ................... 191

subfamilies distinguished by flagella...... 20

Fischer, B.,

bacteria in sca-air................. 255

germicidal action of light through water... 244

Fish-parasites ................. 2I3, 2 I4

Fixation of plant material containing bacteria. 8

Fixing fluids......................... 202

Flagella .............................. 219

classifications based on........... 20, 157

earlicst demonstrations of ............. 20

stains ..................... 20, 190 lagella-staining

cultures best suited for............... I90

literature on ..................... 259

technique ..................... 189

Flasks, for storing distilled water......... I2n

Flax, retting of............... 257, 258

Flemming,

fixing fluid...................... 202

triple stain...................... 188

Flexner's anilin gentian violet............ 187

Flocculence in fluid-cultures............. 22

Florideae, source of agar........... 32, 224

Fluorescine ....................... 65

Focus-difference, with achromatic objectives. I40

Foerster, Chromatium Okenii, cells connected sidewise .................... 216

Folmer \& Schwing, enlarging, reducing, and copying camera................. I46

Formaldehyd .......................... 74

Formalin ...................... 74

differential effect on bacteria............ 229 gcrmicidal action............... 252, 253 preservation of cultures by use of ........ 263

Formulæ ..................... 187

Forster, gelatin with high melting point..... 225

Foth's spore-stain..................... 218

Fractional method of culture.............. 226

Fraenkel \& Voges' solution.............. 197

Franklaind,

effect of gases on bacteria.............23I

photographic action of bacteria.......... 242

Frankland \& Ward, method for study of antagonism .................. 73

Freer \& Novy, germicidal action of organic

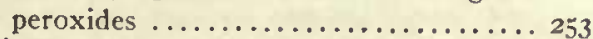

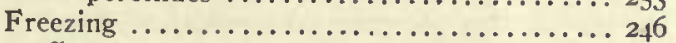

cffect on anthrax, etc.......................... 247

effect on B. typhosus............. 247, 258

effect on bacteria of pest and diphtheria... 247

osmotic pressure a factor in............ 247

with liquid air................. $79-83$

with salt and ice....................... 83

Frost,

antagonism .................... 73

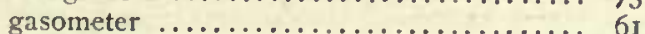

Friedlaender,

acid-fast stain.................... I87

capsule-stain .....................220

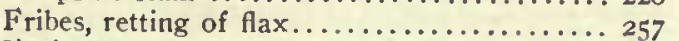

Fruit-ether-forming bacteria............. 259

Fuchsin, anilin........................ 187

Fuller's scale...................... 69

Funck, cleaning of cover-glasses............ 227

Fürbringer und Freyhan, disinfection of hands $\ldots \ldots \ldots \ldots \ldots \ldots \ldots \ldots \ldots \ldots . \ldots \ldots 252$

Gabbett's stain ..................... 88

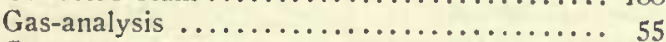

Gases, compressed.................... ${ }_{81}^{55}$

Gas-generator,

de Koninck...................... 54

hydrogen, with wash-bottles.................. 55

Kipp ........................ 54

Gasometer, Frost's...........................

Gas-pressurc regulator, Murrill's......... 78 
Page.

Gauze, surgeon's, uses in laboratory....... I02

Gelatin,

antiseptic salts in................. 30

brands recommended for bacteriological work ........................ 3 I

composition of.................... 30

impurities in...................... 30

melting point of................. 30

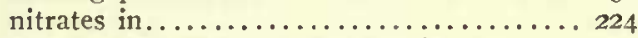

per cent recommended for media........ 30

plate-cultures, stabs, streaks.......... 29

standard nutrient, preparation of......... Ig6

sterilization of.................... g 98

variation of same organism on.......... I80

with cane-sugar................... 5I

with high melting point............ 225

with malic acid..................... 5 I

with soluble starch, etc............. 5I

Gelatinization, of old milk-cultures......... 46

Gelidium, species, source of agar-agar...... 31

Generic characters based on morphology...... I56

Generic names rejected............... I74

Gentian violet,

Ehrlich's anilin-water............. I87

Flexner's anilin...................... 187

Gerlach, germicidal action of lysol........ 25I

Germicides ........................ 74

literature on.................... 250

Germination, spores should be subjected to... 2I

Gessard, green-fluorescent bacteria........ 237

Giltay \& Aberson, culture-medium for denitrifying organisms............... I98

\section{Glassware}

cleaning and sterilization of........... Ioo

pencils for writing on................. II I

solubility of ..................... I29, 223

Globig, thermophilic bacteria............. 248

Glue, blue-pigment bacteria injurious to..... 237

Glycerin,

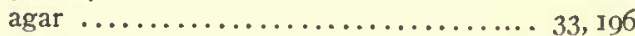

gelatin .......................... 262

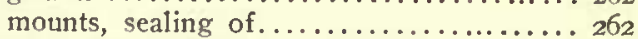

Goriansky, wood-vinegar as a disinfectant... 252

Gram's stain....................... I88

Nicolle's modification.................. 222

Grape-sugar

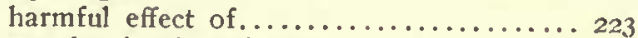

test for, in plant tissues................. 208

Green, germicidal value of copper salts...... 25I

Green bacteria.................... 237, 238

Green-fluorescent bacteria.............. ó

Gessard's studies.................. 237

Jordan's studies....................... 238

Thumm's studies.......................... 238

Griess-Ilosvay's reagent................... 229

Grimbert, on value of synthetic media........ 529

Growth of bacteria,

manner and rapidity of $\ldots \ldots \ldots \ldots \ldots \ldots 27$

on media exhausted for other organisms... 2I I

rates of, in fluid cultures...............

restrained by acid gelatin................ 30

Grove, glycerin mounts rendered air-tight.... 262

Gruber, resistance of spores............. 246
Guillebeau \& de Freudenreich, agar made

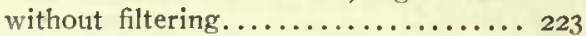

Haegler, centrifuging agar.............. 225

Halation, means of avoiding............ 136

Hallier, views concerning morphology...... I76

Hands, disinfection of ................. 252

Hanging-drop cultures................ 22

containing single organism........... 27

manner and rapidity of growth at given temperatures ................. 27

Hankin, germicidal action of river water.... 25I

Harris, collodion sacs, method of making.... 229

Haswell, method of substituting alcohol for water $\ldots \ldots \ldots \ldots \ldots \ldots \ldots \ldots \ldots \ldots .226$

Hatiser,

spore-stain ...................... I94

preservation of cultures for museums..... 263

Heat,

as a means of separating organisms....... 106

as a sterilizer for surface of tissues....... I3

dry, cause of resistance of spores to...... 218

effect on pigmentation, pathogenicity, sporulation $\ldots \ldots \ldots \ldots \ldots \ldots \ldots \ldots \ldots \ldots, 8_{7}$

enzymes injured by moist............ 67

influence of substratum on resistance to. 219, 247

Heidenhain's iron-haematoxylin........... I 89

Heim, anaërobic cultures of............ 23i

Hellstroem, grape-sugar, harmful effect of... 223

Hempel,

burette for gas-analysis.............. 55

pipette for liquid reagents.............. 55

Henle, on proofs of pathogenesis........... 9

Herter \& Foster's test for indol............. 20I

Hesse,

media for water-bacteria.......... I96, 258

method of cultivating anaërobes............. 230

Hill's hanging-block method........... 22, 228

Hinterberger, method of staining flagella... 220

Hiss, media of,

for differentiation of motile bacteria...... 26

for differentiation of typhoid, colon, and allied bacilli...................230

Hitchens, on autoclaving louillon containing

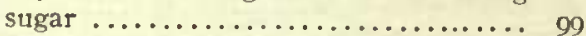

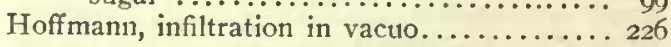

Hoods,

improvised .......................... 104

in laboratories..................... 104

Host, color changes in,

due to injury other than that caused by

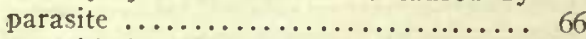

due to oxidation phenomena............... 65

due to parasite..................... $6_{5}$

Host, reaction to parasitic attack............. 8

Host-plants, kinds attacked by a single parasite .............................. 87

Hydrochloric acid, in culture-media.......... 98

Hydrogen,

compressed, where oltained........... 8I

cultures in....................... 56,57

test for, in fermentation-tubes........... 61

Hydrogen-cellulose ferment............. 106, 209 
Hydrogen generated with zinc.......... 54, 55 hydrogen sulplide in, means of avoiding evolution of.

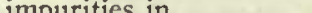
removal of last traces of oxygen from..... 57 washing of ................. 50́, 57

Hydrogen peroxide,

use in staining spores...............218 substance causing liberation of oxygen

from ..................67,234

Hydrogen sulphide............. 62, 242, 243

Hypo for fixing................... I42

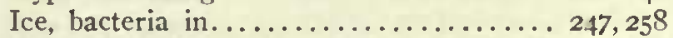

India oil-stone .................. I2I

Indigo-carmine, reduction of, by bacteria..... 62

Indigo-blue, production of............. 257

Indol,

production of, media suitable for........ 62 tests for....................62, 20 r

Infection,

carriers of .................. 9I, 178,2 I 5

conditions favoring............... I6

due to ultramicroscopical organisms.... I 8, 2I I

natural methods of.............. 8,92

Infection, stomatal........ 84, 86, 90, 92, 108, I 26

Infection-experiments, value of direct....... 9

Infectious matcrial, final disposal of........ I06

Infiltration,

in vacuo......................8, 226

with paraffi11................... II8

Injection-needle ................. I01, 227

Inoculated organism, method of proving viru-

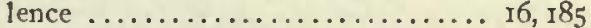

Inoculated plants, labeling of........... I I2 Inoculation,

cages .......................... I08

checks on.................... I6, I 86

cross ......................... I 86

methods of ...................... Ios

with more or less exact numbers of bac-

teria ...................... 226

Inoculation-experiments,

conditions favoring................. I6

how carried on .......................

importance of ................... I4

where best made.................... I6

with mixed organisms............. 9,72

Insects, inoculation by mcans of. . 91, I08, I78, 2 I 5

Instruments, sterilization of......... 100, 107

Intensifying negatives............... I42

Invertase ....................... 66

Investigation, training necessary for....... I8I

Involution-forms .............. 23, I77

Iodine-starch test for nitrites.............. ó3

Iron-haematoxylin............... I 88,189

Irritation, contact................. 27

Isochromatic plates,

for photographing stained sections........ I40

time of exposure with............... I43

uses of ........................ I 36

Isolation of bacteria,

from diseased tissucs, methods of........ II

on slant agar, etc.................... 227
Page.

Iwanoff, penetrating power of formalin..... 252 Jeffer, ruled counting plate.............. 36

Jennings, contact-irritation........... 27, 254

Johan-Olsen, branching forms...........217

Jolles und Winkler, bacteria in oleomargarine and butter.................. 259

Jones, enzymes from soft-rot organisms.... 68

Jordan, pigments produced by green-fluorescent bacteria..................... $6_{5}$

Kabrhel, methylen blue as oxygen indicator. . 232 Kaiser, glycerin-gelatin................ 262

Karten, chemical analysis of agar-agar..... 32

Kasansky, effect of winter cold on bacteria... 247

Kaufmann, method of staining capsules..... I94

Kedrowski, anaërobes grown with aërobes... 231

Kendall, decimal system............... 176

Kephir ..........................214

Kern, two endospores in a cell........... 22

Kipp gas-generator.................. 54

Kitasato flask.................... 68

Klebs, fractional method of culture........ 226

Klein, A.,

anaërobic apparatus of............... 232

spore-stain ..................... 219

Klein, L., bacilli bearing grcen spores....... 218

Klepzoff, freczing experiments of........ 246

Knauer, cleaning slides and cover-glasses.... 226

Knives, microtome................. I22

Koch, A., branching of B. pediculatum...... 22I

Koch, R.,

comma bacillus of................ I73

demonstration of flagella by stains........ 20

importance of photography in microscopic

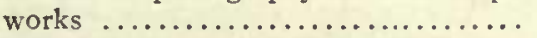
magnification recommended for photomicrographs ....................... 24 methods of isolating parasite from tissue. II, 226 paper on tuberculosis................. I53 rules of proof................ I8, 226 streak-method of isolating bacteria...... I I, 226 views concerning morphology.......... I76

Kontádi, germicidal action of soaps.............253

Kraemer, germicidal action of copper.......253

Kratschmer und Niemelowicz, stringy bread. . 260

Krause, Bacillus pyocyaneus............. 223

Krueckmann, preservation of cultures for museums ................... 263

Kuehne,

carbol methylene blue............ I88, 222

malachite green..................... 222

Küntsler, animal origin of bacteria......... 264

Kuntze, medium for Bacillus prodigiosus..... 238

Kuprianow, device for filling test tubes...... 227

Labels, for tubes, flasks, etc........... IIO, II I

Lab ferment..................... 67

Laboratory,

care of....................... 96

equipment of................... 94

things to be considered in location of..... 94

Lamella, middle, dissolution of........... 67

Lamprocystis ..................... Ió3

Lantern-slides,

apparatus for making............ I43, I46 
Lantern-slides-continued.

developinent of ................ 146, 201

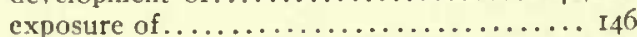

Larkspur, natural infection in........ 92, 1.39

Laser, on action of hydrogen peroxide..... 2,34

Lautenschläger oven................. I00

Lead acetate paper.................. 62

Leguminosae,

root-tubercle bacilli of, fixation of nitrogen

by $\ldots \ldots \ldots \ldots \ldots \ldots \ldots \ldots \ldots \ldots \ldots$

Moore's culture-medium for........... I97

L,enses,

achromatic, defects of .............. I40

apochromatic, in photomicrography....... I39

for bacteriological work ............. 23

Lenses, photographic,

Goerz ...................... 130

Voigtlaender .................... 130

Zeiss Double-Protar.............. 130, 132

Zeiss Planar.................... I32

Zeiss Protar.................... 132

Zeiss Unar...................... 132

Lenticels, natural infection througlı........ 92

Lepeschkin, branched form described....... 218

Leucin ........................ 63

Leuconostoc mesenterioides, isolation of.... 106

Levin, bacteria rare in Arctic............. 255

Levy, physical properties of enzynes....... 68

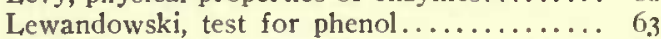

Liborius, oxygen in depths of agar........230

Light,

action on bacteria............71, 243,244

bactericidal action ascribed to hydrogen peroxide .....................244

germicidal action on dust greatest when moistened ......................244 germicidal in hydrogen............. 244 germicidal action in water............ 214

Light filter for photomicrography,

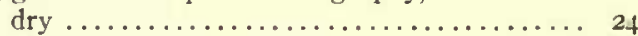

Zettnow's .................... 24, 201, 263

Lilac blight......................... 64

Liquefaction in gelatin stab-cultures, characters to be noted................. 29 interferences of various substances with.... 29

Liquid air, effect of, on bacteria........ 79, 247 temperature of .................. 80

Lister, dilution method for obtaining pure cultures ....................27,226

Litmus-lactose-agar .............. 33, 196

Litmus milk,

cultures in, observations on............. 48

preparation of .................. 48,196

Litmus paper, for testing acidity......... $6 \mathrm{I}$

Litmus, reduction of, by bacteria........... 62

Loeb, typhoid bacillus, branching forms in... 218

Loeffier,

alkaline methylene blue............. I 88

extraction of enzymes................ 68

flagella-stain $\ldots \ldots \ldots \ldots \ldots \ldots \ldots \ldots \ldots$ I90

Loew,

culture-medium for Bacillus prodigiosus... 239 enzymic fermentation of tobacco......... 257
London, resistance to starvation......... 223

Loops, platinum-iridium, for making transfers. $\quad 4.3$

Loquat, bacterial disease of............. 88

Löwit's flagella-stain................. 192

Luminous bacteria...............60, 24 I

cause of luminosity of ............... 60

culture-medium for................ 198

Dubois' fluid medium for............. $24_{2}$

effect of chlorides on............... ó

effect of magnesium sulfate on.......... 60

cffect of manganese stzlfate on.......... 60

effect of potassium iodide on........... 60

effect of potassium nitrate on........... 60

effect of potassium sulfate on........... 60

in or near salt water............... 60

in sand-fleas...................... 60

Molisch's work on................ 60

on meat exposed in markets............. 60

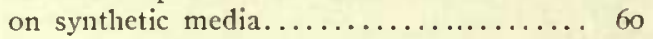

spectrum of .................... 242

thermal relations of ............... 60

Lunt, stock-cultures of water-bacteria, how best kept.....................263

Lysol,

for sterilizing sturface of diseased material. It germicidal action of ................ 25I

Maassen,

branching forms produced at will by..... 2,3

culture-fluid of ...................... Igs

fruit-ether-forming bacteria........... 259

reducing powers of bacteria.........62, 243

Macé,

recuperation of pigmentation and pathogen-

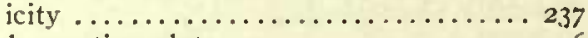

ruled counting-plate.................. 36

Macfadyen,

effect of liquid air on bacteria.......... 247

thermophilic bacteria................ 248

Mackensie's culture-fluid................ 198

Magnesium chloride, effect on luminous bacteria ........................ 60

Magnesium sulfate, effect on luminous bacteria ........................ 60

Magnification, determination of.......... 115

Maize,

artificial infection of ............... 90 cross-section of stem............... 4

natural infection in.................. 92

Malachite green, use of............. 18g, 222

Maltose-agar ..................... 33

Manganese sulfate, effect on luminous bacteria $\ldots \ldots \ldots \ldots \ldots \ldots \ldots \ldots \ldots .60 . \ldots \ldots$

Marmier et Abraham, germicidal action of ozone ........................ 252

Marpinanil,

"chromo-agars" for differentiating....... 229

germicidal action of sodiun fluoride..... 253

iron bacteria....................... 26I

Marsh gas.................... 61, 209

Maxinum temperature,

how determined.................. 75

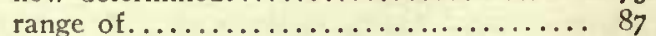

Mayer's culture-fluid................. 197

Mazé, root-tubercle bacteria........... 240 
Meat-cxtracts, bacteria in............. 20́ Media for cultures,

agar........................... 31, 195

animal fluids..................... 45

gelatin...................... 29, 196

milk ...................... 46, 196

non-synthetic ..................... I95

plant juices....................... 4I

silicate-jelly ...................... 4I

special ......................... 49

starch-jelly ................... 50, 196

sterilization of ................... 85

synthetic ................. 49, 197

vegetable media, solid.............. 39

Media free from spores, easy sterilization of. 40,85

Mercaptan ...................... 6́2, 243

Mercuric chloride.................. 74

for sterilizing plants beforc inoculation. 108,109 for sterilizing surface of diseased material. I4 germicidal action of ............... 252 in hot alcohol, as a fixing fluid......... 8 preservation of cultures by use of........ 263

Messea, classification of............20, 20.4

Mctcalf, bacillus softening agar........... 32

Meters, for photographic exposures........ I 43

Methane-cellulose ferment.............. 106

Methods of work,

checking $\ldots \ldots \ldots \ldots \ldots \ldots \ldots \ldots \ldots \ldots$. 84

litcrature on..................... 226

Methylene blue,

as a test for free oxygen.......... 57,232

Loeffler's alkaline................... 188

reduction of, by bacteria............62, 239

Methyl violet, as a germicide............ 74

Meyer, effect of liquid air on bacteria....... 247

Michaelis, thermophilic bacteria............ 248

Micrococcus ...................... I60

Micrococcus progrediens, small size of ..... 18

Micrometers, stage.................. I I5

Micro-organisms, cell-life without.........2 II

Microscope,

achromatic objectives for .......... 140, 265

apochromatic objectives for............. 130

for recording exact location of desirable fields ........................ 129

L $\operatorname{citz} \ldots \ldots \ldots \ldots \ldots \ldots \ldots \ldots \ldots \ldots \ldots$ I 29

octulars ......................... I 30

Spencer ........................ 129

Zeiss, for bacteriological investigations..... 129

Zciss, for photomicrographic work........ I29

Microspira ................... I6I, I72

Microtome, kind preferred.............. I22

Microtome-knives .................... I22

Microtome-sections,

cutting and care of $\ldots \ldots \ldots \ldots \ldots \ldots \ldots$ I 19

mounting of .................... I I

staining of ................... I 19, 120

Microzymas of Béchamp.................. 176

Migula, classification of.............. 159

Milk,

a good culture-medium............. 47

allaërobes in........................ 46
Milk-continued.

Page.

clearing of .................. 46, 267

coagulation of, by bacteria................ 67

enormous numbers of bacteria in ........ 196

litmus .......................... I96 observations to be made on cultures in.... 46 preparation of, for culture-medium...... 46 reddened by bacteria................ 259 resistant spores in................. 46 ropiness in.................. 259, 260 sterilization of.................. 46,98 temperature governs bacterial multiplica-

tion in.................... 20́o

Minervini, bactericidal action of alcohol.... 252

Minimum temperature,

for growth, how determined........... 76

range of ......................... 87

Miquel,

bacteria in sea-air................ 255

thermophilic bacteria ............. 247, 248

Mixed cultures, behavior of........... 72

Möller's spore-stain................... 218

Molisch, on luminous bacteria............ 60

Monas ........................... I73

Moore, A., capsule-stain................ 22 I

Moore, G. T.,

copper sulphate as a germicide........ 74 culture-medium for root-tubercle bacilli.... I97 root-tubercle bacteria................ 24I soil-inoculation for legumes............ 64

Moore, V. A.,

flagella-stain ................... I90

Moore \& Kellerman, action of copper on $\ddot{B}$.

typhosus in water.............. 97

Morphological characters,

change in, due to changed environment.... 222 value of ....................... 176

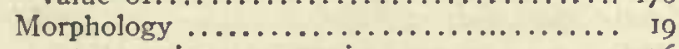

extreme views concerning............ I76 general account of $\ldots \ldots \ldots \ldots \ldots \ldots \ldots$ is generic characters should be based on..... 156 insufficient for differentiation of many spe-

cies .......................... 25

literature on ..................... 215

modern views concerning............. 177

Morton, flagella-stain............... 220

Motility of bacteria..................... 26

Motor-reflex in bacteria................254

Mueller, bacterial reduction processes....... 239

Müller, genus Vibrio................ I72

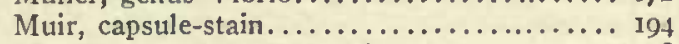

Murrill, gas-pressure regulator........... 78

Museums, preservation of cultures for... 262, 263

Mustard, natural infection in............ 92

Mycobacterium .................... 172

Myconostoc ......................... I6 I

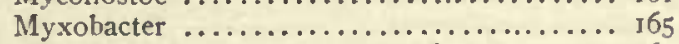

Myxobacteriaceae, characters of............. I64

Myxococcus........................ เó5

Naegeli's nutrient solution............. I97

Nakanishi, nucleus, existence of, in bacteria.. 217

Nectaries, natural infection through....... 92

Necdlc-punctures, inoculation by.......... r 08 
Needles, platinum-iridium, for making transfers $\ldots \ldots \ldots \ldots \ldots \ldots \ldots \ldots \ldots \ldots, 43$

Negatives,

development of .................... I40

records on ........................ I42

Nessler's test, how used............... 6r

Neisser's spore-stain................. 194

Neumann, variability of pigment-formation... 238

Neutral red........................ 230

Nicolle, modification of Gram's method..... 222

Night-blue,

capsule-stain ..................... 221

stain for flagella.................. 220

Nitrate bacteria,

fluid culture-medium for isolation of...... I99

nutrient agar for isolation of........... I99

Nitrate bouillon....................... 63

diphenylamin test................ 267

Nitrates, reduction of, test for........... 63

Nitrifying organisms, magnesia-gypsum blocks for ....................... 200

Nitrite bacteria, fluid medium for isolation of. 199

Nitrites, test for..................... 63

Nitro-bacteria ................... I75

Nitrogen-assimilating soil-bacteria, medium for $\ldots \ldots \ldots \ldots \ldots \ldots \ldots \ldots \ldots \ldots$. 199

Nitrogen-bacteria .................. 175

Nitrogen-free media............... 5I, Ig 8

Nitrogen,

fixation of, by bacteria............. 64 growth in, apparatus for testing............. 58 removal of oxygen from............ 57

Nitrogen-nutrition, a basis for classification.. I75

Nitrogen salts, in special media........ 5 197

Nitromonas ....................... 240

Nitrous and nitrate bacteria............ 175

Nomenclature ..................... 154

Non-halation plates, uses of ........... I36

Novy,

a new thermoregulator................ 228

jar for anaërobic cultures...... 56, 57, 58, 231

Nucleus, existence of, in bacteria. I59, 216, 217,219

Nutrient material, amount needed by bac-

teria ....................... 225

Objectives, achromatic,

disadvantages of .................... I40

of excellent definition............... 265

Objectives, apochromatic,

Spencer $16 \mathrm{~mm} . \ldots \ldots \ldots \ldots \ldots \ldots \ldots . \ldots . \ldots$

Zeiss ............................ 130

Occlusion of vascular system due to bacteria.. 8, 12

Oculars ........................... 130

for photomicrography................ 139

Ohlmüller, germicidal action of ozone....... 25I

Oleomargarine, bacteria in............ 259

Olive-knot organism,

artificial inoculations................ 10

crystals produced by.................. 66

optimum temperature for............. 85

Omélianski,

blocks for nitrifying organisms.........200 isolation of hydrogen-cellulose ferment. 106, 209 sodium-formate medium.............. 50 spore readily stained by anilin dyes....... 22
Optimum reaction of medium for bacterial growth ..................... 69

Optimum temperatures................ 75,85

Origin of bacteria.................. I77

Ortol developer...................... I40

Ostwald-Pfeffer water-bath.............. 78

Oven, paraffin...................... I I

Oversteaming, effect of................ o8

Oxidases ......................... 67

Oxidation, pigments due to............. 66

Oxygen,

compressed, where obtained............ 8I

little, in deep layers of agar............ 230 pigment-formation, dependent on..... 238, 239 removal from hydrogen, nitrogen, and car-

bon dioxide.................. 57

Oxygen, relation of bacteria to, in,

fermentation-tubes $\ldots \ldots \ldots \ldots \ldots \ldots \ldots \ldots, 52$

surface and deep growths............ 51

Ozone, action on bacteria......... 25 r, 252, 253

Pacinia ....................... I 72

Pake, ruled counting-plate............... 36

Paper,

blue-print, for pen-and-ink work......... I50

drawing-board ................... 266

salted silver, for pen-and-ink work....... ${ }_{50}$

Paraffin,

infiltration with............... I I 8, 226 melting point of that used for embedding... I I9 recommended for cotton plugs......... 99, 263 trueing edge of blocks............... 123

Paraffin-oven ..................... I I9

Parasite,

relation of, to tissues of host......... 8, 10 reaction of host to.................. 8 means of gaining access to tissues of host. 8,92

Parasites, animal, harbored by plants....... 89

Paratrophic bacteria.................. 175

Parenchyma, intercellular spaces of, occupied by bacteria................... 8

Park, effect of freezing on B. typhosts...... 247

Pasteur,

culture-fluid .................. I97 dcfinition of aërobe and anaërobe........230 influence on bacteriology............. I52

Pathogenesis, rules of proof............ 9

Pathogenicity,

developed by association........... 72,215 of plant parasites to animals............ 88 regeneration of ..................... 237

Pane, Pneumococcus, origin of capsule.....221

Payen, agar-agar, composition of......... 223

Pear-blight organism,

action of light on................ 7 I

blackening of foliage attacked by......... 65 differentiated from B. coli by $\mathrm{KNO}_{3} \ldots$... 5I, II3

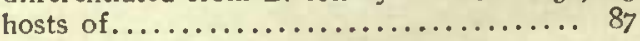
natural infection.................. 92 result of inoculations with........... 202 Pedesis ......................... 10 Peirce, root-tubercles of bur clover......... 64 Pelargonium, natural infection in......... 92 Pencils for writing on glass............. II I

Pepsin .......................... 66 
Peptone,

commercial ..................... 45

reaction of cholera organism with........ 229

tests for purity of ..................229

Peptone-bacteria ................... I75

Peroxides, organic, germicidal action of..... 253

Petri, nitrates in commercial gelatin....... 224

Petri-dishes .......................226

for excluding light................. 228

for quantitative work and photographing... 36́ of good quality, where obtained.......... 82

sterilization of ................... 100

Petri und Maassen, hydrogen sulphide from

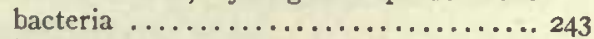

Phenol ............................ 74

tests for...................... 63

Phenolphthalein,

for use in titration................. 99

neutral point of................... 69

Photographic enlargements.............. 147

Photographic plates, for special work...... 136

Photographic prints,

drawings or..................... I5I

making of ................... 150

Photographing,

of bacteria in tissues............... 136

of poured-plate colonies................. I34

of test-tube cultures............... 135

Photography,

focusing planars................. 132

lenses for..................... 130, 133

Photomicrography ................ 263,264

Photomicrographic apparatus.........23, 129, 136

care of ...................... 139

Photomicrographs,

making of....................... 138

time of exposure for................. I43

Phragmidiothrix .................. 162

Physical conditions, influence of, on morphology .................. 177, 222

Physiological changes due to changed environment ...................... 222

Physiological peculiarities, for identification of species.................... 25

Picric acid,

as a fixing agent.................. 8

germicidal properties of..............250

Pierce, work on walnut disease.......... I76

Pigment-formation,

conditions of......................239

discussion of ................. 65,223

effect of symbiosis on.............. 223

how regenerated.................. 237

literature on...................... 236

variability of................ 222, 238

Pipettes,

discarded, care of .................. 107

sterilization of ...................... 100

Pitfield's flagella stain................. I9I

Planococcus ........................ I60

Plant acids, sensitiveness of bacteria to..... 69

Plant juices used as culture-media.......... $4 \mathrm{I}$
Plasmolysis, corcentration necessary for.....

necessary for.... 254

............... I76

Plate-cultures,

advantages of, for isolating bacteria....... II

arrangement of rods in colonies on......... 27

characters to be noted................. 29

discarded, care of..................... 107

how to avoid contaminations in.......... I03

Koch's, for obtaining pure cultures...... 226

labeling of ....................... II I

poured, how made................... 105

Plates,

isochromatic, for photographing stained sections ...................... 140 isochromatic, time of exposure with...... I43 isochromatic, uses of.............. 136 non-halation, uses of.................. 136 non-isochromatic, when preferable........ 136

Platinum black, enzyme-like action of....... 234

Platinum-iridium, inoculating noedles and loops ........................ 43

Pleomorphism ................... 176

Pleuro-pneumonia, organism causing,

at limit of vision................. I8 cultivation of, outside animal body....... 2I3

Plugs, paraffined..................... 99

Plum,

natural infection in..........86,88, 92,148

organism from................... I 8

subject to pear-blight............... 88

Pneumococcus, origin of capsule..........22I

Polyangium ....................... 165

Popoff, germicidal action of mercuric chloride. 252

Potassium,

chloride, effect on luminous bacteria...... 60

iodide, effect on luminous bacteria........ 60

nitrate, effect on luminous bacteria....... 60

nitrate, for differential purposes.......... 5I

sulfate, effect on luminous bacteria....... 60

Potato, steaming of.................... 98

Potato-broth, preparation of............ 42

Potato-starch, aseptic, preparation of....... 50

Prazmowski,

arthrospores ..................... 218

culture-fluid ..................... 197

Precipitate, in culture-fluids, nature of..... 42

Pregl, method of staining............... 222

Preparation of nutrient agar............. I95

Pressure, effect on bacteria.............. 245

Prevention of disease, methods of......... 93

Proskauer \& Beck's culture-fluid............ 198

Prudden, bacteria in ice............... 258

Pseudomonas ................. I60, 173

Ps. indigofera, small size of............. I8

Ps. syringae, reaction to nitrates........... 64

Pseudo-zoogloeae ................... 22

Pure cultures, how obtained............. II

Pyocyanin, test for.................... 65

Pyoktanin ........................ 74

Pyrogallol, with caustic potash as absorbent of oxygen ..................... 57

Pyrogallol developer.................. 200, 201 


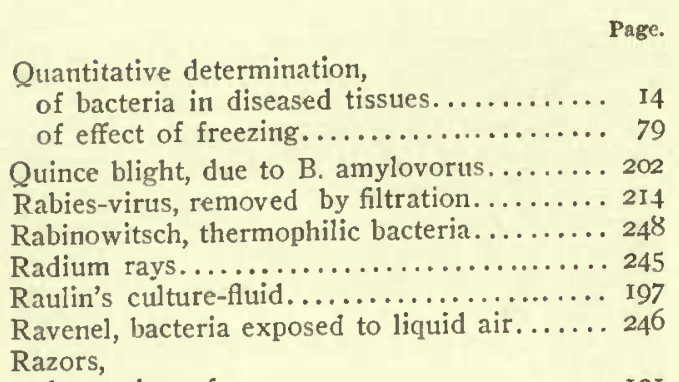

sharpening of $\ldots \ldots \ldots \ldots \ldots \ldots \ldots \ldots$ I2I

Torrey, Rogers, Lentz............. 123

Reaction,

for maximum growth in liquid media... 69, 203

of host to parasite................ 8

Record-books,

for culture-media.................. I09

for field-notes................... I Io

Records, methods of keeping............. I09

Reducing negatives................. 142

Reducing powers of bacteria............ 62

Reichenbach, branching in Spirillum...... 217

Reichert, thermo-regulator, improved....... 78

Reimers, bacteria in soil.............. 255

Rein, Florideae, source of agar.......... 224

Reinitzer, on gum-ferment............ 233

Re-isolations, necessity for............ I6

Relationships of bacteria.............. I77

Rennet ........................ 67

Rhabdochromatium .................. I64

Ribbert, method of staining capsules........ I94

Rice for culture-media................. 48

Ridgway, color scheme of............... 263

Roentgen rays...................... 245

Rogers, pathogenicity developed by association. 2 I5

Rohrbeck thermostat................. 75

Roll-cultures, Esmarch's................ 226

Root-tubercle bacteria............64, 240,24I

Roth, contact-irritation............... 253

Rothberger,

differential diagnosis with anilin dyes.....230

toluidin red for differentiation........... 230

Rothert, effect of ether and chloroform...... 254

Roux filter, for culture-fluids, etc......... 44

Roux thermo-regulator............... 78

Rubber,

caps for tubes of media.............. 99

note on best solvents for............. 207

Rulers for measuring colonies, glass, steel.... II

Rules of proof....................... 9, Io

Russell \& Babcock, fermentation of silage... 257

Ruzicka, inner structure of bacteria........217

Saccardo, color scheme of ............... 263

Sachs, reduction of cane-sugar in plants..... 66

Safranin-picro-nigrosin ................ 189

Salicylic acid..................... 74

Salt-bouillon ...................... 5I

Salt-water bacteria, minimum temperature for .................... 87,255

Sander, growth of tubercle bacteria on vegetable media.....................222

Sand-fleas, bacterium of luminous.......60, 242
Saponification of casein in milk-cultures.... 46

Saprophytes,

behavior of, when injected into plants.... 89 presence in diseased parts long affected.... I 3

Sarcina ......................... I60

Sauerkraut, fermentation of......... 257, $25^{8}$

Scales for photographic exposures......... I43

Schaffner's safranin-picro-nigrosin......... I 89

Schaudinn,

bacillus of large size................ I9

two endospores in a cell............. 22

Scheffler, neutral red for differentiating..... 230

Schild, formalin for detection of B. typhosus.. 229

Schill, preparation of cultures for museums. . 262

Schilow, germicidal value of hydrogen peroxide ........................ 25I

Schmeider, studies on pigment-formation.... 237

Schottelius,

B. prodigiosus, non-pigmented races of.... 222 preparation of nutrient agar........... 223

Schlitter, effect of acids on bacteria........ 249 Schultz, structural changes due to antiseptics. 252 Schumburg, bromine, water treated with.... 252

Schutz, method of making nutrient agar..... 34

Schwartz, on antiseptics................. 250

Sclavo's flagella-stain................. I92

Sclerothrix ...................... I72

Sea-weeds furnishing agar............ 33

Sections, microtome,

balsam for mounting............... II

boxes for preservation of.............. II7

cutting and care of $\ldots \ldots \ldots \ldots \ldots \ldots \ldots \ldots$ II

for photographing.................. I 40

keeping of material for.............. II

mounting of ...................... II9

preparation of ...................... I 8

staining of $\ldots \ldots \ldots \ldots \ldots \ldots \ldots \ldots \ldots \ldots$ II

Sedgwick \& Winslow, influence of cold on

B. typhosus ................... 247

Setchell, thermophilic bacteria............ 248

Signs of disease.................... 7

Silage-fermentation,

bacteria active in ....................256

bacteria not active in.............. 257

Silicate-jelly,

for differential purposes............... 39

method of preparing.............. 37,206

value, as a culture-medium............. 36

Winogradsky-Sleskin ................ Ig8

Sjoebring, nucleus in bacteria................ 216

Skschivan, branched forms............2I7

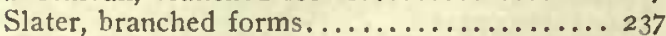

Slide-boxes ..................... II7

Slides,

care of discarded................ IO

numbering of....................... T2I

Smith \& Swingle, effect of freezing on bacteria ........................ 83

Smith, Theobald,

discovers cause of Texas fever.......... I53

method of filtering.................... 226 tubercle bacteria difficult to destroy by heat. 247

Soaps, germicidal action of certain......... 253 
Sodium clloride,

effect on luminous bacteria............. 60 restraining influence of........... 70,252

Sodium fluoride, germicidal action of ...... 253

Sodium hydrate, method of increasing toleration of $\ldots \ldots \ldots \ldots \ldots \ldots \ldots \ldots \ldots \ldots$. 70

Sodium nitrite, used for indol test......... 62

Softening hard tissues, fluid for............ 200

Soft-rot bacteria, many plants attacked by.... 87 Soil,

bacteria in upper layers of............255

parasites carried in................

sterilization of ................... 85

Solid vegctable media,

behavior of organisms on............ 40

preparation of....................... 40

substances recommended.............. 40

Solio paper, toning bath for............. 20I

Solubility of glassware .............. 129, 223

Solution of tissues occupied by bacteria..... I0

Solution persulphate of iron, preparation of.. I 88

Sorghum, natural infection in........... 92

Soy-bean, natural infection in............ 92

Sphaerotilus .................... 162

Species,

morphology not sufficient for differentiation. 25

Specimens, method of substituting alcohol for water in....................... 226

Spectrum, part possessing germicidal action. . 244

Spencer microscopes................... 129

Spina, studies of reduction processes......2 239

Spirillum ........................ I6I

branching in .......................... 217

double staining of ......................... 217

Ehrewberg's genus................... 173

Spirillum undula,

action of ether on................. 254

flagella of ........................ 20

Spirillum volutans,

flagella of ...................... 20

reaction to stimuli................. 27

Spirochaeta ....................... Iór

Spirodiscus ........................ I62

Spiromonas ....................... I62

Spirosoma ....................... I6

Spores,

action of lieat on .................. 84

Aujeszky's stain.................. 219

bacilli bearing green................. 218

cause of resistance to dry heat............. 218

classification based on............... I57

common in stringy bread................ 26I

effect of stcam on..................246

Fiocca's stain.................... 218

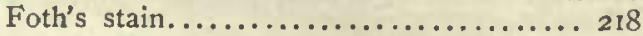

germination of ...................... 2 I

influence of environment on formation

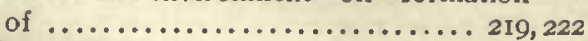

Klein's stain..................... 219

mcans for identification of............ 2 I

Moeller's stain......................... 218

reaction to stains.................... 27
Spores-continued.

Page. resistance to high temperatures and steam

heat ................... 21,84, 246 resistant, present in meat-extracts........260 resistant, present in milk............. 46 stains for........................ I94

Spraying, inoculation by............. I08

Stadler, effect of sodium chloride on bacteria. 252

Stage-micrometer ................... II

Staining,

bacteria in tissues................ 29, 222

double ...................... 217, 218

microtome-sections ................ I I9

Staining-media, groups of ............... 28

Staining methods......................221 bacteria, vegetative forms........... 27, 187 capsules ...................... 19, 194 flagella ................. 20, 21, 27, 189 spores .................... 27, 194

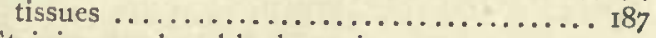

Staining produced by bacteria,

in host-plant.................... 65

in nutrient substrata........ $65,211,214,237$

Stains,

anilin, alcoholic solutions of........... I87

general and miscellancous, ................. 187

Starch from potato, preparation of......... 50

Starch-jelly, nutrient................. 50, 196

Starch, test for slime derived from........... 221

Starrett cross-level...................... 149

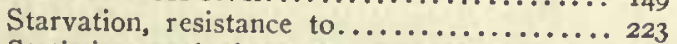

Statistics, need of, on plant diseases......... 90

Steam,

spores resistant to................ 84 sterilization by, possible source of error in. 47 vegetative bacteria sensitive to......... 83

Steaming,

media in tubes.................. 48

milk for culture-media................... 46, 47

Steam-sterilizer, Arnold.................. 47

Stephens, flagella-stain.................. 47

Sterilization,

cold, of culture-fluids............4 43, 52

cotton $\ldots \ldots \ldots \ldots \ldots \ldots \ldots \ldots \ldots \ldots \ldots \ldots . \ldots \ldots$. 53

culture-media ..................... 85

dry, of pipettes, scalpels, etc............ 4 I

glassware, instruments............100, 107

infectious material................... I06

milk ......................... 46

oven for........................ 100

silicate-jelly $\ldots \ldots \ldots \ldots \ldots \ldots \ldots \ldots \ldots \ldots . .39$

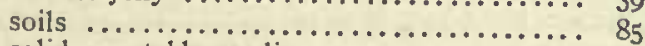

solid vegetable media................... $4^{5}$

starch-jelly ...................... 50

surface of plants before making cultures

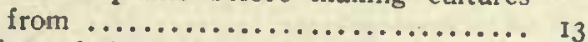

surface of plants to be inoculated.......... I, IO8

syringes $\ldots \ldots \ldots \ldots \ldots \ldots \ldots \ldots \ldots \ldots \ldots$.......... 102

with metallic copper................ 97, 253 Still,

for water, in small quantities........... 128

for water, on a large scale............... 124 
Page.

Stock-cultures, how best kept......... 72, I23

Stoddart, media for differentiation of motile bacteria .................... 26

Stolz, peculiar growths in Pnetımococcus, etc. 2I7 Stomata,

artificial infections by way of....... 108, 126 natural infection through........... 90,92

Stored media, effect of loss of water on..... 99

Streak-cultures, characters to be noted..... 30

Streblothrichia .................... I62

Streptococcus ...................... I60

Streptococcus mesenterioides, isolation of by heat $\ldots \ldots \ldots \ldots \ldots \ldots \ldots \ldots \ldots$ I06

Streptothrix ..................... Ió2

Succession of organisms in diseased tissues.. 73

Sugar-cane, red stain in bundles of........ 66

Sugars,

effect on liquefaction of gelatin......... 29

growth retarded by.............. 223, 248

proper sterilization of media containing.... 99

reagents for.................. 208, 234

Sulphur-bacteria ................ I62, 26r

Sunlight,

effect of....................... 7 I

in photomicrography................ 24

Surface organisms, partial removal by washing. I4

Surface sterilization.................. I3

Synthetic culture-media,

kinds of .................... 49, I97

value of ...................... 5 I

Syringes, hypodermic................ I02

Systematic position of bacteria........... I77

Szyszylowicz, corallin as a microchemical reagent ...................... $22 \mathrm{r}$

Tannin, method for detecting in cells....... 207

Temperature,

of liquid air ................ 83,247

optimum ....................... 75

maximum ........................ 75

minimum $\ldots \ldots \ldots \ldots \ldots \ldots \ldots \ldots \ldots \ldots . \ldots \ldots$

range of, suited to growth........... 86

Temperature, influence on,

geographical distribution............. 7

involution-forms $\ldots \ldots \ldots \ldots \ldots \ldots \ldots \ldots . . \ldots 22$

Teratological growths.................. 23

Test-tube cultures, inoculation of .................... I05

labeling of $\ldots \ldots \ldots \ldots \ldots \ldots \ldots \ldots \ldots$ III

photographing of................... I35

Test-tubes,

device for filling rapidly........... 98, 227

holder for....................... I04

Jena glass........................ 8

resistant glass..................... 82

tests of solubility................... 129

Tetanus poison, lethal dose of............ 213

Thaxter, Myxobacteria ................ I6 64

Thermal death-point,

apparatus for ................... 78

method of determining .............. 77

range of......................... 87
Thermal death-point experiments, methods of checking $\ldots \ldots \ldots \ldots \ldots \ldots \ldots \ldots \ldots$ I85

Thermal limits, effect of, on pigment production, pathogenicity, sporulation....... 87

Thermal relations,

of bacteria...................... 75

of enzymes....................... 67

Thermometers, Anschütz normal......... 78

Thermophilic bacteria,

common in digestive-tract............. 248

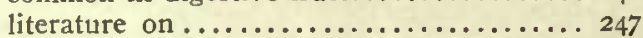

maximum temperature for.......... 87

minimum temperature for............. 87

often spore-bearing............... 248

Thermo-regulator,

Novy ........................... 228

Reichert ........................ 78

Roux ......................... 78

Tollens ........................ 37

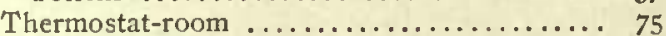

Thermostats ........................ 75

Thermotaxis ...........................254

Thiocapsa $\ldots \ldots \ldots \ldots \ldots \ldots \ldots \ldots \ldots \ldots \ldots . \ldots \ldots$

Thiocystis ........................ I63

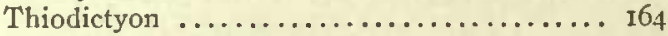

Thiopedia ....................... I63

Thiopolycoccus ................... I64

Thiosarcina ........................ I63

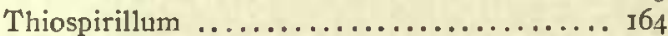

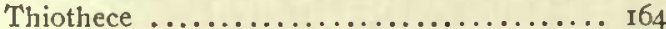

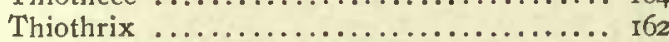

Thomann, bacterium of stringy bread.......26I

Thumm, green-fluorescent bacteria......... 238

Thymol ......................... 74

Tischutkin, preparation of nutrient agar.... 224

Tissues, solution of, by bacteria........... I0

Titration of culture-media...........69, 99

Tobacco, fermentation of............... 257

Tollens, thermo-regulator.............. 37

Toluidin red, for differentiation............. 230

Toning bath for solio paper............. 201

Transfers, how to avoid contaminations in making $\ldots \ldots \ldots \ldots \ldots \ldots \ldots \ldots \ldots$ I03

Trenkmann, flagella-stain.............. 2 I9

Trevisan, genus Pacinia.............. I72

Trikresol ........................... 74

Trypsin .......................... 66

Tsiklinsky, thermophilic bacteria......... 248

Tubes,

care of discarded.................. 107

rapid filling, with fluid media........... 99

Tumors produced by bacteria............ 8

Typhoid bacillus, effect of copper on. . 74, 250, 253

Tyrosin, qualitative test for............. 63

Ultramicroscopical organisms........ I8, 2 II, 2 I3

Unguentum resinae.................. 228

Urocephalum ................... I59, 264

Uschinsky's solution,

cultures in dilute, for flagella staining..... 20

formula ....................... 197

in silicate-jelly................... 39

modified ...................... 197 
Page.

U-tubes, for testing growth in nitrogen...... 58

Vacuo, concentration of fluids in ............. 68 growth in...................... 54

Vallin, cleaning filters............... 227

Van Ermengem,

flagella-stain .................. Igr

germicidal effect of ozone............25I

van't Hoff, modification of plate-method.... 228

van Tieghem, thermophilic hacteria........ 247

Varietal resistance to disease......... 93, 186

Vascular system occupied by bacteria...... 8

Velox-prints ..................... I5I

Ventilation, of dark-room.............. 149

Vernhout, bacterial fermentation of tohacco.. 257

Vibrio, 11se of, as a genus name.......... I73

Vibrio cholerae,

action of copper on.............74, 250

classification ....................... I72

Vibrio, Müller's genus............... 172

Viscidity ........................ 42

of bacterial growths............... I9

of milk........................ 46

of Uschinsky's solution.............. 20

Vitality on various media.............. 72

Voges,

blue water-bacteria............... 237

cultivates Cholera vibrio on potato........ 249

Voigtlaender, physical properties of agar.... 224

von Esmarch, roll-cultures of............ 226

von Freudenreich, filtration of agar........ 224

von Rozsahegyi, pigmented-media for differentiation ..................... 229

V-shaped forms................. 23, 217

Wager exposure scalc................ I43

Waldo \& Walsh, bread not fully. sterilized by baking .......................... 26!

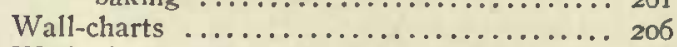

Wall of cell, outer, reaction to stains....... 28

Walliczek,

cffect of dry air on bacteria.......... 249

effect of tannin on bacteria................ 25 I

Ward, A. R., ropy milk............. 259,260

Ward, H. M., bacteria from Tliames water... 258

Warming ..................... 20

Water,

apparatus for distilling............. I24

bacteria in, literature on............. 258

Water-bacteria,

blue and violet.................. 237

Hesse \& Niedner's nutricnt agar for......... 196
Water-hacteria-continued.

Page.

how best kept.................. 263

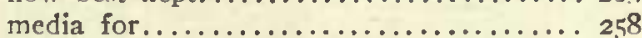

Water, examination of. English methods for. 220

Water-hath, Ostwald-Pfeffer............. 78

Water-pores, infection through...... 92, 102, 124

Wax-mixture, Darwin's................. 200

Wehmer, fermentation of sauerkraut...... 248

Weigert, early use of anilin stains......... 29

Weiss,

bacteria from soured foods............ 2.35

ruled counting-plate............... 36

Welch,

capsule-stain ....................20, 194

influence of ................... I52

Welcke, flagella-stain................. 220

Wescner, eggs as a culture-medium........ 225

Weyl, ozone as a germicide............. 252

Wilhelmy, bacteria in meat-extracts........ 260

Williams, flagella-stain............... I93

Winogradsky,

agar for isolation of nitrate bacteria...... I99

elective cultures................... I06 medium for nitrogen-assimilating bacteria. I99 nitrifying bacteria.................... 240

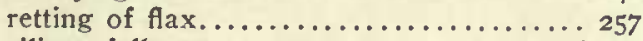
silicate-jelly ...................... $36,-240$ red sulphur-bacteria ............... 263

Winogradsky \& Omélianski, fluid-media for isolating nitrate and nitrite bacteria... I99

Winogradsky-Sleskin silicate-jelly......... Ig8

Winslow \& Rogers, Coccaceae revised by... 265

Wood-vinegar, an energetic disinfectant.... 252

Wounds,

disinfection of ................. I07

natural infection through.............. 92

Wright, anaërobes, simple metliods of culti-

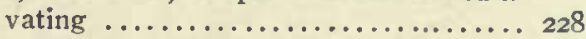

Wynne exposure meter............... 143

Yendo, source of commercial agar.......... 225

Yersen, pest carried by rats............. 215

Yokote, filtration of agar............... 225

Y-shaped forms...................... 23

Zeiss lenses for photograplic work,

Double-Protar .................... I30

Planar .......................... 132

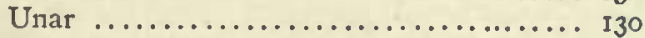

Zeiss microscopes................ I29, I30

Zettnow,

cleaning cover-glasses................ 227

flagella-stain $\ldots \ldots \ldots \ldots \ldots \ldots \ldots \ldots \ldots \ldots . \ldots \ldots$ I $^{2}$

light-filter...................... 





